Universidade de São Paulo

Instituto de Astronomia, Geofísica e Ciências Atmosféricas

Departamento de Astronomia

Felipe Donizeti Teston Navarete

\title{
Procura de Estrelas de Alta Massa em Formação
}

São Paulo 

Felipe Donizeti Teston Navarete

\section{Procura de Estrelas de Alta Massa em Formação}

Dissertação apresentada ao Departamento de Astronomia do Instituto de Astronomia, Geofísica e Ciências Atmosféricas da Universidade de São Paulo como requisito parcial para a obtenção do título de Mestre em Ciências.

Área de Concentração: Astronomia Orientador: Prof. Dr. Augusto Damineli Neto

Versão corrigida. O original encontra-se disponível na Unidade.

São Paulo 

Aos meus pais, Donizeti e Lidia, com todo o meu amor e gratidão. 



\section{Agradecimentos}

A elaboração deste trabalho não teria sido possível sem a colaboração, estímulo e empenho de diversas pessoas. Gostaria de expressar minha gratidão a todos aqueles que contribuíram para que esta tarefa se tornasse uma realidade. A todos, aqui citados ou não, quero manifestar os meus sinceros agradecimentos.

Aos meus pais, Donizeti e Lidia, pelo amor, carinho e as lições de vida que recebi ao longo de toda a minha existência. Palavras não são capazes de expressar a minha eterna gratidão e, a eles dedico este trabalho.

Ao meu orientador, Prof. Dr. Augusto Damineli, pela oportunidade de trabalhar com um tema encantador, por sua paciência, amizade e imprescindível orientação acadêmica.

Ao meu relator, Prof. Dr. Marcos Diaz, pelas suas críticas construtivas e sugestões. Aos professores Dr. Cássio Leandro, Dr. Francisco Jablonski, Dr. Gabriel Hickel e Dr. Alessandro Moisés, pelos ensinamentos e discussões durante a realização deste trabalho.

Aos colegas do IAG, em especial ao Mairan Teodoro, Marcus Duarte, Bruno Quint, Diana Gama, Márcio Avellar, Paulo Jakson, Fellipy Silva, Bruno Mota, Oscar Cavicha, Pedro Beaklini, Tiago Ricci, Leonardo Almeida, Rafael Santucci, Luciene Coelho; pelas conversas, risadas, os cafés (principalmente os cafés!) e aventuras que enfrentamos juntos ao longo desses anos. Um agradecimento especial à equipe técnica e administrativa do Depto. de Astronomia, que contribuíram para o andamento deste trabalho.

Aos queridos colegas do IQ-USP: Erich Tahara, Cleverson Busso, Ariel Cardoso, Bruno Queliconi, Bruno Chausse, Camille Caldeira, Fernanda Cunha, Fernanda Cerqueira, Graciele Oliveira, Maynara Fornazari, Phillipe Pessoa; que acompanharam de perto o meu primeiro contato com a ciência e sempre foram meus exemplos de grandes pessoas e pesquisadores. Não poderia deixar de agradecer à $\operatorname{Prof}^{a}$. $\operatorname{Dr}^{a}$. Alicia J. Kowaltowski, por 
guiar meus primeiros passos na pesquisa acadêmica e por todo o incentivo e disposição em orientar um físico "perdido" no fascinante universo das mitocôndrias.

Aos companheiros de república Marco Antônio, Paulo Bianchi e Jonathan Sena; pela amizade, companheirismo e pelo apoio nas horas mais difíceis. Aos amigos, de longe e de perto: André Teruya, Adriano Campanhola, Cecilia Garcia, Mario Ageu, Natália Monteiro e Vitor Aguiar. Ao meu querido professor do ensino médio, Máximo A. Faggian, que me incentivou desde muito cedo a seguir na Astronomia. Agradeço à Marcela, que esteve ao meu lado nos momentos mais difíceis e decisivos deste trabalho, sendo tão companheira e carinhosa.

A los amigos de Chile que me recibieron tan bien en su país: Carolina Abarca y Cristian Osório, Claudiño Arqueros y Nevenka Monardez, Leonardo Álvarez, Mayte Alfaro, Odette Toloza, Piera Andrea; igracias por todo!

Ao Laboratório Nacional de Astrofísica e Observatório Gemini Sul, pela oportunidade de participar efetivamente no comissionamento do instrumento FLAMINGOS-2 durante o ano que trabalhei em La Serena (Chile), complementando minha formação como astrônomo. Aos astrônomos e amigos Sérgio Scarano, Tina Armond, Tiago Ribeiro e Eder Martioli, que tornaram possível a realização das observações apresentadas nesse trabalho.

Finalmente, agradeço ao povo brasileiro que financiou meu trabalho por meio do CNPq, sob o projeto $\mathrm{n}^{o} 133691 / 2011-0$.

Este trabalho foi

parcialmente baseado em observações obtidas pelo instrumento WIRCam, um projeto conjunto do CFHT por instituições de Taiwan, Coréia, Canadá, França e o telescópio CFHT (Canada-France-Hawaii Telescope), operado por National Research Council (Canadá), Institute National des Sciences de l'Univers of the Centre National de la Recherche Scientifique (França), e Universidade do Havaí (Havaí);

parcialmente baseado em observações obtidas pelo telescópio SOAR, um projeto conjunto do Ministério da Ciência, Tecnologia, e Inovação (Brasil), National Optical Astronomy Observatory (Estados Unidos), Universidade da Carolina do Norte (Estados Unidos), e Universidade de Michigan (Estados Unidos).

Esta dissertação foi escrita em LATEX com a classe IAGTESE, para teses e dissertações do IAG. 
"Mesmo que a rota da minha vida me conduza a uma estrela, nem por isso fui dispensado de percorrer os caminhos do mundo."

José Saramago (1922-2010) 



\section{Resumo}

O mecanismo de formação de estrelas de alta massa é um dos problemas fundamentais em Astrofísica e um dos menos compreendidos. Duas teorias predizem a formação destes objetos, que se formariam via $i$ ) colisão de estrelas de baixa massa, ou $i i$ ) acreção por disco circunstelar. Atualmente, ambas as teorias carecem de testes observacionais críticos. Não obstante, o número de estrelas de alta massa jovens já identificadas na Galáxia corresponde a uma fração muito menor do que o esperado pela função de massa inicial.

Este trabalho apresenta um estudo observacional de candidatos a MYSOs, selecionados a partir do levantamento Red MSX Source. Observações de 376 objetos nos filtros estreitos do $\mathrm{H}_{2}$ em $2.12 \mu \mathrm{m}$ e num contínuo adjacente foram realizadas para identificar jatos moleculares colimados e 296 delas são apresentadas nesse trabalho. As observações do hemisfério Norte foram realizadas com o telescópio CFHT (Havaí) enquanto os objetos do hemisfério Sul, foram observados com o telescópio SOAR (Chile).

A análise dos mapas de emissão em $\mathrm{H}_{2}$ permitiu concluir que que 150 dos 296 objetos $\left(\approx 51 \%\right.$ ) estão associados a emissões extensas em $\mathrm{H}_{2}$, e 62 delas foram classificadas como emissões polares. A análise da razão de aspecto das estruturas identificadas mostra que as emissões associadas a fontes com maior luminosidade apresentam baixo grau de colimação, tal como sugere o cenário de geração dos jatos a partir de ventos emanados pela pressão de radiação do disco circunstelar. A baixa fração de emissões polares (apenas $\approx 21 \%$ da amostra) indica que o tempo de vida dessas estruturas devem ser curtos. As evidências observacionais encontradas nesse trabalho corroboram o cenário de acreção via disco circunstelar e invalidam o modelo formação via coalescência de estrelas de baixa massa, que requer ambientes relativamente densos e não é capaz de produzir jatos colimados. 



\section{Abstract}

Very few massive stars in early formation stages were clearly identified in our Galaxy. The formation process of these objects is still unclear and two theories predict the formation of massive stars: $i$ ) by merging of low mass stars or $i i$ ) by an accretion disk. There are no critical observational evidences to choose between them. The lack of observational evidences combined with the small number of known massive stars in formation in our Galaxy does not allow us to choose between these scenarios.

We present a near-infrared survey of MYSOs candidates selected from the Red MSX Source survey. Such catalog is based on an accurate revision of distances and luminosities, overcoming the limitations and failures in previous searches of this kind. 376 targets were observed through the $\mathrm{H}_{2}$ narrow-band filter at 2.12 microns and in the continuum to identify collimated molecular jets. 296 targets were successfully processed using the THELI pipeline and are presented. Observations in the Northern Hemisphere were carried at the CFHT telescope (Hawaii) while the Southern targets were observed with the Soar Telescope (Chile).

The results show that 150 of the 296 sources display extended $\mathrm{H}_{2}$ emission and 62 of them are polar. The analysis of the aspect ratio of the structures indicates that emissions associated with higher luminosity sources have low degree of collimation. This is in agreement with the scenario of the radiation pressure-driven outflows from the circunstellar discs. The low fraction of sources associated with polar jets $(\approx 21 \%)$ indicates a short timescale of such structures. The observational evidences found on this work support the accretion scenario and show that coalescence of low-mass stars (which may require relatively dense environments and is not expected to produce jet-like structures) is not likely to explain most of the studied MYSOs candidates. 



\section{Sumário}

Lista de Acrônimos . . . . . . . . . . . . . . . . . . . . . . . . . . . . . 17

Lista de Palavras de Língua Estrangeira . . . . . . . . . . . . . . . . . . . . . . . 19

Símbolos, Constantes e Grandezas . . . . . . . . . . . . . . . . . . . . . . . . 21

1. Introducãd . . . . . . . . . . . . . . . . . . . . . . . 25

1.1 As Regiões de Formacão de Estrelas de Alta Massa _ . . . . . . . . . . . 27

1.2 Estágios Evolutivos na Pré-sequência Principal e suas Propriedades . . . . 28

1.3 Aspectos Observacionais da Formacão de Estrelas de Alta Massa . . . . . . 31

1.4 Comparacão entre Formacão de Estrelas de Alta e Baixa Massa . . . . . . 33

1.5 Problemas Teóricos na Formacão de Estrelas de Alta Massa $\ldots . . . .36$

1.6 Cenários de Formacão de Estrelas de Alta Massa _ . . . . . . . . . . . 37

1.7 Modelos Numéricos da Formacão de Estrelas de Alta Massa de Krumholz . 49

1.8 Estimativa do número de MYSOs na Galáxia $\ldots \ldots \ldots \ldots \ldots$. . . . . 51

1.9 Motivacão e Objetivos desta Dissertacão $\ldots$. . . . . . . . . . . . . . . . 53

2. Levantamentos de Candidatos a MYSOs . . . . . . . . . . . . . . . . . 55

2.1 Histórico e Avancos Instrumentais . . . . . . . . . . . . . . . . . . . 55

2.2 Amostras de candidatos a MYSOs Baseadas em Cores Infravermelhas . . . 59

2.3 Amostras de Candidatos a MYSOs selecionadas por outros critérios . . . . 62

$2.4 \quad$ O Levantamento Red MSX Source. . . . . . . . . . . . . . . . . . . . . 62

2.5 Importância do levantamento RMS para o presente trabalho . . . . . . . 73 
3. Observacões no Infravermelho Próximo . . . . . . . . . . . . . . . . . . . . 81

3.1 Planeiamento e Desenho do Projeto Observacional . . . . . . . . . . . . . . 81

3.2 A Influência Atmosférica nas Observacões . . . . . . . . . . . . . . . . . . 83

3.3 Instrumentos no Infravermelho Próximo f . . . . . . . . . . . . . . . 85

3.4 Consideracões sobre Observacões no Infravermelho Próximo . . . . . . . . 89

3.5 Processamento das Imagens Utilizando o THELI . . . . . . . . . . . . . . 92

3.6 Comparacão entre Resultados obtidos com o IRAF e com o THELI . . . . 100

3.7 Criação dos Mapas de Emissão em $\mathrm{H}_{2}$. . . . . . . . . . . . . . . . . . . . . 103

4. Catálogo de Fontes com Emissão em $H_{2}$. . . . . . . . . . . . . . . . . . . . . . 109

4.1 Desempenho Fotométrico . . . . . . . . . . . . . . . . . . . . . . . . . 109

4.2 Relacão Massa-luminosidade . . . . . . . . . . . . . . . . . . . . . . 122

4.3 Distâncias e Luminosidades da Amostra de Candidatos a MYSOs . . . . . 123

4.4 Classificacão Morfológica das Emissões em $\mathrm{H}_{2}$. . . . . . . . . . . . . . . . 125

4.5 Análise individual dos campos . . . . . . . . . . . . . . . . . . . . . . . 127

4.6 Fontes com Emissão Polar no filtro do $\mathrm{H}_{2} \ldots \ldots$. . . . . . . . . . . . . . . 139

5. Análise e Discussão dos Resultados . . . . . . . . . . . . . . . . . . . . 185

5.1 Estatísticas Gerais da Amostra . . . . . . . . . . . . . . 185

5.2 Emissões Polares e Comparação com Outras Amostras . . . . . . . . . . . 193

6. Consideracões Finais . . . . . . . . . . . . . . . . . . . . . . . . . 199

6.1 Conclusões . . . . . . . . . . . . . . . . . . . . . . . . . 199

6.2 Perspectivas e Trabalhos Futuros . . . . . . . . . . . . . . . . . . . . 201

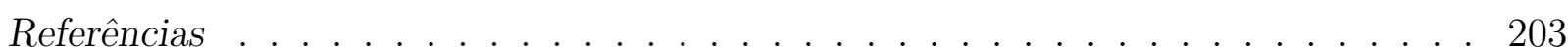

Apêndice 219

Apêndice . . . . . . . . . . . . . . . . . . . . . . . . . . 221

A. Imagens RGB e Mapas de Emissão em $H_{2}$. . . . . . . . . . . . . . . . . . . . 221

A.1 Fontes RMS com Emissão $\mathrm{H}_{2}$ Não-polar $\ldots . . . . . . . .221$

A.2 Fontes RMS sem Emissão Extensa em $\mathrm{H}_{2} \ldots \ldots$. . . . . . . . . . . . . . . 251 
B. Rotinas em IDL Desenvolvidas Durante o Trabalhd . . . . . . . . . . . . . . . . 301 B.1 prepare_images.pro . . . . . . . . . . . . . . . . . . . . . . . . . . 301

B.2 create_images.pro . . . . . . . . . . . . . . . . . . 303 



\section{Lista de Acrônimos}

- 2MASS: Two Micron All Sky Survey

- ADU: Analog-to-Digital Units

- AGB: Asymptotic Giant Branch

- ALMA: Atacama Large Millimeter/submillimeter Array

- ALTAIR: ALTtitude conjugate Adaptive optics for the InfraRed

- APEX: Atacama Pathfinder EXperiment

- AURA: Association of Universities for Research in Astronomy

- CFHT: Canada France Hawaii Telescope

- CL: Command Language

- FFT: Fast Fourier Transform

- FIR: Far Infrared

- FOV: Field-of-View

- FWHM: Full Width at Half Maximum

- GLIMPSE: Galactic Legacy Infrared Mid-Plane Survey Extraordinary

- GMC: Giant Molecular Cloud

- HC: Hot Core

- HCH II: Hyper Compact HII (region)

- IDL: Interactive Data Language

- IFU: Integral Field Unit

- IGA: IRAS Galaxy Atlas

- IMF: Initial Mass Function

- IRAC: InfraRed Array Camera

- IRAF: Image Reduction and Analysis Facility 
- IRAS: InfraRed Astronomical Satellite

- IRAS PSC: IRAS Point Source Catalog

- ISO: Infrared Space Observatory

- MIPS: Multiband Imaging Photometer for Spitzer

- MIPSGAL: MIPS Galactic Plane

- MIR: Mid Infrared

- MSX: Midcourse Space Experiment

- MYSO: Massive Young Stellar Object

- NIFS: Near-Infrared Integral Field Spectrometer

- NIR: Near Infrared

- NOAO: National Optical Astronomy Observatory

- OSIRIS: Ohio State Infrared Imager/Spectrometer

- PA: position angle

- PSC: Prestellar core

- PSF: Point Spread Function

- RMS: Red MSX Source

- SED: Spectral Energy Distribution

- SOAR: Southern Astrophysics Research Telescope

- SP: Sequência Principal

- SPIZ: Sequência Principal de Idade Zero

- UCH II: Ultra Compact HII (region)

- UV: ultra-violeta

- VLA: Very Large Array

- WIRCam: Wide-field InfraRed Camera

- YSO: Young Stellar Object 


\section{Lista de Palavras de Língua Estrangeira}

- Asymptotic Giant Branch: Ramo Assimtótico das Gigantes

- Clump: aglomeração

- Dithering: padrão de pontilhamento

- Far Infrared: Infravermelho distante

- Full Width at Half Maximum: Largura à meia altura

- Giant Molecular Cloud: nuvem molecular gigante

- Hot core: núcleo quente

- Hyper Compact H II region: região H II hiper-compacta

- InfraRed Astronomical Satellite: Satélite Astronômico do Infravermelho

- Initial Mass Function: função de massa inicial

- Maser: emissão estimulada

- Massive Young Stellar Object: Objeto estelar jovem de alta massa

- Near Infrared: Infravermelho próximo

- Prestellar core: núcleo pré-estelar

- Point Spread Function: fun $\tilde{A} \S \tilde{A} £ o$ resposta à estímulo pontual

- RGB: abreviatura do sistema de cores formado por Vermelho (Red), Verde (Green) e Azul (Blue)

- Spectral Energy Distribution: Distribuição Espectral de Energia

- Throughput: Transmitância total no intervalo de comprimento de onda

- Ultra Compact HII region: região H II ultra-compacta

- Young Stellar Object: Objeto estelar jovem (de baixa massa) 



\section{Símbolos, Constantes e Grandezas}

$\mathrm{A}_{\lambda}$ : Extinção fotométrica (mag)

$A_{P S F}$ : área da PSF $\left(\operatorname{arcsec}^{2}\right)$

$\alpha_{m a g}:$ coeficiente angular da transformação entre magnitudes instrumentais e magnitudes no catálogo 2MASS (adimensional)

$b$ : latitude galática $\left(^{o}\right)$

$d_{\odot}$ : distância galactocêntrica do Sol $(8.5 \mathrm{kpc})$

$\Delta$ mag: faixa dinâmica de magnitudes das fontes contidas num dado campo (mag)

$f_{0, K_{s}}$ : fluxo correspondente à magnitude de ponto zero da banda $\mathrm{K}_{s}$ do catálogo 2MASS $\left(\mathrm{W} \mathrm{cm}^{-2} \mu \mathrm{m}^{-1}\right)$

$f_{\text {bol }}$ : fluxo bolométrico $\left(\mathrm{W} \mathrm{m}^{-2}\right)$

$f_{\text {grav }}$ : força específica gravitacional $\left(\mathrm{N} \mathrm{kg}^{-1}\right)$

$f_{\text {min }}$ : fluxo mínimo correspondente à magnitude $\mathrm{K}_{\text {s,limite }}(\mathrm{em} \mathrm{ADU}$ ou ADU/s)

$f_{\text {rad }}$ : força específica radiativa $\left(\mathrm{N} \mathrm{kg}^{-1}\right)$

$f_{s f}$ : fluxo determinado pelo StarFinder (ADU ou ADU s ${ }^{-1}$ )

$F_{\lambda}$ : fluxo medido num dado filtro

$\mathrm{G}$ : constante gravitacional universal $\left(6.67 \times 10^{-11} \mathrm{~m}^{3} \mathrm{~kg}^{-1} \mathrm{~s}^{-2}\right)$

$i$ : ângulo de inclinação com relação à linha de visada $\left(^{\circ}\right)$

$\eta_{* f}$ : eficiência da formação estelar

$k_{B}$ : constante de Boltzmann $\left(1.38 \times 10^{-23} \mathrm{~J} \mathrm{~K}^{-1}\right)$

$\mathrm{K}_{\text {s,compl }}$ : limite de completeza fotométrica das fontes contidas num dado campo (mag)

$\mathrm{K}_{\text {s,limite }}$ : limite de detecção das fontes contidas num dado campo (mag)

$\mathrm{K}_{s, s a t}$ : limite de saturação das fontes contidas num dado campo (mag)

$\kappa$ : opacidade média por unidade de massa $\left(\mathrm{cm}^{2} \mathrm{~g}^{-1}\right)$ 
$\kappa_{s} f$ : constante de normalização opacidade média por unidade de massa $\left(\mathrm{cm}^{2} \mathrm{~g}^{-1}\right)$

$L_{\text {bol }}$ : luminosidade bolométrica $\left(L_{\odot}\right)$

$\mathrm{L}_{\odot}$ : luminosidade solar $\left(3.86 \times 10^{26} \mathrm{~W}\right)$

$\lambda$ : comprimento de onda $(\mu \mathrm{m})$

$\lambda_{c}$ : comprimento de onda central $(\mu \mathrm{m})$

$\ell$ : longitude galática $\left(^{o}\right)$

$\ell_{\text {proj }}$ : dimensão projetada das estruturas presentes nos campos observados (pc)

$\ell_{\text {real }}$ : dimensão real das estruturas presentes nos campos observados (pc)

$\mathrm{M}_{\odot}:$ massa solar $\left(1.99 \times 10^{30} \mathrm{~kg}\right)$

$\mathrm{M}_{c}$ : massa da nuvem molecular $\left(\mathrm{M}_{\odot}\right)$

$\dot{M}_{*}:$ taxa de acreção $\left(\mathrm{M}_{\odot} \operatorname{ano}^{-1}\right)$

$m_{0}$ : coeficiente linear da transformação entre magnitudes instrumentais e magnitudes no catálogo 2MASS (mag)

$m_{2 M A S S}:$ magnitude no sistema padrão e contido no catálogo 2MASS (mag)

$m_{\text {instr }}:$ magnitude instrumental (mag)

$m_{H}$ : massa do Hidrogênio $\left(1.67 \times 10^{-27} \mathrm{~kg}\right)$

$\mu$ : peso molecular médio

$N_{*}\left(M_{1} \rightarrow M_{2}\right)$ : número de estrelas com massa entre $\mathrm{M}_{1}$ e $\mathrm{M}_{2}$

$n$ : densidade de partículas $\left(\mathrm{cm}^{-3}\right)$

pc: $\operatorname{parsec}\left(3.09 \times 10^{11} \mathrm{~m}\right)$

$r$ : distância radial (UA)

$R$ : razão de aspecto dos jatos moleculares

$\mathrm{R}_{B}$ : raio de Bondi (pc)

$\mathrm{R}_{c}$ : raio da nuvem molecular $(\mathrm{pc})$

$\mathrm{R}_{J}$ : raio de Jeans $(\mathrm{pc})$

$\mathrm{R}_{\odot}$ : raio solar $\left(6.96 \times 10^{8} \mathrm{~m}\right)$

$r_{\text {dust }}$ : raio de destruição da poeira presente no disco (UA)

$r_{\text {evap }}$ : raio de evaporação da poeira do disco (UA)

$\rho$ : densidade volumétrica de massa $\left(\mathrm{g} \mathrm{cm}^{-3}\right)$

$\sigma$ : desvio padrão das contagens das imagens (ADU ou $\mathrm{ADU} \mathrm{s}^{-1}$ )

$\sigma_{f}$ : incerteza do fluxo determinado pelo StarFinder (ADU ou $\mathrm{ADU} \mathrm{s}^{-1}$ ) 
$\sigma_{\text {lim }}$ : limite da densidade de fluxo das imagens $\left(\mathrm{W} \mathrm{m}^{-2} \operatorname{arcsec}^{-2}\right)$

$\sigma_{m}$ : incerteza da magnitude instrumental (mag)

$\sigma_{v}:$ dispersão de velocidades $\left(\mathrm{km} \mathrm{s}^{-1}\right)$

$t_{*}$ : tempo de formação de uma dada estrela (anos)

$\tau_{K H}$ : escala de Kelvin-Helmholtz (anos)

$\theta$ : coordenada azimutal (rad)

UA: unidade astronômica $\left(1.496 \times 10^{11} \mathrm{~m}\right)$

$\mathrm{v}_{A}$ : velocidade de Alfvén $\left(\mathrm{km} \mathrm{s}^{-1}\right)$

$\mathrm{v}_{\text {esc }}$ : velocidade de escape $\left(\mathrm{km} \mathrm{s}^{-1}\right)$

$\mathrm{v}_{s}$ : velocidade do som $\left(\mathrm{km} \mathrm{s}^{-1}\right)$

$\mathrm{v}_{T}$ : velocidade devido à turbulência $\left(\mathrm{km} \mathrm{s}^{-1}\right)$

$v_{\odot}$ : velocidade radial do sistema do Sol $\left(220 \mathrm{~km} \mathrm{~s}^{-1}\right)$

$\xi(m)$ : expoente da função de massa inicial $\left(\mathrm{M}_{\odot}\right.$ ano $\left.{ }^{-1}\right)$ 

Capítulo 1

\section{Introdução}

Estrelas de alta massa $\left(M>8 \mathrm{M}_{\odot}\right.$ ou tipo espectral igual ou mais quente que B3) são os principais objetos responsáveis pela evolução e enriquecimento do meio interestelar. Durante sua existência, elas emitem radiação ionizante e são responsáveis pela deposição de energia mecânica e momentum no meio interestelar através de intensos ventos. Ao término de suas vidas, elas explodem como supernovas, injetam elementos pesados no meio interestelar e podem disparar a formação estelar subsequente nas suas proximidades.

Embora estes objetos sejam fundamentais para o entendimento da evolução local e global das galáxias, os mecanismos de formação de estrelas de alta massa ainda são pouco compreendidos e representam um importante tema na Astrofísica Estelar. Comparadas às estrelas de baixa massa, as estrelas de maior massa são formadas num intervalo de tempo relativamente curto e apresentam uma rápida evolução, dificultando a detecção direta dos objetos muito jovens e o estudo das suas fases iniciais de formação.

A formação de estrelas de baixa massa é bem descrita pelo cenário de acreção via disco circunstelar (Shu et al., 1987). Palla e Stahler (1993) mostraram que a acreção via disco circunstelar é capaz de explicar a formação de objetos com massas $\lesssim 6 \mathrm{M}_{\odot}$. No entanto, o processo de acreção proposto por esses autores não é capaz de explicar a formação de estrelas com massa acima deste limite, que apresentam intensos campos de radiação. Recentemente, simulações numéricas tridimensionais mostraram que a presença de um disco circunstelar seria suficientemente eficaz para direcionar a radiação na direção polar da estrela, possibilitando que o material seja acrescido pelo objeto central através de filamentos de alta densidade (Kuiper et al., 2011a, $\underline{\text { b) }}$ ).

Visto que o cenário de formação de estrelas de alta massa não está consolidado, foram 
propostos cenários alternativos para explicar a formação destes objetos, tais como a acreção competitiva. Segundo essa idéia, as estrelas de alta massa seriam formadas via coalescência e aglutinação de estrelas de baixa massa, pressupondo que a massa do objeto central seja determinado pela massa das estrelas pré-existentes. Ambos os cenários serão apresentados nas seções seguintes, mas somente o cenário de formação a partir de acreção via disco será tratado detalhadamente.

Para contextualizar o cenário no qual se enquadra a pesquisa desenvolvida no presente trabalho, este capítulo está organizado de acordo com os seguintes tópicos: $i$ ) as principais propriedades das regiões de formação das estrelas de alta massa; ii) os estágios evolutivos da formação das estrelas de alta massa; iii) os aspectos observacionais dos estágios evolutivos na pré-sequência principal; iv) os problemas teóricos associados à formação de estrelas de alta massa; v) a comparação entre a teoria de formação de estrelas de alta e baixa massa; vi) o cenário da formação das estrelas de alta massa; vii) o modelo de formação de estrelas via disco de acreção de Krumholz et al. (2009) Por fim, apresentamos viii) uma estimativa do número de MYSOs na Galáxia e $i x$ ) as motivações do estudo apresentado nesse trabalho.

O ponto (".") foi adotado como separador decimal para apresentação dos números contidos nas figuras e no texto desse trabalho. Embora alguns termos da lingua inglesa tenham sido traduzidos para o português, seus respectivos acrônimos foram mantidos na lingua original devido sua ampla utilização na área. 


\subsection{As Regiões de Formação de Estrelas de Alta Massa}

A formação estelar tem início a partir do colapso de uma nuvem molecular gigante (GMC, Giant Molecular Cloud). As GMCs que supostamente dão origem às estrelas de alta massa possuem propriedades físicas bastante distintas das observadas nos bercários de estrelas de baixa massa (Jijina et al., 1999; Kurtz et al., 2000; Beuther et al., 2007). Enquanto as nuvens moleculares de pequeno porte têm massas e tamanhos típicos de $M_{c} \sim$ $10^{2} \mathrm{M}_{\odot}$ e $R_{c} \sim 10 \mathrm{pc}$, respectivamente; as GMCs apresentam valores de $M_{c} \sim 10^{4-6} \mathrm{M}_{\odot} \mathrm{e}$ $R_{c} \sim 100$ pc. As nuvens moleculares pequenas são relativamente frias $(10-20 \mathrm{~K})$ quando comparadas às GMCs $(50-100 \mathrm{~K})$. As propriedades físicas das GMCs indicam que efeitos de turbulência desempenham um importante papel na dinâmica dessas estruturas. A dispersão de velocidades $\left(\sigma_{v}\right)$ é uma medida relacionada à energia cinética das GMCs e bastante empregada para caracterizar a influência da turbulência nos seus interiores. Medidas de $\sigma_{v}$ associadas às regiões mais internas das GMCs apresentam valores uma ordem de grandeza maiores que os valores estimados para regiões de formação de estrelas de baixa massa (Jijina et al., 1999; Beuther et al., 2007).

Um parâmetro amplamente utilizado para caracterizar a turbulência no interior das GMCs é dado pelo parâmetro de virial $\left(\alpha_{\text {vir }}\right)$, definido como

$$
\alpha_{v i r} \equiv \frac{5 \sigma_{v}^{2} R_{c}}{G M_{c}}
$$

onde $\sigma_{v}$ é a dispersão de velocidades, $R_{c}$ o raio da nuvem e $M_{c}$ sua massa. Valores de $\alpha_{v i r}<1$ indicam que a energia gravitacional do sistema é maior que a energia cinética associada aos seus componentes, ou seja, a estrutura é gravitacionalmente ligada. Nos casos em que $\alpha_{v i r}>1$, a energia cinética é alta o suficiente para impedir o colapso das estruturas e, consequentemente, a formação de estrelas. Onishi et al. (1996) determinaram o valor de $\alpha_{\text {vir }}=0.9$ para uma região de formação de estrelas de baixa massa no complexo de Taurus e Yonekura et al. (2005) encontraram $0.5 \lesssim \alpha_{v i r} \lesssim 1.4$ para a região de Carina, onde existe um número considerável de estrelas de alta massa em formação.

A turbulência facilita a fragmentação das GMCs em grandes escalas, porém dificulta a acreção de massa em escalas menores. A inclusão de turbulência nas simulações numéricas do interior das GMCs (e.g., MacLow, 2004; Elmegreen e Scalo, 2004) contribuiu para grandes avanços no entendimento da dinâmica destas estruturas. No interior das GMCs 
são encontrados os clumps, estruturas com alta densidade de gás molecular $\left(\sim 10^{5} \mathrm{~cm}^{-3}\right)$, tamanhos típicos entre 0.25 e $0.50 \mathrm{pc}$, temperaturas de $\sim 16 \mathrm{~K}$ e massas de $\sim 10^{2-3} \mathrm{M}_{\odot}$ (Beuther et al., 2002). O início da formação das protoestrelas ocorre a partir da formação dos núcleos pré-estelares, no interior dos clumps. As propriedades dos núcles pré-estelades e os diferentes estágios evolutivos durante a pré-sequência principal serão apresentados na próxima seção.

\subsection{Estágios Evolutivos na Pré-sequência Principal e suas Propriedades}

Churchwell (2002) apresenta uma sequência evolutiva dos primeiros estágios da formação de estrelas de alta massa, inferidos a partir de aspectos observacionais. O esquema proposto por este autor é mostrado na Figura 1.1 e suas principais fases são descritas a seguir.

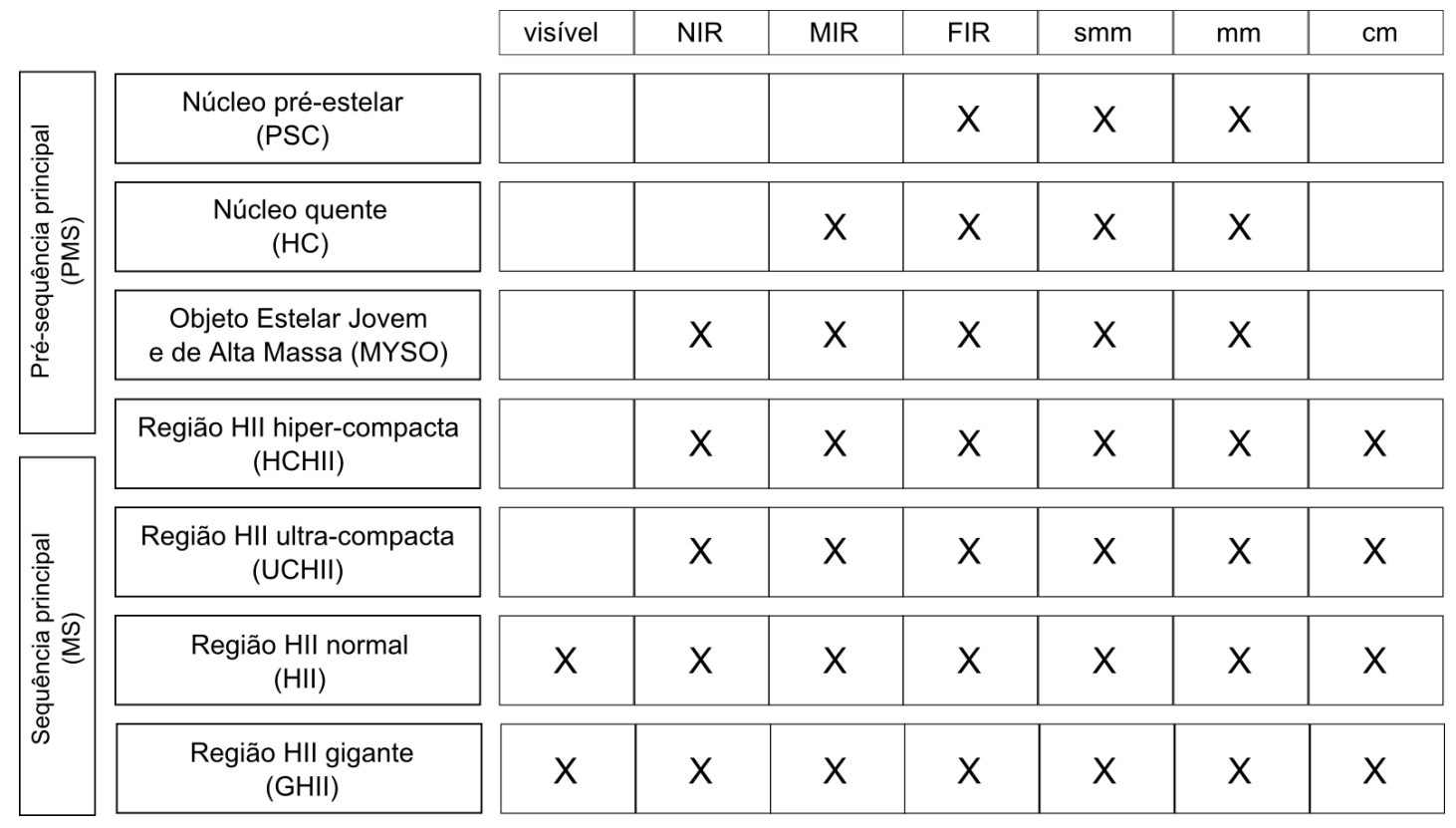

Figura 1.1: Representação esquemática da evolução de estrelas de alta massa até a sequência principal. Adaptado de Churchwell (2002). Ao lado de cada estágio evolutivo estão indicadas as regiões espectrais nas quais os objetos apresentam emissão.

Núcleo pré-estelar - O cenário evolutivo das estrelas de alta massa se inicia a partir da formação de um núcleo pré-estelar (PSC, prestellar core), no interior dos clumps. Os PSCs apresentam características de fontes relativamente frias $(10-20 \mathrm{~K})$ e de baixa densidade $\left(\sim 10^{5} \mathrm{~cm}^{-3}\right)$. Devido suas baixas temperaturas, objetos na fase PSC não apresentam emissão térmica no infravermelho próximo (NIR, Near Infrared), sendo identificados como 
fontes em absorção em relação à emissão de fundo do plano Galático no infravermelho médio (Bacmann et al., 1998) e em emissão na região do infravermelho distante (FIR, far infrared) e sub-milimétrico (Andre et al., 1996). Acredita-se que a fase PSC tenha durações de $\tau_{p s c} \lesssim 10^{6}$ anos (Ward-Thompson et al., 1994), sendo compatível com a escala de contração gravitacional desses objetos, definida pela escala de Kelvin-Helmholtz $\left(\tau_{p s c} \sim \tau_{K H}\right)$.

Núcleo quente - A fase PSC chega ao fim quando as densidades e temperaturas das fontes apresentarem valores superiores a $\sim 10^{7} \mathrm{~cm}^{-3} \mathrm{e} \sim 100 \mathrm{~K}$. Nesse estágio, se inicia a fase de núcleos quentes (HCs, Hot Cores), caracterizada por fontes sem emissão térmica no infravermelho próximo, intensa emissão no infravermelho distante e fraca emissão em rádio. O pico de emissão de objetos na fase $\mathrm{HC}$ ocorre no infravermelho distante, porém em alguns casos é possível detectar emissão de algumas fontes no infravermelho médio (De Buizer, 2003).

A fase MYSO - O término do colapso do núcleo quente dá inicio à próxima fase. As fontes recebem o nome de objetos estelares jovens e de alta massa (MYSOs, Massive Young Stellar Objects). Os MYSOs são objetos compactos, em equilíbrio quase-estático e apresentam elevadas taxas de acreção. De acordo com Lumsden et al. (2002), a definição de MYSO se refere àqueles objetos com fotosfera encoberta por poeira circunstelar e luminosidade $\geq 10^{4} \mathrm{~L}_{\odot}$, cujo fluxo do contínuo de Lyman (fótons com energia suficiente para ionizar o átomo de H) ainda é insuficiente para ionizar o meio interestelar próximo e formar uma região H II. A maior fração da emissão térmica dos objetos na fase MYSO ocorre na região do infravermelho médio e provém do reprocessamento dos fótons de alta energia, emitidos pelo objeto central, no envoltório de poeira. A fase de MYSO corresponde ao estágio no qual ocorre a maior parte da transferência de matéria do envoltório para o objeto central. Observações realizadas na linha do CO mostraram a existência de ventos altamente colimados, sugerindo que a acreção no objeto central está ativa e persiste durante toda a fase MYSO (Beuther et al., 2002).

Regiões H II hiper-compactas - Após um significativo aumento da massa, o campo de radiação da protoestrela é intenso o suficiente para ionizar os átomos de hidrogênio nas regiões mais próximas do objeto central. Nesse estágio, ocorre a transição para a fase de região H II Hiper-compacta (HCH II, Hyper-compact H II Region). O tamanho típico de objetos na fase $\mathrm{HCH}$ II é de $\lesssim 0.03$ pc e suas densidades correspondem a valores de 
$\sim 10^{6} \mathrm{~cm}^{-3}$ Kurtz, 2005). Ainda não está claro se regiões HCH II representam uma classe distinta de objetos jovens ou simplesmente são casos extremos de regiões H II mais compactas e densas.

Regiões H II ultra-compactas - À medida que o campo radiativo da protoestrela se expande na direção do meio interestelar a região H II alcança a fase de região H II ultracompacta (UCH II, Ultra-compact HiI region). Os objetos UCH IIs apresentam tamanhos de $\sim 0.1$ pc e persistem por $10^{5}-10^{6}$ anos e a elevada opacidade causada pela poeira não permite observar estes objetos na faixa do visível. É esperado que o processo de acreção já esteja finalizado na fase UCH II e a passagem da pré-sequência principal para o estágio da sequência principal (SP) ocorrem durante a fase UCH II.

Regiões H II tardias - Ao longo da SP, a região H II associada à estrela de alta massa evolui para estágios mais extensos e difusos, passando pela fase de região H II clássica e, finalmente, alcançando a Região H iı Gigante, como é o caso das regiões W3 (Navarete et al., 2011) e W31 (Blum et al., 2001). Nas fases de região H II normal e gigante, os objetos emitem em todas as faixas do espectro eletromagnético, desde a faixa do ultra-violeta (UV) até comprimentos de onda rádio.

A Tabela 1.1 sintetiza os valores típicos para as dimensões, densidades e a massa de material ionizado presente em cada um das classes de regiões H II.

Tabela 1.1 - Propriedades físicas das regiões H II ao longo da trajetória evolutiva das estrelas de alta massa. Tabela adaptada de Kurtz (2005).

\begin{tabular}{lccc}
\hline \hline Classificação da região & Tamanho $(\mathrm{pc})$ & Densidade $\left(\mathrm{cm}^{-3}\right)$ & Massa Ionizada $\left(\mathrm{M}_{\odot}\right)$ \\
\hline Hiper-compacta & $\lesssim 0.03$ & $\gtrsim 10^{6}$ & $\sim 10^{-3}$ \\
Ultra-compacta & $\lesssim 0.1$ & $\gtrsim 10^{4}$ & $\sim 10^{-2}$ \\
Compacta & $\lesssim 0.5$ & $\gtrsim 5 \times 10^{3}$ & $\sim 1$ \\
Normal & $\sim 10$ & $\sim 100$ & $\sim 10^{5}$ \\
Gigante & $\sim 100$ & $\sim 30$ & $10^{3}-10^{6}$ \\
Supergigante & $>100$ & $\sim 10$ & $10^{6}-10^{8}$ \\
& & & \\
\hline
\end{tabular}




\subsection{Aspectos Observacionais da Formação de Estrelas de Alta Massa}

A função de massa inicial (IMF, Initial Mass Function) prediz que a fração de estrelas de alta massa é muito menor que a esperada para aqueles de menor massa (Salpeter), 1955). Embora os objetos de alta massa sejam intrinsecamente mais luminosos que suas contrapartidas de baixa massa, a elevada extinção interestelar das regiões internas das GMCs $\left(\mathrm{A}_{V}>200 \mathrm{mag}\right.$, Tan, 2003) causa a diminuição dos fluxos observados desses objetos. Dessa forma, os MYSOs são relativamente fracos no infravermelho próximo e geralmente não apresentam contrapartida no visível. Para compreender o processo de formação de estrelas de alta massa e sua relação com o meio interestelar, o estudo destes objetos deve ser realizado a partir de observações com alta resolução espacial no infravermelho, em comprimentos de onda nas proximidades do máximo de sua emissão térmica.

Devido às dificuldades observacionais dos estágios iniciais da formação dos MYSOs, grande parte do estudo nessa área é baseado em observações de estágios mais evoluídos destes objetos: as regiões UCH II e as protoestrelas próximas da sequência principal de idade zero (SPIZ). A Figura 1.2 apresenta as distribuições espectrais de energia típicas de um MYSO e de uma região UCH II. Conforme discutido anteriormente, tanto as UCH IIs quanto os MYSOs emitem no infravermelho médio e na região milimétrica, porém apenas as UCH IIs apresentam emissão na faixa centimétrica (Churchwell, 2002).

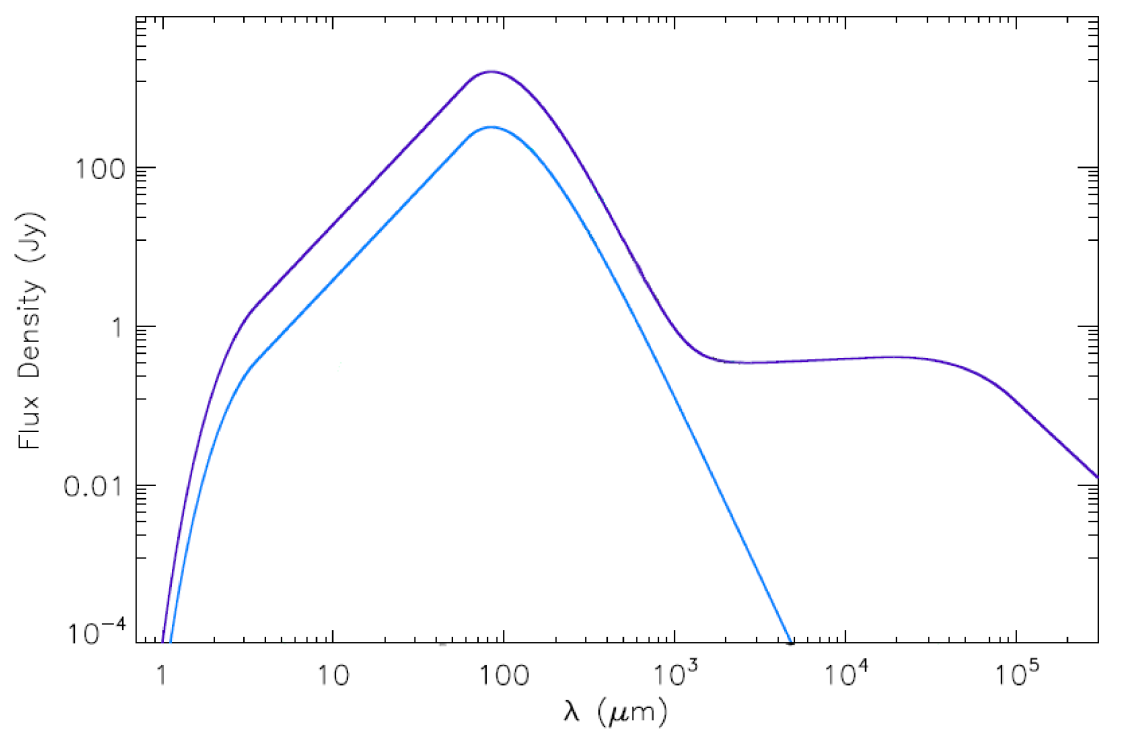

Figura 1.2: Distribuição espectral típica de um MYSO (azul claro) e de uma região UCH II (em azul escuro). Adaptado de Mottram (2008). 


\subsubsection{Emissão do Tipo Maser}

A emissão maser em comprimentos de onda rádio mostra-se um excelente traçador de regiões de alta densidade e, combinada a observações interferométricas, permite medir a velocidade do gás molecular com alta precisão dentro de escalas de algumas unidades astronômicas (UA).

Emissões do tipo maser de moléculas tais como a água $\left(\mathrm{H}_{2} \mathrm{O}\right)$, o metanol $\left(\mathrm{CH}_{3} \mathrm{OH}\right)$ e a hidroxila $(\mathrm{OH})$ geralmente estão associadas aos processos da formação de protoestrelas (Pestalozzi et al., 2005; Walsh et al., 1998; Ellingsen et al., 1996), e são um bom indicativo para diferenciar as estrelas em formação de objetos em estágios mais tardios.

A emissão maser de $\mathrm{H}_{2} \mathrm{O}$ pode indicar tanto a formação de estrelas de baixa quanto de alta massa (Furuya et al., 2003; Urquhart et al., 2009b). No entanto, emissão maser de metanol parecem estar associados exclusivamente com regiões de formação de estrelas de alta massa (Fontani et al., 2010). Embora a emissão maser caracterize objetos jovens, sua origem ainda não é bem compreendida. Trinidad et al. (2009); Goddi et al. (2007) confirmaram a presença de masers de $\mathrm{H}_{2} \mathrm{O}$ em jatos associados a YSOs de baixa massa. Emissão do tipo maser foi identificada em jatos (De Buizer, 2003), e em discos de acreção associados a MYSOs (Torrelles et al., 1998).

De acordo com o trabalho de Menten (1991), a emissão maser de metanol apresenta duas classes distintas. Emissões maser de metanol de Classe II (detectadas em 6.7 e 12 GHz) são coincidentes com a posição de núcleos protoestelares, regiões UCH II e fontes que também apresentam emissão maser de OH. Esse tipo de emissão maser ocorre via bombeamento radiativo (Sobolev et al., 2007; Fontani et al., 2010). Emissões do tipo maser de Classe I (detectadas em 44 e $95 \mathrm{GHz}$ ) também são encontradas em regiões de formação de estrelas de alta massa, e se encontram deslocadas em relação a outras emissões maser, regiões UCH II e outras fontes infravermelhas (Fontani et al., 2010). Emissão maser de Classe I é produzida via bombeamento colisional na interface entre jatos moleculares e gás quiescente no meio interestelar próximo (Plambeck e Menten, 1990). Outros trabalhos mostraram que masers de metanol de Classe I estão associados a objetos em estágios evolutivos mais tardios, tais como gigantes vermelhas em estágios posteriores ao ramo assintótico das gigantes (pósAGB, Asymptotic Giant Branch) e nebulosas protoplanetárias. Nesses casos, a origem da emissão é devida ao choque provocado pela expansão das camadas mais externas das 
estrelas na direção do meio interestelar local.

A emissão maser de $\mathrm{OH}$ também é um indicativo de estrelas jovens. Estudos recentes mostram que os masers de $\mathrm{OH}$ traçam jatos moleculares e discos circunstelares, e podem ser usados para determinação do campo magnético destas regiões (Edris et al., 2007). A presença de masers de $\mathrm{OH}$ também pode ocorrer em estágios evolutivos mais tardios, tais como os objetos pós-AGBs (Cohen et al., 1988).

\subsubsection{Linhas Moleculares}

Além da emissão maser, assinaturas moleculares também são indicativos de alta densidade. Enquanto masers de $\mathrm{H}_{2} \mathrm{O}$ são originados em regiões relativamente pequenas $\left(\sim 10\right.$ UA) e muito densas $\left(10^{7}-10^{9} \mathrm{~cm}^{-3}\right)$, a emissão molecular provêm de regiões maiores $\left(0.1-1.0\right.$ pc) e com densidades médias de $10^{4}-10^{5} \mathrm{~cm}^{-3}$ (Anglada et al., 1996).

A emissão de óxido de silício ( $\mathrm{SiO})$, originada em regiões de choque, é usada para indicar objetos jovens com jatos ativos (Cvganowski et al., 2011). O levantamento de fontes com emissão de $\mathrm{SiO}$ realizado por Harju et al. (1998) sugere que a emissão de SiO provém das zonas em resfriamento na região interna dos choques to tipo arco (Dutrey et al., 1997). Neste caso, o espectro observado apresenta um pico largo e assimétrico, cuja assimetria depende do ângulo de visada. No entanto, muitas fontes também apresentaram emissão estreita e simétrica, cuja explicação se deve ao choque da frente de ionização com o gás quiescente nas proximidades das fontes (Harju et al., 1998).

Uma vez que a formação das estrelas de alta massa ocorre no interior das GMCs, é de se esperar que tais objetos estejam associados à emissão de monóxido de carbono (CO), normalmente evidenciada pelas transições rotacionais da molécula, tais como a linha do ${ }^{12} \mathrm{CO} \mathrm{J}=1-0$ em $115.27 \mathrm{GHz}$ (Yang et al.,, 2002). Isótopos da molécula de CO, tais como o ${ }^{13} \mathrm{CO}$ e o $\mathrm{C}^{17} \mathrm{O}$ (Thomas e Fuller, 2008; Urquhart et al., 2008), também são observados na direção destes objetos. A associação de objetos jovens com a emissão de CO permite que sua detecção seja usada para inferir a distância cinemática das fontes e determinar parâmetros astrofísicos dependentes da distância, tal como a luminosidade das fontes. 


\subsection{Comparação entre Formação de Estrelas de Alta e Baixa Massa}

Uma das principais diferenças entre a formação de estrelas de alta e baixa massa se deve ao fato de que, para massas superiores a $\sim 10 \mathrm{M}_{\odot}$, o tempo necessário para a estrela atingir a SPIZ é menor que o tempo requerido para o término do processo de acreção (Bally e Zinnecker, 2005).

A teoria da formação estelar prediz que o tempo necessário para o colapso de uma nuvem molecular e formação de uma protoestrela seja da ordem da escala de KelvinHelmholtz $\left(\tau_{K H}\right)$, definida como o tempo necessário para que uma esfera de raio $\mathrm{R}$, massa M e luminosidade L converta sua energia potencial em energia térmica (Equação 1.2).

$$
\tau_{K H}=\frac{G M^{2}}{R L}
$$

A escala de Kelvin-Helmholtz para uma uma estrela com $1 \mathrm{M}_{\odot}$ é de $\sim 30$ milhões de anos. Supondo que $\tau_{K H}$ seja válido para qualquer massa estelar, a Equação 1.2 pode ser reescrita na forma

$$
\tau_{K H}=3.0 \times 10^{7}\left(\frac{M}{M_{\odot}}\right)^{2}\left(\frac{L}{L_{\odot}}\right)^{-1}\left(\frac{R}{R_{\odot}}\right)^{-1} \text { anos }
$$

A escala de tempo da formação $\left(\tau_{* f}\right)$ das estrelas de baixa massa é maior que o respectivo valor de $\tau_{K H}$ enquanto no caso dos objetos com maior massa, temos que $\tau_{* f}<\tau_{K H}$. Esse resultado indica que a fusão de Hidrogênio é iniciada nas regiões mais internas das protoestrelas de alta massa antes do término do processo de acreção de massa.

\subsubsection{Formação de Estrelas: Uma Extrapolação para Altas Massas?}

A abordagem mais natural do tratamento da formação das estrelas de alta massa é uma extrapolação da formação das estrelas de menor massa, cuja taxa de acreção $\left(\dot{M}_{*}\right)$ é bem representada por

$$
\dot{M}_{*} \simeq\left(v_{T}^{2}+v_{A}^{2}+c_{s}^{2}\right)^{3 / 2} / G
$$

onde $v_{T}, v_{A}$ e $c_{s}$ representam o valor velocidade devido à turbulência, a velocidade de Alfvén e a velocidade do som, respectivamente; levando em conta os efeitos da pressão magnética, efeitos de turbulência e da pressão do gás (Stahler et al., 1980). Enquanto taxas de $\sim 10^{-6}-10^{-4} \mathrm{M}_{\odot}$ ano ${ }^{-1}$ são suficientes para a formação de estrelas de baixa 
massa (Stahler et al., 1980), a formação dos MYSOs requer taxas de $\dot{M}_{*} \sim 10^{-3} \mathrm{M}_{\odot}$ ano $^{-1}$. Considerando apenas a contribuição de $v_{s}$, taxas dessa ordem de grandeza requerem valores de $v_{s} \sim 1.6 \mathrm{~km} \mathrm{~s}^{-1}$. Assumindo que a velocidade do som seja aproximadamente constante no interior das GMCs, a formação dos MYSOs só pode ocorrer mediante a presença de turbulência ou campos magnéticos.

McKee e Tan (2002, 2003) mostram que a formação dos MYSOs ocorre via colapso gravitacional com suporte de campos magnéticos e turbulência. Em escalas maiores que o raio de Jeans ( $R_{J}$, Equação 1.5), a distribuição da densidade e pressão em meios turbulentos independem da escala e apresenta variação radial na forma de uma lei de potência (por exemplo, $\left.\rho \propto r^{-k}\right)$. Osorio et al. (1999) verificaram que a densidade do meio interestelar apresenta dependência de $r^{-1}$ nas proximidades da protoestrela.

$$
R_{J}=\frac{1}{\mu m_{H}}\left(\frac{15 k_{B} T}{4 \pi G n}\right)^{\frac{1}{2}} \approx 0.15 \mathrm{pc}\left(\frac{T}{10 K}\right)^{\frac{1}{2}}\left(\frac{n_{H_{2}}}{10^{4} \mathrm{~cm}^{-3}}\right)^{-\frac{1}{2}}
$$

Keto (2002, 2003) estudou o crescimento de MYSOs assumindo que o meio interestelar nas proximidades da protoestrela seja isotérmico e homogêneo e que estrelas de alta massa sejam formadas via acreção esférica do tipo Bondi-Hoyle $\left(\dot{M}_{*} \propto M_{*}^{2}\right)$. O modelo adotado naqueles trabalhos pressupõe que a auto-gravitação do gás seja desprezível, tornando necessário que a massa no interior do raio de Bondi $\left(R_{B}=G M_{*} / c_{s}^{2}\right)$ seja muito menor que a massa da estrela em formação, com taxas de acreção da ordem de $\dot{M}_{*} \lesssim c_{s}^{3} / G$. Assumindo $c_{s} \simeq 0.5 \mathrm{~km} \mathrm{~s}^{-1}$ (Keto, 2002), é possível obter um limite superior para a taxa de acreção, $\dot{M}_{*} \lesssim 3.0 \times 10^{-5} \mathrm{M}_{\odot}$ ano $^{-1}$. No entanto, esse resultado é menor que a taxa de acreção observada para estrelas do tipo $\mathrm{O} 5\left(\dot{M}_{*}=2.01 \times 10^{-4} \mathrm{M}_{\odot}\right.$ ano $\left.{ }^{-1}\right)$ e para estrelas do tipo B0.5 $\left(\dot{M}_{*}=0.47 \times 10^{-4} \mathrm{M}_{\odot}\right.$ ano $\left.^{-1}\right)$, determinados no mesmo trabalho. 


\subsection{Problemas Teóricos na Formação de Estrelas de Alta Massa}

Existem essencialmente dois argumentos teóricos que dão suporte à ideia de que a acreção via disco não seja o mecanismo dominante da formação dos MYSOs. Conforme discutido anteriormente, o primeiro argumento provém do fato de que, em comparação às estrelas de menor massa, os MYSOs apresentam escalas de Kelvin-Helmholtz relativamente curtas.

A escala de Kelvin-Helmhotz, definida pela Equação [1.2, para uma estrela B0 na sequência principal (classe de luminosidade do tipo V) com $\mathrm{M}=18.4 \mathrm{M}_{\odot}, \log \left(L / L_{\odot}\right)=$ 4.881 e $R=8.3 \mathrm{R}_{\odot}$ (Vacca et al., 1996), apresenta valores de $\tau_{K H} \approx 16 \times 10^{3}$ anos. Supondo, em primeira aproximação, que a taxa de acreção no objeto central $(\dot{M})$ seja constante ao longo do tempo de Kelvin-Helmholtz, temos

$$
\dot{M}=\frac{M_{*}}{\tau_{K H}}
$$

onde $M_{*}$ é a massa da estrela e $\tau_{K H}$ sua escala de tempo de Kelvin-Helmholtz. Para a formação de uma estrela do tipo solar, temos $\dot{M} \approx 10^{-8} \mathrm{M}_{\odot}$ ano ${ }^{-1}$ enquanto uma estrela do tipo B0V requer $\dot{M} \approx 10^{-3} \mathrm{M}_{\odot} \mathrm{ano}^{-1}$. Este resultado evidencia que o cenário de formação de estrelas de alta massa necessita de um mecanismo de acreção mais eficiente que o observado para as estrelas de menor massa.

A protoestrela de alta massa recém-formada apresenta um campo radiativo que pode se tornar intenso o suficiente para interromper o processo de acreção. Isso ocorre quando a força devido à pressão radiativa é maior do que a força gravitacional, condição que pode ser expressa por

$$
\frac{f_{\text {rad }}}{f_{\text {grav }}}=\frac{\left(\frac{L \kappa}{4 \pi c r^{2}}\right)}{\left(\frac{G M}{r^{2}}\right)}=\frac{L \kappa}{4 \pi G M c}>1
$$

onde $f_{\text {rad }}$ e $f_{\text {grav }}$ correspondem, respectivamente, à força específica (força por unidade de massa) radiativa e gravitacional, $L$ é a luminosidade emitida pela protoestrela, $\kappa$ é a opacidade média por unidade de massa do gás, $M$ é a massa da protoestrela, $r$ é a distância de um ponto até a protoestrela e as demais são constantes conhecidas. Considerando um caso de acreção isotrópica e adotando $\kappa=4.0 \mathrm{~cm}^{2} \mathrm{~g}^{-1}$, a condição $f_{\text {rad }} / f_{\text {grav }} \gtrsim 1$ é atingida para objetos com massa de $\sim 17 \mathrm{M}_{\odot}$ (entre os tipos espectrais B0 e B1) e luminosidade $L \sim 5 \times 10^{4} \mathrm{~L}_{\odot}$, evidenciando que objetos com maior massa não poderiam ser formados (via acreção isotrópica) mediante à intensa pressão de radiação gerada pela própria estrela. 
Conforme será discutido nas próximas seções, a presença de um disco equatorial ao redor das protoestrelas de alta massa seria capaz de diminuir consideravelmente a influência da pressão radiativa na região mais próxima à protoestrela, possibilitando a formação de tais objetos mesmo na presença de campos radiativos intensos.

O segundo fator que limita a formação dos MYSOs via disco de acreção decorre dos fortes ventos estelares associados a esses objetos. Alguns trabalhos mostram que os ventos de estrelas de alta massa podem apresentar momentum de 10 a 100 vezes maiores do que seu campo radiativo (Lada, 1985; Richer et al., 2000). Observações de protoestrelas de alta massa e simulações numéricas tri-dimensionais (Kuiper et al., 2011a) mostram que esses ventos são altamente colimados e não são capazes de impedir a acreção no objeto central. Como consequência dessa anisotropia, o material em acréscimo flui para a região equatorial da estrela, formando um disco. Simulações mais recentes sugerem que esse processo viabiliza a formação de estrelas com massa de até $137.2 \mathrm{M}_{\odot}$ (Kuiper et al., $2011 \mathrm{~b}$ ).

\subsection{Cenários de Formação de Estrelas de Alta Massa}

Enquanto a formação de estrelas de baixa massa é bem explicada pelo modelo de acreção via disco circunstelar, a teoria de formação dos MYSOs carece de detalhes e não está consolidada. O panorama atual é constituído por dois cenários distintos, que visam explicar a formação das estrelas de alta massa via mecanismos diferentes. A primeira teoria prediz que os objetos de alta massa seriam formados nos centros de aglomerados estelares densos a partir da fusão de estrelas de baixa massa. A segunda consiste num cenário análogo ao estabelecido para a formação dos YSOs de menor massa, com mecanismos de acreção mais eficientes e capazes de superar a pressão da radiação nas regiões próximas à protoestrela. Os diferentes cenários serão discutidos a seguir.

\subsubsection{Coalescência de Estrelas de Baixa Massa}

Inicialmente, o cenário de formação via disco não era capaz de explicar todos os aspectos de formação das estrelas de alta massa. O modelo de coalescência, proposto por Bonnell et al. (1998) surgiu como um cenário alternativo para a formação desses objetos.

Resumidamente, o cenário de coalescência proposto por Bonnell et al. (1998) sugere que estrelas de alta massa seriam formadas na região central de aglomerados de estrelas 
de baixa massa. As estrelas de baixa massa seriam formadas logo após a fragmentação da nuvem molecular. Num instante posterior, e dependendo da densidade do meio, as estrelas recém formadas sofreriam atração gravitacional entre si, colidindo e formando objetos sucessivamente mais massivos.

Dentre as principais falhas do cenário de coalescência, os seguintes pontos merecem destaque. O primeiro deles se refere ao fato de que o processo de coalescência depende estritamente da densidade do aglomerado e não teria um limite superior de massa para os objetos formados. No entanto, para que a coalescência seja efetivamente possível, o meio deve possuir densidades realmente altas ( $\gtrsim 10^{8}$ estrelas $\mathrm{pc}^{-3}$, Beuther et al., 2007). Finalmente, a baixa seção de choque do processo de coalescência de estrelas é um fator adicional que invalida esse cenário. A seção de choque $\left(\sigma_{*}\right)$ de um objeto com raio $R_{*}$ visto de frente é definida pela Equação 1.6. Considerando os casos de a) uma estrela na sequência principal sem envoltório ou disco $\left.\left(R_{*} \sim R_{\odot}\right), b\right)$ um sistema estrela+disco (fase MYSO, $R_{*, d} \approx 500 \mathrm{UA}$ e $c$ ) um núcleo quente (fase $\mathrm{HC}, R_{H C} \sim 0.1 \mathrm{pc} \approx 2.0 \times 10^{4} \mathrm{UA}$ ), as respectivas seções de choque desses objetos são estimadas em $\left.a) \sigma_{*} \lesssim 6.8 \times 10^{-5} \mathrm{UA}^{2} ; b\right)$ $\sigma_{*, d} \lesssim 7.9 \times 10^{5} \mathrm{UA}^{2}$ e $\left.c\right) \sigma_{H C} \lesssim 2.8 \times 10^{13} \mathrm{UA}^{2}$. Esses valores indicam que tanto a seção de choque quanto a probabilidade de colisão dos objetos ao longo da tragetória evolutiva na pré-sequência principal sofrem uma diminuição.

$$
\sigma_{*}=\pi R_{*}^{2}
$$

A Figura 1.3 ilustra os diferentes tipos de interação que poderiam ocorrer nos diferentes estágios da formação estelar. Na primeira linha, são mostradas as interações com maior seção de choque e, portanto, maior probabilidade de ocorrerem. Devido à natureza difusa dos núcles quentes, as colisões envolvendo esses objetos são as menos energéticas. Comparados aos objetos anteriores, a interação entre MYSOs são mais energéticos e apresentam menor probabilidade de ocorrência. Finalmente, as colisões mais energéticas e com probabilidades mais baixas são aquelas que envolvem duas estrelas sem envoltórios ou discos.

Existem algumas previsões observacionais que podem ser confrontadas com o cenário de formação via coalescência. São elas:

a) A energia liberada pelas colisões seria insuficiente para a formação e colimação dos jatos moleculares, tais como as estruturas identificadas em trabalhos anteriores 


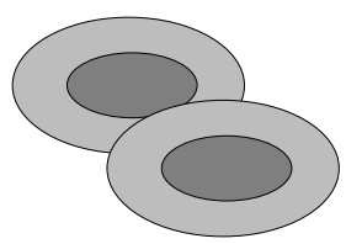

CoreCore

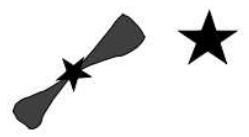

DiskStar

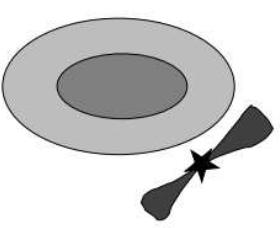

CoreDisk

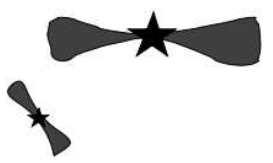

DiskDisk

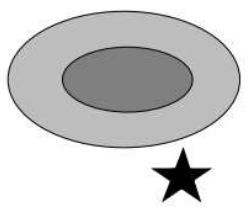

CoreStar

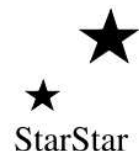

Figura 1.3: Possíveis colisões que poderiam ocorrer ao longo dos diferentes estágios da formação estelar em meios com alta densidade. A seção de choque (e consequente probabilidade de choque) diminui de cima para baixo e da esquerda para a direita, enquanto a energia liberada pelas colisões aumenta na mesma ordem. Adaptado de Bally e Zinnecker (2005).

(Davies et al., 2010; Varricatt et al., 2010) e o material não ligado gravitacionalmente ao sistema em colisão seria ejetado na forma de choques esporádicos e via ejeções não colimadas;

b) os estágios evolutivos definidos na Seção1.2 não seriam observados e as propriedades das fontes seriam influenciadas pelas características do meio, e não pelos processos astrofísicos intrínsecos da estrela em formação. Nesse sentido, não seria esperado observar objetos com distribuição espectral de energia tais como as apresentadas na Figura 1.2 ,

c) neste cenário, as estrelas de alta massa seriam formadas nas regiões centrais de aglomerados densos de estrelas de baixa massa. No entanto, nem todas as estrelas de alta massa em estágios pré-sequência principal conhecidas estão associadas a aglomerados estelares muito densos.

Contudo, as evidências observacionais que corroboram o cenário de coalescência são escassas. Uma das possíveis explicações se deve ao fato de que tais aglomerados seriam obscurecidos pela elevada extinção intrínseca $\left(A_{V}>200 \mathrm{mag}\right)$ das regiões de formação estelar. As simulações de n-corpos realizadas por distintos grupos (Baumgardt e Klessen, 
2011; Moeckel e Clarke, 2011) indicaram que a colisão estelar começa a se tornar um processo importante apenas na região central de aglomerados com populações estelares de ¿ 30 mil estrelas. No entanto, aglomerados tão populosos são relativamente raros na Galáxia e seu número é insuficiente para explicar a origem de todas as estrelas de alta massa conhecidas.

\subsubsection{Formação via Acreção por Disco}

O processo de acreção via disco circunstelar é uma extensão direta e análoga ao mecanismo de formação de estrelas de baixa massa, proposta por Shu et al. (1987). Nesse cenário, os discos circunstelares em estrelas de alta massa seriam estruturas naturalmente geradas pela conservação de momento angular durante a transferência de matéria do envoltório para o objeto central.

De acordo com os estágios evolutivos definidos na Seção1.2, a fase MYSO, iniciada logo após a contração do núcleo quente e caracterizada por objetos com alta densidade e elevada taxas de acreção, apresenta as propriedades adequadas para a formação de discos equatoriais ao redor do objeto central. Essa hipótese se mostra válida a partir de evidências indiretas de discos de acreção ao redor de MYSOs (Bik e Thi, 2004; Blum et al., 2004). Maiores detalhes sobre evidências observacionais dos discos serão vistas mais adiante.

A seguir, os principais componentes estruturais presentes nesse cenário - os discos, a formação e evolução dos jatos bipolares - serão descritos com maiores detalhes.

\section{A) Os Discos de Acreção}

Os discos circunstelares são a base da teoria de formação via acreção. O modelo mais simples de um disco de acreção é dado por uma estrutura com rotação diferencial do tipo Kepleriana (ou seja, a velocidade decresce com a raíz quadrada da distância ao objeto central). A composição do disco é dominada pela presença de moléculas de Hidrogênio $\left(\mathrm{H}_{2}\right)$ e $\mathrm{CO}$, as espécies moleculares mais abundantes das GMCs.

Em geral, as escalas associadas ao tamanho dos discos circunstelares ao redor de estrelas de alta massa são estimadas em 1000 UA (de Wit et al., 2009). O tamanho angular de um disco, localizado à distância de $\sim 1000$ pc (um valor típico para distâncias galácticas) corresponde a $\theta_{d} \sim 1^{\prime \prime}$ (um segundo de arco). Esse resultado ilustra a dificuldade em resol- 
ver espacialmente a estrutura dos discos circunstelares através de métodos diretos (imagens). Imagens diretas de discos circunstelares foram obtidas apenas para regiões relativamente próximas, tais como objetos pertencentes à nuvem de Órion (McCaughrean et al., 1998). Embora a identificação dos discos tenha contribuído efetivamente para o estabelecimento do cenário de acreção, a detecção de discos ativos se mostrou limitada a objetos de baixa massa.

Embora seja natural esperar que os discos associados a estrelas com maior massa sejam maiores, mais massivos e, portanto, de mais fácil detecção, as evidências de discos ao redor de estrelas de alta massa em formação são escassas. Dentre os efeitos que dificultam a detecção dessas estruturas, são destacados: i) os efeitos associados ao disco: dependendo da razão entre as massas do disco e da protoestrela, os discos de estrelas massivas são instáveis e têm curto tempo de vida (Cesaroni, 2002); ii) os efeitos associados aos processos astrofísicos estelares: a elevada pressão de radiação, fluxo UV e os fortes ventos estelares das protoestrelas OB contribuiriam para a fotoevaporação do disco, acelerando sua destruição (Yorke e Welz, 1996).

Poucas evidências observacionais de discos de acreção ao redor de objetos de alta massa em formação foram documentadas em trabalhos anteriores ao de Davies et al. (2010). Em alguns casos, os discos foram identificados através do ajuste de linhas de emissão na banda do CO, em $2.29 \mu \mathrm{m}$, em espectros de alta resolução no infravermelho próximo (Bik e Thi, 2004; Blum et al., 2004) ou em imagens na região milimétrica, centradas em linhas moleculares, tais como as transicões de amônia - $\mathrm{NH}_{3}-$ (Zhang et al., 1998, 2002) e de metil-cianeto - $\mathrm{CH}_{3} \mathrm{CN}$ (Cesaroni et al., 1997; Rosero et al., 2013).

Um modelo estrutural dos discos de acreção ao redor de estrelas de alta massa, mostrado na Figura 1.4, foi proposto por Zinnecker e Yorke (2007). De acordo com o cenário proposto por aqueles autores, a transferência de material ocorre no plano equatorial, fluindo desde as regiões mais afastadas do disco até a região central. Uma cavidade polar é gerada devido os intensos ventos e pressão de radiação produzidos pela protoestrela. A frente de ionização de maior energia penetra o disco e dissocia o gás de hidrogênio neutro $\left(\mathrm{H}_{2}\right)$, criando uma região de átomos de hidrogênio neutro $(\mathrm{HI})$. Os fótons UV de menor energia penetram até uma camada mais externa e geram uma terceira região, composta por átomos de hidrogênio ionizados (H II). Os grãos de poeira são destruídos no raio $r_{\text {dust }}$ enquanto o raio 
$r_{\text {evap }}$ define a região onde o gás é ligado gravitacionalmente ao disco $\left(r<r_{\text {evap }}\right)$ e a região onde a velocidade do som é maior que a velocidade de escape $\left(r>r_{\text {evap }}\right)$. Nas regiões mais próximas à estrela em formação, a velocidade de escape $\left(v_{e s c}\right)$ apresenta valores maiores que a velocidade do som $\left(v_{s}\right)$ e o gás ionizado permanece ligado gravitacionalmente. Para regiões mais distantes que o raio definido por $\mathrm{r}_{\text {evap }}$, a energia cinética do gás ionizado é maior que sua energia de ligação ao disco e a fotoevaporação dissipa uma fração da massa do disco, que é expelida para o meio interestelar.

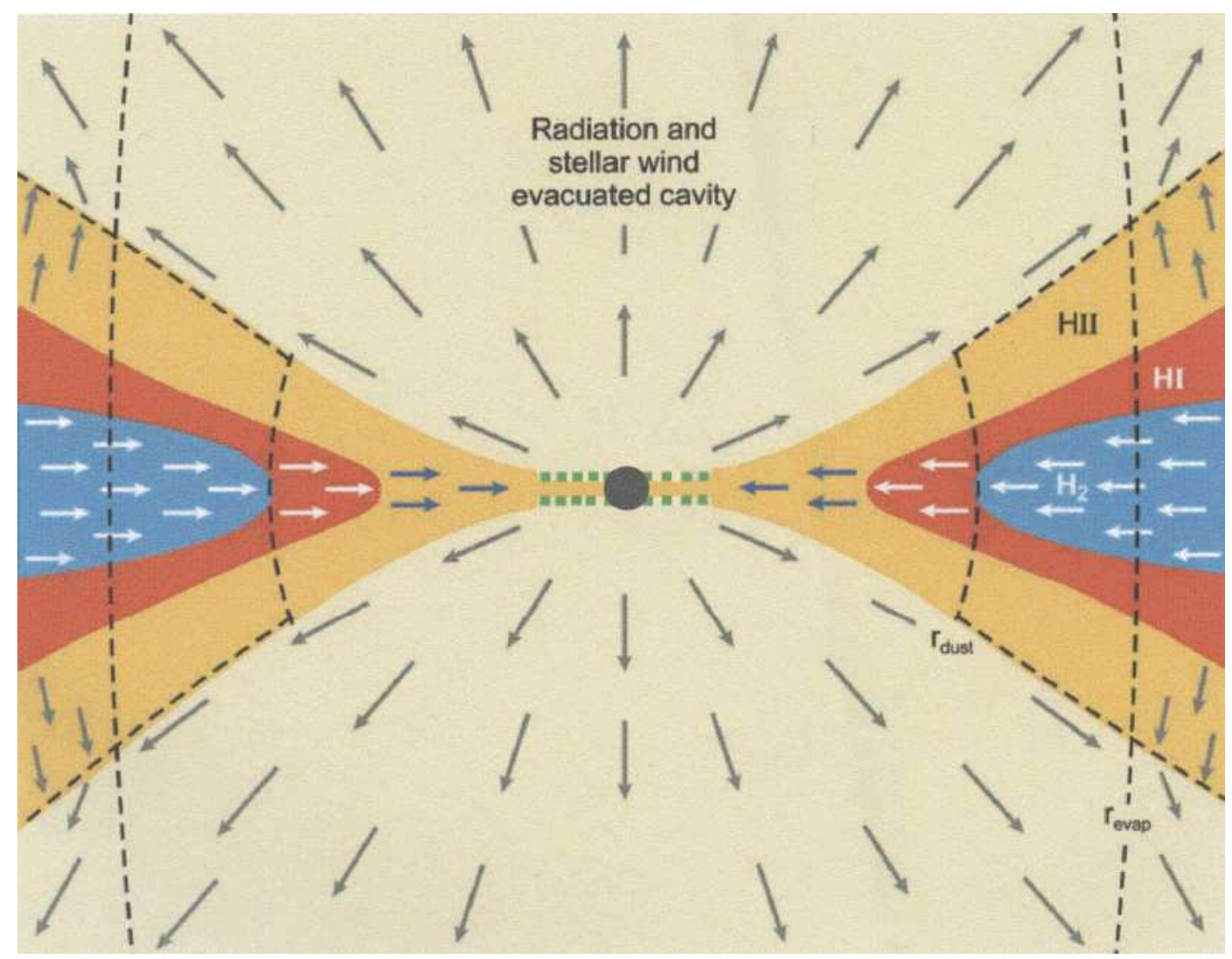

Figura 1.4: Modelo de formação via acreção por disco, adaptado de Zinnecker e Yorke (2007). As cores indicam regiões com diferentes composições e temperatura. Dois raios definem as regiões onde o hidrogênio ionizado não está gravitacionalmente ligado ao disco $\left(\mathrm{r}_{\text {evap }}\right)$ e a região a partir da qual ocorre a sublimação da poeira $\left(\mathrm{r}_{\text {dust }}\right)$.

Recentemente, a protoestrela Cepheus A HW2 se mostrou um caso bastante interessante de objeto de alta massa com evidências de disco circunstelar. Utilizando observações em rádio, Patel et al. (2005) identificaram a presença de uma estrutura oblata ao redor do objeto central, com massa estimada em $15 \mathrm{M}_{\odot}$ (Figura 1.5). A estrutura é orientada perpendicularmente e também coincide com a região central dos rádio-jatos associados à fonte central. 


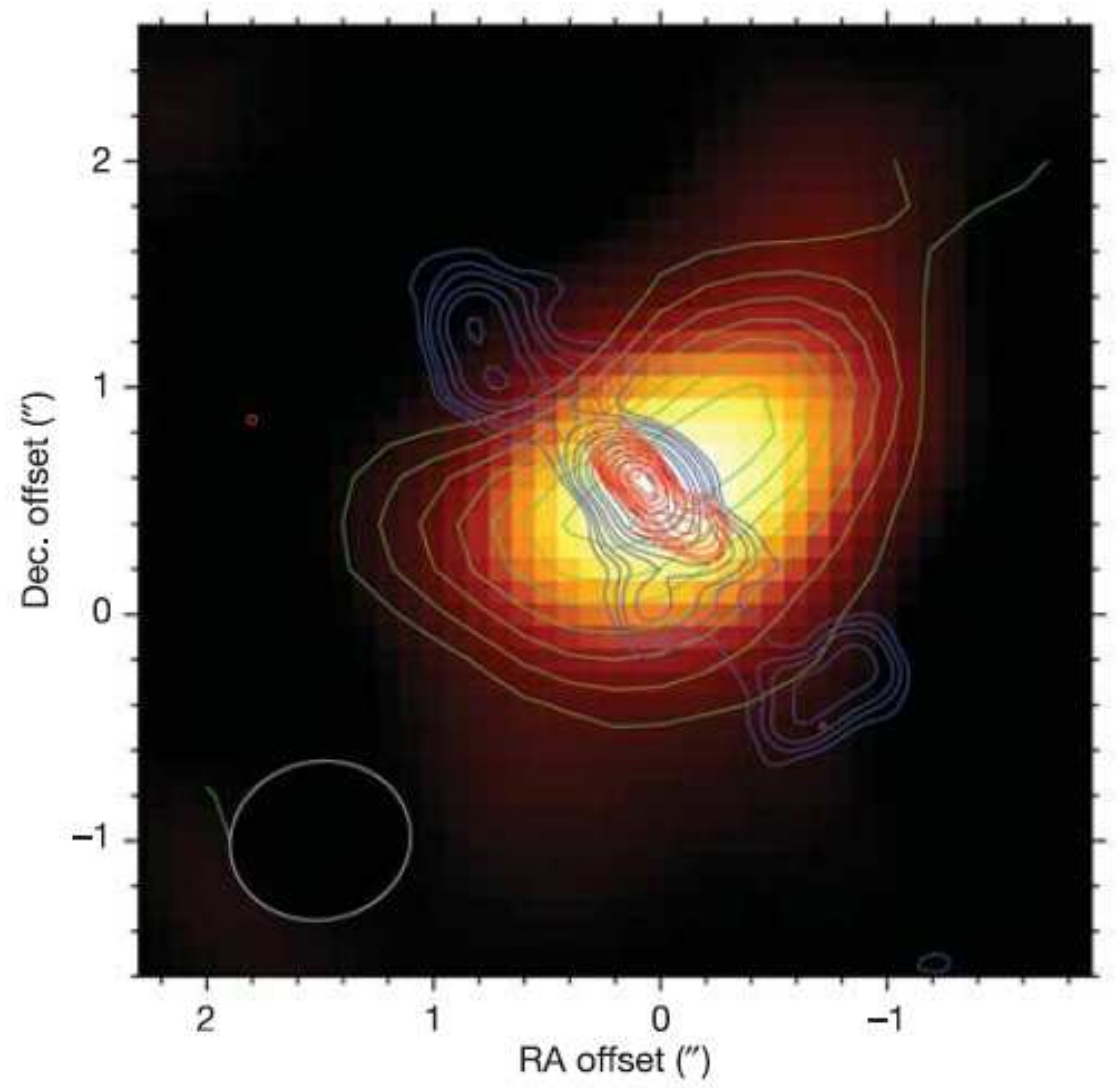

Figura 1.5: Protoestrela Cepheus A HW2. A imagem mostra a emissão da poeira em $327 \mathrm{GHz}$, os contornos (em cinza) mostram a emissão de $\mathrm{CH}_{3} \mathrm{CN}$ enquanto os contornos em azul indicam a emissão do contínuo em $1.3 \mathrm{~cm}$, delineando as partes mais internas do jato bipolar. Retirado de Patel et al. (2005).

Estruturas estendidas com aparência de jatos foram identificadas ao redor de objetos precursores de estrelas de tipo espectral B, sendo um dos casos mais conhecidos o objeto IRAS 20126+4102 (Cesaroni et al., 1997, 1999, 2005; Zhang et al., 1998). Outros trabalhos identificaram estruturas oblatas achatadas e perpendiculares aos jatos bipolares, sugerindo a presença de discos circunstelares ao redor destes objetos (Zhang et al., 2002; Beuther et al., 2005; Davies et al., 2010).

Supondo que o modelo de acreção circunstelar explique satisfatoriamente a formação das estrelas de alta massa, a presença de um disco e a ejeção de material colimada na forma de jatos devem estar estritamente relacionados, de modo que ambos os fenômenos devem ser estudados em detalhes e simultaneamente. Dessa maneira, a detecção de jatos ao redor de protoestrelas de alta massa é um teste crucial para caracterizar o cenário de formação desses objetos. 


\section{B) Jatos Bipolares}

Os jatos estelares são identificados a partir de observações em linhas proibidas ([Fe II] em $1.64 \mu \mathrm{m}$ no infravermelho próximo), em linhas atômicas (H $\alpha$, em $656.28 \mathrm{~nm}$ ) e transições moleculares $\left(\mathrm{H}_{2}\right.$ em $2.12 \mu \mathrm{m}$ e $\mathrm{CO}$ em $\left.230.5 \mathrm{GHz}\right)$. O fenômeno associado aos jatos não é restrito a estrelas jovens: Solf (1993) identificou estruturas semelhantes associadas a nebulosas planetárias enquanto Meisenheimer et al. (1996) verificou a existência de jatos extragaláticos em galáxias ativas. Em todos estes casos, os jatos estão intimamente ligados ao processo de ejeção de material pelo objeto central.

A identificação de jatos bipolares pode ser útil na investigação das propriedades das protoestrelas em formação e atuam como guias para a identificação do seu ponto de origem, geralmente obscurecido e não visível em comprimentos de onda ópticos (Eislöffel, 2000). A formação e evolução dos jatos estão estritamente ligadas à massa do objeto central. No caso de estrelas de baixa massa com intensa atividade magnética, o material proveniente do disco circunstelar e não acrescido pela protoestrela é direcionado pelas linhas do campo magnético na direção perpendicular ao disco, formando jatos moleculares altamente colimados. Nesse caso, é esperado que os jatos apresentem rotação, transportando o excesso de momentum angular do disco via acoplamento magnético. No entanto, são raros os casos em que foi detectada a rotação em jatos moleculares associados a objetos jovens (Pesenti et al., 2004; Chrysostomou et al., 2008).

Os efeitos magnéticos são menos intensos em estrelas de alta massas e a intensidade do campo magnético não é capaz de gerar jatos análogos aos observados em estrelas de baixa massa. Nesse caso, é esperado que a base de lançamento do jato seja o próprio disco de acreção, produzindo estruturas com menor grau de colimação (Drew et al., 1998).

O grau de colimação de um jato é estimado a partir da medida de sua razão de aspecto $(\mathrm{R}=$ comprimento/largura): quanto maior o valor de $R$, mais colimada é a estrutura observada. A determinação de $R$ permite estabelecer semelhanças e diferenças entre os cenários de formação das estrelas de alta e baixa massa, tais como mostra o trabalho de Wu et al. (2004). Aqueles autores obtiveram as razões de aspecto médias para uma grande amostra de estrelas de baixa $\left(R_{y s o}=2.8 \pm 2.2\right)$ e alta massa $\left(R_{\text {myso }}=2.1 \pm 1.0\right)$.

Observações em diversos comprimentos de onda mostram que a presença de jatos ocorre tanto em estrelas de baixa quanto de alta massa (Qiu e Leurini, 2011). Levantamentos 
realizados na transição (1-0) do CO (em $115 \mathrm{MHz}$ ) comprovam a existência de jatos moleculares ao redor de YSOs de baixa massa (Bachiller, 1996). Mais recentemente, estruturas análogas foram identificadas em YSOs de massa intermediária e em objetos jovens com massas relativamente altas a partir de observações na transição $(2-1)$ do $\mathrm{H}_{2}(2.12 \mu \mathrm{m})$ no infravermelho próximo (Figura 1.6, Varricatt et al., 2010).
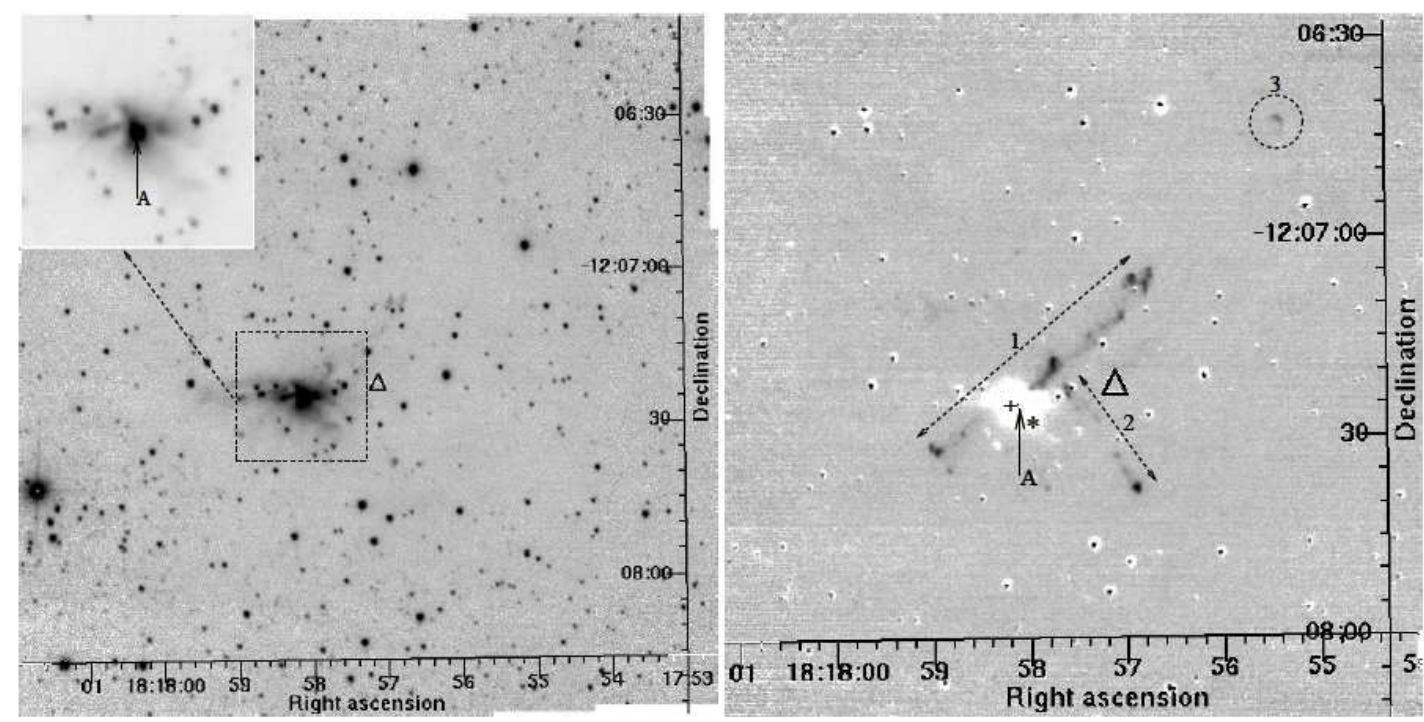

Figura 1.6: Fonte IRAS 18151-1208 na banda K (esquerda) e um mapa de emissão em $\mathrm{H}_{2}$ da região (direita), indicando a presença de dois jatos bipolares associados ao objeto central, com $\mathrm{L}=2.0 \times 10^{4}[d / 3.0 \mathrm{kpc}] \mathrm{L}_{\odot}$ e massa $M \sim 15 \mathrm{M}_{\odot}$. Adaptado de Varricatt et al. (2010).

Assumindo a função de massa inicial de Salpeter $(1955)-N_{*}(m) \propto M^{-2.35}-$, a fração de estrelas de alta massa é muito inferior quando comparada à população de baixa massa. Como consequência direta, o número de jatos originados em MYSOs deve ser bem menor que o observado para os YSOs de baixa massa. Tal raciocínio evidencia a pequena amostragem de objetos de alta massa associados a discos, que vem dificultado bastante o progresso desse campo nas últimas décadas. Com objetivo de melhorar esta situação, Varricatt et al. (2010) conduziram um levantamento visando a detecção de jatos bipolares em candidatos a MYSOs. Os resultados observacionais daquele trabalho mostraram que cerca de $76 \%$ dos alvos apresentam emissão em $\mathrm{H}_{2}$, e em $50 \%$ dos alvos observados, a emissão em $\mathrm{H}_{2}$ possui certa simetria, sugerindo a existência de jatos colimados. A Figura 1.6 apresenta um exemplo de jato bipolar associado ao objeto IRAS 18151-1208, uma fonte de alta luminosidade $\left(\mathrm{L}=2.0 \times 10^{4}[d / 3.0 \mathrm{kpc}] \mathrm{L}_{\odot}\right)$ observada por aqueles autores. Embora nenhuma estrela do tipo O de maior massa tenha sido identificada na amostra de Varricatt et al. (2010), os 
resultados observacionais apresentados naquele trabalho são importantes e corroboram a teoria de formação via acreção, uma vez que o modelo baseado na coalescência de estrelas (Bonnell et al., 1998) é incapaz de produzir jatos colimados.

\section{C) Formação e Evolução dos Jatos Bipolares}

O modelo clássico da formação de estrelas de baixa massa de Shu et al. (1987) discute em detalhes a origem e formação dos jatos associados àqueles objetos. Mais recentemente, Goodson et al. (1997) apresentam um modelo e simulações numéricas da formação dos jatos associados a objetos jovens. Aqueles autores sugerem que a ejeção de matéria na forma de jatos bipolares é decorrente da interação entre a magnetosfera estelar e o disco circunstelar. Num trabalho posterior, Goodson et al. (1999) identificaram duas componentes distintas em jatos associados a objetos jovens: uma componente interna, com alta velocidade e baixa densidade; e uma externa, mais lenta e mais densa. Observações do HST realizadas por Bacciotti et al. (2000) corroboram o modelo de Goodson et al. (1997) e indicam velocidades de até $200 \mathrm{~m} \mathrm{~s}^{-1}$ e densidades superiores à $10^{4} \mathrm{~cm}^{-3}$ na região mais interna do jato pertencente a DG Tau.

O material do meio interestelar quiescente é aquecido e excitado devido aos choques produzidos pela interação com os jatos protoestelares, gerando a emissão observada. Choques não magnéticos (ou pure jump shocks) não são capazes de explicar temperaturas superiores à $500 \mathrm{~K}$. Nestes casos, o $\mathrm{H}_{2}$ é dissociado na frente de choque e o gás se resfria via emissão rotacional na região pós-choque (Kwan et al., 1977). Choques dissociativos com precursores magnéticos, ou choques de salto (tipo J, jump shocks) são assim denominados devido ao fato de que os parâmetros magnetohidrodinâmicos são descontínuos ao longo da frente de choque. Choques contínuos (tipo C) apresentam parâmetros contínuos ao longo do choque, e têm origem em regiões com fortes campos magnéticos. Neste caso, o amortecimento magnético resulta numa pequena (ou nula) dissociação do $\mathrm{H}_{2}$ ao longo do choque (Draine, 1980; Draine et al., 1983). Observações espectroscópicas de 6 objetos do tipo T Tauri indicam que a razão de linhas de diversas transições do $\mathrm{H}_{2}$ no infravermelho próximo são consistentes com previsões para choques do tipo C. Temperaturas da ordem de $\sim 2.0 \times 10^{3} \mathrm{~K}$ indicam que grande parte da emissão é formada a partir de gás em equilíbrio termodinâmico (Beck et al., 2008). 
Estudos em YSOs de baixa massa revelaram que os jatos moleculares persistem até os estágios mais tardios de estrelas T Tauri e Herbig Ae/Be (Corcoran e Rav,, 1998; Mundt e Eislöffel, 1998), desaparecendo à medida em que o processo de acreção termina e o disco evolui passivamente ao estágio de disco protoplanetário (Eislöffel, 2000).

\section{D) Influência do Discos e Jatos na Distribuição Espectral de Energia}

A distribuição espectral de energia (SED, Spectral Energy Distribution) permite inferir propriedades intrínsecas dos objetos em estudo, fornecendo informações para a compreensão dos fenômenos físicos associados à formação das protoestrelas. No entanto, a determinação da SED de protoestrelas é uma tarefa complicada, principalmente devido ao fato de que, enquanto as regiões de formação estelar são facilmente resolvidas espacialmente por técnicas interferométricas em comprimentos de onda rádio (Cesaroni et al., 1999; Shepherd et al., 2003; Beuther et al., 2004), a determinação do fluxo destes objetos em menores comprimentos de onda é dificultada pela elevada extinção interestelar das regiões de formação estelar $\left(A_{V} \sim 200 \mathrm{mag}\right)$ e, ainda, pela confusão de fontes em meios de alta densidade estelar.

Os dados obtidos com o satélite IRAS possibilitaram a obtenção da luminosidade integrada de objetos jovens utilizando ajustes com duas componentes de corpo cinza (Hunter et al., 2000; Sridharan et al., 2002) e o modelamento das SEDs permitiu inferir as características das protoestrelas nas regiões de formação de estrelas de alta massa (Osorio et al., 1999). As observações realizadas pelo satélite SPITZER tornaram possível o refinamento da fotometria obtida pelo satélite IRAS e, devido sua maior resolução angular, foi capaz de resolver fontes múltiplas, melhorando consideravelmente a determinação das SEDs individuais.

Lada e Wilking (1984) desenvolveram uma classificação esquemática de estrelas jovens de baixa massa a partir da análise de suas SEDs. Essa classificação foi aprimorada por André e Montmerle (1994), tomando como base aspectos observacionais dos diferentes estágios da formação estelar. A Figura 1.7 ilustra o esquema proposto por aqueles autores e apresenta as 4 classes definidas a partir do perfil da SED observada, a saber:

- Classe 0: são objetos extremamente jovens que apresentam um espectro equivalente a um corpo negro de baixa temperatura $(\mathrm{T} \sim 30 \mathrm{~K})$; 
- Classe I: é constituída por objetos jovens (10 5 anos), cujo espectro possui uma componente quente, devido a radiação do objeto central, e uma componente fria, originada pelo reprocessamento da radiação estelar pelo disco de acreção;

- Classe II: são objetos em estágios mais tardios $\left(10^{6}\right.$ anos $)$ e mostram um espectro com menor excesso de emissão no vermelho;

- Classe III: representa a última etapa do processo de formação e é constituída por objetos no término do período de acreção. A influência do disco é praticamente desprezível e o espectro observado possui apenas a componente estelar.
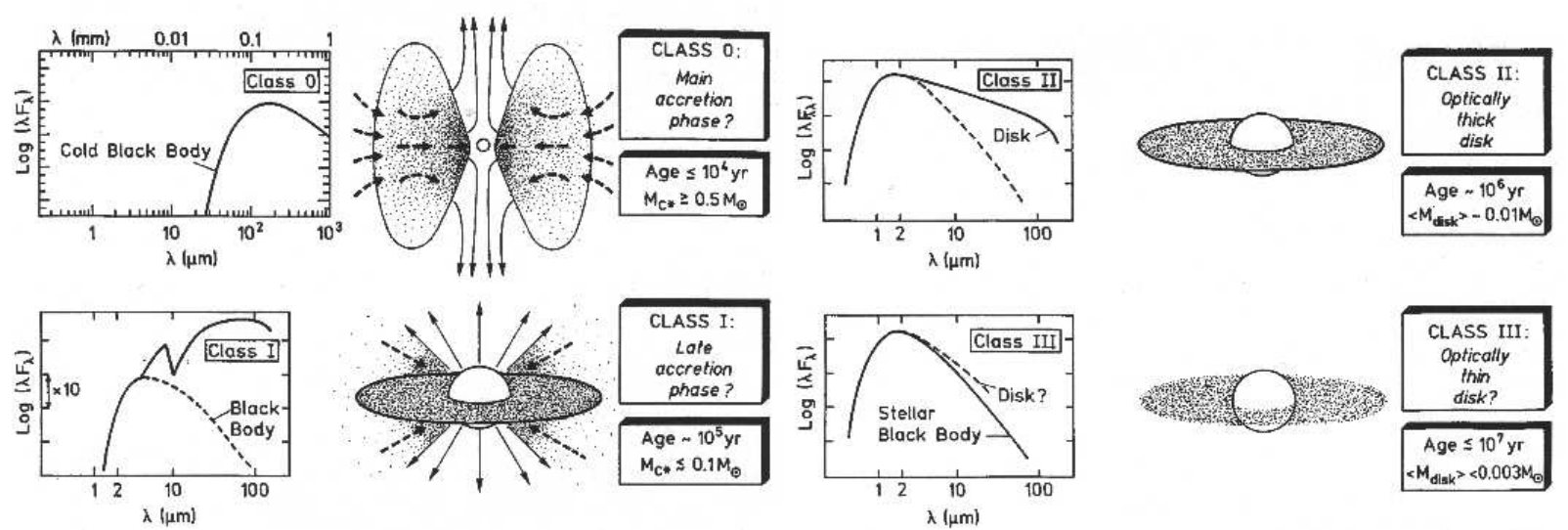

Figura 1.7: Diagrama esquemático dos estágios da formação de estrelas de baixa massa, baseado na distribuição espectral de energia. Retirado de Bachiller (1996).

Supondo que o cenário de acreção possa explicar a formação de estrelas de alta massa, o critério para classificar as protoestrelas de baixa massa também deveria ser válido para a classificação de objetos com maior massa. De fato, é possível encontrar semelhanças entre a SED de um YSO de Classe 0 (Painel A, Figura 1.7) com a SED de um objeto de alta massa na fase MYSO (Figura 1.2).

De acordo com a classificação de Lada e Wilking (1984) e André e Montmerle (1994), é esperado que jatos associados a objetos de classe 0 apresentem alto grau de colimação, objetos de classe I estejam associados a jatos menos colimados e, no caso de objetos em estágios mais tardios, espera-se a ausência de jatos ou jatos com baixo grau de colimação.

Apresentados os principais componentes do modelo de formação estelar via acreção - seus discos, os jatos e sua distribuição espectral ao longo da trajetória evolutiva -, é 
interessante apresentar um modelo temporal da evolução de tais estruturas como função do tempo. Dessa forma, o modelo de Krumholz et al. (2009) será brevemente discutido a seguir.

\subsection{Modelos Numéricos da Formação de Estrelas de Alta Massa de Krumholz}

A partir de simulações numéricas tridimensionais do processo de formação de estrelas de alta massa, Krumholz et al. (2009) apresentam um modelo bastante detalhado desse cenário. Enquanto simulações bidimensionais mostram que a pressão de radiação impedem o processo de acreção por disco em estrelas com massas de $\geq 40 \mathrm{M}_{\odot}$ (Jijina e Adams, 1996), a inclusão de uma dimensão extra permite estudar com maior clareza as instabilidades que determinam a interação entre o gás e a radiação (e.g. instabilidades de Raleigh-Taylor). Visando estudar apenas os efeitos relacionados à radiação, as simulações não consideraram efeitos devido à turbulência e a presença de jatos bipolares.

Os autores estudaram a evolução das equações hidrodinâmicas gravito-radiativas (gravitoradiation-hydrodynamics) num modelo cinza (opacidade $\kappa$ independente do comprimento de onda) e na aproximação difusiva, adotando como condições iniciais uma nuvem de $100 \mathrm{M}_{\odot}$, raio de $0.1 \mathrm{pc}$, temperatura de $20 \mathrm{~K}$ e perfil de densidade $\rho \propto r^{-3 / 2}$ [consistentes com as propriedades do ambiente de formação de estrelas de alta massa estabelecidas em McKee e Tan (2002, 2003) e as observações sub-milimétricas realizadas por Beuther et al. (2007)].

A Figura 1.8 apresenta imagens da simulação realizada por Krumholz et al. (2009) em cinco instantes: $\mathrm{t}=17500(\mathrm{~A}), \mathrm{t}=25000(\mathrm{~B}), \mathrm{t}=34000(\mathrm{C}), \mathrm{t}=41700(\mathrm{D})$ e $\mathrm{t}=55900 \operatorname{anos}(\mathrm{E})$. Os principais resultados da simulação serão brevemente descritos a seguir.

O colapso da nuvem é iniciado rapidamente e a formação da protoestrela tem início após $3.6 \times 10^{3}$ anos. Ao término dos primeiros $\sim 17$ mil anos, a acreção via disco possibilita a formação de um objeto central com massa de $11 \mathrm{M}_{\odot}$ (Painel A, Figura 1.8). Nesta fase, a razão entre a luminosidade e a massa se mantém abaixo de $\mathrm{L} / \mathrm{M} \leq 1000 \mathrm{~L}_{\odot} / \mathrm{M}_{\odot}$ e a pressão de radiação ainda não é suficiente para gerar efeitos relevantes. 

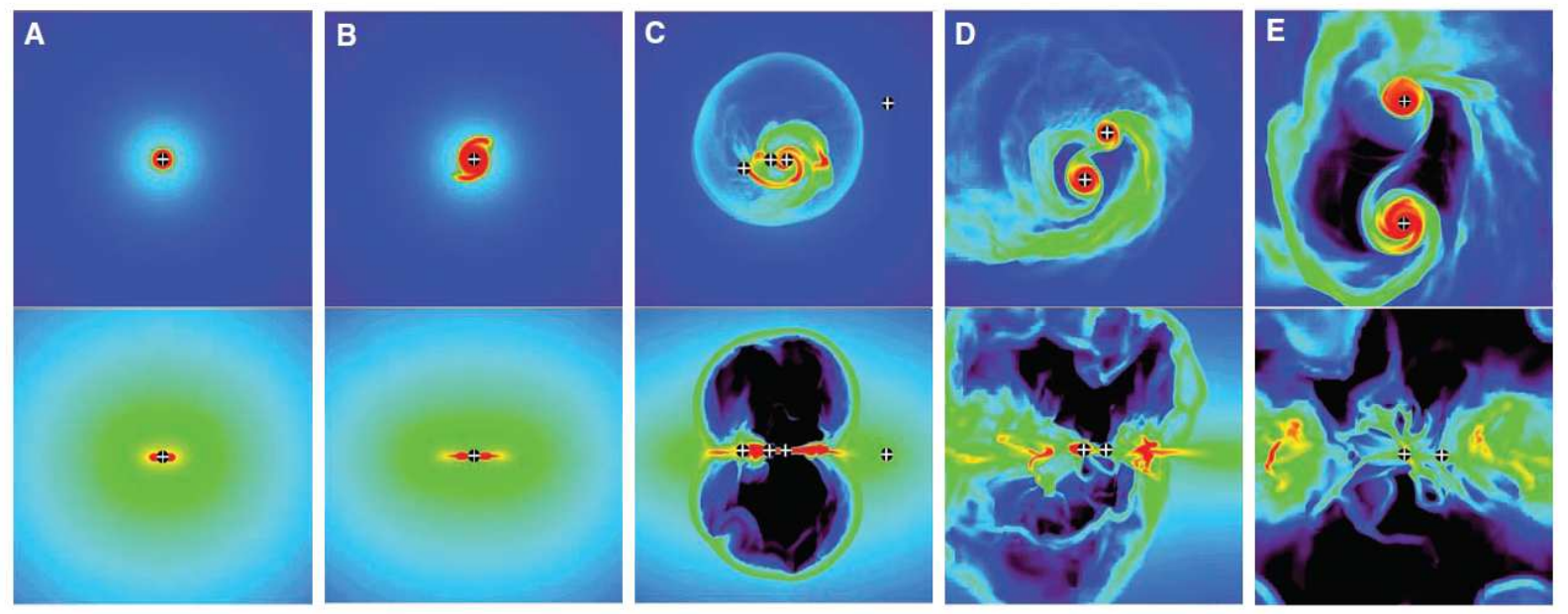

Figura 1.8: Imagens das simulações em (A) 17500 anos, (B) 25000 anos, (C) 34000 anos, (D) 41700 anos, and (E) 55900 anos, retirado de Krumholz et al. (2009). Em cada painel, a figura superior mostra a densidade colunar perpendicular ao eixo de rotação numa escala de 3000 unidades astronômicas enquanto a figura inferior apresenta o perfil de densidade volumétrica em um corte paralelo ao eixo de rotação. A escala de cores logarítimica apresenta os valores mínimos em preto e os valores máximos em vermelho, de $10^{0}$ para $10^{2.5} \mathrm{~g} \mathrm{~cm}^{-2}$ (superior) e $10^{-18}$ para $10^{-14} \mathrm{~g} \mathrm{~cm}^{-3}$ (inferior). Os símbolos (+) indicam a posição projetada das estrelas.

Em $\sim 20$ mil anos, o disco torna-se gravitacionalmente instável e é redistribuído na forma de dois braços espirais, transportando efetivamente o excesso de momento angular da protoestrela para o material circundante (Painel B, Fig. 1.8).

A acreção persiste até $\sim 26$ mil anos, quando a massa central da estrela atinge $\sim 17 \mathrm{M}_{\odot}$. Nesse ponto, a pressão de radiação torna-se importante, gerando "bolhas" de radiação que se expandem na direção radial, entre entre os polos da estrela e o plano do disco circunstelar (Painel C, Fig. 1.8). Os efeitos radiativos alteram significativamente a geometria do sistema. São geradas zonas de compressão nas regiões de interface entre a radiação e o material quiescente. Embora a geometria do sistema seja alterada significativamente devido aos efeitos radiativos, a acreção não é interrompida. O material presente nas imediações da estrela flui através da interface entre a radiação e o gás, alimentando o disco circunstelar. Nesta fase, a assimetria do disco aumenta gradativamente enquanto uma série de objetos de baixa massa são formados na região circunstelar. Esses objetos são advectados para a direção interna do disco devido ao efeito da fricção dinâmica e colidem com a protoestrela de alta massa. A taxa de acreção no objeto central, outrora dominada pelo disco, se torna variável devido à coalescência das estrelas de baixa massa. Neste estágio, a combinação entre a coalescência de estrelas de menor massa e o processo de acreção competitiva são 
responsáveis pela formação de um segundo corpo, que permanece ligado gravitacionalmente ao sistema.

Em $\sim 35$ mil anos, o objeto gerado a partir das fusões estelares possui massa suficiente para resistir ao arraste (Painel D, Fig.1.8). Esta segunda estrela orbita a protoestrela central, interceptando o gás do disco e aumentando gradativamente sua massa via acreção competitiva. Nesse ponto, o disco se fragmenta em duas estruturas, formando um disco ao redor de cada protoestrela e a taxa de acreção total é dividida entre as duas protoestrelas.

A simulação numérica foi interrompida em $\sim 55$ mil anos, após 20 mil anos sem mudanças significativas no sistema. Ao término, o sistema binário apresentou massa total de $70.7 \mathrm{M}_{\odot}$ e luminosidade total de $5 \times 10^{5} \mathrm{~L}_{\odot}$ (Painel E, Fig. 1.8). As massas individuais atigiram valores de 41.5 e $29.2 \mathrm{M}_{\odot}$, e as estrelas se mantiveram em órbita com uma separação de 1590 UA. Distâncias semelhantes foram observadas em sistemas de estrelas O jovens (Mason et al., 1998).

O trabalho de Krumholz et al. (2009) mostra que ambos os processos de acreção via disco e coalescência de estrelas de baixa massa estão ativos durante a formação de estrelas de alta massa. No entanto, a contribuição da coalescência representa uma pequena fração $(<5 \%)$ da massa total das protoestrelas (o ganho de massa devido à fusão de estrelas foi de $\sim 1.8 \mathrm{M}_{\odot}$ para a estrela de $\sim 40 \mathrm{M}_{\odot}$ e $1.2 \mathrm{M}_{\odot}$ para a de $\left.\sim 30 \mathrm{M}_{\odot}\right)$.

A eficiência da formação estelar foi de $\eta_{* f} \sim 70 \%$ e a maior parte da acreção ocorreu durante os primeiros 52.5 mil anos. Krumholz et al. (2009) discutem que a inclusão de efeitos associados aos jatos bipolares reduziriam o valor de $\eta_{* f}$ para $\sim 50 \%$ (Matzner, 2007). Por fim, os autores também sugerem que que as cavidades geradas pelos jatos reduziriam os efeitos da pressão de radiação ainda mais, modificando a geometria das bolhas de radiação ou mesmo impedindo a formação das mesmas.

\subsection{Estimativa do número de MYSOs na Galáxia}

Como motivação para o estudo da formação dos MYSOs, esta seção apresenta uma estimativa quantitativa da população de estrelas de alta massa em formação na Galáxia. O método mais convencional para se obter este valor é assumir uma IMF. Sabendo o tempo de vida neste estágio evolutivo, que também é uma função da massa dos objetos 
considerados, pode-se obter o número de MYSOs $\left(N_{*}\right)$ com massa entre $\mathrm{M}_{1}$ e $\mathrm{M}_{2}$ como

$$
N_{*}\left(M_{1} \rightarrow M_{2}\right)=\int_{M_{1}}^{M_{2}} t_{*}(m) \xi(m) \mathrm{d} m
$$

onde $t_{*}$ corresponde ao tempo de formação de uma estrela com massa $m$ e $\xi(m)$ é a IMF para uma dada massa $m$, cuja dimensão é $\mathrm{M}_{\odot}$ ano $^{-1}$. A IMF de Salpeter (1955) é dada por

$$
\xi(m) \mathrm{d} m=\kappa_{s f} M(m)^{-2.35} \mathrm{~d} m
$$

onde $\kappa_{s f}$ é uma constante de normalização obtida a partir da taxa média de formação de estrelas da Galáxia (6 $\mathrm{M}_{\odot}$ ano $^{-1}$, Guesten e Mezger, 1982) na seguinte forma

$$
\begin{array}{r}
\int_{M_{\min }}^{M_{\max }} M(m) \xi(m) \mathrm{d} m=6 \mathrm{M}_{\odot} \mathrm{ano}^{-1} \\
\Rightarrow \kappa_{s f} \int_{M_{\min }}^{M_{\max }} M(m)^{-1.35} \mathrm{~d} m=6 \mathrm{M}_{\odot} \mathrm{ano}^{-1} \\
\Rightarrow \kappa_{s f}=\frac{2.1}{M_{\text {min }}^{-0.35}-M_{\text {max }}^{-0.35}}
\end{array}
$$

Assumindo $M_{\max }=150 \mathrm{M}_{\odot}$ e $M_{\min }=0.1 \mathrm{M}_{\odot}$ como limites de massa da IMF (Equação 1.9), o valor da constante é determinado em $\kappa_{s f}=1.017$. Supondo que $t_{*}(m)$ seja da ordem da escala de tempo de contração de Kelvin-Helmholtz $\left(\tau_{H K}=3.1 \times\right.$ $\left.10^{7}\left(M / M_{\odot}\right)^{-2}\right)$, a Equação 1.7 é reescrita como:

$$
\begin{aligned}
N_{*}\left(M_{1} \rightarrow M_{2}\right) & =\int_{M_{1}}^{M_{2}} t_{K H}(m) \kappa M(m)^{-2.35} \mathrm{~d} m \\
& =3.1 \times 10^{7} \kappa \int_{M_{1}}^{M_{2}} M(m)^{-4.35} \mathrm{~d} m \\
\Rightarrow N_{*}\left(M_{1} \rightarrow M_{2}\right) & =9.4 \times 10^{6} \kappa\left(M_{1}^{-3.35}-M_{2}^{-3.35}\right)
\end{aligned}
$$

Para um intervalo de massa entre $15 \mathrm{M}_{\odot}(\mathrm{B} 0)$ e $150 \mathrm{M}_{\odot}$ (estrelas do tipo O), são esperados 1079 MYSOs. Relaxando o limite inferior de massa para $8 \mathrm{M}_{\odot}$ (B3), a população de estrelas de alta massa aumenta para 8867. No entanto, estrelas de tipos espectrais entre B0 e B3 seriam mais difíceis de se detectar ao longo da Galáxia. Além disso, a estimativa de $N_{*}$ está sujeita a limites e restrições das aproximações e modelo de IMF utilizados. Mudanças destes parâmetros podem aumentar ou diminuir o valor de $N_{*}$.

Modelos de IMF mais recentes, obtiveram valores de $\alpha=2.3$ (Kroupa, 2007) para estrelas com massa superior à $0.5 \mathrm{M}_{\odot}$. Adotando este valor, a quantidade de MYSOs com massa superior à $15 \mathrm{M}_{\odot}$ seria de 1439 . 


\subsection{Motivação e Objetivos desta Dissertação}

Dada a escassez de dados sobre os processos envolvidos durante a formação de estrelas de alta massa e a falta de evidências dos cenários de coalescência e acreção por disco, este trabalho apresenta um estudo observacional de fontes na fase pré-UCH IIs (candidatos a MYSOs) selecionadas a partir do levantamento Red MSX Source (RMS, Mottram et al., 2011). Conforme será apresentado nos próximos capítulos, candidatos a estrelas de alta massa foram selecionadas a partir de critérios de cor no infravermelho e, também, mediante evidências observacionais relacionadas à formação estelar. No entanto, estudos posteriores revelaram que os objetos com maior luminosidade das amostras eram compatíveis com estrelas de massas intermediárias. Esses resultados sugerem a existência de falhas nos critérios de seleção das fontes e indica a necessidade de um estudo multi-espectral para selecionar objetos realmente massivos. O levantamento Red MSX Source (discutido em detalhes no Caṕitulo 2) apresenta uma série de observações em diferentes comprimentos de onda, utilizadas como critério de seleção de uma amostra de $\sim 400$ candidatos a MYSOs.

Esta dissertação apresenta um levantamento de candidatos a MYSOs, selecionados pelo levantamento RMS, observados no filtro do $\mathrm{H}_{2}$ no infravermelho próximo. A emissão em $\mathrm{H}_{2}$ traça a geometria do material ejetado durante o processo de acreção e corrobora o cenário de acreção via disco circunstelar. Dentre os principais objetivos do presente trabalho, destacam-se

i) a apresentação e análise dos mapas de emissão em $\mathrm{H}_{2}$ dos candidatos a MYSOs, observados nos telescópios CFHT e SOAR, entre 2010 e 2012; e

ii) a seleção de bons candidatos a MYSOs em fase de acreção, a serem explorados com técnicas mais poderosas em telescópios maiores.

O levantamento também poderá ser usado para obter informações estatísticas, como a iii) frequência de jatos e $i v$ ) a taxa de colimação em função da luminosidade infravermelha. O primeiro parâmetro está ligado ao tempo característico dessas estruturas e a taxa de acreção, enquanto o segundo está relacionado ao papel do disco na geração dos jatos.

A dissertação está estruturada em 6 capítulos. O Capítulo 2 apresenta a) uma revisão dos diversos levantamentos que selecionaram candidatos a estrelas de alta massa em 
formação utilizando critérios de seleção em diferentes comprimentos de onda e $b$ ) descreve as observações realizadas pelo levantamento Red $M S X$ Source. A metodologia adotada é descrita no Capítulo 3. O Capítulo 4 apresenta os resultados observacionais e em especial, as fontes associadas à emissões polares. A análise e discussão dos resultados são mostradas no Capítulo 5. Por fim, o Capítulo 6 sintetiza as principais conclusões da dissertação e apresenta as perspectivas para a continuidade do trabalho. 


\section{Capítulo 2}

\section{Levantamentos de Candidatos a MYSOs}

\subsection{Histórico e Avanços Instrumentais}

Até meados de 1985, observações no infravermelho se basearam em imagens obtidas a partir do solo e com resolução angular de alguns minutos de arco ('). Os primeiros catálogos de candidatos a MYSOs (Wynn-Williams, 1982; Henning et al., 1984), foram obtidos a partir de observações no infravermelho próximo e médio, entre 2 e $13 \mu \mathrm{m}$. Tais catálogos apresentaram uma pequena lista contendo apenas $\approx 50$ objetos, representando menos de $10 \%$ do número esperado para a população de estrelas de alta massa jovens na Galáxia.

A seguir, serão apresentados os avanços instrumentais, desde o lançamento do satélite IRAS até as observações realizadas com o satélite MSX, e suas implicações na seleção de candidatos a estrelas de alta massa em formação.

\subsubsection{A Missão IRAS}

O lançamento do satélite astronômico infravermelho (IRAS, InfraRed Astronomical Satellite) possibilitou que candidatos a MYSOs fossem selecionados a partir de fotometria no infravermelho distante (FIR). O satélite IRAS observou $\sim 96 \%$ do céu e detectou cerca de 250 mil objetos puntuais, contidos no catálogo de fontes puntuais do IRAS. As observações realizadas pelo IRAS tornou possível a coleta de informações na faixa espectral em que ocorre o pico da emissão térmica dos objetos estelares jovens (entre 60 e $120 \mu \mathrm{m}$, Mottram et al., 2011), constituindo um bom ponto de partida para a seleção de candidatos a estrelas em formação. De fato, os primeiros levantamentos clássicos de candidatos YSOs (Wood e Churchwell, 1989; Palla et al., 1991; Fontani et al., 2005) usaram critérios 
de índices de cor no infravermelho distante (FIR, Far Infrared) de fontes contidas no catálogo de fontes puntuais do IRAS.

Embora as amostras baseadas nas cores IRAS tenham contribuído significativamente para o estudo nesta área, a quase totalidade das amostras resultou em objetos de baixa massa e os altos valores associados às incertezas fotométricas foram responsáveis por incluir outros objetos com cores no FIR semelhantes, tais como regiões H II normais, estrelas frias (pós-AGBs) e nebulosas protoplanetárias (pPNe). Além disso, a baixa resolução angular, entre 45" e 120" para os diferentes filtros (vide Figura 2.3), impossibilitou a obtenção do fluxo de objetos individuais em regiões de alta densidade estelar.

\subsubsection{O Satélite ISO}

O Observatório Espacial Infravermelho (ISO, Infrared Space Observatory) esteve em operação entre 1996 e 1998, observando o céu entre 2.5 e $240 \mu \mathrm{m}$ com quatro instrumentos a bordo, duas câmeras imageadoras e dois espectrometros. Seus maiores legados na área de formação estelar foram: $i$ ) a descoberta de emissão de vapor de água em regiões de formação estelar (Harwit et al., 1998); ii) a primeira detecção de uma estrela nos estágios primordiais de formação, a L1689B (Ward-Thompson et al., 1998); e iii) a procura por discos protoplanetários, base dos primeiros estágios da formação planetária (van Dishoeck et al., 1999; Ward-Thompson et al., 2004).

A Figura 2.1 apresenta os mapas do núcleo pré-estelar L1544, obtidos a partir de observações com o ISOPHOT nos comprimentos de onda de 90, 170 e $200 \mu \mathrm{m}$ (Nisini et al., 2005). Dada sua baixa temperatura ( $\mathrm{T} \sim 10 \mathrm{~K}$ ), a intensidade da fonte em $90 \mu \mathrm{m}$ é relativamente baixa quando comparada aos comprimentos de onda mais longos.

A resolução angular das observações realizadas com a ISOCam esteve limitada entre 1.5" (em $2.5 \mu \mathrm{m})$ e 17" (em $15 \mu \mathrm{m})$. Observações realizadas com a ISOPHOT apresentaram resolução angular de 43" para comprimentos de onda entre 30 e $100 \mu \mathrm{m}$, e 89" para a região de 100 - $200 \mu \mathrm{m}$ (Vigroux et al., 1993). Embora os dados obtidos pelo ISO tenham contribuído significativamente para o desenvolvimento da astronomia no infravermelho médio, a cobertura espacial da missão foi bastante restrita: os apontamentos realizados pelo satélite eram limitados a regiões do céu com separação angular alta o suficiente para evitar contaminação pelas fontes de radiação infravermelha mais próximas (valores entre 

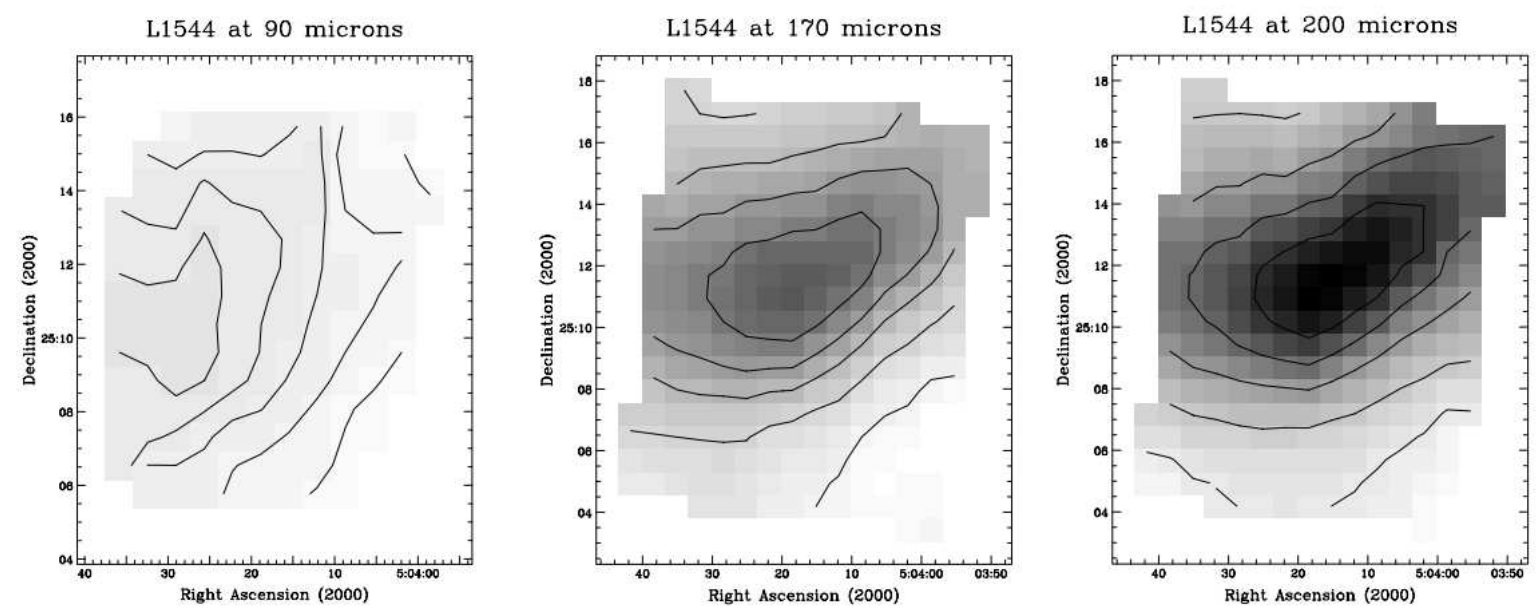

Figura 2.1: Imagens do núcleo pré-estelar L1544 obtidas pelo satélite ISO em 90, 170 e $200 \mu \mathrm{m}$. Retirado de Nisini et al. (2005).

60 a $120^{\circ}$ para o Sol, $77^{\circ}$ para a Terra, $24^{\circ}$ para a Lua e $7^{\circ}$ para Júpiter). Devido a tais restrições, apenas $15 \%$ do céu foi observado pelo satélite.

\subsubsection{O Satélite MSX}

Em meados da década de 90, o satélite Midcourse Space Experiment (MSX) obteve medidas fotométricas de fontes contidas no plano Galático $\left(0^{\circ}<\ell<360^{\circ}, b \leq 5^{\circ}\right)$ em quatro bandas do MIR: banda A $(8.28 \mu \mathrm{m})$, banda C $(12.13 \mu \mathrm{m})$, banda D $(14.65 \mu \mathrm{m})$ e banda $\mathrm{E}(21.34 \mu \mathrm{m})$. Comparado aos levantamentos anteriores, esse programa realizou medidas fotométricas com maior resolução angular (18.3" em todas as suas bandas, Figura 2.3). Os dados obtidos pelo satélite MSX possibilitaram a seleção prévia da lista de objetos que fazem parte do levantamento Red MSX Source (RMS) e das fontes apresentadas no presente trabalho. O levantamento RMS será discutido em detalhes na Seção 2.4.

\subsubsection{O Satélite Spitzer}

Em 2003, o satélite Spitzer entrou em operação, realizando medidas fotométricas e espectroscópicas de objetos em regiões de formação estelar entre 3.6 e $160 \mu \mathrm{m}$. O programa Galactic Legacy Infrared Mid-Plane Survey Extraordinary (GLIMPSE, Benjamin et al., 2003) observou a região interna do plano Galático nos filtros de 3.6, 4.5, 5.8 e $8.0 \mu \mathrm{m}$ da câmera IRAC (InfraRed Array Camera), atingindo resolução espacial de $\sim 2^{\prime \prime}$ (Figura2.3). O levantamento MIPS Galactic Plane (MIPSGAL, Carey et al.,, 2009) foi outro programa 
da missão Spitzer de grande importância. O MIPSGAL obteve imagens em 24 e $70 \mu \mathrm{m}$ utilizando a câmera MIPS (Multiband Imaging Photometer for Spitzer).

Dentre os levantamentos de candidatos a MYSOs realizados com dados do Spitzer, destacam-se os trabalhos de Kumar e Grave (2007); Grave e Kumar (2009). Das 16 fontes estudadas por Grave e Kumar (2009), apenas uma apresentou massa relativamente alta $\left(18566+0408 \mathrm{mms} 1, M=40 \mathrm{M}_{\odot}\right)$. Cerca de $\sim 70 \%$ da amostra apresentou massas < $12 \mathrm{M}_{\odot}$. O fator mais significativo que impediu a seleção de candidatos a MYSOs a partir das imagens obtidas pela câmera IRAC foi a saturação das fontes brilhantes em maiores comprimentos de onda $(5.8$ e $8.0 \mu \mathrm{m})$, tais como os objetos de maior massa identificados por Kumar e Grave (2007) (Figura 2.2).
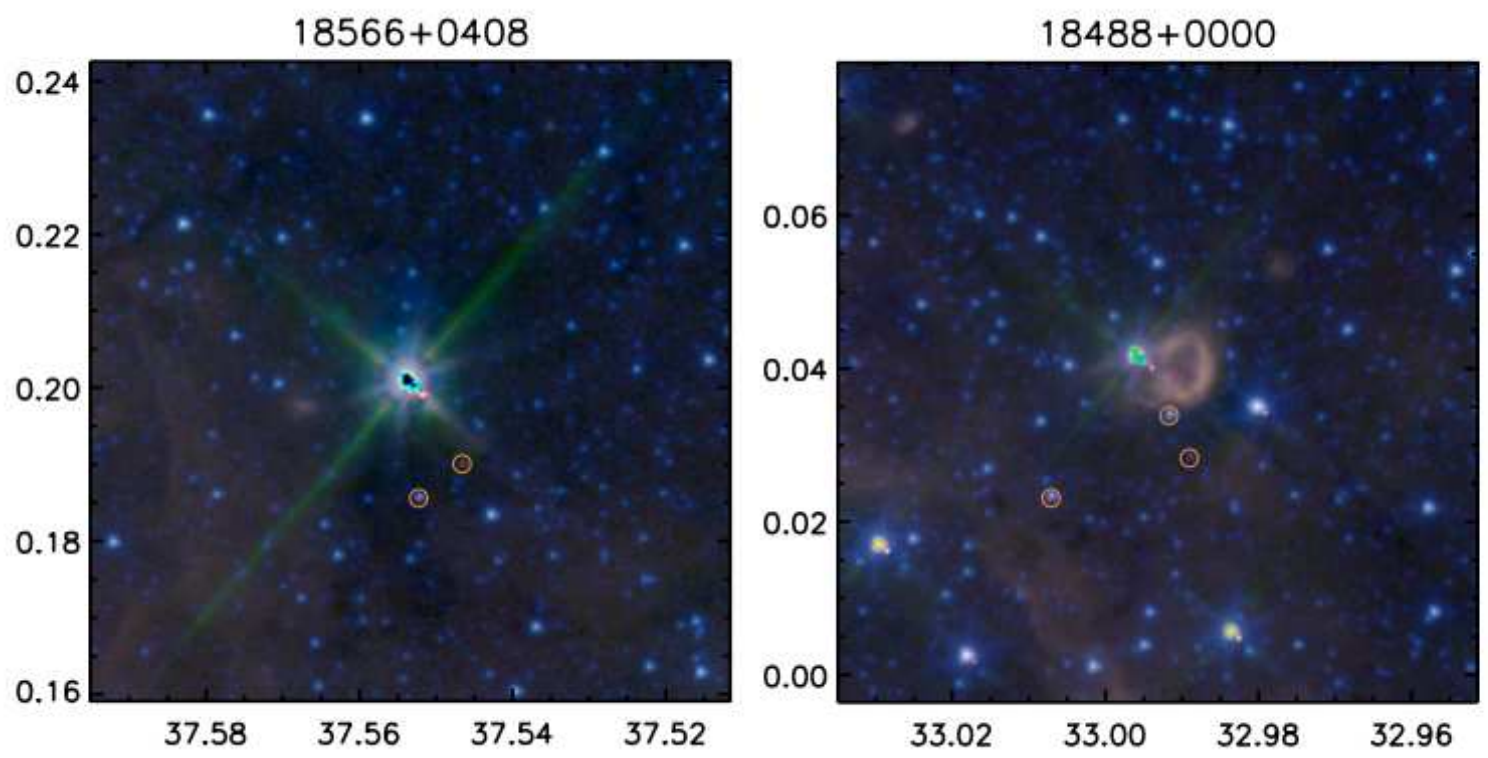

Figura 2.2: Imagens do programa GLIMPSE nos filtros de 4.5 (azul), 5.8 (verde) e $8.0 \mu \mathrm{m}$ (vermelho), mostrando candidatos a objetos de alta massa como fontes saturadas. Retirado de Kumar e Grave (2007).

\subsubsection{O levantamento 2MASS}

Amostras de candidatos a MYSOs foram também selecionadas por fotometria no infravermelho próximo (NIR, Near Infrared), utilizando fotometria do catálogo 2MASS (TwoMicron All Sky Survey). O 2MASS obteve imagens de $\approx 99.998 \%$ do céu nas bandas J $(1.25 \mu \mathrm{m}), \mathrm{H}(1.65 \mu \mathrm{m})$ e $\mathrm{K}_{s}(2.16 \mu \mathrm{m})$, com resolução angular de 2" (Figura 2.3) e precisão astrométrica de $\sim 0.1^{\prime \prime}$. O programa 2MASS forneceu imagens e fotometria com alta 
sensibilidade e boa resolução angular. No entanto, a baixa cobertura espectral do 2MASS, combinada ao fato de que apenas uma fração ínfima da energia dos MYSOs é emitida na faixa NIR, não foi capaz de selecionar criteriosamente candidatos a MYSOs.

Visto que a maior parte do fluxo bolométrico dos MYSOs é emitido na região do infravermelho, as melhorias na sensibilidade e resolução angular dos grandes programas fotométricos são fundamentais para a seleção de amostras de candidatos a MYSOs cada vez mais refinadas e com significativa redução de contaminação por outros objetos com propriedades semelhantes. A Figura 2.3 apresenta a resolução angular em função do comprimento de onda para os diversos instrumentos e levantamentos utilizados para a seleção de candidatos a MYSO.

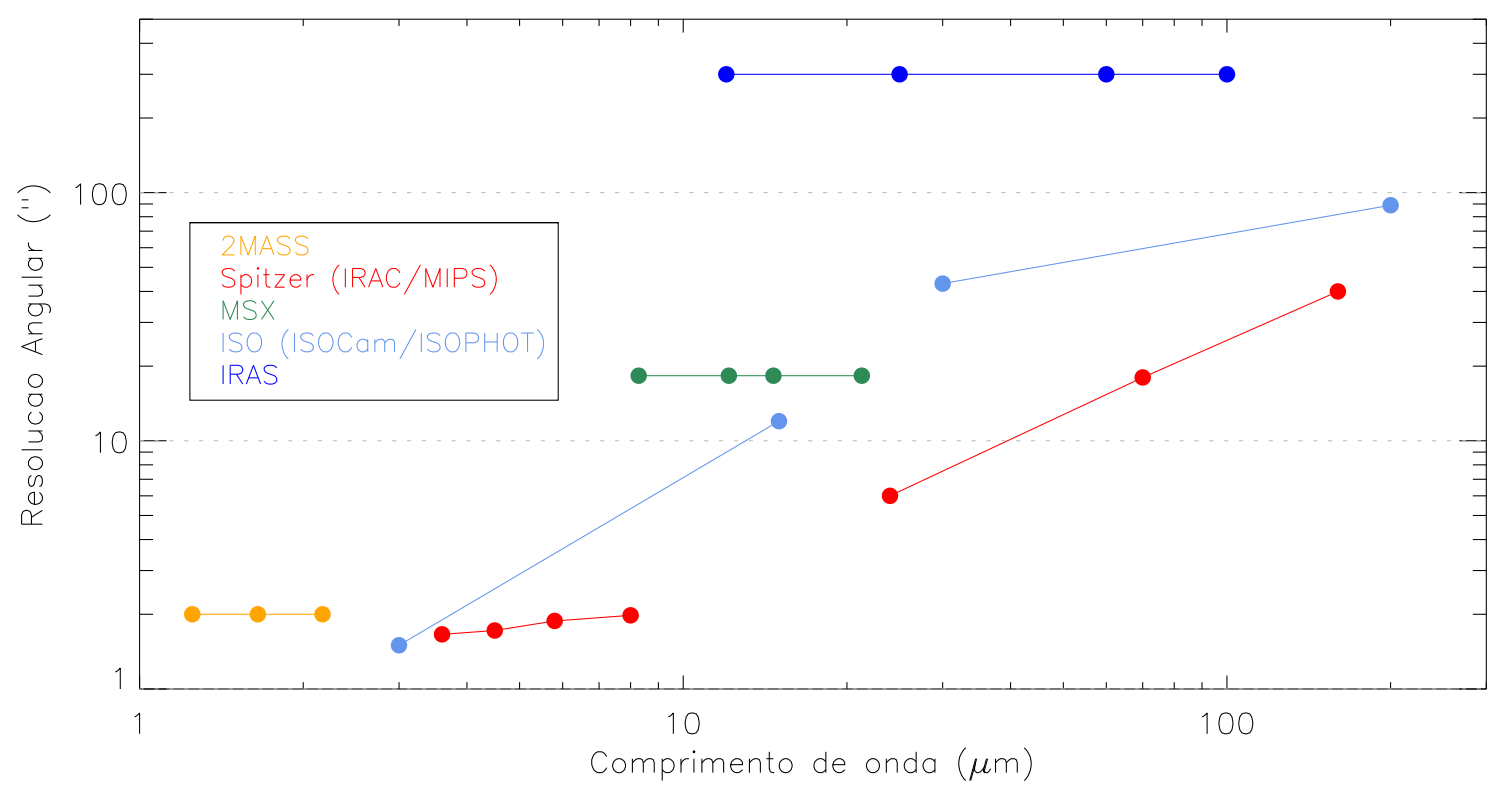

Figura 2.3: Resolução angular (Painel B) dos diversos instrumentos e levantamentos utilizados para a seleção de candidatos a MYSOs. Os pontos indicam o comprimento de onda central de cada filtro e as linhas mostram a cobertura espectral de cada levantamento, a saber: 2MASS (amarelo), Spitzer (vermelho), MSX (verde), ISO (azul claro) e IRAS (azul).

\subsection{Amostras de candidatos a MYSOs Baseadas em Cores Infravermelhas}

Os primeiros levantamentos de candidatos a YSOs usaram critérios de índices de cor no FIR de fontes contidas no catálogo de fontes galáticas do IRAS (Wood e Churchwell, 1989; 
Palla et al., 1991; Fontani et al., 2005). Embora as amostras baseadas nas cores IRAS tenham contribuído significativamente para o estudo nesta área, a quase totalidade dos candidatos resultou em objetos de baixa massa. Utilizando dados fotométricos nos filtros de 12, 25 e $60 \mu \mathrm{m}$ do satélite IRAS, Wood e Churchwell (1989) estabeleceram dois critérios para selecionar objetos jovens, definidos a partir da razão entre seus fluxos no FIR $\left(F_{12}\right.$, $\left.F_{25}, F_{60}\right)$. São eles:

- $\log F_{60} / F_{12} \geq 1.30$

- $\log F_{25} / F_{12} \geq 0.57$.

A Figura 2.4 apresenta os diagramas cor-cor de fontes Wood e Churchwell (1989). Em ambos os diagramas, as fontes classificadas como objetos UCH II estão bem definidas. No diagrama de cores [60-12] e [25-12], é possível verificar que os critérios definidos por aqueles autores estão de acordo com a região na qual estão contidas as fontes UCH II (delimitada pelo retângulo pontilhado).
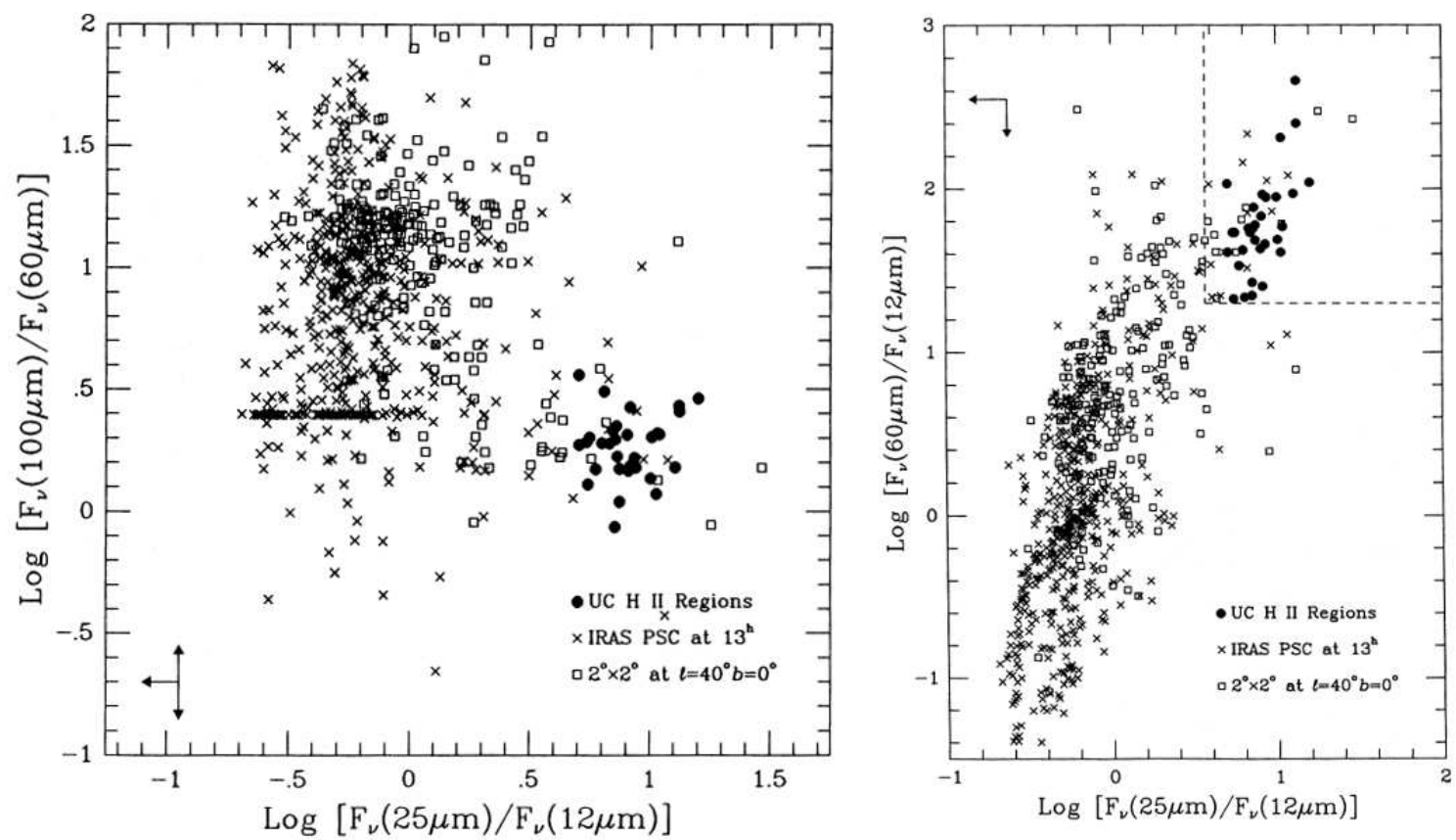

Figura 2.4: Cores no infravermelho distante de fontes IRAS associadas com regiões UCH II $(\bullet)$ comparadas com demais fontes IRAS presentes num campo de $2^{\circ} \times 2^{\circ}(\square)$ e um grupo de fontes IRAS com ascensão reta entre $13 \mathrm{~h} 00 \mathrm{~m}$ e $13 \mathrm{~h} 10 \mathrm{~m}(\times)$. A área delimitada pelo retângulo pontilhado (Painel à direita) corresponde aos critérios estabelecidos por Wood e Churchwell (1989) para a seleção de fontes IRAS classificadas como regiões UCH II. Retirado de Wood e Churchwell (1989). 
Analogamente, Palla et al. (1991) definiram critérios de cores IRAS para selecionar regiões $\mathrm{UCH}$ II no hemisfério $\operatorname{Sul}\left(\delta \leq-30^{\circ}\right)$, a partir dos fluxos em 25, 60 e $100 \mu \mathrm{m}$ :

- $0.61 \leq \log F_{60} / F_{25} \leq 1.74$

- $0.087 \leq \log F_{100} / F_{60} \leq 0.52$;

- $F_{60} \geq 100 \mathrm{Jy}$.

Dos 260 objetos selecionados por Palla et al. (1991), 125 satisfazem os critérios definidos por Wood e Churchwell (1989), ou seja, são candidatos a estrelas OB jovens associadas a regiões UCH II. Os autores afirmam que dentre os demais 135 objetos, existem fontes com baixa temperatura superficial, alta luminosidade, baixa opacidade em grandes comprimentos de onda e associados a nuvens moleculares densas, características de estrelas de alta massa nos estágios iniciais de formação. Observações realizadas posteriormente permitiram: i) confirmar a existência de objetos com luminosidades $L \geq 10^{3} \mathrm{~L}_{\odot}$ em ambas as sub-amostras; ii) verificar que 57\% das fontes que satisfazem aos critérios de Wood e Churchwell (1989) estão associadas a regiões UCH II (Molinari et al.,, 1998); e iii) que $76 \%$ das fontes que não satisfazem aos critérios de Wood e Churchwell (1989) são precursores de estrelas de alta massa $\left(\mathrm{M} \geq 10 \mathrm{M}_{\odot}\right)$.

Fontani et al. (2005) realizaram uma seleção de objetos IRAS no hemisfério Ssul $(\delta \leq$ $-30^{\circ}$ ) utilizando os mesmos critérios de Palla et al. (1991). Os autores obtiveram uma lista de 298 fontes que satisfizeram os critérios de Wood e Churchwell (1989) e 131 fontes classificadas como candidatos a protoestrelas mais jovens. A contaminação por regiões H II na amostra de Fontani et al. (2005) é maior devido a escassez de levantamentos de regiões H II localizadas no hemisfério Sul. Os autores mostraram a existência de uma forte correlação entre as 298 fontes supostamente associadas a regiões UCH II, e a presença de gás de alta densidade mapeado a partir de observações em CS, CO e emissão térmica na faixa milimétrica $(1.2 \mathrm{~mm})$. A emissão em $1.2 \mathrm{~mm}$ também sugere a presença de clumps com diâmetros entre 0.2 e 2.0 pc; e com massas $\leq 10^{5} \mathrm{M}_{\odot}$. Os autores verificaram um excesso emissão em $12 \mu$ m nas fontes do grupo que não satisfaz as condições de Wood e Churchwell (1989), e sugerem que tal excesso seja decorrente da presença de aglomerados estelares associados às fontes. No entanto, os autores também afirmam a necessidade de observações no infravermelho com maior resolução angular. 
O levantamento Red MSX Source (RMS) selecionou uma amostra de candidatos a MYSOs a partir de fotometria no infravermelho próximo e médio (Lumsden et al., 2002). Posteriormente, a amostra foi refinada a partir da eliminação de objetos associados a envelopes de poeira em estágios evolutivos avançados (tais como as estrelas no estágio posterior ao Ramo Assintótico das Gigantes - pós-AGB - e nebulosas planetárias) e estrelas de baixa massa em formação, ambos com cores infravermelhas semelhantes às observadas para os MYSOs. Além da descontaminação da amostra, o fluxo bolométrico foi determinado para cada uma das fontes classificadas como candidatos a MYSO, considerando os fluxos medidos desde a região espectral do infravermelho próximo até o milimétrico. A Seção2.4 descreverá detalhadamente as observações realizadas ao longo do levantamento RMS, que proveu a lista de candidatos a MYSOs apresentados nesta dissertação.

\subsection{Amostras de Candidatos a MYSOs selecionadas por outros critérios}

Recentemente, Varricatt et al. (2010) selecionaram candidatos a MYSOs com indicativos observacionais esperados para estrelas de alta massa e jovens e não necessariamente ligados às cores infravermelhas das fontes. Os objetos apresentados naquele trabalho apresentam os seguintes indicativos: $i$ ) fontes com emissão de $\mathrm{NH}_{3}$ e maser de água, selecionadas do catálogo de Molinari et al. (1996); ii)fontes com emissão do tipo maser de água e etanol contidas no levantamento de Sridharan et al. (2002); iii)fontes com evidências de efluxos na linha molecular do CO contidas nos catálogos de Shepherd e Churchwell (1996) e Churchwell (1999). Aparentemente, as fontes também satisfizeram os critérios de cor para MYSOs, mostrando uma correlação entre as propriedades fotométricas no infravermelho e aquelas determinadas por observações em outros comprimentos de onda.

\subsection{O Levantamento Red MSX Source}

O levantamento Red MSX Source (RMS) (Lumsden et al., 2002; Hoare et al., 2005; Urquhart et al., 2008) selecionou uma amostra de candidatos a MYSOs a partir de observações no infravermelho médio (MIR), entre 8 e $21 \mu \mathrm{m}$. Essa seção apresentará os detalhes das observações realizadas ao longo do levantamento RMS, que resultou na lista de candidatos a MYSOs estudados no presente trabalho. Serão apresentadas $i$ ) as ob- 
servações no MIR realizadas por Mottram et al. (2007); ii) observações de alta resolução no FIR (Mottram et al., 2010); iii) observações em $6 \mathrm{~cm}$ por Urquhart et al. (2007); iv) determinação dos fluxos no submilimétrico (Di Francesco et al., 2008a); v) associação com emissões moleculares de amônia e maser de água (Urquhart et al., 2009b, 2011); vi) determinação da distância cinemática das fontes (Urquhart et al., 2007, 2008); e vii) determinação do fluxo bolométrico das fontes RMS por Mottram et al. (2011).

Lumsden et al. (2002) utilizaram critérios de cores no MIR e NIR e selecionaram $\approx 3000$ objetos contidos no catálogo de fontes pontuais MSX (Egan et al., 1999, 2003). Os critérios de seleção utilizados por aqueles autores foram:

- $F_{8}<F_{14}<F_{21}$;

- $F_{21} / F_{8}>2$;

- $F_{8} / F_{K}>5$;

- $F_{K} / F_{J}>2$.

As entradas dos diferentes catálogos (2MASS e MSX) foram cruzadas, adotando um erro de $\leq 10^{\prime \prime}$ para diferenças entre a posição das fontes em diferentes comprimentos de onda. Lumsden et al. (2002) afirmam que os critérios de cor para o infravermelho próximo foram suficientes para a eliminação de $\approx 2 / 3$ das nebulosas planetárias e estrelas evoluídas que satisfizeram os critérios adotados para as cores no MIR.

As cores infravermelhas dos MYSOs são similares às observadas tanto para os YSOs de baixa massa, regiões UCH IIs, e os demais objetos evoluídos ainda presentes na amostra. Dessa forma, diversas observações adicionais foram realizadas para $i$ ) identificar possíveis contaminações na amostra, e ii) definir algumas propriedades físicas dos MYSOs. As observações e seus principais resultados serão descritos a seguir.

\subsubsection{Observações em 10 mícrons}

Observações com alta resolução espacial no infravermelho médio foram conduzidas por Mottram et al. (2007) com a finalidade de identificar possíveis MYSOs em sistemas múltiplos ou mesmo fontes estendidas nas regiões do céu não observadas pelo levantamento GLIMPSE/Spitzer. A emissão no MIR associada aos MYSOS tem origem na poeira 
aquecida (grande parte da emissão térmica em $10 \mu \mathrm{m}$ está associada a temperaturas de $\sim 300 \mathrm{~K})$ pela protoestrela. As imagens em alta resolução angular $\left(\sim 1^{\prime \prime}\right)$ foram usadas para identificar possíveis fontes RMS múltiplas, não resolvidas nas imagens MSX devido sua resolução angular de 18".

Aqueles autores observaram 346 fontes situadas no Hemisfério Sul e 221 delas foram classificadas como fontes não-resolvidas (candidatos a MYSOs ou estrelas evoluídas), enquanto 83 fontes apresentaram emissão extensa em $10.4 \mu \mathrm{m}$ e receberam a classificação de região H II. Exemplos de fontes puntiforme e extensa são mostrados na Figura 2.5.
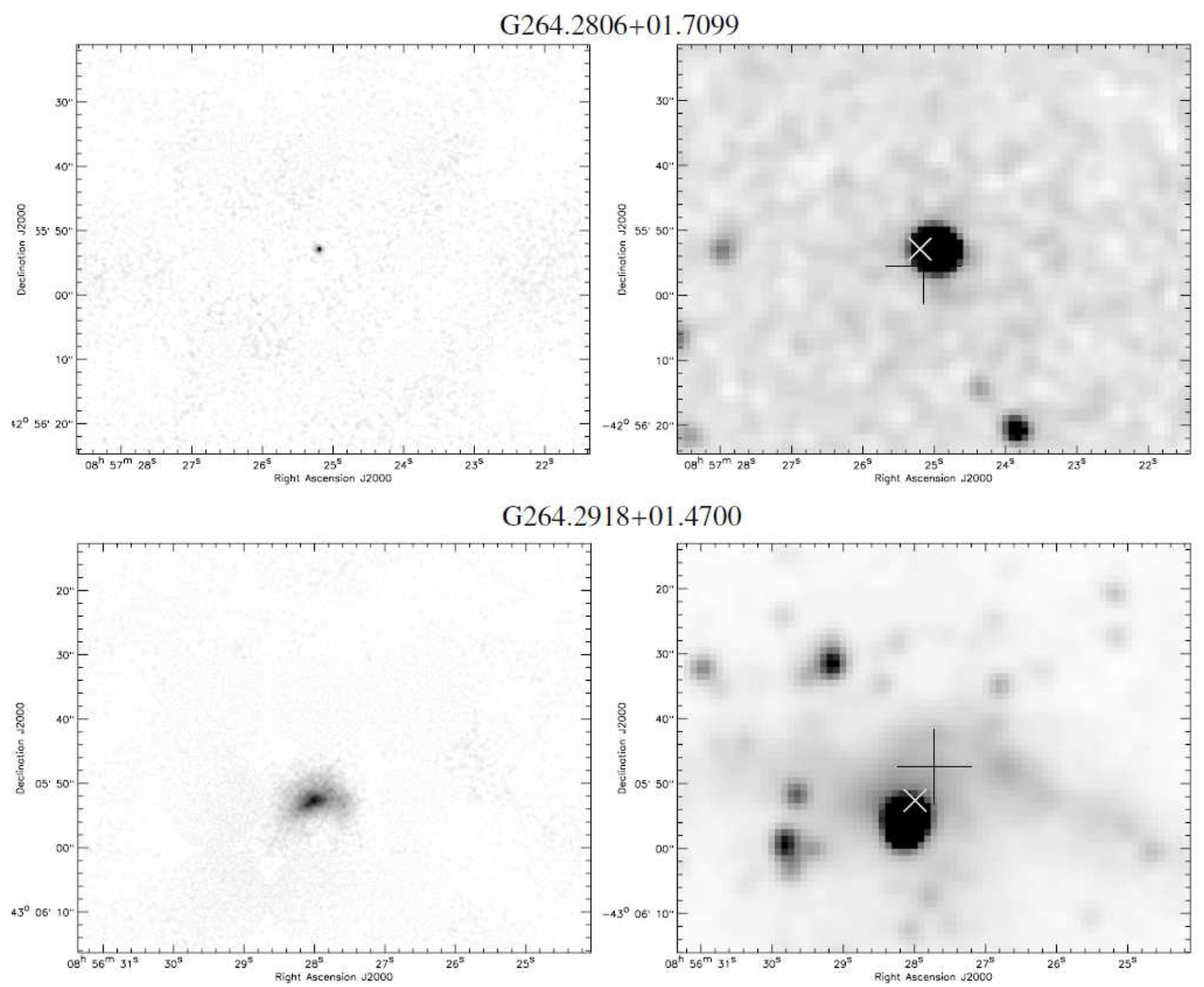

Figura 2.5: Painéis superiores: Fonte G264.2806+01.7099 identificada como uma fonte puntiforme em $10.4 \mu \mathrm{m}$ (esquerda) e $2 \mu \mathrm{m}$ (direita). Painéis inferiores: Fonte G264.2918+01.4700, um objeto com emissão extensa em $10.4 \mu \mathrm{m}$ (esquerda) e $2 \mu \mathrm{m}$ (direita). Os eixos horizontal e vertical são mostrados em unidades de ascensão reta e declinação, respectivamente. Retirado de Mottram et al. (2007). 


\subsubsection{Observações no Infravermelho Distante}

Os mapas obtidos pelo satélite IRAS foram reprocessados, dando origem ao catálogo IRAS Galaxy Atlas (IGA) (Cao et al., 1997). O IGA consiste em imagens em 60 e $100 \mu \mathrm{m}$ com resolução angular de $1.0^{\prime} \times 1.7^{\prime}$ e $1.7^{\prime} \times 2.2^{\prime}$, respectivamente (Mottram et al., 2010). Embora grande parte das fontes RMS estejam presentes nas observações realizadas pelo IRAS, cerca de $\sim 28 \%$ das fontes RMS não fazem parte do catálogo de fontes puntuais IRAS (Beichman et al., 1988) enquanto outros $\sim 30 \%$ das fontes RMS apenas apresentam um limite superior para os fluxos em 60 e $100 \mu \mathrm{m}$.

O fluxo no FIR das fontes situadas na região interna do plano Galático $\left(5^{\circ}<\ell<63^{\circ}\right.$, $\left.298^{\circ}<\ell<355^{\circ}\right)$ foi determinado a partir de imagens com maior resolução angular $\left(\sim 18^{\prime \prime}\right.$ em $70 \mu \mathrm{m}$ ) obtidas pelo levantamento Spitzer/MIPSGAL (Carey et al., 2009). Os fluxos de 1336 fontes RMS foram determinados via fotometria de abertura, dos quais apenas 734 apresentaram medidas aceitáveis utilizando as imagens do programa IGA. Outras 724 fontes tiveram seus fluxos determinados a partir de imagens do programa MIPSGAL. A Figura 2.6 apresenta imagens de um dado campo, observadas no filtro de $60 \mu \mathrm{m}$ do satélite IRAS, seu reprocessamento pelo IGA e observações em $70 \mu \mathrm{m}$ do MIPSGAL. O considerável aumento da resolução angular nas imagens possibilitou resolver a multiplicidade de fontes no FIR e permitiu a extração do fluxo de objetos em regiões densas.
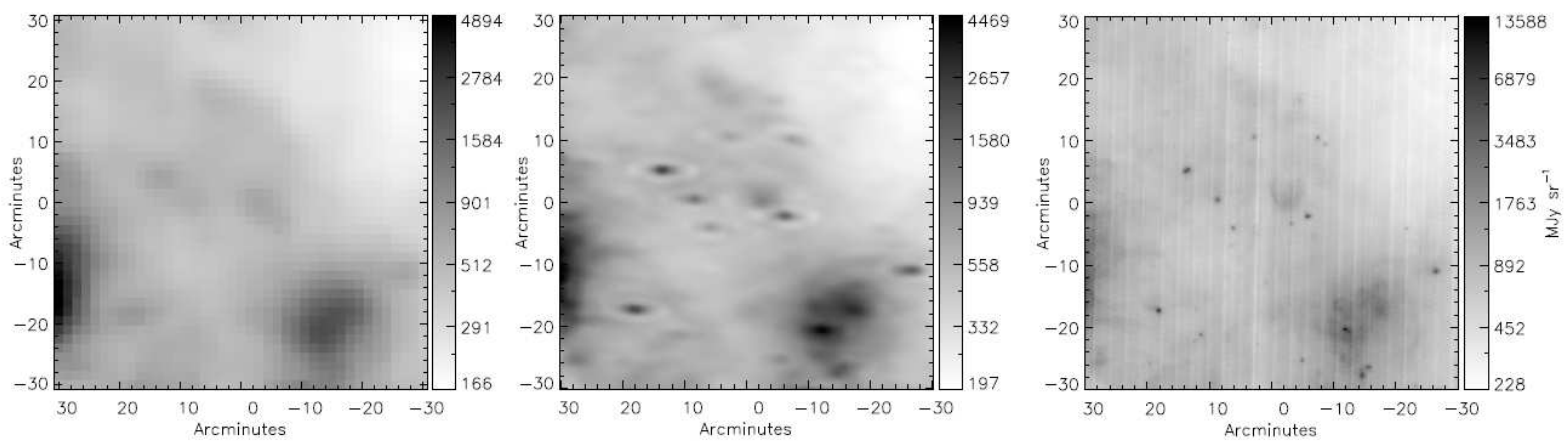

Figura 2.6: Comparação entre imagens em $60 \mu \mathrm{m}$ do IRAS (esquerda), a mesma imagem reprocessada pelo catálogo IGA (centro) e uma imagem em $70 \mu \mathrm{m}$ do Spitzer/MIPSGAL (direita). Os eixos horizontal e vertical são mostrados em unidades de minutos de arco. Ao lado de cada imagem, uma escala de intensidade é mostrada em unidades de $\mathrm{mJy} \mathrm{sr}^{-1}$. Retirado de Mottram et al. (2010). 


\subsubsection{Observações na faixa de rádio em $6 \mathrm{~cm}$}

Observações na faixa centimétrica foram realizadas com o objetivo de identificar candidatos a MYSOs associados à regiões UCH IIs. É esperado que o fluxo integrado em rádio das regiões UCH IIs seja ordens de grandeza maior que o observado para os fluxos dos MYSOs mais próximos ( 1 mJy, Urquhart et al., 2007). A diferença entre essas duas fases se dá pela emissão devido às transições livre-livre, que geram uma componente de intensidade constante na faixa rádio na SED de um objeto na fase UCH II (Figura 1.2, na página 31). Das 1927 fontes observadas por Urquhart et al. (2007, 2009a), 391 representam regiões UCH II $(\approx 20 \%), 79$ são PNe $(\approx 4 \%)$ e 199 correspondem a fontes de origem extragalática $(\approx 10 \%)$. A Figura 2.7 apresenta quatro objetos com emissão em $6 \mathrm{~cm}$, observados por Urquhart et al. (2009a).
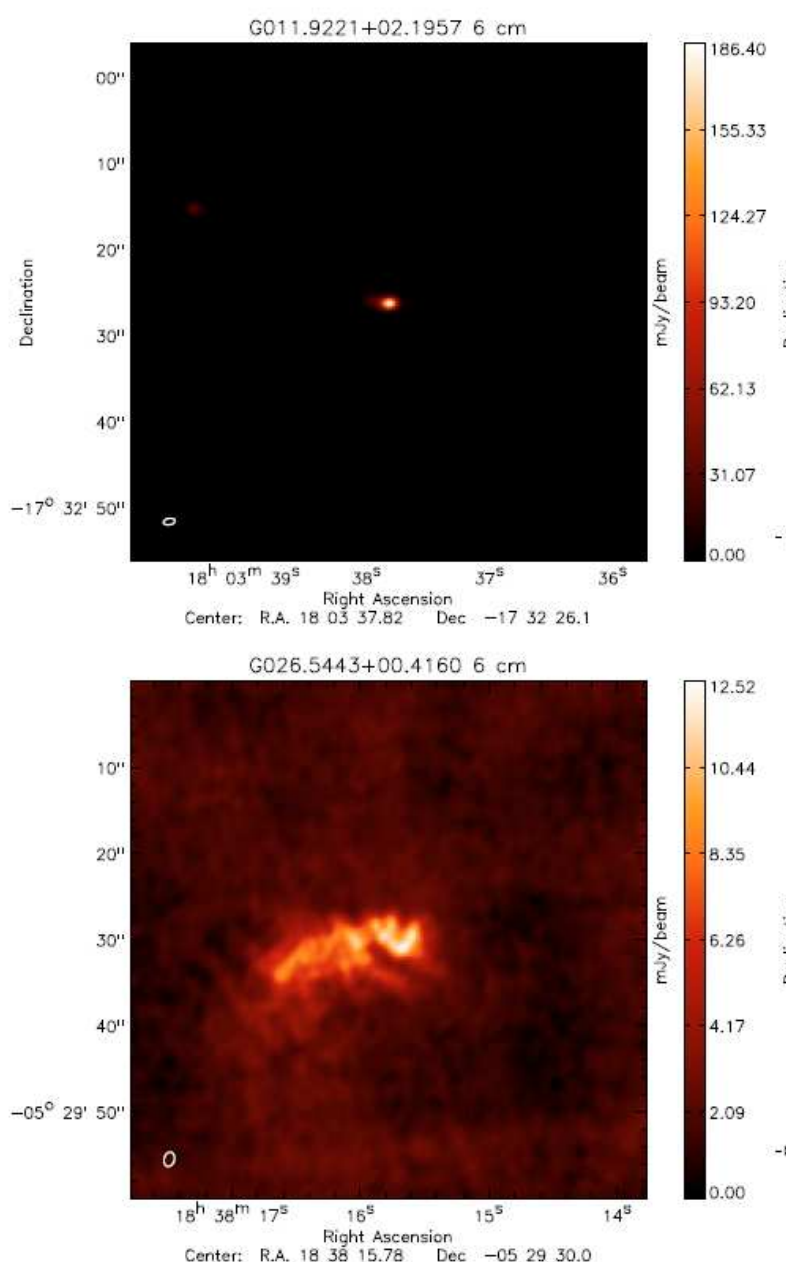
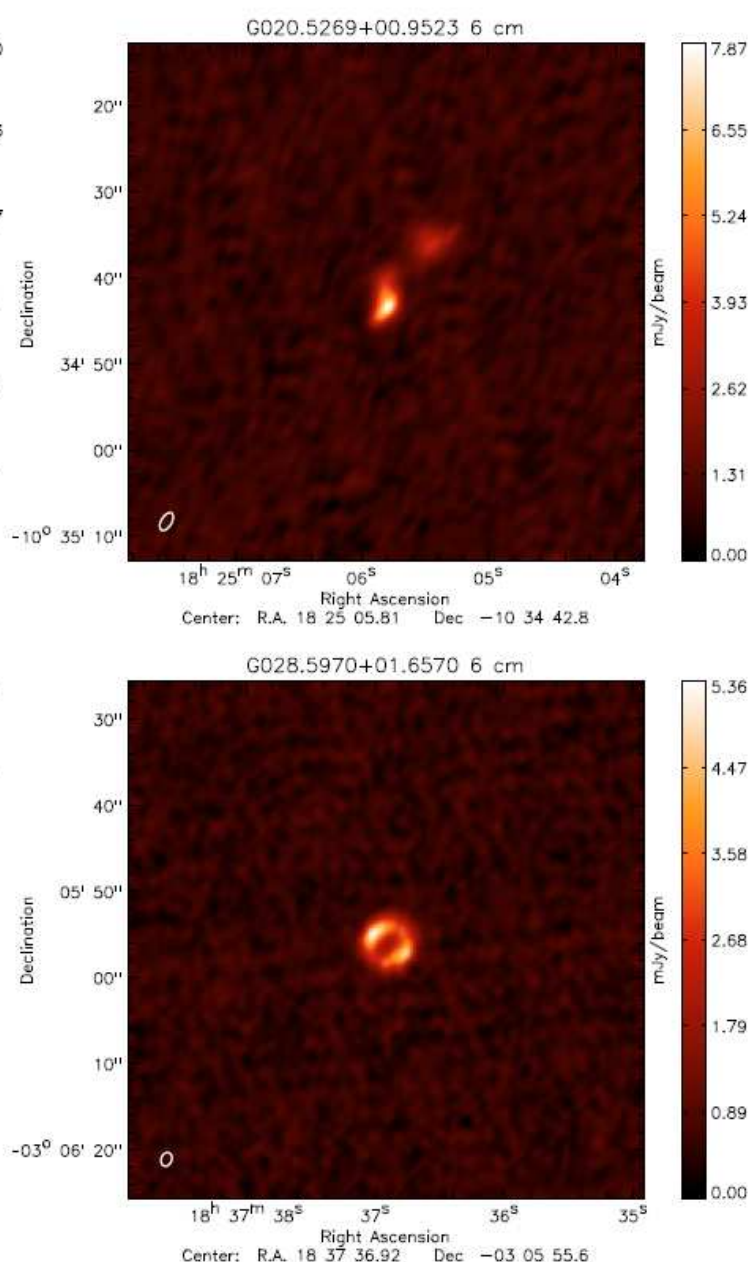

Figura 2.7: Exemplos de fontes que apresentam emissão em rádio. Os eixos horizontal e vertical são mostrados em unidades de ascensão reta e declinação, respectivamente. As escalas de intensidade são mostradas em unidades de mJy feixe ${ }^{-1}$. Retirado de Urquhart et al. (2009a). 


\subsubsection{Observações submilimétricas}

Os fluxos das fontes RMS em 450 e $850 \mu \mathrm{m}$ foram determinados por Di Francesco et al. (2008b) a partir de observações realizadas com o Submillimetre Common-User Bolometer Array (SCUBA). Um deslocamento máximo de 14" (menor que o tamanho das fontes pontuais no catálogo MSX 18") foi usado como critério de associação entre uma detecção submilimétrica e uma fonte no infravermelho médio.

\subsubsection{Fluxos em outros comprimentos de onda}

As fontes RMS que possuem contrapartida no catálogo 2MASS tiveram seus fluxos do NIR utilizados como limite de frequências mais altas. Foram considerados apenas os fluxos dos objetos com erro astrométrico $\leq 7.6^{\prime \prime}$ entre as coordenadas 2MASS e MSX. Embora este valor pareça relativamente alto, ele é menor do que a resolução das observações realizadas pelo satélite MSX (18", Mottram et al., 2011).

Quando disponíveis, fluxos em $1.2 \mathrm{~mm}$ foram utilizados como limites de baixas frequências para a determinação do fluxo bolométrico das fontes RMS. Os fluxos milimétricos foram obtidos por Faúndez et al. (2004); Hill et al. (2005); Beltrán et al. (2006), com incertezas de $\pm 40 \mathrm{mJy}$.

\subsubsection{Observações de emissão molecular de $\mathrm{NH}_{3}$ e maser de $\mathrm{H}_{2} \mathrm{O}$}

Urquhart et al. (2009b, 2011) realizaram um levantamento de fontes RMS com emissão do tipo maser de água em $22.235 \mathrm{GHz}$ e emissão molecular de amônia $\left(\mathrm{NH}_{3}\right)$ em $~ 24 \mathrm{GHz}$. Das $\sim 500$ fontes observadas no hemisfério sul, 163 apresentaram emissão maser de $\mathrm{H}_{2} \mathrm{O}$ com intensidade acima do limite de detecção (1 Jy). 308/597 fontes do hemisfério norte apresentaram emissão maser de $\mathrm{H}_{2} \mathrm{O}$ com intensidade maior que o limite de detecção $(0.2 \mathrm{~K})$ e 479 desses objetos apresentam detecção de, pelo menos, uma transição da molécula de $\mathrm{NH}_{3}$.

A temperatura cinemática obtida a partir das linhas de amônia apresentou um valor médio de $\sim 20 \mathrm{~K}$, cerca de duas vezes o valor previsto para aquecimento devido o campo de radiação do meio interestelar ( $10 \mathrm{~K}$, Evans, 1999), indicando que as regiões são aquecidas internamente (i.e. o aquecimento ocorre devido à radiação emitida pelas protoestrelas de alta massa). A taxa de deteç̧ão de fontes maser $(\sim 50 \%)$ para as classes YSOs e regiões 
H IIs sugere que ambas as fases apresentem as condições necessárias para a geração da emissão maser. Dessa forma, aqueles autores sugerem que a não-detecção de emissão do tipo maser de água é uma característica de estrela em estágios mais evoluídos. Os autores também mostram que cerca de $75 \%$ das fontes com detecções positivas possuem distâncias cinemáticas menores que $7 \mathrm{kpc}$, indicando que o levantamento pode apresentar um viés devido à sensibilidade limitada das observações.

\subsubsection{Observações na linha do ${ }^{13} \mathrm{CO}$}

Urquhart et al. (2007, 2008) realizadam observações nas transições 1-0 (em $110.2 \mathrm{GHz})$ ou $2-1$ (em $220.4 \mathrm{GHz}$ ) do ${ }^{13} \mathrm{CO}$ para determinar a velocidade radial associada às fontes RMS. As distâncias cinemáticas das fontes foram obtidas a partir das velocidades radiais e da curva de rotação Galática de Brand e Blitz (1993), assumindo $d_{\odot}=8.5 \mathrm{kpc}$ para a distância galactocêntrica solar e $v_{\odot}=220 \mathrm{~km} \mathrm{~s}^{-1}$ para a velocidade do sistema solar.

Os espectros de ${ }^{13} \mathrm{CO}$ tem a vantagem de serem relativamente mais simples quando comparados aos espectros de ${ }^{12} \mathrm{CO}$, que podem apresentar estruturas complexas (componentes múltiplas) e perfis espectrais com forte auto-absorção (Urquhart et al., 2007). Visto que estrelas evoluídas geralmente não estão associadas a regiões com forte emissão de CO (Loup et al., 1993), a não-detecção de CO favorece a classificação da fonte MSX como uma estrela em estágios evolutivos pós-sequência principal.

Das fontes observadas no Hemisfério Sul, 752 de 854 apresentaram emissão de ${ }^{13} \mathrm{CO}$. Das deteç̧ões positivas, 461 fontes apresentaram espectros com picos múltiplos (Figura 2.8), indicando estruturas complexas e/ou sobreposição de estruturas na mesma linha de visada. Nesses casos, outras linhas moleculares (por exemplo, maser de água, metanol e CN, que geralmente estão associadas a regiões de formação de estrelas de alta massa) foram utilizadas para identificar o pico corresponde ao objeto de interesse. Esta técnica possibilitou a determinação da distância de 82 dos 461 objetos com componentes múltiplas. Em 78 dos 82 casos resolvidos, os masers e linhas de CN estavam associados com a componente CO mais forte. Esta informação foi utilizada para resolver a ambiguidade na distância cinemática de outros 218 objetos da amostra Sul. Para o Hemisfério Norte, a emissão de ${ }^{13} \mathrm{CO}$ foi detectada na direção de 780 dos 911 candidatos a MYSOs observados. 520 fontes apresentaram espectros com múltiplas componentes e a distância de 175 delas foi determi- 
nada a partir das velocidades de CS e de emissões maser. No total foram determinadas as distâncias cinemáticas de 591 dos 752 objetos do hemisfério Sul (Urquhart et al., 2007) e 638 dos 911 objetos do hemisfério Norte (Urquhart et al., 2008).
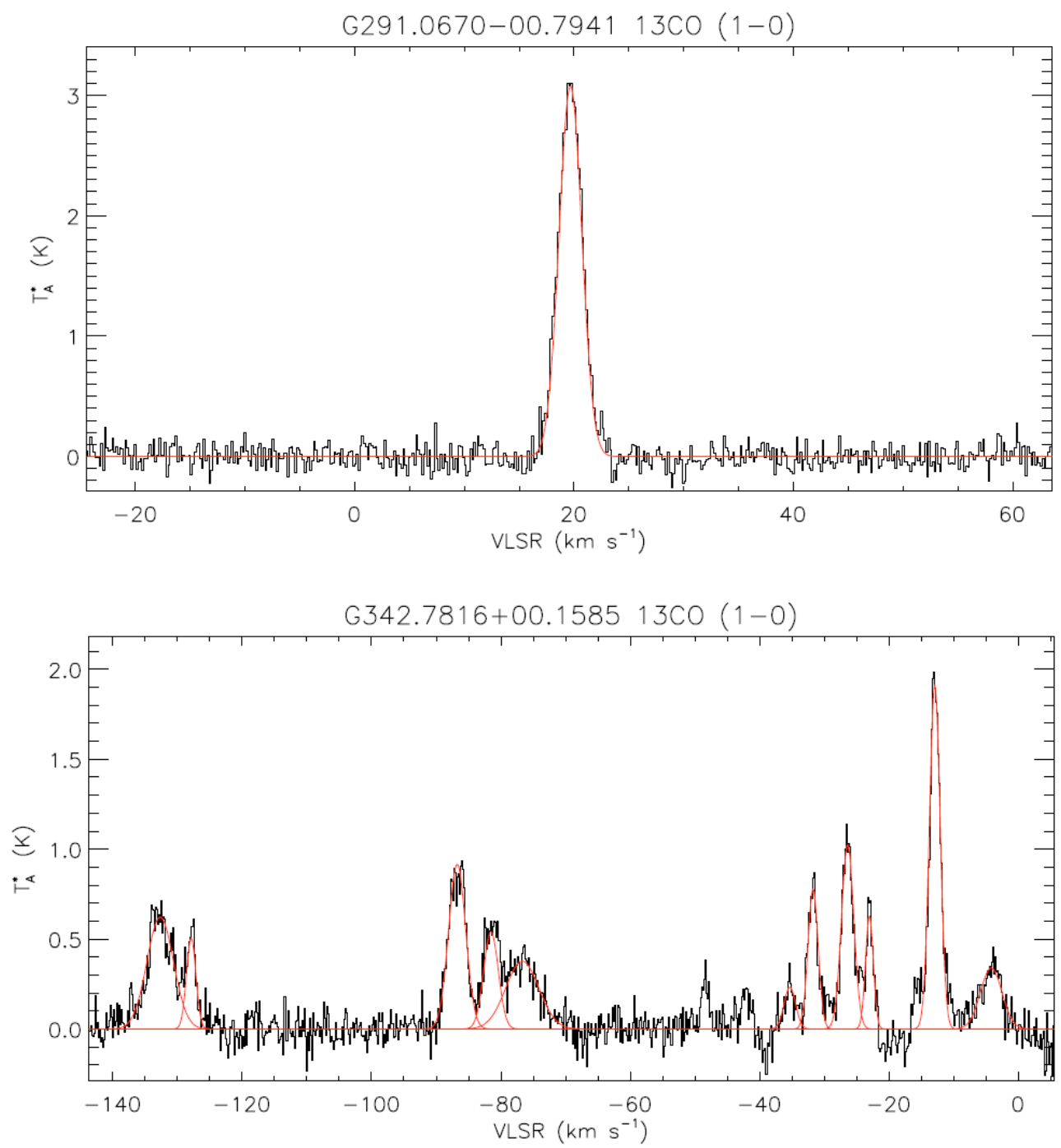

Figura 2.8: Exemplos de espectros de ${ }^{13} \mathrm{CO}$ com perfil simples (espectro superior) e perfil com múltiplos picos (inferior). Retirado de Urquhart et al. (2007).

\subsubsection{Determinação do fluxo bolométrico das fontes}

Mottram et al. (2011) obteveram o fluxo bolométrico $\left(f_{\text {bol }}\right)$ das fontes RMS utilizando o modelo da distribuição espectral de energia (SED) de Robitaille et al. (2007) e os fluxos determinados na região entre o infravermelho próximo e o milimétrico. O ajuste da distribuição espectral de energia (SED) dos MYSOs requer um modelo que seja capaz de 
reproduzir um amplo intervalo de propriedades das estrelas, dos discos e dos envelopes estelares, considerando diferentes ângulos de inclinação para cada objeto. O modelo de transferência radiativa de Robitaille et al. (2007) satisfaz estas condições e utiliza os fluxos medidos em diversas faixas espectrais como parâmetros de entrada para o ajuste da SED de cada estrela. As principais vantagens deste modelo são $i$ ) a inclusão de características da poeira no espectro dos objetos, tais como a absorção de silicato em $9.7 \mu \mathrm{m}$; e ii) a consideração de geometria não-esférica para o material circunstelar. Este modelo apresenta 14 parâmetros livres que devem ser fornecidos para ajustar cada SED. Os melhores ajustes de SED são obtidos para MYSOs que apresentam discos de poeira relativamente massivos, identificados em observações interferométricas na região do infravermelho médio, tal como mostra o trabalho de de Wit et al. (2010) ao estudar o objeto W33A, um MYSO com tipo espectral O7.5.

O fluxo bolométrico de cada objeto foi obtido como a média de $\geq 10$ ajustes de modo a garantir que o resultado seja independente de possíveis erros introduzidos por uma determinada SED. O valor de $f_{b o l}$ é uma combinação da luminosidade do objeto central e da luminosidade de acreção, tanto no disco circunstelar, quanto na proto-estrela. Mottram et al. (2011) compararam ajustes de SEDs completas (ou seja, considerando os fluxos determinados ao longo de todo o espectro; Painel A, Figura 2.9) contra ajustes com ausência de fluxos em alguma região espectral. Aqueles autores verificaram que a ausência de fluxos na região do FIR (região de maior emissão térmica dos MYSOs) leva a erros com valores da mesma ordem de grandeza do fluxo bolométrico ( $\sigma_{f} \sim f$; Painel B, Figura 2.9) $)$, enquanto a não inclusão de fluxos na região do sub-milimétrico e rádio não alteram significativamente o valor do fluxo bolométrico (Painel C, Figura 2.9).

Um total de 1069 objetos tiveram seus fluxos bolométricos determinados com precisão $\sigma_{f} / f_{b o l} \leq 0.5$. Para 280 fontes sem fluxos determinados na faixa do FIR, o valor de $f_{b o l}$ foi estimado a partir da seguinte relação

$$
\frac{f_{b o l}}{F_{21 \mu \mathrm{m}}}=\frac{F_{b o l, \text { modelo }}}{F_{21 \mu \mathrm{m}, \text { modelo }}}
$$

onde $F_{21 \mu \mathrm{m}}$ representa o fluxo medido na banda de $21 \mu \mathrm{m}$ do MSX; $F_{b o l}$ e $F_{21 \mu \mathrm{m} \text {, modelo }}$ correspondem aos valores do fluxo bolométrico e o fluxo medido em $21 \mu \mathrm{m}$ determinados pelo modelo de SED, respectivamente. 

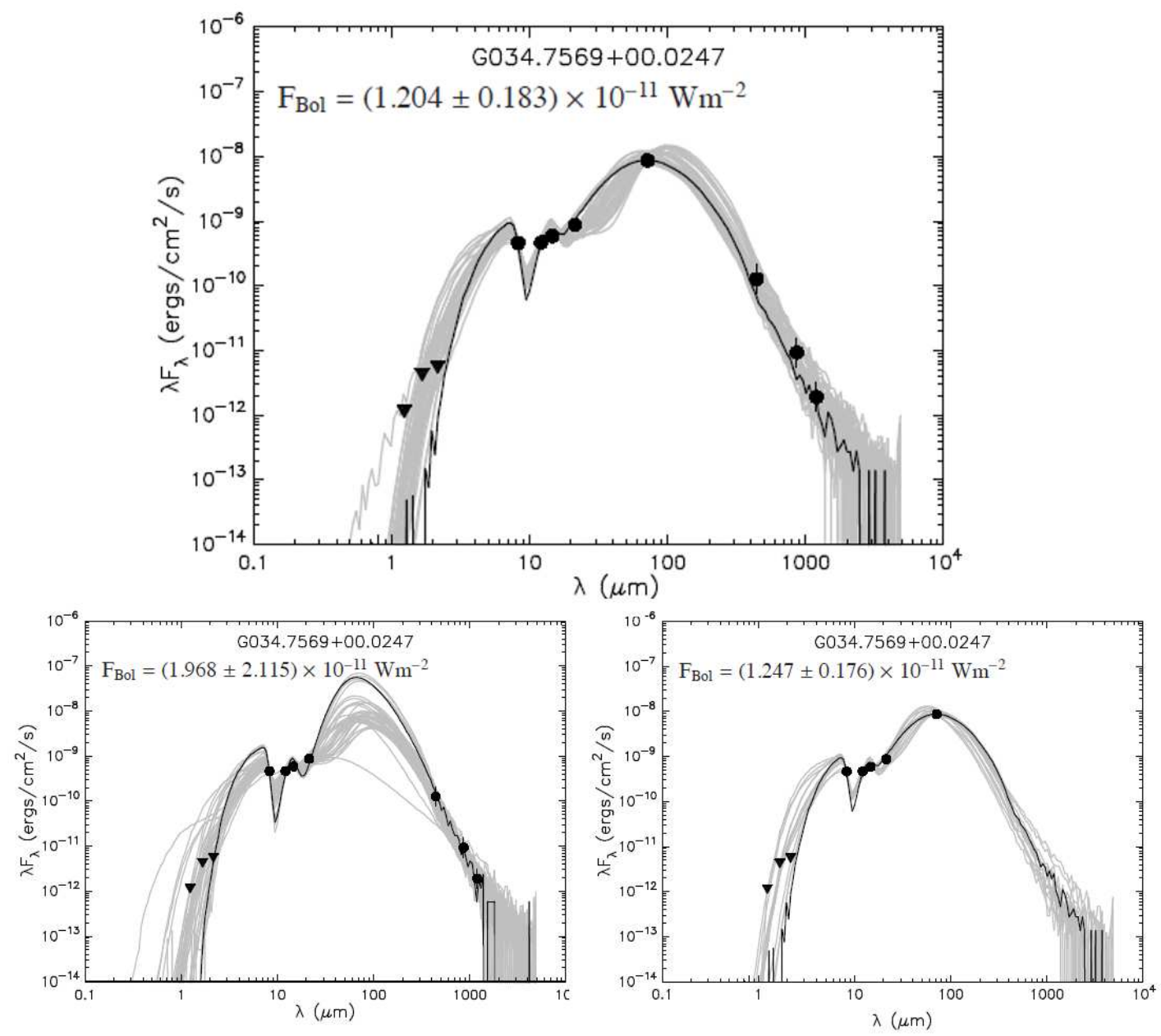

Figura 2.9: Comparação entre os ajustes de SED, considerando a) todos fluxos ao longo do espectro (painel superior, A), b) a não inclusão de fluxos na região do infravermelho distante (painel inferior esquerdo, B) e c) a não inclusão dos fluxos na região do milimétrico (painel inferior direito, C). Os valores dos fluxos bolométricos $\left(F_{b o l}\right)$ retornados pelo modelo de Robitaille et al. (2007) são mostrados acima de cada ajuste. Adaptado de Mottram et al. (2011).

\subsubsection{Luminosidade das fontes}

Utilizando o valor dos fluxos bolométricos $\left(f_{\text {bol }}\right)$ determinados por Mottram et al. (2011) e as distâncias cinemáticas $(d)$ de Urquhart et al. (2008, 2007), a luminosidade das fontes é obtida a partir da Equação 2.2.

$$
L_{b o l}=4 \pi d^{2} f_{b o l}
$$

A Figura 2.10 mostra a distribuição da luminosidade dos candidatos a MYSOs (em preto) e regiões H II (em vermelho) contidos no catálogo RMS. A distribuição das regiões H II apresenta um pico em $L \approx 3 \times 10^{4} \mathrm{~L}_{\odot}$ e um decréscimo acentuado de fontes com luminosidade superior à $10^{5} \mathrm{~L}_{\odot}$. Os MYSOs correspondem a uma população de objetos menos 
luminosos quando comparados à distribuição das regiões H II, que apresenta um máximo em $\mathrm{L}=5 \times 10^{3} \mathrm{~L}_{\odot}$. A curva mostra um decréscimo de fontes com luminosidade superior à $2 \times 10^{4} \mathrm{~L}_{\odot}$ e poucos objetos possuem $L \gtrsim 10^{5} \mathrm{~L}_{\odot}$ (equivalente a estrelas com tipos espectrais superiores à $\mathrm{O} 7.5$ e massas $\gtrsim 26 \mathrm{M}_{\odot}$, usando Martins et al., 2005). Essas propriedades da distribuicão das fontes jovens corroboram uma característica já esperada pela IMF Galática (Salpeter, 1955), ou seja, a existência de uma pequena população de estrelas de altas massas em comparação àquelas com menores massas.

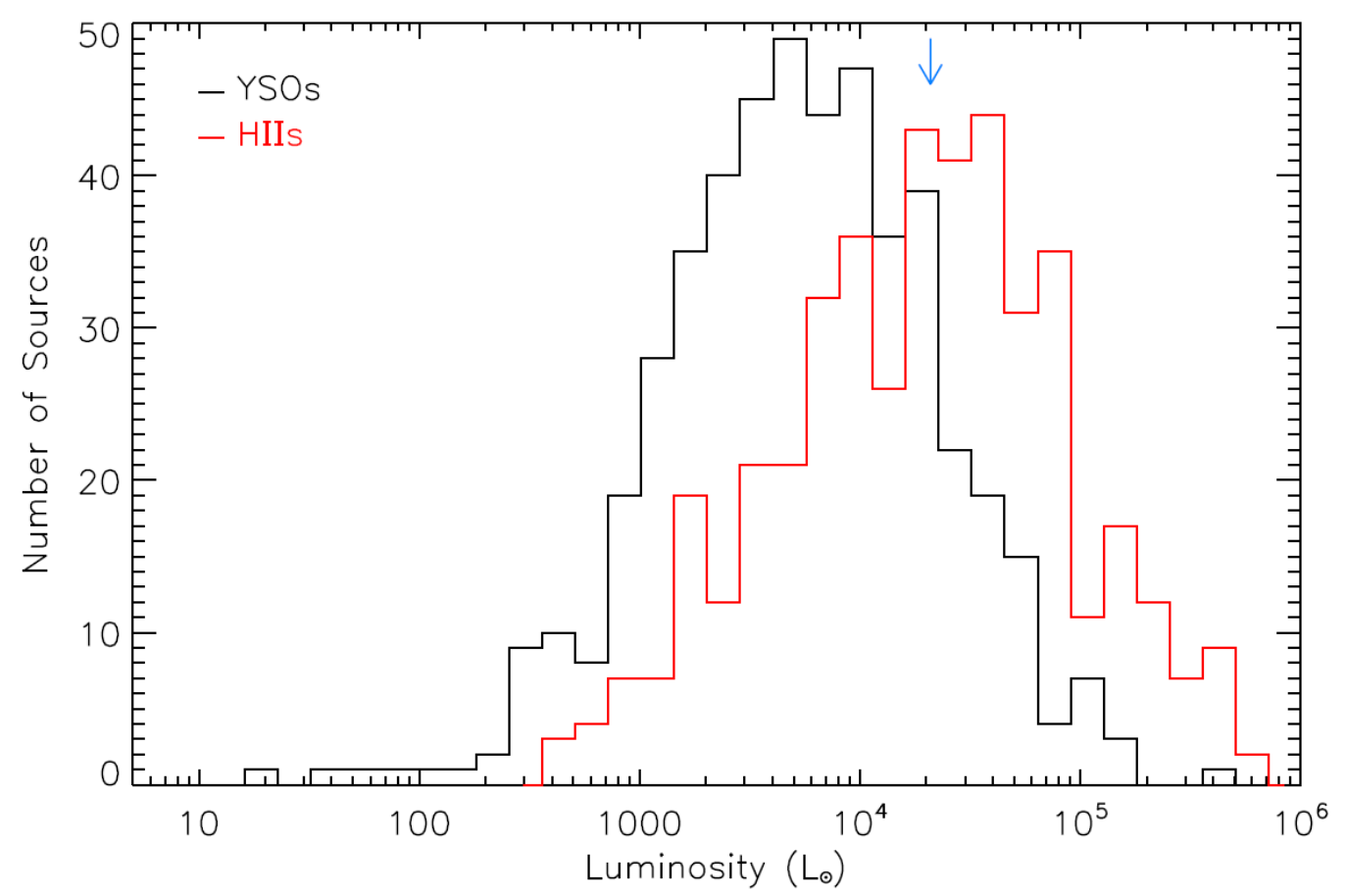

Figura 2.10: Número de fontes em função da luminosidade para a amostra de candidatos a MYSOs e regiões H II. A seta azul indica a luminosidade de uma estrela do tipo espectral B0. Retirado de Mottram et al. (2011). 


\subsection{Importância do levantamento RMS para o presente trabalho}

A Seção2.4 apresentou as observações realizadas ao longo do levantamento RMS, utilizadas como critérios para a seleção de candidatos a MYSOs a partir de uma lista contendo $\approx 3000$ objetos. O resultado final, apresentado em Mottram et al. (2011), contém uma lista de $\sim 400$ candidatos a estrelas jovens e de alta massa, dos quais 296 serão apresentados nesse trabalho. A Tabela 2.1 apresenta o nome das fontes RMS (coluna 1), as coordenadas equatoriais das fontes $(\alpha, \delta$, colunas 2 e 3$)$, a distância cinemática da fonte (coluna 4), o logaritimo da luminosidade bolométrica (coluna 5) e o instrumento utilizado para a aquisição das imagens (coluna 6). Mais detalhes sobre as observações serão apresentadas no próximo capítulo.

Tabela 2.1 - Lista de candidatos a MYSOs apresentados no presente trabalho.

\begin{tabular}{|c|c|c|c|c|c|}
\hline Objeto & $\begin{array}{c}\alpha \\
\text { (hh:mm:ss) }\end{array}$ & $\begin{array}{c}\delta \\
\text { (dd:mm:ss) }\end{array}$ & $\begin{array}{c}\mathrm{d}^{a} \\
(\mathrm{kpc})\end{array}$ & $\log \left(L / L_{\odot}\right)^{b}$ & Instrumento $^{c}$ \\
\hline G016.7981+00.1264 & $18: 20: 55.28$ & $-14: 15: 30.8$ & 14.6 & 5.14 & OSIRIS \\
\hline G018.6608+00.0372 & $18: 24: 50.24$ & $-12: 39: 22.4$ & 10.8 & 4.29 & WIRCam \\
\hline G019.8817-00.5347 & $18: 29: 14.68$ & $-11: 50: 23.6$ & 3.5 & 3.94 & WIRCam \\
\hline G019.9386-00.2079 & $18: 28: 09.88$ & $-11: 38: 22.9$ & 4.5 & 3.35 & WIRCam \\
\hline G020.5143+00.4936 & $18: 26: 43.49$ & $-10: 48: 18.5$ & 13.6 & 4.10 & WIRCam \\
\hline G022.3554+00.0655 & $18: 31: 44.20$ & $-09: 22: 17.0$ & 5.2 & 4.23 & WIRCam \\
\hline G023.2628+00.0713 & $18: 33: 24.76$ & $-08: 33: 50.0$ & 4.9 & 3.88 & WIRCam \\
\hline G023.4394-00.2394 & $18: 34: 51.32$ & $-08: 32: 55.0$ & 6.0 & 4.36 & WIRCam \\
\hline G023.6566-00.1273 & $18: 34: 51.56$ & $-08: 18: 21.6$ & 5.0 & 4.17 & WIRCam \\
\hline G023.8176+00.3841 & $18: 33: 19.54$ & $-07: 55: 37.8$ & 4.8 & 3.62 & WIRCam \\
\hline G023.8983+00.0648 & $18: 34: 37.18$ & $-08: 00: 12.4$ & 3.0 & 3.86 & WIRCam \\
\hline G024.0946+00.4565 & $18: 33: 34.92$ & $-07: 38: 53.5$ & 5.6 & 3.50 & WIRCam \\
\hline G024.6343-00.3233 & $18: 37: 22.68$ & $-07: 31: 41.5$ & 12.3 & 4.90 & WIRCam \\
\hline G024.7320+00.1530 & $18: 35: 50.91$ & $-07: 13: 27.2$ & 9.1 & 4.26 & WIRCam \\
\hline G025.4118+00.1052 & $18: 37: 16.99$ & $-06: 38: 25.4$ & 5.7 & 3.97 & WIRCam \\
\hline G025.6498+01.0491 & $18: 34: 20.89$ & $-05: 59: 42.5$ & 12.3 & 5.50 & OSIRIS \\
\hline G026.0552+00.5421 & $18: 36: 54.62$ & $-05: 52: 05.5$ & 12.1 & 4.38 & WIRCam \\
\hline G026.3176-00.0134 & $18: 41: 35.92$ & $-05: 58: 50.7$ & 6.0 & 4.20 & WIRCam \\
\hline G026.5254-00.2667 & $18: 40: 40.25$ & $-05: 49: 12.9$ & 8.9 & 3.72 & WIRCam \\
\hline G026.6085-00.2122 & $18: 40: 37.58$ & $-05: 43: 21.3$ & 8.8 & 4.48 & WIRCam \\
\hline G027.1852-00.0812 & $18: 41: 13.26$ & $-05: 08: 57.7$ & 2.0 & 3.35 & WIRCam \\
\hline G028.8621+00.0657 & $18: 43: 46.24$ & $-03: 35: 29.2$ & 8.7 & 5.30 & WIRCam \\
\hline G029.5904-00.6144 & $18: 47: 31.70$ & $-03: 15: 14.0$ & 10.1 & 4.25 & WIRCam \\
\hline G030.2971+00.0549 & $18: 46: 25.79$ & $-02: 19: 13.7$ & 12.0 & 4.31 & WIRCam \\
\hline G030.8185+00.2729 & $18: 46: 36.58$ & $-01: 45: 22.4$ & 6.2 & 4.09 & WIRCam \\
\hline
\end{tabular}

Continua na próxima página... 
Tabela 2.1 - Continuação

\begin{tabular}{|c|c|c|c|c|c|}
\hline Objeto & $\begin{array}{c}\alpha \\
\text { (hh:mm:ss) }\end{array}$ & $\begin{array}{c}\delta \\
(\mathrm{dd}: \mathrm{mm}: \mathrm{ss})\end{array}$ & $\begin{array}{c}\mathrm{d}^{a} \\
(\mathrm{kpc})\end{array}$ & $\log \left(L / L_{\odot}\right)^{b}$ & Instrumento $^{c}$ \\
\hline G030.9959-00.0771 & $18: 48: 10.65$ & $-01: 45: 25.3$ & 9.5 & 4.21 & WIRCam \\
\hline G031.1593+00.0456 & $18: 48: 02.22$ & $-01: 33: 23.2$ & 11.8 & 4.06 & WIRCam \\
\hline G033.3891+00.1989 & $18: 51: 33.82$ & $+00: 29: 51.0$ & 5.5 & 4.08 & WIRCam \\
\hline G033.3933+00.0100 & $18: 52: 14.66$ & $+00: 24: 55.0$ & 6.9 & 4.17 & WIRCam \\
\hline G033.5237+00.0198 & $18: 52: 26.83$ & $+00: 32: 08.5$ & 6.9 & 3.98 & WIRCam \\
\hline G034.4035+00.2282 & $18: 53: 18.70$ & $+01: 24: 48.1$ & 10.3 & 4.39 & WIRCam \\
\hline G034.7123-00.5946 & $18: 56: 48.23$ & $+01: 18: 47.5$ & 3.0 & 3.95 & WIRCam \\
\hline G035.3449+00.3474 & $18: 54: 36.14$ & $+02: 18: 20.2$ & 6.8 & 3.95 & WIRCam \\
\hline G035.8546+00.2663 & $18: 55: 49.41$ & $+02: 43: 21.0$ & 2.0 & 3.12 & WIRCam \\
\hline G036.9194+00.4825 & $18: 56: 59.78$ & $+03: 46: 03.9$ & 12.7 & 4.00 & WIRCam \\
\hline G037.3412-00.0600 & $18: 59: 42.28$ & $+03: 53: 49.1$ & 9.8 & 4.19 & WIRCam \\
\hline G037.4974+00.5301 & $18: 57: 53.37$ & $+04: 18: 17.5$ & 0.6 & 2.12 & WIRCam \\
\hline G038.3543-00.9519 & 19:04:44.86 & $+04: 23: 17.88$ & 1.1 & 2.81 & WIRCam \\
\hline G039.3880-00.1421 & 19:03:45.29 & $+05: 40: 42.4$ & 4.6 & 3.39 & WIRCam \\
\hline G039.4943-00.9933 & 19:06:59.68 & $+05: 22: 53.4$ & 3.6 & 3.90 & WIRCam \\
\hline G039.9284-00.3741 & 19:05:35.27 & $+06: 03: 01.3$ & 8.9 & 3.82 & WIRCam \\
\hline G040.4247+00.6989 & 19:02:39.62 & $+06: 59: 08.5$ & 0.8 & 1.64 & WIRCam \\
\hline G041.0780-00.6365 & 19:08:39.23 & $+06: 57: 07.2$ & 7.0 & 3.57 & WIRCam \\
\hline G042.1099-00.4466 & 19:09:53.57 & $+07: 57: 14.5$ & 8.7 & 3.95 & WIRCam \\
\hline G043.0786+00.0033 & 19:10:05.01 & $+09: 01: 15.6$ & 0.9 & 1.63 & WIRCam \\
\hline G043.7955-00.1275 & 19:11:54.07 & $+09: 35: 50.2$ & 9.2 & 5.16 & OSIRIS \\
\hline G043.8152-00.1172 & 19:11:54.09 & $+09: 37: 10.5$ & 8.9 & 3.99 & WIRCam \\
\hline G043.9956-00.0111 & 19:11:51.64 & $+09: 49: 40.4$ & 6.9 & 4.32 & WIRCam \\
\hline G044.2836-00.5249 & 19:14:14.92 & $+09: 50: 43.8$ & 6.1 & 3.88 & WIRCam \\
\hline G045.1894-00.4387 & 19:15:39.02 & $+10: 41: 15.4$ & 5.9 & 3.84 & WIRCam \\
\hline G053.0366+00.1110 & $19: 28: 55.65$ & $+17: 51: 59.5$ & 10.0 & 3.60 & WIRCam \\
\hline G061.7201+00.8630 & $19: 44: 23.64$ & $+25: 48: 43.4$ & 15.9 & 4.89 & WIRCam \\
\hline G076.0902+00.1412 & $20: 23: 27.29$ & $+37: 34: 53.9$ & 4.5 & 3.85 & WIRCam \\
\hline G076.1877+00.0974 & $20: 23: 55.10$ & $+37: 38: 09.7$ & 4.9 & 4.91 & WIRCam \\
\hline G077.4052-01.2136 & $20: 32: 54.10$ & $+37: 51: 29.7$ & 4.6 & 3.67 & WIRCam \\
\hline G077.8999+01.7678 & $20: 21: 55.01$ & $+39: 59: 45.5$ & 4.5 & 3.88 & WIRCam \\
\hline G077.9550+00.0058 & $20: 29: 31.76$ & $+39: 01: 20.7$ & 4.7 & 4.24 & WIRCam \\
\hline G077.9637-00.0075 & $20: 29: 36.88$ & $+39: 01: 15.6$ & 4.5 & 5.14 & WIRCam \\
\hline G078.0515+00.6180 & $20: 27: 15.50$ & $+39: 27: 28.0$ & 4.2 & 3.87 & WIRCam \\
\hline G078.4373+02.6584 & 20:19:38.49 & $+40: 56: 33.7$ & 3.8 & 4.71 & WIRCam \\
\hline G078.7641+01.6862 & $20: 24: 51.66$ & $+40: 39: 25.2$ & 12.4 & 4.77 & WIRCam \\
\hline G078.8699+02.7602 & $20: 20: 30.48$ & $+41: 21: 25.9$ & 1.6 & 3.92 & WIRCam \\
\hline G078.8867+00.7087 & $20: 29: 24.86$ & $+40: 11: 19.4$ & 4.7 & 5.56 & WIRCam \\
\hline G079.1272+02.2782 & $20: 23: 23.83$ & $+41: 17: 39.3$ & 4.1 & 4.19 & WIRCam \\
\hline G079.3202+01.3131 & $20: 28: 10.24$ & $+40: 53: 37.8$ & 8.5 & 4.69 & WIRCam \\
\hline G079.3248+01.2901 & $20: 28: 16.15$ & $+40: 52: 57.9$ & 8.5 & 4.72 & WIRCam \\
\hline G079.3398+00.3417 & $20: 32: 22.17$ & $+40: 20: 17.1$ & 3.6 & 3.28 & WIRCam \\
\hline
\end{tabular}

Continua na próxima página... 
Tabela 2.1 - Continuação

\begin{tabular}{|c|c|c|c|c|c|}
\hline Objeto & $\begin{array}{c}\alpha \\
(\mathrm{hh}: \mathrm{mm}: \mathrm{ss})\end{array}$ & $\begin{array}{c}\delta \\
(\mathrm{dd}: \mathrm{mm}: \mathrm{ss})\end{array}$ & $\begin{array}{c}\mathrm{d}^{a} \\
(\mathrm{kpc})\end{array}$ & $\log \left(L / L_{\odot}\right)^{b}$ & Instrumento $^{c}$ \\
\hline G080.8282+00.5670 & $20: 36: 07.53$ & $+41: 40: 09.0$ & 1.3 & 3.53 & WIRCam \\
\hline G081.7624+00.5916 & 20:39:03.72 & $+42: 25: 29.6$ & 3.9 & 3.74 & WIRCam \\
\hline G081.8652+00.7800 & $20: 38: 35.42$ & $+42: 37: 15.9$ & 1.2 & 3.41 & WIRCam \\
\hline G082.0333+02.3249 & $20: 32: 21.91$ & $+43: 40: 56.2$ & 3.0 & 4.00 & WIRCam \\
\hline G082.5682+00.4040 & $20: 42: 33.76$ & $+42: 56: 51.3$ & 1.0 & 3.32 & WIRCam \\
\hline G084.5978+00.1408 & $20: 50: 42.81$ & $+44: 21: 55.4$ & 2.9 & 3.10 & WIRCam \\
\hline G085.0331+00.3629 & $20: 51: 18.38$ & $+44: 50: 33.0$ & 2.7 & 3.22 & WIRCam \\
\hline G090.7764+02.8281 & $21: 02: 21.50$ & $+50: 48: 34.5$ & 3.1 & 3.39 & WIRCam \\
\hline G093.1610+01.8687 & $21: 17: 14.17$ & $+51: 54: 23.0$ & 8.4 & 4.17 & WIRCam \\
\hline G094.3228-00.1671 & $21: 31: 45.16$ & $+51: 15: 35.6$ & 5.6 & 3.96 & WIRCam \\
\hline G094.4637-00.8043 & 21:35:09.11 & $+50: 53: 09.6$ & 6.2 & 4.51 & WIRCam \\
\hline G094.6028-01.7966 & $21: 39: 58.25$ & $+50: 14: 20.9$ & 6.2 & 4.84 & WIRCam \\
\hline G095.0531+03.9724 & $21: 15: 55.63$ & $+54: 43: 31.0$ & 10.7 & 4.27 & WIRCam \\
\hline G096.3597+01.2982 & 21:35:05.01 & $+53: 43: 00.4$ & 9.0 & 4.34 & WIRCam \\
\hline G096.4353+01.3233 & $21: 35: 21.23$ & $+53: 47: 12.0$ & 8.7 & 4.26 & WIRCam \\
\hline G097.9978+01.4688 & $21: 42: 43.19$ & $+54: 55: 51.9$ & 8.1 & 3.85 & WIRCam \\
\hline G098.8555+02.9344 & $21: 40: 28.98$ & $+56: 35: 55.6$ & 0.5 & 2.14 & WIRCam \\
\hline G100.2124+01.8829 & $21: 52: 57.15$ & $+56: 39: 54.2$ & 7.4 & 4.22 & WIRCam \\
\hline G100.3779-03.5784 & $22: 16: 10.35$ & $+52: 21: 34.7$ & 4.8 & 4.46 & WIRCam \\
\hline G102.3340+03.6094 & $21: 57: 25.70$ & $+59: 19: 59.1$ & 10.5 & 4.01 & WIRCam \\
\hline G107.6823-02.2423 & $22: 55: 29.82$ & $+57: 09: 24.9$ & 6.1 & 3.84 & WIRCam \\
\hline G108.4714-02.8176 & $23: 02: 32.03$ & $+56: 57: 53.2$ & 5.9 & 3.94 & WIRCam \\
\hline G108.7575-00.9863 & $22: 58: 47.49$ & $+58: 45: 01.0$ & 5.5 & 4.35 & WIRCam \\
\hline G109.0775-00.3524 & $22: 58: 58.89$ & $+59: 27: 35.6$ & 5.3 & 3.62 & WIRCam \\
\hline G109.8715+02.1156 & $22: 56: 17.97$ & $+62: 01: 54.4$ & 1.5 & 4.58 & WIRCam \\
\hline G110.0931-00.0641 & $23: 05: 25.08$ & $+60: 08: 16.0$ & 5.7 & 4.30 & WIRCam \\
\hline G110.1082+00.0473 & $23: 05: 10.15$ & $+60: 14: 42.7$ & 5.6 & 4.69 & WIRCam \\
\hline G110.4771+01.4803 & $23: 03: 12.86$ & $+61: 42: 24.1$ & 1.5 & 2.59 & WIRCam \\
\hline G111.5234+00.8004 & $23: 13: 32.39$ & $+61: 29: 06.2$ & 6.2 & 4.56 & WIRCam \\
\hline G111.5320+00.7593 & $23: 13: 43.89$ & $+61: 26: 58.2$ & 6.1 & 4.33 & WIRCam \\
\hline $\mathrm{G} 111.5671+00.7517$ & $23: 14: 01.70$ & $+61: 27: 19.0$ & 6.1 & 5.39 & WIRCam \\
\hline G111.5851+00.7976 & $23: 14: 01.68$ & $+61: 30: 16.5$ & 6.0 & 4.45 & WIRCam \\
\hline G111.6115+00.3735 & $23: 15: 31.22$ & $+61: 07: 09.4$ & 6.0 & 5.31 & WIRCam \\
\hline $\mathrm{G} 114.0835+02.8568$ & $23: 28: 27.86$ & $+64: 17: 37.3$ & 5.5 & 4.08 & WIRCam \\
\hline $\mathrm{G} 120.1483+03.3745$ & $00: 23: 57.07$ & $+66: 05: 51.0$ & 7.3 & 4.54 & WIRCam \\
\hline G124.0144-00.0267 & 01:00:55.24 & $+62: 49: 30.0$ & 4.3 & 3.46 & WIRCam \\
\hline G125.6045+02.1038 & $01: 16: 36.21$ & $+64: 50: 38.4$ & 5.5 & 3.89 & WIRCam \\
\hline G126.4274-01.2348 & $01: 20: 44.25$ & $+61: 26: 16.0$ & 1.3 & 2.23 & WIRCam \\
\hline G126.7144-00.8220 & $01: 23: 33.17$ & $+61: 48: 48.2$ & 1.4 & 3.98 & WIRCam \\
\hline G133.6945+01.2166 & $02: 25: 30.99$ & $+62: 06: 20.9$ & 4.6 & 5.22 & WIRCam \\
\hline $\mathrm{G} 134.2792+00.8561$ & 02:29:01.96 & $+61: 33: 31.6$ & 5.6 & 4.39 & WIRCam \\
\hline G135.2774+02.7981 & $02: 43: 28.65$ & $+62: 57: 09.3$ & 9.3 & 4.83 & WIRCam \\
\hline
\end{tabular}

Continua na próxima página... 
Tabela 2.1 - Continuação

\begin{tabular}{|c|c|c|c|c|c|}
\hline Objeto & $\begin{array}{c}\alpha \\
\text { (hh:mm:ss) }\end{array}$ & $\begin{array}{c}\delta \\
(\mathrm{dd}: \mathrm{mm}: \mathrm{ss})\end{array}$ & $\begin{array}{c}\mathrm{d}^{a} \\
(\mathrm{kpc})\end{array}$ & $\log \left(L / L_{\odot}\right)^{b}$ & Instrumento $^{c}$ \\
\hline G136.3542+00.9543 & $02: 45: 10.41$ & $+60: 49: 37.5$ & 7.5 & 4.06 & WIRCam \\
\hline G136.5370+02.8934 & 02:53:43.36 & $+62: 29: 23.6$ & 5.3 & 3.36 & WIRCam \\
\hline G138.2957+01.5552 & 03:01:31.63 & $+60: 29: 12.1$ & 4.0 & 4.43 & WIRCam \\
\hline G139.9091+00.1969 & 03:07:24.52 & $+58: 30: 43.3$ & 4.3 & 4.30 & WIRCam \\
\hline G141.9996+01.8202 & $03: 27: 38.76$ & $+58: 47: 00.1$ & 1.4 & 3.64 & WIRCam \\
\hline G142.2446+01.4299 & $03: 27: 31.37$ & $+58: 19: 21.8$ & 5.7 & 4.46 & WIRCam \\
\hline G143.8118-01.5699 & $03: 24: 51.04$ & $+54: 57: 30.6$ & 3.5 & 4.27 & WIRCam \\
\hline G144.6678-00.7136 & 03:33:10.01 & $+55: 10: 54.9$ & 2.8 & 2.87 & WIRCam \\
\hline G148.1201+00.2928 & 03:56:15.36 & $+53: 52: 13.0$ & 4.3 & 3.84 & WIRCam \\
\hline G151.6120-00.4575 & 04:10:11.86 & $+50: 59: 54.4$ & 8.9 & 4.61 & WIRCam \\
\hline G172.8742+02.2687 & $05: 36: 52.46$ & $+36: 10: 57.3$ & 16.8 & 4.34 & WIRCam \\
\hline G173.4815+02.4459 & 05:39:12.96 & $+35: 45: 51.4$ & 17.0 & 5.73 & WIRCam \\
\hline G173.4839+02.4317 & 05:39:09.92 & $+35: 45: 17.2$ & 22.3 & 5.55 & WIRCam \\
\hline G173.5826+02.4452 & $05: 39: 28.65$ & $+35: 40: 41.8$ & 20.9 & 4.64 & WIRCam \\
\hline G173.6328+02.8064 & 05:41:07.03 & $+35: 49: 34.8$ & 34.0 & 5.94 & WIRCam \\
\hline G173.6339+02.8218 & 05:41:11.18 & $+35: 50: 03.4$ & 34.0 & 6.18 & WIRCam \\
\hline G188.9479+00.8871 & 06:08:53.40 & $+21: 38: 28.1$ & 1.0 & 3.37 & WIRCam \\
\hline G189.0307+00.7821 & 06:09:20.01 & $+20: 39: 33.4$ & 0.8 & 3.50 & WIRCam \\
\hline G189.8557+00.5011 & 06:08:40.52 & $+21: 31: 00.4$ & 2.7 & 3.33 & WIRCam \\
\hline G192.6005-00.0479 & $06: 12: 54.04$ & $+17: 59: 22.5$ & 1.8 & 4.45 & WIRCam \\
\hline G192.9089-00.6259 & $06: 11: 23.69$ & $+17: 26: 29.7$ & 8.0 & 4.78 & WIRCam \\
\hline G194.9349-01.2224 & $06: 13: 16.14$ & $+15: 22: 43.3$ & 3.7 & 3.97 & WIRCam \\
\hline G196.1620-01.2546 & $06: 15: 34.56$ & $+14: 17: 04.9$ & 2.1 & 3.32 & WIRCam \\
\hline G196.4542-01.6777 & $06: 14: 36.82$ & $+13: 49: 35.8$ & 3.9 & 4.70 & WIRCam \\
\hline G200.0789-01.6323 & $06: 21: 47.59$ & $+10: 39: 21.5$ & 7.9 & 4.15 & WIRCam \\
\hline G202.6270+02.3747 & 06:41:02.49 & $+10: 15: 03.9$ & 1.0 & 2.72 & WIRCam \\
\hline G203.3166+02.0564 & $06: 41: 10.12$ & $+09: 29: 33.7$ & 1.0 & 3.50 & WIRCam \\
\hline G203.7637+01.2705 & 06:39:09.91 & $+08: 44: 09.2$ & 1.3 & 3.10 & WIRCam \\
\hline G206.7804-01.9395 & 06:33:15.91 & $+04: 34: 54.1$ & 1.8 & 3.42 & WIRCam \\
\hline G207.2654-01.8080 & $06: 34: 37.74$ & $+04: 12: 44.2$ & 1.6 & 3.85 & WIRCam \\
\hline G212.0641-00.7395 & $06: 47: 13.31$ & $+00: 26: 06.0$ & 6.4 & 4.40 & WIRCam \\
\hline G212.2344-03.5038 & $06: 37: 41.59$ & $-00: 58: 37.7$ & 6.7 & 3.65 & WIRCam \\
\hline $\mathrm{G} 212.9626+01.2954$ & $06: 56: 06.32$ & $+00: 33: 47.7$ & 5.7 & 3.37 & WIRCam \\
\hline G213.9180+00.3786 & $06: 54: 35.14$ & $-00: 42: 17.8$ & 5.3 & 3.32 & WIRCam \\
\hline G214.4934-01.8103 & $06: 47: 50.25$ & $-02: 12: 53.2$ & 3.0 & 3.11 & WIRCam \\
\hline G215.8902-02.0094 & $06: 49: 40.23$ & $-03: 32: 52.4$ & 8.3 & 3.69 & WIRCam \\
\hline G217.6047-02.6170 & $06: 50: 37.41$ & $-05: 21: 00.9$ & 9.2 & 3.88 & WIRCam \\
\hline G222.4278-03.1357 & $06: 57: 35.20$ & $-09: 52: 40.8$ & 1.1 & 2.73 & WIRCam \\
\hline G224.6065-02.5563 & 07:03:43.16 & $-11: 33: 06.2$ & 1.3 & 3.52 & WIRCam \\
\hline G224.6075-01.0063 & 07:09:20.55 & $-10: 50: 28.1$ & 1.6 & 3.20 & WIRCam \\
\hline G225.3266-00.5318 & $07: 12: 24.40$ & $-11: 15: 34.9$ & 1.6 & 2.87 & WIRCam \\
\hline G231.7986-01.9682 & 07:19:35.92 & $-17: 39: 18.0$ & 4.3 & 3.74 & WIRCam \\
\hline
\end{tabular}

Continua na próxima página... 
Tabela 2.1 - Continuação

\begin{tabular}{|c|c|c|c|c|c|}
\hline Objeto & $\begin{array}{c}\alpha \\
(\mathrm{hh}: \mathrm{mm}: \mathrm{ss})\end{array}$ & $\begin{array}{c}\delta \\
(\mathrm{dd}: \mathrm{mm}: \mathrm{ss})\end{array}$ & $\begin{array}{c}\mathrm{d}^{a} \\
(\mathrm{kpc})\end{array}$ & $\log \left(L / L_{\odot}\right)^{b}$ & Instrumento $^{c}$ \\
\hline G231.9005-02.1378 & $07: 19: 10.17$ & $-17: 49: 27.4$ & 4.4 & 2.96 & WIRCam \\
\hline G232.0766-02.2767 & $07: 18: 59.92$ & $-18: 02: 41.2$ & 4.1 & 3.67 & WIRCam \\
\hline G232.6207+00.9959 & 07:32:09.66 & $-16: 58: 12.8$ & 1.6 & 4.00 & WIRCam \\
\hline G233.8306-00.1803 & $07: 30: 16.65$ & $-18: 35: 48.8$ & 4.4 & 4.27 & WIRCam \\
\hline G242.9402-00.4501 & $07: 48: 43.12$ & $-26: 39: 31.3$ & 6.7 & 3.71 & Spartan \\
\hline G251.2337-01.9535 & 08:02:43.10 & $-34: 31: 49.0$ & 5.9 & 4.31 & Spartan \\
\hline G254.0491-00.5615 & $08: 15: 57.12$ & $-36: 08: 08.1$ & 4.1 & 3.85 & Spartan \\
\hline G259.0453-01.5559 & $08: 26: 17.22$ & $-40: 48: 40.5$ & 7.0 & 4.06 & Spartan \\
\hline G259.0459-01.9107 & $08: 24: 44.85$ & $-41: 01: 00.4$ & 2.2 & 2.18 & Spartan \\
\hline G259.6154-02.6940 & 08:23:03.86 & $-41: 55: 55.9$ & 6.6 & 3.62 & Spartan \\
\hline G259.6695-01.3181 & 08:29:13.82 & $-41: 10: 48.3$ & 7.0 & 3.40 & Spartan \\
\hline G259.7592-02.8378 & $08: 22: 52.22$ & $-42: 07: 55.9$ & 2.1 & 3.31 & Spartan \\
\hline G259.9395-00.0419 & 08:35:31.01 & $-40: 38: 22.1$ & 1.7 & 2.62 & Spartan \\
\hline G260.9252+00.1149 & $08: 39: 20.20$ & $-41: 19: 50.8$ & 2.0 & 3.07 & Spartan \\
\hline G261.6429-02.0922 & 08:32:07.46 & $-43: 13: 48.7$ & 2.7 & 2.72 & Spartan \\
\hline G263.5846-03.9973 & $08: 29: 53.20$ & $-45: 55: 09.5$ & 14.9 & 3.97 & Spartan \\
\hline $\mathrm{G} 263.7434+00.1161$ & $08: 48: 48.64$ & $-43: 32: 29.0$ & 2.6 & 3.85 & Spartan \\
\hline G263.7759-00.4281 & $08: 46: 34.84$ & $-43: 54: 29.8$ & 1.6 & 3.66 & Spartan \\
\hline G264.1444+02.0190 & 08:58:12.81 & $-42: 37: 38.6$ & 2.0 & 3.83 & Spartan \\
\hline $\mathrm{G} 264.2918+01.4700$ & $08: 56: 27.71$ & $-43: 05: 47.4$ & 1.9 & 3.97 & Spartan \\
\hline G265.1438+01.4548 & $08: 59: 27.40$ & $-43: 45: 03.7$ & 2.0 & 3.75 & Spartan \\
\hline G265.3344+01.3916 & 08:59:53.20 & $-43: 56: 13.9$ & 1.9 & 2.55 & Spartan \\
\hline G267.7336-01.1058 & 08:58:04.20 & $-47: 23: 10.0$ & 2.1 & 3.66 & Spartan \\
\hline G267.9094+01.7816 & 09:11:14.23 & $-45: 35: 11.0$ & 1.1 & 2.60 & Spartan \\
\hline G268.0594-00.8040 & 09:00:41.06 & $-47: 26: 01.6$ & 2.1 & 2.70 & Spartan \\
\hline G268.3921-03.0659 & 08:51:37.05 & $-49: 09: 08.6$ & 1.6 & 2.54 & Spartan \\
\hline G268.3957-00.4842 & 09:03:25.15 & $-47: 28: 27.1$ & 3.1 & 3.91 & Spartan \\
\hline G268.4452-00.8442 & 09:02:01.00 & $-47: 45: 00.3$ & 1.9 & 2.35 & Spartan \\
\hline G269.5205-01.2510 & 09:04:29.25 & $-48: 49: 24.9$ & 2.3 & 2.83 & Spartan \\
\hline G269.7431-00.3193 & 09:09:32.98 & $-48: 21: 33.7$ & 10.4 & 4.93 & Spartan \\
\hline G269.8539-00.0630 & 09:11:08.33 & $-48: 15: 56.3$ & 10.2 & 5.08 & Spartan \\
\hline G271.2225-01.7712 & 09:09:11.16 & $-50: 25: 55.3$ & 10.5 & 4.69 & Spartan \\
\hline G271.6511-02.1492 & 09:09:16.20 & $-51: 00: 10.8$ & 10.3 & 4.75 & Spartan \\
\hline G275.8190-03.6009 & $09: 21: 29.24$ & $-55: 00: 39.5$ & 9.3 & 4.23 & Spartan \\
\hline G281.0472-01.5432 & 09:59:16.51 & $-56: 54: 43.2$ & 1.6 & 3.88 & Spartan \\
\hline G281.2206-01.2556 & 10:01:33.40 & $-56: 47: 15.7$ & 0.2 & 0.07 & Spartan \\
\hline G281.9780-01.3712 & $10: 05: 31.53$ & $-57: 19: 53.0$ & 6.3 & 3.55 & Spartan \\
\hline G282.7848-01.2869 & $10: 11: 31.70$ & $-57: 47: 05.3$ & 2.7 & 2.92 & Spartan \\
\hline G282.8667-03.1483 & 10:02:55.92 & $-59: 17: 18.6$ & 3.8 & 3.31 & Spartan \\
\hline G282.8969-01.2727 & $10: 11: 31.70$ & $-59: 47: 05.3$ & 2.8 & 3.73 & Spartan \\
\hline G284.6942-00.3600 & $10: 26: 36.40$ & $-58: 00: 32.0$ & 6.2 & 4.83 & Spartan \\
\hline G286.2086+00.1694 & $10: 38: 32.70$ & $-58: 19: 14.3$ & 2.3 & 4.89 & Spartan \\
\hline
\end{tabular}

Continua na próxima página... 
Tabela 2.1 - Continuação

\begin{tabular}{|c|c|c|c|c|c|}
\hline Objeto & $\begin{array}{c}\alpha \\
\text { (hh:mm:ss) }\end{array}$ & $\begin{array}{c}\delta \\
(\mathrm{dd}: \mathrm{mm}: \mathrm{ss})\end{array}$ & $\begin{array}{c}\mathrm{d}^{a} \\
(\mathrm{kpc})\end{array}$ & $\log \left(L / L_{\odot}\right)^{b}$ & Instrumento $^{c}$ \\
\hline G287.2238-00.5339 & $10: 42: 48.88$ & $-59: 25: 29.2$ & 2.5 & 2.68 & Spartan \\
\hline G287.8768-01.3618 & $10: 44: 17.85$ & $-60: 27: 46.0$ & 7.1 & 5.03 & Spartan \\
\hline G287.8893-00.9316 & $10: 46: 00.23$ & $-60: 05: 16.8$ & 2.5 & 2.67 & Spartan \\
\hline G288.1760-00.8351 & $10: 48: 24.23$ & $-60: 08: 02.0$ & 6.1 & 4.77 & Spartan \\
\hline G288.9862+00.2533 & $10: 57: 59.95$ & $-59: 30: 41.6$ & 0.0 & 0.00 & Spartan \\
\hline G289.9446-00.8909 & 11:01:10.67 & $-60: 57: 08.3$ & 9.4 & 5.52 & Spartan \\
\hline G290.8768-01.2170 & 11:07:11.38 & $-61: 37: 31.6$ & 8.0 & 4.50 & Spartan \\
\hline G291.5765-00.4310 & 11:15:04.60 & $-61: 09: 37.4$ & 7.9 & 5.64 & Spartan \\
\hline G293.5607-00.6703 & 11:30:07.10 & $-62: 03: 12.9$ & 3.3 & 4.66 & Spartan \\
\hline G294.6168-02.3440 & $11: 34: 32.85$ & $-63: 58: 03.0$ & 0.8 & 2.13 & Spartan \\
\hline G295.1523-00.5890 & $11: 43: 25.23$ & $-62: 25: 40.8$ & 10.8 & 5.27 & Spartan \\
\hline G295.5570-01.3787 & $11: 45: 04.73$ & $-63: 17: 46.1$ & 11.1 & 4.87 & Spartan \\
\hline G296.4036-01.0185 & $11: 53: 08.22$ & $-63: 08: 56.6$ & 10.4 & 4.41 & Spartan \\
\hline G296.7256-01.0382 & $11: 55: 52.75$ & $-63: 14: 18.9$ & 10.0 & 5.00 & Spartan \\
\hline G296.8926-01.3050 & $11: 56: 49.75$ & $-63: 32: 04.9$ & 9.9 & 4.22 & Spartan \\
\hline G298.8591-00.4372 & $12: 15: 25.27$ & $-63: 01: 17.0$ & 11.1 & 5.20 & Spartan \\
\hline G300.3412-00.2190 & $12: 28: 36.09$ & $-62: 58: 33.2$ & 4.2 & 3.76 & Spartan \\
\hline G300.5047-00.1745 & 12:30:03.60 & $-62: 56: 48.4$ & 9.7 & 4.08 & Spartan \\
\hline G300.7221+01.2007 & $12: 32: 50.83$ & $-61: 35: 28.6$ & 4.1 & 4.15 & Spartan \\
\hline G301.1726+01.0034 & $12: 36: 31.94$ & $-61: 49: 02.6$ & 4.3 & 4.14 & Spartan \\
\hline G301.8147+00.7808 & $12: 41: 53.86$ & $-62: 04: 14.6$ & 4.4 & 4.33 & Spartan \\
\hline G302.1515-00.9488 & $12: 44: 21.93$ & $-63: 48: 36.0$ & 12.1 & 3.83 & Spartan \\
\hline G302.4546-00.7401 & $12: 47: 08.62$ & $-63: 36: 30.0$ & 12.6 & 4.36 & Spartan \\
\hline G302.4867-00.0308 & $12: 47: 31.72$ & $-62: 53: 57.4$ & 4.5 & 4.10 & Spartan \\
\hline G302.5005-00.7701 & $12: 47: 33.11$ & $-63: 38: 19.3$ & 12.1 & 3.94 & Spartan \\
\hline G304.7592-00.6299 & 13:07:47.42 & $-63: 26: 37.0$ & 12.2 & 3.64 & Spartan \\
\hline G305.4748-00.0961 & $13: 13: 45.78$ & $-62: 51: 27.6$ & 6.1 & 3.57 & Spartan \\
\hline G305.4840+00.2248 & $13: 13: 36.04$ & $-62: 32: 13.5$ & 4.9 & 3.89 & Spartan \\
\hline G305.5393+00.3394 & $13: 13: 59.56$ & $-62: 25: 07.6$ & 3.2 & 3.51 & Spartan \\
\hline G305.5610+00.0124 & 13:14:26.36 & $-62: 44: 30.4$ & 5.9 & 4.96 & Spartan \\
\hline G306.1160+00.1386 & 13:19:07.89 & $-62: 33: 42.8$ & 2.8 & 4.39 & Spartan \\
\hline G307.3950-00.5838 & $13: 31: 04.05$ & $-63: 06: 42.4$ & 13.6 & 4.10 & Spartan \\
\hline G307.6138-00.2559 & $13: 32: 31.24$ & $-62: 45: 17.0$ & 7.4 & 4.59 & Spartan \\
\hline G307.7359-00.5945 & 13:34:03.39 & $-63: 04: 04.6$ & 14.0 & 4.30 & Spartan \\
\hline G308.0049-00.3868 & $13: 36: 04.87$ & $-62: 49: 05.1$ & 7.4 & 3.96 & Spartan \\
\hline G308.0108+02.0146 & $13: 32: 46.46$ & $-60: 26: 56.0$ & 1.7 & 4.02 & Spartan \\
\hline G308.6480+00.6469 & $13: 39: 55.98$ & $-61: 40: 58.9$ & 6.1 & 4.30 & Spartan \\
\hline G308.7008+00.5312 & $13: 40: 32.64$ & $-61: 47: 19.9$ & 6.3 & 3.66 & Spartan \\
\hline G308.9176+00.1231 & 13:43:01.70 & $-62: 08: 51.2$ & 5.3 & 5.27 & Spartan \\
\hline G309.4230-00.6208 & $13: 48: 38.86$ & $-62: 46: 09.5$ & 3.6 & 3.51 & Spartan \\
\hline G309.9206+00.4790 & $13: 50: 42.33$ & $-61: 35: 07.8$ & 5.3 & 5.10 & Spartan \\
\hline G310.0135+00.3892 & 13:51:37.91 & $-61: 39: 07.5$ & 3.3 & 4.74 & Spartan \\
\hline
\end{tabular}

Continua na próxima página... 
Tabela 2.1 - Continuação

\begin{tabular}{|c|c|c|c|c|c|}
\hline Objeto & $\begin{array}{c}\alpha \\
(\mathrm{hh}: \mathrm{mm}: \mathrm{ss})\end{array}$ & $\begin{array}{c}\delta \\
(\mathrm{dd}: \mathrm{mm}: \mathrm{ss})\end{array}$ & $\begin{array}{c}\mathrm{d}^{a} \\
(\mathrm{kpc})\end{array}$ & $\log \left(L / L_{\odot}\right)^{b}$ & Instrumento $^{c}$ \\
\hline G311.1359-00.2372 & 14:02:09.92 & $-61: 58: 37.7$ & 14.3 & 4.09 & Spartan \\
\hline G311.4925+00.4021 & $14: 03: 34.80$ & $-61: 15: 52.1$ & 5.5 & 3.61 & Spartan \\
\hline G311.5131-00.4532 & $14: 05: 45.83$ & $-62: 04: 49.1$ & 7.1 & 4.13 & Spartan \\
\hline G311.6050-00.6369 & $14: 06: 58.14$ & $-62: 13: 49.2$ & 14.7 & 4.34 & Spartan \\
\hline G311.9799-00.9527 & $14: 10: 51.43$ & $-62: 25: 16.3$ & 3.1 & 2.87 & Spartan \\
\hline G313.5769+00.3267 & $14: 20: 08.35$ & $-60: 41: 55.3$ & 8.3 & 4.67 & OSIRIS \\
\hline G314.3197+00.1125 & $14: 26: 26.28$ & $-60: 38: 31.5$ & 3.6 & 4.10 & Spartan \\
\hline G316.1386-00.5009 & $14: 42: 01.87$ & $-60: 30: 09.5$ & 7.6 & 3.62 & Spartan \\
\hline G316.6412-00.0867 & $14: 44: 18.84$ & $-59: 55: 10.5$ & 11.0 & 4.92 & OSIRIS \\
\hline G316.9386-03.8102 & $15: 00: 33.60$ & $-63: 06: 55.8$ & 0.3 & 2.00 & Spartan \\
\hline G316.9531-03.8130 & 15:00:41.06 & $-63: 06: 39.6$ & 0.3 & 1.65 & Spartan \\
\hline G317.7477+00.0112 & $14: 51: 51.97$ & $-59: 21: 04.2$ & 14.7 & 4.24 & Spartan \\
\hline G318.0489+00.0854 & $14: 53: 42.33$ & $-59: 08: 52.3$ & 3.4 & 3.84 & Spartan \\
\hline G318.9480-00.1969 & $15: 00: 55.31$ & $-58: 58: 52.6$ & 2.4 & 3.80 & Spartan \\
\hline G319.8366-00.1963 & $15: 06: 54.49$ & $-58: 32: 58.7$ & 0.9 & 2.35 & Spartan \\
\hline G320.1750+00.8001 & $15: 05: 25.36$ & $-57: 30: 56.1$ & 2.7 & 3.46 & Spartan \\
\hline G320.2046+00.8626 & $15: 05: 21.83$ & $-57: 26: 49.2$ & 2.8 & 3.74 & Spartan \\
\hline G320.2437-00.5619 & $15: 11: 01.72$ & $-58: 39: 38.8$ & 9.5 & 4.26 & Spartan \\
\hline G320.2878-00.3069 & $15: 10: 18.73$ & $-58: 25: 08.7$ & 8.6 & 4.21 & Spartan \\
\hline G321.0523-00.5070 & $15: 16: 06.11$ & $-58: 11: 41.7$ & 9.1 & 4.86 & OSIRIS \\
\hline G321.3803-00.3016 & $15: 17: 23.38$ & $-57: 51: 02.7$ & 9.4 & 4.35 & Spartan \\
\hline G322.1729+00.6442 & $15: 18: 38.13$ & $-56: 37: 32.5$ & 3.8 & 4.02 & Spartan \\
\hline G323.7410-00.2552 & $15: 31: 43.96$ & $-56: 30: 26.6$ & 10.4 & 5.24 & OSIRIS \\
\hline G324.1594+00.2622 & $15: 32: 03.90$ & $-55: 50: 35.7$ & 8.0 & 4.25 & Spartan \\
\hline G326.4755+00.6947 & $15: 43: 18.94$ & $-54: 07: 35.4$ & 2.8 & 3.64 & Spartan \\
\hline G326.5437+00.1684 & $15: 45: 53.26$ & $-54: 30: 01.3$ & 9.5 & 3.99 & Spartan \\
\hline G326.6618+00.5207 & $15: 45: 02.84$ & $-54: 09: 03.0$ & 11.5 & 5.78 & OSIRIS \\
\hline G326.7249+00.6159 & $15: 44: 59.42$ & $-54: 02: 17.4$ & 11.4 & 5.21 & OSIRIS \\
\hline G327.1192+00.5103 & $15: 47: 32.80$ & $-53: 52: 39.3$ & 5.3 & 4.68 & OSIRIS \\
\hline G328.2523-00.5320 & $15: 57: 59.82$ & $-53: 58: 00.4$ & 3.1 & 4.66 & OSIRIS \\
\hline G328.3442-00.4629 & 15:58:09.62 & $-53: 51: 18.2$ & 11.5 & 4.73 & OSIRIS \\
\hline G328.5487+00.2717 & $15: 56: 01.48$ & $-53: 09: 43.9$ & 3.9 & 3.32 & Spartan \\
\hline G329.0663-00.3081 & 16:01:09.93 & $-53: 16: 02.3$ & 11.7 & 4.82 & Spartan \\
\hline G331.0890+00.0163 & $16: 09: 38.88$ & $-51: 40: 43.8$ & 5.8 & 3.56 & Spartan \\
\hline G331.3546+01.0638 & $16: 06: 25.78$ & $-50: 43: 22.2$ & 4.8 & 4.82 & OSIRIS \\
\hline G331.5651+00.2883 & $16: 10: 42.37$ & $-51: 09: 19.8$ & 11.2 & 4.00 & Spartan \\
\hline G331.6191-00.0442 & $16: 12: 24.61$ & $-51: 21: 42.4$ & 10.2 & 3.98 & Spartan \\
\hline G331.7318+02.6747 & $16: 01: 30.72$ & $-49: 16: 06.2$ & 1.9 & 2.98 & Spartan \\
\hline G332.4683-00.5228 & $16: 18: 26.53$ & $-51: 07: 12.0$ & 11.5 & 4.53 & OSIRIS \\
\hline G332.7013-00.5874 & $16: 19: 47.46$ & $-51: 00: 06.6$ & 11.3 & 4.63 & OSIRIS \\
\hline G333.1075-00.5020 & $16: 21: 14.22$ & $-50: 39: 12.6$ & 3.7 & 3.50 & Spartan \\
\hline G333.3151+00.1053 & $16: 19: 29.06$ & $-50: 04: 40.8$ & 3.3 & 3.67 & Spartan \\
\hline
\end{tabular}

Continua na próxima página... 
Tabela 2.1 - Continuação

\begin{tabular}{|c|c|c|c|c|c|}
\hline Objeto & $\begin{array}{c}\alpha \\
(\mathrm{hh}: \mathrm{mm}: \mathrm{ss})\end{array}$ & $\begin{array}{c}\delta \\
(\mathrm{dd}: \mathrm{mm}: \mathrm{ss})\end{array}$ & $\begin{array}{c}\mathrm{d}^{a} \\
(\mathrm{kpc})\end{array}$ & $\log \left(L / L_{\odot}\right)^{b}$ & Instrumento $^{c}$ \\
\hline G334.8438+00.2095 & $16: 25: 40.51$ & $-48: 55: 16.2$ & 10.4 & 3.16 & Spartan \\
\hline G336.3684-00.0033 & $16: 32: 55.85$ & $-47: 57: 45.5$ & 7.8 & 4.21 & Spartan \\
\hline G336.8308-00.3752 & $16: 36: 26.16$ & $-47: 52: 30.9$ & 13.7 & 4.71 & OSIRIS \\
\hline G337.0963-00.9291 & $16: 39: 57.78$ & $-48: 02: 48.3$ & 12.4 & 4.16 & Spartan \\
\hline G337.3071-00.1521 & $16: 37: 21.57$ & $-47: 22: 19.5$ & 4.5 & 3.47 & Spartan \\
\hline G338.0008-00.1498 & $16: 40: 04.02$ & $-46: 51: 18.1$ & 11.3 & 4.54 & OSIRIS \\
\hline G338.1127-00.1905 & $16: 40: 40.84$ & $-46: 47: 54.9$ & 12.1 & 3.83 & Spartan \\
\hline G338.2801+00.5419 & $16: 38: 09.14$ & $-46: 11: 04.5$ & 11.5 & 4.26 & Spartan \\
\hline G338.5459+02.1175 & $16: 32: 32.18$ & $-44: 55: 30.0$ & 8.1 & 0.91 & Spartan \\
\hline G338.9196+00.5495 & $16: 40: 34.12$ & $-45: 42: 08.2$ & 4.4 & 4.55 & OSIRIS \\
\hline G340.1537+00.5116 & $16: 45: 20.10$ & $-44: 47: 49.8$ & 12.0 & 4.10 & Spartan \\
\hline G340.7455-01.0021 & 16:54:04.05 & $-45: 18: 50.0$ & 13.4 & 5.05 & OSIRIS \\
\hline G342.7057+00.1260 & $16: 56: 02.80$ & $-43: 04: 51.2$ & 12.6 & 4.80 & OSIRIS \\
\hline G343.8354-00.1058 & $17: 00: 50.86$ & $-42: 20: 17.4$ & 2.6 & 3.03 & Spartan \\
\hline G345.1876+01.0308 & 17:00:30.76 & $-40: 34: 22.4$ & 2.0 & 3.30 & Spartan \\
\hline G345.6985-00.0894 & $17: 06: 50.64$ & $-40: 50: 59.5$ & 0.8 & 2.43 & Spartan \\
\hline G347.0775-00.3927 & $17: 12: 25.81$ & $-39: 55: 19.9$ & 14.9 & 5.21 & OSIRIS \\
\hline G348.0030+00.0728 & $17: 13: 18.24$ & $-38: 53: 58.5$ & 13.3 & 4.43 & OSIRIS \\
\hline G348.5477+00.3721 & $17: 13: 41.71$ & $-38: 16: 57.7$ & 1.4 & 2.05 & Spartan \\
\hline
\end{tabular}

Notas: ${ }^{a}$ A distância cinemática de cada objeto foi obtida de Urquhart et al. (2007, 2008); ${ }^{b}$ A luminosidade bolométrica (L) foi obtida a partir do fluxo bolométrico de Mottram et al. (2011) e a distância cinemática de Urquhart et al. (2007, 2008). O valor de $\mathrm{L}_{\odot}$ foi adotado como $4.0 \times 10^{26} \mathrm{~W} ;{ }^{c}$ Instrumento utilizado para observação da fonte: WIRCam para fontes do hemisfério norte e com $\delta \geq-15^{\circ}$; OSIRIS e Spartan para fontes $\operatorname{com} \delta<-15^{\circ}$. 
Capítulo 3

\section{Observações no Infravermelho Próximo}

Este capítulo descreve a metodologia utilizada para o estudo das emissões extensas no filtro $\mathrm{H}_{2}$ identificadas ao redor dos candidados a MYSOs, selecionados a partir do levantamento RMS e observados nos telescópios SOAR e CFHT. As observações foram realizadas utilizando uma metodologia análoga à empregada por Varricatt et al. (2010). No decorrer do trabalho, não só foram desenvolvidos novos procedimentos para otimizar o processamento e visualização das imagens no infravermelho próximo (NIR), mas também aprimoramentos de técnicas já existentes. O capítulo está estruturado da seguinte forma: i) apresentação do planejamento e da estratégia observacional adotada para a aquisição das imagens no NIR; ii) a influência atmosférica nas observações realizadas a partir do solo; iii) as características dos instrumentos utilizado nas observações; $i v$ ) considerações a respeito de observações no NIR; $v$ ) o processamento das imagens utilizando o pacote THELI; vi) a comparação entre imagens processas com o THELI e com o IRAF; e vii) as tarefas executadas aṕos o processamento e a criação das imagens apresentadas no presente trabalho.

\subsection{Planejamento e Desenho do Projeto Observacional}

As imagens apresentadas nesta dissertação fazem parte de um levantamento no infravermelho próximo, conduzido nos telescópios CFHT e SOAR entre o segundo semestre de 2010 e o segundo semestre de 2012. A lista completa das fontes observadas totaliza 376 candidatos a MYSOs, dos quais 252 estão situados no hemisfério Sul $\left(\delta<0^{\circ}\right)$ e 124 no hemisfério Norte $\left(\delta>0^{\circ}\right)$. As observações de 113 fontes do Norte e 183 do Sul (152 com a câmera WIRCam, 122 com a Spartan e 22 com a OSIRIS) foram processadas con- 
forme a metodologia que será apresentada nas próximas seções. As fontes não processadas totalizam 80 objetos que apresentaram problemas durante o processamento e deverão ser tratadas posteriormente. A Tabela 3.1 apresenta os projetos observacionais aprovados para a execução em modo fila nos telescópios SOAR e CFHT ao longo da fase de aquisição de dados do presente trabalho (entre 2010 e 2012).

Tabela 3.1 - Projetos executados nos telescópios CFHT e SOAR para a aquisição das imagens apresentadas no presente trabalho.

\begin{tabular}{ccccc}
\hline \hline Semestre & Telescópio & Instrumento & Projeto & Horas Concedidas \\
\hline 2010B & CFHT & WIRCam & CF2010B-002 & $32.0 \mathrm{~h}$ \\
2011A & CFHT & WIRCam & CF2011A-003 & $5.0 \mathrm{~h}$ \\
2011B & CFHT & WIRCam & CF2011B-006 & $13.5 \mathrm{~h}$ \\
2012A & CFHT & WIRCam & CF2012A-005 & $14.6 \mathrm{~h}$ \\
& & & & \\
$2011 \mathrm{~A}$ & SOAR & OSIRIS & SO2011A-016 & $21.0 \mathrm{~h}$ \\
2011B & SOAR & Spartan & SO2011B-004 & $30.5 \mathrm{~h}$ \\
2012A & SOAR & Spartan & SO2012A-015 & $36.0 \mathrm{~h}$ \\
2012B & SOAR & Spartan & SO2012B-014 & $28.5 \mathrm{~h}$ \\
\hline
\end{tabular}

A metodologia consiste na análise de mapas de emissão da transição roto-vibracional $\nu=$ $2-1 \mathrm{~S}(1) 1$ do hidrogênio molecular $\left(\mathrm{H}_{2}\right)$, com comprimento de onda central em $2.1218 \mu \mathrm{m}$. Como no trabalho de Varricatt et al. (2010), cada objeto foi observado nos filtros estreitos do $\mathrm{H}_{2}\left(\lambda_{c}=2.1218 \mu \mathrm{m}, \Delta \lambda=0.031 \mu \mathrm{m}\right)$ e num contínuo próximo $\left(\lambda_{c}=2.20 \mu \mathrm{m}\right.$, $\Delta \lambda=0.34 \mu \mathrm{m})$. O tempo de exposição de cada objeto foi de 600 segundos (10 minutos) por filtro, dividido entre 4 exposições de 150 segundos. As principais diferenças na metodologia empregada por Varricatt et al. (2010) e a utilizada neste trabalho foram:

1. Seleção dos alvos: nenhum critério fotométrico foi adotado para selecionar os 50 objetos da amostra de Varricatt et al. (2010), que apresentam emissão maser de $\mathrm{H}_{2} \mathrm{O}$ e $\mathrm{CH}_{3} \mathrm{OH}$, emissão molecular de $\mathrm{NH}_{3}$ e indicativos de jatos em alta velocidade, mapeados em observações em linhas do CO. O levantamento RMS, por sua vez, utilizou critérios de cor no infravermelho médio como condição inicial para selecionar candidatos a MYSOs, seguidas de observações adicionais para eliminar objetos que possuem

\footnotetext{
${ }^{1}$ a nomenclatura indica uma transição entre os níveis $\nu=1 \rightarrow 0$ e $J=3 \rightarrow 1$
} 
índices de cor semelhantes as fontes de interesse, porém em estágios evolutivos mais tardios (e.g. estrelas no pós-AGB, nebulosas protoplanetárias e regiões H II).

2. Subtração do Contínuo: Varricatt et al. (2010) realizaram a subtração da emissão no contínuo a partir de imagens obtidas num filtro de banda larga com comprimento de onda central $\lambda_{c} \sim 2.2 \mu \mathrm{m}$. No presente trabalho, a emissão do contínuo foi subtraída a partir de imagens obtidas num filtro estreito com comprimento de onda central próximo ao da linha do $\mathrm{H}_{2}\left(\lambda_{c} \approx 2.14\right.$ ou $2.22 \mu \mathrm{m}$, dependendo do conjunto de filtros de cada instrumento utilizado).

As emissões extensas na faixa espectral abrangida pelo filtro $\mathrm{H}_{2}$ podem provir também do espalhamento do contínuo estelar pela poeira de regiões nebulares (emissões do tipo livre-livre). A contribuição das emissões de natureza térmica pode ser descontada a partir da subtração de uma imagem do mesmo campo, observada no filtro estreito adjacente à linha do $\mathrm{H}_{2}$. Embora o uso de um filtro aumente relativamente o tempo de integração total quando comparado ao uso de um filtro de banda larga, tal estratégia evita a contaminação por emissões extensas presentes em outras linhas espectrais, tais como o caso do Brackett$\gamma$. Dessa forma, o mapa gerado pela subtração das imagens nos diferentes filtros $\left(\mathrm{H}_{2^{-}}\right.$ Contínuo) evidenciará a emissão exclusiva da transição molecular do $\mathrm{H}_{2}$.

Visto que este trabalho se baseia em observações no infravermelho próximo, é importante ressaltar algumas considerações sobre os processos que contaminam a radiação nesta faixa espectral e os procedimentos para otimizar sua detecção. As seções a seguir irão caracterizar os efeitos atmosféricos mais importantes, os instrumentos utilizados neste trabalho e as etapas do processamento das imagens.

\subsection{A Influência Atmosférica nas Observações}

Conforme visto no Capítulo1, as regiões de formação de estrelas de alta massa apresentam elevada extinção, impossibilitando observá-las em comprimentos de onda na região do visível. Por essa razão, as estrelas de alta massa se tornam acessíveis na faixa espectral do óptico somente após percorrerem $10 \%$ de sua trajetória evolutiva na sequência prin-

cipal (Garmany et al., 1982). Dessa maneira, o estudo dos estágios iniciais da formação 
destes objetos deve ser realizado em maiores comprimentos de onda, nos quais a radiação emitida pelas estrelas é menos afetada pela extinção circunstelar (e.g. infravermelho, submilimétrico e rádio). Por exemplo, a relação entre a extinção na banda $\mathrm{V}$ do visível $\left(\lambda_{V}=0.55 \mu \mathrm{m}\right)$ e na banda $\mathrm{K}$ do infravermelho próximo $\left(\lambda_{K}=2.19 \mu \mathrm{m}\right)$ é de $A_{V} \sim 10 \mathrm{~A}_{\mathrm{K}}$ (Mathis, 1990). Os comprimentos de onda do infravermelho próximo são longos o suficiente para minimizar os efeitos de extinção circunstelar e curtos o suficiente para permitir o acesso às fotosferas das estrelas jovens.

A absorção dos fótons pela atmosfera terrestre representa outro efeito que deve ser levado em consideração ao se realizar observações em solo. A absorção ocorre principalmente devido às moléculas de $\mathrm{H}_{2} \mathrm{O}, \mathrm{CO}_{2}$ e $\mathrm{OH}$ presentes na atmosfera e impede que as observações astronômicas em solo sejam realizadas em algumas faixas espectrais do NIR, definido entre $\sim 1 \mu \mathrm{m}$ e $\sim 5 \mu \mathrm{m}$. Esse efeito é minimizado nas regiões espectrais denominadas "janelas atmosféricas", que definem os filtros de banda larga do sistema fotométrico padrão (filtros Y, J, H, K, L e M; indicados na Figura 3.1).

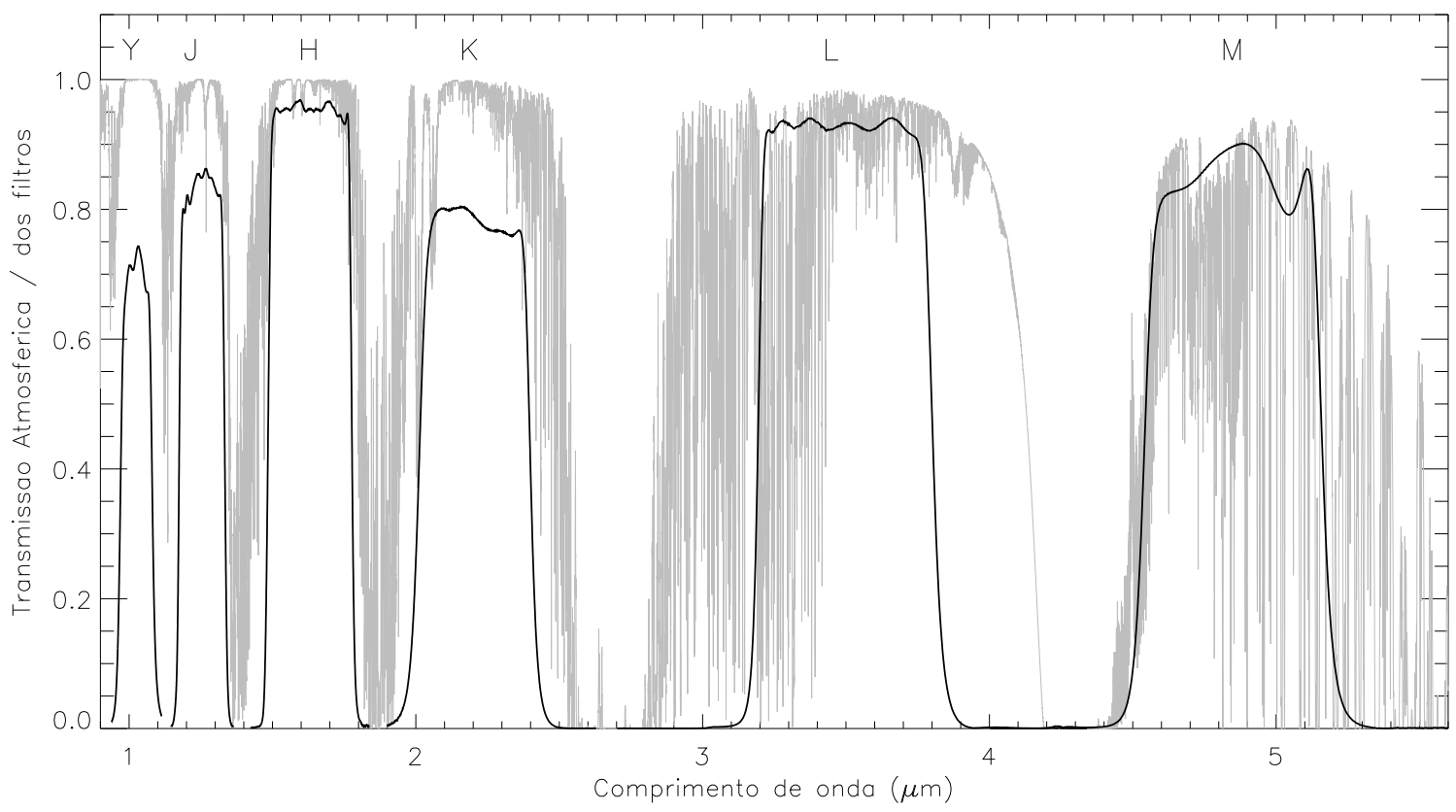

Figura 3.1: Curva de transmissão atmosférica no infravermelho próximo $(1 \mu \mathrm{m}-5 \mu \mathrm{m}$, em cinza) sobreposta aos perfis espectrais dos filtros de banda larga Y, J, H, K, L e M do sistema fotométrico padrão (em preto). Os perfis dos filtros Y, J e H foram obtidos do instrumento WIRCam (CFHT) enquanto os perfis dos filtros K, L e M são do instrumento NSFCam (NASA Infrared Telescope Facility). A transmissão dos filtros foi normalizada para 1.

A Figura 3.11ilustra o efeito da absorção atmosférica no NIR, para uma coluna de vapor 
d'água de $3 \mathrm{~mm}$ e massa de ar igual a 1, no sítio astronômico do Mauna Kea no Havaí. Valores de transmissão próximos a 1 indicam que a atmosfera é transparente para um dado comprimento de onda, enquanto valores $\sim 0$ significam que a atmosfera é opaca.

A emissão atmosférica representa outro efeito relevante e possui duas componentes no NIR: uma não-térmica, gerada pela excitação de moléculas de $\mathrm{OH}$ por fótons da faixa ultra-violeta (UV) emitidos pelo Sol, dominando a emissão de fundo entre 1 e $2.5 \mu \mathrm{m}$; e uma componente térmica devido à radiação de corpo negro emitida pela própria atmosfera, dominando a emissão para comprimentos de onda maiores que $3 \mu \mathrm{m}$.

\subsection{Instrumentos no Infravermelho Próximo}

As fontes apresentadas nesse trabalho foram observadas utilizando a câmera WIRCam montada no telescópio CFHT (Havaí), e as câmeras OSIRIS e Spartan, instrumentos do telescópio de $4.1 \mathrm{~m}$ SOAR (Chile). A Tabela 3.2 sintetiza as características das câmeras utilizadas nesse trabalho, que serão descritas brevemente nas próximas subseções.

Tabela 3.2 - Propriedades dos instrumentos utilizados neste trabalho.

\begin{tabular}{lccc}
\hline \multicolumn{1}{c}{ Propriedade } & SPARTAN & OSIRIS & WirCAM \\
\hline Detetores & $2 \times 2$ & 1 & $2 \times 2$ \\
Razão focal & $f / 12$ & $f / 7$ & $f / 12$ \\
Escala de placa (mas/pixel) & 68 & 139 & 306 \\
Campo (') & 5.2 & 2.4 & 21.5 \\
Ganho (e ${ }^{-} /$ADU) & 2.8 & 3.0 & 3.8 \\
Limite de Linearidade (ADU) & não definido & 28000 & 20000 \\
Limite de Saturação (ADU) & $\sim 25000$ & $\sim 30000$ & $\sim 35000$ \\
\hline
\end{tabular}

\subsubsection{WIRCam (CFHT)}

A câmera WIRCam (Wide-field InfraRed Camera) é um imageador infravermelho do tipo mosaico que utiliza quatro detectores HAWAII2-RG, feitos com HgCdTe, de $2048 \times$ 2048 píxeis $(2 \mathrm{k} \times 2 \mathrm{k})$ píxeis de $18 \mu \mathrm{m}$, dispostos na forma de $2 \times 2$ sub-arrays, e otimizado para comprimentos de onda entre 1.0 e $2.6 \mu \mathrm{m}$. A WIRCam opera com uma razão focal de $f / 12$, tendo como características principais a escala de placa de $0.3 "$ / píxel e seu amplo 
campo de visão (FOV, Field-of-View) de $\sim 20^{\prime} \times 20^{\prime}$.

Existe um espaço não-observável entre os detectores do instrumento, com tamanho de $\sim 3 \%$ do FOV do instrumento $\left(\sim 35^{\prime \prime}\right)$. De modo a cobrir todo o FOV do instrumento, as observações devem ser realizadas adotando-se adequadamente um padrão de pontilhamento, técnica também conhecida como dithering. O uso do dithering tem como objetivo principal evitar que a imagem final apresente falhas devido a defeitos intrínsecos ao detector (píxeis ruins). As fontes observadas com a câmera WIRCam foram posicionadas na região central do detector \#4, localizado no canto superior esquerdo do array.

\subsubsection{Spartan $(S O A R)$}

A câmera Spartan (Spartan Infrared Camera) é um imageador do tipo mosaico que utiliza quatro detectores HAWAII-2, feitos de $\mathrm{HgCdTe}$, de $2 \mathrm{k} \times 2 \mathrm{k}$, dispostos na forma de $2 \times 2$ sub-arrays, e otimizado para comprimentos de onda entre 1.0 e $2.5 \mu \mathrm{m}$. Esse instrumento opera em dois modos, com razões focais $f / 12$ e $f / 21$. O modo de baixa resolução $(f / 12)$ possui escala de placa de 0.068" / píxel e um campo de visão (FOV) de $316 "$ " ( $\left.5.2^{\prime}\right)$; enquanto o modo de alta resolução $(f / 21)$ possui escala de 40 mas/píxel e FOV de 180" $\left(\sim 3^{\prime}\right)$.

Assim como a WIRCam, a câmera Spartan também apresenta um espaço entre os detectores do instrumento, com tamanho de $\sim 10 \%$ do FOV do instrumento $\left(\sim 30^{\prime \prime} \mathrm{e}\right.$ $\sim 17^{\prime \prime}$ para os modos de baixa e alta resolução, respectivamente). De modo a cobrir todo o FOV do instrumento, as observações devem ser realizadas adotando-se um padrão de dithering adequado. A Figura 3.2 mostra a disposição dos detectores da câmera Spartan. As fontes observadas com a Spartan foram posicionadas no centro do detector "d3", que apresenta as melhores propriedades dentre os 4 detectores. O detector "d3" está localizado no canto superior esquerdo do array.

\subsubsection{OSIRIS (SOAR)}

A câmera Spartan esteve inoperante durante o primeiro ano (2010B-2011A) do levantamento. Dessa forma, 50 objetos foram observados com a câmera OSIRIS visando não prejudicar o andamento do projeto observacional. A câmera OSIRIS (Ohio State InfraRed Imager/Spectrometer) utiliza um detector HAWAII, feito de HgCdTe, com $1024 \times 1024$ 


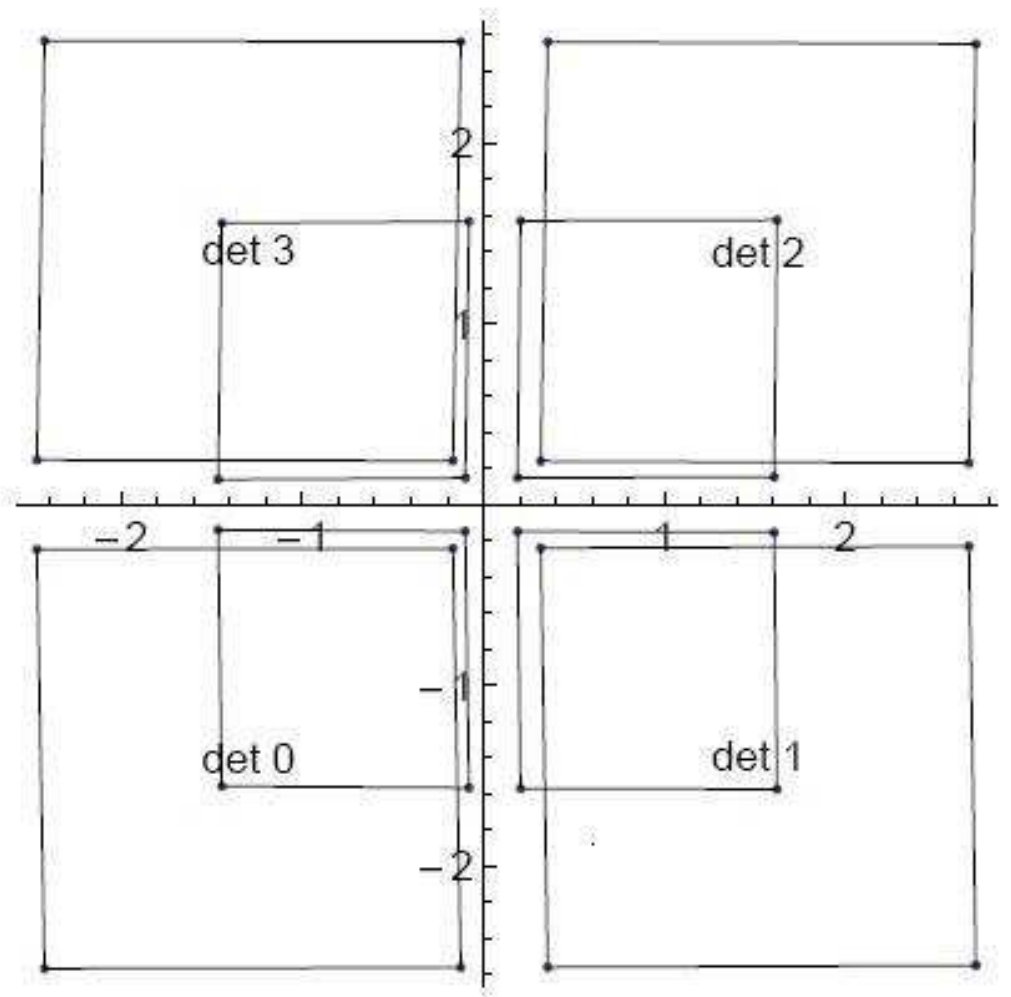

Figura 3.2: Disposição dos detectores do instrumento Spartan tanto no modo de baixa resolução ( $f / 12$, maior FOV), quanto para o modo de alta resolução $(f / 21$, menor FOV). Os eixos da imagem são mostrados em unidades de minutos de arco.

píxeis de $18.5 \mu \mathrm{m}$ e otimizado para comprimentos de onda entre 0.8 e $2.4 \mu \mathrm{m}$. Esse instrumento possui dois modos de operação, $f / 3$ e $f / 7$, tendo como características principais a escala de placa de $0.331 "$ / píxel e o campo de visão de 338" ( 5.6') para o modo de baixa resolução $(f / 3)$; escala de $0.139 "$ / píxel e FOV de $142 "\left(\sim 2.4^{\prime}\right)$ no modo de alta resolução $(f / 7)$. Para as observações apresentadas nesse trabalho, o instrumento foi utilizado apenas no modo $f / 7$.

\subsubsection{Comparação entre os Filtros Estreitos}

Cada instrumento possui seu próprio conjunto de filtros que apresentam algumas diferenças entre si. As observações foram realizadas utilizando um filtro com comprimento de onda central próximo ao da linha do $\mathrm{H}_{2}$ em $2.12 \mu \mathrm{m}$ e um segundo filtro, num contínuo adjacente. A Figura 3.3 mostra as curvas de transmissão dos filtros estreitos utilizados nas observações, sobrepostas à curva de transmissão atmosférica no intervalo de 1.95 a $2.40 \mu \mathrm{m}$. Enquanto os instrumentos do SOAR possuem um filtro estreito do contínuo 
adjacente ao filtro $\mathrm{H}_{2}$, a câmera WIRCam possui apenas um filtro estreito do contínuo na região de $2.2 \mu \mathrm{m}$. As principais características dos filtros usados nesse trabalho estão sintetizadas na Tabela 3.3, que apresenta o comprimento de onda central $\left(\lambda_{0}\right)$ de cada filtro, sua largura espectral $(\Delta \lambda)$, a transmissão em $\lambda_{0}$ e a transmissão integrada no intervalo de comprimento de onda (do inglês, throughput; $\int \tau_{\lambda} d \lambda$ ) do filtro.

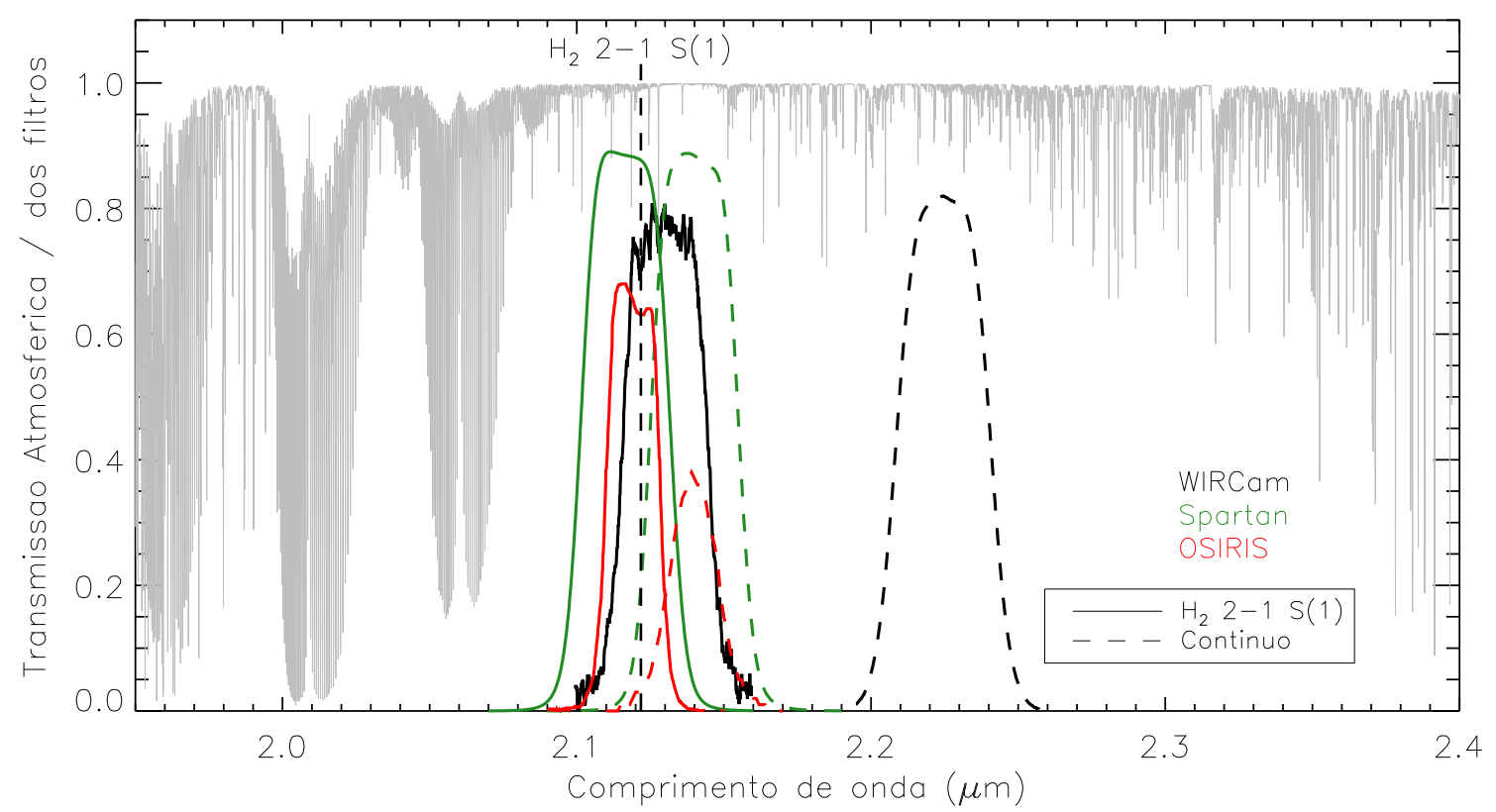

Figura 3.3: Perfis espectrais dos filtros de banda estreita, $\mathrm{H}_{2}$ (curvas contínuas) e Contínuo (curvas pontilhadas) para os instrumentos OSIRIS/SOAR (em vermelho), Spartan/SOAR (em verde) e WIRCam/CFHT (em preto). O comprimento central da transição do $\mathrm{H}_{2}$ é mostrado como uma linha tracejada, posicionada em $\lambda=2.1218 \mu \mathrm{m}$. Os perfis dos filtros estão sobrepostos à curva de transmissão atmosférica na banda $\mathrm{K}(2.0-2.5 \mu \mathrm{m}$, em cinza). Todas as curvas foram normalizadas em relação a 1.

Tabela 3.3 - Propriedades dos filtros utilizados nas observações.

\begin{tabular}{lccccc}
\hline \hline \multirow{2}{*}{ Instrumento } & Filtro & $\lambda_{0}(\mu \mathrm{m})$ & $\Delta \lambda(\mu \mathrm{m})$ & Transmissão máxima & Transmissão integrada $(\mu \mathrm{m})$ \\
\hline \multirow{2}{*}{ WIRCam } & $\mathrm{H}_{2}$ & 2.122 & 0.032 & 0.84 & 0.0610 \\
& Contínuo & 2.218 & 0.033 & 0.84 & 0.0296 \\
\multirow{2}{*}{ Spartan } & $\mathrm{H}_{2}$ & 2.117 & 0.031 & 0.88 & 0.0278 \\
& Contínuo & 2.140 & 0.030 & 0.88 & 0.0272 \\
\multirow{2}{*}{ Osiris } & $\mathrm{H}_{2}$ & 2.116 & 0.035 & 0.68 & 0.0130 \\
& Contínuo & 2.139 & 0.050 & 0.34 & 0.0747 \\
\hline
\end{tabular}




\subsection{Considerações sobre Observações no Infravermelho Próximo}

Uma imagem astronômica é o resultado da convolução do sinal astrofísico com diversos efeitos devidos ao caminho óptico que o feixe de luz percorre ao passar pela atmosfera, pelo telescópio e pelo instrumento. Simplificadamente, um sinal astrofísico $\left(I_{a s t r}\right)$ pode ser decomposto da seguinte forma

$$
I_{\text {astr }}=\left(I_{0}-S_{\text {fundo }}\right) \cdot \alpha_{\text {flat }}
$$

onde $I_{0}$ representa a imagem astronômica sem tratamento (ou seja, contém o objeto astronômico e a contribuicão do céu), $S_{\text {fundo }}$ corresponde à corrente de fundo e erro de leitura do detector e $\alpha_{\text {flat }}$ é a resposta instrumental de cada píxel, obtida a partir de imagens de flat-field.

O primeiro passo no processamento das imagens consiste em subtrair os efeitos aditivos $\left(S_{\text {fundd }}{ }^{2}\right)$ e corrigir os efeitos multiplicativos $\left(\alpha_{\text {flat }}\right)$, ambos de natureza instrumental. A remoção da corrente de fundo é realizada a partir da subtração da mediana de $\geq 3$ imagens obtidas com o mesmo tempo de integração dos objetos de ciência, porém com todas as fontes de luz apagadas e com o obturador da câmera fechado.

A etapa seguinte visa corrigir diferenças da resposta píxel-a-píxel do detector. Para isso, um modelo de flat-field é construído a partir da subtração entre imagens de uma região relativamente plana e iluminada por uma lâmpada de intensidade uniforme (também chamada de flat-on) e imagens da mesma superfície, porém com as luzes apagadas (flat-off). As imagens de flat-on apresentam altas contagens e evidenciam a diferença de sensibilidade à incidência de fótons, píxel a píxel. Em contrapartida, as imagens de flat-off apresentam baixas contagens e tornam visíveis os píxeis quentes, que apresentam contagens mesmo na ausência de fótons. O resultado da subtração é, então, normalizado pela média das contagens, resultando em valores $>1$ para os píxeis com contagens acima da média. Os valores dos coeficientes $\alpha_{\text {flat }}$ são definidos como o inverso da resposta normalizada de cada píxel.

Após a minimização dos efeitos instrumentais nas imagens astronômicas, o próximo passo visa a eliminação dos efeitos causados pela atmosfera e a contaminação por raios

\footnotetext{
${ }^{2}$ Embora haja dependência da corrente de fundo como funcção do tempo de exposição, assumimos que sua contribuição seja aproximadamente aditiva para um tempo de integração $t_{\text {exp }}$
} 
cósmicos. Os efeitos de absorção e emissão atmosférica, discutidos no início deste Capítulo, afetam as observações no infravermelho próximo e devem ser corrigidos. A contribuição da emissão atmosférica pode ser descontada por meio da subtração de um modelo de céu. Dependendo da ciência que se deseja fazer, o modelo de céu pode ser gerado por duas estratégias observacionais distintas:

1. Imagens de um campo de referência, com poucas estrelas e baixa emissão nebular são utilizadas para gerar o modelo de céu a ser subtraído das imagens de ciência. É importante salientar que a contribuição devido ao céu apresenta variabilidade em relação à posição e ao tempo. Dessa forma, o campo de referência deve ser escolhido numa região próxima e observado logo após (ou antes) o objeto de ciência. Embora essa estratégia observacional forneça um modelo bastante robusto, ela é operacionalmente ineficaz pois utiliza duas vezes mais o tempo necessário para observar um único objeto de ciência.

2. A partir de um padrão de dithering adequado, as próprias imagens de ciência podem ser utilizadas para gerar o modelo de céu. Esse procedimento não é aconselhado para observações de regiões com elevada emissão nebular ou aglomerados estelares muito densos.

Um padrão de dithering foi adotado de modo a gerar um modelo de céu conforme descrito pelo método (2) e, também, para remover os píxeis ruins nas imagens finais. Esta técnica consiste em obter imagens do mesmo campo, ligeiramente deslocadas em cada um dos apontamentos realizados pelo telescópio. Foi adotado um padrão de dithering com 4 posições, deslocadas em 30" nas direções norte (N) e leste (E, East) para as observações realizadas no SOAR, enquanto o padrão adotado para as observações no CFHT consistiu de deslocamentos ligeiramente maiores (40"). Ao determinar a mediana das imagens propriamente deslocadas, os raios cósmicos são eliminados e o sinal das fontes astronômicas é otimizado.

Os procedimentos descritos acima são realizados a partir de softwares desenvolvidos para o processamento de dados astronômicos, tais como o pacote de redução e análise de imagens IRAF3 (Image Reduction and Analysis Facility). De maneira análoga, softwares

\footnotetext{
${ }^{3}$ IRAF é distribuído pelo NOAO, operado pela AURA, Inc., em cooperação com a National Science
} 
alternativos podem ser utilizados para o processamento das imagens, tais como o PyRAF, que integra os scripts desenvolvidos em linguagem CL (do IRAF) utilizando o Python; o IDL (Interactive Data Language) e o THELI (Erben et al., 2005).

Em geral, o processamento de poucos campos é realizados com as tarefas e rotinas do IRAF. No entanto, o estabelecimento de uma metodologia capaz de processar uma grande quantidade de dados, obtidos com diferentes instrumentos, é dificultado pelos seguintes problemas:

1. Padrão de dithering variável: as configurações intrumentais e posição do telescópio não são os mesmos para todas as observações. Isso pode decorrer de mudanças no ângulo de posiçãd4 (PA, do inglês, Position Angle) ou pequenos desvios devido ao posicionamento do telescópio. Neste caso não é possível definir os desvios das imagens baseando-se nas coordenadas $(\mathrm{x}, \mathrm{y})$ do detector. Para isso, torna-se necessário o uso da astrometria das imagens.

2. Imagens não astrometrizadas ou com astrometria incorreta: nestes casos, as imagens deverão ser calibradas astrometricamente antes de serem combinadas. Para realizar a astrometrização de uma imagem astronômica, torna-se necessário identificar a posição $(\mathrm{x}, \mathrm{y})$ de fontes presentes no campo que estejam associadas a um catálogo conhecido (para o infravermelho próximo, o catálogo 2MASS é o mais apropriado), ou seja, possuem medidas as coordenadas $(\alpha, \delta)$. A astrometrização é realizada a partir da transformação $(\mathrm{x}, \mathrm{y}) \rightarrow(\alpha, \delta)$. ;

3. Distorções óticas não legíveis pelo IRAF: Para o caso de câmeras com multi-detectores, a astrometria do campo não é bem expressa por uma função linear em relação à posição nas coordenadas da imagem. Nestes casos, existe uma distorção que deve ser levada em conta ao se interpretar a solução astrométrica da imagem e sua relação com as coordenadas $(\mathrm{x}, \mathrm{y})$ do detector. Tal distorção deve ser armazenada no cabeçalho (header) das imagens, adotando um sistema de coordenadas que possa ser interpretado corretamente. Um dos sistemas de coordenadas mais comuns utilizado pelo

\footnotetext{
Foundation.

${ }^{4}$ como exemplo, a transformação das coordenadas geométricas $(\alpha, \delta)$ nas coordenadas locais $(\mathrm{x}, \mathrm{y})$ para $\mathrm{PA}=0^{\circ}$ é $(\alpha \rightarrow x, \delta \rightarrow y) ;$ no caso de $\mathrm{PA}=90^{\circ}$, temos $(\alpha \rightarrow y, \delta \rightarrow x)$
} 
IRAF é o TNX5. No entanto, não são todos os instrumentos que fornecem a distorção das imagens no sistema TNX. O Spartan, por exemplo, escreve a distorção do campo utilizando o sistema SIP6 (do inglês, Simple Polynomial method), não legível pelo IRAF. Nesses casos, o IRAF realiza a conversão das coordenadas locais para coordenadas celestes sem levar em consideração as distorções do campo.

Esses problemas inviabilizam o uso dos pacotes do IRAF para processar e fornecer imagens calibradas astrometricamente. Visando a obtenção de uma amostra homogênea de imagens dos candidatos a MYSOs, observados com diferentes instrumentos e em diferentes telescópios, o processamento das observações foi realizado pelos pacotes e tarefas do THELI (Erben et al., 2005). As principais etapas do processamento das imagens serão discutidas a seguir.

\subsection{Processamento das Imagens Utilizando o THELI}

O THELI é um software que realiza o processamento de observações de maneira sistemática e bastante flexível, oferecendo diversos recursos adicionais ao longo do processamento das imagens. Trabalha com observações no óptico, infravermelho próximo e médio. Atualmente, cerca de 60 instrumentos de diferentes observatórios em todo o mundo estão pré-configurados. A adoção de uma metodologia baseada no THELI possibilitou que as observações realizadas tanto com o WIRCam (CFHT), quanto com o Spartan (SOAR) podessem ser processadas de maneira similar. Visto que as etapas envolvidas no processamento de dados a partir do THELI são bastante sensíveis em relação aos parâmetros fornecidos, a metodologia empregada será descrita detalhadamente a seguir.

\subsubsection{Inicialização do pacote THELI}

A primeira etapa consiste em definir os parâmetros gerais das observações (instrumento), a localização dos arquivos que serão processados e o número de núcleos de pro-

\footnotetext{
${ }^{5}$ maiores informações sobre o sistema TNX em http://fits.gsfc.nasa.gov/registry/tnx.html (em inglês)

${ }^{6}$ maiores informações sobre o sistema SIP em http://fits.gsfc.nasa.gov/registry/sip.html (em inglês)
} 
cessamento (cores) que serão utilizados ao longo do processamento. As configurações são organizadas em três blocos principais, a saber:

- Project and Global Settings: devem ser definidos $i$ ) um nome para o projeto, que será armazenado pelo THELI como um arquivo de log contendo as definições do processamento atual; e ii) o número de núcleos de processamento do computador (valores mais comuns variam entre 1 e 4 núcleos, dependendo da configuração de hardware do usuário). Visto que as câmeras WIRCam e Spartan possuem 4 detectores, o processamento das observações é otimizado se for realizado com 2 ou 4 núcleos.

- Data directories: os diretórios que contêm as imagens originais são definidos nesse bloco. Para melhor associação, as imagens de corrente de fundo foram colocadas no diretório "darks", os diretórios "flatH" e "flatHoff" contém as imagens de flat-field com lâmpadas acesas e apagadas, respectivamente; e as imagens de ciência em "sciH". Nos casos em que o céu foi observado separadamente ou haja observações de uma estrelapadrão fotométrica, as imagens correspondentes devem ser fornecidas aos diretórios "sky" e "standard", respectivamente.

- Instrument Selection: o instrumento utilizado nas observações deve ser escolhido em uma das três classes de instrumentos disponíveis: os instrumentos pré-definidos pelo THELI, câmeras comerciais ou instrumentos definidos pelo próprio usuário.

\subsubsection{Preparação das Imagens}

Após definidos os parâmetros globais do processamento, o usuário deve executar a tarefa "Split FITS/correct header", que iá renomear as imagens de entrada e reorganizará o cabeçalho (header) das imagens, excluindo informações não utilizadas no decorrer do processamento.

\subsubsection{Calibração Instrumental}

A calibração instrumental consiste em subtrair o padrão de corrente de fundo e aplicar a correção da resposta pixel-a-pixel a partir de um modelo de flat-field normalizado. Nesta etapa, também é gerado um modelo primário da emissão de fundo de céu, calculado a partir das próprias imagens de ciência.

Primeiramente, são gerados os modelos da corrente de fundo e as respostas instrumen- 
tais para cada um dos detectores. A Figura 3.4 apresenta as duas imagens geradas para o detector d3 da câmera Spartan: o modelos da corrente de fundo, em unidades de ADUs (do inglês, Analog-Digital Units) e a resposta instrumental, obtida a partir da subtração entre as imagens de flat-field com lâmpadas acesas e apagadas. A Figura 3.5 apresenta um campo observado no filtro $\mathrm{H}_{2}$ e posicionado no centro do detector d3, antes e após a calibração instrumental. É possível verificar que a calibração corrige os baixos valores do fluxos da região superior esquerda do campo ( 300 ADU), e os torna compatíveis ao fluxo médio dos demais píxeis do detector $(\sim 500 \mathrm{ADU})$.
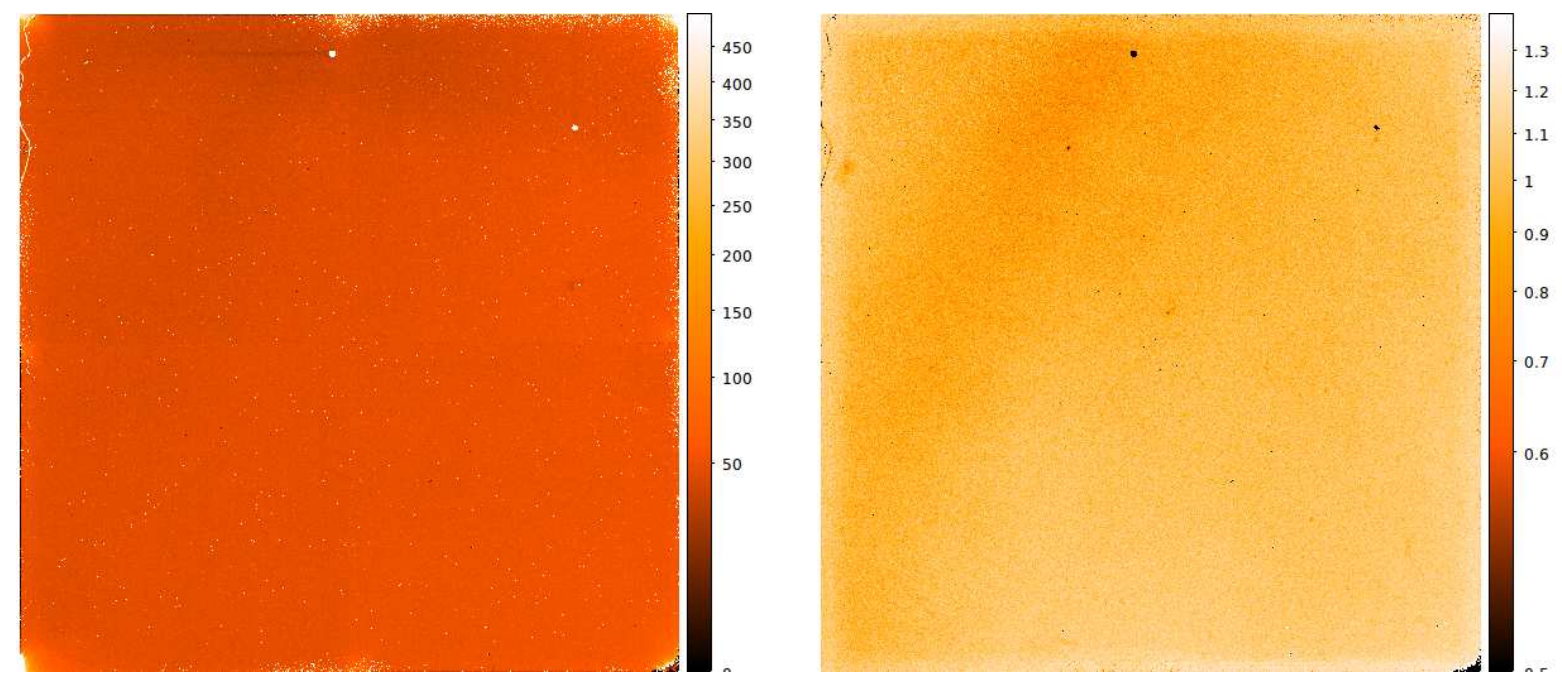

Figura 3.4: Imagens da calibração instrumental do detector 'd3' do Spartan. Esquerda: modelo da corrente de fundo (em ADUs). Direita: Resposta instrumental para o filtro $\mathrm{H}_{2}$, obtida a partir da subtração das imagens de flat-field com lâmpadas acesas e apagadas.

\subsubsection{Modelo de Emissão de Fundo de Céu}

Para comprimentos de onda do infravermelho, é provável que a correção instrumental não seja capaz de eliminar todas as variações de intensidade no campo observado. As principais contribuições decorrem de $i$ ) iluminação inadequada do detector, $i i$ ) variação espacial da emissão de fundo de céu e iii) presença de franjas de interferência. A maior parte destes efeitos aparecem como variações espaciais de baixa frequência ao longo do campo, com amplitudes que podem atingir valores de até $10 \%$ do fundo de céu. É possível atenuar tais efeitos a partir de um modelo de fundo de céu, gerado a partir da mediana das imagens de ciência. Em seguida, o modelo de fundo de céu é subtraído de cada uma das imagens previamente calibradas. A Figura 3.6 apresenta o campo no detector 'd3', 

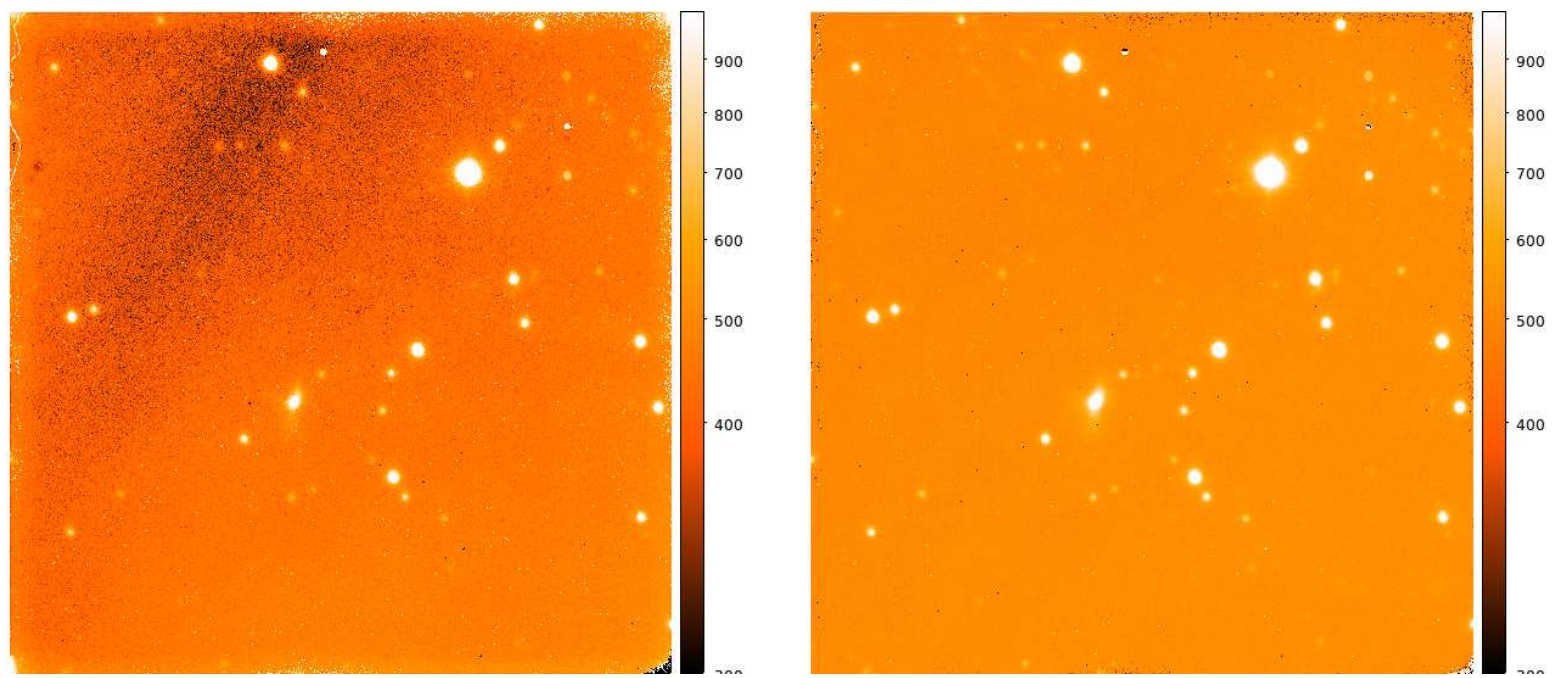

Figura 3.5: Imagem de ciência observada no filtro $\mathrm{H}_{2}$ com o detector 'd3' antes (esquerda) e após a calibração instrumental (direita). Ambas as imagens apresentam a mesma faixa dinâmica, definida entre 300 e 1000 ADU.

observado com o filtro $\mathrm{H}_{2}$, antes (painel esquerdo) e após a subtração do modelo de fundo de céu (painel central). O modelo utilizado nessa etapa é mostrado no painel direito da mesma figura.
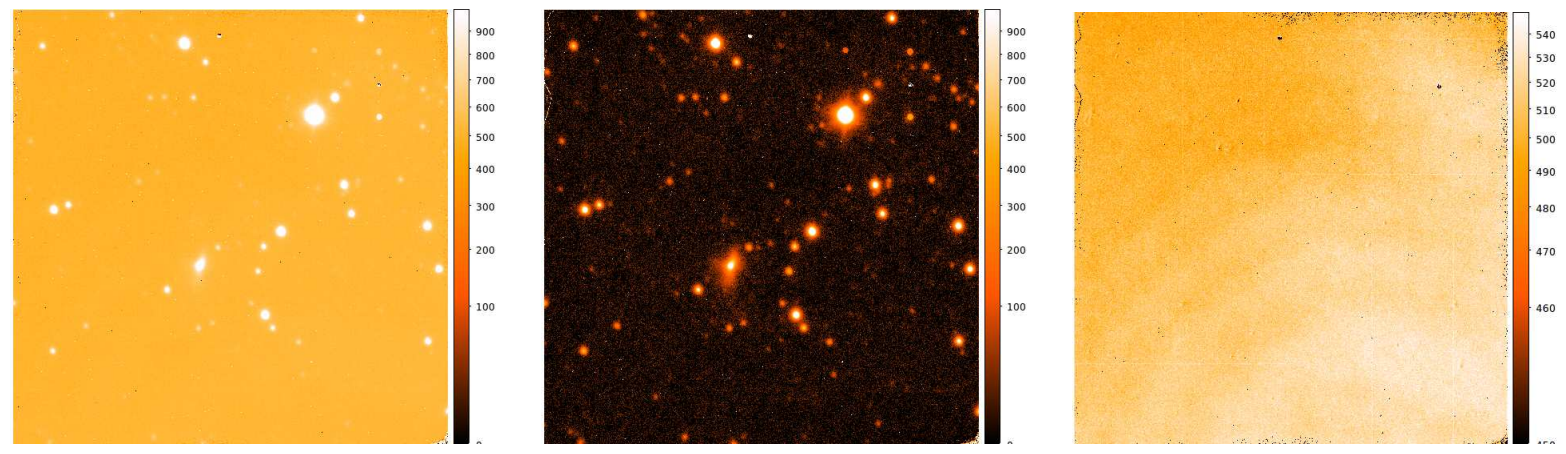

Figura 3.6: Imagem antes (esquerda) e após subtração do modelo de fundo de céu (centro). Ambas as imagens apresentam a mesma escala dinâmica (0-1000 ADUs). O modelo de céu utilizado para a correção é mostrado à direita, com escala dinâmica mais restringida (450-550 ADUs).

\subsubsection{Ponderação das Imagens de Ciência}

Os resultados finais do THELI são ponderados por pesos estatísticos, determinados a partir das imagens de flat-field e de ciência. Para a execução dessa etapa, todos os parâmetros foram mantidos com seus valores padrões. Até essa etapa, as observações em diferentes filtros foram tratadas individualmente. Para a realização das próximas etapas, as imagens devem ser reorganizadas por campos observados e não mais por filtros. Para 
isso, um novo diretório deve ser criado e informado na aba Initialise, conforme realizado na Subseção 3.5.1.

\subsubsection{Correção Astrométrica}

A correção astrométrica é realizada em três etapas:

- Seleção de um catálogo: um bom catálogo de referência deve a) ser compatível com o comprimento de onda das observações; e b) conter fontes presentes no campo observado. Dentre os catálogos disponibilizados pelo THELI, o catálogo de fontes puntiformes do 2MASS se mostrou o mais adequado para comparação com as observações realizadas.

- Detecção das fontes: as fontes presentes nas imagens de ciência são detectadas pelo pacote SExtractor, utilizando as configurações padrões. Nos casos de campos pouco densos, deve-se utilizar um menor valor para o parâmetro DETECT_THRES (seu valor padrão ÃC) 5.0), de modo a incluir fontes menos brilhantes na solução astrométrica. Para os casos de campos de alta densidade estelar, o valor do parâmetro DEBLEND_MINCONT (valor padrão 0.0005) pode ser alterado para maiores valores para que a solução astrométrica seja obtida utilizando apenas as fontes isoladas do campo. Se as imagens apresentarem contaminação por píxeis ruins, a opção Data is well sampled, but plagued with hot pixels deve ser selecionada.

- Comparação entre as detecções e as fontes contidas no catálogo: em seguida, o Scamp compara as listas geradas pelo SExtractor com os resultados do catálogo selecionado, e determina a solução astrométrica para os quatro detectores simultaneamente. Ao término, são gerados alguns gráficos com informações sobre a solução astrométrica encontrada. Os principais deles são mostrados na Figura 3.7 e são descritos a seguir:

- fgroups_1.ps (Painel superior esquerdo, Figura 3.7): Apresenta o padrão de dithering utilizado nas observações, sobreposto às fontes encontradas no catálogo de referência (em verde) e aquelas não identificadas pelo SExtractor (em vermelho).

- distort_1.ps (Painel superior direito, Figura 3.7): Mostra a variação espacial da escala de placa em função da posição no detector. Um resultado semelhante foi apresentado por Loh et al. (2012). Aqueles autores discutem que a não concentricidade da distorção do campo é devido a efeitos introduzidos pelo fato de que o caminho óptico 
para cada detector é do tipo off-axis (mais detalhes no apêndice B1 de Loh et al., 2012).

- astr_referror1d_1.ps (Painel inferior, Figura 3.7): Indica os resíduos de cada fonte projetada no plano do céu, em relação à sua posição no catálogo de referência. Espera-se obter uma solução astrométrica com resíduos menores que $\leq 0.5^{\prime \prime}$. Para o presente caso, a maior parte das incertezas são menores que 0.1", indicando uma boa solução astrométrica do campo observado.

As soluções astrométricas determinadas para os campos observados com o WIRCam e o Spartan permitiram concluir que é possível obter soluções com precisão de décimos de segundo de $\operatorname{arco}\left(\sim 0.1^{\prime \prime}\right)$.

\subsubsection{Imagem Final}

Por fim, a última etapa do processamento consiste no i) nivelamento das contagens do céu e ii) obtenção da imagem final, combinando as imagens de ciência a partir da solução astrométrica determinada pelo Scamp. O nivelamento das contagens do céu é realizado a partir da subtração do valor da moda das contagens em cada uma das imagens. Dessa forma, o nível de céu das imagens apresenta valores em torno de $\sim 0$ ADU. Em seguida, o usuário deve alterar os valores dos seguintes campos presentes na janela "Coaddition":

- Ref RA | Dec: as coordenadas centrais do campo, obtidas a partir da imagem fgroups_1.png (Painel superior esquerdo, Figura 3.7), deve ser informada;

- Coadd this FILTER: o usuário deve informar o filtro a ser processado;

- Combine type: o método utilizado para combinar as imagens deve ser escolhido dentre as opções disponíveis: média ponderada, mediana, média, mínimo, máximo ou $\chi^{2}$. Nesse trabalho, as imagens finais foram obtidas a partir da mediana das imagens de entrada.

A imagem final, apresentada em unidades de fluxo $\left(\mathrm{ADU} \mathrm{s}^{-1}\right)$, é mostrada na Figura 3.8 . Fontes contidas no catálogo 2MASS com magnitude na banda $K_{s} \leq 11.5$ mag são mostradas como círculos verdes sobre a imagem final do filtro $\mathrm{H}_{2}$. Ao final do processamento, as imagens finais dos filtros $\mathrm{H}_{2}$ e Contínuo da banda $\mathrm{K}$ estão localizadas nos subdiretórios "coadd_H2" e "coadd_Cont2", respectivamente. 

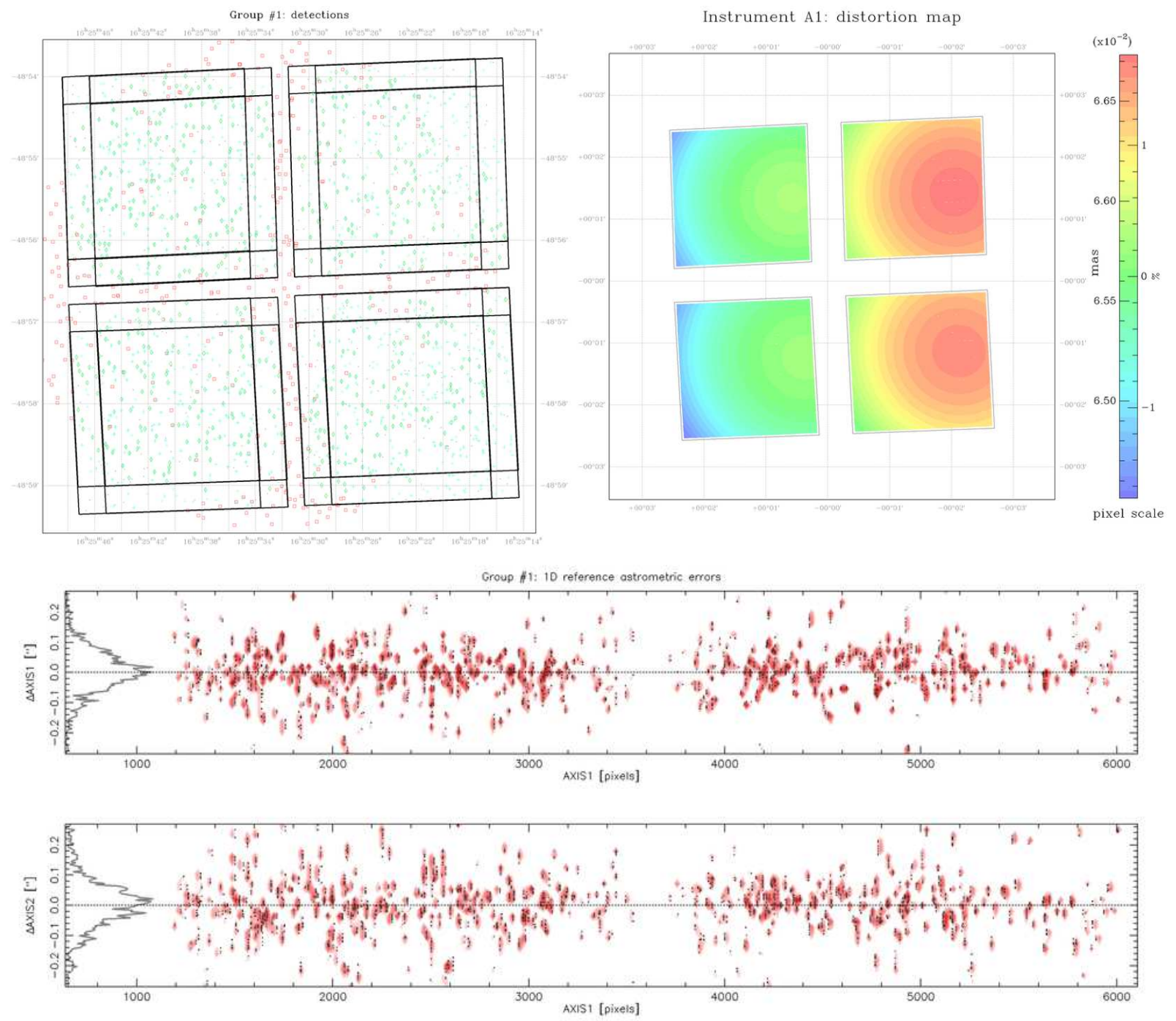

Figura 3.7: Resultados da solução astrométrica determinada pelo Scamp. Esquerdo superior: Projeção dos quatro detectores do SPARTAN em coordenadas equatoriais; Direito superior: Distorção de campo para os quatro detectores do SPARTAN; Inferior: Erros astrométricos das fontes presentes no campo observado, em unidades de segundos de arco.

\subsubsection{Subtração das Imagens Finais}

O último procedimento realizado pelo THELI é o alinhamento das imagens, realizado pela tarefa "Prepare color image". Após a execução da tarefa, as imagens estão alinhadas, possuem o mesmo tamanho e a mesma distorção e podem ser subtraídas facilmente com rotinas usuais, tais como o IMARITH sob ambiente IRAF. A Figura 3.9 apresenta o mapa de emissão em $\mathrm{H}_{2}$, após subtração da imagem do contínuo. 


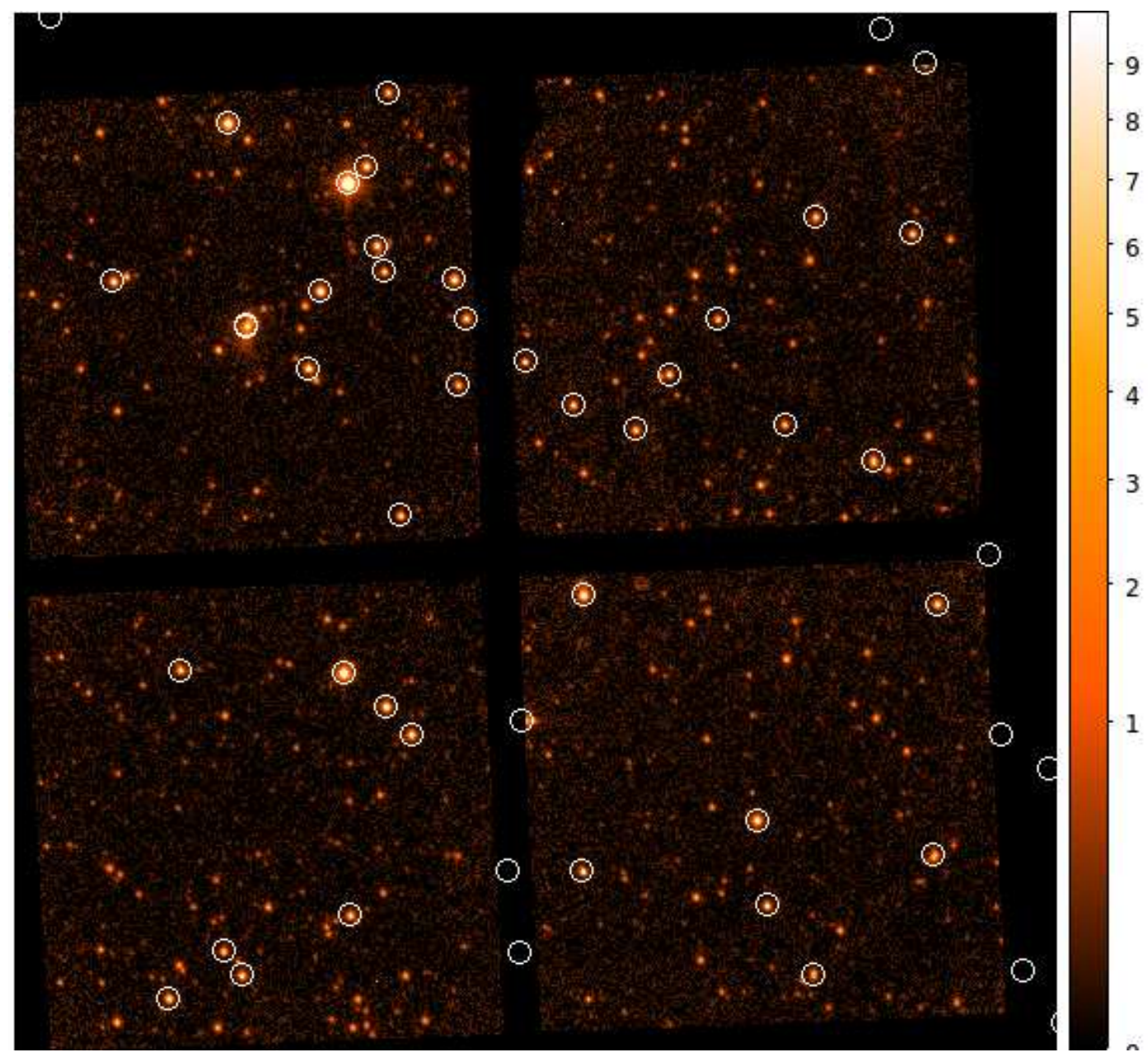

Figura 3.8: Imagem final, obtida a partir da mediana das imagens dos quatro detectores. Os círculos brancos indicam as fontes do catálogo $2 \mathrm{MASS}$ com $K_{s} \leq 11.5 \mathrm{mag}$.
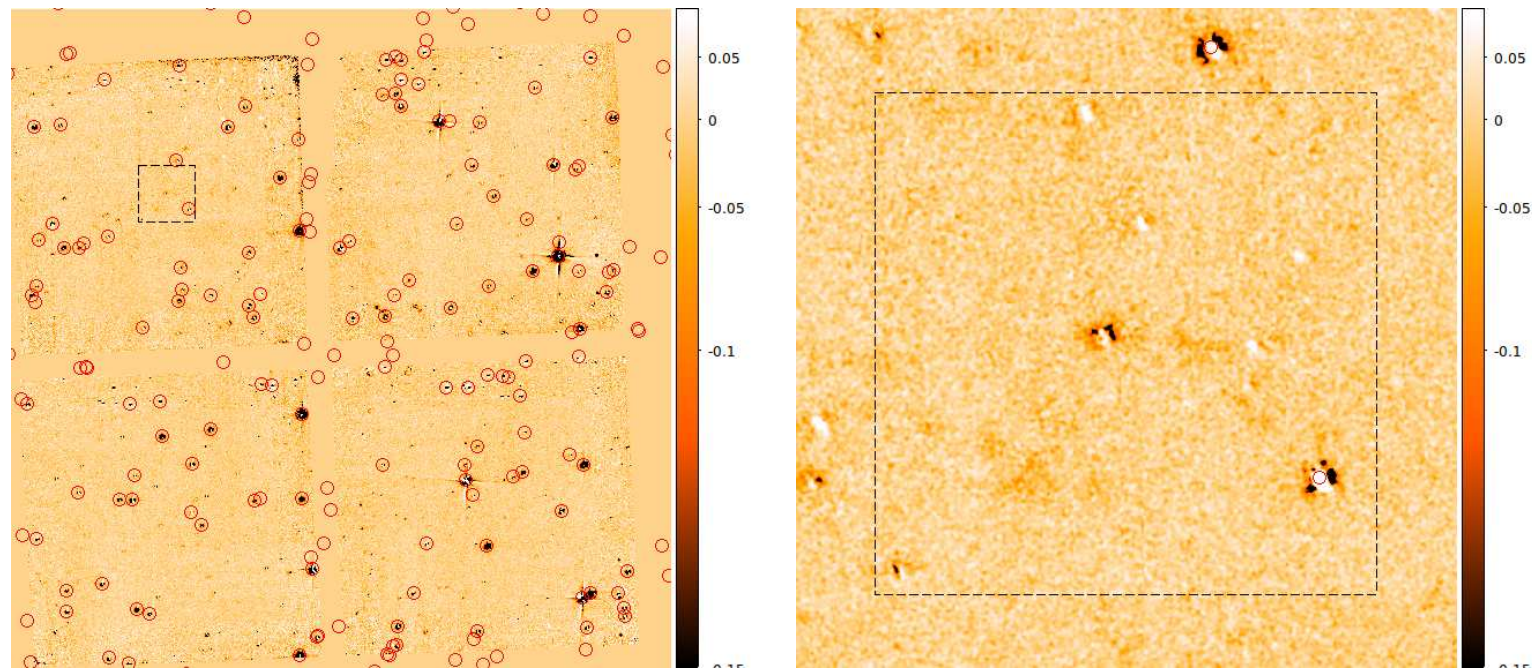

Figura 3.9: Painel esquerdo: Imagem final no filtro do contínuo mostrando o campo dos quatro detectores. Em vermelho, estão as fontes do catálogo 2MASS com $K_{s} \leq 11.5$ mag. Painel direito: detalhes do mapa de emissão em $\mathrm{H}_{2}$ após subtração da imagem do contínuo. A região delimitada pelo quadrado pontilhado possui a mesma dimensão da região indicada na imagem do contínuo. 


\subsection{Comparação entre Resultados obtidos com o IRAF e com o THELI}

As observações de um mesmo campo foram processadas com o IRAF e o THELI para comparar os resultados obtidos com ambos os programas. As imagens finais, obtidas para ambos os filtros $\mathrm{H}_{2}$ e contínuo, são mostradas na Figura 3.10.
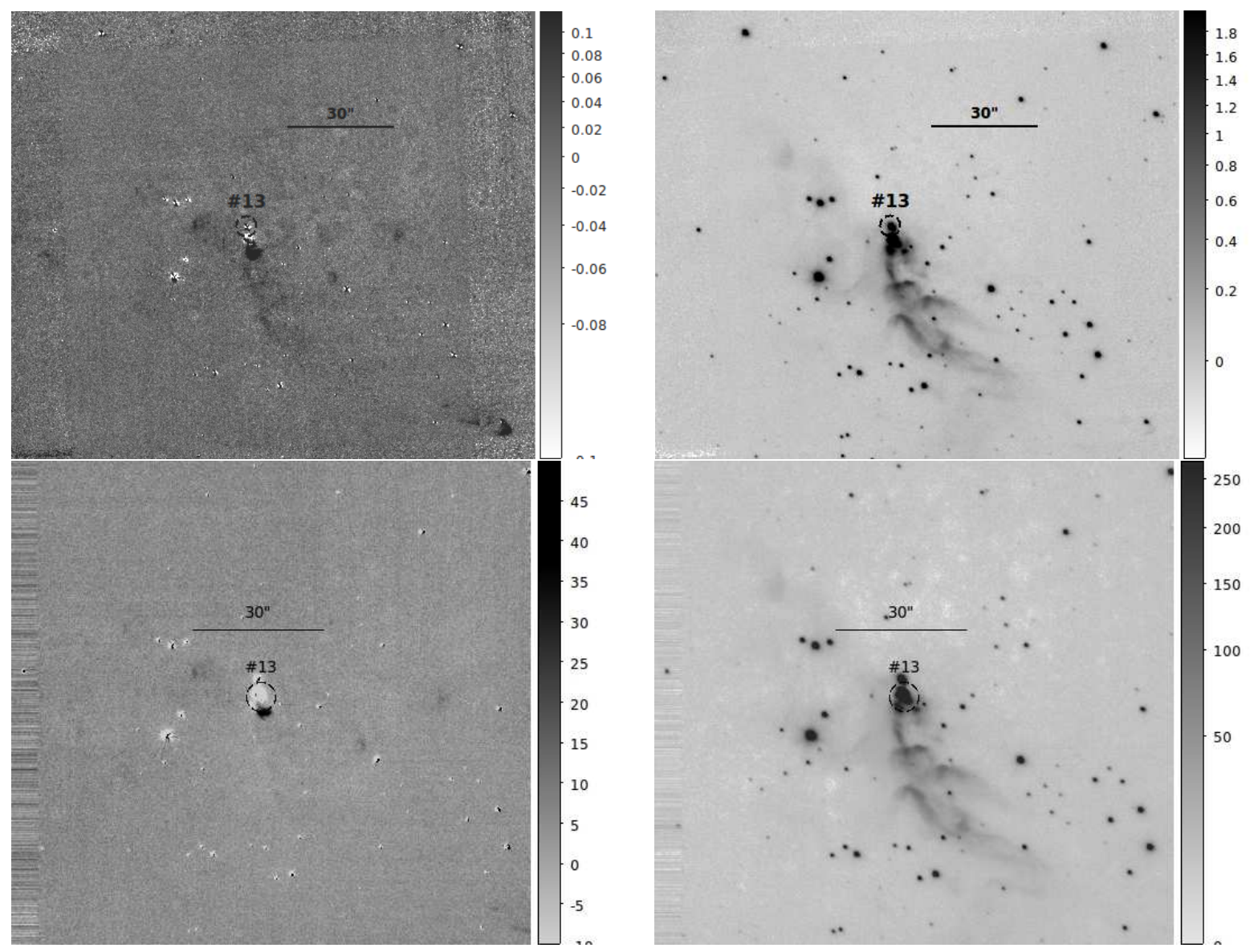

Figura 3.10: Imagens da fonte G259.9395-00.0419, processadas com o THELI (imagens superiores, em ADU/s) e com o IRAF (imagens inferiores, em ADU). O mapa de emissão em $\mathrm{H}_{2}$ da fonte é mostrado à esquerda enquanto a imagem no contínuo da mesma região é mostrado à direita.

Uma rotina em IDL foi desenvolvida para verificar a qualidade das imagens finais a partir de mapas da distribuição da largura à meia altura (FWHM, Full Width at Half Maximum) das fontes presentes no campo. Primeiramente, uma lista com a posição (x,y) de objetos com FWHM próximas ao valor estabelecido pelo usuário $\left(\mathrm{FWHM}_{0}\right)$ é gerada a partir da rotina FIND, que utiliza os mesmos algoritmos da rotina DAOFIND 7. Em seguida, o valor da FWHM de cada objeto é refinado a partir de um ajuste individual do tipo gaussiano, lorentziano ou do tipo Moffat. Para os resultados apresentados nesse trabalho,

\footnotetext{
${ }^{7}$ DAOFIND é uma rotina do pacote DAOPHOT, sob ambiente IRAF.
} 
foram utilizados ajustes do tipo gaussiano. Embora a função de PSF das fontes não seja bem descrita por um ajuste gaussiano, o resultado global (ou seja, a variação da FWHM em função da posição no campo) pode ser interpretado adequadamente. Ao término da execução da rotina, três imagens de diagnóstico são geradas.

A primeira delas é mostrada na Figura 3.11, que apresenta o campo observado sobreposto às fontes identificadas pela rotina. É possível verificar que grande parte dos objetos puntiformes foram identificados em ambas as imagens, entretanto alguns objetos identificados no campo processado com o IRAF (imagem à direita) não estão presentes no campo do THELI (imagem à esquerda). A origem de tais detecções pode decorrer do processamento inadequado das imagens que, neste caso, devem apresentar valores de FWHM não compatíveis com as estrelas do campo.
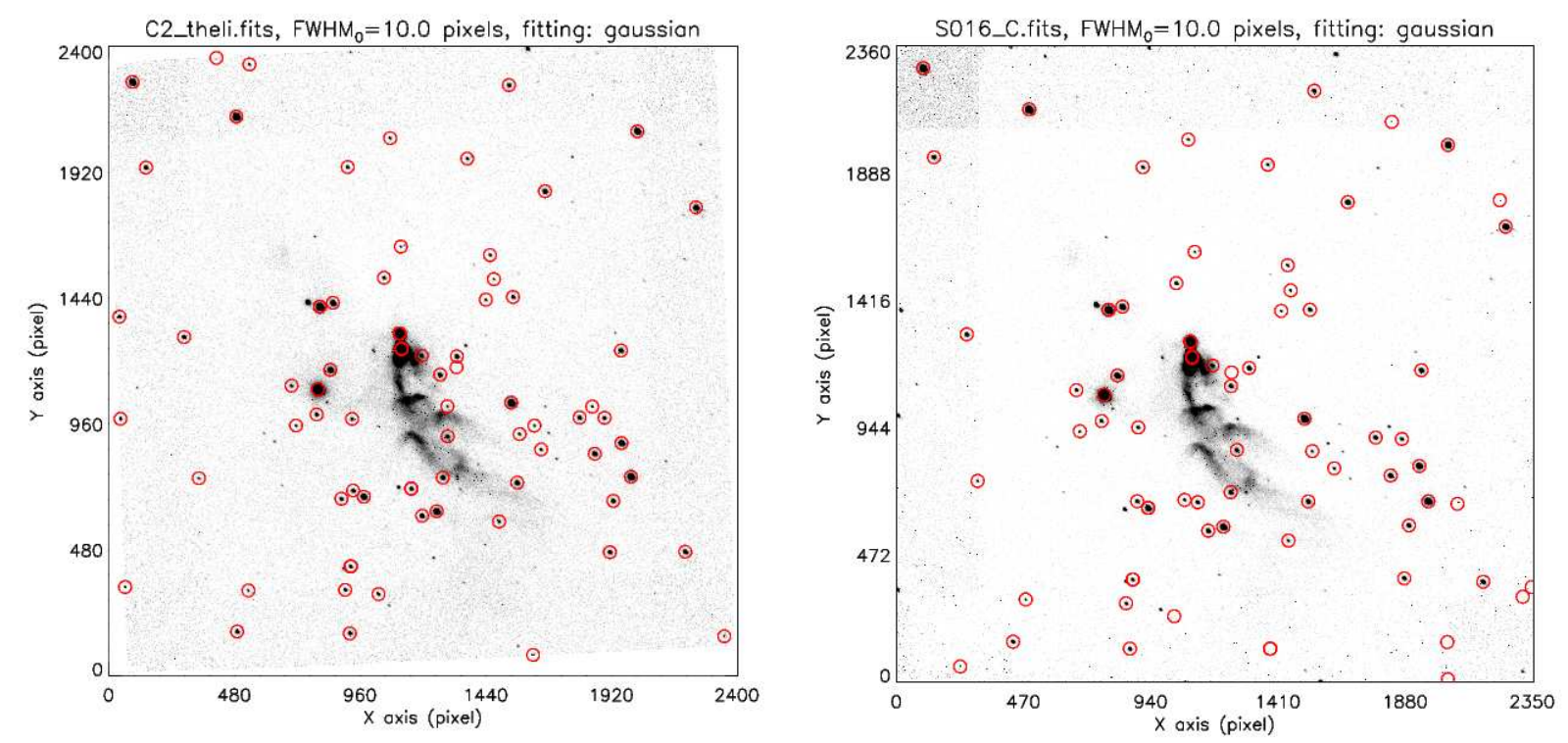

Figura 3.11: Imagem da fonte G259.9395-00.0419 no filtro estreito do contínuo da banda K, processada com o THELI (esquerda) e com o IRAF (direita). Os objetos puntiformes, identificados pela rotina, estão indicados como círculos vermelhos.

A Figura 3.12 apresenta a distribuição da FWHM das fontes identificadas na imagem processada com o THELI (em preto) e com o IRAF (em vermelho). As medidas associadas à imagem processada com o THELI apresenta um espalhamento menor quando comparada ao observado para a imagem processada com o IRAF, indicando que o processamento pelo THELI retorna campos com menor variação da PSF. Os valores médios das FWHMs da imagem processada pelo THELI e pelo IRAF foram estimados em $0.57^{\prime \prime} \pm 0.05^{\prime \prime}$ e $0.59^{\prime \prime} \pm 0.17^{\prime \prime}$, respectivamente. A distribuição em vermelho apresenta um excesso de 
detecções em FWHM $>0.60^{\prime \prime}$. O alargamento das fontes decorre, principalmente, do fato de que o IRAF não considera a deformação astrométrica do campo. A terceira imagem de diagnóstico gerada pela rotina mostrou que as fontes mais alargadas estejam localizadas nas regiões mais afastadas do centro do detector.

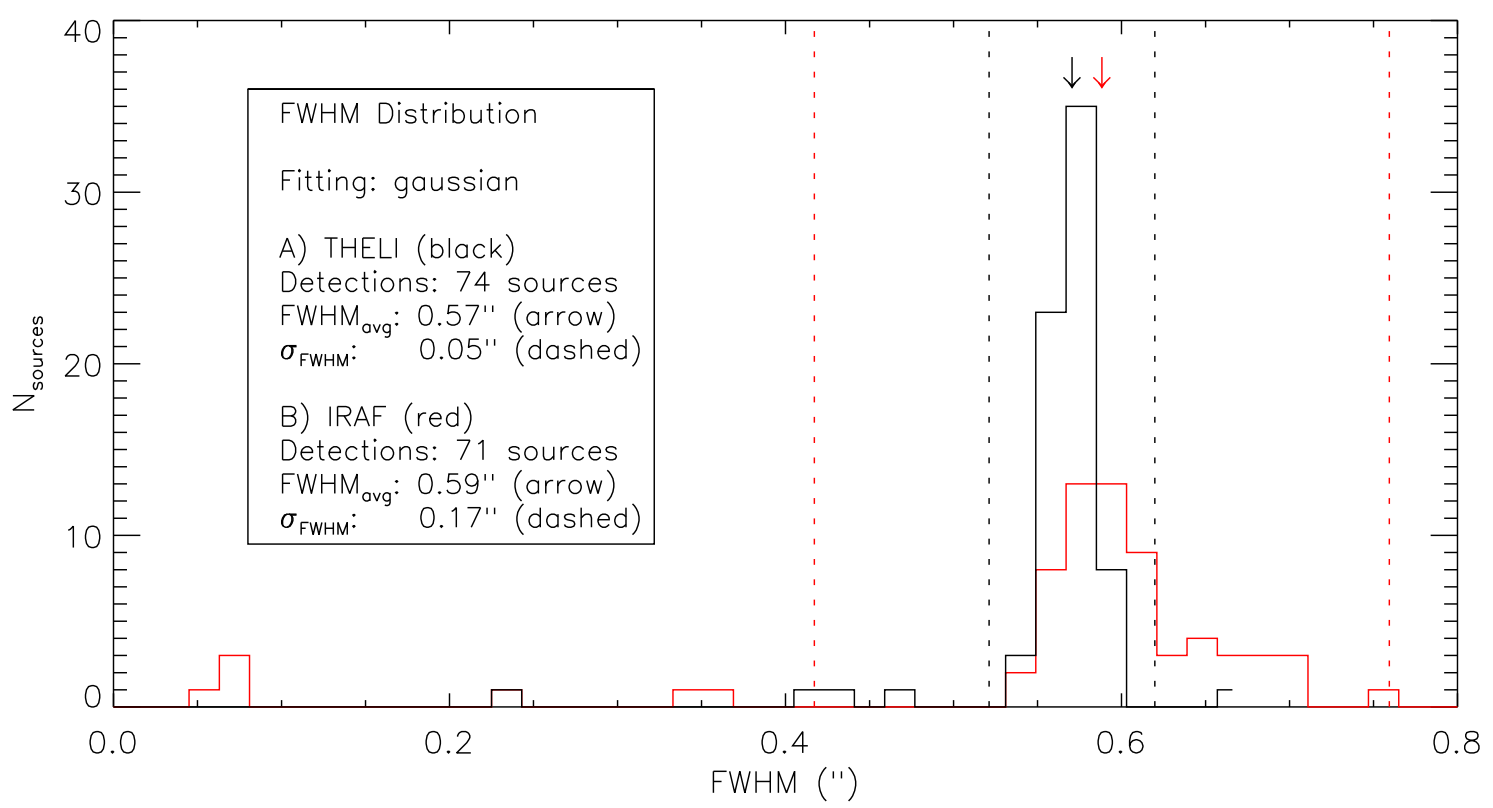

Figura 3.12: Histograma da distribuição da FWHM (em unidades de segundos de arco) dos objetos identificados no campo da fonte G259.9395-00.0419 para a imagem processada com o THELI (em preto) e com o IRAF (em vermelho). A seta indica o valor médio da distribuição $\left(\mathrm{FWHM}_{a v g}\right)$ e o desvio padrão é mostrado pelas linhas vermelhas tracejadas, representadas pelos valores de médios da FWHM com suas respectivas incertezas.

Finalmente, a Figura 3.13 apresenta a variação da FWHM ao longo do campo da fonte G259.9395-00.0419 processado com o THELI (esquerda) e com o IRAF (direita). Ambos os mapas são mostrados na mesma escala (os limites mínimo e máximo correspondem aos valores de $\mathrm{FWHM}=0.51$ " e 0.79 ", respectivamente) e, embora os mapas estejam truncados na região lateral esquerda, é possível verificar que os valores de FWHM medidos na imagem processada com o THELI apresenta menor variação espacial que aquela obtida com o IRAF. A imagem processada com o IRAF mostra maior variação da FWHM para as fontes mais próximas das bordas da imagem, corroborando as informações da Figura 3.12. As imagens de diagnóstico apresentadas na Figura 3.13 permitem concluir que o processamento via THELI apresentam resultados com qualidade fotométrica superior às imagens processadas utilizando apenas as tarefas usuais do IRAF. 

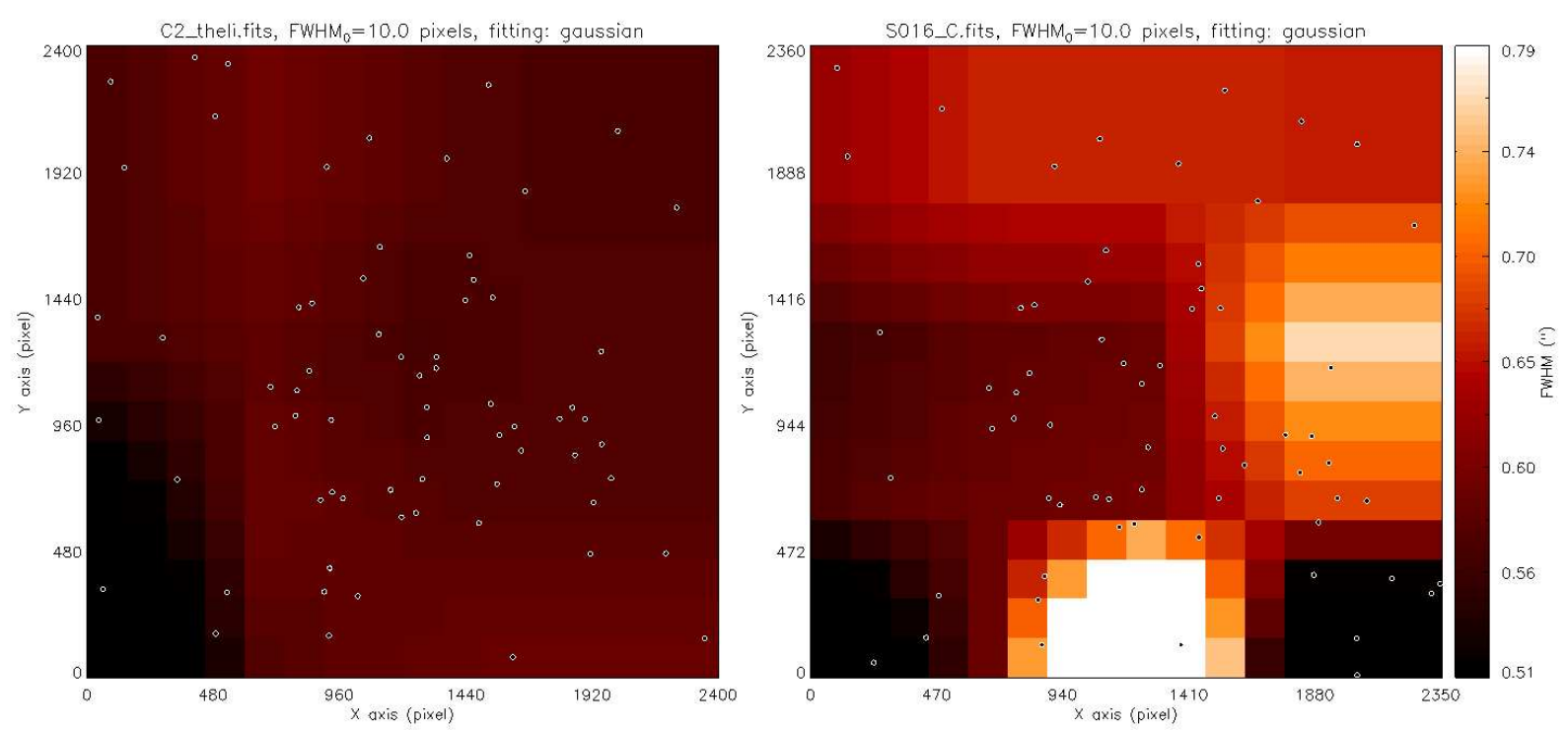

Figura 3.13: Mapa da distribuição da FWHM dos objetos identificados no campo da fonte G259.9395-00.0419, processado com o THELI (esquerda) e com o IRAF (direita). A posição das fontes é indicada pelos círculos pretos. A imagem colorida foi obtida a partir da interpolação das medições. Ambas as imagens apresentam a mesma escala (entre 0.51" e 0.79").

\subsection{Criação dos Mapas de Emissão em $\mathrm{H}_{2}$}

Conforme apresentado na seção anterior, o THELI é capaz de fornecer imagens calibradas astrometricamente e com melhor qualidade de imagem, sendo uma ferramenta recomendada para lidar com levantamentos de grande e médio porte, tal como o apresentado nesse trabalho. Antes de realizar a subtração das imagens nos filtros dentro e fora da linha do $\mathrm{H}_{2}$, algumas correções e manipulações adicionais foram realizadas. Dentre elas, destacam-se:

- Seleção da região de interesse: visto que as dimensões das imagens $\left(\sim 20^{\prime}\right.$ ou $\sim 5^{\prime}$ ) são maiores do que o tamanho esperado para as estruturas associadas aos objetos de estudo deste trabalho $\left(\sim 1^{\prime}\right)$, as imagens foram cortadas em regiões menores, centralizadas na posição da fonte RMS;

- Correção de fluxo: Devido a transmissão dos filtros, variações nas condições atmosféricas durante as observações ou nos parâmetros intrínsecos estelares, o fluxo das fontes puntiformes presentes no campo podem ou não apresentar fluxos aproximadamente iguais em ambos filtros observados. Para que a subtração das imagens seja capaz de eliminar grande parte da contribuição das estrelas do campo, um fator de normalização foi aplicado à imagem observada no filtro do contínuo. 
Duas rotinas, escritas em IDL, foram desenvolvida para realizar os passos descritos acima e retornar o mapa de emissão em $\mathrm{H}_{2}$ de cada campo observado. As rotinas utilizam como arquivos de entrada $i$ ) as imagens em ambos os filtros e ii) uma tabela com as seguintes colunas:

(1) Nome da fonte RMS;

(2) Ascenção reta (em graus);

(3) Declinação (em graus);

(4) Luminosidade bolométrica da fonte $\operatorname{RMS}\left[\operatorname{em~} \log \left(L / L_{\odot}\right)\right]$;

(5) Distância cinemática $(\mathrm{kpc})$;

(6) Dimensão da imagem final (em píxeis);

(7) Posição dos detalhes no filtro do contínuo: canto superior esquerdo (UL, Up-Left) ou direito (UR, Up-Right), canto inferior esquerdo (DL, Down-Left);

(8) Tamanho da imagem com detalhes da emissão no contínuo (fração do tamanho da imagem final);

(9) Limite superior da faixa dinâmica do mapa de emissão em $\mathrm{H}_{2}$ (em $\sigma$ );

(10) Limite superior da faixa dinâmica dos detalhes no filtro contínuo (em $\sigma$ );

(11) Fator de normalização do fluxo no contínuo: assume valores $<1$ caso o fluxo no contínuo seja maior que no filtro $\mathrm{H}_{2}$; caso contrário, $>1$;

(12) Limite superior da faixa dinâmica da imagem RGB (em $\sigma)$.

A rotina PREPARE_ImAge.Pro (ApêndiceB), escrita em IDL, localiza a posição (x,y) referente às coordenadas da fonte RMS no campo observado e gera um código em linguagem CL para criação das imagens menores, centralizadas na fonte RMS e com tamanhos definidos pela coluna (6) da tabela de entrada. O código também padroniza a nomemclatura das imagens de saída, facilitando a manipulação dos arquivos de saída. Ao término do processamento, o usuário deve executar o arquivo CROP_IMAGES.CL em ambiente IRAF ou PyRAF para criar as novas imagens. 
Em seguida, a rotina CREATE_IMAGES.PRo (ApêndiceB) lê as imagens recém criadas e a tabela de entrada, gerando o mapa de emissão em $\mathrm{H}_{2}$ de cada fonte observada e uma imagem em cores falsas, composta por uma combinação RGB das imagens no filtro $\mathrm{H}_{2}$ e no contínuo. As imagens são mostradas em função do desvio padrão $(\sigma)$ das contagens do céu, determinado a partir da rotina MMm8, em IDL. O algoritmo da rotina retorna a moda do céu, descontando a contribuição das estelas do campo (e.g. para um mesmo campo, os valores da moda e desvio padrão determinados pela rotina IMSTATISTICS sob ambiente IRAF foram -2565 e 13699 ADUs, respectivamente; os valores retornados pela rotina MMM são -2739.996 e 1930.65 ADUs, respectivamente). Para exemplificar as imagens geradas pelas rotinas, as Figuras 3.14 e 3.15 apresentam o mapa de emissão em $\mathrm{H}_{2}$ e a imagem RGB da fonte G109.8715+02.1156. Os detalhes de cada uma das imagens geradas pela rotina são descritos a seguir.

\subsubsection{Mapa de emissão em $\mathrm{H}_{2}$}

A Figura 3.14 apresenta o mapa de emissão em $\mathrm{H}_{2}$, obtido a partir da subtração das imagens no filtro $\mathrm{H}_{2}$ e no filtro do contínuo. As principais componentes da imagem são:

- Mapa de emissão em $\mathbf{H}_{2}$ ( $\mathbf{H}_{2}$-Contínuo): Uma escala de cor divergente foi adotada para visualização do mapa de emissão em $\mathrm{H}_{2}$ - regiões onde $\sigma_{\text {sub }}=0$ são mostradas na cor branca, regiões com excesso de emissão em $\mathrm{H}_{2}\left(\sigma_{\text {sub }}>0\right)$ são vistas em azul; e aquelas com excesso de emissão no contínuo $\left(\sigma_{\text {sub }}<0\right)$ são mostradas em vermelho. Os limites da faixa dinâmica do mapa foram definidos, simetricamente em $\sigma_{s u b}=0$, com máximo igual ao valor da coluna (9) da tabela de entrada. A escala de cor com os correspondentes valores de $\sigma$ é mostrada à direita do mapa de emissão em $\mathrm{H}_{2}$;

- Contornos: as curvas de nível mostradas na imagem principal correspondem aos contornos em $\sigma_{\text {sub }}=1$ e 3 (em azul) e $\sigma_{\text {cont }}=3,6$ e 10 (em vermelho). Enquanto os contornos da emissão em $\mathrm{H}_{2}$ auxiliam na identificação de estruturas estendidas, os contornos do contínuo ajudam a identificar a posição das estrelas do campo, eliminadas pela subtração das imagens, e as regiões que apresentam emissão nebular no contínuo;

- Detalhes da região central no filtro do contínuo: A região delimitada por um quadrado pontilhado, cujo tamanho é definido pela coluna (8) da tabela de entrada, é

\footnotetext{
${ }^{8}$ uma adaptação da rotina de mesmo nome presente no pacote DAOFIND sob ambiente IRAF
} 
mostrada em detalhes na imagem localizada em um dos cantos do mapa de emissão em $\mathrm{H}_{2}$. Essa imagem apresenta uma faixa dinâmica com mínimo em zero e máximo definido pela coluna (10) da tabela de entrada. O limite superior da faixa dinâmica foi escolhido de modo a garantir que as fontes infravermelhas estivessem completamente visíveis e bem amostradas (exceto para fontes saturadas);

- Orientação: A orientação foi definida a partir das setas indicadas no canto inferior direito da imagem principal. As direções Norte e Leste foram definidas para cima e para a esquerda, respectivamente;

- Escala de tamanho: Uma escala de dimensão projetada $\left(\ell_{\text {proj }}\right)$ baseada na distância cinemática da fonte $(d)$ é mostrada no canto inferior direito da imagem. O valor de $\ell_{\text {proj }}$ foi calculado a partir da seguinte expressão

$$
\ell_{\text {proj }}(\mathrm{pc})=d(\mathrm{pc}) \cdot \sin (\Delta \theta) \approx d(\mathrm{pc}) \cdot \Delta \theta(\mathrm{rad})
$$

onde $\Delta \theta$ é o tamanho angular da escala (em radianos).

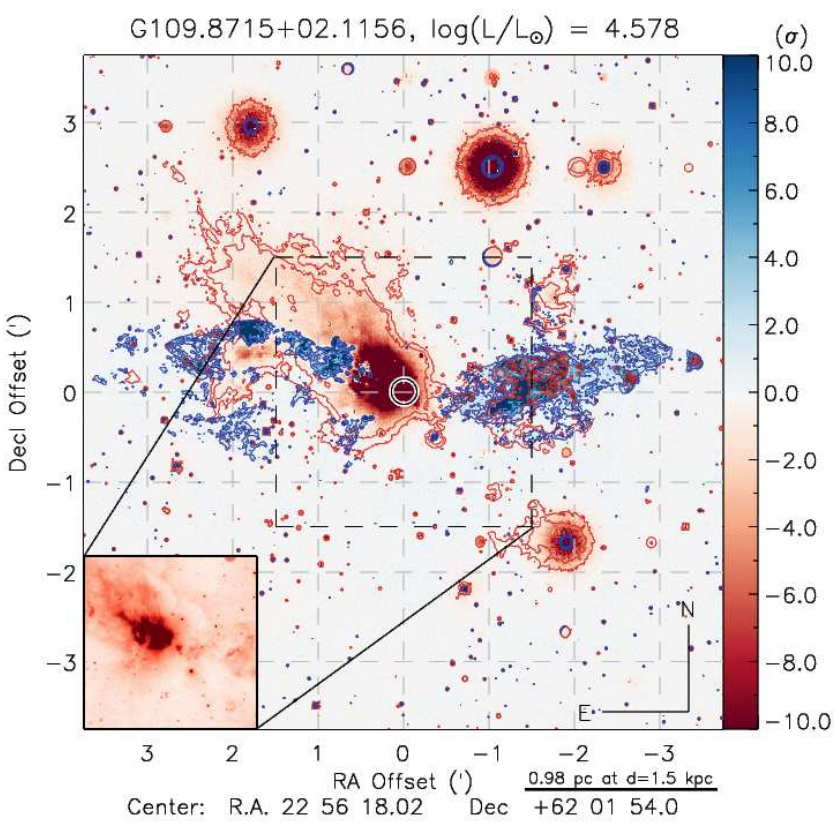

Figura 3.14: Mapa de emissão em $\mathrm{H}_{2}$ da fonte $\mathrm{G} 109.8715+02.1156$. O nome da fonte e sua luminosidade bolométrica são mostrados no topo da imagem. A imagem principal apresenta o mapa de $\mathrm{H}_{2}$ em escala de cor divergente (as cores azul e vermelho indicam excesso de emissão em $\mathrm{H}_{2}$ e no contínuo, respectivamente); a posição da fonte RMS é indicada pelo círculo pontilhado, com diâmetro correspondente ao feixe do MSX (18"); a imagem no canto inferior esquerdo mostra os detalhes da emissão no contínuo na região limitada pelo quadrado pontilhado ao redor do objeto central. As coordenadas equatoriais da fonte RMS são mostradas logo abaixo do mapa, juntamente com uma escala de dimensões projetadas, calculada a partir da distância da fonte. 


\subsubsection{Imagem em cores-falsas (RGB)}

A Figura 3.15 apresenta a imagem RGB da fonte G109.8715+02.1156, composta por uma combinação das imagens no filtro $\mathrm{H}_{2}$ e no contínuo. O canal azul é composto pela imagem em $\mathrm{H}_{2}$, o vermelho corresponde à imagem no contínuo e a média de ambos os filtros compõe o canal verde. Cada um dos canais foi normalizado pelo respectivo desvio padrão e apresentam a mesma escala dinâmica, com o limite superior, definido pela coluna (12) da tabela de entrada, estabelecido de modo a ressaltar possíveis emissões extensas presentes no campo.

$\mathrm{G} 109.8715+02.1156, \log \left(L / L_{\odot}\right)=4.578$

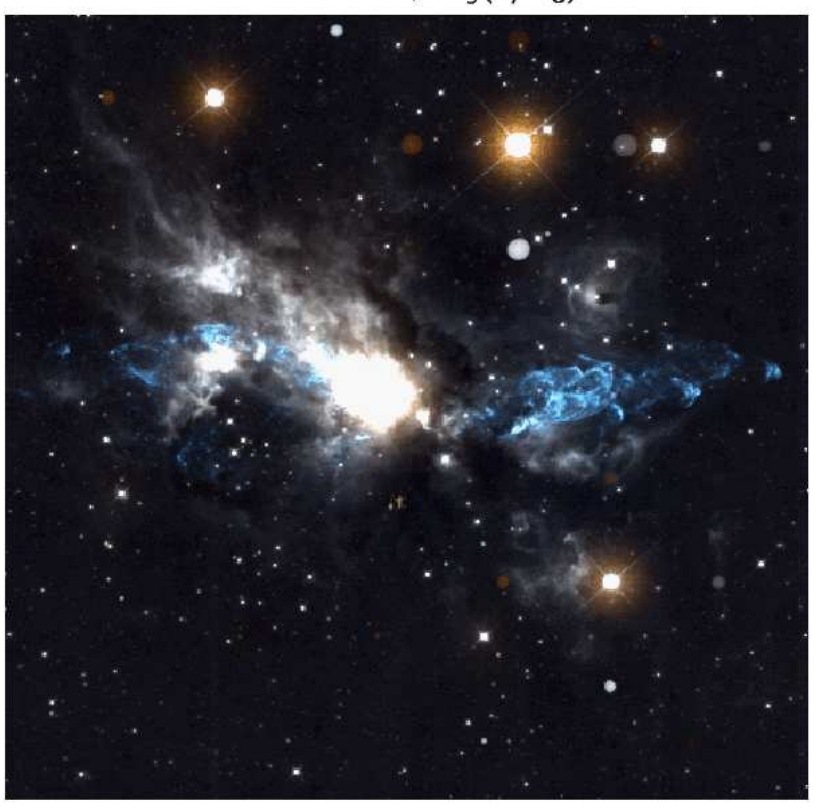

Figura 3.15: Imagem RGB da fonte G109.8715+02.1156. O nome da fonte e sua luminosidade bolométrica são mostrados no topo da imagem. A imagem RGB é composta pela imagem obtida no filtro do $\mathrm{H}_{2}$ (canal azul), a imagem do contínuo (canal vermelho) e a média entre as duas imagens (canal verde). 
Capítulo 4

\section{Catálogo de Fontes com Emissão em $\mathrm{H}_{2}$}

Nesse capítulo, serão apresentados os resultados do levantamento de candidatos a MYSOs, obtidos a partir das observações realizadas nos telescópios SOAR e CFHT. A estrutura do capítulo está organizada da seguinte maneira: i) determinação do desempenho fotométrico do levantamento; ii) caracterização das fontes RMS no plano distâncialuminosidade; iii) apresentação da classificação morfológica das emissões em $\mathrm{H}_{2}$ identificadas nos campos; iii) análise geral dos campos; e $i v$ ) a análise individual das fontes associadas à emissões polares

\subsection{Desempenho Fotométrico}

Os resultados observacionais apresentados nesta dissertação foram obtidos a partir de imagens adquiridas em diferentes telescópios e processadas utilizando a mesma metodologia. Os instrumentos utilizados apresentam diferenças significativas entre si (para maiores detalhes, veja a Tabela 3.2 na Seção 3.3) e alguns testes foram realizados para $i$ ) analisar o desempenho de cada instrumento e $i$ ) verificar o limite fotométrico de cada um deles.

O desempenho fotométrico de cada instrumento foi avaliado a partir da fotometria das fontes contidas em alguns dos campos observados. A maneira mais adequada de se determinar a fotometria das fontes contidas em campos relativamente grandes é obtida a partir da determinação da função de espalhamento de fonte puntual (PSF). Esta técnica é conhecida como fotometria PSF e pode ser realizada com as tarefas do pacote DAOPHOT, sob ambiente IRAF, ou utilizando o pacote de fotometria StarFinder, escrito em IDL e adotado nesse trabalho. Uma descrição detalhada sobre os aspectos técnicos, algoritmos e procedimentos operacionais do pacote StarFinder podem ser encontrados em Diolaiti et al. 
(2000). A seguir, uma breve descrição dos procedimentos adotados para determinação da fotometria utilizando o StarFinder é apresentada.

A PSF é construída a partir dos perfis das estrelas presentes no campo em estudo. Para isso, as estrelas selecionadas não podem ser fontes saturadas e devem apresentar fluxos relativamente altos para que as asas da PSF sejam bem amostradas. Para o presente estudo, o perfil médio de $\geq 10$ estrelas selecionadas em cada campo foi obtido, seu fluxo normalizado (fluxo total da PSF igual a 1) e adotado como o modelo da PSF. A Figura 4.1 apresenta os modelos de PSF para cada instrumento, gerados pelo StarFinder. A comparação entre as PSFs permite verificar que as características intrínsecas das observações (tais como a qualidade da imagem e instrumento utilizado) alteram significativamente a forma da PSF, mostrando sua relevância na determinação do fluxo de objetos puntuais.
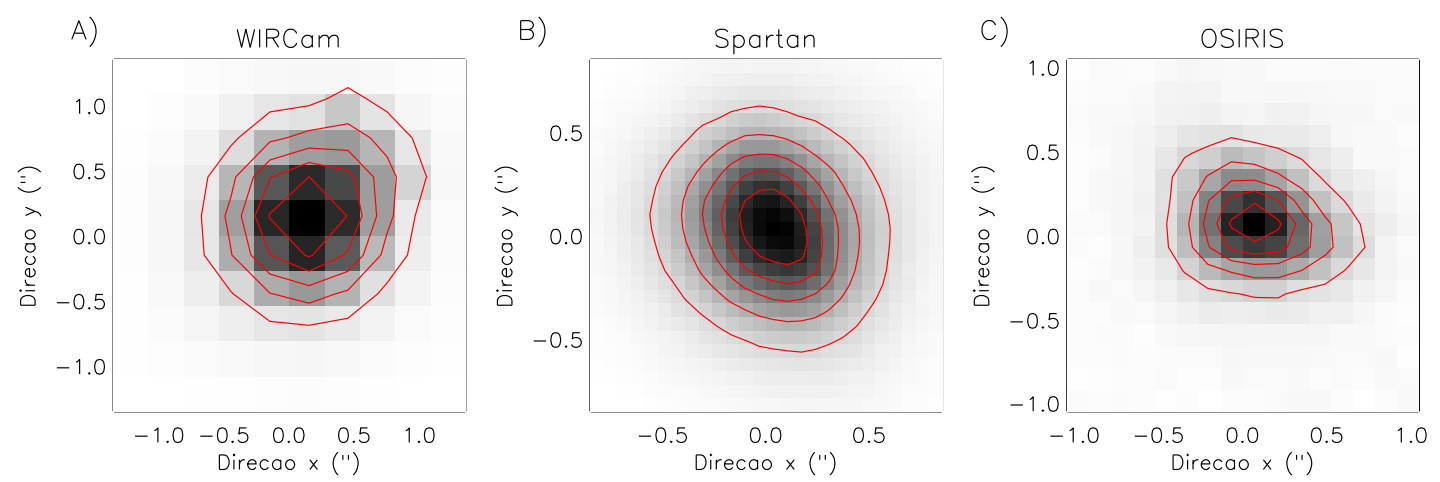

Figura 4.1: Modelos das PSFs de campos observados com diferentes instrumentos: WIRCam (Painel A), Spartan (Painel B) e OSIRIS (Painel C). Cada painel mostra a imagem da PSF gerada pelo StarFinder, sobreposta ao respectivo mapa de contornos (em vermelho) que representam os mesmos níveis isofotais em cada um dos modelos. O tamanho angular de cada imagem é de 2.7"(WIRCam), 1.8" (Spartan) e 2.1"(OSIRIS).

Em seguida, o modelo da PSF é utilizado para determinacão do fluxo das fontes puntuais do campo. Ao término, o StarFinder retorna uma lista com sete colunas, contendo as seguintes informações de cada objeto identificado no campo:

(1) posição central em x $\left(x_{c}\right)$;

(2) posição central em y $\left(y_{c}\right)$;

(3) fluxo $\left(f_{s f}\right)$;

(4) incerteza na posição em x $\left(\sigma_{x}\right)$; 
(5) incerteza na posição em y $\left(\sigma_{y}\right)$;

(6) incerteza no fluxo $\left(\sigma_{f}\right)$;

(7) desvio da PSF (valores entre 0 e 1; assume valor 1 se ajuste for perfeito).

A fotometria dos campos foi obtida a partir de uma rotina escrita em IDL, que realiza i) a leitura do arquivo de saída do StarFinder; ii) a conversão dos fluxos $f_{s f}$ em magnitudes instrumentais e suas incertezas $\left(m_{\text {instr }}\right.$ e $\sigma_{m}$; Equações4.1 e 4.2); e $\left.i i i\right)$ determina a transformação para magnitudes do sistema padrão a partir das fontes que possuem medidas bem determinadas na banda $\mathrm{K}_{s}$ do catálogo de fontes puntuais do 2MASS.

$$
\begin{gathered}
m_{\text {instr }}=-2.5 \log \left(f_{s f}\right) \\
\sigma_{m}=-\frac{2.5}{\ln (10)} \ln \left(\frac{\sigma_{f}}{f_{s f}}\right)
\end{gathered}
$$

De modo geral, a transformação para o sistema padrão é determinada a partir de um ajuste do tipo

$$
m_{K_{s}, 2 M A S S}=\alpha_{m a g} \cdot m_{i n s t r}+m_{0}+\beta_{m a g} \cdot\left(m_{H, 2 M A S S}-m_{K_{s}, 2 M A S S}\right)
$$

onde $m_{0}$ corresponde ao coeficiente linear, $\alpha_{m a g}$ é o coeficiente angular dependente da magnitude instrumental e $\beta_{\text {mag }}$ corresponde ao coeficiente dependente do índice de cor do objeto no catálogo de referência. Como primeira aproximação, o coeficiente $\beta_{m a g}$ foi considerado nulo e, a transformação foi realizada a partir de um ajuste linear em função da magnitude instrumental, tal como mostrado pela Equação 4.4. O tamanho dos campos submetidos à fotometria foi definido de acordo com o instrumento utilizado: foram estudados campos de $5^{\prime} \times 5^{\prime}$ para observações com a WIRCam; $3^{\prime} \times 3^{\prime}$ para a Spartan; e $1.5^{\prime} \times 1.2^{\prime}$ para a OSIRIS.

$$
m_{K_{s}, 2 M A S S}=\alpha_{m a g} \cdot m_{\text {instr }}+m_{0}
$$

A transformação entre as magnitudes instrumentais e as magnitudes na banda $K_{s}$ do 2MASS foi determinada a partir de um ajuste robusto baseado no método de menor desvio absoluto. O algoritmo do ajuste desconsidera pontos que apresentem resíduos absolutos 
muito altos, possibilitando que associações ruins entre fontes identificadas nas imagens e objetos do catálogo tenham menor influência nos resultados. Os resultados da calibração fotométrica para o campo da fonte G109.0775-00.3524, observado com a câmera WIRCam (CHFT), são mostrados na Figura 4.2, A Figura apresenta $i$ ) a curva de calibração fotométrica das fontes identificadas no campo e contidas no catálogo do 2MASS (painel superior esquerdo); $i$ ) a distribuição das magnitudes na banda $\mathrm{K}_{s}$ das fontes identificadas no campo (painel inferior esquerdo); e iii) a imagem do campo, sobreposta às fontes identificadas pelo StarFinder, representadas como círculos azuis, e aquelas contidas no catálogo do 2MASS, mostradas como círculos vermelhos (painel direito).
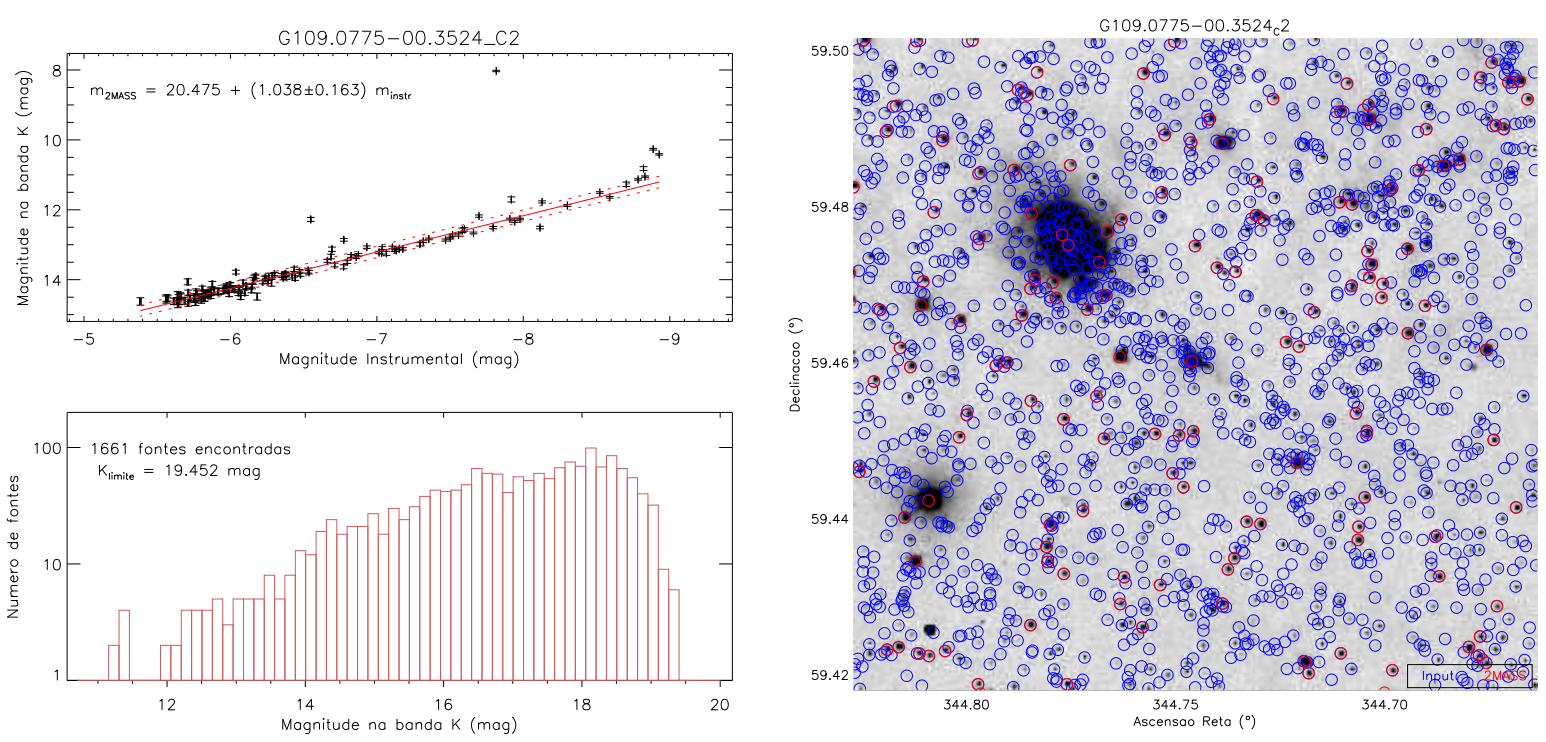

Figura 4.2: Calibração fotométrica das magnitudes das fontes puntuais contidas no campo do objeto G109.0775-00.3524, observado com o WIRCam no filtro do contínuo em $2.14 \mu \mathrm{m}$. Painel superior esquerdo: Curva de calibração fotométrica é mostrada juntamente com os parâmetros do ajuste (linha cheia), indicados na região inferior direita do painel. As linhas tracejadas indicam a incerteza da transformação. Painel inferior esquerdo: Distribuição das magnitudes na banda $\mathrm{K}_{s}$ das fontes identificadas no campo. Painel direito: Detecções no campo. Os círculos azuis mostram as fontes identificadas pelo StarFinder enquanto os círculos vermelhos indicam as fontes contidas no catálogo $2 \mathrm{MASS}$.

Os parâmetros do melhor ajuste (linha cheia) é indicado na região inferior direita do ajuste (Painel A, Figura 4.2), onde $\mathrm{K}_{s}$ e $m_{\text {instr }}$ são as magnitudes na banda $\mathrm{K}_{s}$ do $2 \mathrm{MASS}$ e as magnitudes instrumentais no filtro estreito do contínuo da banda $\mathrm{K}$, respectivamente. As incertezas das magnitudes $\mathrm{K}_{s}$ foram obtidas a partir do catálogo de fontes puntuais do 2MASS enquanto as incertezas em $m_{\text {instr }}$ foram determinadas a partir da incerteza no fluxo calculado pelo StarFinder (Equação4.2). 
A distribuição das magnitudes $\mathrm{K}_{s}$ das fontes contidas no campo é mostrada logo abaixo da transformação. O número de fontes detectadas no campo e a magnitude $\mathrm{K}_{s}$ da fonte mais fraca $\left(\mathrm{K}_{\text {s,limite }}\right)$ são mostrados no canto superior esquerdo da curva. A diferença entre as magnitudes limites $\left(\mathrm{K}_{s, \text { sat }}\right.$ e $\left.\mathrm{K}_{\text {s,limite }}\right)$ fornece uma estimativa da faixa dinâmica fotométrica $(\Delta \mathrm{mag})$ das observações. Assumindo que a quantidade de estrelas num campo decai exponencialmente para magnitudes mais fracas, o limite de completeza fotométrica é determinado na magnitude $\mathrm{K}_{s, c o m p l}$, tal que a distribuição apresente um decréscimo de fontes em relação à distribuição exponencial.

A Tabela 4.1 sintetiza os limites fotométricos de cada instrumento utilizado e são apresentados os limites de saturação $\left(K_{s, \text { sat }}\right.$, coluna 2$)$ e de detecção $\left(K_{s, l i m i t e}\right.$, coluna 3$)$; a faixa dinâmica das observações $(\Delta \mathrm{mag}$, coluna 4$)$; o limite de completeza $\left(\mathrm{K}_{s, c o m p l}\right.$, coluna $5)$; e o limite de densidade de fluxo $\left(\sigma_{\text {lim }}\right.$, coluna 6$)$, definido mais a diante no texto.

Tabela 4.1 - Propriedades fotométricas médias dos campos observados com os diferentes instrumentos utilizados no levantamento.

\begin{tabular}{lcccccc}
\hline \hline Instrumento & Filtro & $\begin{array}{c}K_{s, \text { sat }} \\
(\mathrm{mag})\end{array}$ & $\begin{array}{c}K_{\text {s,limite }} \\
(\mathrm{mag})\end{array}$ & $\begin{array}{c}\Delta \mathrm{mag} \\
(\mathrm{mag})\end{array}$ & $\begin{array}{c}K_{\text {s,compl }} \\
(\mathrm{mag})\end{array}$ & $\begin{array}{c}\sigma_{\text {lim }} \\
\left(\mathrm{W} \mathrm{m}^{-2} \operatorname{arcsec}^{2}\right)\end{array}$ \\
\hline \multirow{2}{*}{ WIRCam } & Contínuo & $11.30 \pm 0.24$ & $19.14 \pm 0.19$ & $7.84 \pm 0.30$ & $18.30 \pm 0.23$ & $5.9 \times 10^{-18}$ \\
Spartan & Contínuo & $9.05 \pm 0.84$ & $16.97 \pm 0.42$ & $7.92 \pm 0.94$ & $16.25 \pm 0.26$ & $2.6 \times 10^{-17}$ \\
OSIRIS & Contínuo & $11.25 \pm 0.64$ & $16.52 \pm 0.27$ & $5.27 \pm 0.70$ & $15.80 \pm 0.45$ & $8.6 \times 10^{-17}$ \\
\hline WIRCam & $\mathrm{H}_{2}$ & $11.60 \pm 0.18$ & $19.66 \pm 0.45$ & $8.06 \pm 0.48$ & $18.90 \pm 0.53$ & $3.1 \times 10^{-18}$ \\
Spartan & $\mathrm{H}_{2}$ & $8.95 \pm 0.73$ & $16.74 \pm 0.51$ & $7.79 \pm 0.89$ & $16.30 \pm 0.44$ & $3.6 \times 10^{-17}$ \\
OSIRIS & $\mathrm{H}_{2}$ & $10.40 \pm 1.23$ & $16.84 \pm 0.59$ & $6.44 \pm 1.36$ & $16.15 \pm 0.58$ & $6.8 \times 10^{-17}$ \\
\hline
\end{tabular}

A seguir, são apresentados os resultados do desempenho fotométrico de cada um dos instrumentos utilizados, tanto para o filtro do Contínuo quanto o filtro do $\mathrm{H}_{2}$.

\subsubsection{Filtro do Contínuo}

As Figuras 4.3, 4.4 e 4.5 apresentam os resultados fotométricos de 8 campos observados com os 3 instrumentos utilizados no presente trabalho (totalizando 3 campos por instrumento), no filtro do contínuo da banda $\mathrm{K}$.

Uma transformação média de cada instrumento foi determinada a partir das trans- 
formações de cada campo estudado e são dadas pelas Equações 4.5.

$$
\begin{aligned}
K_{s, \text { WIRCam }} & =(20.33 \pm 0.11)+(1.00 \pm 0.13) m_{\text {instr }} \\
K_{s, \text { Spartan }} & =(20.285 \pm 0.062)+(0.98 \pm 0.11) m_{i n s t r} \\
K_{s, \text { OSIRIS }} & =(17.86 \pm 0.17)+(1.00 \pm 0.13) m_{\text {instr }}
\end{aligned}
$$
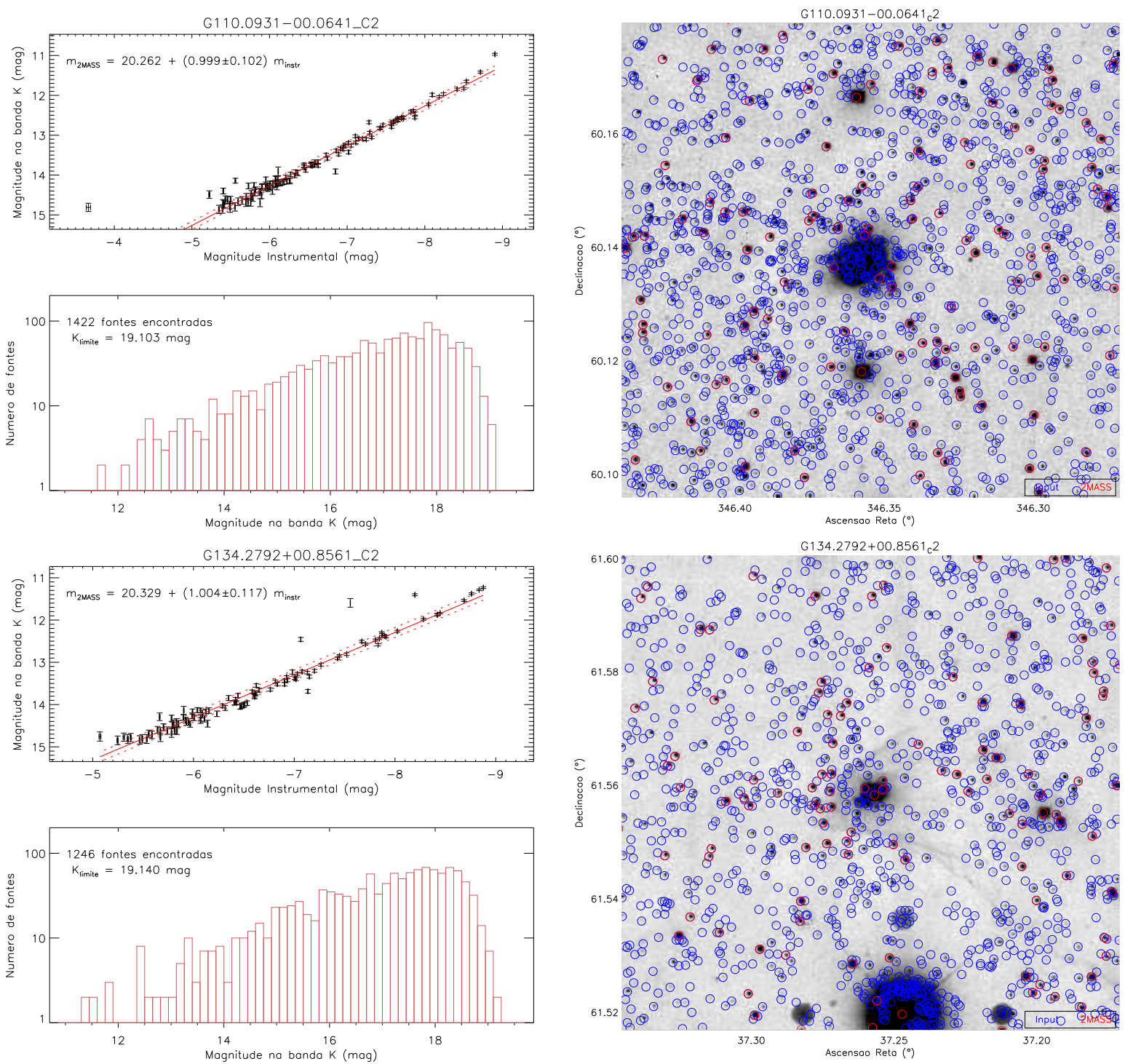

Figura 4.3: Continuação da Figura 4.2. Fotometria dos campos ao redor das fontes G110.093100.0641 (superior) e G134.2792+00.8561 (inferior), observados com a câmera WIRCam (CFHT) no filtro do contínuo da banda $\mathrm{K}\left(\lambda_{c} \approx 2.2 \mu \mathrm{m}\right)$. 

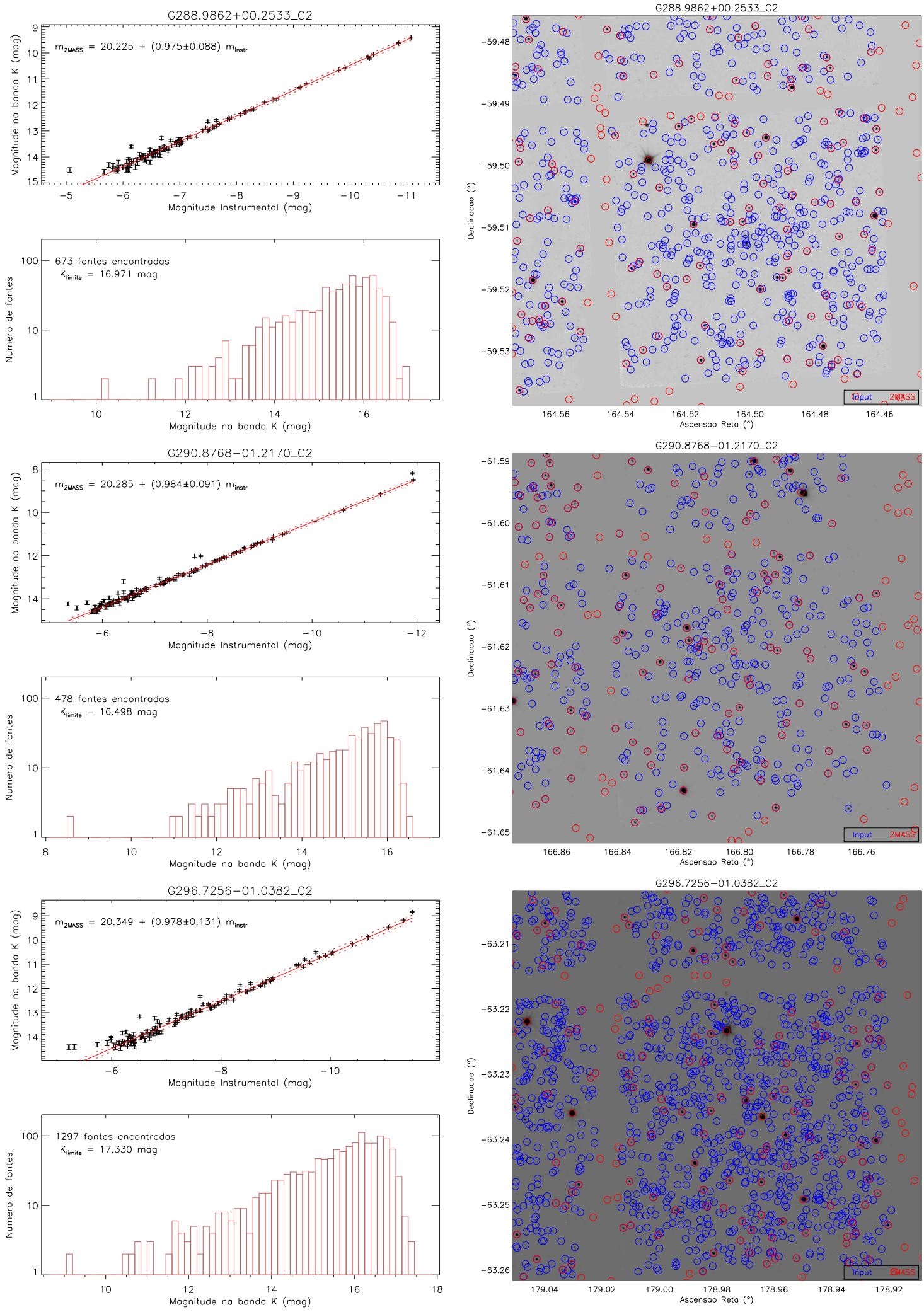

Figura 4.4: Análogo à Figura 4.2 para os campos das fontes G288.9862+00.2533 (superior), G290.8768-01.2170 (centro) e G296.7256-01.0382 (inferior), observados com a câmera Spartan (SOAR) no filtro do contínuo da banda $\mathrm{K}\left(\lambda_{c} \approx 2.1 \mu \mathrm{m}\right)$. 

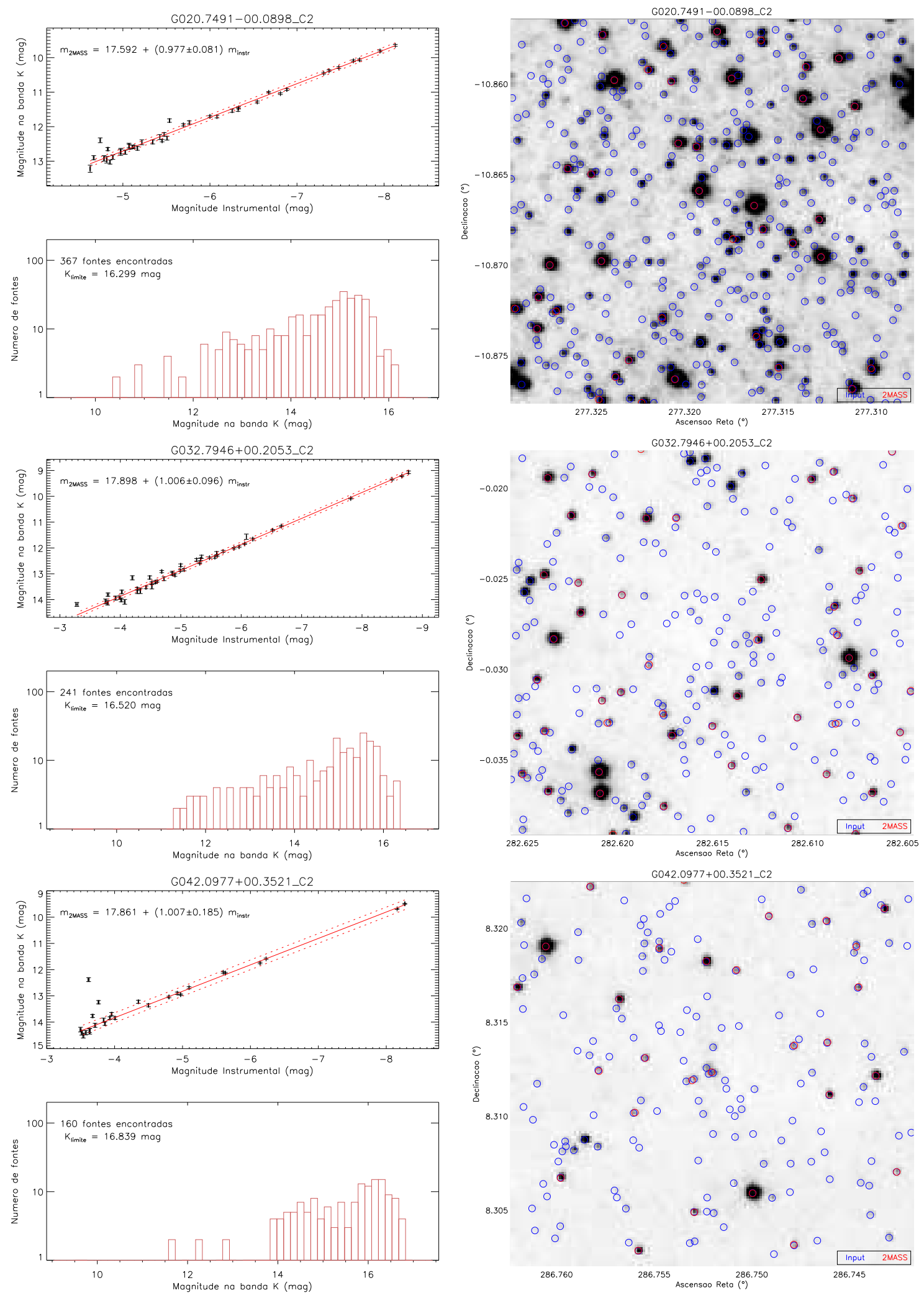

Figura 4.5: Análogo à Figura 4.2 para os campos das fontes G020.7491-00.0898 (superior), G032.7946+00.2053 (centro) e G042.0977+00.3521 (inferior), observados com o OSIRIS (SOAR) no filtro do contínuo da banda $\mathrm{K}\left(\lambda_{c} \approx 2.1 \mu \mathrm{m}\right)$. 
As imagens obtidas com tempos de integração de 150 segundos e realizadas com as câmeras WIRCam e Spartan, apresentam limites de saturação $\mathrm{K}_{s, s a t}=11.30 \pm 0.24 \mathrm{e}$ $9.05 \pm 0.84 \mathrm{mag}$, respectivamente. Nas mesmas imagens, fontes mais fracas que $\mathrm{K}_{s, \text { limite }}=$ $19.14 \pm 0.19$ e $16.97 \pm 0.42$ mag estão abaixo do limite de detecção estabelecido (3 vezes o valor do desvio padrão do céu). Para as imagens obtidas com a câmera OSIRIS, utilizando um maior tempo de exposição (180 segundos), os limites de saturação e de detecção foram estimados em $\mathrm{K}_{s, \text { sat }}=11.25 \pm 0.64 \mathrm{mag}^{\mathrm{e}} \mathrm{K}_{\text {s,limite }}=16.52 \pm 0.27 \mathrm{mag}$, respectivamente. $\mathrm{O}$ limite de completeza das fontes do campo foi determinado em $\mathrm{K}_{s, c o m p l}=18.30 \pm 0.23 \mathrm{mag}$ para as observações realizadas com a câmera WIRCam; $16.25 \pm 0.26$ mag para a Spartan; e $15.80 \pm 0.45$ mag para a OSIRIS.

\subsubsection{Filtro do $\mathrm{H}_{2}$}

As Figuras 4.6, 4.7 e 4.8 apresentam os resultados fotométricos dos mesmos campos apresentados na subseção anterior, porém utilizando as imagens no filtro do $\mathrm{H}_{2}$.

Analogamente, uma transformação média de cada instrumento foi determinada a partir das transformações de cada campo estudado e são dadas pelas Equações 4.6.

$$
\begin{aligned}
K_{s, \text { WIRCam }} & =(20.63 \pm 0.20)+(1.02 \pm 0.14) m_{\text {instr }} \\
K_{s, \text { Spartan }} & =(20.27 \pm 0.12)+(0.98 \pm 0.10) m_{\text {instr }} \\
K_{s, \text { OSIRIS }} & =(18.54 \pm 0.27)+(1.01 \pm 0.13) m_{\text {instr }}
\end{aligned}
$$

A Tabela 4.1 indica que a fotometria obtida a partir do filtro $\mathrm{H}_{2}$ é sistematicamente mais profunda que os valores determinados para o filtro do contínuo. Por exemplo, o limite de completeza no filtro $\mathrm{H}_{2}$ foi estimado em $\mathrm{K}_{s, \text { compl }}=18.90 \pm 0.53,16.30 \pm 0.44$ mag e $16.15 \pm 0.58$ mag para o WIRCam, Spartan e OSIRIS, respectivamente. 

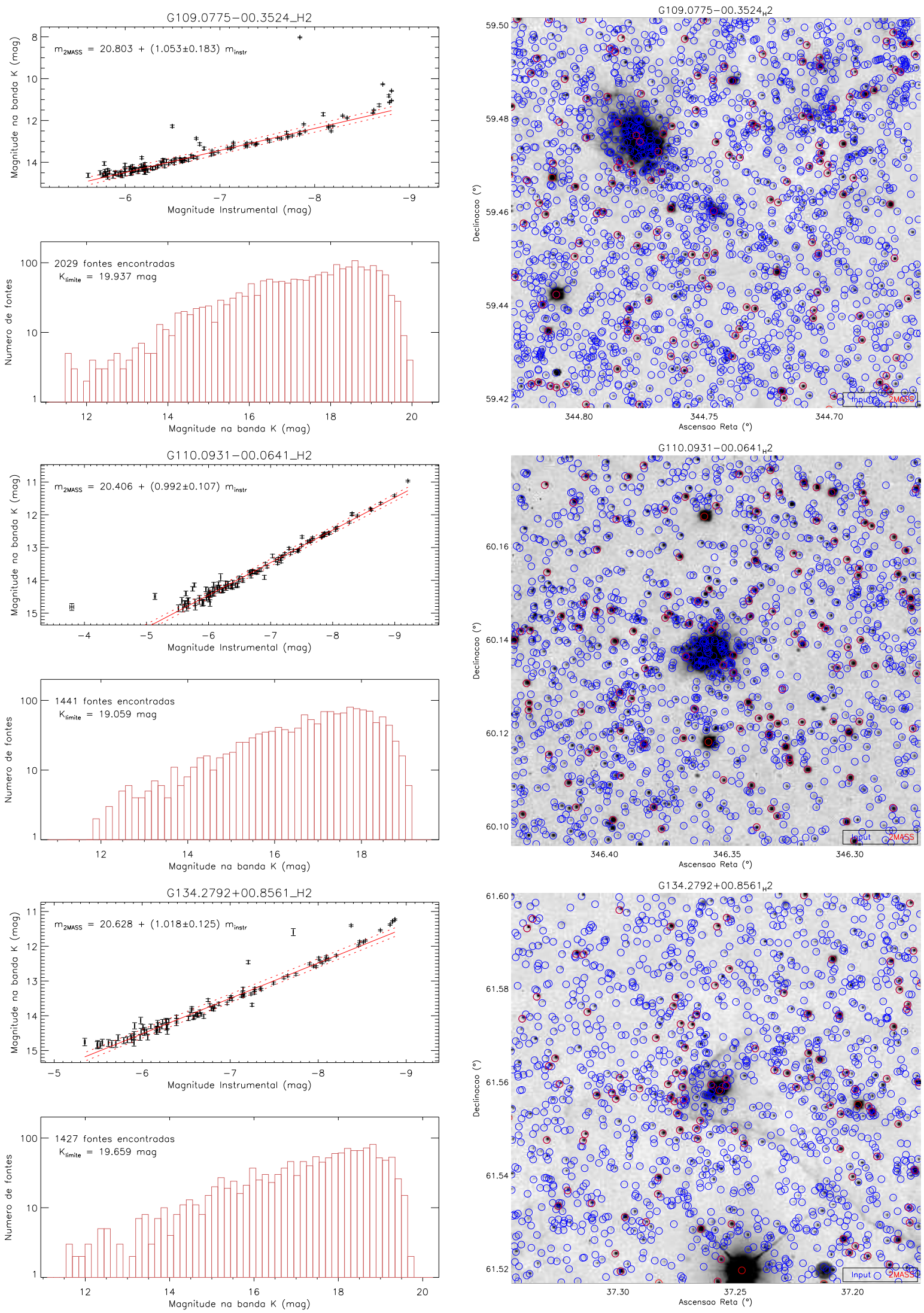

Figura 4.6: Continuação da Figura 4.2. Fotometria dos campos ao redor das fontes G109.077500.3524 (superior), G110.0931-00.0641 (centro) e G134.2792+00.8561 (inferior), observados com a câmera WIRCam (CFHT) no filtro do $\mathrm{H}_{2}\left(\lambda_{c} \approx 2.12 \mu \mathrm{m}\right)$. 

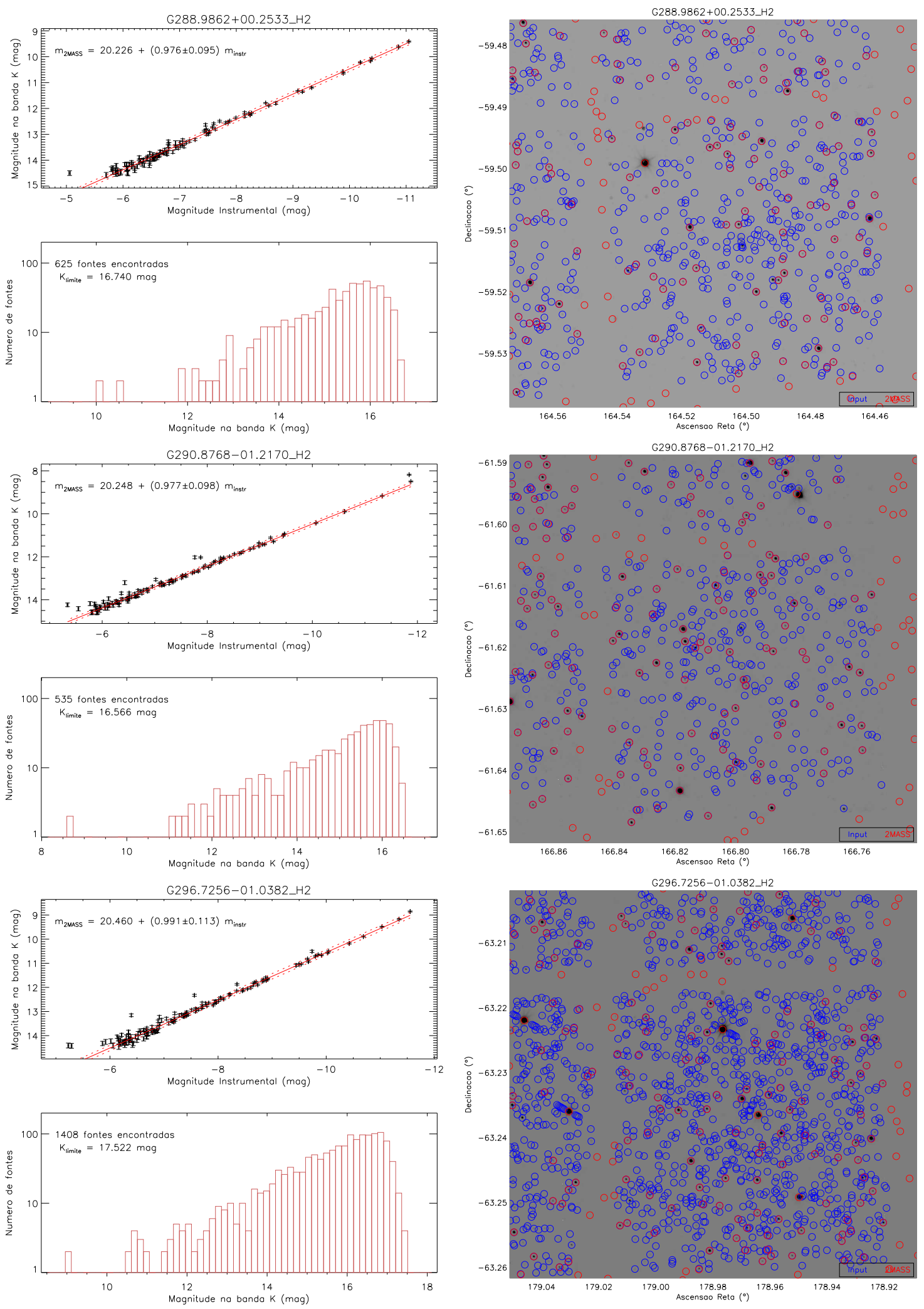

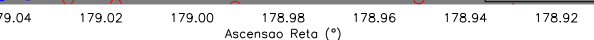

Figura 4.7: Análogo à Figura 4.2 para os campos das fontes G288.9862+00.2533 (superior), G290.8768-01.2170 (centro) e G296.7256-01.0382 (inferior), observados com a câmera Spartan (SOAR) no filtro do $\mathrm{H}_{2}\left(\lambda_{c} \approx 2.12 \mu \mathrm{m}\right)$. 

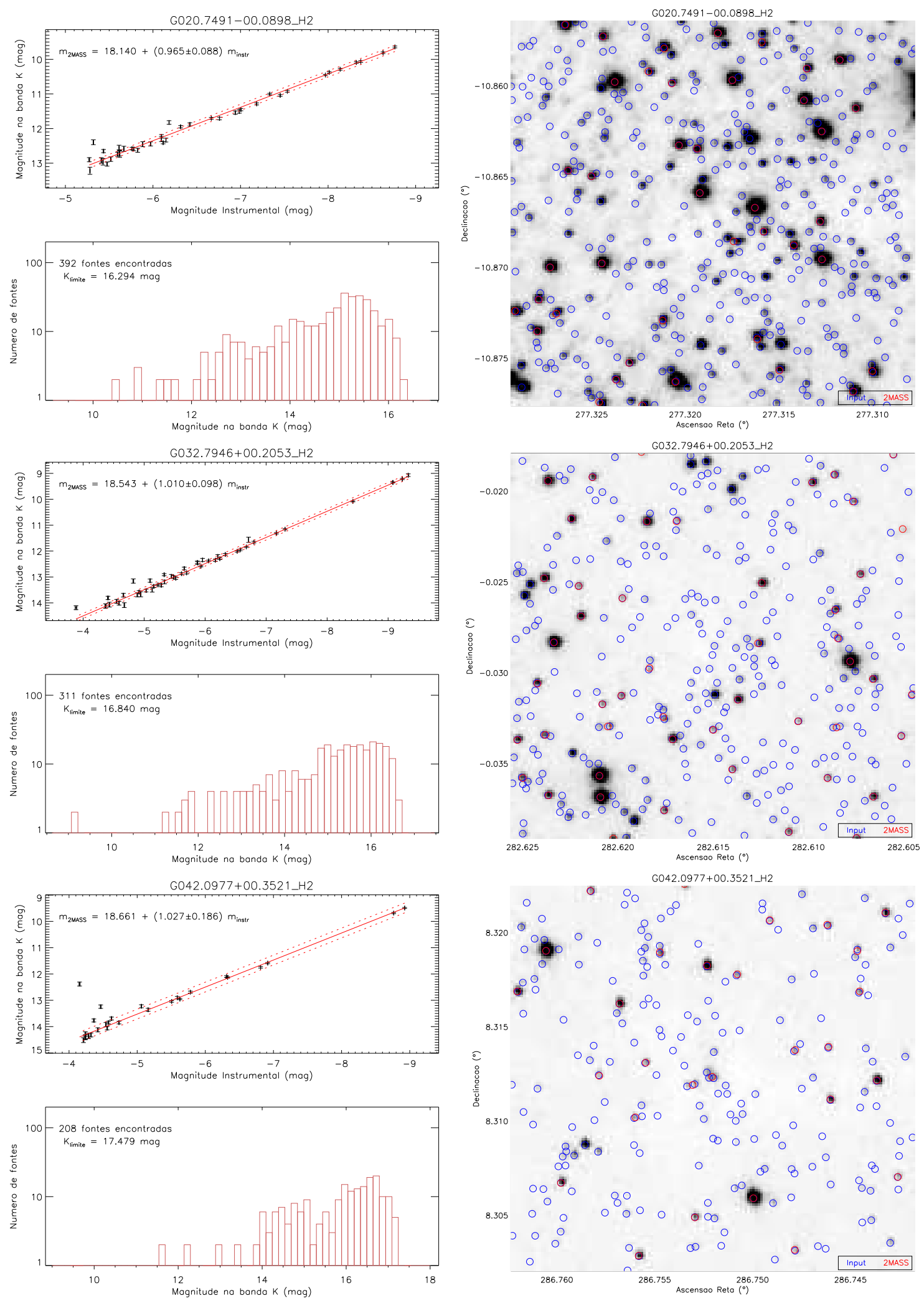

Figura 4.8: Análogo à Figura 4.2 para os campos das fontes G020.7491-00.0898 (superior), G032.7946+00.2053 (centro) e G042.0977+00.3521 (inferior), observados com o OSIRIS (SOAR) no filtro do $\mathrm{H}_{2}\left(\lambda_{c} \approx 2.12 \mu \mathrm{m}\right)$. 
A análise do desempenho fotométrico de cada instrumento utilizado permite concluir que $i$ ) as observações realizadas no hemisfério Norte, utilizando a câmera WIRCam, são sistematicamente mais profundas que as obtidas com os instrumentos do SOAR; ii) os valores de $\Delta$ mag para os instrumentos utilizados mostram que a faixa dinâmica da câmera Spartan é compatível com a faixa dinâmica da câmera WIRCam. Ambas as câmeras apresentam faixa dinâmica superior àquela determinada para a OSIRIS; iii) a Spartan possibilita a observação de fontes com intensidade superior ao limite de saturação das demais câmeras (WIRCam e OSIRIS).

Outra abordagem utilizada para caracterizar as observações de fontes extensas é definida pelo limite da densidade de fluxo das imagens $\left(\sigma_{\text {lim }}\right)$. Para estimar o valor de $\sigma_{\text {lim }}$, foram utilizados $i$ ) o modelo da PSF determinada pelo StarFinder e ii) a magnitude do limite de completeza $K_{s_{l i m}}$ do instrumento. Utilizando o valor do limite inferior para as magnitudes na banda $\mathrm{K}_{s}\left(\mathrm{~K}_{s, \text { limite }}\right.$, Tabela4.1) e a área da PSF média $\left(A_{P S F}\right)$ de cada instrumento, o limite da densidade de fluxo das imagens é definida como

$$
\sigma_{l i m}=\frac{f_{\min }}{A_{P S F}}
$$

com unidades de fluxo por unidade de elemento de área. O fluxo mínimo $\left(f_{\min }\right)$ é definido a partir da magnitude limite como

$$
f_{\text {min }}=10^{-\frac{K_{s, l i m}}{2.5}} \cdot f_{0, K_{s}}
$$

onde $\mathrm{K}_{s, \text { lim }}$ representa a magnitude limite na banda $\mathrm{K}_{s}$ do 2 MASS e $f_{0, K_{s}}$ é o fluxo correspondente à magnitude de ponto zero no mesmo comprimento de onda $\left(\mathrm{f}_{0, K_{s}}=\right.$ $4.28 \times 10^{-14} \pm 8.05 \times 10^{-16} \mathrm{~W} \mathrm{~cm}^{-2} \mu \mathrm{m}^{-1}$ e $\Delta \lambda=0.278 \mu \mathrm{m}$, Cohen et al., 2003).

Os resultados obtidos a partir da Equação 4.7 mostram que o limite da densidade de fluxo das observações realizadas com o filtro do Contínuo da Banda K e a câmera WIRCam é de $\sigma_{\text {lim,WIRCam,Cont }}=5.9 \times 10^{-18} \mathrm{~W} \mathrm{~m}^{-2} \operatorname{arcsec}^{2}$, seguida de $\sigma_{\text {lim,Spartan,Cont }}=2.6 \times$ $10^{-17} \mathrm{~W} \mathrm{~m}^{-2} \operatorname{arcsec}^{2}$ para o Spartan e, finalmente, $\sigma_{\text {lim, OSIRIS,Cont }}=8.6 \times 10^{-17} \mathrm{~W} \mathrm{~m}^{-2} \operatorname{arcsec}^{2}$ para o OSIRIS. Os mesmos resultados obtidos para as observações no filtro do $\mathrm{H}_{2}$ apresentam valores de $\sigma_{\text {lim,WIRCam } H_{2}}=3.1 \times 10^{-18} \mathrm{~W} \mathrm{~m}^{-2} \operatorname{arcsec}^{2}$, seguida de $\sigma_{\text {lim,Spartan } H_{2}}=$ $3.6 \times 10^{-17} \mathrm{~W} \mathrm{~m}^{-2} \operatorname{arcsec}^{2}$ para o Spartan e, finalmente, $\sigma_{\text {lim }, \text { OSIRIS }, H_{2}}=6.7 \times 10^{-17} \mathrm{~W} \mathrm{~m}^{-2} \operatorname{arcsec}^{2}$, mostrando que, as observações no filtro $\mathrm{H}_{2}$ são ligeiramente mais profundas que aquelas realizadas com o filtro do contínuo. 
O limite de densidade de fluxo das observações realizadas por Varricatt et al. (2010) foi estimado em $\sigma_{\text {lim }, \text { Varr } 10}=1.3 \times 10^{-18} \mathrm{~W} \mathrm{~m}^{-2} \operatorname{arcsec}^{2}$. Comparando o valor de $\sigma_{\text {lim }}$ estimados por aqueles autores com os limites determinados no presente trabalho, é possível concluir que as observações realizadas no hemisfério Norte são da mesma ordem de profundidade que aquelas realizadas por Varricatt et al. (2010) $\left(\sigma_{\text {lim,Norte }} \sim \sigma_{\text {lim,Varr10 }}\right)$, enquanto as observações no hemisfério Sul apresentam profundidade uma ordem de grandeza inferior que o valor medido por aqueles autores $\left(\sigma_{\text {lim,Sul }} \sim 10 \sigma_{\text {lim,Varr } 10}\right)$.

\subsection{Relação Massa-luminosidade}

De maneira geral, a relação entre a massa e a luminosidade de estrelas é expressa por

$$
\frac{L}{L_{\odot}}=\left(\frac{M}{M_{\odot}}\right)^{\beta}
$$

onde $M$ e $L$ representam a massa e a luminosidade da estrela, $M_{\odot}$ e $L_{\odot}$ são os valores de referência (e.g. massa e luminosidade do Sol) e $\beta$ corresponde ao expoente da relação. O valor de $\beta$ depende da faixa de massa considerada: $\beta=4.0$ descreve satisfatoriamente estrelas com massa inferior a $2 \mathrm{M}_{\odot}$, enquanto $\beta=3.5$ é mais indicado para estrelas com maior massa. Dessa maneira, o valor de $\beta=3.5$ será adotado nesse trabalho e a Equação 4.9 é reescrita como

$$
\frac{L}{L_{\odot}}=\left(\frac{M}{M_{\odot}}\right)^{3.5}
$$

A relação entre o valor de $\log \left(L / L_{\odot}\right)$ e o tipo espectral para estrelas do tipo $\mathrm{O}$ e sequência principal (classe V) foram obtidas de Martins et al. (2005), enquanto as relações para estrelas entre tipos B0.5 e B3 na SPIZ foram obtidas de Panagia (1973). Embora no caso de YSOs, o fluxo não venha diretamente da fotosfera do objeto, assumimos que esse fluxo seja totalmente absorvido pelo meio circunstelar e reemitido no infravermelho. Assim, o fluxo bolométrico medido corresponde ao mesmo fluxo emitido por uma estrela com fotosfera nua e mesmo tipo espectral. A Tabela 4.2 sintetiza as propriedades de cada tipo espectral. 
Tabela 4.2 - Valores da luminosidade e massa em função do tipo espectral.

\begin{tabular}{|c|c|c|c|}
\hline Tipo Espectral & $\log \left(L / L_{\odot}\right)$ & $\mathrm{M}\left(\mathrm{M}_{\odot}\right)^{a}$ & Referência $^{b}$ \\
\hline O3 & 5.83 & 46.3 & M05 \\
\hline O4 & 5.68 & 42.0 & M05 \\
\hline O5 & 5.51 & 37.5 & M05 \\
\hline O5.5 & 5.41 & 35.1 & M05 \\
\hline O6 & 5.30 & 32.7 & M05 \\
\hline O6.5 & 5.20 & 30.6 & M05 \\
\hline $\mathrm{O} 7$ & 5.10 & 28.7 & M05 \\
\hline O7.5 & 5.00 & 26.8 & M05 \\
\hline $\mathrm{O} 8$ & 4.90 & 25.1 & M05 \\
\hline O8.5 & 4.82 & 23.8 & M05 \\
\hline O9 & 4.72 & 22.3 & M05 \\
\hline O9.5 & 4.62 & 20.9 & M05 \\
\hline B0 & 4.40 & 18.1 & P73 \\
\hline B0.5 & 4.04 & 14.3 & P73 \\
\hline B1 & 3.72 & 11.6 & P73 \\
\hline B2 & 3.46 & 9.7 & P73 \\
\hline B3 & 3.02 & 7.3 & P73 \\
\hline
\end{tabular}

Notas: (a) Massa calculada a partir da relação massa-luminosidade $L \propto M^{3.5}$;

(b) Referência para cada intervalo de tipo espectral: M05 (Martins et al., 2005) e P73 (Panagia, 1973 ).

\subsection{Distâncias e Luminosidades da Amostra de Candidatos a MYSOs}

A Figura 4.9 apresenta a distribuição galactocêntrica da amostra de candidatos a MYSOs estudadas nesse trabalho. A posição de cada fonte foi estabelecida de acordo com suas coordenadas galáticas e o valor da distância heliocêntrica. A cor de cada objeto foi definida de acordo com o valor do $\log \left(L / L_{\odot}\right)$ : fontes com baixa luminosidade são representadas por triângulos vermelhos enquanto fontes mais luminosas são azuis. O centro galático (CG) foi posicionado em $x=8.5 \mathrm{kpc}$ e $y=0 \mathrm{kpc}$. Os três círculos concêntricos indicam as distâncias galactocêntricas de $r_{1}=4.5, r_{2}=8.5$ e $r_{3}=12.5 \mathrm{kpc}$. A distribuição das fontes RMS no plano galático mostra 5 objetos localizados na longitude galática $\ell \sim 170^{\circ}$, que apresentam distâncias heliocêntricas entre 16 e 34 kpc. Como consequência das grandes distâncias, essas fontes possuem elevadas luminosidades bolométricas $\left(\geq 10^{4} \mathrm{~L}_{\odot}\right)$. Visto que não é esperado que uma fonte galática apresente distâncias maiores do que $\sim 20 \mathrm{kpc}$, é provável que as distâncias cinemáticas de tais objetos estejam erradas. A ausência de fon- 
tes mais distantes que o CG é outra característica da amostra e decorre de dois motivos. O tamanho angular do feixe das observações realizadas com o MSX (18") impossibilita distinguir fontes em regiões muito densas, tais como aquelas localizadas na direção do CG. Como consequência disso, a cobertura longitudinal das observações realizadas pelo levantamento Red MSX Source excluiu a região interna do GC $\left(345^{\circ}<\ell<15^{\circ}\right)$.

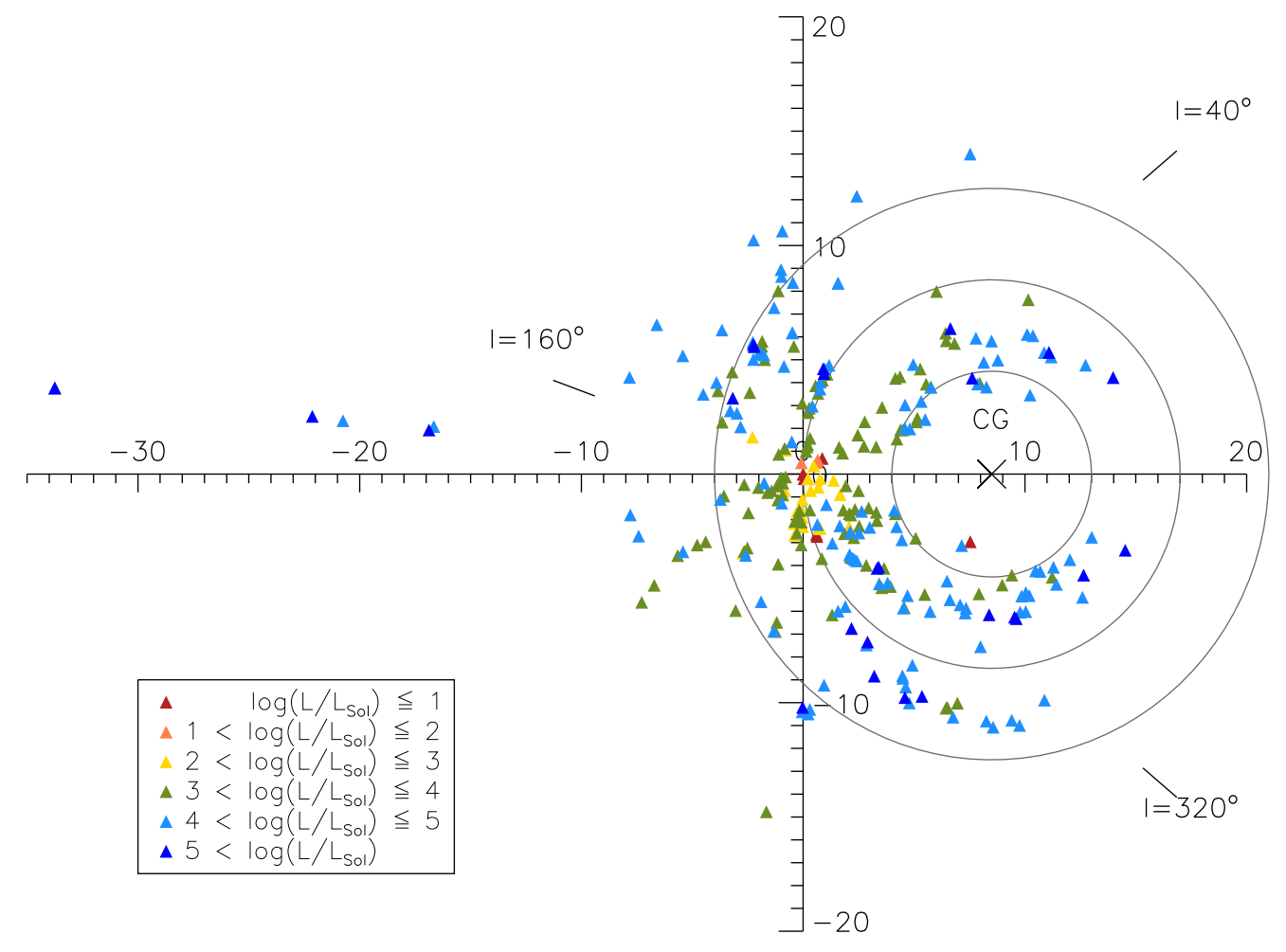

Figura 4.9: Distribuição da amostra no plano galático. A posição do Sol está localizada no centro das coordenadas e o centro galático $(\mathrm{CG})$ na posição $x=8.5 \mathrm{kpc}$. A longitude galática cresce no sentido anti-horário, a partir da direção do CG. A cor de cada ponto está relacionada ao valor da luminosidade bolométrica correspondente. Os três círculos (em cinza) indicam as distâncias galactocêntricas de $4.5 \mathrm{kpc}, 8.5 \mathrm{kpc}$ e $12.5 \mathrm{kpc}$.

A Figura 4.10 apresenta a distribuição dos objetos no plano distância-luminosidade, em unidades de fontes por unidade de luminosidade e distância (fontes $/ \Delta \log \left(\mathrm{L} / \mathrm{L}_{\odot}\right) / \Delta \mathrm{d}$ ), onde $\Delta \log \left(\mathrm{L} / \mathrm{L}_{\odot}\right)=0.2$ e $\Delta \mathrm{d}=0.5 \mathrm{kpc}$. A distribuição das fontes indica a presença de três regiões com propriedades distintas e bem definidas:

i) grande parte dos objetos $\operatorname{com} \log \left(\mathrm{L} / \mathrm{L}_{\odot}\right)>3.5\left(\mathrm{M} \gtrsim 10 \mathrm{M}_{\odot}\right)$ apresentam distâncias cinemáticas $d>3 \mathrm{kpc}$, ou seja, são poucas as estrelas de alta massa nas proximidades do Sol. Esta distância também delimita a detecção das fontes menos luminosas; 
ii) algumas regiões apresentam uma maior concentração de fontes de alta massa e são localizadas em $d \approx 4.0,7.0$ e $10.0 \mathrm{kpc} ;$

ii) Existem dois pontos de alta densidade $\left(>10\right.$ fontes $\left./ \Delta \log \left(\mathrm{L} / \mathrm{L}_{\odot}\right) / \Delta \mathrm{d}\right)$ localizado em $d \sim 2.0 \mathrm{kpc}$, sendo um de alta luminosidade $\left(\log \left(L / L_{\odot}\right) \sim 3.5, \mathrm{M} \gtrsim 10 \mathrm{M}_{\odot}\right)$ e outro de menor luminosidade $\left(\log \left(L / L_{\odot}\right) \sim 2.5, \mathrm{M} \gtrsim 5 \mathrm{M}_{\odot}\right)$. Nessa distância, estão localizadas algumas regiões de formação de estrelas de alta massa, tais como o complexo de regiões H II W3 (Navarete et al., 2011) e as associações de estrelas OB presentes na região de Cignus (Guarcello et al., 2013), que também formam estrelas de menor massa.

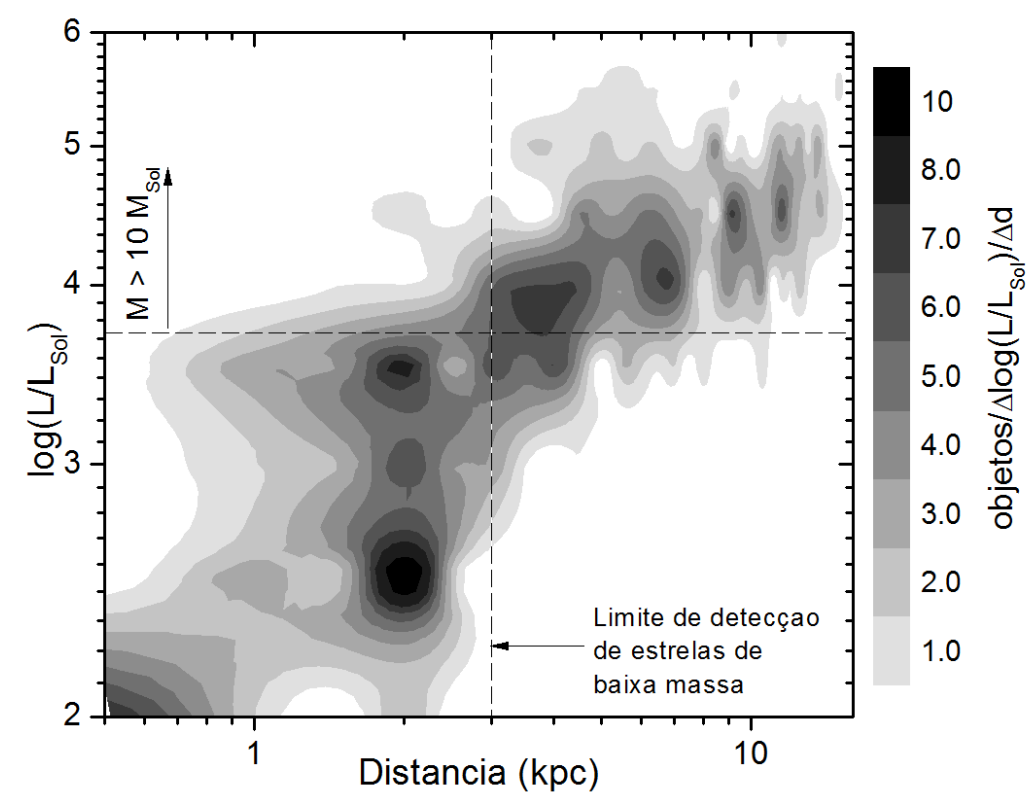

Figura 4.10: Distribuição dos objetos RMS, no plano Distância-Luminosidade. A escala em cinza representa o número de fontes por unidade de luminosidade e distância (fontes $/ \Delta \log \left(L / L_{\odot}\right) / \Delta d$ ), onde $\Delta \log \left(L / L_{\odot}\right)=0.2$ e $\Delta d=0.5 \mathrm{kpc}$. A linha tracejada vertical em $d=3.0 \mathrm{kpc}$ indica o limite de detecção de estrelas de menor massa enquanto a linha tracejada horizontal em $\log \left(L / L_{\odot}\right)=3.7$ indica a luminosidade de uma estrela do tipo B1 e delimita a luminosidade de estrelas de alta e baixa massa $\left(\mathrm{M}>10 \mathrm{M}_{\odot}\right.$.

\subsection{Classificação Morfológica das Emissões em $\mathrm{H}_{2}$}

Os mapas de emissão em $\mathrm{H}_{2}$ foram analisados e as detecções positivas ao redor das fontes RMS foram classificadas de acordo com sua morfologia, em quatro tipos morfológicos: as 
fontes não associadas à emissões estendidas em $\mathrm{H}_{2}$ (tipo $\mathrm{N}$ ), fontes com emissão bipolar (tipo BP, bipolar), objetos associados a emissões do tipo nodal (tipo K, knot) ou emissões do tipo difusa (D, diffuse). As classificações morfológicas são descritas a seguir.

- Emissões Bipolares (BP): estruturas em $\mathrm{H}_{2}$ que sugerem jatos colimados, jatos bipolares ou multipolares. As emissões são classificadas de acordo com o número de polos identificados ao redor de cada fonte: BP1 representa uma emissão monopolar, BP2 são fontes bipolares e BPn, com $n>2$, representa casos multipolares. Exemplos de emissões do tipo BP são mostradas na Figura4.11;
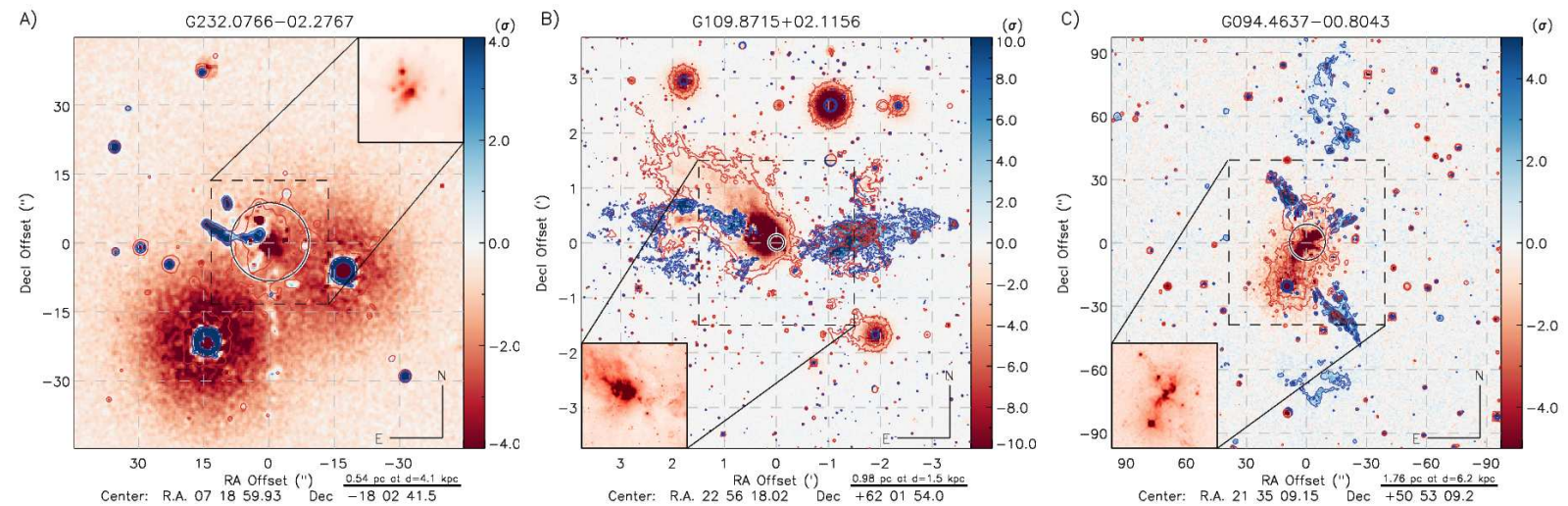

Figura 4.11: Exemplos de emissões classificadas como BP1 (A), BP2 (B) e BP5 (C).

- Emissão Nodal (K): emissões amorfas, geradas - ou não - pela fonte em estudo. Inclui estruturas floculares e/ou as regiões mais intensas de ejeções de baixo brilho superficial. Um exemplo de emissão do tipo K é mostrada no Painel A da Figura 4.12:

- Emissão do tipo Difusa (D): representam os casos em que as estruturas em $\mathrm{H}_{2}$ não estão diretamente associadas à fonte em estudo, porém são ligadas às regiões mais próximas do meio interestelar local. Um exemplo de emissão classificada como difusa é mostrada no Painel B da Figura 4.12,

- Não-detecções (N): Objetos que não apresentam estruturas extensas nos mapas de emissão em $\mathrm{H}_{2}$ (Painel C, Figura 4.12) foram classificados com morfologia do tipo N.

É esperado que as emissões do tipo BP estejam necessariamente associadas aos objetos centrais enquanto as emissões identificadas como tipos K e D podem ou não estar ligadas às fontes: podem representar regiões mais brilhantes de um jato de baixo brilho superficial ou são decorrentes da interação entre a radiação e o meio interestelar nas proximidades da protoestrela; ou podem ser estruturas projetadas na linha de visada da fonte, porém 

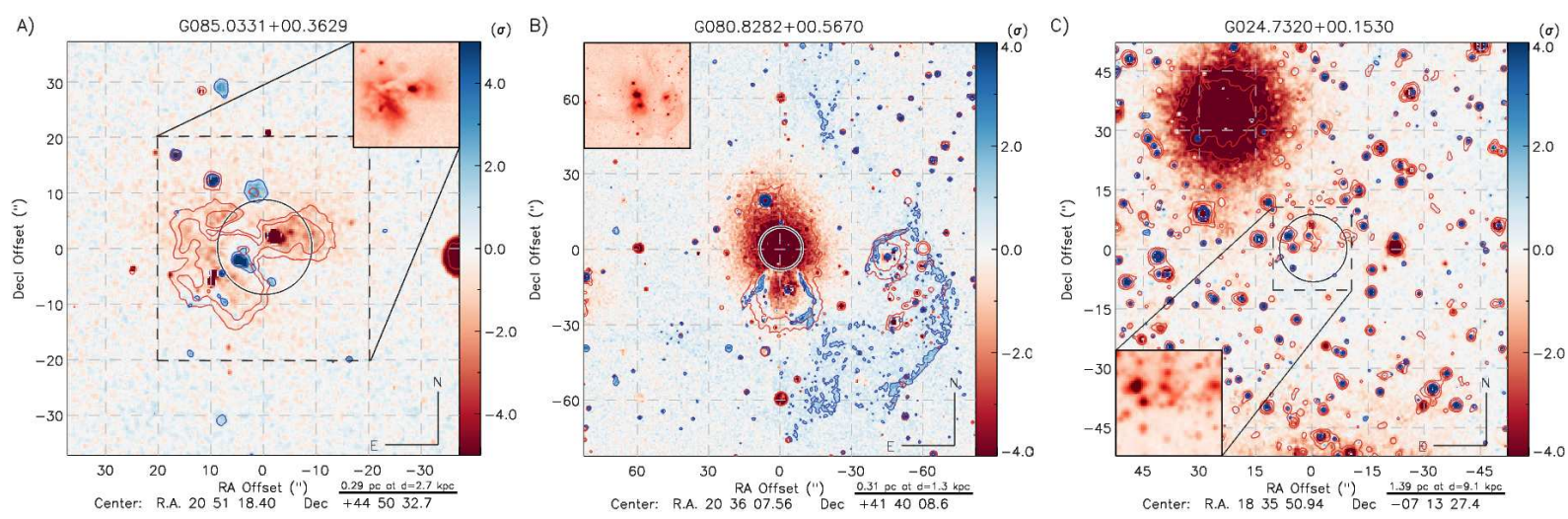

Figura 4.12: Exemplos de emissões classificadas como K (A), D (B) e N (C).

localizadas a distâncias diferentes dos objetos em estudo.

Os 296 objetos foram classificadas conforme os tipos morfológicos descritos acima. Uma classificação secundária foi atribuída às fontes que apresentaram emissão em $\mathrm{H}_{2}$ com mais de um tipo morfológico. Para essas fontes, um critério foi estabelecido para priorizar a identificação de jatos e outras estruturas extensas associadas ao objeto central. Dessa forma, as emissões foram classificadas de acordo com a seguinte ordem de importância:

$$
(B P)>(K)>(D) .
$$

De acordo com esse critério, uma fonte com emissão bipolar e do tipo nodal seria classificada como BP2,K e um objeto com emissão monopolar e difusa receberia a classificação BP1,D.

\subsection{Análise individual dos campos}

Os mapas de emissão em $\mathrm{H}_{2}$ e as imagens RGB de cada um dos campos observados são apresentados na Seção 4.6 e no Apêndice A. Os candidatos a MYSOs foram catalogados a partir da análise das imagens, de acordo com os seguintes itens:

1) Existência de uma contrapartida no infravermelho próximo associada às coordenadas da fonte RMS;

2) Classificação morfológica da emissão em $\mathrm{H}_{2}$;

3) Emissão estendida no filtro do contínuo;

4) Presença de aglomerado estelar associado à fonte RMS; 
5) Dimensões projetadas (em pc) das estruturas identificadas no campo, considerando a distância cinemática de cada fonte RMS.

A identificação de contrapartida no infravermelho próximo é um indicativo do estágio evolutivo do objeto central. Não é esperado observar uma contrapartida no NIR associada a uma estrela de alta massa numa fase evolutiva análoga à Classe 0 (Figura 1.7). A detecção das fontes nessa região espectral indica que o objeto já percorreu uma parte de seu trajeto evolutivo na pré-sequência principal. A identificação de emissão estendida no filtro do contínuo pode indicar emissão do tipo livre-livre do gás ionizado ou de espalhamento da radiação pela poeira. Não é possível distinguir a origem da emissão utilizando apenas o filtro do contínuo. Emissões nebulares seriam evidenciadas a partir de observações no filtro do Brackett- $\gamma$ (em $2.16 \mu \mathrm{m})$.

A Tabela 4.3 sintetiza a classificação das fontes com emissão do tipo BP e está organizada na seguinte forma: o nome do objeto RMS (coluna 1), o logaritmo da sua luminosidade bolométrica (coluna 2), sua distância cinemática (coluna 3), presença de contrapartida no NIR (coluna 4), classificação morfológica da emissão em $\mathrm{H}_{2}$ (coluna 5), emissão estendida no contínuo (coluna 6), presença de aglomerado estelar (coluna 7), dimensão projetada da estrutura principal identificada no campo (coluna 8), razão de aspecto da emissão polar (coluna 9) e referência da página que contém as figuras relacionadas ao objeto (coluna 10). A Tabela 4.4 mostra os objetos classificados como $\mathrm{K}$ ou $\mathrm{D}$, e as fontes sem emissão estendida em $\mathrm{H}_{2}$ são apresentadas na Tabela 4.5.

As próximas seções deste capítulo irão descrever individualmente as i) 62 fontes associadas a emissões em $\mathrm{H}_{2}$ do tipo $\mathrm{BP}$ e as $i$ ) 12 fontes com massas superiores à $32 \mathrm{M}_{\odot}$. 
Tabela 4.3 - Classificação individual das fontes com emissões do tipo BP, identificadas no filtro $\mathrm{H}_{2}$.

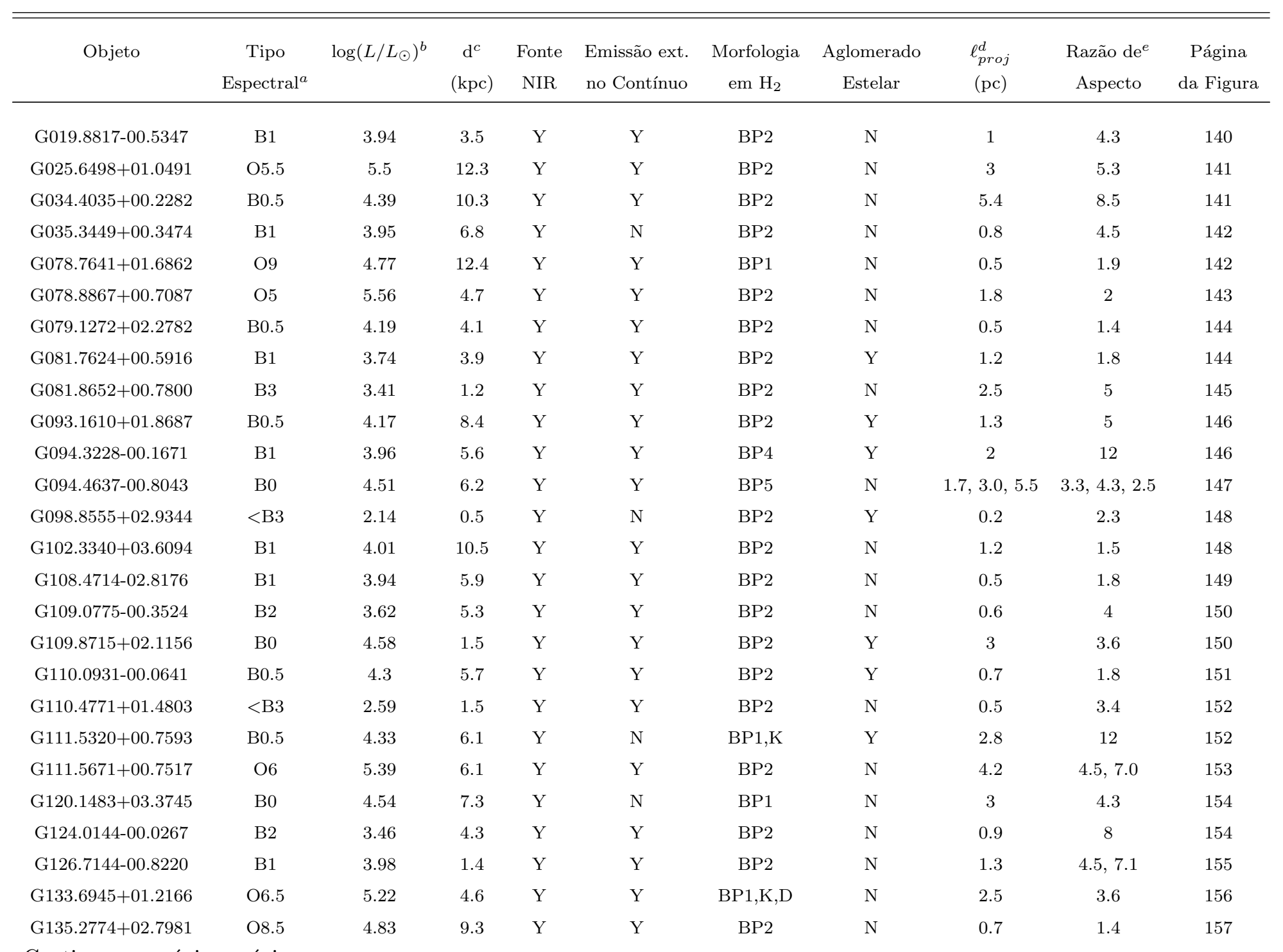


Tabela 4.3 - Continuação

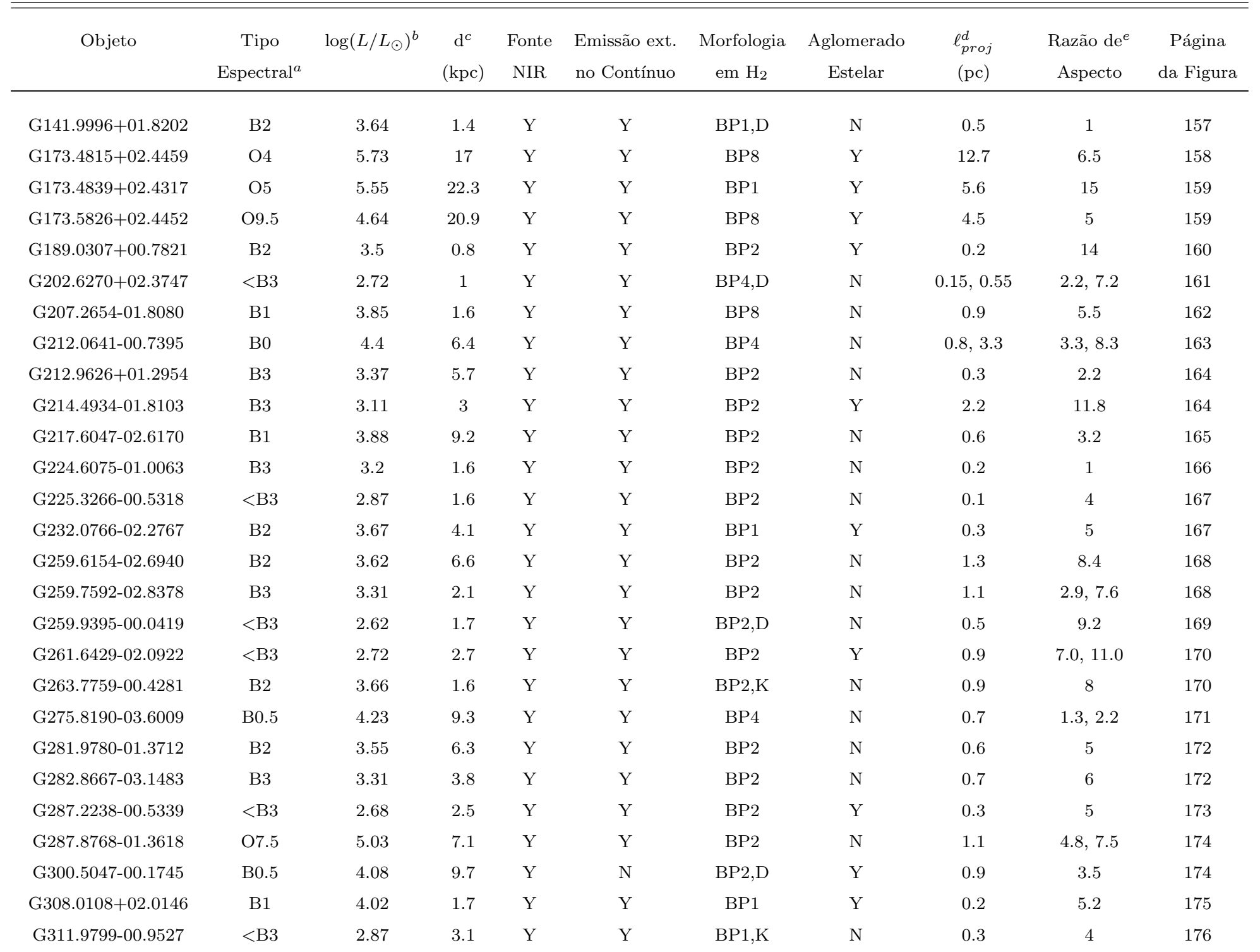

Continua na próxima página. . 
Tabela 4.3 - Continuação

\begin{tabular}{|c|c|c|c|c|c|c|c|c|c|c|}
\hline Objeto & $\begin{array}{c}\text { Tipo } \\
\text { Espectral }^{a}\end{array}$ & $\log (L / L \odot)^{b}$ & $\begin{array}{c}\mathrm{d}^{c} \\
(\mathrm{kpc})\end{array}$ & $\begin{array}{c}\text { Fonte } \\
\text { NIR }\end{array}$ & $\begin{array}{l}\text { Emissão ext. } \\
\text { no Contínuo }\end{array}$ & $\begin{array}{c}\text { Morfologia } \\
\text { em } \mathrm{H}_{2}\end{array}$ & $\begin{array}{c}\text { Aglomerado } \\
\text { Estelar }\end{array}$ & $\begin{array}{l}\ell_{p r o j}^{d} \\
(\mathrm{pc})\end{array}$ & $\begin{array}{r}\text { Razão de } \\
\text { Aspecto }\end{array}$ & $\begin{array}{c}\text { Página } \\
\text { da Figura }\end{array}$ \\
\hline G313.5769+00.3267 & O9.5 & 4.67 & 8.3 & $\mathrm{Y}$ & $\mathrm{N}$ & BP1 & $\mathrm{N}$ & 0.4 & 3.6 & 176 \\
\hline G318.0489+00.0854B & B1 & 3.84 & 3.4 & Y & $\mathrm{Y}$ & BP5 & $\mathrm{N}$ & 0.7 & 6 & 177 \\
\hline G318.9480-00.1969 & B1 & 3.8 & 2.4 & Y & $\mathrm{Y}$ & BP2 & $\mathrm{N}$ & 0.4 & 3.8 & 178 \\
\hline G326.4755+00.6947 & B2 & 3.64 & 2.8 & $\mathrm{Y}$ & $\mathrm{Y}$ & $\mathrm{BP} 2$ & $\mathrm{~N}$ & 0.3 & $3.2,6.4$ & 178 \\
\hline G326.7249+00.6159B & O6.5 & 5.21 & 11.4 & $\mathrm{Y}$ & $\mathrm{Y}$ & BP1 & $\mathrm{N}$ & 1.6 & 0.9 & 179 \\
\hline G328.2523-00.5320 & O9.5 & 4.66 & 3.1 & $\mathrm{~N}$ & $\mathrm{~N}$ & BP1 & $\mathrm{N}$ & 0.3 & 7.0 & 180 \\
\hline G328.5487+00.2717 & B3 & 3.32 & 3.9 & $\mathrm{Y}$ & $\mathrm{Y}$ & $\mathrm{BP} 2$ & $\mathrm{~N}$ & 0.5 & 4 & 180 \\
\hline G331.7318+02.6747 & $<$ B3 & 2.98 & 1.9 & $\mathrm{Y}$ & $\mathrm{Y}$ & BP4 & $\mathrm{N}$ & 0.1 & 1 & 181 \\
\hline G333.3151+00.1053 & B2 & 3.67 & 3.3 & $\mathrm{Y}$ & $\mathrm{Y}$ & $\mathrm{BP} 2$ & $\mathrm{~N}$ & 0.2 & 3.8 & 182 \\
\hline G338.2801+00.5419 & B0.5 & 4.26 & 11.5 & $\mathrm{Y}$ & $\mathrm{Y}$ & $\mathrm{BP} 4$ & $\mathrm{~N}$ & 1 & 5.5 & 182 \\
\hline G338.5459+02.1175 & $<\mathrm{B} 3$ & 0.91 & 8.1 & $\mathrm{Y}$ & $\mathrm{Y}$ & BP2 & $\mathrm{N}$ & 1.5 & 3.3 & 183 \\
\hline
\end{tabular}

Notas: (a) tipo espectral determinado a partir das relações estabelecidas por Martins et al. (2005); Panagia (1973); (b) distância cinemática determinada por Urquhart et al. (2007. 2008); (c) logaritmo da luminosidade bolométria obtido a partir do fluxo bolométrico medido por Mottram et al. (2011) e as distâncias cinemáticas de Urquhart et al. (2007, 2008);

(d) dimensões projetadas das emissões em $\mathrm{H}_{2}$ do tipo BP, assumindo a distância cinemática da fonte correspondente; (e) razão de aspecto da emissão em $\mathrm{H}_{2}$ do tipo BP, $R=$ comprimento/largura. 
Tabela 4.4 - Classificação individual das fontes com emissão não-polar, identificadas no filtro $\mathrm{H}_{2}$.

\begin{tabular}{|c|c|c|c|c|c|c|c|c|c|}
\hline Objeto & $\begin{array}{c}\text { Tipo } \\
\text { Espectral }^{a}\end{array}$ & $\log \left(L / L_{\odot}\right)^{b}$ & $\begin{array}{c}\mathrm{d}^{c} \\
(\mathrm{kpc})\end{array}$ & $\begin{array}{l}\text { Fonte } \\
\text { NIR }\end{array}$ & $\begin{array}{l}\text { Emissão ext. } \\
\text { no Contínuo }\end{array}$ & $\begin{array}{c}\text { Morfologia } \\
\text { em } \mathrm{H}_{2}\end{array}$ & $\begin{array}{l}\text { Aglomerado } \\
\text { Estelar }\end{array}$ & $\begin{array}{l}\ell_{p r o j}^{d} \\
(\mathrm{pc})\end{array}$ & $\begin{array}{c}\text { Página } \\
\text { da Figura }\end{array}$ \\
\hline G028.8621+00.0657 & O6 & 5.3 & 8.7 & $\mathrm{Y}$ & $\mathrm{Y}$ & $\mathrm{K}$ & $\mathrm{Y}$ & 1.20 & 221 \\
\hline G034.7123-00.5946 & $\mathrm{B} 1$ & 3.95 & 3 & $\mathrm{Y}$ & Y & $\mathrm{D}$ & $\mathrm{Y}$ & 0.30 & 221 \\
\hline G038.3543-00.9519 & $<$ B3 & 2.81 & 1.1 & $\mathrm{Y}$ & $\mathrm{Y}$ & K & $\mathrm{Y}$ & 0.05 & 222 \\
\hline G043.9956-00.0111 & B0.5 & 4.32 & 6.9 & $\mathrm{Y}$ & Y & $\mathrm{K}$ & $\mathrm{Y}$ & 0.40 & 222 \\
\hline G044.2836-00.5249 & B1 & 3.88 & 6.1 & $\mathrm{Y}$ & Y & $\mathrm{K}$ & Y & 0.20 & 222 \\
\hline G061.7201+00.8630 & O8.5 & 4.89 & 15.9 & $\mathrm{Y}$ & Y & $\mathrm{D}$ & Y & 1.50 & 223 \\
\hline G076.0902+00.1412 & B1 & 3.85 & 4.5 & $\mathrm{Y}$ & Y & $\mathrm{K}$ & $\mathrm{Y}$ & 0.30 & 223 \\
\hline G077.8999+01.7678 & B1 & 3.88 & 4.5 & $\mathrm{Y}$ & Y & $\mathrm{K}$ & $\mathrm{Y}$ & 0.80 & 223 \\
\hline G077.9550+00.0058 & B0.5 & 4.24 & 4.7 & Y & Y & $\mathrm{D}$ & Y & 0.80 & 224 \\
\hline G077.9637-00.0075 & $\mathrm{O} 7$ & 5.14 & 4.5 & Y & Y & $\mathrm{D}$ & Y & 1.50 & 224 \\
\hline G078.4373+02.6584B & O9.5 & 4.71 & 3.8 & Y & Y & $\mathrm{D}$ & Y & 2.00 & 224 \\
\hline G079.3202+01.3131 & O9.5 & 4.69 & 8.5 & $\mathrm{Y}$ & Y & $\mathrm{D}$ & Y & 0.30 & 225 \\
\hline G079.3248+01.2901 & O9 & 4.72 & 8.5 & $\mathrm{Y}$ & Y & $\mathrm{D}$ & $\mathrm{Y}$ & 1.30 & 225 \\
\hline G079.3398+00.3417 & B3 & 3.28 & 3.6 & $\mathrm{Y}$ & Y & $\mathrm{D}$ & Y & 0.20 & 225 \\
\hline G080.8282+00.5670 & B2 & 3.53 & 1.3 & Y & Y & $\mathrm{D}$ & $\mathrm{Y}$ & 0.25 & 226 \\
\hline G082.0333+02.3249 & B1 & 4 & 3 & $\mathrm{Y}$ & Y & $\mathrm{D}$ & $\mathrm{Y}$ & 3.00 & 226 \\
\hline G082.5682+00.4040 & B3 & 3.32 & 1 & $\mathrm{Y}$ & $\mathrm{Y}$ & $\mathrm{D}$ & $\mathrm{Y}$ & 0.30 & 226 \\
\hline G084.5978+00.1408 & B3 & 3.1 & 2.9 & Y & Y & $\mathrm{D}$ & $\mathrm{Y}$ & 3.00 & 227 \\
\hline G085.0331+00.3629 & B3 & 3.22 & 2.7 & Y & Y & $\mathrm{K}$ & $\mathrm{Y}$ & 0.40 & 227 \\
\hline G090.7764+02.8281 & B3 & 3.39 & 3.1 & Y & Y & $\mathrm{D}$ & $\mathrm{Y}$ & 0.40 & 227 \\
\hline G096.3597+01.2982 & B0.5 & 4.34 & 9 & Y & Y & $\mathrm{D}$ & $\mathrm{Y}$ & 0.40 & 228 \\
\hline G096.4353+01.3233 & B0.5 & 4.26 & 8.7 & Y & Y & $\mathrm{D}$ & $\mathrm{Y}$ & 1.20 & 228 \\
\hline G097.9978+01.4688 & B1 & 3.85 & 8.1 & Y & $\mathrm{N}$ & $\mathrm{D}$ & $\mathrm{N}$ & 2.30 & 228 \\
\hline G100.2124+01.8829 & B0.5 & 4.22 & 7.4 & Y & Y & $\mathrm{K}$ & $\mathrm{Y}$ & 0.80 & 229 \\
\hline G100.3779-03.5784 & B0 & 4.46 & 4.8 & Y & Y & $\mathrm{D}$ & $\mathrm{Y}$ & 0.75 & 229 \\
\hline G107.6823-02.2423 & B1 & 3.84 & 6.1 & $\mathrm{Y}$ & Y & $\mathrm{K}, \mathrm{D}$ & $\mathrm{Y}$ & 1.00 & 229 \\
\hline
\end{tabular}

Continua na próxima página... 
Tabela 4.4 - Continuação

\begin{tabular}{|c|c|c|c|c|c|c|c|c|c|}
\hline Objeto & $\begin{array}{c}\text { Tipo } \\
\text { Espectral }^{a}\end{array}$ & $\log \left(L / L_{\odot}\right)^{b}$ & $\begin{array}{c}\mathrm{d}^{c} \\
(\mathrm{kpc})\end{array}$ & $\begin{array}{l}\text { Fonte } \\
\text { NIR }\end{array}$ & $\begin{array}{l}\text { Emissão ext. } \\
\text { no Contínuo }\end{array}$ & $\begin{array}{c}\text { Morfologia } \\
\text { em } \mathrm{H}_{2}\end{array}$ & $\begin{array}{l}\text { Aglomerado } \\
\text { Estelar }\end{array}$ & $\begin{array}{l}\ell_{p r o j}^{d} \\
(\mathrm{pc})\end{array}$ & $\begin{array}{c}\text { Página } \\
\text { da Figura }\end{array}$ \\
\hline G108.7575-00.9863 & B 0.5 & 4.35 & 5.5 & $\mathrm{Y}$ & $\mathrm{Y}$ & $\mathrm{D}$ & $\mathrm{Y}$ & 0.80 & 230 \\
\hline G110.1082+00.0473B & O9.5 & 4.69 & 5.6 & $\mathrm{Y}$ & $\mathrm{Y}$ & $\mathrm{D}$ & $\mathrm{Y}$ & 4.00 & 230 \\
\hline G111.5234+00.8004 & B0 & 4.56 & 6.2 & $\mathrm{Y}$ & $\mathrm{Y}$ & $\mathrm{D}$ & $\mathrm{Y}$ & 4.50 & 230 \\
\hline G111.5851+00.7976 & B0 & 4.45 & 6 & $\mathrm{Y}$ & $\mathrm{Y}$ & K & $\mathrm{Y}$ & 0.70 & 231 \\
\hline G111.6115+00.3735 & O6 & 5.31 & 6 & Y & $\mathrm{Y}$ & K & $\mathrm{Y}$ & 0.60 & 231 \\
\hline G114.0835+02.8568 & B0.5 & 4.08 & 5.5 & Y & $\mathrm{Y}$ & K & $\mathrm{Y}$ & 0.50 & 231 \\
\hline G125.6045+02.1038B & B1 & 3.89 & 5.5 & Y & $\mathrm{Y}$ & K & $\mathrm{Y}$ & 0.50 & 232 \\
\hline G134.2792+00.8561 & B0.5 & 4.39 & 5.6 & Y & Y & $\mathrm{D}$ & $\mathrm{Y}$ & 1.40 & 232 \\
\hline G136.3542+00.9543 & B0.5 & 4.06 & 7.5 & Y & $\mathrm{Y}$ & $\mathrm{K}$ & $\mathrm{Y}$ & 0.30 & 232 \\
\hline G138.2957+01.5552 & B0 & 4.43 & 4 & Y & $\mathrm{Y}$ & $\mathrm{K}, \mathrm{D}$ & $\mathrm{Y}$ & 0.70 & 233 \\
\hline G139.9091+00.1969 & B0.5 & 4.3 & 4.3 & Y & Y & $\mathrm{D}$ & $\mathrm{Y}$ & 1.50 & 233 \\
\hline G143.8118-01.5699 & B0.5 & 4.27 & 3.5 & Y & $\mathrm{Y}$ & $\mathrm{D}$ & Y & 0.20 & 233 \\
\hline G144.6678-00.7136 & $<\mathrm{B} 3$ & 2.87 & 2.8 & $\mathrm{Y}$ & $\mathrm{N}$ & K & $\mathrm{N}$ & 0.20 & 234 \\
\hline G151.6120-00.4575 & B0 & 4.61 & 8.9 & $\mathrm{Y}$ & $\mathrm{N}$ & $\mathrm{D}$ & $\mathrm{N}$ & 4.30 & 234 \\
\hline G173.6328+02.8064 & $>\mathrm{O} 3$ & 5.94 & 34 & $\mathrm{Y}$ & $\mathrm{Y}$ & $\mathrm{D}$ & $\mathrm{Y}$ & 27.00 & 234 \\
\hline G173.6339+02.8218 & $>\mathrm{O} 3$ & 6.18 & 34 & $\mathrm{Y}$ & $\mathrm{Y}$ & $\mathrm{D}$ & $\mathrm{Y}$ & 27.00 & 235 \\
\hline G188.9479+00.8871 & B3 & 3.37 & 1 & $\mathrm{Y}$ & $\mathrm{Y}$ & K & $\mathrm{Y}$ & 0.60 & 235 \\
\hline G189.8557+00.5011B & B3 & 3.33 & 2.7 & $\mathrm{Y}$ & $\mathrm{Y}$ & $\mathrm{D}$ & $\mathrm{Y}$ & 1.60 & 235 \\
\hline G192.6005-00.0479 & B0 & 4.45 & 1.8 & $\mathrm{Y}$ & $\mathrm{Y}$ & $\mathrm{D}$ & $\mathrm{Y}$ & 2.00 & 236 \\
\hline G192.9089-00.6259 & O9 & 4.78 & 8 & Y & $\mathrm{Y}$ & $\mathrm{D}$ & $\mathrm{Y}$ & 1.20 & 236 \\
\hline G194.9349-01.2224 & B1 & 3.97 & 3.7 & Y & $\mathrm{Y}$ & K & Y & 1.00 & 236 \\
\hline G196.1620-01.2546 & B3 & 3.32 & 2.1 & Y & $\mathrm{Y}$ & K & Y & 0.08 & 237 \\
\hline G196.4542-01.6777 & O9.5 & 4.7 & 3.9 & Y & $\mathrm{Y}$ & $\mathrm{K}, \mathrm{D}$ & Y & 1.75 & 237 \\
\hline G200.0789-01.6323 & B0.5 & 4.15 & 7.9 & $\mathrm{Y}$ & $\mathrm{N}$ & K & $\mathrm{N}$ & 1.20 & 237 \\
\hline G203.3166+02.0564 & B2 & 3.5 & 1 & Y & $\mathrm{Y}$ & $\mathrm{K}, \mathrm{D}$ & Y & 0.60 & 238 \\
\hline G206.7804-01.9395 & B3 & 3.42 & 1.8 & $\mathrm{Y}$ & $\mathrm{Y}$ & $\mathrm{D}$ & $\mathrm{Y}$ & 1.60 & 238 \\
\hline G215.8902-02.0094 & $\mathrm{B} 2$ & 3.69 & 8.3 & $\mathrm{Y}$ & $\mathrm{Y}$ & K & $\mathrm{Y}$ & 1.00 & 238 \\
\hline
\end{tabular}


Tabela 4.4 - Continuação

\begin{tabular}{|c|c|c|c|c|c|c|c|c|c|}
\hline Objeto & $\begin{array}{c}\text { Tipo } \\
\text { Espectral }^{a}\end{array}$ & $\log \left(L / L_{\odot}\right)^{b}$ & $\begin{array}{c}\mathrm{d}^{c} \\
(\mathrm{kpc})\end{array}$ & $\begin{array}{l}\text { Fonte } \\
\text { NIR }\end{array}$ & $\begin{array}{l}\text { Emissão ext. } \\
\text { no Contínuo }\end{array}$ & $\begin{array}{c}\text { Morfologia } \\
\text { em } \mathrm{H}_{2}\end{array}$ & $\begin{array}{l}\text { Aglomerado } \\
\text { Estelar }\end{array}$ & $\begin{array}{l}\ell_{p r o j}^{d} \\
(\mathrm{pc})\end{array}$ & $\begin{array}{c}\text { Página } \\
\text { da Figura }\end{array}$ \\
\hline G232.6207+00.9959 & B1 & 4 & 1.6 & $\mathrm{Y}$ & $\mathrm{Y}$ & $\mathrm{D}$ & $\mathrm{Y}$ & 0.80 & 239 \\
\hline G254.0491-00.5615 & B1 & 3.85 & 4.1 & $\mathrm{Y}$ & $\mathrm{N}$ & $\mathrm{D}$ & $\mathrm{N}$ & 0.20 & 239 \\
\hline G259.0453-01.5559 & B0.5 & 4.06 & 7 & Y & $\mathrm{Y}$ & $\mathrm{D}$ & Y & 0.30 & 239 \\
\hline G259.0459-01.9107 & $<$ B3 & 2.18 & 2.2 & Y & $\mathrm{Y}$ & K & Y & 0.07 & 240 \\
\hline G260.9252+00.1149 & B3 & 3.07 & 2 & Y & $\mathrm{Y}$ & $\mathrm{D}$ & Y & 0.10 & 240 \\
\hline G263.7434+00.1161 & B1 & 3.85 & 2.6 & Y & $\mathrm{Y}$ & $\mathrm{D}, \mathrm{K}$ & Y & 0.15 & 240 \\
\hline G264.2918+01.4700 & B1 & 3.97 & 1.9 & Y & $\mathrm{Y}$ & $\mathrm{D}$ & Y & 1.00 & 241 \\
\hline G265.1438+01.4548 & B1 & 3.75 & 2 & Y & $\mathrm{Y}$ & $\mathrm{D}$ & Y & 1.20 & 241 \\
\hline G267.7336-01.1058 & B2 & 3.66 & 2.1 & Y & $\mathrm{Y}$ & $\mathrm{D}$ & Y & 0.40 & 241 \\
\hline G268.3921-03.0659 & $<\mathrm{B} 3$ & 2.54 & 1.6 & Y & $\mathrm{Y}$ & K & Y & 0.05 & 242 \\
\hline G281.0472-01.5432 & B1 & 3.88 & 1.6 & $\mathrm{Y}$ & $\mathrm{Y}$ & $\mathrm{D}$ & $\mathrm{Y}$ & 0.30 & 242 \\
\hline G282.8969-01.2727 & B1 & 3.73 & 2.8 & $\mathrm{Y}$ & $\mathrm{Y}$ & K & $\mathrm{Y}$ & 0.25 & 242 \\
\hline G286.2086+00.1694 & O 8.5 & 4.89 & 2.3 & $\mathrm{Y}$ & $\mathrm{Y}$ & $\mathrm{D}$ & $\mathrm{Y}$ & 0.60 & 243 \\
\hline G287.8893-00.9316 & $<$ B3 & 2.67 & 2.5 & $\mathrm{Y}$ & $\mathrm{N}$ & $\mathrm{D}$ & $\mathrm{N}$ & 0.80 & 243 \\
\hline G288.9862+00.2533 & $<$ B3 & 0 & 0 & $\mathrm{Y}$ & $\mathrm{Y}$ & $\mathrm{D}$ & $\mathrm{Y}$ & 0.00 & 243 \\
\hline G289.9446-00.8909A & O5 & 5.52 & 9.4 & $\mathrm{Y}$ & $\mathrm{N}$ & K & $\mathrm{N}$ & 0.00 & 244 \\
\hline G290.8768-01.2170 & B0 & 4.5 & 8 & $\mathrm{Y}$ & $\mathrm{Y}$ & $\mathrm{D}$ & Y & 0.40 & 244 \\
\hline G293.5607-00.6703 & O9.5 & 4.66 & 3.3 & $\mathrm{Y}$ & $\mathrm{Y}$ & $\mathrm{K}, \mathrm{D}$ & Y & 0.40 & 244 \\
\hline G295.1523-00.5890 & O6.5 & 5.27 & 10.8 & Y & $\mathrm{N}$ & K & $\mathrm{N}$ & 0.60 & 245 \\
\hline G295.5570-01.3787A & O8.5 & 4.87 & 11.1 & Y & $\mathrm{Y}$ & $\mathrm{D}$ & Y & 1.70 & 245 \\
\hline G296.4036-01.0185 & B0 & 4.41 & 10.4 & Y & $\mathrm{N}$ & $\mathrm{D}$ & $\mathrm{N}$ & 0.50 & 245 \\
\hline G296.7256-01.0382 & O7.5 & 5 & 10 & Y & $\mathrm{N}$ & K & $\mathrm{N}$ & 0.20 & 246 \\
\hline G296.8926-01.3050 & B0.5 & 4.22 & 9.9 & Y & $\mathrm{Y}$ & $\mathrm{D}$ & Y & 0.30 & 246 \\
\hline G301.8147+00.7808 & B0.5 & 4.33 & 4.4 & Y & Y & K & $\mathrm{Y}$ & 0.00 & 246 \\
\hline G305.5610+00.0124 & O7.5 & 4.96 & 5.9 & Y & Y & $\mathrm{D}$ & $\mathrm{Y}$ & 0.30 & 247 \\
\hline G306.1160+00.1386 & B0.5 & 4.39 & 2.8 & Y & $\mathrm{Y}$ & $\mathrm{D}$ & Y & 0.00 & 247 \\
\hline G307.6138-00.2559B & O9.5 & 4.59 & 7.4 & Y & $\mathrm{Y}$ & $\mathrm{K}, \mathrm{D}$ & $\mathrm{Y}$ & 1.60 & 247 \\
\hline
\end{tabular}


Tabela 4.4 - Continuação

\begin{tabular}{cccccccccc}
\hline \hline Objeto & $\begin{array}{c}\text { Tipo } \\
\text { Espectral }^{a}\end{array}$ & $\log \left(L / L_{\odot}\right)^{b}$ & $\begin{array}{c}\mathrm{d}^{c} \\
(\mathrm{kpc})\end{array}$ & $\begin{array}{c}\text { Fonte } \\
\mathrm{NIR}\end{array}$ & $\begin{array}{c}\text { Emissão ext. } \\
\text { no Contínuo }\end{array}$ & $\begin{array}{c}\text { Morfologia } \\
\text { em H }\end{array}$ & $\begin{array}{c}\text { Aglomerado } \\
\text { Estelar }\end{array}$ & $\begin{array}{c}\ell_{\text {proj }}^{d} \\
(\mathrm{pc})\end{array}$ & $\begin{array}{c}\text { Página } \\
\text { da Figura }\end{array}$ \\
\hline G308.6480+00.6469 & $\mathrm{B} 0.5$ & 4.3 & 6.1 & $\mathrm{Y}$ & $\mathrm{N}$ & $\mathrm{D}$ & $\mathrm{N}$ & 0.00 & 248 \\
G320.1750+00.8001 & $\mathrm{B} 2$ & 3.46 & 2.7 & $\mathrm{Y}$ & $\mathrm{N}$ & $\mathrm{D}$ & $\mathrm{N}$ & 1.20 & 248 \\
G320.2046+00.8626B & $\mathrm{B} 1$ & 3.74 & 2.8 & $\mathrm{Y}$ & $\mathrm{Y}$ & $\mathrm{D}$ & $\mathrm{Y}$ & 0.40 & 248 \\
G320.2878-00.3069 & $\mathrm{B} 0.5$ & 4.21 & 8.6 & $\mathrm{Y}$ & $\mathrm{N}$ & $\mathrm{K}$ & $\mathrm{N}$ & 0.00 & 249 \\
G323.7410-00.2552B & $\mathrm{O} 6.5$ & 5.24 & 10.4 & $\mathrm{Y}$ & $\mathrm{N}$ & $\mathrm{D}$ & $\mathrm{N}$ & 0.00 & 249 \\
G331.3546+01.0638 & $\mathrm{O} 8.5$ & 4.82 & 4.8 & $\mathrm{Y}$ & $\mathrm{Y}$ & $\mathrm{D}$ & $\mathrm{Y}$ & 1.30 & 249 \\
G333.1075-00.5020 & $\mathrm{B} 2$ & 3.5 & 3.7 & $\mathrm{Y}$ & $\mathrm{Y}$ & $\mathrm{D}$ & $\mathrm{Y}$ & 0.15 & 250 \\
G340.1537+00.5116 & $\mathrm{B} 0.5$ & 4.1 & 12 & $\mathrm{Y}$ & $\mathrm{Y}$ & $\mathrm{D}$ & $\mathrm{Y}$ & 0.30 & 250 \\
G343.8354-00.1058 & $\mathrm{B} 3$ & 3.03 & 2.6 & $\mathrm{Y}$ & $\mathrm{Y}$ & $\mathrm{D}$ & $\mathrm{Y}$ & 0.25 & 250 \\
\hline
\end{tabular}

Notas: (a) tipo espectral determinado a partir das relações estabelecidas por Martins et al. (2005); Panagia (1973); (b) distância cinemática determinada por Urquhart et al. (2007. 2008); (c) logaritmo da luminosidade bolométria obtido a partir do fluxo bolométrico medido por Mottram et al. (2011) e as distâncias cinemáticas de Urquhart et al. (2007, 2008);

(d) dimensões projetadas das estruturas identificadas em cada campo, assumindo a distância cinemática da fonte correspondente. 
Tabela 4.5 - Classificação individual das fontes sem emissão extensa no filtro $\mathrm{H}_{2}$.

\begin{tabular}{|c|c|c|c|c|c|c|c|c|}
\hline Objeto & $\begin{array}{c}\text { Tipo } \\
\text { Espectral }^{a}\end{array}$ & $\log (L / L \odot)^{b}$ & $\begin{array}{c}\mathrm{d}^{c} \\
(\mathrm{kpc})\end{array}$ & $\begin{array}{l}\text { Fonte } \\
\text { NIR }\end{array}$ & $\begin{array}{l}\text { Emissão ext. } \\
\text { no Contínuo }\end{array}$ & $\begin{array}{c}\text { Aglomerado } \\
\text { Estelar }\end{array}$ & $\begin{array}{l}\ell_{p r o j}^{d} \\
(\mathrm{pc})\end{array}$ & $\begin{array}{l}\text { Página } \\
\text { da Figura }\end{array}$ \\
\hline G016.7981+00.1264 & O7 & 5.14 & 14.6 & $\mathrm{Y}$ & $\mathrm{Y}$ & $\mathrm{N}$ & 0.9 & 251 \\
\hline G018.6608+00.0372 & B0.5 & 4.29 & 10.8 & $\mathrm{Y}$ & $\mathrm{N}$ & $\mathrm{N}$ & - & 251 \\
\hline G019.9386-00.2079 & B3 & 3.35 & 4.5 & $\mathrm{Y}$ & $\mathrm{N}$ & $\mathrm{N}$ & - & 252 \\
\hline G020.5143+00.4936 & B0.5 & 4.1 & 13.6 & Y & $\mathrm{N}$ & $\mathrm{N}$ & - & 252 \\
\hline G022.3554+00.0655 & B0.5 & 4.23 & 5.2 & $\mathrm{Y}$ & Y & $\mathrm{N}$ & - & 252 \\
\hline G023.2628+00.0713 & B1 & 3.88 & 4.9 & $\mathrm{Y}$ & $\mathrm{N}$ & $\mathrm{N}$ & - & 253 \\
\hline G023.4394-00.2394 & B0.5 & 4.36 & 6 & $\mathrm{Y}$ & $\mathrm{N}$ & $\mathrm{N}$ & - & 253 \\
\hline G023.6566-00.1273 & B0.5 & 4.17 & 5 & $\mathrm{Y}$ & $\mathrm{N}$ & $\mathrm{N}$ & - & 253 \\
\hline G023.8176+00.3841 & $\mathrm{B} 2$ & 3.62 & 4.8 & $\mathrm{Y}$ & $\mathrm{N}$ & $\mathrm{N}$ & - & 254 \\
\hline G023.8983+00.0648 & B1 & 3.86 & 3 & $\mathrm{~N}$ & $\mathrm{~N}$ & $\mathrm{~N}$ & - & 254 \\
\hline G024.0946+00.4565 & B2 & 3.5 & 5.6 & $\mathrm{Y}$ & $\mathrm{N}$ & $\mathrm{N}$ & - & 254 \\
\hline G024.6343-00.3233 & O8 & 4.9 & 12.3 & Y & $\mathrm{Y}$ & $\mathrm{N}$ & - & 255 \\
\hline G024.7320+00.1530 & B0.5 & 4.26 & 9.1 & $\mathrm{Y}$ & $\mathrm{N}$ & $\mathrm{N}$ & - & 255 \\
\hline G025.4118+00.1052 & B1 & 3.97 & 5.7 & $\mathrm{Y}$ & $\mathrm{N}$ & $\mathrm{N}$ & - & 255 \\
\hline G026.0552+00.5421 & B0.5 & 4.38 & 12.1 & $\mathrm{Y}$ & $\mathrm{N}$ & $\mathrm{N}$ & - & 256 \\
\hline G026.3176-00.0134 & B0.5 & 4.2 & 6 & $\mathrm{Y}$ & $\mathrm{N}$ & $\mathrm{N}$ & - & 256 \\
\hline G026.5254-00.2667 & B1 & 3.72 & 8.9 & $\mathrm{Y}$ & $\mathrm{N}$ & $\mathrm{N}$ & - & 256 \\
\hline G026.6085-00.2122 & B0.5 & 4.48 & 8.8 & Y & $\mathrm{N}$ & $\mathrm{N}$ & - & 257 \\
\hline G027.1852-00.0812 & B3 & 3.35 & 2 & $\mathrm{~N}$ & $\mathrm{~N}$ & $\mathrm{~N}$ & - & 257 \\
\hline G029.5904-00.6144 & B0.5 & 4.25 & 10.1 & $\mathrm{Y}$ & $\mathrm{N}$ & $\mathrm{N}$ & - & 257 \\
\hline G030.2971+00.0549 & B0.5 & 4.31 & 12 & $\mathrm{Y}$ & $\mathrm{N}$ & $\mathrm{N}$ & - & 258 \\
\hline G030.8185+00.2729 & B0.5 & 4.09 & 6.2 & $\mathrm{Y}$ & $\mathrm{Y}$ & $\mathrm{Y}$ & 0.3 & 258 \\
\hline G030.9959-00.0771 & B0.5 & 4.21 & 9.5 & $\mathrm{Y}$ & $\mathrm{N}$ & $\mathrm{N}$ & - & 258 \\
\hline G031.1593+00.0456 & B0.5 & 4.06 & 11.8 & $\mathrm{Y}$ & $\mathrm{N}$ & $\mathrm{N}$ & - & 259 \\
\hline G033.3891+00.1989 & B0.5 & 4.08 & 5.5 & $\mathrm{Y}$ & $\mathrm{N}$ & $\mathrm{N}$ & - & 259 \\
\hline G033.3933+00.0100 & B0.5 & 4.17 & 6.9 & $\mathrm{~N}$ & $\mathrm{~N}$ & $\mathrm{~N}$ & - & 259 \\
\hline G033.5237+00.0198 & B1 & 3.98 & 6.9 & $\mathrm{Y}$ & $\mathrm{N}$ & $\mathrm{N}$ & - & 260 \\
\hline G035.8546+00.2663 & B3 & 3.12 & 2 & Y & $\mathrm{N}$ & $\mathrm{N}$ & - & 260 \\
\hline G036.9194+00.4825 & B1 & 4 & 12.7 & $\mathrm{Y}$ & $\mathrm{N}$ & $\mathrm{N}$ & - & 260 \\
\hline G037.3412-00.0600 & B0.5 & 4.19 & 9.8 & $\mathrm{~N}$ & $\mathrm{~N}$ & $\mathrm{~N}$ & - & 261 \\
\hline G037.4974+00.5301 & $<$ B3 & 2.12 & 0.6 & $\mathrm{~N}$ & $\mathrm{~N}$ & $\mathrm{~N}$ & - & 261 \\
\hline G039.3880-00.1421B & B3 & 3.39 & 4.6 & $\mathrm{Y}$ & $\mathrm{N}$ & $\mathrm{N}$ & - & 261 \\
\hline G039.4943-00.9933 & B1 & 3.9 & 3.6 & $\mathrm{Y}$ & $\mathrm{Y}$ & $\mathrm{N}$ & 0.4 & 262 \\
\hline G039.9284-00.3741 & B1 & 3.82 & 8.9 & $\mathrm{Y}$ & $\mathrm{N}$ & $\mathrm{N}$ & - & 262 \\
\hline G040.4247+00.6989 & $<\mathrm{B} 3$ & 1.64 & 0.8 & $\mathrm{Y}$ & $\mathrm{N}$ & $\mathrm{N}$ & - & 262 \\
\hline G041.0780-00.6365 & B2 & 3.57 & 7 & $\mathrm{Y}$ & $\mathrm{N}$ & $\mathrm{N}$ & - & 263 \\
\hline G042.1099-00.4466 & B1 & 3.95 & 8.7 & $\mathrm{Y}$ & $\mathrm{Y}$ & $\mathrm{N}$ & - & 263 \\
\hline G043.0786+00.0033 & $<$ B3 & 1.63 & 0.9 & $\mathrm{Y}$ & $\mathrm{N}$ & $\mathrm{N}$ & - & 263 \\
\hline G043.7955-00.1275 & O7 & 5.16 & 9.2 & $\mathrm{Y}$ & $\mathrm{N}$ & $\mathrm{N}$ & - & 264 \\
\hline G043.8152-00.1172 & B1 & 3.99 & 8.9 & $\mathrm{Y}$ & $\mathrm{N}$ & $\mathrm{N}$ & - & 264 \\
\hline G045.1894-00.4387 & B1 & 3.84 & 5.9 & $\mathrm{Y}$ & $\mathrm{N}$ & $\mathrm{N}$ & - & 264 \\
\hline
\end{tabular}

Continua na próxima página... 
Tabela 4.5 - Continuação

\begin{tabular}{|c|c|c|c|c|c|c|c|c|}
\hline Objeto & $\begin{array}{c}\text { Tipo } \\
\text { Espectral }^{a}\end{array}$ & $\log \left(L / L_{\odot}\right)^{b}$ & $\begin{array}{c}\mathrm{d}^{c} \\
(\mathrm{kpc})\end{array}$ & $\begin{array}{c}\text { Fonte } \\
\text { NIR }\end{array}$ & $\begin{array}{l}\text { Emissão ext. } \\
\text { no Contínuo }\end{array}$ & $\begin{array}{c}\text { Aglomerado } \\
\text { Estelar }\end{array}$ & $\begin{array}{l}\ell_{p r o j}^{d} \\
(\mathrm{pc})\end{array}$ & $\begin{array}{c}\text { Página } \\
\text { da Figura }\end{array}$ \\
\hline G053.0366+00.1110 & B2 & 3.6 & 10 & $\mathrm{Y}$ & $\mathrm{Y}$ & $\mathrm{N}$ & - & 265 \\
\hline G076.1877+00.0974 & $\mathrm{O} 8$ & 4.91 & 4.9 & Y & $\mathrm{Y}$ & $\mathrm{N}$ & 0.7 & 265 \\
\hline G077.4052-01.2136 & $\mathrm{B} 2$ & 3.67 & 4.6 & $\mathrm{Y}$ & $\mathrm{Y}$ & $\mathrm{N}$ & 0.3 & 265 \\
\hline G078.0515+00.6180 & B1 & 3.87 & 4.2 & $\mathrm{Y}$ & $\mathrm{Y}$ & $\mathrm{Y}$ & 0.8 & 266 \\
\hline G078.8699+02.7602 & B1 & 3.92 & 1.6 & $\mathrm{Y}$ & $\mathrm{Y}$ & $\mathrm{N}$ & 0.8 & 266 \\
\hline G094.6028-01.7966 & O8.5 & 4.84 & 6.2 & $\mathrm{Y}$ & $\mathrm{N}$ & $\mathrm{N}$ & - & 266 \\
\hline G095.0531+03.9724 & B0.5 & 4.27 & 10.7 & Y & $\mathrm{N}$ & $\mathrm{Y}$ & 0.5 & 267 \\
\hline G126.4274-01.2348 & $<$ B3 & 2.23 & 1.3 & $\mathrm{Y}$ & $\mathrm{N}$ & $\mathrm{N}$ & - & 267 \\
\hline G136.5370+02.8934 & B3 & 3.36 & 5.3 & $\mathrm{Y}$ & $\mathrm{Y}$ & $\mathrm{N}$ & 0.3 & 267 \\
\hline G142.2446+01.4299 & B0 & 4.46 & 5.7 & $\mathrm{Y}$ & $\mathrm{Y}$ & $\mathrm{Y}$ & 0.6 & 268 \\
\hline G148.1201+00.2928 & B1 & 3.84 & 4.3 & $\mathrm{Y}$ & $\mathrm{Y}$ & $\mathrm{Y}$ & 0.4 & 268 \\
\hline G172.8742+02.2687 & B0.5 & 4.34 & 16.8 & Y & $\mathrm{N}$ & $\mathrm{N}$ & 6.5 & 268 \\
\hline G203.7637+01.2705 & B3 & 3.1 & 1.3 & Y & $\mathrm{Y}$ & $\mathrm{N}$ & 0.7 & 269 \\
\hline G212.2344-03.5038 & B2 & 3.65 & 6.7 & $\mathrm{Y}$ & $\mathrm{N}$ & $\mathrm{N}$ & - & 269 \\
\hline G213.9180+00.3786 & B3 & 3.32 & 5.3 & $\mathrm{Y}$ & $\mathrm{Y}$ & $\mathrm{N}$ & 0.75 & 269 \\
\hline G222.4278-03.1357 & $\mathrm{B} 2$ & 2.73 & 1.1 & Y & $\mathrm{Y}$ & $\mathrm{N}$ & - & 270 \\
\hline G224.6065-02.5563 & $\mathrm{B} 2$ & 3.52 & 1.3 & $\mathrm{Y}$ & $\mathrm{N}$ & $\mathrm{N}$ & - & 270 \\
\hline G231.7986-01.9682 & B1 & 3.74 & 4.3 & $\mathrm{Y}$ & $\mathrm{N}$ & $\mathrm{Y}$ & 0.75 & 270 \\
\hline G231.9005-02.1378 & $<\mathrm{B} 3$ & 2.96 & 4.4 & $\mathrm{Y}$ & $\mathrm{Y}$ & $\mathrm{N}$ & 0.5 & 271 \\
\hline G233.8306-00.1803 & B0.5 & 4.27 & 4.4 & $\mathrm{Y}$ & $\mathrm{Y}$ & $\mathrm{N}$ & - & 271 \\
\hline G242.9402-00.4501 & B2 & 3.71 & 6.7 & $\mathrm{Y}$ & $\mathrm{Y}$ & $\mathrm{Y}$ & 0.3 & 271 \\
\hline G251.2337-01.9535 & B 0.5 & 4.31 & 5.9 & $\mathrm{Y}$ & $\mathrm{Y}$ & $\mathrm{Y}$ & 0.3 & 272 \\
\hline G259.6695-01.3181 & B3 & 3.4 & 7 & $\mathrm{Y}$ & $\mathrm{N}$ & $\mathrm{Y}$ & 0.5 & 272 \\
\hline G263.5846-03.9973 & B1 & 3.97 & 14.9 & $\mathrm{Y}$ & $\mathrm{N}$ & $\mathrm{Y}$ & - & 272 \\
\hline G264.1444+02.0190 & B1 & 3.83 & 2 & $\mathrm{Y}$ & $\mathrm{Y}$ & $\mathrm{N}$ & 0.2 & 273 \\
\hline G265.3344+01.3916 & $<$ B3 & 2.55 & 1.9 & Y & $\mathrm{N}$ & $\mathrm{N}$ & - & 273 \\
\hline G267.9094+01.7816 & $<$ B3 & 2.6 & 1.1 & $\mathrm{Y}$ & $\mathrm{Y}$ & $\mathrm{N}$ & 0.15 & 273 \\
\hline G268.0594-00.8040 & $<\mathrm{B} 3$ & 2.7 & 2.1 & $\mathrm{Y}$ & $\mathrm{Y}$ & $\mathrm{N}$ & 0.25 & 274 \\
\hline G268.3957-00.4842 & B1 & 3.91 & 3.1 & $\mathrm{Y}$ & $\mathrm{N}$ & $\mathrm{N}$ & - & 274 \\
\hline G268.4452-00.8442 & $<\mathrm{B} 3$ & 2.35 & 1.9 & $\mathrm{Y}$ & $\mathrm{N}$ & $\mathrm{N}$ & - & 274 \\
\hline G269.5205-01.2510 & $<\mathrm{B} 3$ & 2.83 & 2.3 & $\mathrm{Y}$ & $\mathrm{N}$ & $\mathrm{Y}$ & 0.75 & 275 \\
\hline G269.7431-00.3193 & O7.5 & 4.93 & 10.4 & $\mathrm{Y}$ & $\mathrm{N}$ & $\mathrm{N}$ & - & 275 \\
\hline G269.8539-00.0630 & O7.5 & 5.08 & 10.2 & $\mathrm{Y}$ & $\mathrm{N}$ & $\mathrm{Y}$ & 0.9 & 275 \\
\hline G271.2225-01.7712 & O9.5 & 4.69 & 10.5 & $\mathrm{Y}$ & $\mathrm{N}$ & $\mathrm{N}$ & 0.7 & 276 \\
\hline G271.6511-02.1492 & O9 & 4.75 & 10.3 & $\mathrm{Y}$ & $\mathrm{N}$ & $\mathrm{N}$ & - & 276 \\
\hline G281.2206-01.2556 & $<$ B3 & 0.07 & 0.2 & $\mathrm{Y}$ & $\mathrm{N}$ & $\mathrm{Y}$ & - & 276 \\
\hline G282.7848-01.2869 & $<\mathrm{B} 3$ & 2.92 & 2.7 & $\mathrm{Y}$ & $\mathrm{N}$ & $\mathrm{N}$ & - & 277 \\
\hline G284.6942-00.3600 & O8.5 & 4.83 & 6.2 & $\mathrm{Y}$ & $\mathrm{Y}$ & $\mathrm{N}$ & 0.4 & 277 \\
\hline G288.1760-00.8351 & O9 & 4.77 & 6.1 & $\mathrm{Y}$ & $\mathrm{N}$ & $\mathrm{N}$ & - & 277 \\
\hline G291.5765-00.4310 & $\mathrm{O} 5$ & 5.64 & 7.9 & $\mathrm{Y}$ & $\mathrm{N}$ & $\mathrm{N}$ & - & 278 \\
\hline G294.6168-02.3440 & $<\mathrm{B} 3$ & 2.13 & 0.8 & $\mathrm{Y}$ & $\mathrm{Y}$ & $\mathrm{Y}$ & 0.08 & 278 \\
\hline G298.8591-00.4372 & O6.5 & 5.2 & 11.1 & $\mathrm{Y}$ & $\mathrm{Y}$ & $\mathrm{Y}$ & 1.75 & 278 \\
\hline
\end{tabular}

Continua na próxima página... 
Tabela 4.5 - Continuação

\begin{tabular}{|c|c|c|c|c|c|c|c|c|}
\hline Objeto & $\begin{array}{c}\text { Tipo } \\
\text { Espectral }^{a}\end{array}$ & $\log \left(L / L_{\odot}\right)^{b}$ & $\begin{array}{c}\mathrm{d}^{c} \\
(\mathrm{kpc})\end{array}$ & $\begin{array}{c}\text { Fonte } \\
\text { NIR }\end{array}$ & $\begin{array}{l}\text { Emissão ext. } \\
\text { no Contínuo }\end{array}$ & $\begin{array}{c}\text { Aglomerado } \\
\text { Estelar }\end{array}$ & $\begin{array}{l}\ell_{p r o j}^{d} \\
(\mathrm{pc})\end{array}$ & $\begin{array}{c}\text { Página } \\
\text { da Figura }\end{array}$ \\
\hline G300.3412-00.2190 & B1 & 3.76 & 4.2 & $\mathrm{Y}$ & $\mathrm{N}$ & $\mathrm{Y}$ & 0.5 & 279 \\
\hline G300.7221+01.2007 & B0.5 & 4.15 & 4.1 & $\mathrm{Y}$ & $\mathrm{Y}$ & $\mathrm{Y}$ & 0.4 & 279 \\
\hline G301.1726+01.0034 & B0.5 & 4.14 & 4.3 & $\mathrm{Y}$ & $\mathrm{Y}$ & $\mathrm{N}$ & - & 279 \\
\hline G302.1515-00.9488 & B1 & 3.83 & 12.1 & $\mathrm{Y}$ & $\mathrm{Y}$ & $\mathrm{Y}$ & - & 280 \\
\hline G302.4546-00.7401 & B0.5 & 4.36 & 12.6 & $\mathrm{Y}$ & $\mathrm{N}$ & $\mathrm{N}$ & - & 280 \\
\hline G302.4867-00.0308 & B0.5 & 4.1 & 4.5 & $\mathrm{Y}$ & $\mathrm{N}$ & $\mathrm{N}$ & - & 280 \\
\hline G302.5005-00.7701 & $\mathrm{B} 1$ & 3.94 & 12.1 & $\mathrm{Y}$ & $\mathrm{N}$ & $\mathrm{N}$ & - & 281 \\
\hline G304.7592-00.6299 & B2 & 3.64 & 12.2 & $\mathrm{Y}$ & $\mathrm{N}$ & $\mathrm{N}$ & - & 281 \\
\hline G305.4748-00.0961 & B2 & 3.57 & 6.1 & $\mathrm{Y}$ & Y & $\mathrm{N}$ & 0.3 & 281 \\
\hline G305.4840+00.2248 & B1 & 3.89 & 4.9 & $\mathrm{Y}$ & $\mathrm{Y}$ & $\mathrm{N}$ & - & 282 \\
\hline G305.5393+00.3394 & B2 & 3.51 & 3.2 & $\mathrm{Y}$ & $\mathrm{Y}$ & $\mathrm{N}$ & 0.05 & 282 \\
\hline G307.3950-00.5838 & B0.5 & 4.1 & 13.6 & $\mathrm{Y}$ & Y & $\mathrm{N}$ & 1.25 & 282 \\
\hline G307.7359-00.5945 & B0.5 & 4.3 & 14 & $\mathrm{Y}$ & $\mathrm{N}$ & $\mathrm{N}$ & - & 283 \\
\hline G308.0049-00.3868 & B1 & 3.96 & 7.4 & $\mathrm{Y}$ & $\mathrm{N}$ & $\mathrm{N}$ & - & 283 \\
\hline G308.7008+00.5312 & B2 & 3.66 & 6.3 & $\mathrm{Y}$ & $\mathrm{N}$ & $\mathrm{N}$ & - & 283 \\
\hline G308.9176+00.1231 & O6.5 & 5.27 & 5.3 & $\mathrm{Y}$ & $\mathrm{N}$ & $\mathrm{N}$ & - & 284 \\
\hline G309.4230-00.6208 & $\mathrm{B} 2$ & 3.51 & 3.6 & $\mathrm{Y}$ & $\mathrm{N}$ & $\mathrm{Y}$ & - & 284 \\
\hline G309.9206+00.4790B & $\mathrm{O} 7$ & 5.1 & 5.3 & $\mathrm{Y}$ & $\mathrm{Y}$ & $\mathrm{N}$ & - & 284 \\
\hline G310.0135+00.3892 & O9 & 4.74 & 3.3 & $\mathrm{Y}$ & $\mathrm{Y}$ & $\mathrm{N}$ & 0.4 & 285 \\
\hline G311.1359-00.2372 & B 0.5 & 4.09 & 14.3 & $\mathrm{Y}$ & $\mathrm{N}$ & $\mathrm{N}$ & - & 285 \\
\hline G311.4925+00.4021 & B2 & 3.61 & 5.5 & $\mathrm{Y}$ & $\mathrm{N}$ & $\mathrm{N}$ & 0.08 & 285 \\
\hline G311.5131-00.4532 & B0.5 & 4.13 & 7.1 & $\mathrm{Y}$ & $\mathrm{Y}$ & $\mathrm{N}$ & 0.2 & 286 \\
\hline G311.6050-00.6369 & B 0.5 & 4.34 & 14.7 & Y & $\mathrm{N}$ & $\mathrm{N}$ & - & 286 \\
\hline G314.3197+00.1125 & B0.5 & 4.1 & 3.6 & $\mathrm{Y}$ & $\mathrm{N}$ & $\mathrm{N}$ & - & 286 \\
\hline G316.1386-00.5009B & B2 & 3.62 & 7.6 & $\mathrm{Y}$ & Y & $\mathrm{N}$ & 1.2 & 287 \\
\hline G316.6412-00.0867 & O7.5 & 4.92 & 11 & $\mathrm{Y}$ & $\mathrm{N}$ & $\mathrm{N}$ & - & 287 \\
\hline G316.9386-03.8102 & $<$ B3 & 2 & 0.3 & $\mathrm{Y}$ & $\mathrm{N}$ & $\mathrm{N}$ & - & 287 \\
\hline G316.9531-03.8130 & $<$ B3 & 1.65 & 0.3 & $\mathrm{Y}$ & $\mathrm{Y}$ & $\mathrm{N}$ & 0.05 & 288 \\
\hline G317.7477+00.0112 & B0.5 & 4.24 & 14.7 & Y & $\mathrm{N}$ & $\mathrm{N}$ & 0.2 & 288 \\
\hline G319.8366-00.1963 & $<$ B3 & 2.35 & 0.9 & $\mathrm{Y}$ & $\mathrm{N}$ & $\mathrm{N}$ & - & 288 \\
\hline G320.2437-00.5619 & B0.5 & 4.26 & 9.5 & $\mathrm{Y}$ & $\mathrm{N}$ & $\mathrm{N}$ & - & 289 \\
\hline G321.0523-00.5070 & O8.5 & 4.86 & 9.1 & $\mathrm{Y}$ & Y & $\mathrm{N}$ & 0.5 & 289 \\
\hline G321.3803-00.3016 & B0.5 & 4.35 & 9.4 & $\mathrm{Y}$ & $\mathrm{N}$ & $\mathrm{N}$ & - & 289 \\
\hline G322.1729+00.6442 & B1 & 4.02 & 3.8 & $\mathrm{Y}$ & $\mathrm{N}$ & $\mathrm{N}$ & - & 290 \\
\hline G324.1594+00.2622 & B0.5 & 4.25 & 8 & $\mathrm{Y}$ & $\mathrm{N}$ & $\mathrm{N}$ & 0.25 & 290 \\
\hline G326.5437+00.1684 & B1 & 3.99 & 9.5 & Y & $\mathrm{Y}$ & $\mathrm{N}$ & 0.5 & 290 \\
\hline G326.6618+00.5207 & $\mathrm{O} 4$ & 5.78 & 11.5 & Y & $\mathrm{N}$ & $\mathrm{N}$ & - & 291 \\
\hline G327.1192+00.5103 & O9.5 & 4.68 & 5.3 & $\mathrm{Y}$ & $\mathrm{Y}$ & $\mathrm{N}$ & 1 & 291 \\
\hline G328.3442-00.4629 & O9 & 4.73 & 11.5 & $\mathrm{Y}$ & $\mathrm{N}$ & $\mathrm{N}$ & - & 291 \\
\hline G329.0663-00.3081 & O 8.5 & 4.82 & 11.7 & $\mathrm{Y}$ & $\mathrm{N}$ & $\mathrm{N}$ & - & 292 \\
\hline G331.0890+00.0163 & B2 & 3.56 & 5.8 & $\mathrm{Y}$ & $\mathrm{N}$ & $\mathrm{N}$ & 0.25 & 292 \\
\hline G331.5651+00.2883 & B1 & 4 & 11.2 & $\mathrm{Y}$ & $\mathrm{Y}$ & $\mathrm{N}$ & - & 292 \\
\hline
\end{tabular}

Continua na próxima página... 
Tabela 4.5 - Continuação

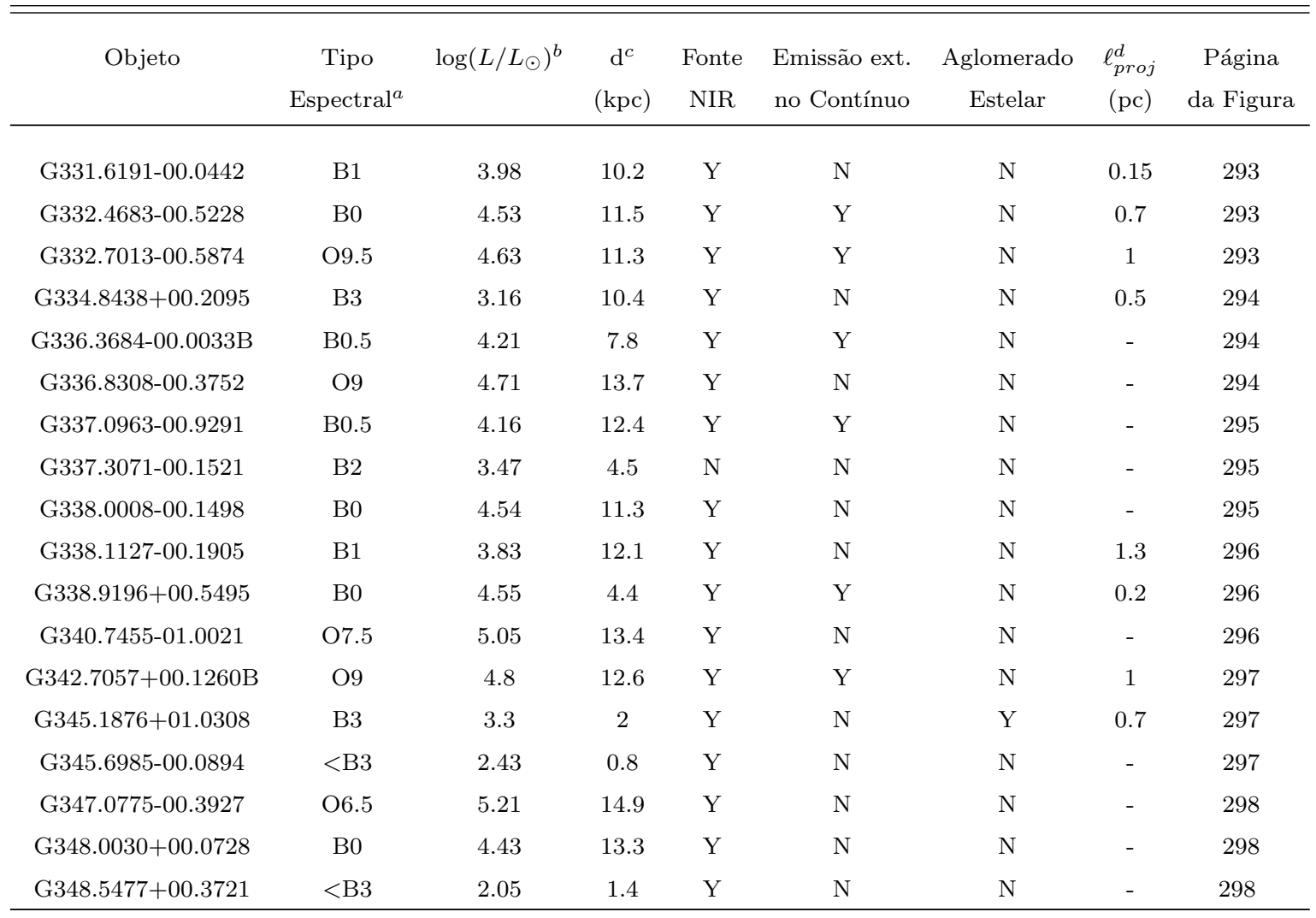

Notas: (a) tipo espectral determinado a partir das relações estabelecidas por Martins et al. (2005); Panagia (1973); (b) distância cinemática determinada por Urquhart et al. (2007, 2008); (c) logaritmo da luminosidade bolométria obtido a partir do fluxo bolométrico medido por Mottram et al. (2011) e as distâncias cinemáticas de Urquhart et al. (2007, 2008);

(d) dimensões projetadas das estruturas identificadas em cada campo, assumindo a distância cinemática da fonte correspondente.

\subsection{Fontes com Emissão Polar no filtro do $\mathrm{H}_{2}$}

A identificação de estruturas polares associadas a objetos jovens é uma evidência observacional do cenário de acreção via disco circunstelar, e representa um dos principais objetivos desse trabalho. Além da classificação morfológica das estruturas identificadas no filtro $\mathrm{H}_{2}$, outras propriedades foram estimadas para caracterização das emissões polares: sua razão de aspecto $(\mathrm{R}=$ comprimento/largura $)$ e as dimensões projetadas $\left(\ell_{\text {proj }}\right)$ das emissões.

A estimativa de $\ell_{\text {proj }}$ é importante para $i$ ) verificar inconsistências na determinação da distância cinemática da fonte e $i i$ ) identificar relações entre a morfologia e características intrínsecas da fonte geratriz da emissão. Um fator sen $(i)$, onde $i$ representa a inclinação entre estrutura e a linha de visada, está agregado ao valor de $\ell_{\text {proj }}$. Nesse caso, o valor de 
$\ell_{\text {proj }}$ representa um limite inferior para a dimensão real da estrutura.

Uma breve descrição das 62 fontes associadas a emissões classificadas como BP é mostrada a seguir. A relação massa-luminosidade $L \propto M^{3.5}$ (Seção 4.2) foi adotada para estimar a massa das fontes centrais. A relação entre o tipo espectral e a luminosidade foi obtida a partir dos trabalhos de Martins et al. (2005) e Panagia (1973) para as estrelas do tipo espectral O na sequência principal (classe V) e B na SPIZ (classe $\mathrm{V}_{0}$ ), respectivamente. As orientações das estruturas estão indicadas pelas seguintes direções: norte $(\mathrm{N})$, nordeste (NE), leste (E), sudeste (SE), sul (S), sudoeste (SW), oeste (W) e noroeste (NW). Por exemplo, $i$ ) uma emissão orientada na direção Norte-Sul e ii) um jato identificado na direção noroeste-sudeste são indicados por $i$ ) N-S e ii) NW-SE, respectivamente.

- G019.8817-00.5347 $\left(L=8.7 \times 10^{3}[d(k p c) / 3.5 \mathrm{kpc}]^{2} \mathrm{~L}_{\odot}, \mathrm{B} 1 \mathrm{~V}_{0}\right)$ : A fonte RMS possui luminosidade compatível com uma estrela do tipo B1 na pré-sequência principal (classe $\left.\mathrm{V}_{0}\right)$. No centro do campo, é possível identificar uma região pequena $(\sim 0.1 \mathrm{pc})$ com emissão no contínuo e uma emissão bipolar em $\mathrm{H}_{2}$ do tipo BP2 na direção E-W. A dimensão projetada $\left(\ell_{\text {proj }}\right)$ do lóbulo mais intenso (na direção $W$ ) foi estimada em $\ell_{\text {proj }}=0.9 \mathrm{pc}$ e sua razão de aspecto foi determinada em $R=4.3$. A diferença na intensidade de cada componente do jato bipolar sugere que a emissão na direção W seja correspondente ao lóbulo azul da emissão.

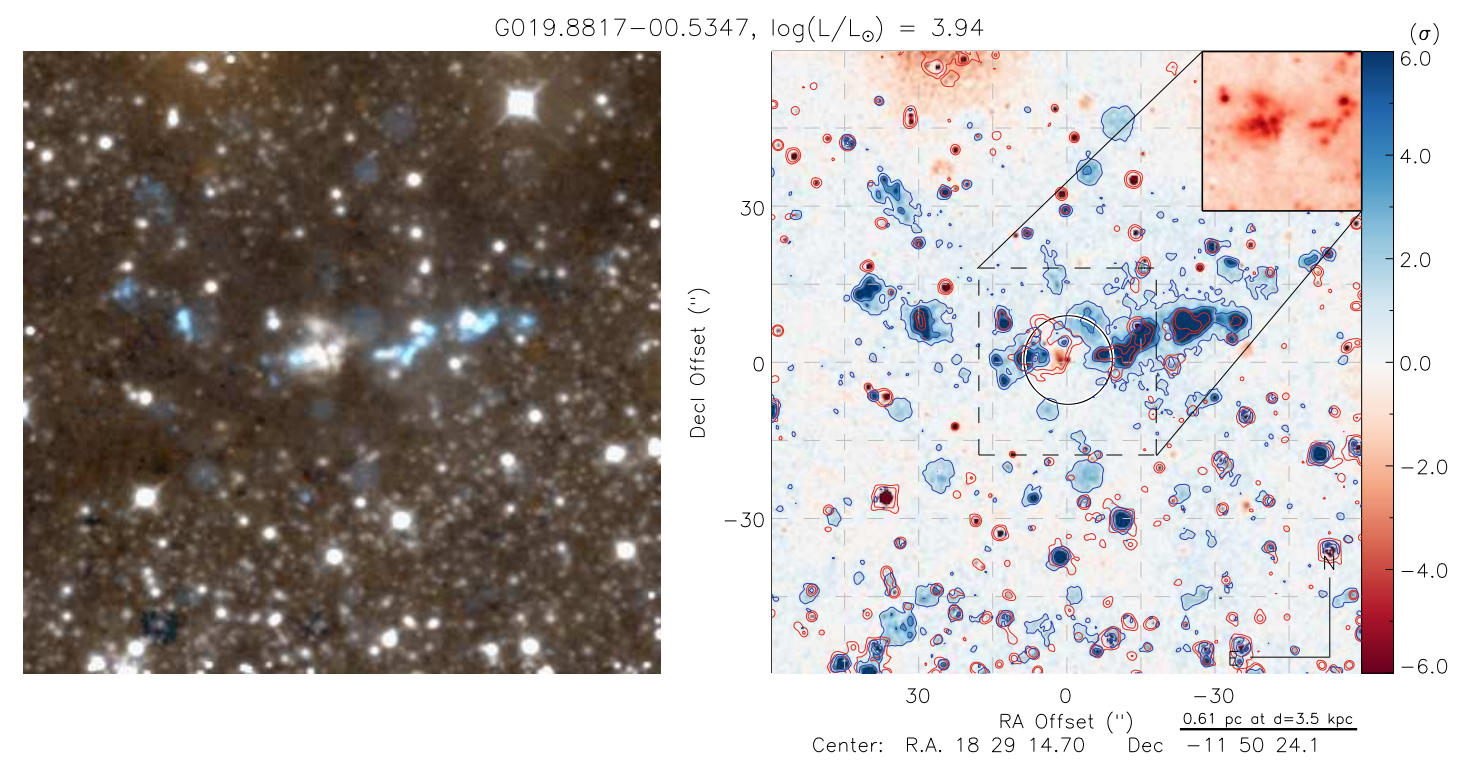


- G025.6498+01.0491 $\left(L=3.1 \times 10^{5}[d(k p c) / 12.3 \mathrm{kpc}]^{2} \mathrm{~L}_{\odot}, \mathrm{O} 5.5 \mathrm{~V}\right):$ O objeto possui luminosidade compatível com uma estrela do tipo $05.5 \mathrm{~V}$ e apresenta emissão estendida no contínuo na direção Norte-Sul (N-S), com dimensões projetadas de 0.6 pc. Alguns nós em $\mathrm{H}_{2}$ foram identificados na direção SE-NW da fonte e sugerem uma emissão com morfologia bipolar (BP2). Assumindo que a estrutura bipolar esteja ligada à fonte central, sua dimensão projetada foi estimada em $\ell_{\text {proj }}=3.3 \mathrm{pc}$, com razão de aspecto $R=5.3$.
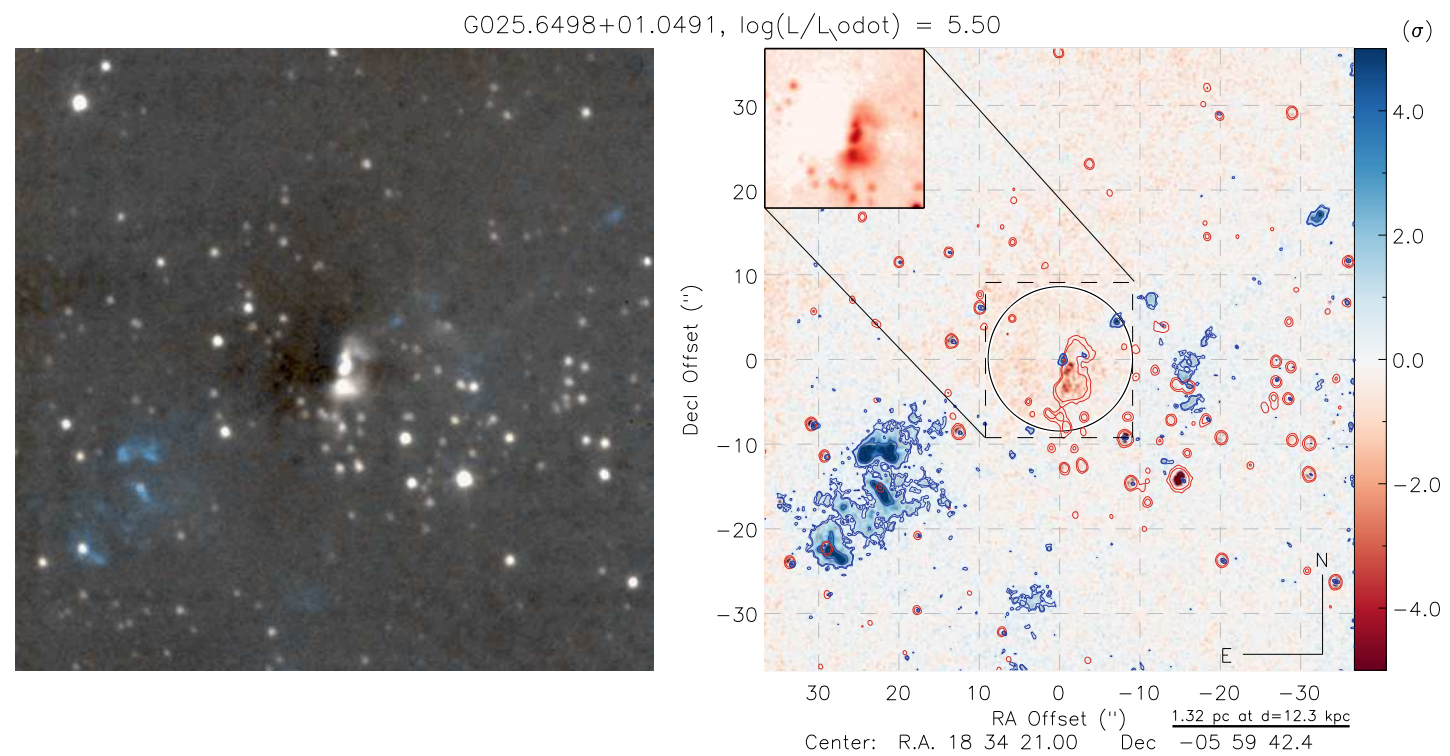

- G034.4035+00.2282 $\left(L=2.4 \times 10^{4}[d(k p c) / 10.3 \mathrm{kpc}]^{2} \mathrm{~L}_{\odot}, \mathrm{B} 0.5 \mathrm{~V}_{0}\right):$ A fonte está associada a uma região com emissão estendida presente em ambos os filtros $\left(\mathrm{H}_{2}\right.$ e contínuo) com tamanho de 0.75 pc. O mapa de emissão em $\mathrm{H}_{2}$ apresenta uma estrutura com morfologia do tipo BP2 orientada na direção N-S. A componente sul possui $\ell_{\text {proj,S }}=3.0$ pc e sua razão de aspecto foi estimada em $R_{S}=8.5$ enquanto a componente $\mathrm{N}$ tem $\ell_{\text {proj,N }}=2.2 \mathrm{pc}$ e $R_{N}=5.0$. 

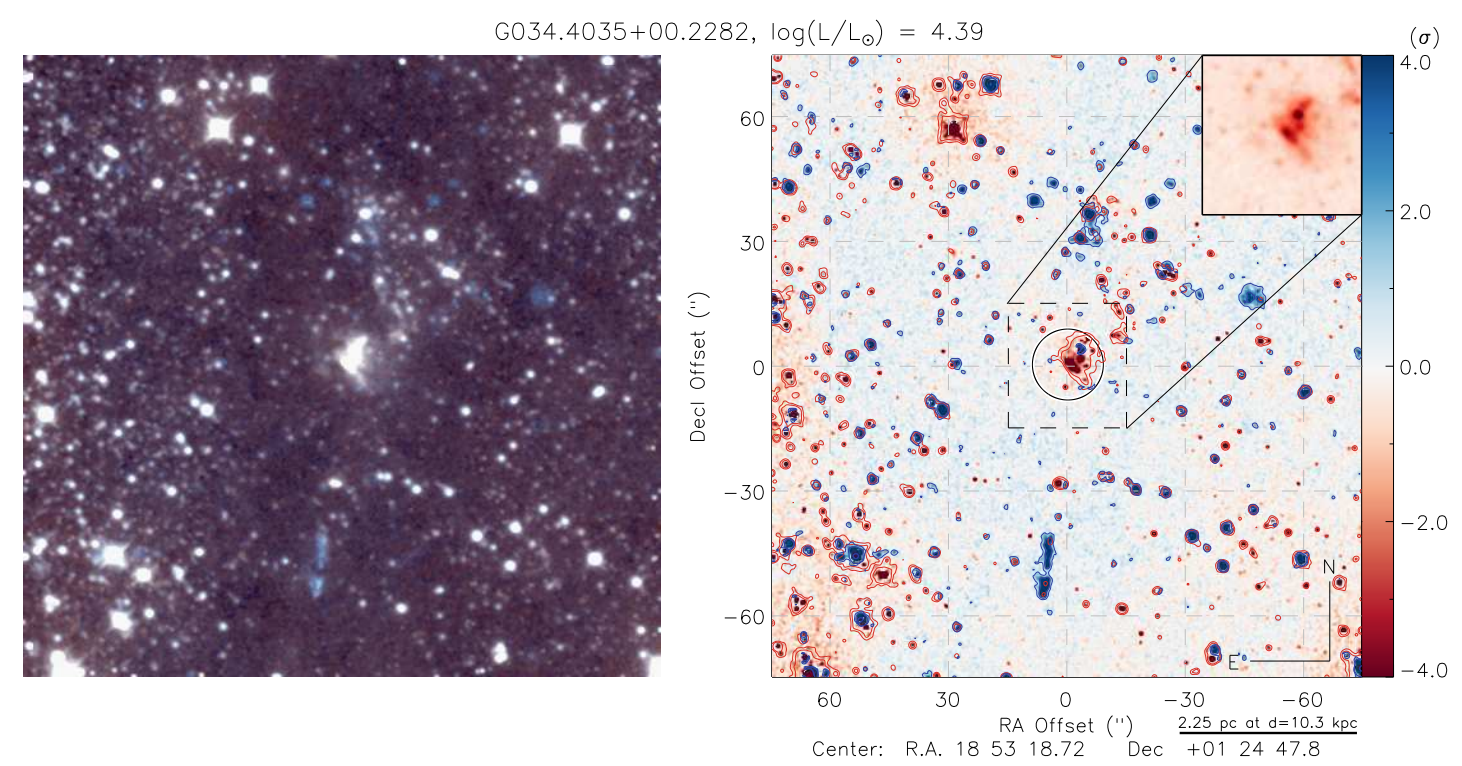

- G035.3449+00.3474 $\left(L=9.0 \times 10^{3}[d(k p c) / 6.8 \mathrm{kpc}]^{2} \mathrm{~L}_{\odot}, \mathrm{B} 1 \mathrm{~V}_{0}\right):$ A fonte apresenta emissão em $\mathrm{H}_{2}$ com morfologia do tipo BP2, orientada na direção NE-SW. A comparação entre a intensidade dos lóbulos sugere que a emissão NE, com $R=4.5$ e dimensão projetada estimada em $\ell_{\text {proj }}=0.38$ pc, corresponda ao lado azul da emissão bipolar.

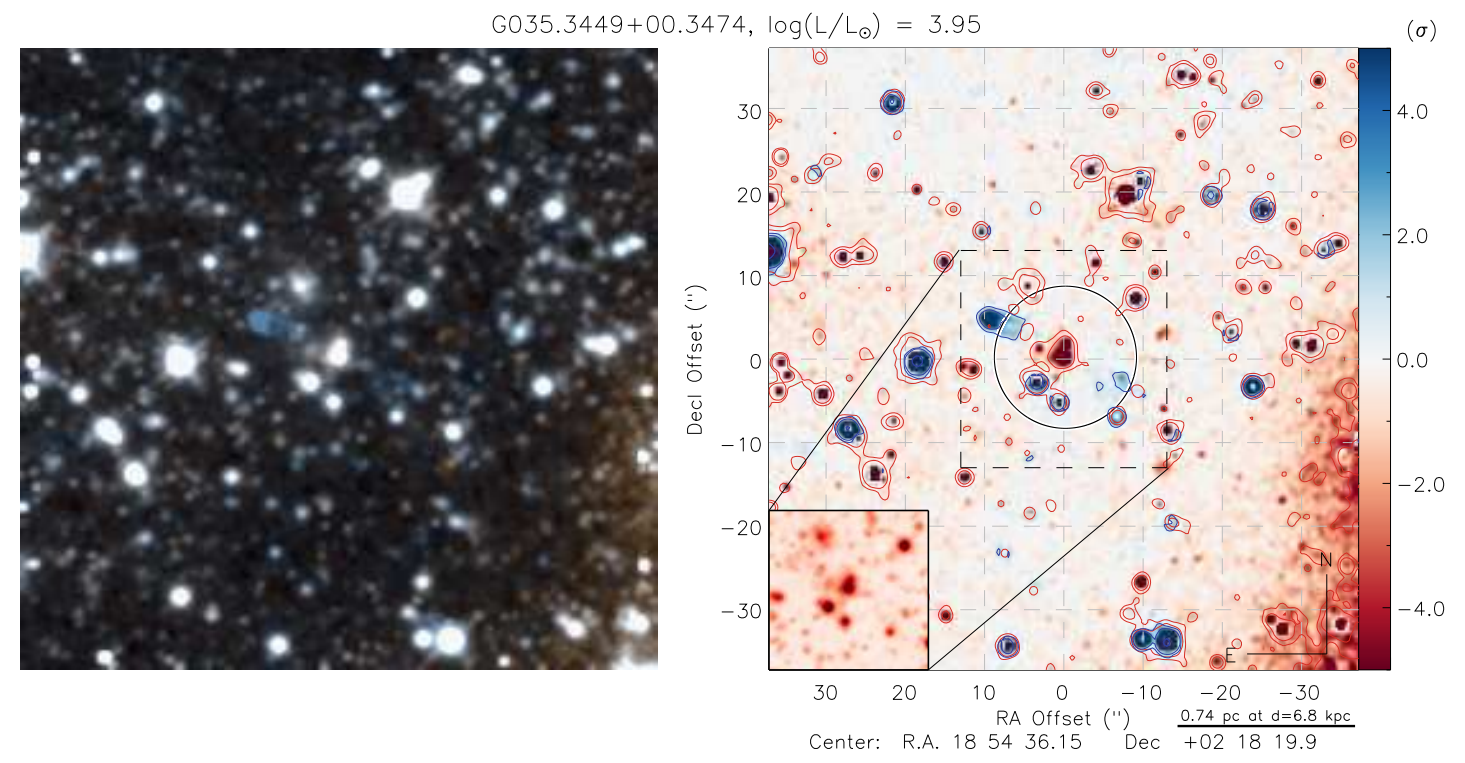

- G078.7641+01.6862 $\left(L=5.8 \times 10^{4}[d(k p c) / 12.4 \mathrm{kpc}]^{2} \mathrm{~L}_{\odot}, \mathrm{B} 1 \mathrm{~V}_{0}\right):$ A fonte está localizada a 90" na direção SW de uma região com emissão extensa no filtro $\mathrm{H}_{2}$ do tipo 
difusa, provavelmente formada a partir da radiação UV emitida pela fonte mais brilhante do campo. A fonte RMS apresenta emissão estendida no contínuo, com dimensões estimadas em 0.5 pc e é alongada na direção NE-SW. Foi possível identificar um excesso de emissão em $\mathrm{H}_{2}$ com morfologia monopolar (BP1) na direção NE. A emissão possui $\ell_{\text {proj }}=0.3$ pc e sua razão de aspecto foi estimada em $R=1.9$.

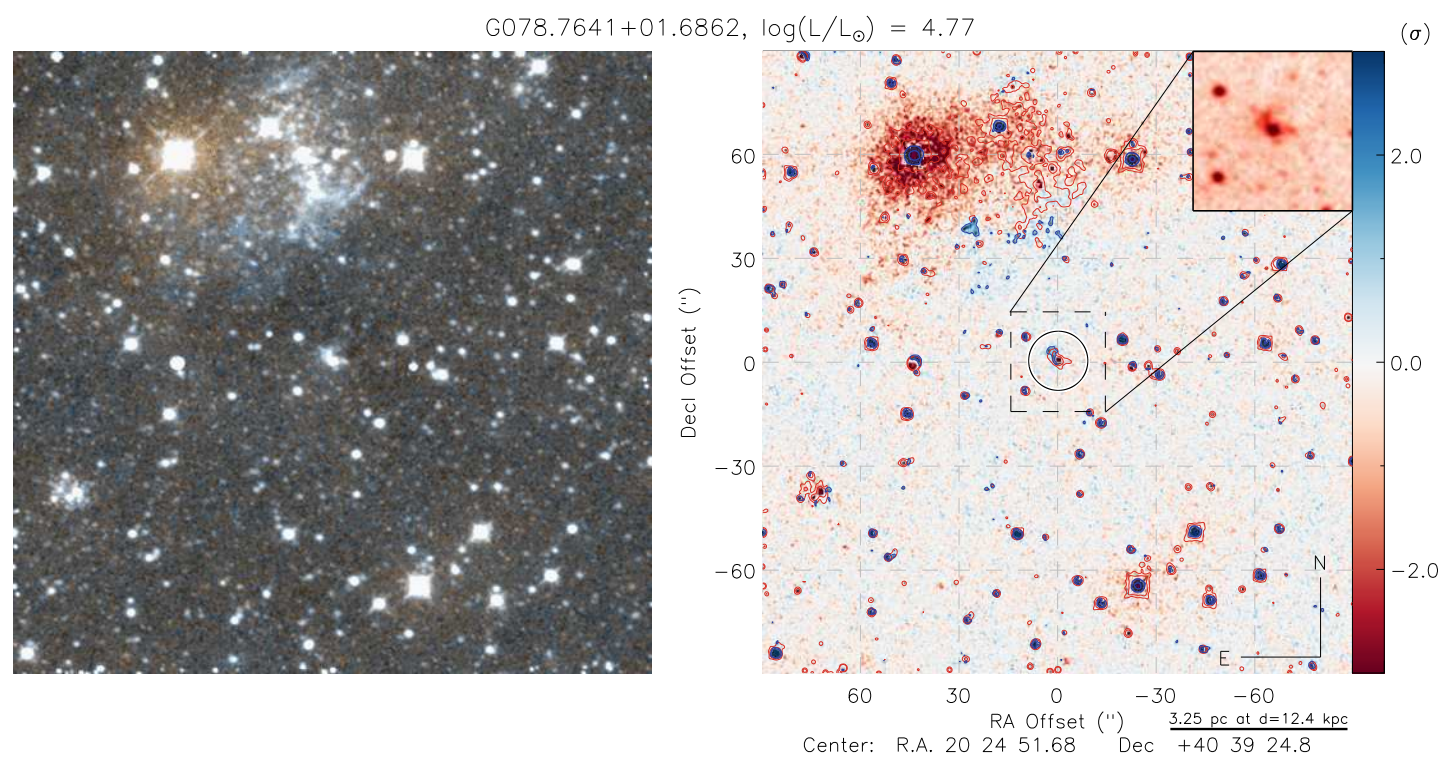

- G078.8867+00.7087 $\left(L=3.6 \times 10^{5}[d(k p c) / 4.7 \mathrm{kpc}]^{2} \mathrm{~L}_{\odot}, \mathrm{O} 5 \mathrm{~V}\right):$ A fonte RMS possui luminosidade compatível com uma estrela do tipo O5 na sequência principal e está localizada numa região com emissão estendida no contínuo que se estende da região central do campo até $\approx 30^{\prime \prime}$ na direção W. Uma emissão do tipo BP2 foi identificada a partir do mapa de emissão em $\mathrm{H}_{2}$ e o lóbulo mais intenso, na direção E, apresenta $\ell_{\text {proj }}=0.95$ pc e razão de aspecto $R \approx 2.0$. 
$\mathrm{G} 078.8867+00.7087, \log \left(L / L_{\odot}\right)=5.56$
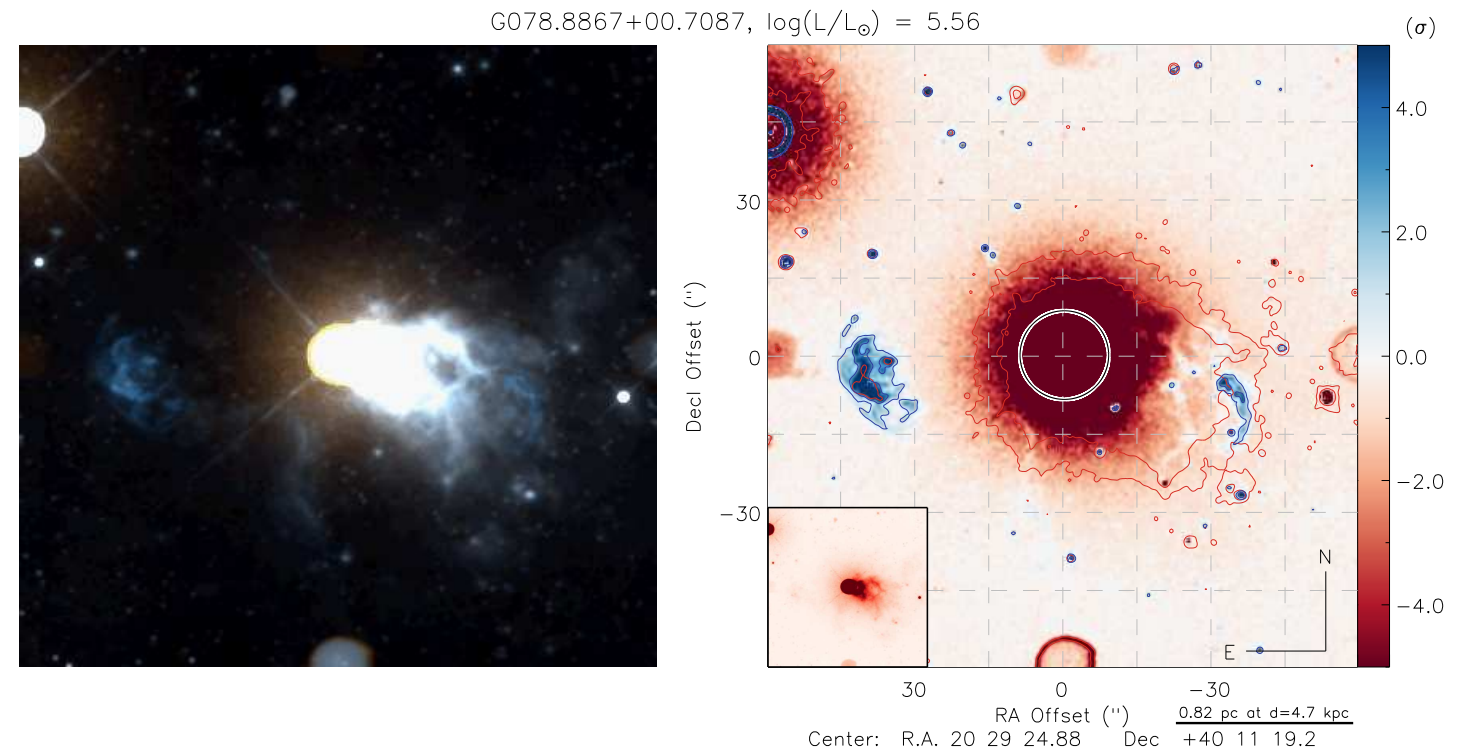

- G079.1272+02.2782 $\left(L=1.6 \times 10^{4}[d(k p c) / 4.1 \mathrm{kpc}]^{2} \mathrm{~L}_{\odot}, \mathrm{B} 0.5 \mathrm{~V}_{0}\right):$ O objeto central está associado a uma região alongada na direção N-S, que emite em ambos os filtros do contínuo e do $\mathrm{H}_{2}$, com morfologia do tipo BP2. O lado mais intenso da emissão em $\mathrm{H}_{2}$ está localizada na direção $\mathrm{S}$, possui $\ell_{\text {proj }}=0.3$ pc e $R=1.4$.

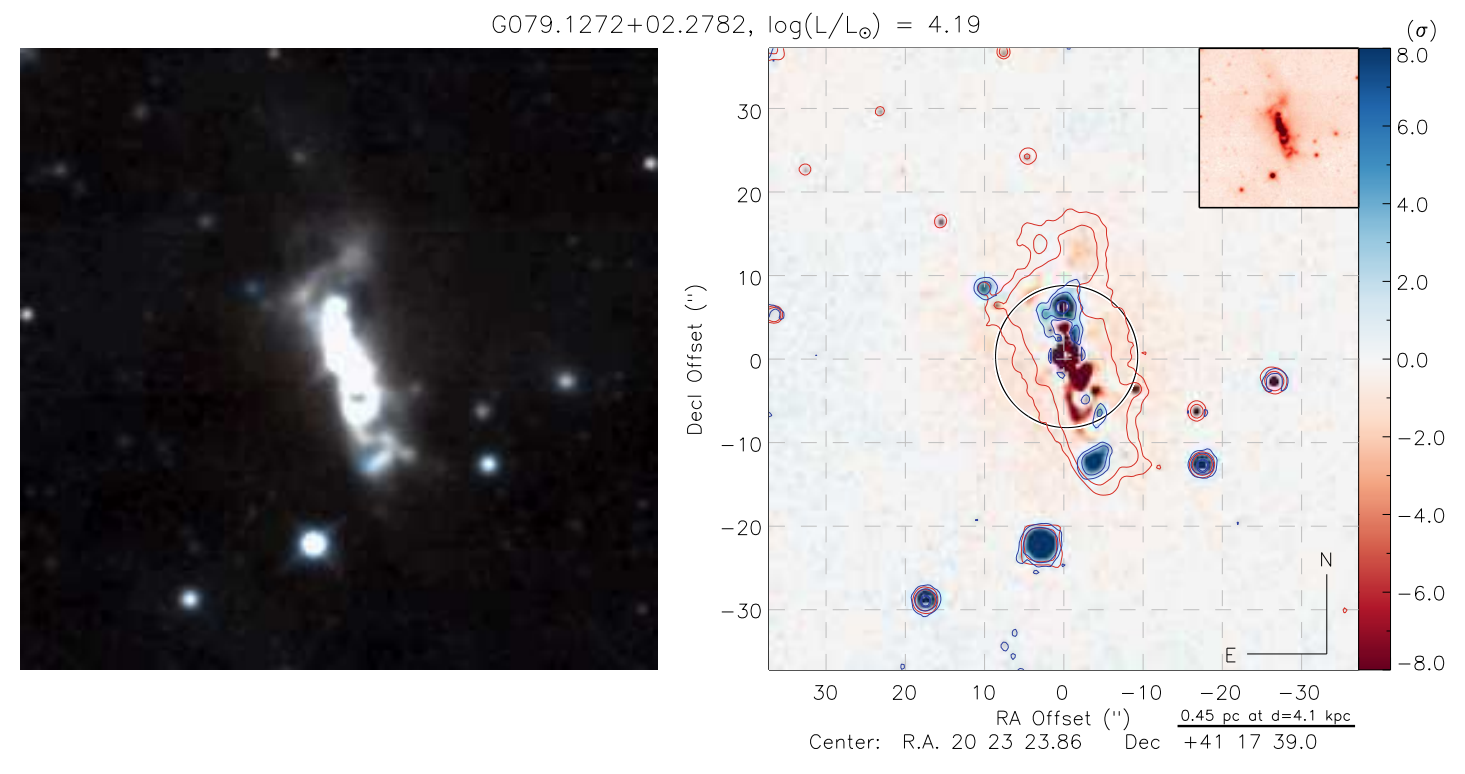

- G081.7624+00.5916 $\left(L=5.5 \times 10^{3}[d(k p c) / 3.9 \mathrm{kpc}]^{2} \mathrm{~L}_{\odot}, \mathrm{B} 1 \mathrm{~V}_{0}\right):$ A fonte RMS está associada a uma emissão do tipo bipolar (BP2) na direção N-S. A estrutura localizada ao 
$\mathrm{N}$ da fonte central apresenta razão de aspecto $R=1.8$ e possui $\ell_{\text {proj }}=0.8$ pc.
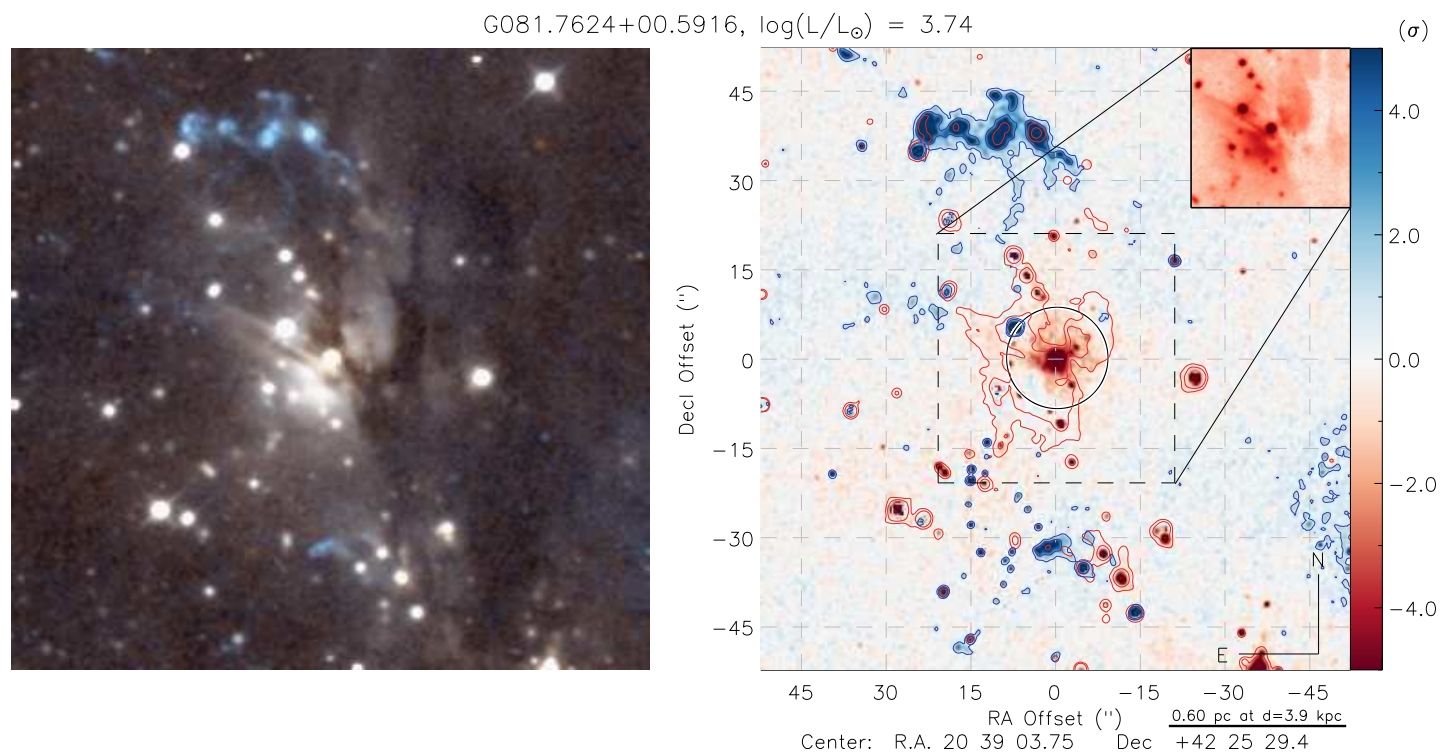

- G081.8652+00.7800 $\left(L=2.6 \times 10^{3}[d(k p c) / 1.2 \mathrm{kpc}]^{2} \mathrm{~L}_{\odot}, \mathrm{B} 3 \mathrm{~V}_{0}\right):$ A fonte RMS está associada a uma região com emissão estendida no contínuo que se estende preferencialmente na direção NE do objeto central e possui dimensões estimadas em $\approx 0.5 \mathrm{pc}$. O mapa de emissão em $\mathrm{H}_{2}$ apresenta um jato bipolar BP2 na direção NE-SW. O lóbulo mais intenso, orientado na direção SW do objeto central, possui $\ell_{\text {proj }}=1.25$ pc e apresenta razão de aspecto estimada em $R=5.0$.

$6081.8652+00.7800, \log \left(L / L_{\odot}\right)=3.41$
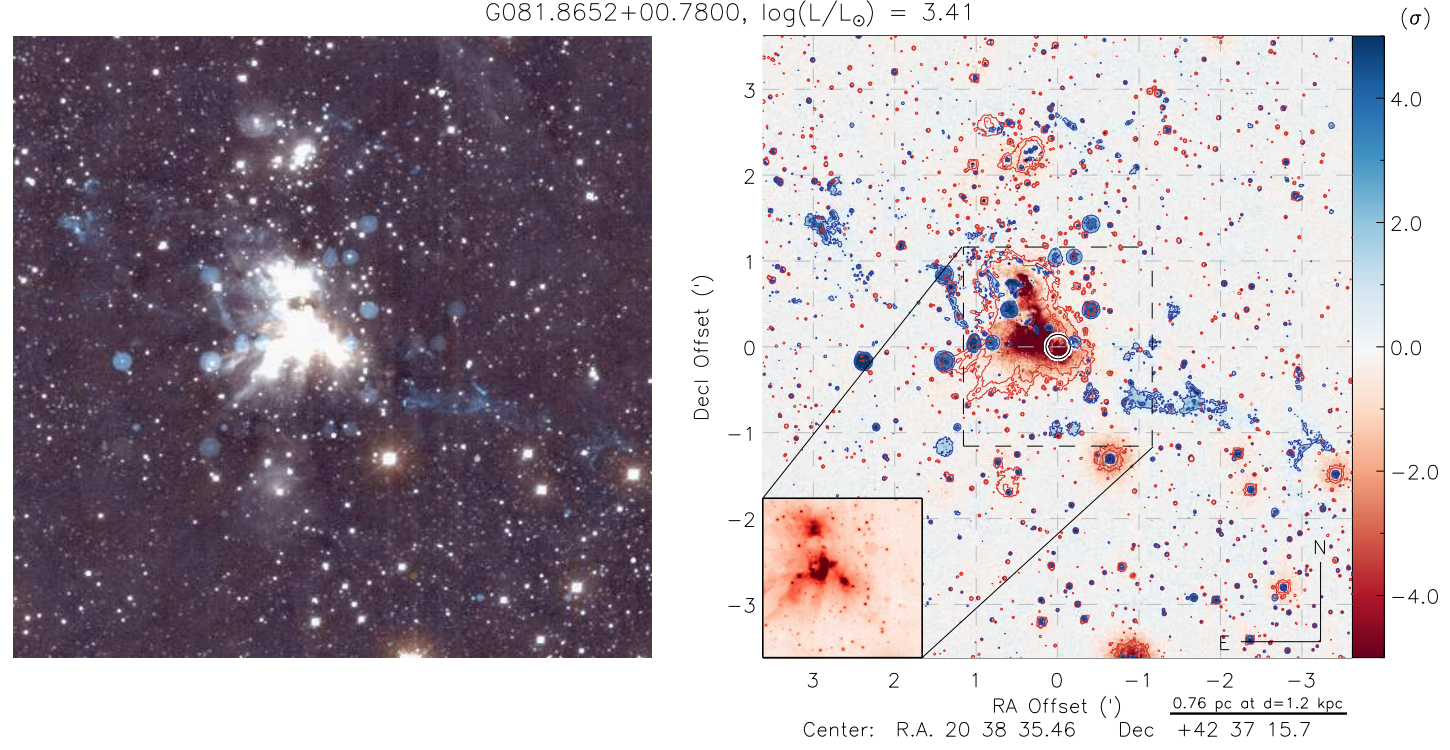
- G093.1610+01.8687 $\left(L=1.5 \times 10^{4}[d(k p c) / 8.4 \mathrm{kpc}]^{2} \mathrm{~L}_{\odot}, \quad\right.$ B0.5 $\left.\mathrm{V}_{0}\right):$ A fonte está localizada na borda de aglomerado estelar e sua luminosidade é equivalente a uma estrela do tipo B0.5 $\mathrm{V}_{0}$. Alguns nós de emissão em $\mathrm{H}_{2}$ foram identificados na direção NE-SW e sugerem uma emissão bipolar do tipo BP2, com extensão de 1.3 pc. O lóbulo mais intenso da emissão bipolar está localizado na direção NE e possui $\ell_{\text {proj }}=0.85$ pc. A razão de aspecto da componente na direção NE foi estimada em $R=2.5$.

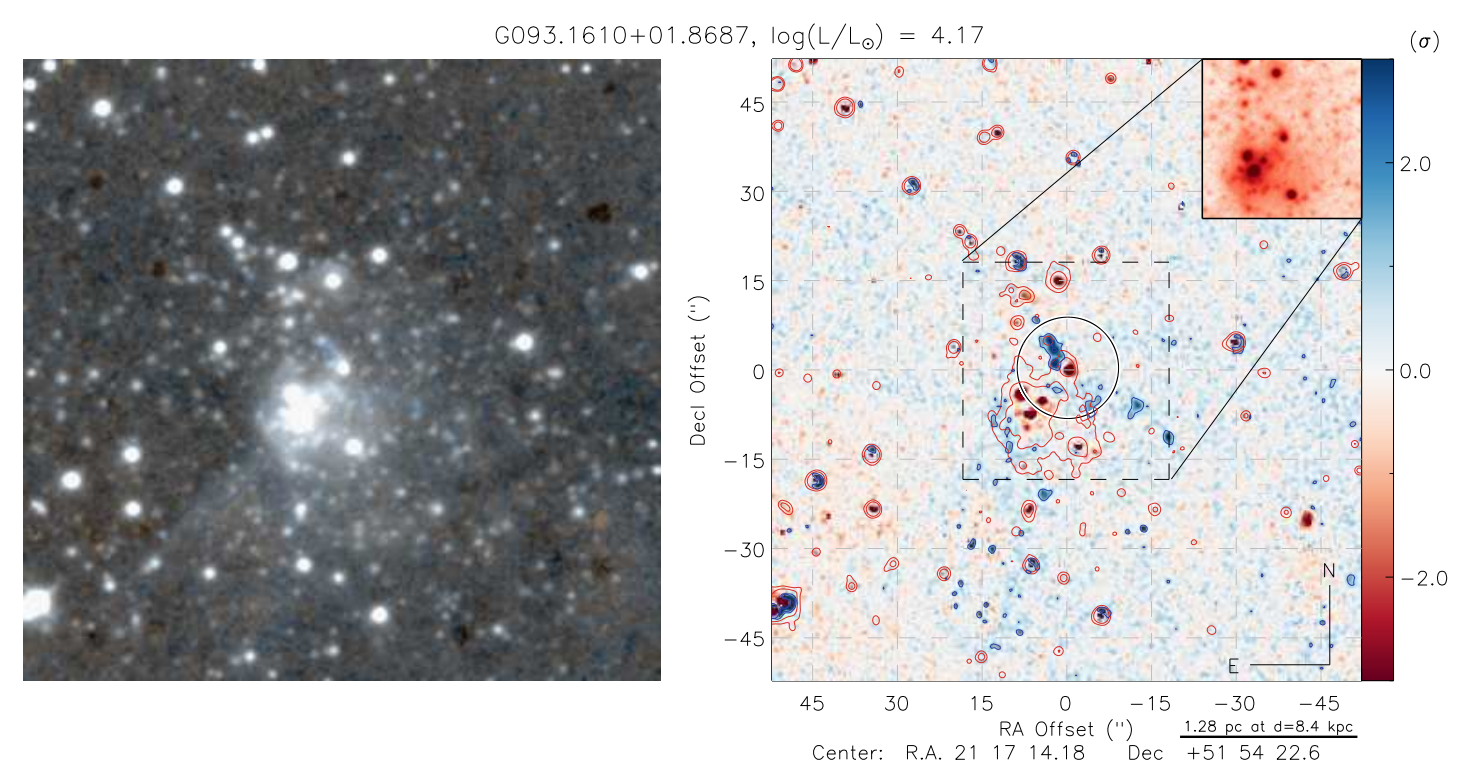

G094.3228-00.1671 $\left(L=9.0 \times 10^{3}[d(k p c) / 5.6 \mathrm{kpc}]^{2} \mathrm{~L}_{\odot}, \mathrm{B} 1 \mathrm{~V}_{0}\right):$ As coordenadas da fonte RMS é compatível com a posição do membro dominante de um aglomerado estelar. O mapa de emissão em $\mathrm{H}_{2}$ apresenta morfologia do tipo BP4 e os 4 nós identificados na imagem parecem traçar a região terminal de jatos multipolares, originados por estrelas pertencentes ao aglomerado. Os nós na direção N-S definem uma dimensão projetada de $\ell_{\text {proj,N-S }} \approx 1.9 \mathrm{pc}$ (cada componente apresenta $\ell_{\text {proj }} \approx 0.95 \mathrm{pc}$ ) enquanto os nós na direção NW-SE possuem $\ell_{p r o j, N W-S E}=1.5$ pc. A razão de aspecto média das estruturas foi estimada em $R \approx 12.0$. 

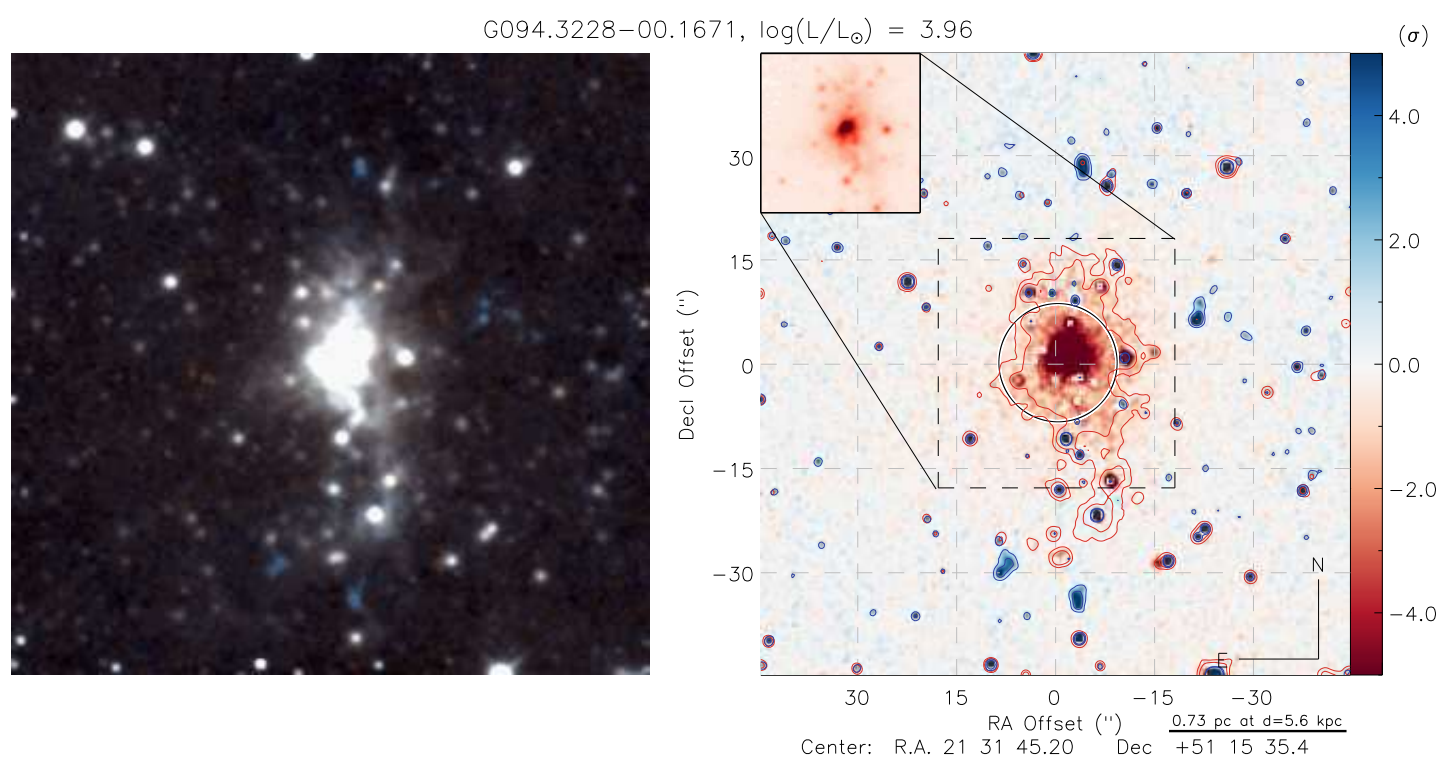

- G094.4637-00.8043 $\left(L=3.2 \times 10^{4}[d(k p c) / 6.2 \mathrm{kpc}]^{2} \mathrm{~L}_{\odot}, \mathrm{B} 0 \mathrm{~V}_{0}\right)$ : Essa fonte possui luminosidade bolométrica equivalente a uma estrela do tipo $\mathrm{B} 0 \mathrm{~V}_{0}$ e apresenta uma das estruturas multipolares mais interessantes da amostra. $\mathrm{O}$ mapa de emissão em $\mathrm{H}_{2}$ mostra uma estrutura com morfologia do tipo BP5 e sugere a presença de três emissões bipolares associadas à fonte RMS. A emissão bipolar mais fraca e mais externa (A) possui extensão total de $\ell_{\text {proj,A }}=5.5$ pc e está orientada na direção N-S. A segunda e mais intensa estrutura (B) está orientada na direção NE-SW e possui $\ell_{p r o j, B}=3.0$ pc. A emissão mais próxima da fonte $(\mathrm{C})$, identificada na direção NW-SE, mostra apenas o lado azul do jato. Nesse último caso, o lado vermelho da emissão deve estar obscurecido pela região nebular nas proximidades da fonte central. A extensão do jato bipolar mais interno foi estimada em $\ell_{\text {proj,C}} \approx 1.7$ pc. A razão de aspecto das três estruturas bipolares são $R_{A}=2.5, R_{B}=4.3 \mathrm{e}$ $R_{C}=3.3$. A presença de multicomponentes sugere que $i$ ) a fonte RMS seja composta por dois ou mais objetos em formação e/ou ii) existe um considerável movimento de precessão associado à(s) fonte(s) central(is), capaz de modificar a direção de propagação dos jatos em períodos relativamente curtos. A presença de jatos bipolares bem definidos e com diferentes orientações no plano do céu sugere que o período de acreção de massa no objeto central não é contínuo. 
G094.4637-00.8043, $\log \left(L / L_{\odot}\right)=4.51$
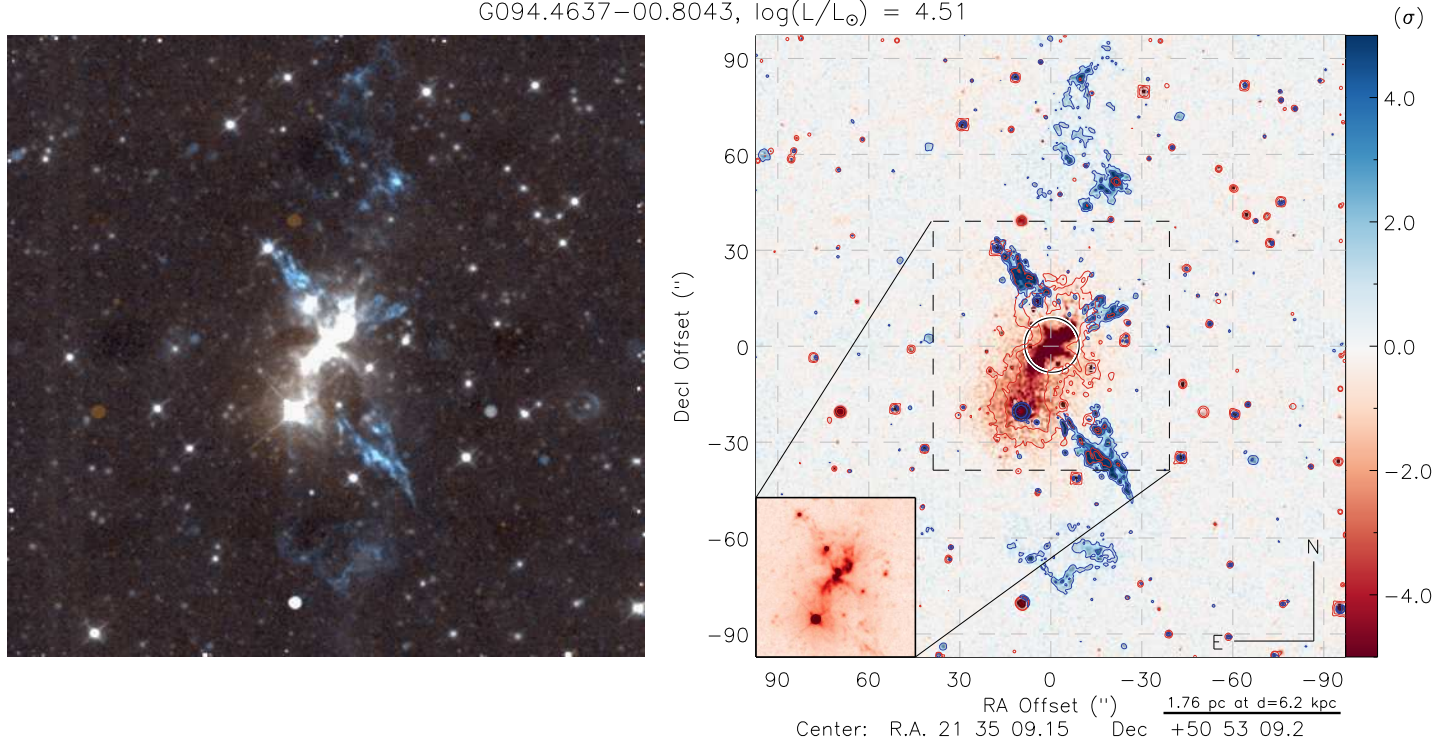

- G098.8555+02.9344 $\left(L=1.4 \times 10^{2}[d(k p c) / 0.5 \mathrm{kpc}]^{2} \mathrm{~L}_{\odot},<\mathrm{B} 3 \mathrm{~V}_{0}\right):$ O objeto central está associado a uma emissão em $\mathrm{H}_{2}$ com morfologia do tipo BP2. A emissão possui dimensão projetada estimada em $\ell_{\text {proj }} \approx 0.2$ pc e está orientada na direção NE-SW. A estrutura observada parece ser originada por diferentes fontes presentes no campo e sua componente mais intensa, localizada na direção $\mathrm{NE}$, possui $\ell_{\text {proj }} \approx 0.12$ pc razâo de aspecto estimado em $R=2.3$.

G098.8555+02.9344, $\log \left(L / L_{\odot}\right)=1.78$
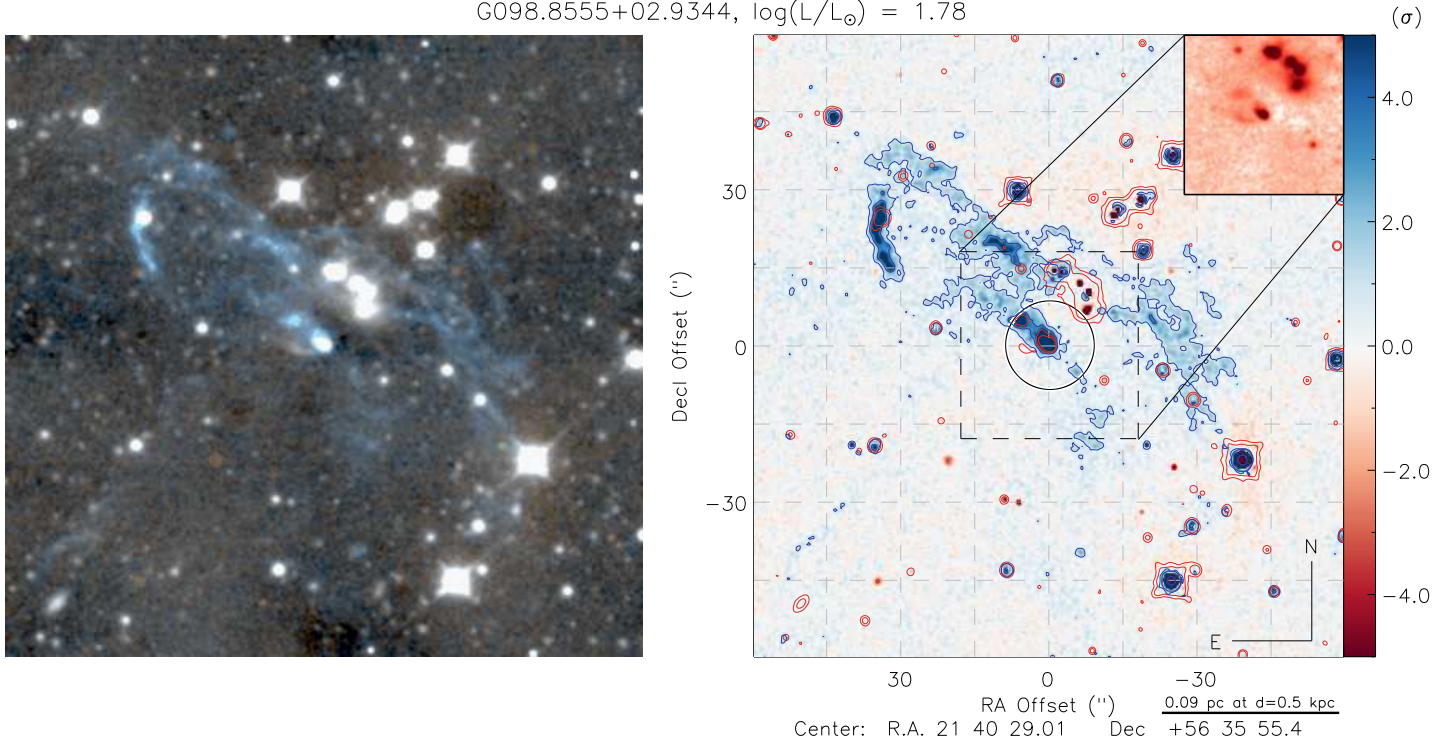
- G102.3340+03.6094 $\left(L=1.0 \times 10^{4}[d(k p c) / 10.5 \mathrm{kpc}]^{2} \mathrm{~L}_{\odot}, \mathrm{B} 1 \mathrm{~V}_{0}\right):$ O mapa de emissão em $\mathrm{H}_{2}$ apresenta uma estrutura bipolar (BP2), na direção NW-SE, associada à fonte RMS. O lóbulo mais intenso se localiza na direção SE, possui $\ell_{\text {proj }}=0.4$ pc e sua razão de aspecto foi estimada em $R \approx 1.5$.

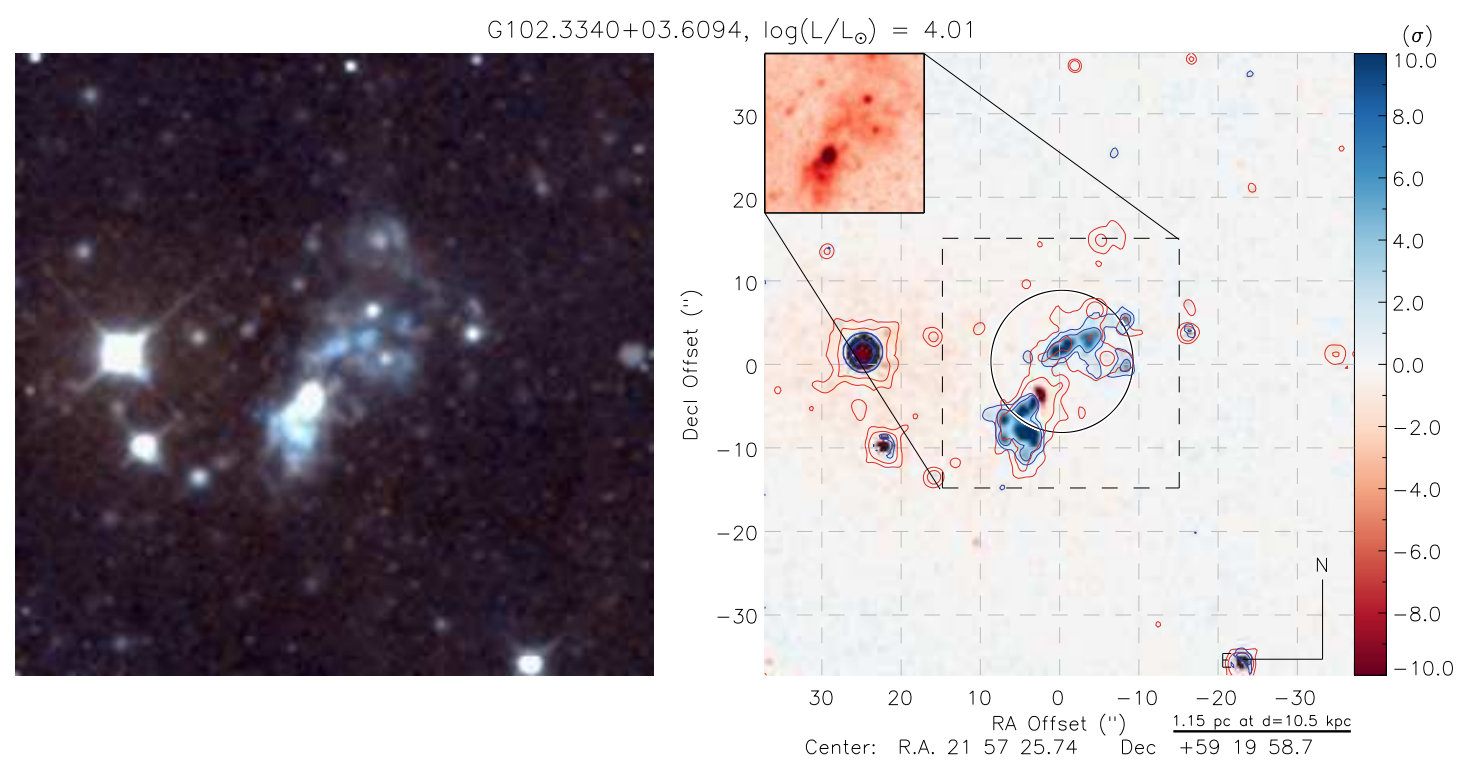

- G108.4714-02.8176 $\left(L=8.7 \times 10^{3}[d(k p c) / 5.9 \mathrm{kpc}]^{2} \mathrm{~L}_{\odot}, \mathrm{B} 1 \mathrm{~V}_{0}\right):$ A fonte está associada a uma emissão do tipo BP2, com extensão de $\ell_{\text {proj }}=0.5$ pc e orientada na direção N-S. O nó sul encontra-se mais pŕoximo da fonte central e possui razão de aspecto $R_{S}=1.75$, enquanto o nó localizado na direção $\mathrm{N}$ possui $R_{N}=2.5$. 

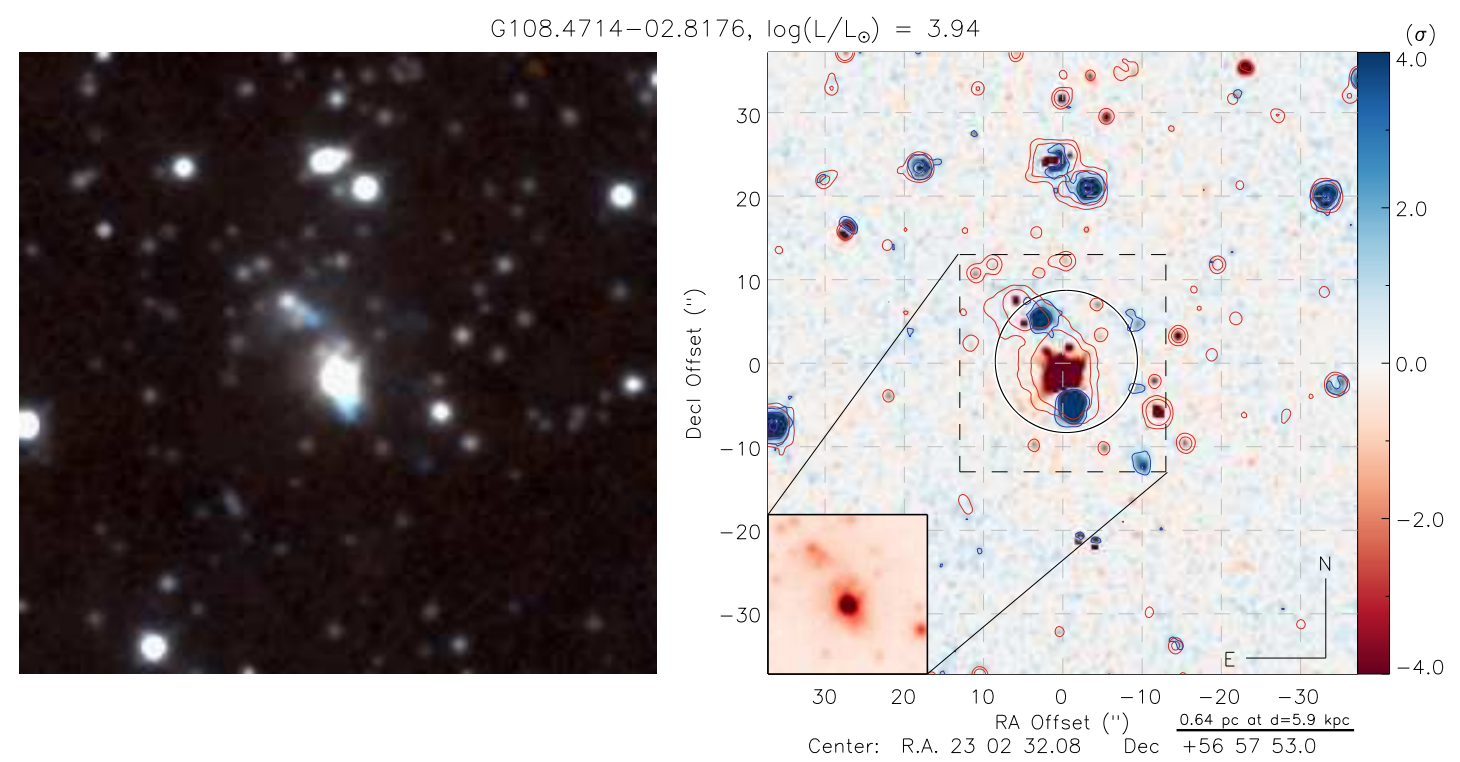

- G109.0775-00.3524 $\left(L=4.2 \times 10^{3}[d(k p c) / 5.3 \mathrm{kpc}]^{2} \mathrm{~L}_{\odot}, \mathrm{B} 2 \mathrm{~V}_{0}\right):$ O objeto central está associado a uma emissão bipolar em $\mathrm{H}_{2}$ (BP2), orientada na direção NE-SW. A dimensão projetada do lóbulo mais intenso, localizado na direção NE, foi estimada em $\ell_{\text {proj }}=0.28$ pc e apresenta razão de aspecto $R=4.0$.

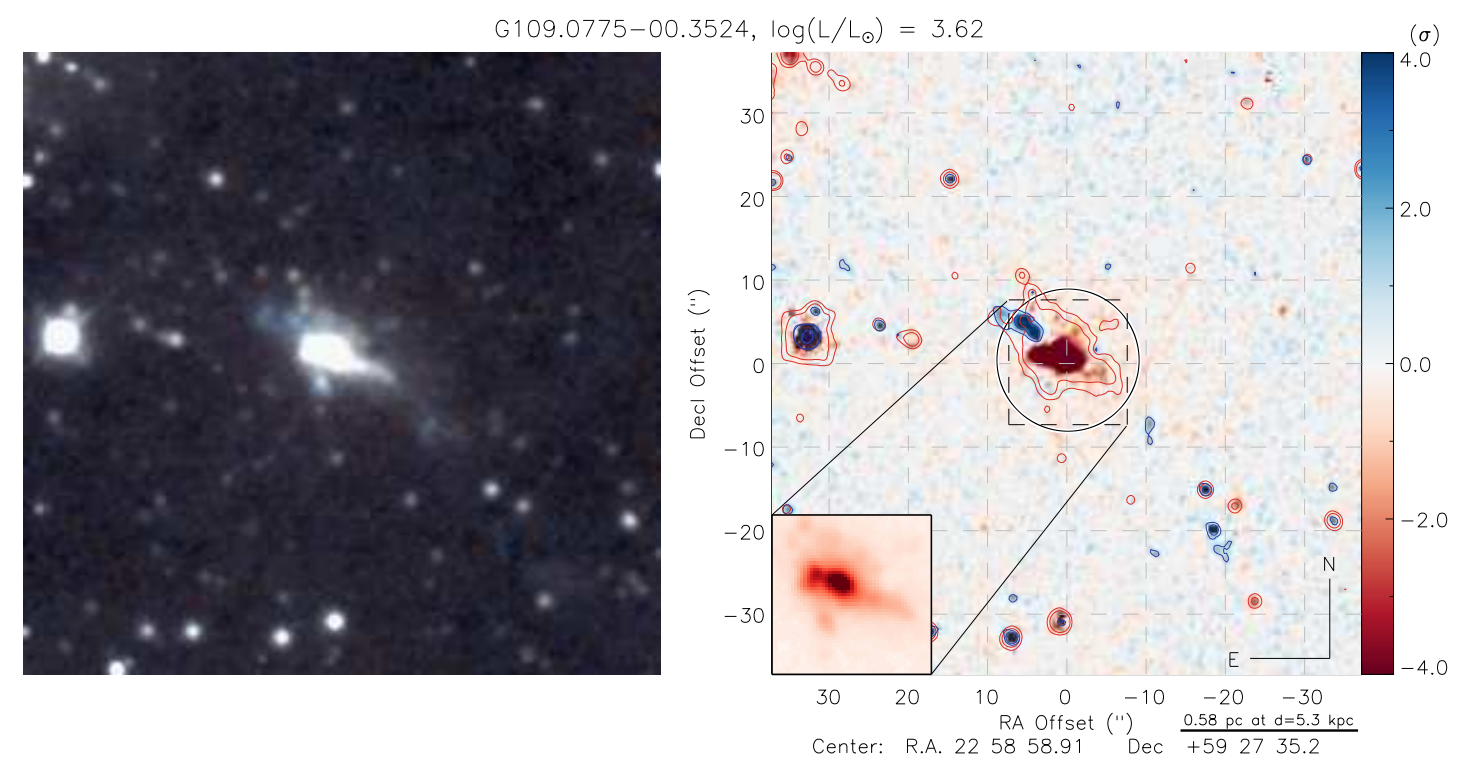

- G109.8715+02.1156 $\left(L=3.8 \times 10^{4}[d(k p c) / 1.5 \mathrm{kpc}]^{2} \mathrm{~L}_{\odot}, \mathrm{B} 0 \mathrm{~V}_{0}\right):$ A fonte RMS corresponde às coordenadas do objeto Cepheus A HW2, estudado exaustivamente por diversos 
autores (Hughes e MacLeod, 1994; Rodriguez et al., 1994; Torrelles et al., 1996, 1998). O objeto está associado a uma emissão do tipo BP2, orientada na direção E-W. A emissão possui extensão total estimada em 3.0 pc. O lóbulo localizado na direção W apresenta razão de aspecto $R=3.6$ e $\ell_{\text {proj }}=1.48$ pc. Diversas sub-estruturas são vistas no mapa de emissão em $\mathrm{H}_{2}$ e sugerem que a fonte central esteja em precessão. Uma região nebular se estende desde a região central do campo até 2.5 ' na direção NE.
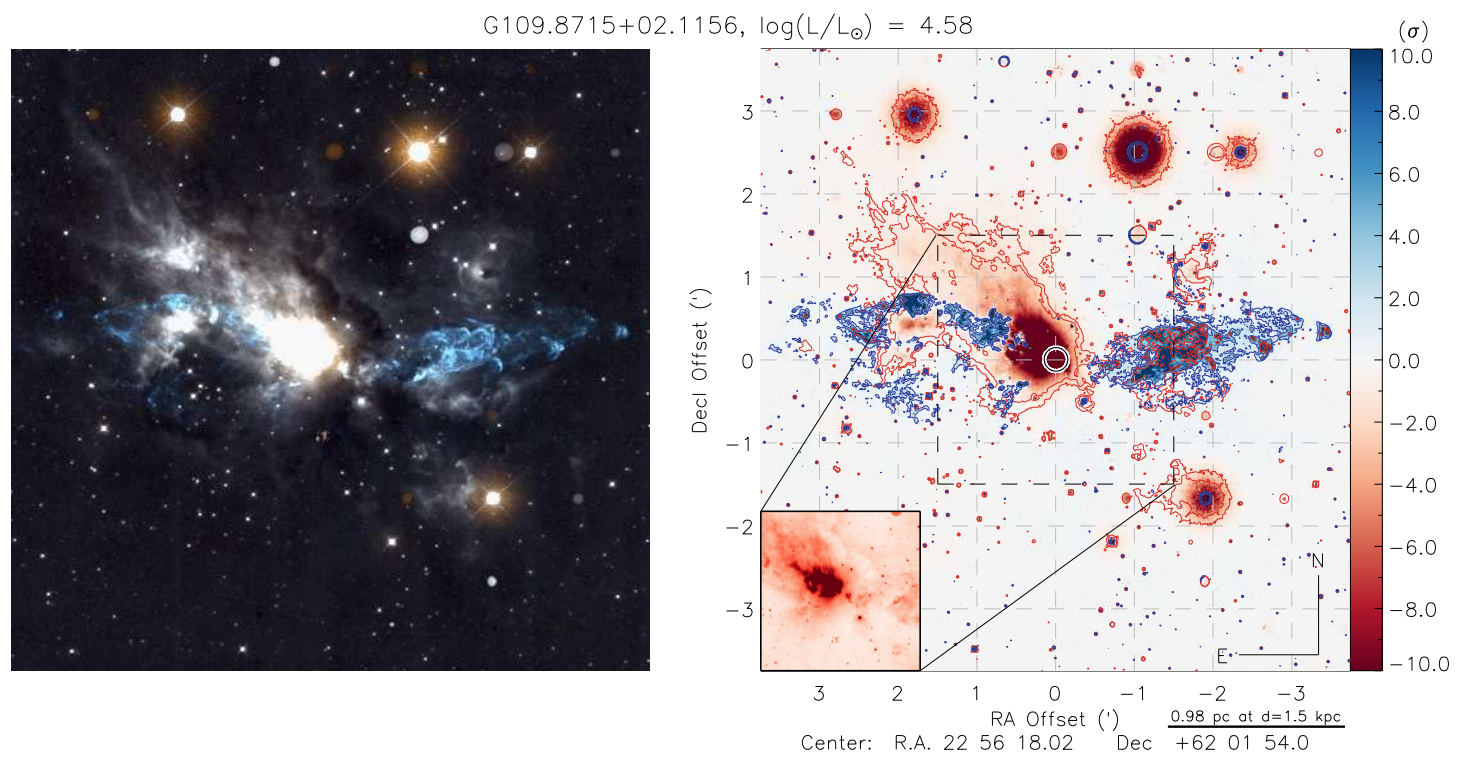

- G110.0931-00.0641 $\left(L=2.0 \times 10^{4}[d(k p c) / 5.7 \mathrm{kpc}]^{2} \mathrm{~L}_{\odot}, \mathrm{B} 0.5 \mathrm{~V}_{0}\right):$ O objeto está localizado na região central de um aglomerado de estrelas com dimensões de $\approx 0.8 \mathrm{pc}$. O mapa de emissão em $\mathrm{H}_{2}$ indica a presença de uma estrutura do tipo BP2, na direção NW-SE, com $\ell_{\text {proj }}=0.7$ pc e baixo grau de colimação $(R \approx 1.8)$. O lóbulo localizado na direção SE possui dimensão $R_{S E}=1.8$. 

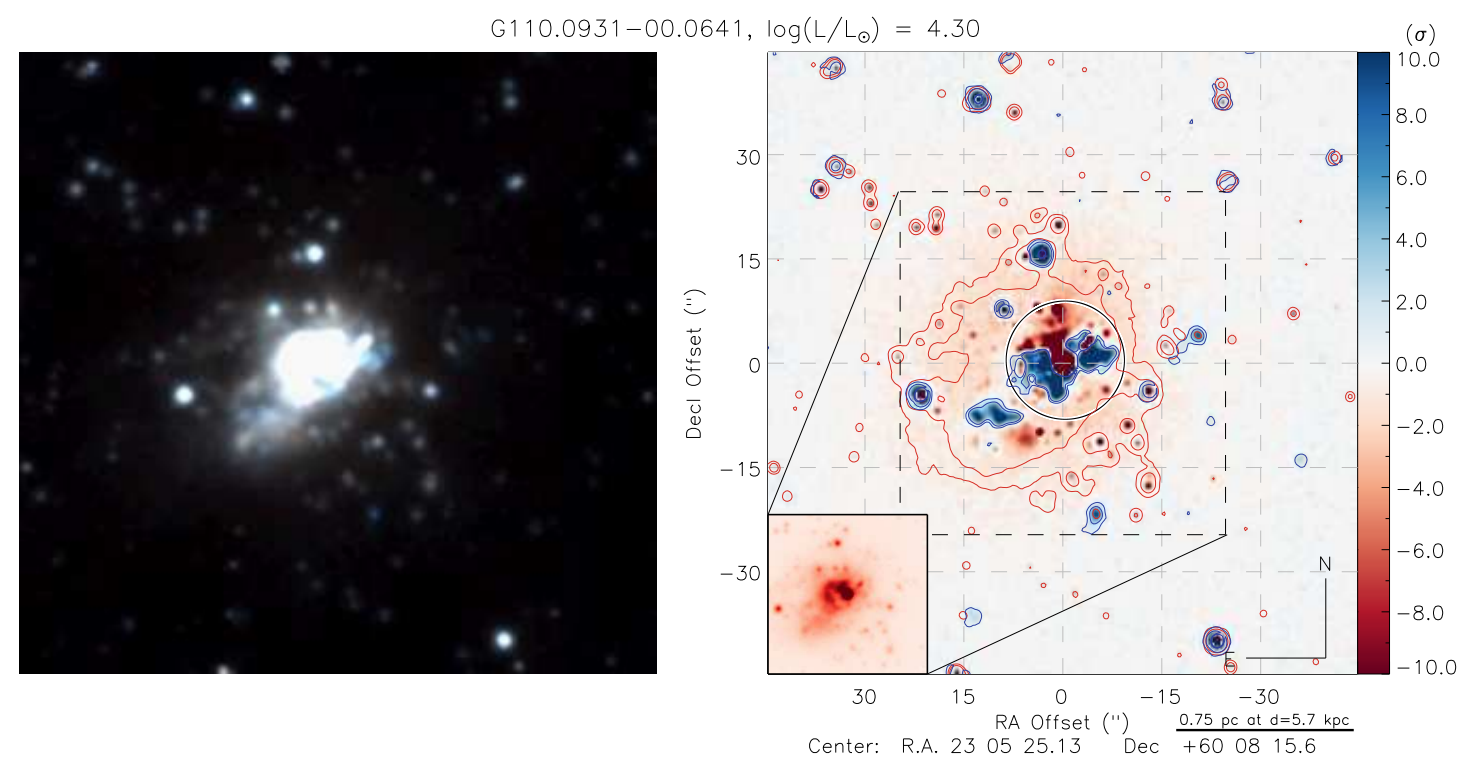

- G110.4771+01.4803 $\left(L=3.9 \times 10^{2}[d(k p c) / 1.5 \mathrm{kpc}]^{2} \mathrm{~L}_{\odot},<\right.$ B3 $\left.\mathrm{V}_{0}\right):$ Um jato bipolar bastante intenso foi identificado na direção N-S. A estrutura possui $\ell_{\text {proj }}=0.5$ pc e foi classificada como uma emissão do tipo BP2. As razões de aspecto dos lóbulos foram estimadas em $R \approx 3.4$ e suas dimensões correspondem a $\ell_{\text {proj }}=0.3 \mathrm{pc}$.

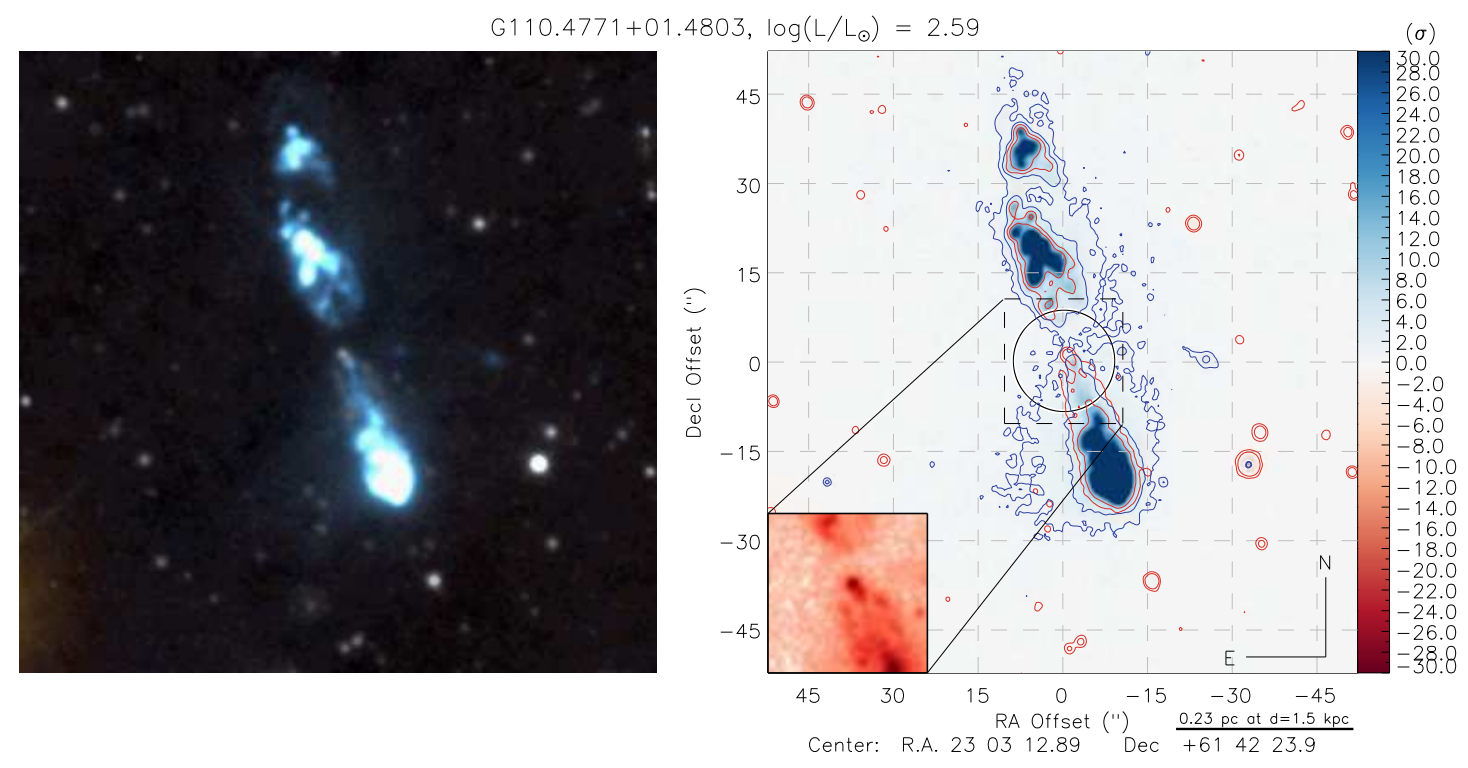

- G111.5320+00.7593 $\left(L=2.1 \times 10^{4}[d(k p c) / 6.1 \mathrm{kpc}]^{2} \mathrm{~L}_{\odot}, \mathrm{B} 0.5 \mathrm{~V}_{0}\right):$ A fonte RMS está associada a diversos nós identificados no mapa de emissão em $\mathrm{H}_{2}$. Alguns deles sugerem a 
presença de emissão colimada e podem traçar a região mais intensa de jatos. Uma estrutura de nós na direção N-S parece traçar uma emissão bipolar (BP2) a partir do objeto central. A emissão na direção $\mathrm{S}$ possui $\ell_{\text {proj }}=1.24$ pc e sua razão de aspecto foi estimada em $R=12.0$.

$G 111.5320+00.7593, \log \left(L / L_{\odot}\right)=4.33$
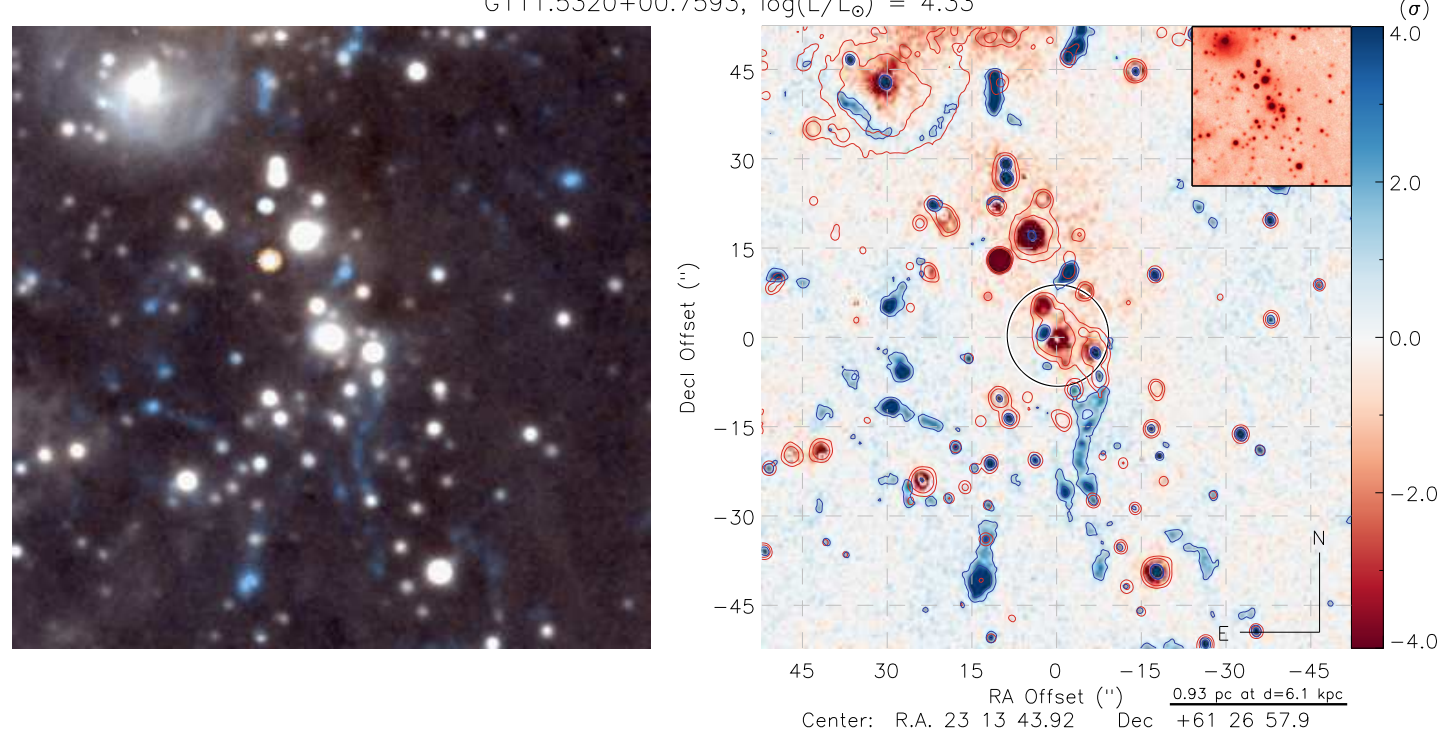

- G111.5671+00.7517 $\left(L=2.4 \times 10^{5}[d(k p c) / 6.1 \mathrm{kpc}]^{2} \mathrm{~L}_{\odot}, \mathrm{O} 6 \mathrm{~V}\right):$ O objeto central apresenta luminosidade compatível com uma estrela do tipo O6 V e está situado na região mais intensa da emissão detectada no filtro do contínuo, que se estende desde a fonte central até $\sim 1.2^{\prime}$ na direção SW. O mapa de emissão em $\mathrm{H}_{2}$ apresenta uma estrutura do tipo BP2, orientada na direção NW-SE. A emissão SE corresponde ao lóbulo mais colimado $(R=7.0)$ enquanto a emissão ao NW possui menor colimaçãp $(R 4.5)$. Ambos os lóbulos apresentam dimensões projetadas estimadas em $\ell_{\text {proj }} \approx 2.0$ pc. 


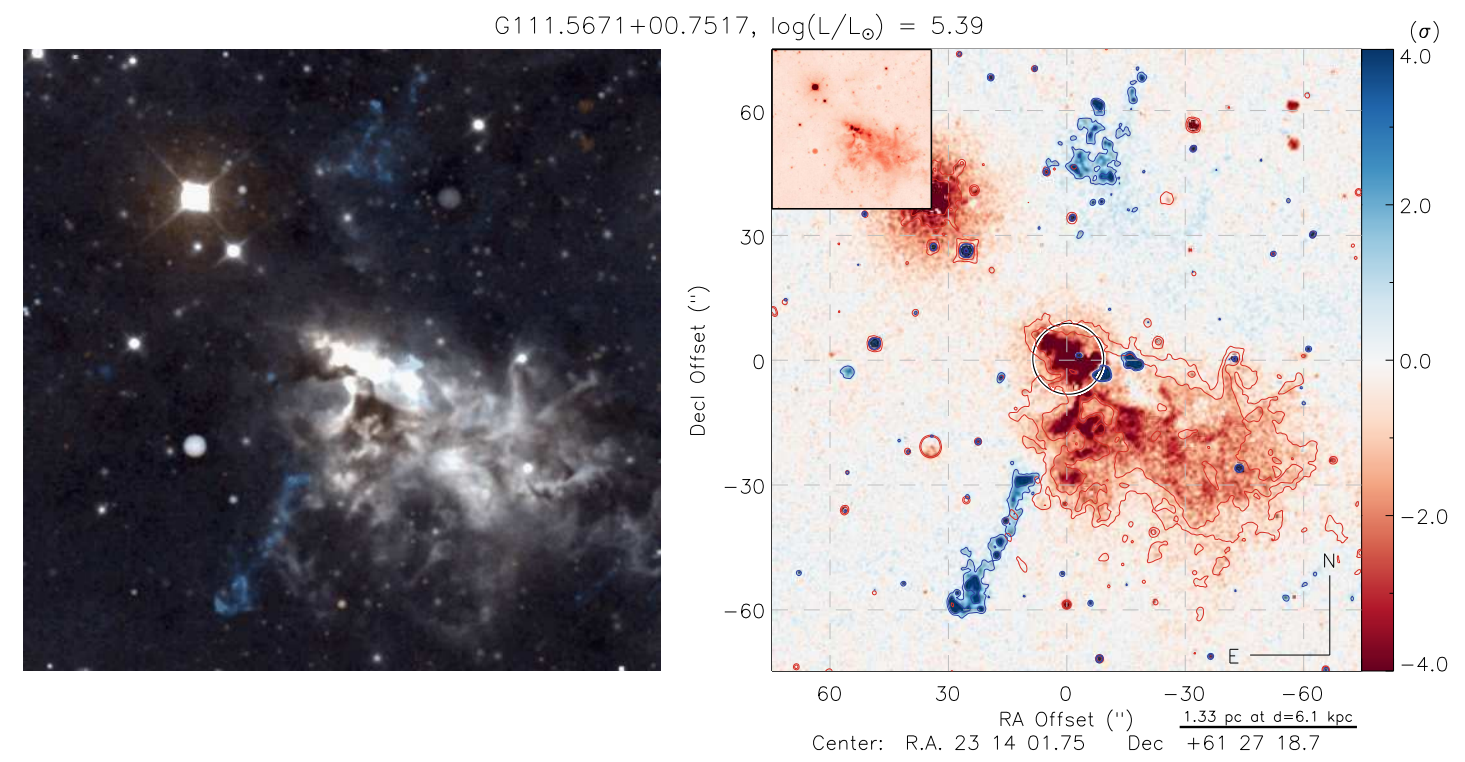

- G120.1483+03.3745 $\left(L=3.4 t i m e s 10^{4}[d(k p c) / 7.3 \mathrm{kpc}]^{2} \mathrm{~L}_{\odot}, \mathrm{B} 0 \mathrm{~V}_{0}\right)$ : a fonte RMS possui uma contrapartida no infravermelho próximo bastante intensa e, é o membro dominante do aglomerado estelar identificado a partir das observações. Uma estrutura polar (BP1) foi identificada no mapa de emissão em $\mathrm{H}_{2}$, com $\ell_{\text {proj }}=2.4$ pc e $R=4.3$.
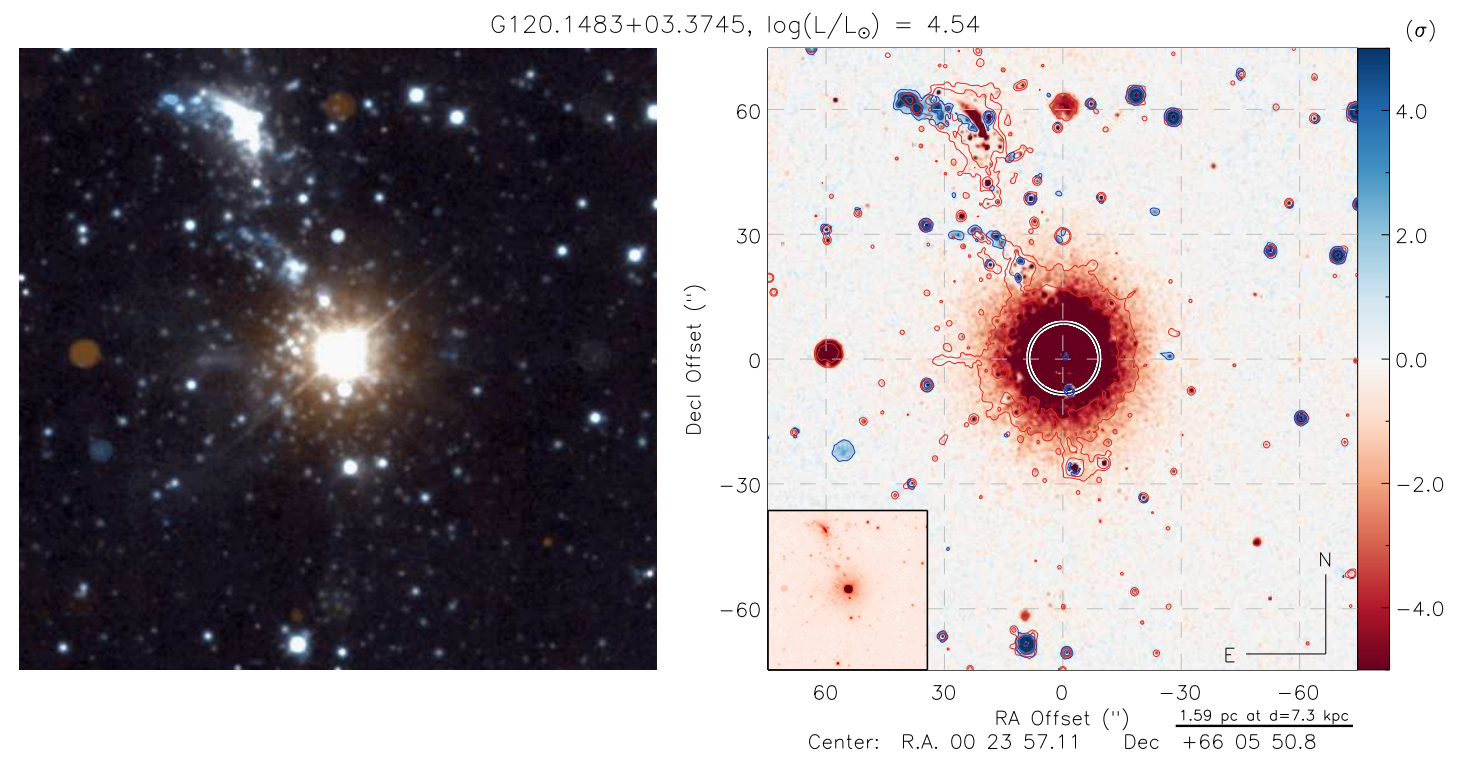

- G124.0144-00.0267 $\left(L=2.9 \times 10^{3}[d(k p c) / 4.3 \mathrm{kpc}]^{2} \mathrm{~L}_{\odot}, \mathrm{B} 2 \mathrm{~V}_{0}\right)$ : o objeto central encontra-se no interior de uma região com emissão estendida no contínuo e apresenta 
emissão bipolar no filtro do $\mathrm{H}_{2}$ (BP2), ambas orientadas na direção N-S. A emissão em $\mathrm{H}_{2}$ possui extensão total estimada em $0.9 \mathrm{pc}$, o lóbulo $\mathrm{N}$ possui razão de aspecto $R=8.0$ e sua dimensão projetada foi estimada em $\ell_{\text {proj }}=0.47 \mathrm{pc}$.
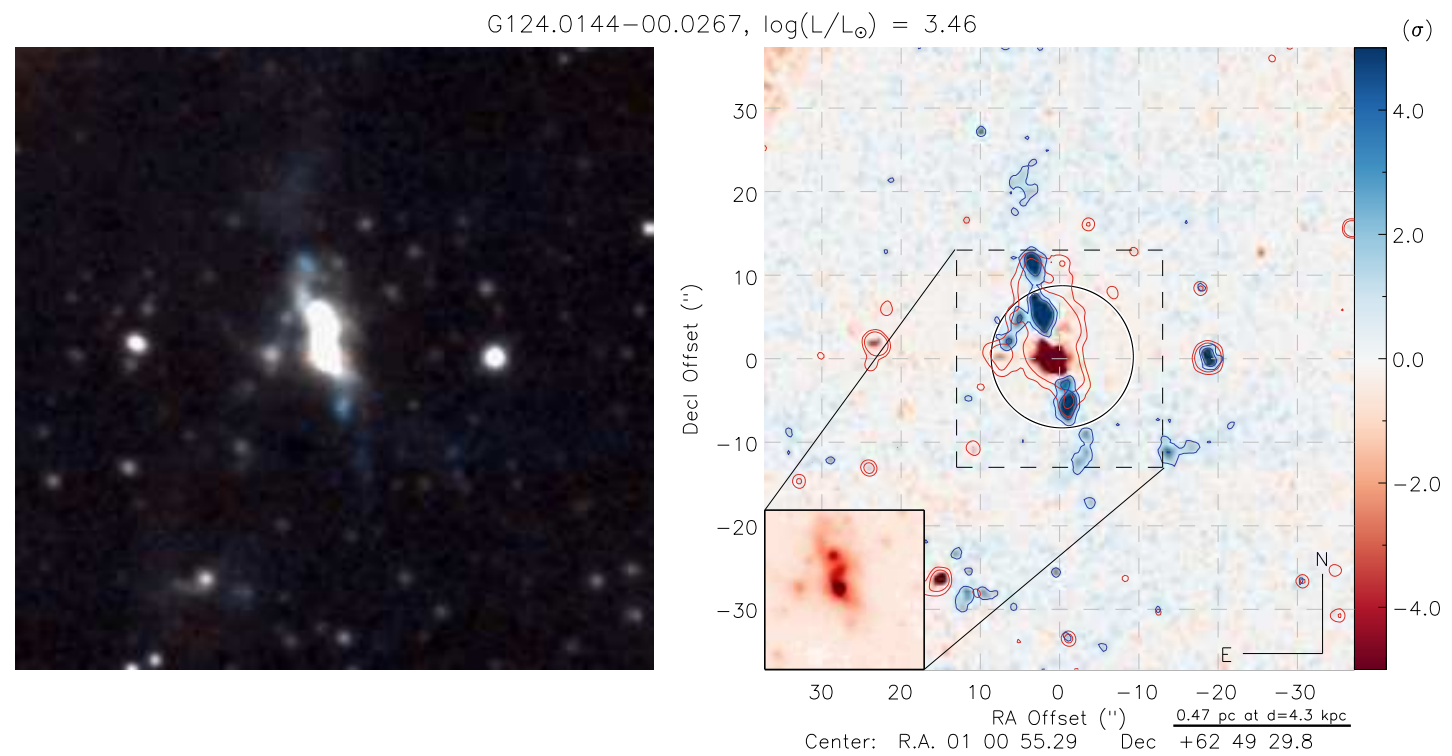

- G126.7144-00.8220 $\left(L=9.6 \times 10^{3}[d(k p c) / 1.4]^{2} \mathrm{~L}_{\odot}, \mathrm{B} 1 \mathrm{~V}_{0}\right):$ A fonte RMS encontra-se na região central de uma região com emissão estendida no contínuo $\left(\ell_{\text {proj }}=0.7\right.$ pc), e estś orientada na direção N-S. O mapa de emissão em $\mathrm{H}_{2}$ apresenta uma estrutura do tipo BP2 com mesma orientação da emissão no contínuo. As razões de aspecto dos nós Norte e Sul foram determinadas em $R_{N}=7.1$ e $R_{S}=4.5$, respectivamente. Um jato bipolar curvado, não associado ao objeto de estudo, foi identificado a 60" na direção SW. Salas et al. (1998, 2000) sugerem que essa estrutura esteja associada a uma estrela do tipo T Tauri em precessão. 

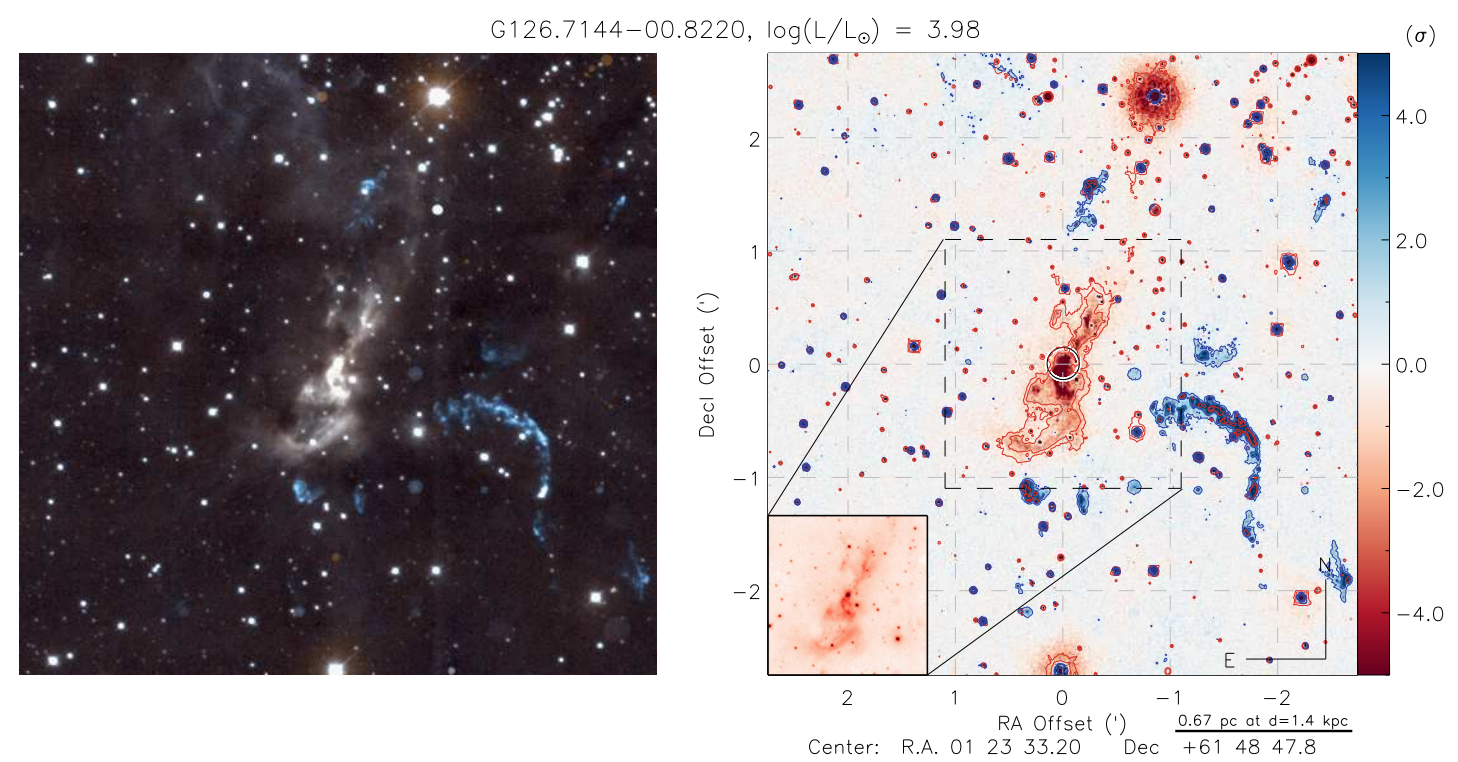

- G133.6945+01.2166 $\left(L=1.6 \times 10^{5}[d(k p c) / 4.6]^{2} \mathrm{~L}_{\odot}, \mathrm{O} 6.5 \mathrm{~V}\right)$ : O objeto possui luminosidade compatível com uma estrela do tipo $06.5 \mathrm{~V}$ e se encontra numa região com diversas estruturas que emitem no contínuo da banda K. Uma série de emissões do tipo nó, alinhadas linearmente, foram identificadas desde o objeto central até $\approx 2^{\prime}$ na direção NW, e sugerem a presença de um jato polar $(\mathrm{BP} 1)$ de baixa intensidade com $\ell_{\text {proj }}=2.5 \mathrm{pc}$ e razão de aspecto estimada em $R=3.6$. O mapa de emissão em $\mathrm{H}_{2}$ também mostra a presença de emissão difusa associada aos demais objetos do campo.
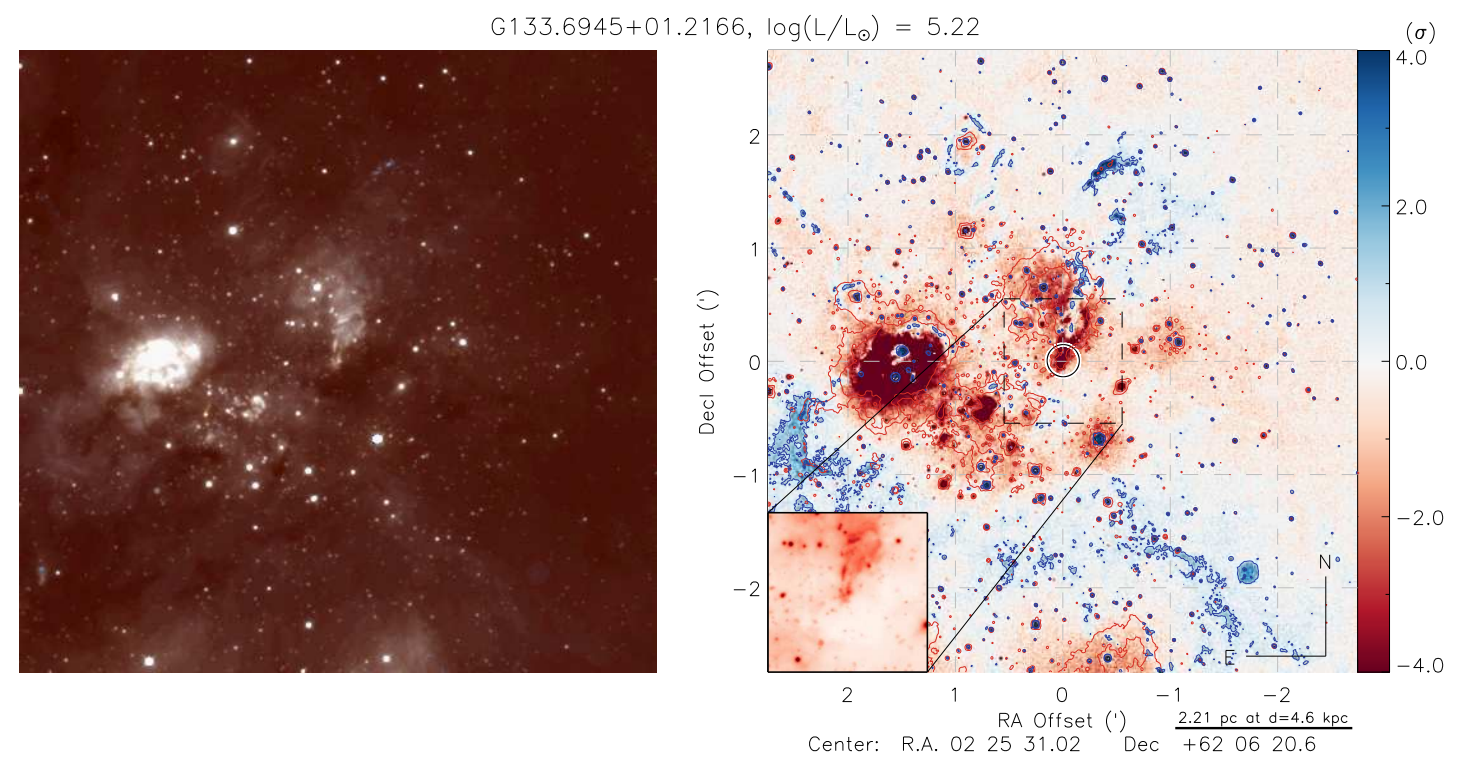
- G135.2774+02.7981 $\left(L=6.8 \times 10^{4}[d(k p c) / 9.3]^{2} \mathrm{~L}_{\odot}, \mathrm{O} 8.5 \mathrm{~V}\right):$ A fonte RMS apresenta luminosidade bolométrica equivalente a uma estrela do tipo O8.5 V e está associada a uma região com emissão estendida no contínuo com dimensões de 0.7 pc. Uma emissão do tipo BP2 foi identificada a partir do mapa de emissão em $\mathrm{H}_{2}$, orientada na direção NE-SW e com tamanho similar à estrutura identificada no filtro do contínuo. As razões de aspecto e dimensões dos lóbulos foram estimadas em $R=1.4$ e $\ell_{\text {proj }}=0.32 \mathrm{pc}$, respectivamente.
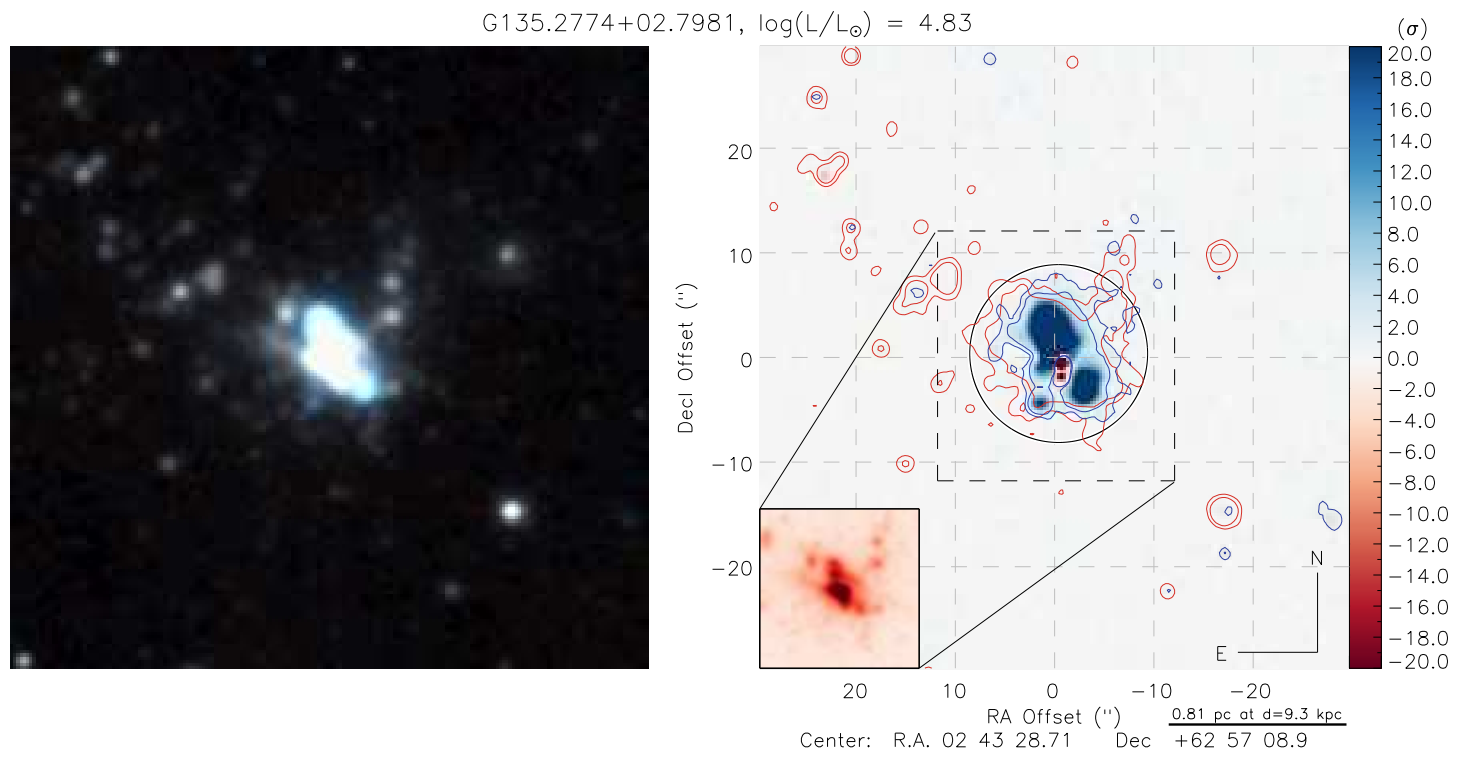

- G141.9996+01.8202 $\left(L=4.4 \times 10^{3}[d(k p c) / 1.4]^{2} \mathrm{~L}_{\odot}, \mathrm{B} 2 \mathrm{~V}_{0}\right):$ A fonte RMS possui contrapartida bastante intensa no infravermelho próximo e está saturada em ambos os filtros. Emissões do tipo polar foram identificadas ao redor do objeto central, orientadas preferencialmente na direção SW. Assumindo que tais estruturas tenham origem na região central do campo, suas dimensões projetadas equivalem a 0.5 pc. Este campo foi posicionado na borda do detector e, em decorrência disso, algumas estruturas originadas por defeitos instrumentais aparecem como emissões nas imagens finais e não devem ser consideradas. 

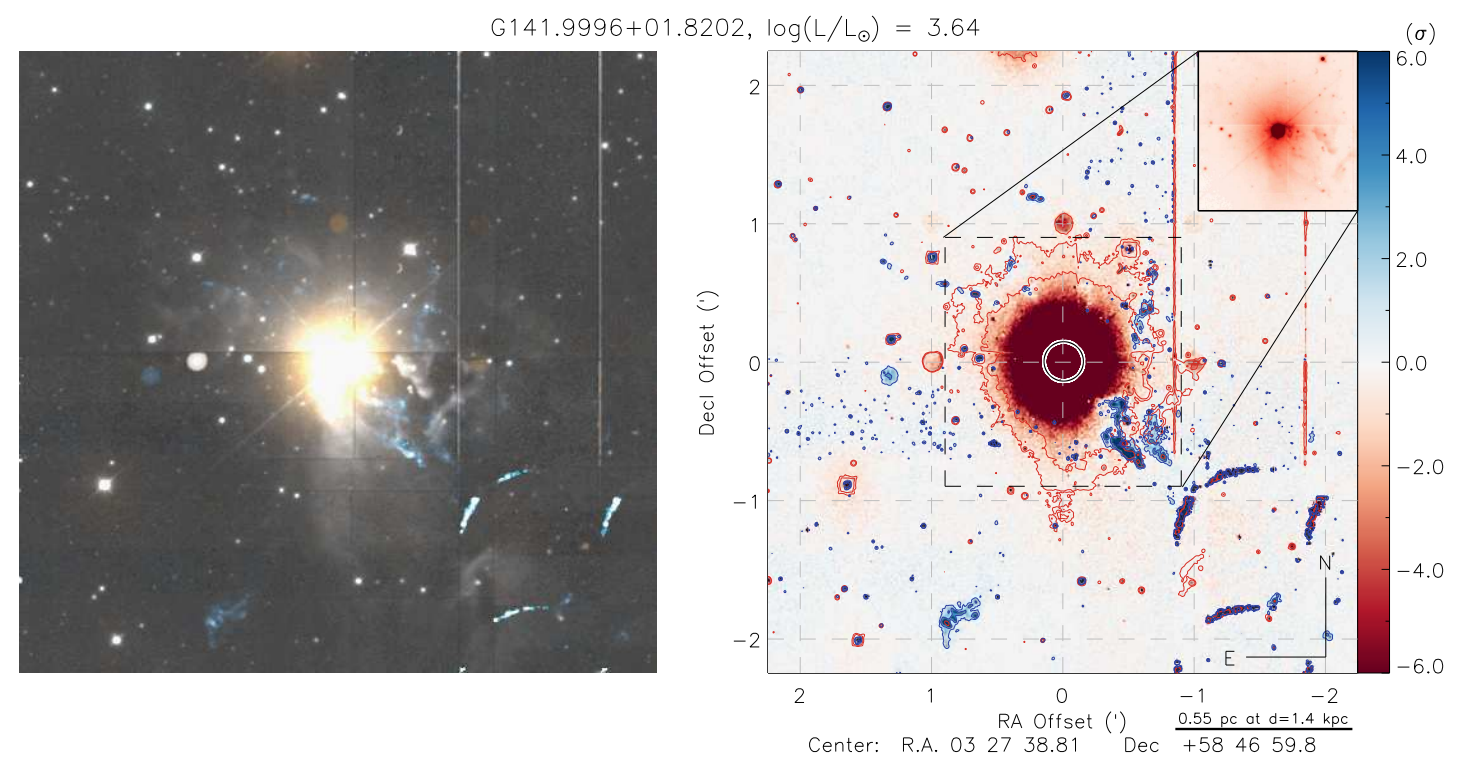

- G173.4815+02.4459 $\left(L=5.4 \times 10^{5}[d(k p c) / 17.0]^{2} \mathrm{~L}_{\odot}, \mathrm{O} 4 \mathrm{~V}\right):$ O objeto central possui luminosidade bolométrica compatível com uma estrela do tipo O4 V. No entanto a distância cinemática da fonte RMS ( $d=17.0 \mathrm{kpc}$, Urquhart et al., 2008), localizada na região do anti-centro galático, é incompatível com valores esperados para fontes galáticas. O mapa de emissão em $\mathrm{H}_{2}$ apresenta uma estrutura bipolar classificada como BP8, sugerindo que duas ou mais fontes em formação estejam presentes na região central, que apresenta intensa emissão no contínuo. A dimensão projetada do maior jato, orientado na direção N-S, foi estimada em 12.7 pc. A razão de aspecto do lóbulo na direção $\mathrm{N}$ foi determinada em $R=6.5$. 

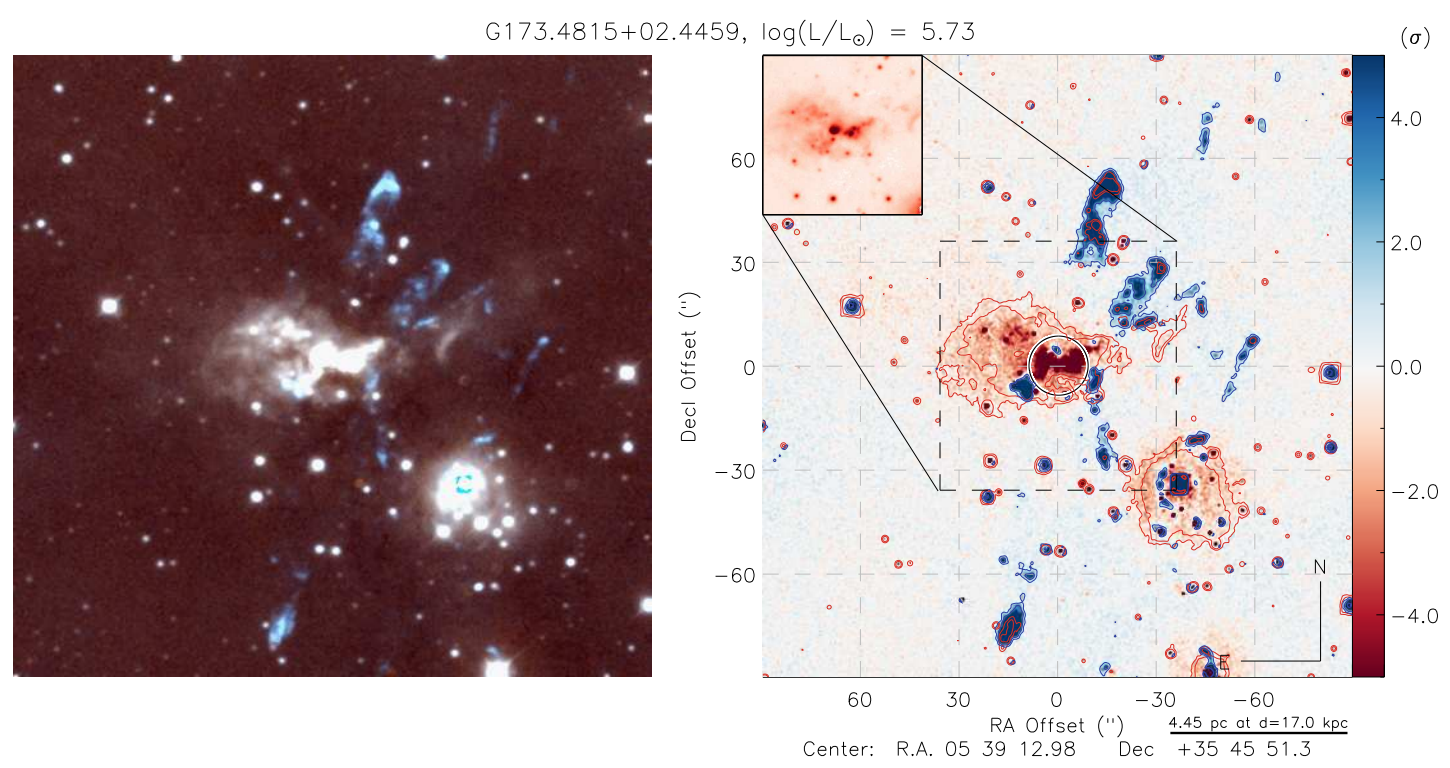

- G173.4839+02.4317 $\left(L=3.5 \times 10^{5}[d(k p c) / 22.3]^{2} \mathrm{~L}_{\odot}, \mathrm{O} 5 \mathrm{~V}\right):$ A fonte RMS localiza-se a 40" na direção SW do objeto G173.4815+02.4459 e também apresenta problemas na determinação de sua distância cinemática ( $d=22.3 \mathrm{kpc}$, Urquhart et al., 2008). O mapa de emissão em $\mathrm{H}_{2}$ apresenta uma estrutura do polar (BP1), orientada na direção NW. A dimensão projetada da emissão foi estimada em $\ell_{\text {proj }}=5.6$ pc, com razão de aspecto $R=15.0$.

$G 173.4839+02.4317, \log \left(L / L_{\odot}\right)=5.55$
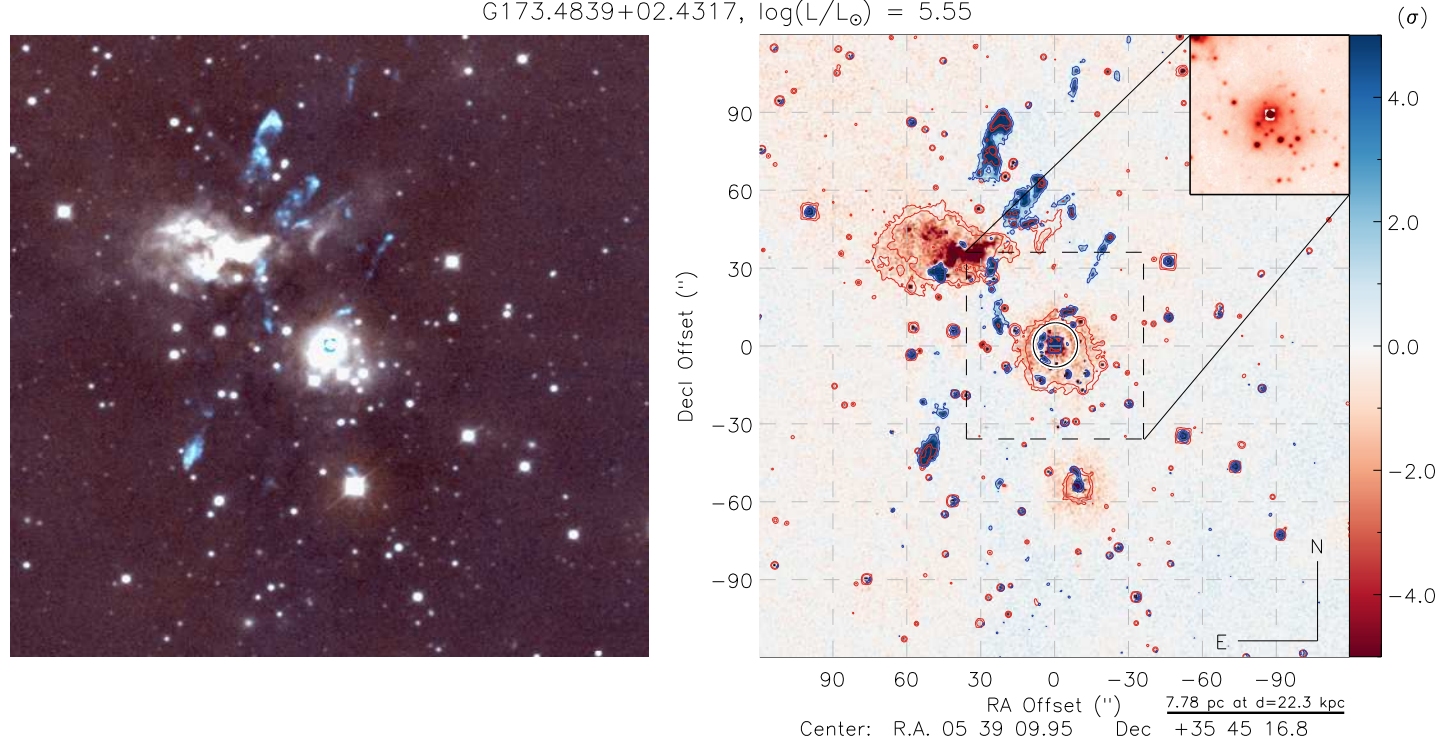
- G173.5826+02.4452 $\left(L=4.4 \times 10^{4}[d(k p c) / 20.9]^{2} \mathrm{~L}_{\odot}, \mathrm{O} 9.5 \mathrm{~V}\right)$ : Emissões multipolares com morfologia do tipo BP8 foram identificadas ao redor da fonte RMS, que possui luminosidade compatível com uma estrela do tipo 09.5 V. No entanto, a distância cinemática do objeto $(d=20.9 \mathrm{kpc}$, Urquhart et al., 2008) é incompatível com valores galáticos, indicando erros em sua determinação. As emissões em $\mathrm{H}_{2}$ apresentam $\ell_{\text {proj }} \approx 3.8 \mathrm{pc}$ e a razão de aspecto média foi estimada em $R \approx 5.0$.

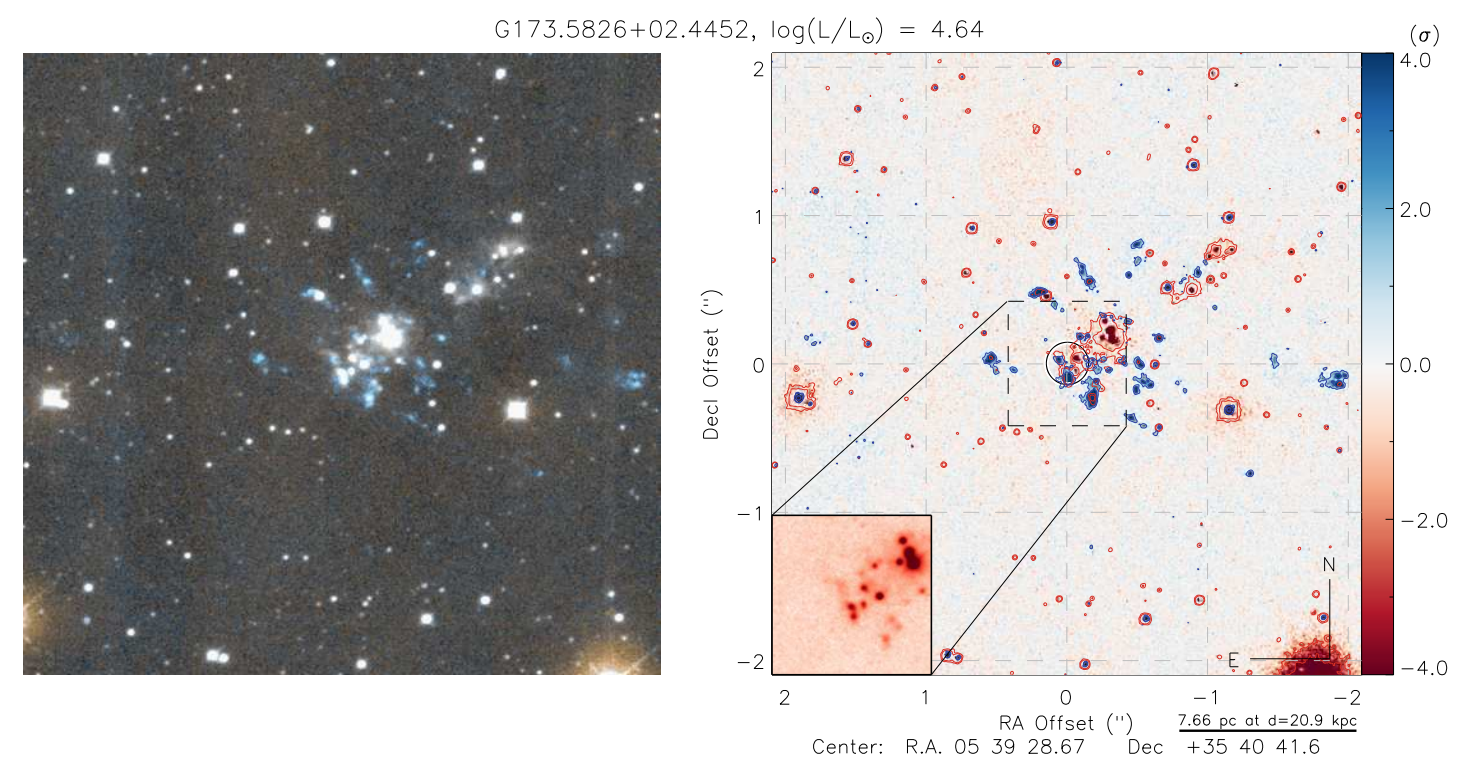

- G189.0307+00.7821 $\left(L=3.1 \times 10^{3}[d(k p c) / 0.8]^{2} \mathrm{~L}_{\odot}, \mathrm{B} 2 \mathrm{~V}_{0}\right)$ : O objeto está associado a uma região com intensa emissão no filtro do contínuo e seu mapa de emissão em $\mathrm{H}_{2}$ apresenta alguns nós alinhados linearmente na direção NW, que sugerem a presença de uma emissão polar (BP1) de baixa intensidade. A estrutura delineada pelos nós possui $\ell_{\text {proj }}=0.2$ pc e possivelmente representa o lóbulo azul de uma emissão bipolar. Nesse caso, o lóbulo vermelho estaria obscurecido pela região nebular associada à fonte central. 

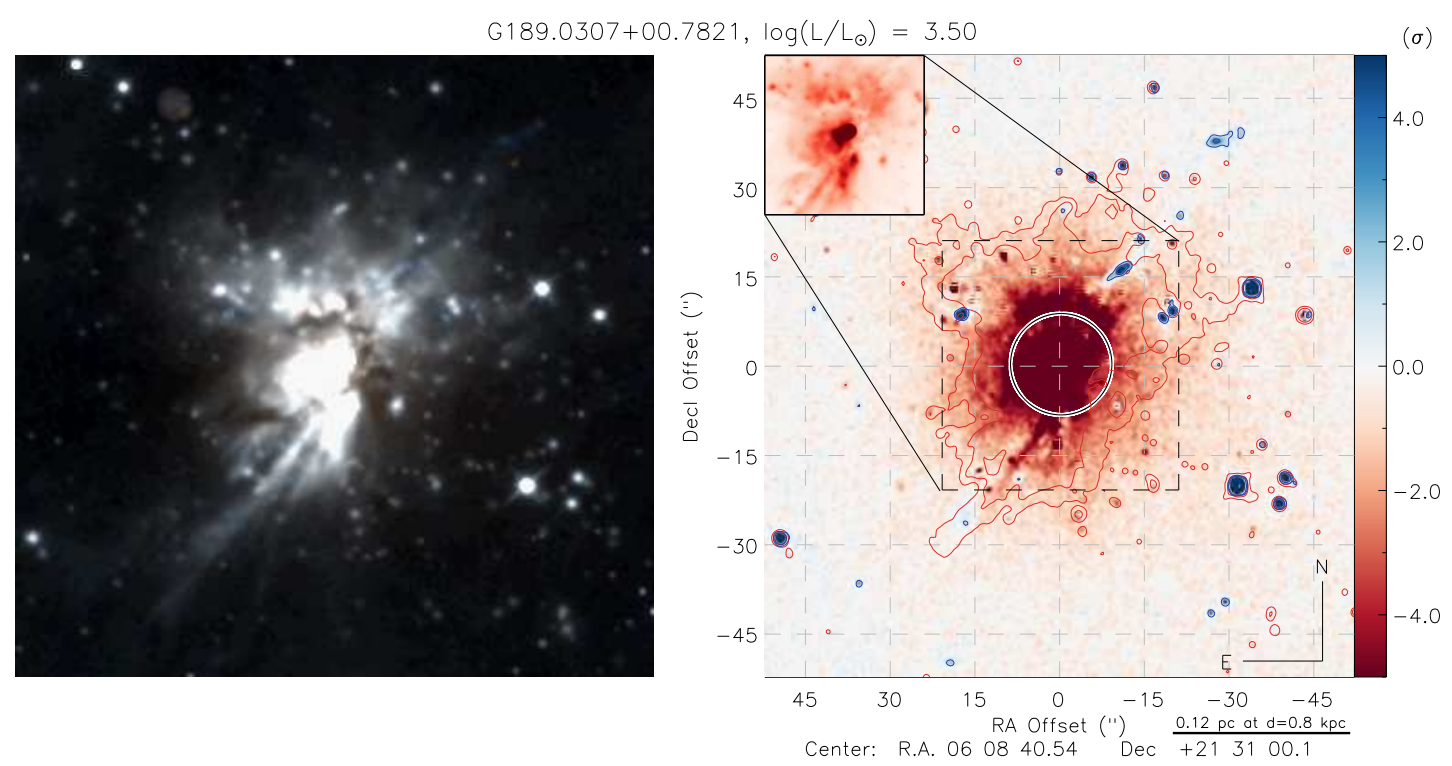

- G202.6270+02.3747 $\left(L=5.2 \times 10^{2}[d(k p c) / 1.0]^{2} \mathrm{~L}_{\odot},<\mathrm{B} 3 \mathrm{~V}_{0}\right):$ A fonte RMS está associada a uma emissão estendida no contínuo que possui dimensão projetada de $\ell_{\text {proj }} \approx$ 0.1 pc. A morfologia da emissão em $\mathrm{H}_{2}$ foi classificada como do tipo BP4 e é constituída por um jato bipolar na direção NW-SE enquanto alguns nós de emissão em $\mathrm{H}_{2}$ na direção NESW sugerem a presença de um segundo jato. A razão de aspecto das estruturas observadas foram estimadas em $R \approx 7.2$ para o primeiro jato e $R \approx 2.2$ para o segundo. Uma terceira emissão bipolar, com origem em $\approx 30^{\prime \prime}$ na direção $\mathrm{E}$ da fonte RMS, apresenta orientação na direção NE-SW e possui razão de aspecto estimado em $R \approx 10.0$, porém não foi possível identificar sua fonte de origem. 


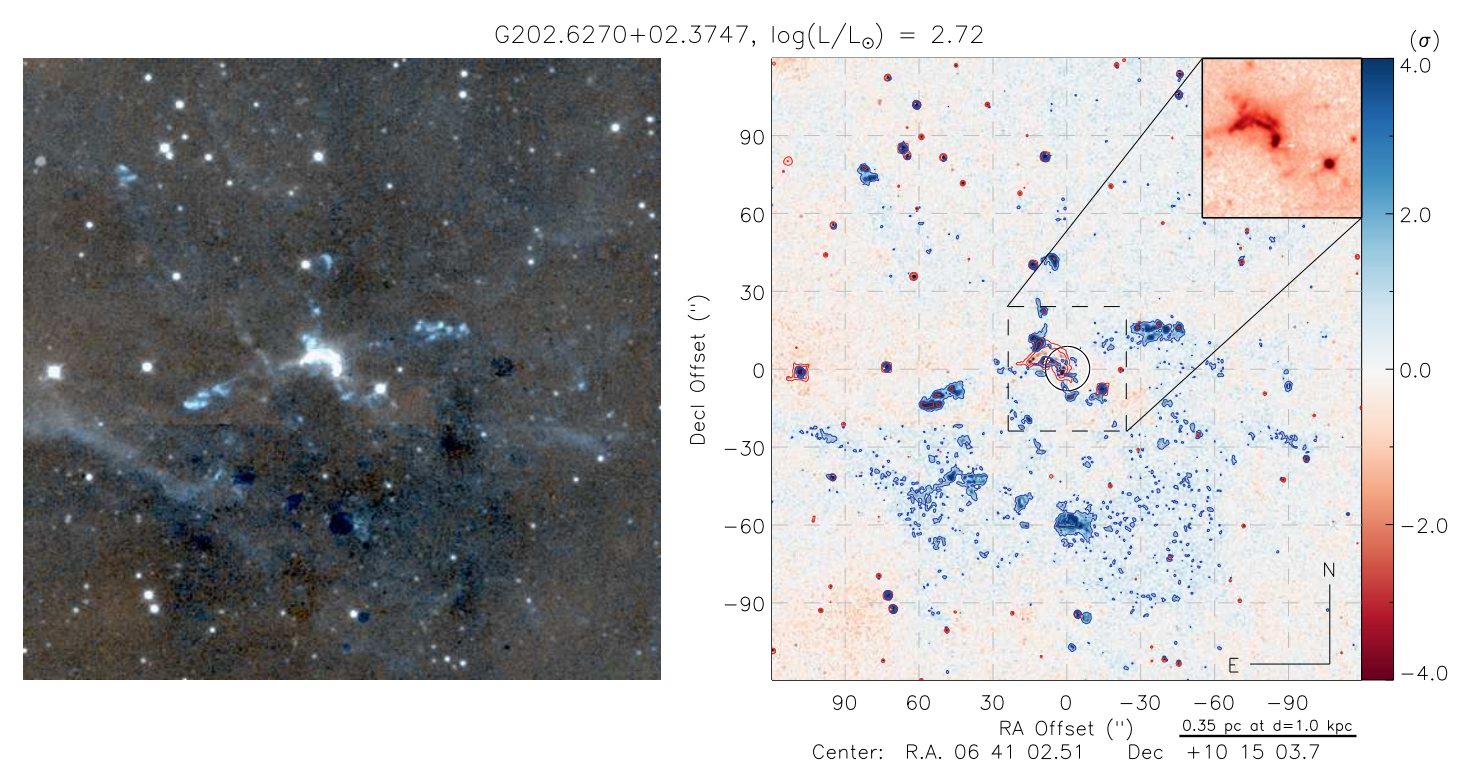

- G207.2654-01.8080 $\left(L=7.0 \times 10^{3}[d(k p c) / 1.6]^{2} \mathrm{~L}_{\odot}, \mathrm{B} 1 \mathrm{~V}_{0}\right)$ : A fonte RMS é um objeto relativamente brilhante no infravermelho próximo, e está saturada em ambos os filtros. Alguns nós de emissão em $\mathrm{H}_{2}$ foram identificados ao redor do objeto central, associado a uma região com intensa emissão estendida no contínuo. A disposição dos nós sugere a presença de emissões multipolares, com morfologia do tipo BP8. Os nós mais brilhantes estão localizados na direção $\mathrm{N}$ da fonte central e apresentam dimensões projetadas de $\ell_{\text {proj }} \approx 0.3$ pc. Assumindo que sejam originadas pela fonte RMS, a razão de aspecto média das emissões é $R \approx 5.0$. Uma série de nós menos intensos foram identificados na direção NE-SW. A emissão sugere a presença de um jato bipolar de baixa intensidade, com dimensão total estimada em $\ell_{\text {proj }}=2.40$ pc e $R=5.5$. 

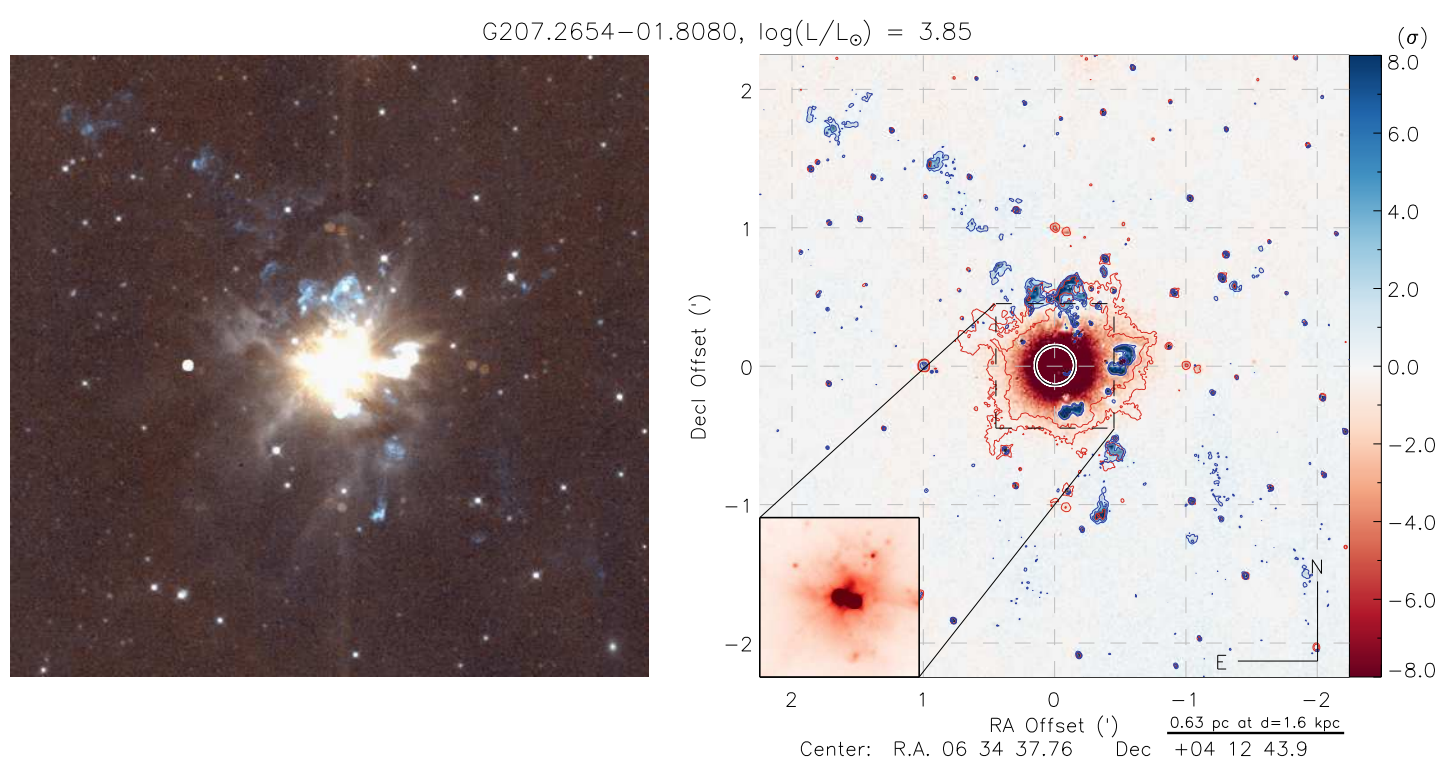

- G212.0641-00.7395 $\left(L=2.5 \times 10^{4}[d(k p c) / 6.4]^{2} \mathrm{~L}_{\odot}, \mathrm{B} 0 \mathrm{~V}_{0}\right):$ O objeto central está associado a uma estrutura multipolar do tipo BP4. A emissão é constituída por a) uma estrutura bipolar mais extensa (cada lóbulo possui $\ell_{\text {proj }}=1.8 \mathrm{pc}$ ) e orientada na direção E-W, e b) um jato bipolar orientado na direção NE-SW, com dimensões semelhantes à emissão extensa detectada no filtro do contínuo (lóbulos com $\ell_{\text {proj }}=0.4$ pc). A razão de aspecto das emissões foram estimadas em $R_{e x t}=8.3$ e $R_{i n t}=3.3$. A diferença entre a orientação das duas estruturas bipolares sugere que o objeto central esteja em movimento de precessão. Visto que as componentes bipolares são bem delimitadas, é possível inferir que a taxa de acreção na fonte central deve variar como função do tempo e a ejeção de matéria não parece ocorrer continuamente. 

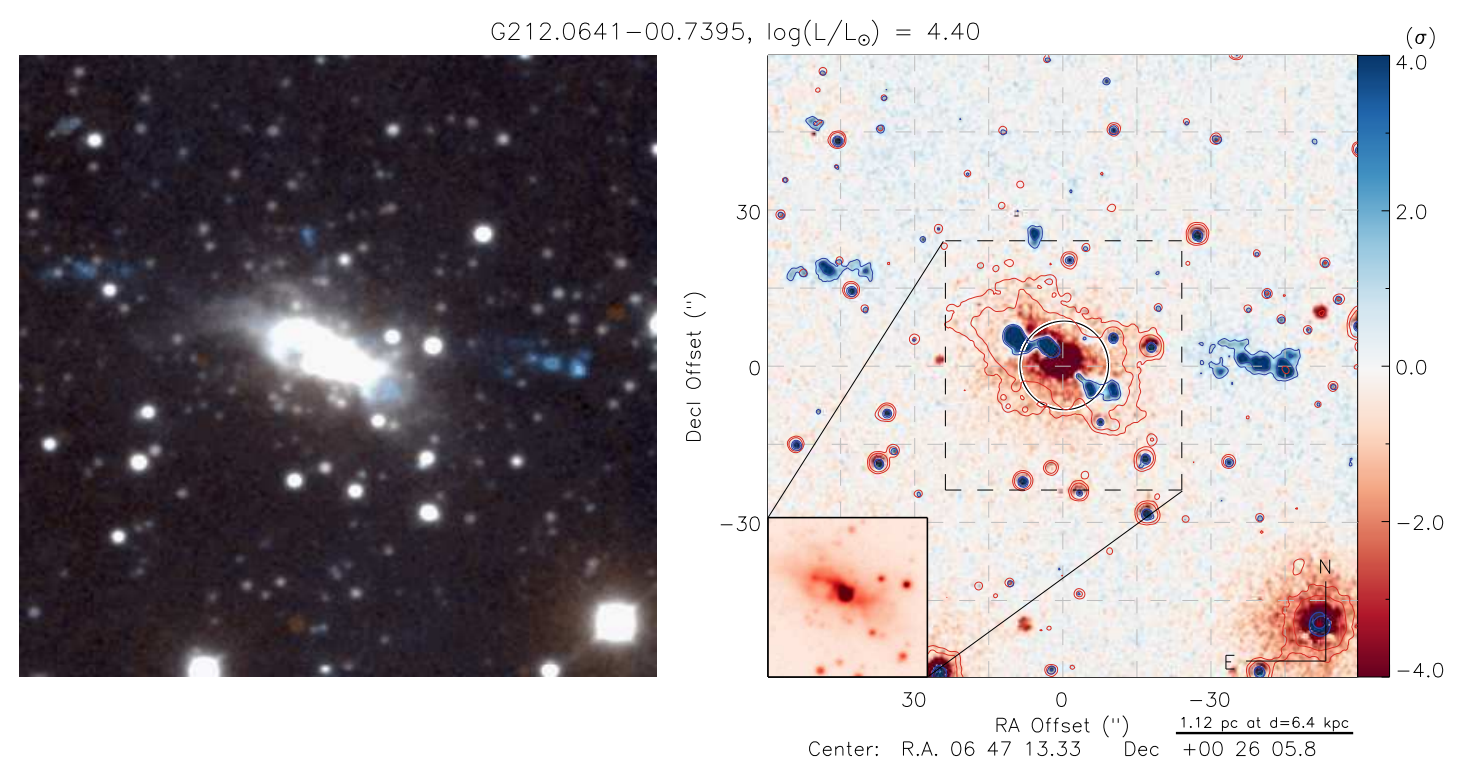

- G212.9626+01.2954 $\left(L=2.4 \times 10^{3}[d(k p c) / 5.7]^{2} \mathrm{~L}_{\odot}, \mathrm{B} 3 \mathrm{~V}_{0}\right)$ : O objeto central está associado a uma emissão estendida detectada no filtro do contínuo, que se estende da região central até 10" na direção W. Dois nós de emissão em $\mathrm{H}_{2}$ sugerem uma emissão com morfologia BP2 e correspondem à região terminal de lóbulos com $\ell_{p r j}=0.15 \mathrm{pc}$, orientados na direção NE-SW.

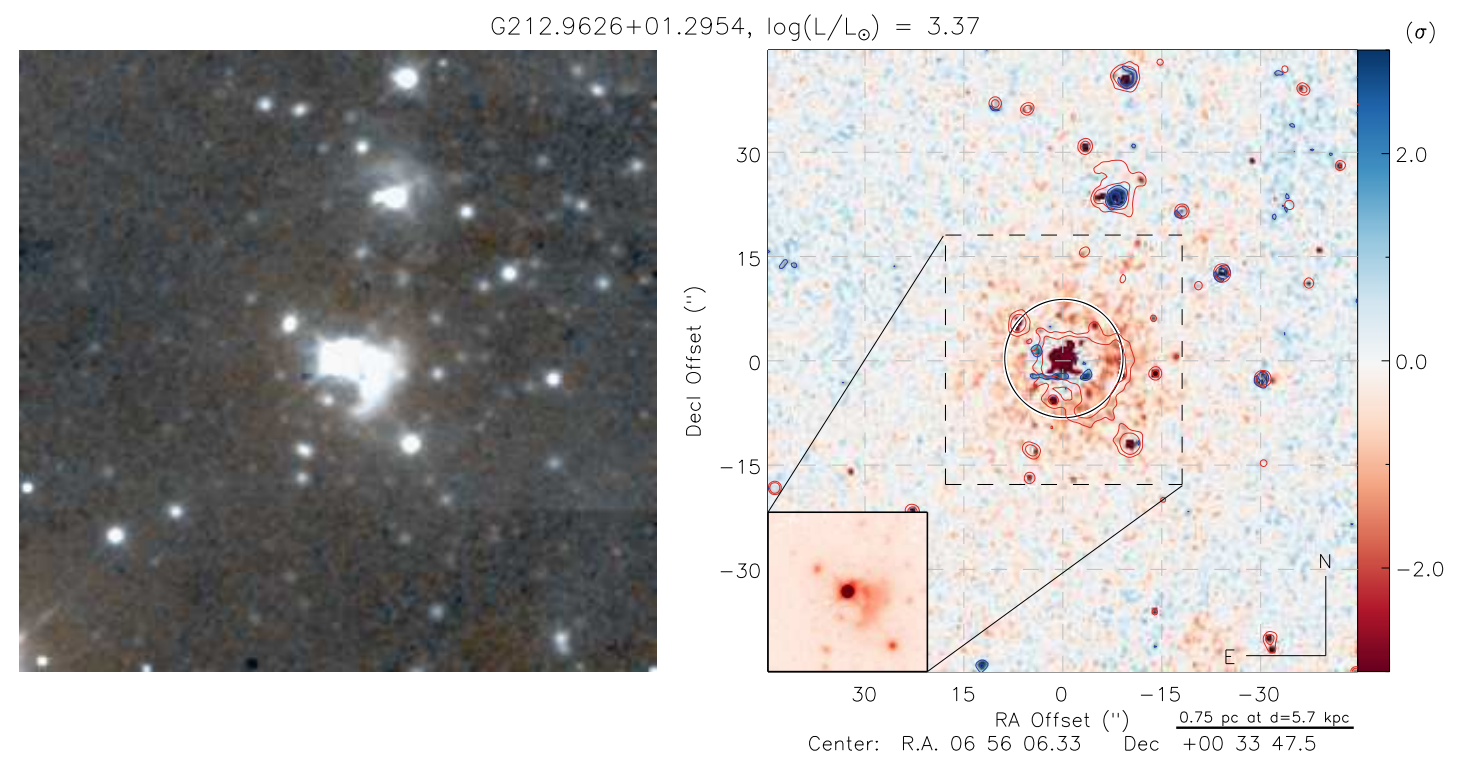

- G214.4934-01.8103 $\left(L=1.3 \times 10^{3}[d(k p c) / 3.0]^{2} \mathrm{~L}_{\odot}\right.$, B3 $\left.\mathrm{V}_{0}\right)$ : A posição da fonte RMS 
é compatível com as coordenadas de um aglomerado de estrelas com tamanho estimado $\mathrm{em} \approx 0.7$ pc. Uma série de nós em $\mathrm{H}_{2}$ indicam uma estrutura do tipo BP2, orientada na direção NE-SW e com origem a $\approx 10^{\prime \prime}$ na direção $\mathrm{S}$ das coordenadas MSX. Os nós delimitam uma emissão bipolar com razão de aspecto estimada em $R=11.8$ e a dimensão de cada um dos lóbulos foi estimada em $\ell_{\text {proj }} \approx 1.1$ pc.

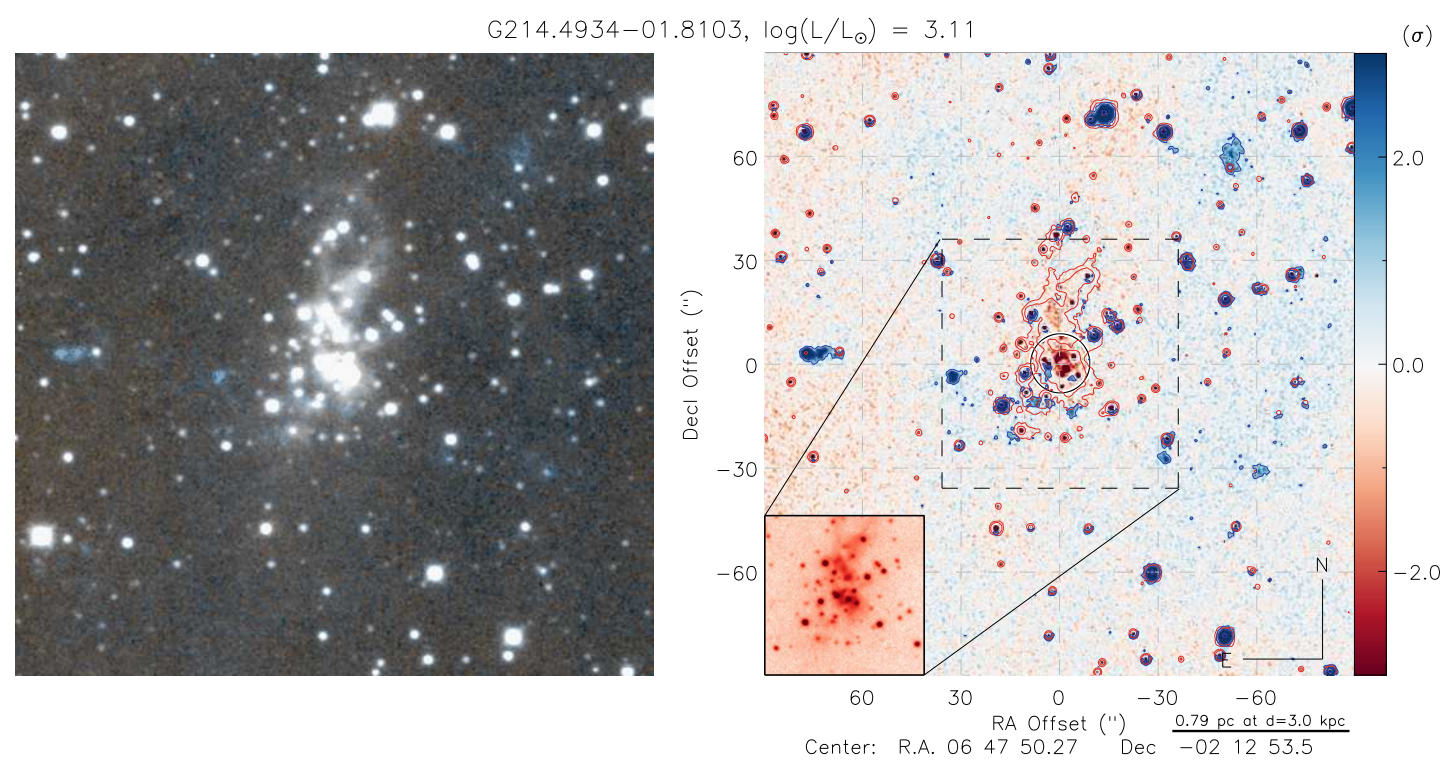

- G217.6047-02.6170 $\left(L=7.6 \times 10^{3}[d(k p c) / 9.2]^{2} \mathrm{~L}_{\odot}, \mathrm{B} 1 \mathrm{~V}_{0}\right):$ A fonte RMS está localizada no centro de uma região com emissão extensa no filtro do contínuo. O mapa de emissão em $\mathrm{H}_{2}$ apresenta uma estrutura com morfologia do tipo BP2, orientada na direção E-W. O lóbulo na direção E possui dimensão projetada de $\ell_{\text {proj }}=0.32 \mathrm{pc}$ e sua razão de aspecto foi estimada em $R=3.2$. 
$G 217.6047-02.6170, \log \left(L / L_{\odot}\right)=3.88$
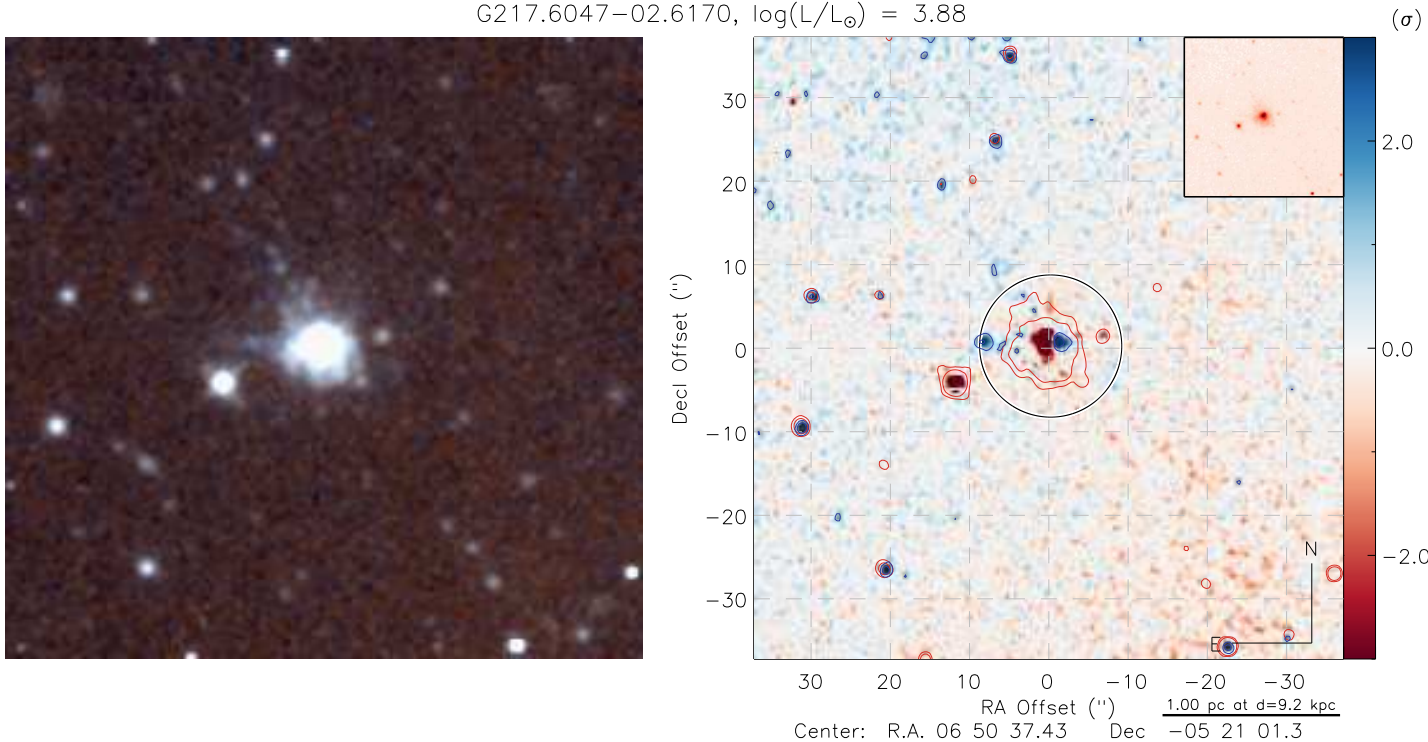

- G224.6075-01.0063 $\left(L=1.6 \times 10^{3}[d(k p c) / 1.6]^{2} \mathrm{~L}_{\odot}, \mathrm{B} 3 \mathrm{~V}_{0}\right)$ : O objeto está associado a uma intensa emissão estendida no contínuo com dimensões de 0.4 pc. Seu mapa de emissão em $\mathrm{H}_{2}$ indica a presença de uma estrutura do tipo BP2, com baixo grau de colimação $(R \approx 1.0)$ e orientada na direção NE-SW. Os lóbulos associados à emissão bipolar possuem dimensões estimadas em $\ell_{\text {proj }} \approx 0.12$ pc. Três pontos brilhantes, localizados a 60 " nas direções $\mathrm{E}, \mathrm{N}$, e W, decorrem de falhas no processamento dos dados e não correspondem a sinais astrofísicos de interesse.

G224.6075-01.0063, $\log \left(L / L_{\odot}\right)=3.20$
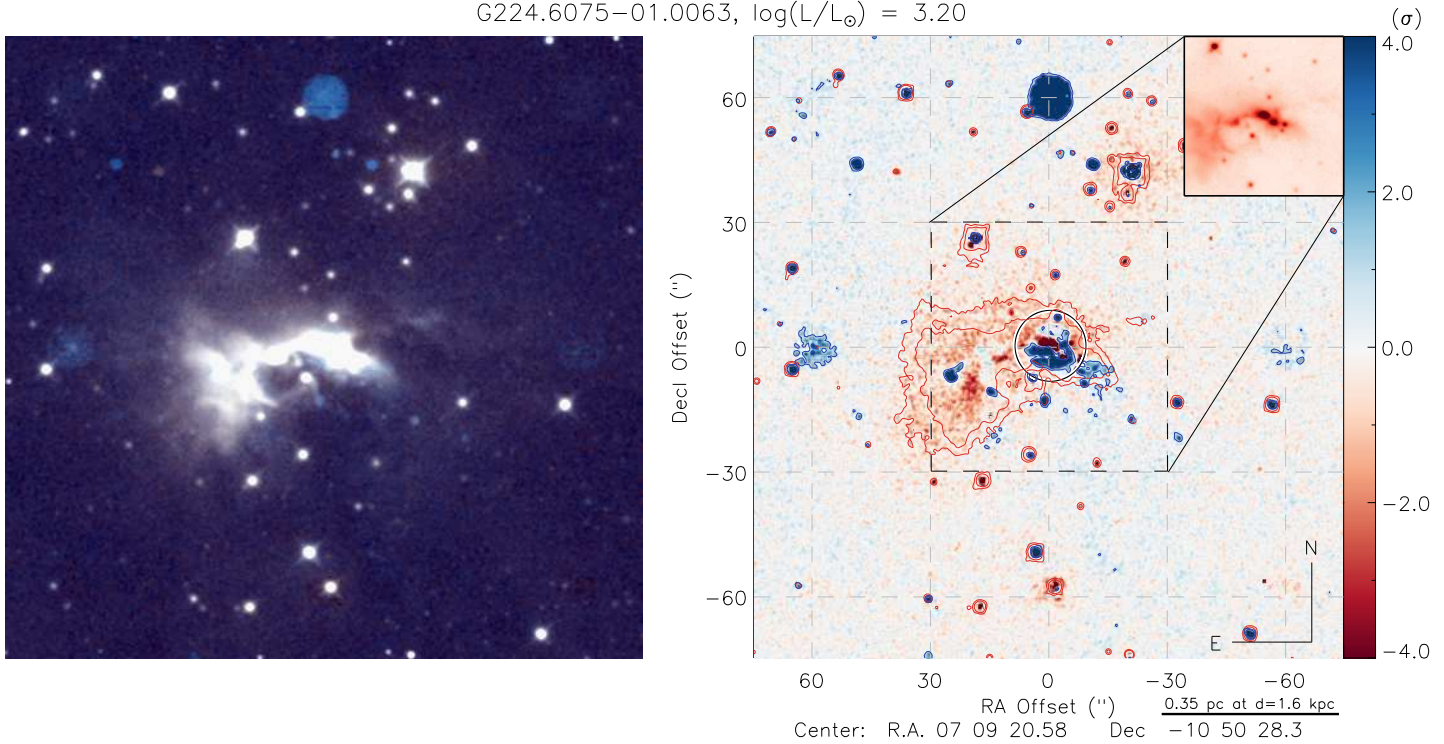
- G225.3266-00.5318 $\left(L=7.4 \times 10^{2}[d(k p c) / 1.6]^{2} \mathrm{~L}_{\odot},<\mathrm{B} 3 \mathrm{~V}_{0}\right):$ A fonte RMS está associada a uma emissão extensa no contínuo, com dimensão projetada de 0.2 pc. Alguns nós de emissão em $\mathrm{H}_{2}$ foram identificados na direção NE-SW e parecem delinear uma emissão bipolar do tipo BP2. A emissão mais intensa localiza-se na direção SW e apresenta $\ell_{\text {proj }}=0.15 \mathrm{pc}$, com $R=4.0$.

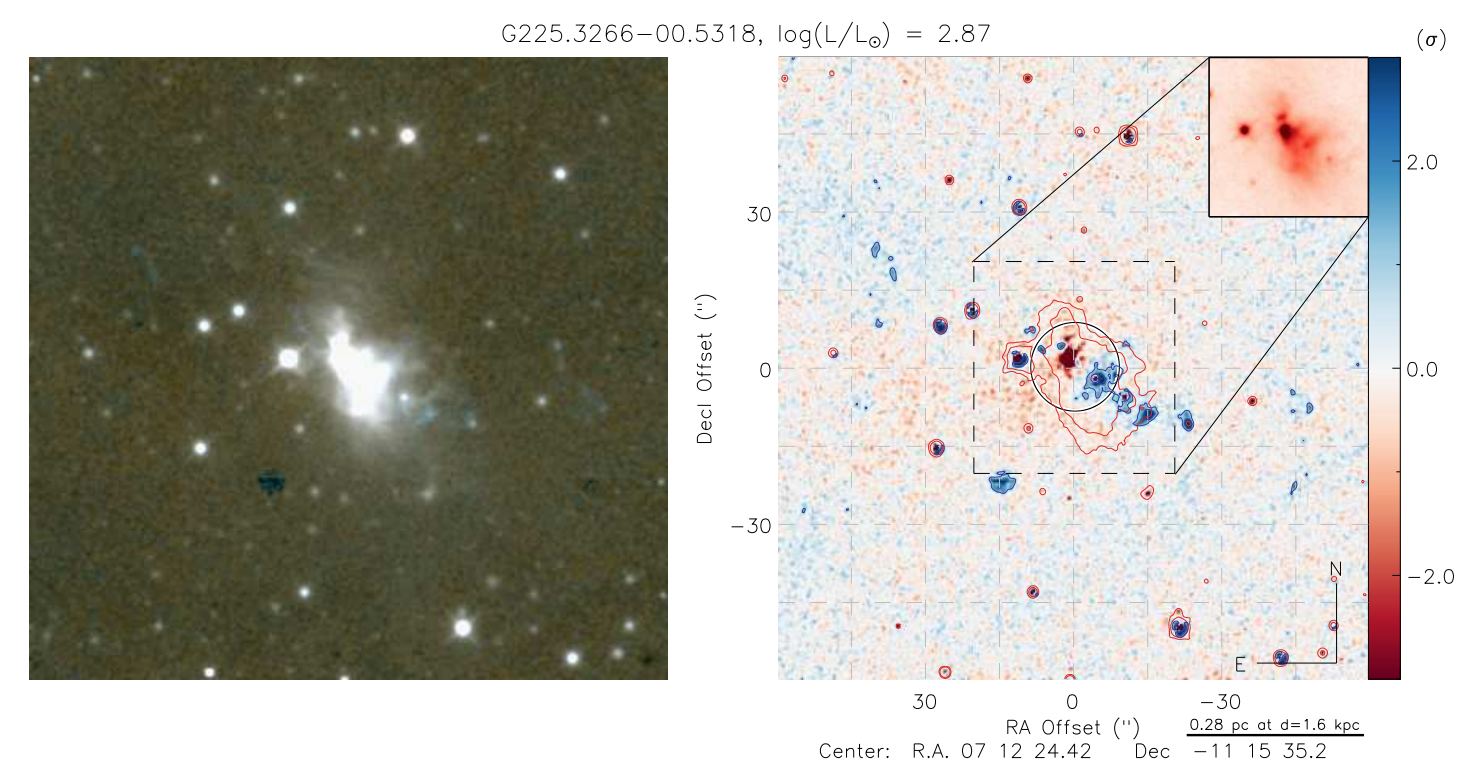

- G232.0766-02.2767 $\left(L=4.7 \times 10^{3}[d(k p c) / 4.1]^{2} \mathrm{~L}_{\odot}, \mathrm{B} 2 \mathrm{~V}_{0}\right)$ : O objeto central está localizado entre duas fontes com intensa emissão no contínuo e pertence a um grupo de estrelas com extensão de $\approx 0.3$ pc. Uma estrutura monopolar (BP1) foi identificada no mapa de emissão em $\mathrm{H}_{2}$, orientada na direção $\mathrm{E}$ da fonte $\mathrm{RMS}$, com $\ell_{\text {proj }}=0.3 \mathrm{pc}$ e $R=5.0$. 

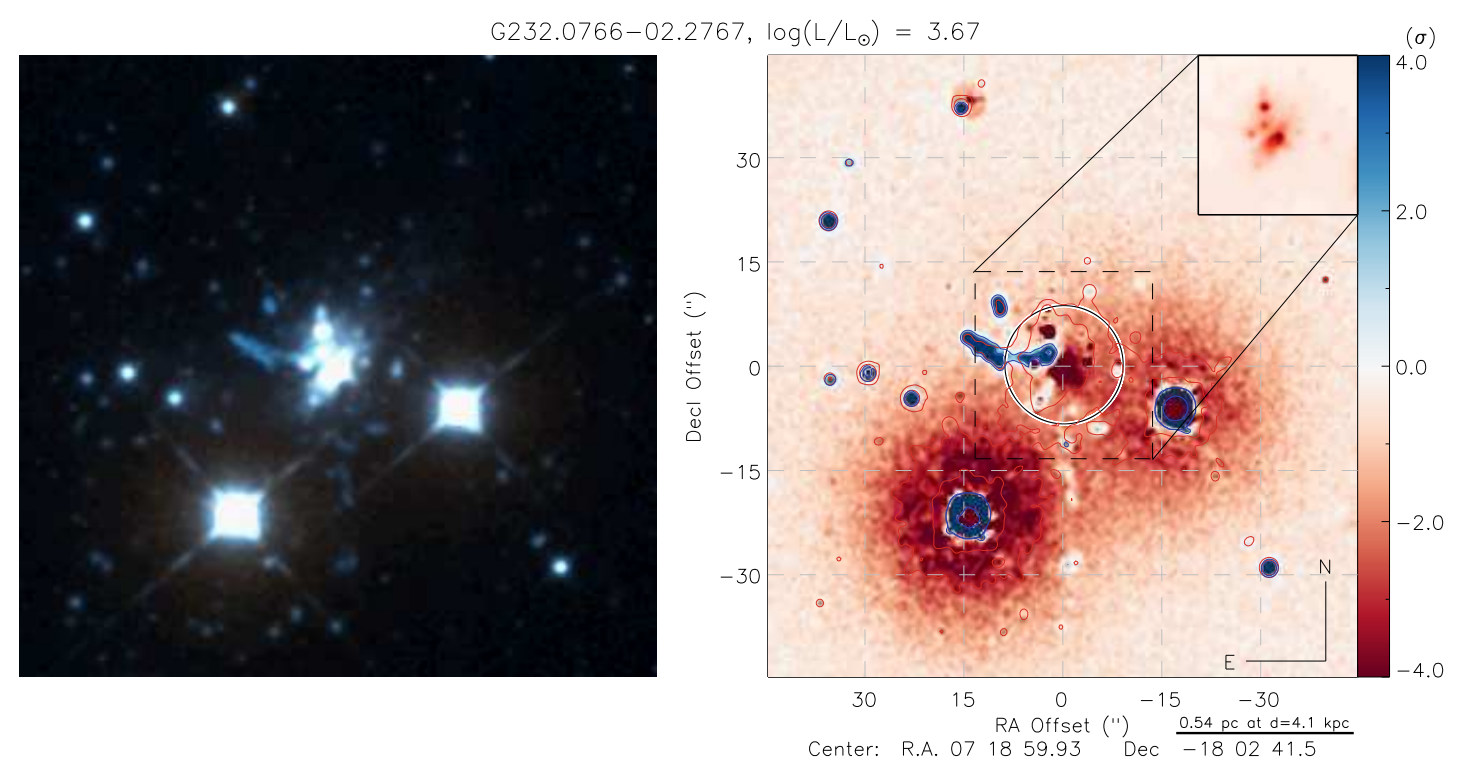

- G259.6154-02.6940 $\left(L=4.2 \times 10^{3}[d(k p c) / 6.6]^{2} \mathrm{~L}_{\odot}, \mathrm{B} 2 \mathrm{~V}_{0}\right):$ A fonte central está localizada no centro de uma região com emissão estendida no filtro do contínuo. Seu mapa de emissão em $\mathrm{H}_{2}$ apresenta dois nós, orientados na direção NW-SE, que parecem traçar a região terminal de uma emissão bipolar $(\mathrm{BP} 2)$ originada pela fonte central. O nó localizado na direção SE delimita uma dimensão de $\ell_{\text {proj }}=0.56$ pc e possui razão de aspecto $R=8.4$.

$G 259.6154-02.6940, \log \left(L / L_{\odot}\right)=3.62$
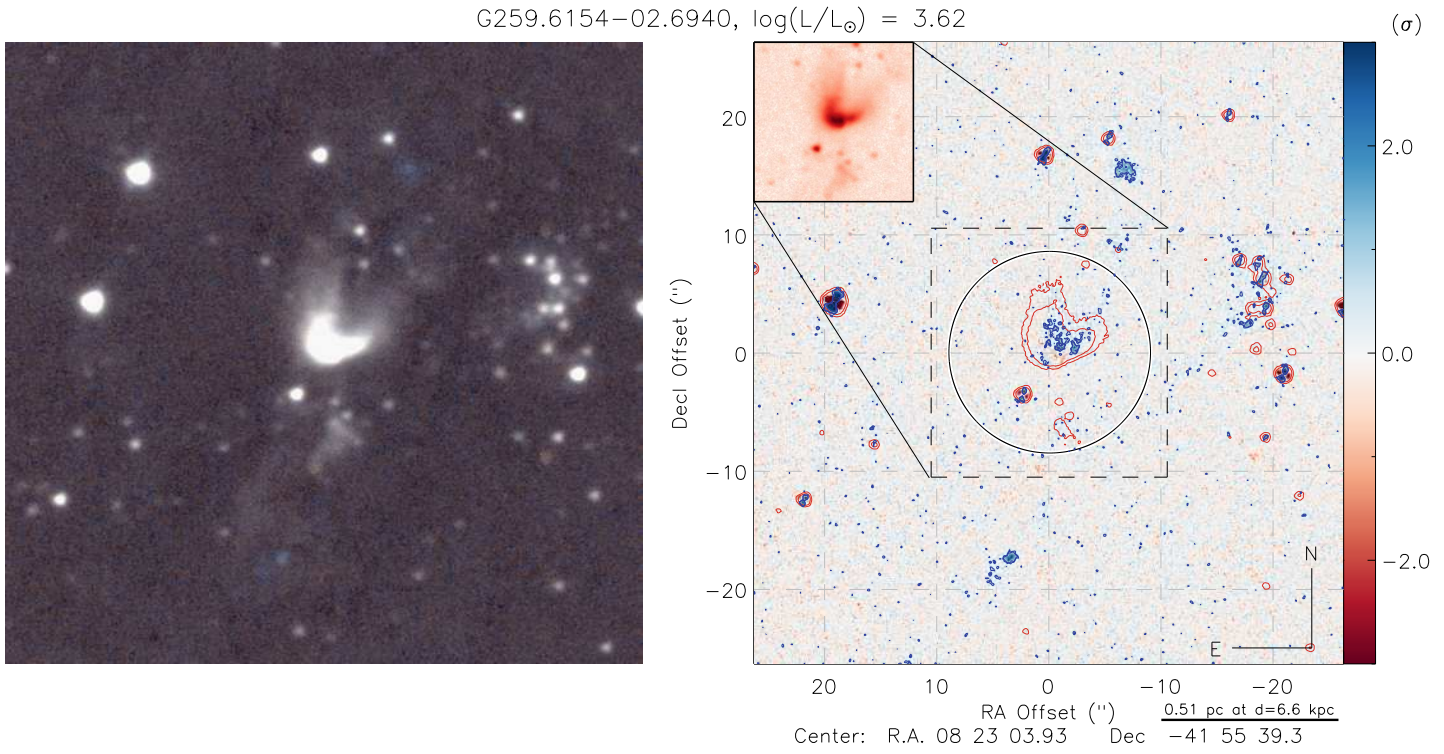
- G259.7592-02.8378 $\left(L=2.0 \times 10^{3}[d(k p c) / 2.1]^{2} \mathrm{~L}_{\odot}, \mathrm{B} 3 \mathrm{~V}_{0}\right)$ : O objeto central está associado a uma emissão no contínuo, que se estende por 0.2 pc. O mapa de emissão em $\mathrm{H}_{2}$ apresenta uma estrutura com morfologia do tipo BP2, orientada na direção NW-SE. A emissão localizada na direção SE possui $\ell_{\text {proj }}=0.62$ pc e sua razão de aspecto foi estimadas em $R=2.9$.
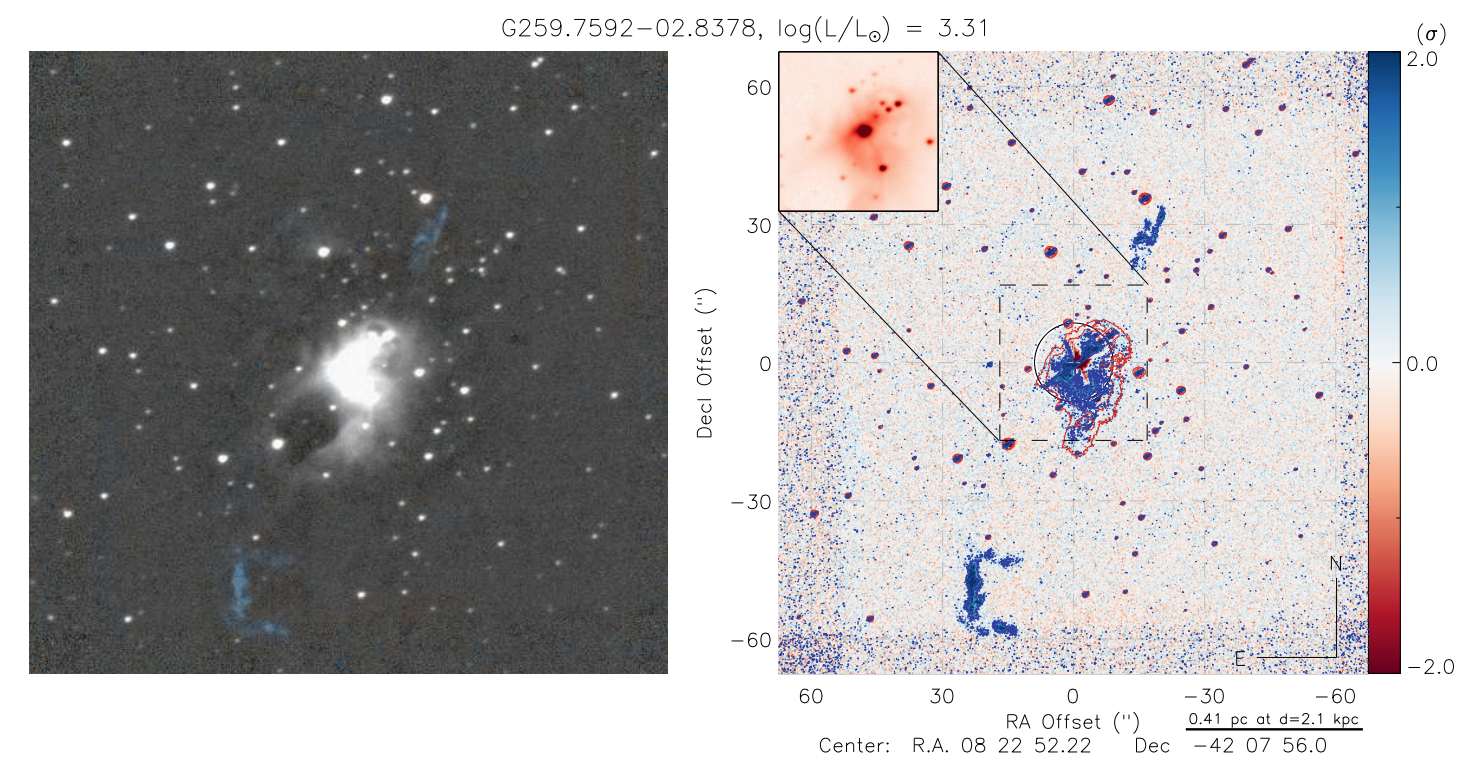

- G259.9395-00.0419 $\left(L=4.1 \times 10^{2}[d(k p c) / 1.7]^{2} \mathrm{~L}_{\odot},<\mathrm{B} 3 \mathrm{~V}_{0}\right):$ A fonte RMS está associada a uma emissão estendida no contínuo, que se estende desde o objeto central até

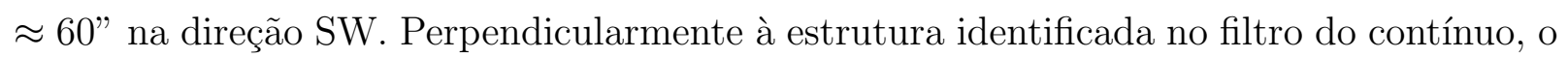
mapa de emissão em $\mathrm{H}_{2}$ exibe dois nós na direção E-W, sugerindo uma estrutura do tipo BP2. O nó mais próximo, localizado na direção E da fonte central, corresponde a uma dimensão projetada de $\ell_{\text {proj }}=0.12$ pc. 
G259.9395-00.0419, $\log \left(L / L_{\odot}\right)=2.62$
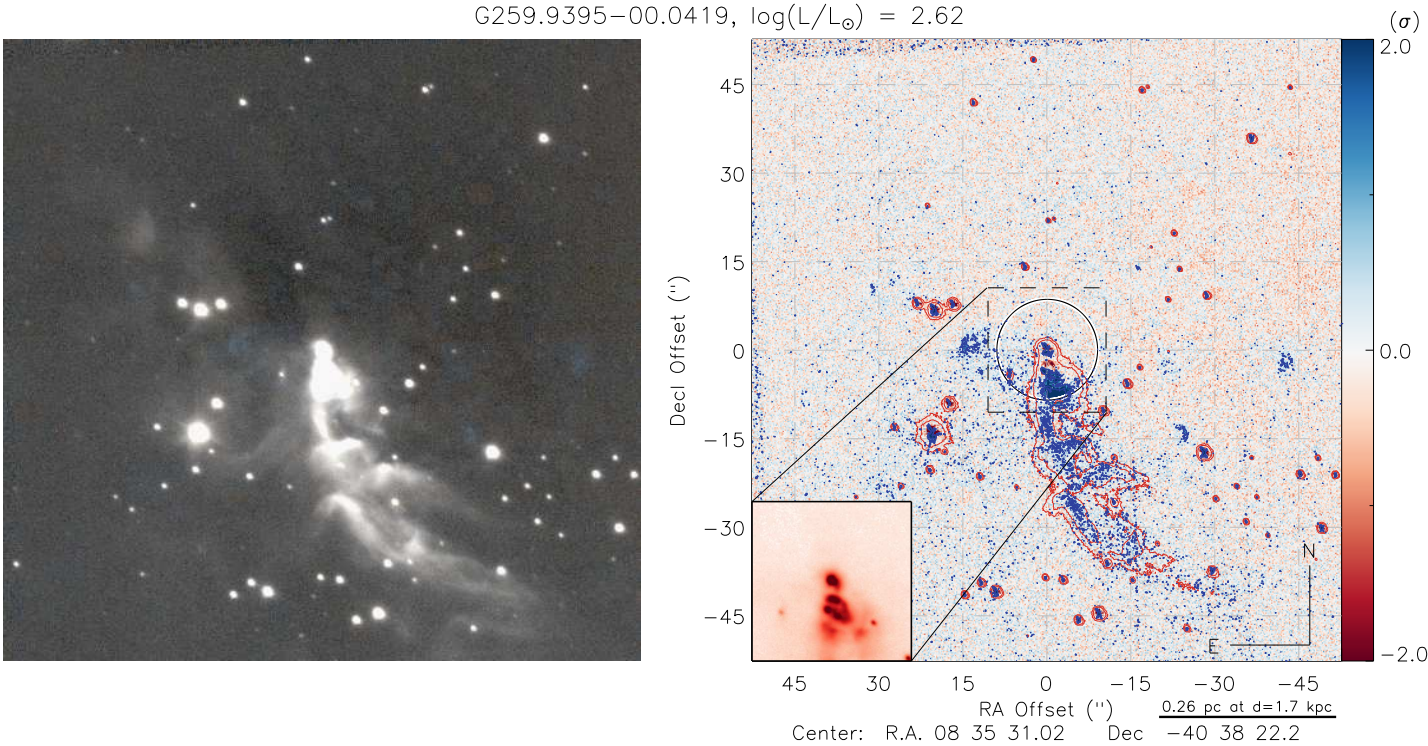

- G261.6429-02.0922 $\left(L=5.3 \times 10^{2}[d(k p c) / 2.7]^{2} \mathrm{~L}_{\odot},<\mathrm{B} 3 \mathrm{~V}_{0}\right):$ O mapa de emissão em $\mathrm{H}_{2}$ mostra uma estrutura com morfologia do tipo BP2, orientada na direção NW-SE. O lóbulo localizado na direção SE possui $\ell_{\text {proj }}=0.55$ pc e sua razão de aspecto foi estimada em $R=11.0$.

$G 261.6429-02.0922, \log \left(L / L_{\odot}\right)=2.72$
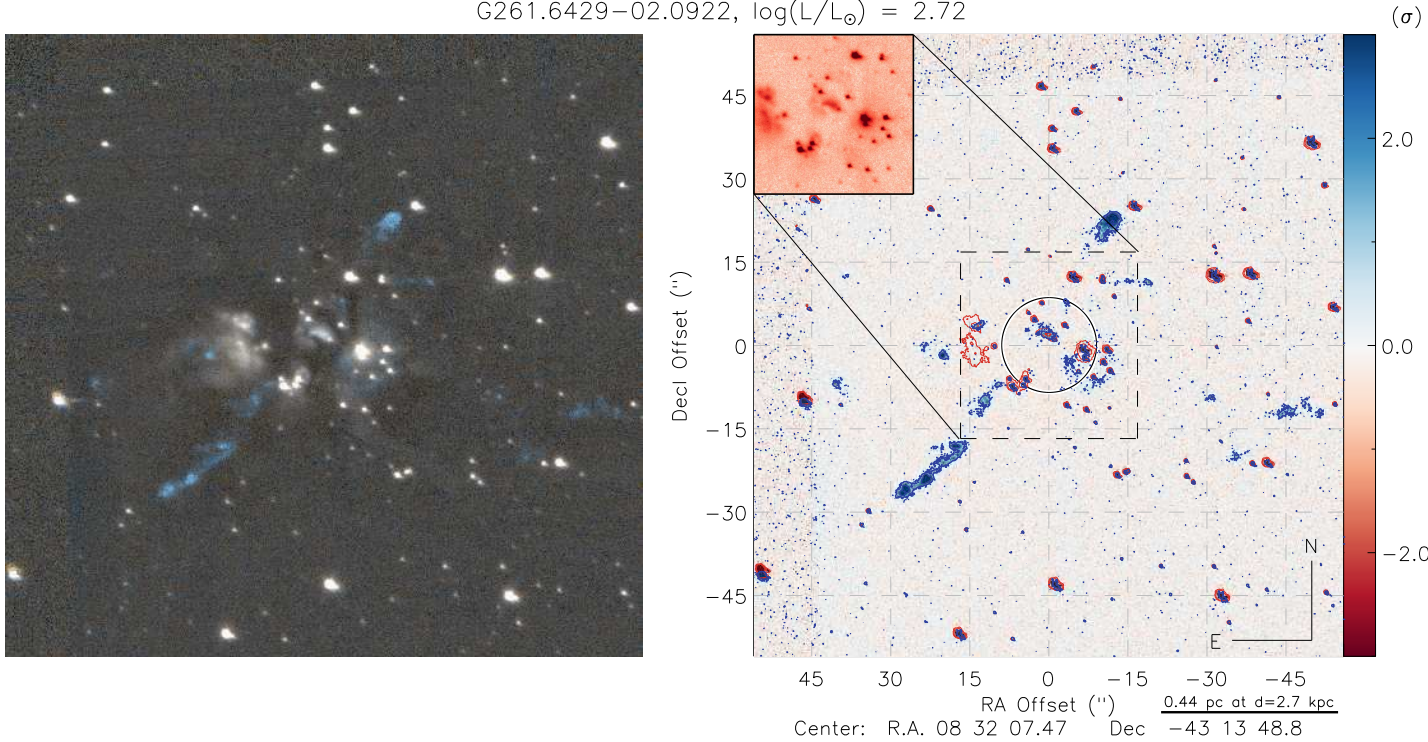

- G263.7759-00.4281 $\left(L=4.5 \times 10^{3}[d(k p c) / 1.6]^{2} \mathrm{~L}_{\odot}, \mathrm{B} 2 \mathrm{~V}_{0}\right):$ A fonte RMS está associada a uma emissão alongada na direção NW-SE, identificada no filtro do contínuo. Um 
excesso de emissão em $\mathrm{H}_{2}$ foi identificado sobre a região delimitada pelos contornos da emissão no contínuo, com razão de aspecto estimada em $R=1.8$. Um jato bipolar foi identificado no campo, porém sua posição não é compatível com a fonte em estudo.

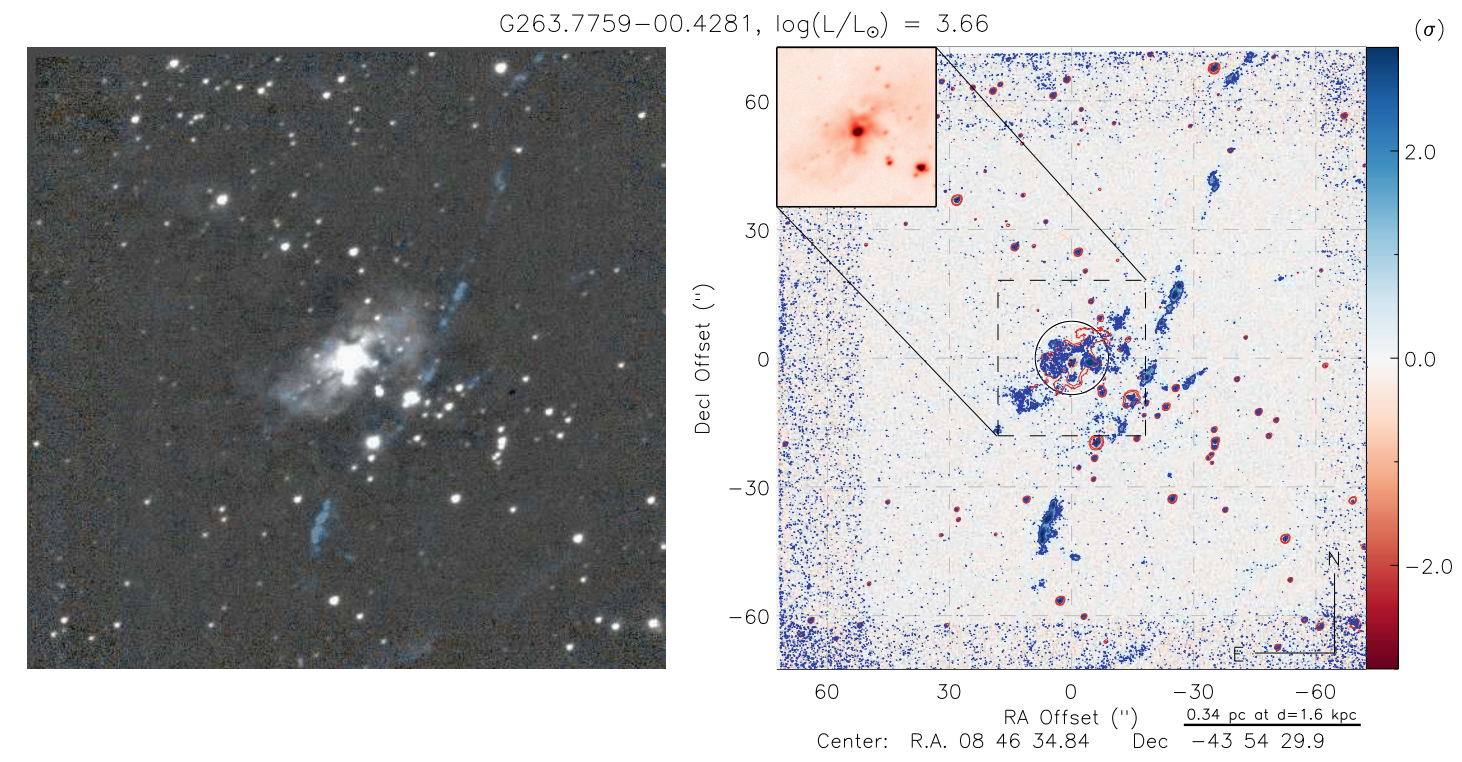

- G275.8190-03.6009 $\left(L=1.7 \times 10^{4}[d(k p c) / 9.3]^{2} \mathrm{~L}_{\odot}, \mathrm{B} 0.5 \mathrm{~V}_{0}\right):$ A fonte RMS está associada a uma emissão em $\mathrm{H}_{2}$ com morfologia do tipo BP4. Duas estruturas de maior intensidade estão localizadas na direção N-S e sugerem a presença de um jato bipolar com elevado ângulo de inclinação. A dimensão projetada do lóbulo mais intenso (localizado na direção N) foi estimada em $\ell_{\text {proj }}=0.35$ pc e sua razão de aspecto corresponde a $R=1.3$. Uma série de nós identificados na direção E-W sugere a presença de outra emissão bipolar associada a um segundo objeto pertencente à região interna do feixe do MSX. Os nós delimitam uma estrutura com $\ell_{\text {proj }}=1.8 \mathrm{pc}$. 


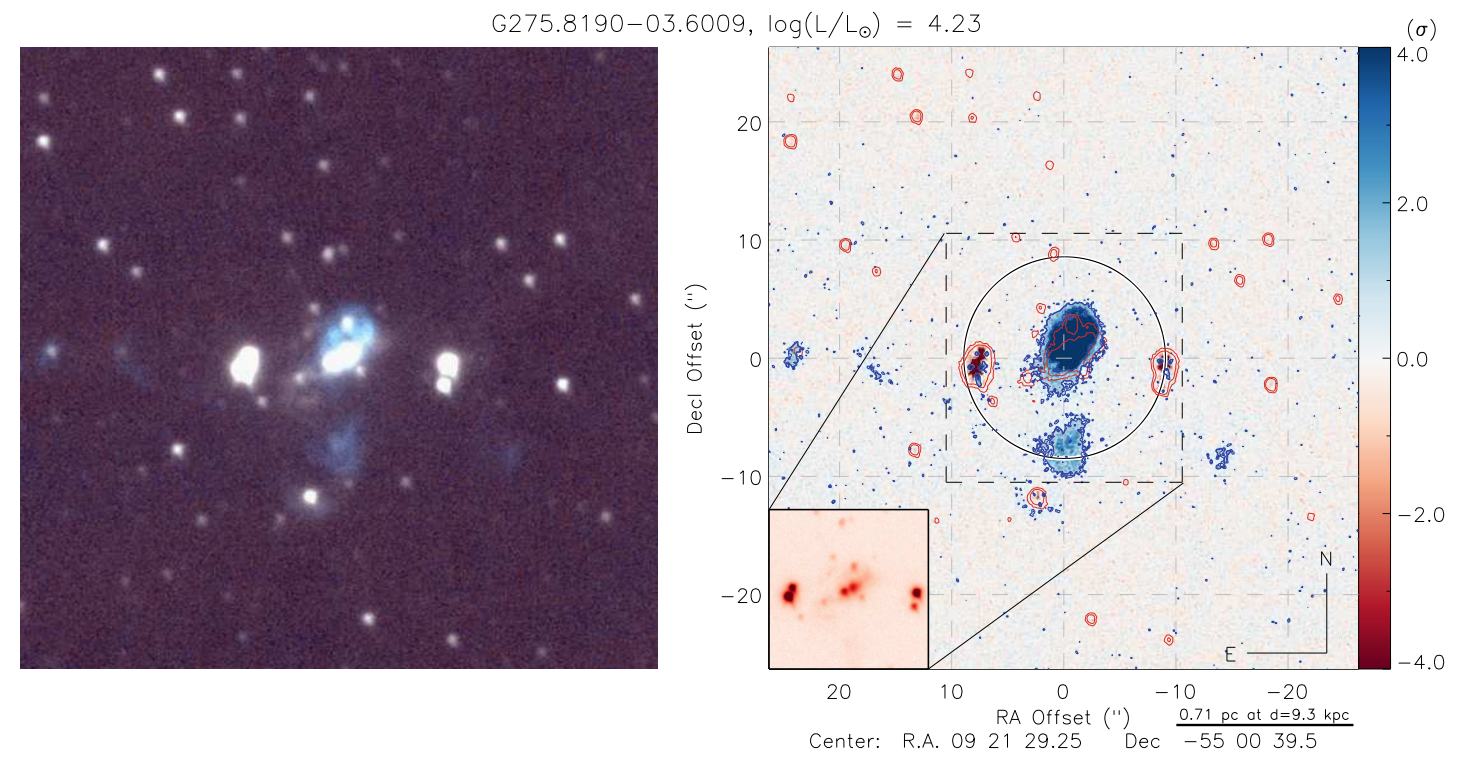

- G281.9780-01.3712 $\left(L=3.5 \times 10^{3}[d(k p c) / 6.3]^{2} \mathrm{~L}_{\odot}, \mathrm{B} 2 \mathrm{~V}_{0}\right):$ O objeto encontra-se na região central de uma emissão extensa no contínuo, orientada na direção NE-SW, com $\ell_{\text {proj }}=0.6$ pc. O mapa de emissão em $\mathrm{H}_{2}$ exibe dois nós também orientados na direção NESW, que parecem delimitar a região terminal de uma estrutura bipolar (BP2) originada a partir do objeto central. A razão de aspecto da emissão em $\mathrm{H}_{2}$ foi estimada em $R \approx 5.0 \mathrm{e}$ cada um dos lóbulos correspondem a $\ell_{\text {proj }} \approx 0.5$ pc.

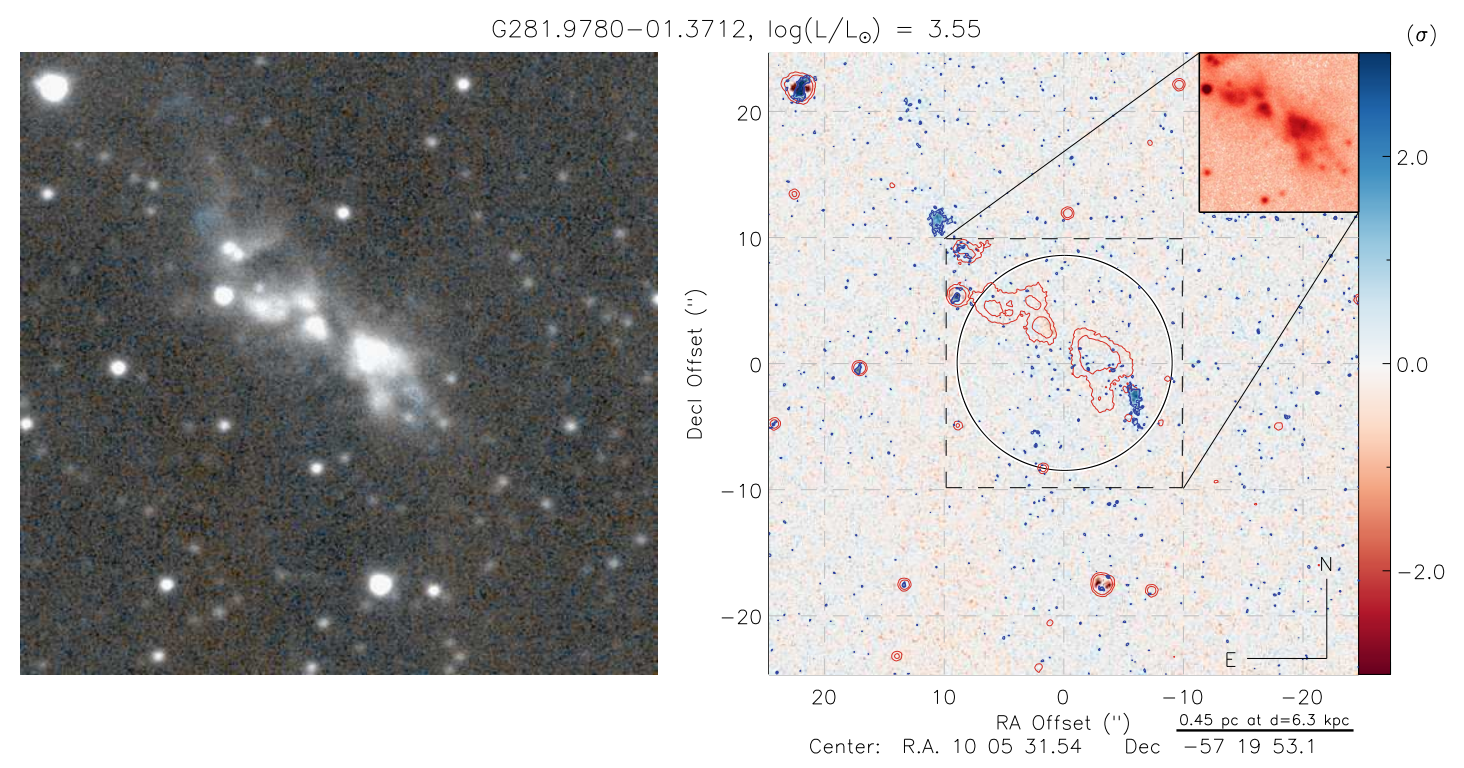


- G282.8667-03.1483 $\left(L=2.0 \times 10^{3}[d(k p c) / 3.8]^{2} \mathrm{~L}_{\odot}\right.$, B3 $\left.\mathrm{V}_{0}\right)$ : A fonte RMS está associado a uma emissão em $\mathrm{H}_{2}$ do tipo BP2, orientada na direç ao N-S. O lóbulo orientado na direção $\mathrm{S}$ corresponde a uma dimensão projetada de $\ell_{\text {proj }} \approx 0.22 \mathrm{pc}$ e sua razão de aspecto foi estimada em $R=6.0$.
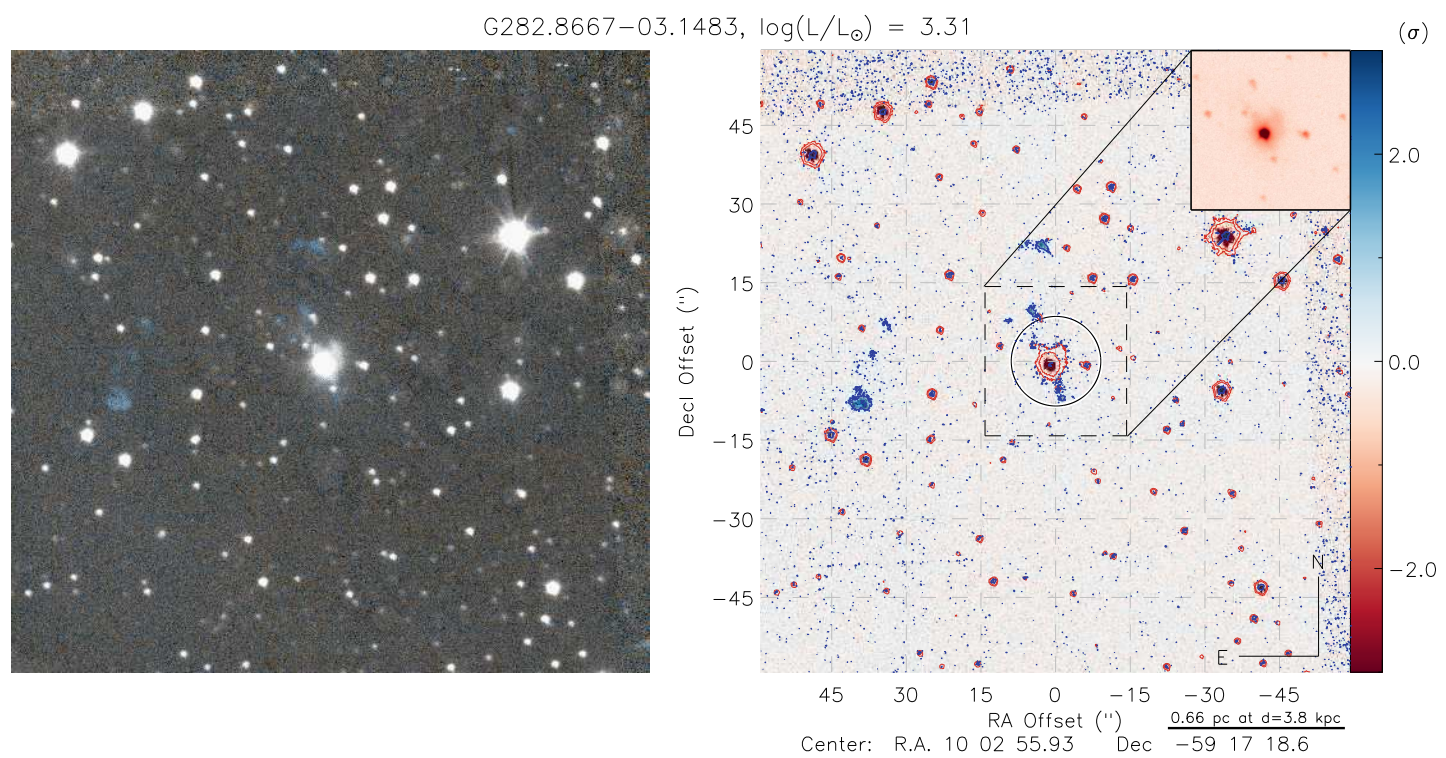

- G287.2238-00.5339 $\left(L=4.8 \times 10^{2}[d(k p c) / 2.5]^{2} \mathrm{~L}_{\odot},<\mathrm{B} 3 \mathrm{~V}_{0}\right):$ A fonte RMS apresenta uma contrapartida no NIR com emissão estendida detectada no filtro do contínuo. O mapa de emissão em $\mathrm{H}_{2}$ exibe uma estrutura bipolar BP2, orientada na direção E-W, com $\ell_{\text {proj }}=0.45$ pc e $R=7.5$. Uma segunda estrutura bipolar orientada na direção NW-SE, parece estar associada à fonte distante de 15" na direção NW da posição central do campo. 

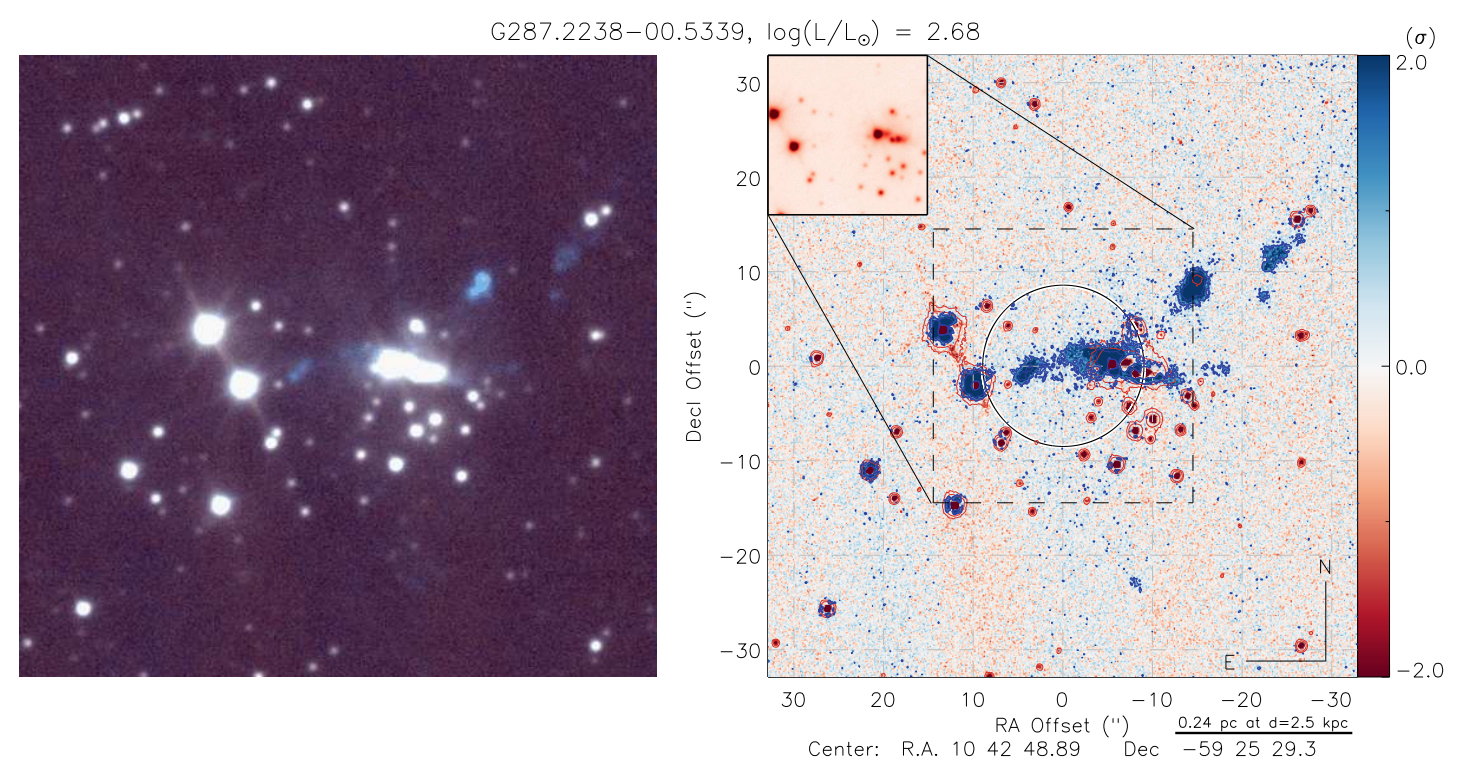

- G287.8768-01.3618 $\left(L=1.1 \times 10^{5}[d(k p c) / 7.1]^{2} \mathrm{~L}_{\odot}, \mathrm{O} 7.5 \mathrm{~V}\right)$ : A fonte RMS possui luminosidade bolométrica compatível com uma estrela do tipo espectral O7.5 na sequência principal. Seu mapa de emissão em $\mathrm{H}_{2}$ apresenta uma estrutura com morfologia do tipo BP2, orientada na direção NE-SW. O lóbulo NE da emissão bipolar corresponde a uma dimensão projetada de $\ell_{\text {proj }}=0.45$ pc e possui razão de aspecto $R=7.5$.

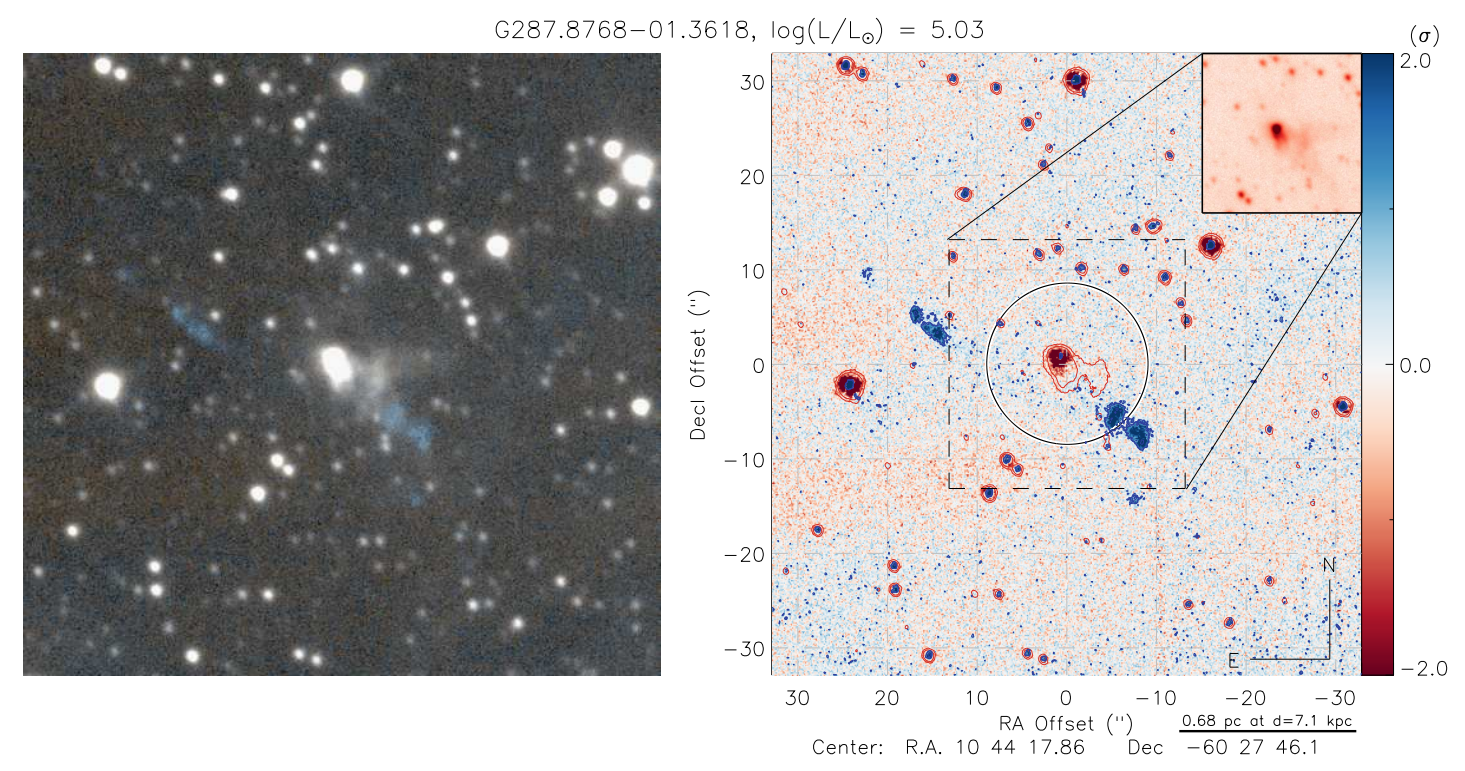

- G300.5047-00.1745 $\left(L=1.2 \times 10^{4}[d(k p c) / 9.7]^{2} \mathrm{~L}_{\odot}, \quad \mathrm{B} 0.5 \mathrm{~V}_{0}\right):$ A fonte central está 
projetada na direção de um aglomerado de estrelas. Seu mapa de emissão em $\mathrm{H}_{2}$ exibe dois nós, orientados na direção E-W, que definem uma estrutura do tipo BP2. O nó mais intenso está localizado na região mais próxima da fonte NIR enquanto o segundo nó está $\mathrm{a} \approx 10^{\prime \prime}$ na direção $\mathrm{W}$ do objeto central.
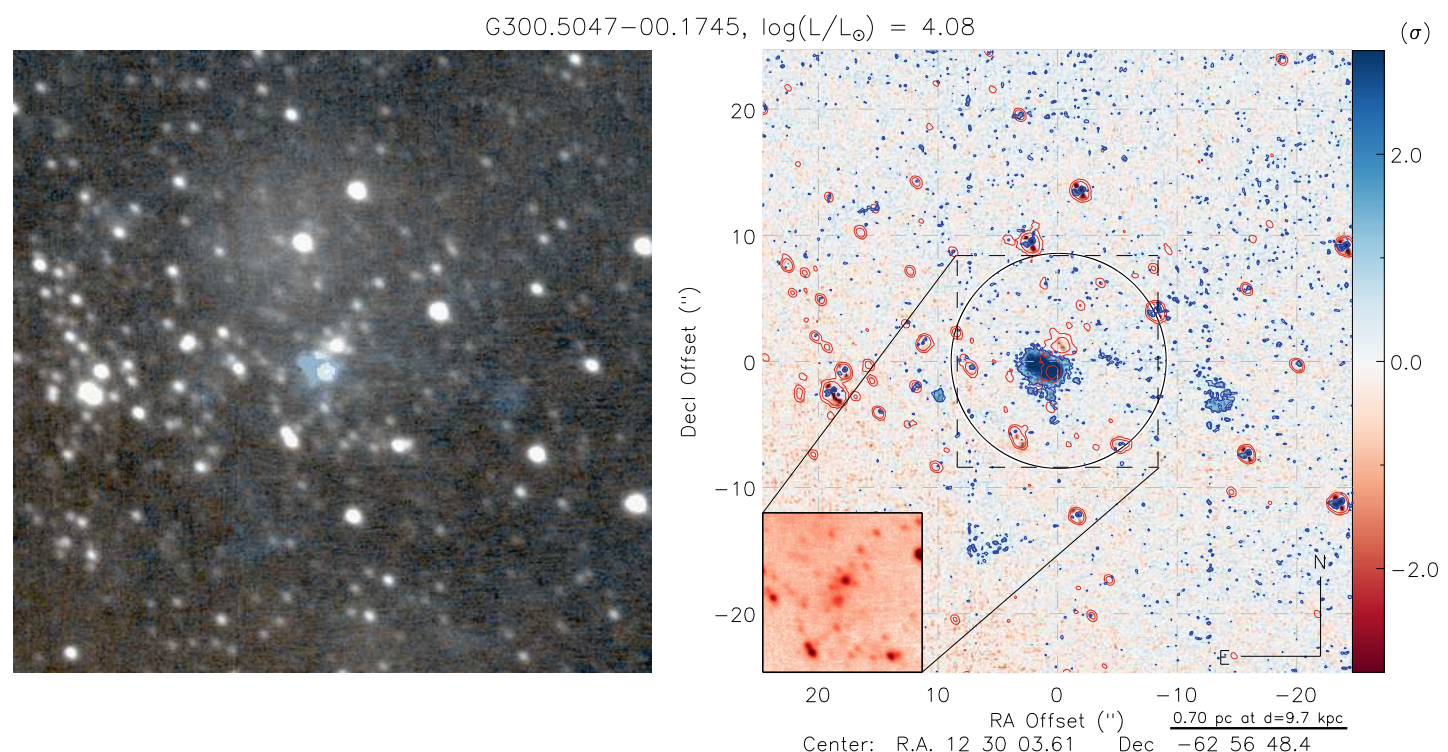

- G308.0108+02.0146 $\left(L=1.1 \times 10^{4}[d(k p c) / 1.7]^{2} \mathrm{~L}_{\odot}, \mathrm{B} 1 \mathrm{~V}_{0}\right)$ : A fonte está associada a uma emissão extensa no filtro do contínuo, que se estende desde a região central até $\sim 10^{\prime \prime}$ na direção W. Uma estrutura do tipo polar (BP1) foi identificada no mapa de emissão em $\mathrm{H}_{2}$. A emissão é orientada na direção $\mathrm{SE}$, possui $\ell_{\text {proj }}=0.2 \mathrm{pc}$ e sua razão de aspecto foi estimada em $R=5.2$. 

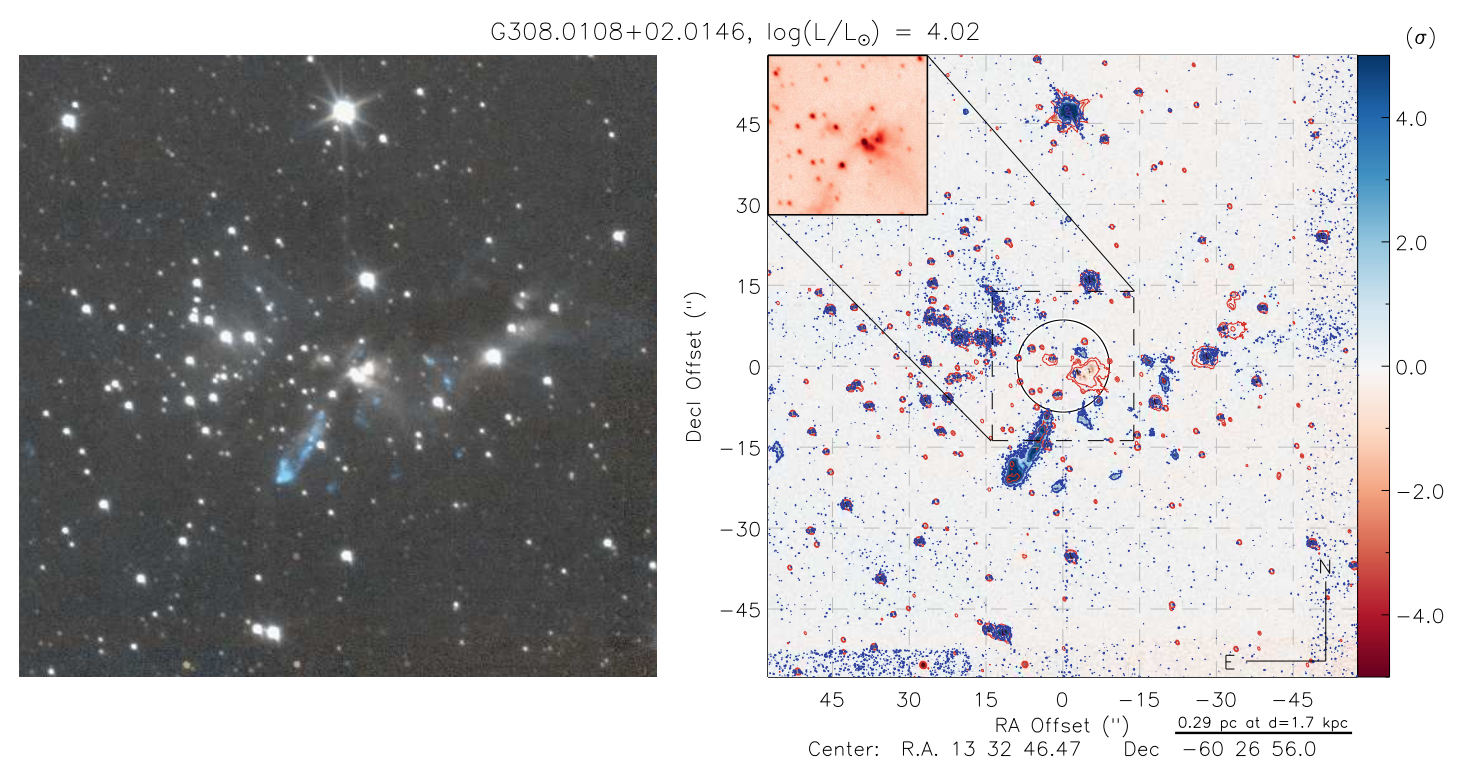

- G311.9799-00.9527 $\left(L=7.4 \times 10^{2}[d(k p c) / 3.1]^{2} \mathrm{~L}_{\odot},<\mathrm{B} 3 \mathrm{~V}_{0}\right)$ : O objeto central apresenta emissão monopolar do tipo BP1, orientada na direção NW. A estrutura possui $\ell_{\text {proj }}=0.25$ pc e sua razão de aspecto foi estimada em $R=4.0$. Alguns nós de emissão em $\mathrm{H}_{2}$ foram identificados na direção SE da fonte NIR, sugerindo uma contrapartida mais distante da emissão polar.

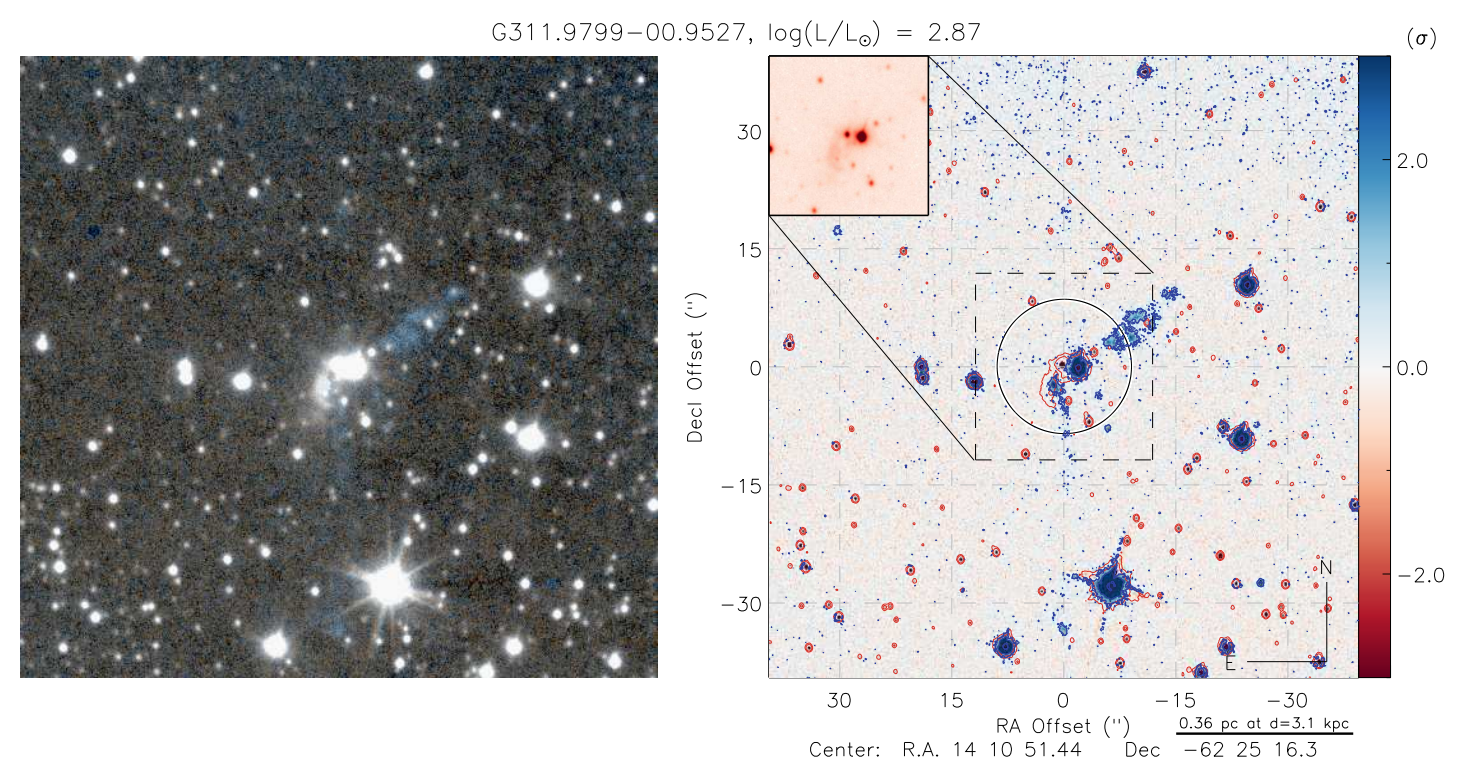

- G313.5769+00.3267 $\left(L=4.7 \times 10^{4}[d(k p c) / 8.3]^{2} \mathrm{~L}_{\odot}, \mathrm{O} 9.5 \mathrm{~V}_{0}\right)$ : O objeto central apre- 
senta emissão monopolar do tipo BP1, orientada na direção NE-SW. A estrutura possui $\ell_{\text {proj }}=0.40$ pc e sua razão de aspecto foi estimada em $R=3.6$.

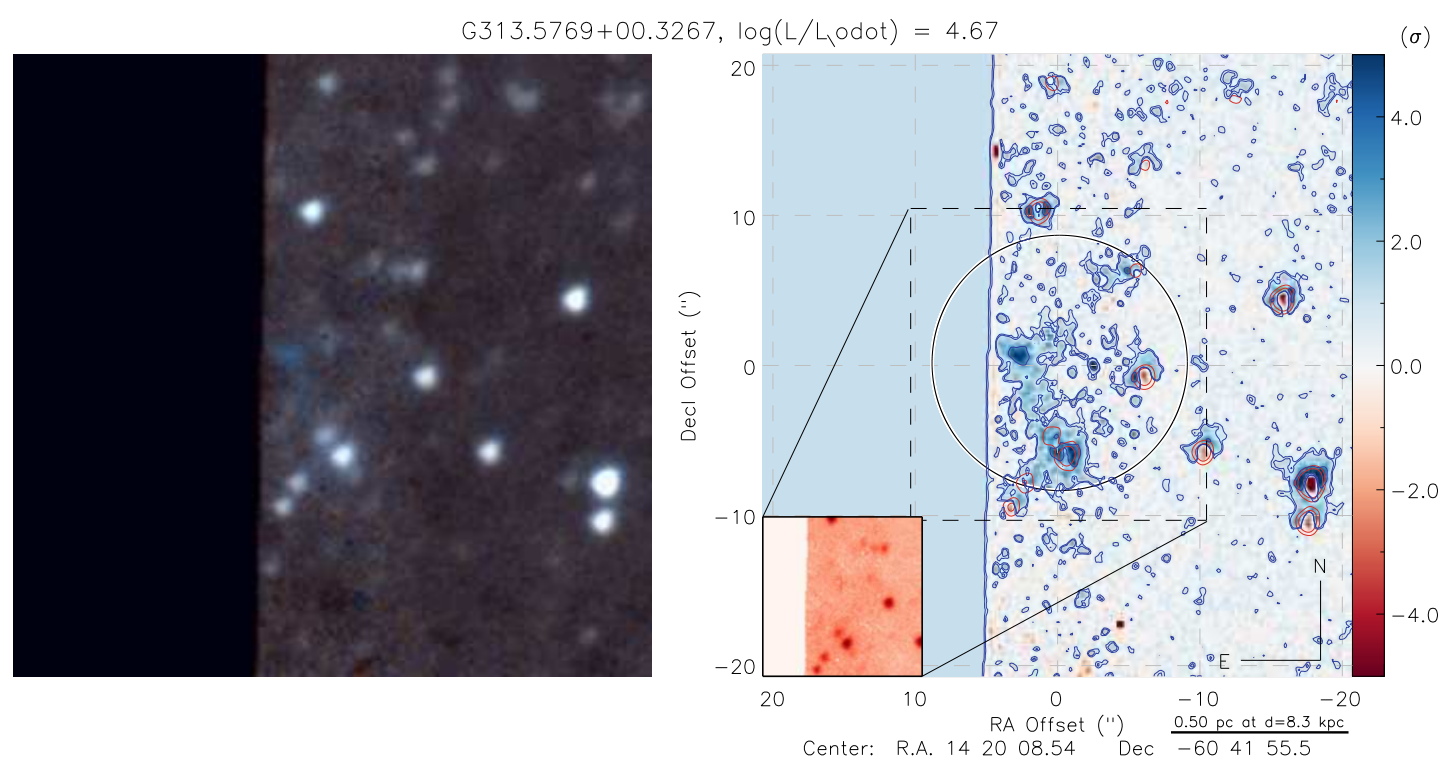

- G318.0489+00.0854B $\left(L=6.9 \times 10^{3}[d(k p c) / 3.4]^{2} \mathrm{~L}_{\odot}, \mathrm{B} 1 \mathrm{~V}_{0}\right):$ O mapa de emissão em $\mathrm{H}_{2}$ apresenta alguns nós distribuídos ao redor da fonte RMS, sugerindo a presença de emissões multipolares classificadas como BP5. Os nós mais externos, orientados na direção E-W, definem uma estrutura com $\ell_{\text {proj }}=0.65$ pc. Uma segunda estrutura bipolar, orientada na direção NE-SW, possui $\ell_{\text {proj }}=0.45$ pc. Finalmente, a terceira emissão nodal é vista na direção NW da fonte central e, embora nenhuma contrapartida vermelha tenha sido identificada no mapa de emissão em $\mathrm{H}_{2}$, é possível que esse nó corresponda ao lóbulo azul de outra estrutura bipolar. 

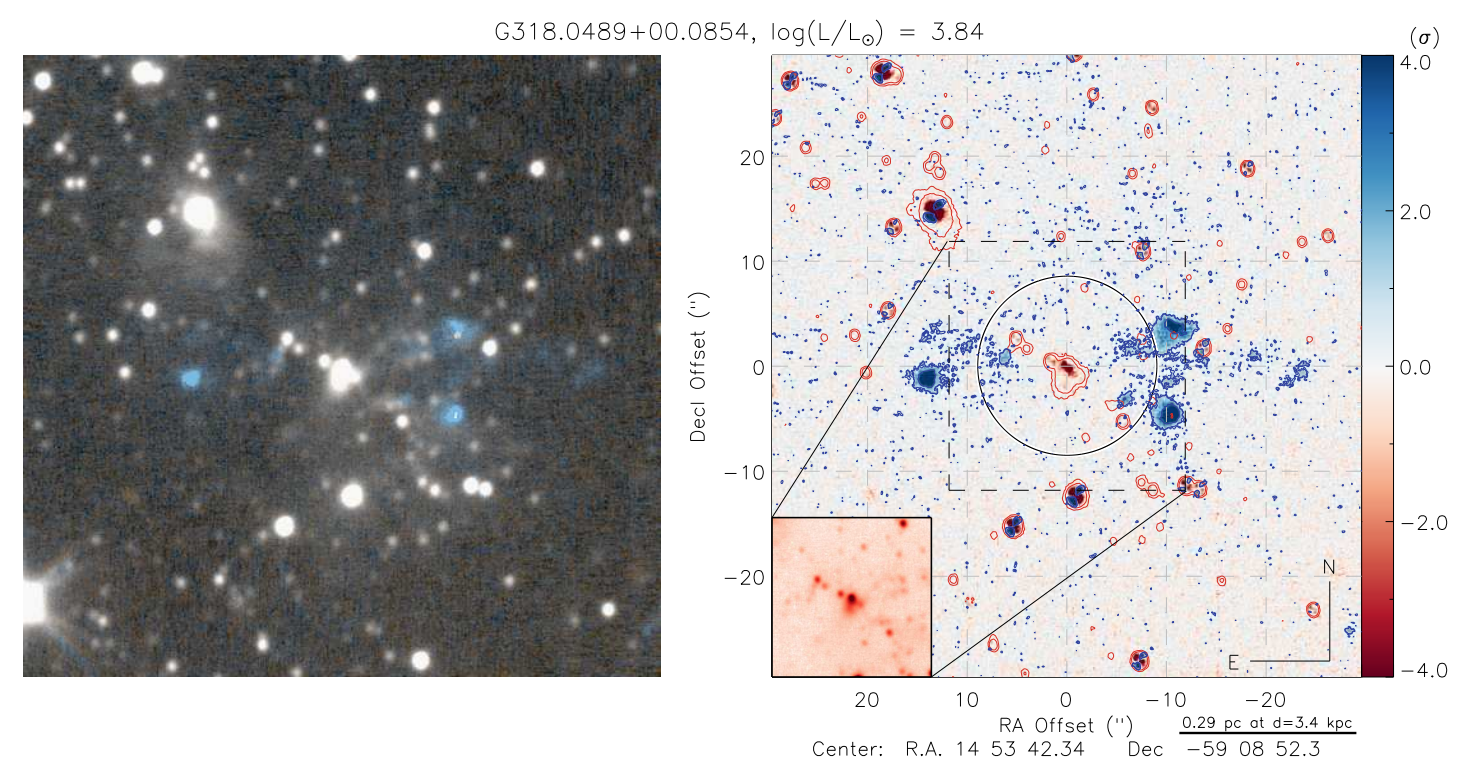

- G318.9480-00.1969 $\left(L=6.3 \times 10^{3}[d(k p c) / 2.4]^{2} \mathrm{~L}_{\odot}, \mathrm{B} 1 \mathrm{~V}_{0}\right):$ A fonte RMS está associada a uma série de nós de emissão em $\mathrm{H}_{2}$, distribuídos ao longo da direção NW-SE. Essa estrutura apresenta morfologia do tipo BP2, e seu lóbulo mais intenso, orientado na direção NW, apresenta $\ell_{\text {proj }}=0.2$ pc e $R=6.0$.

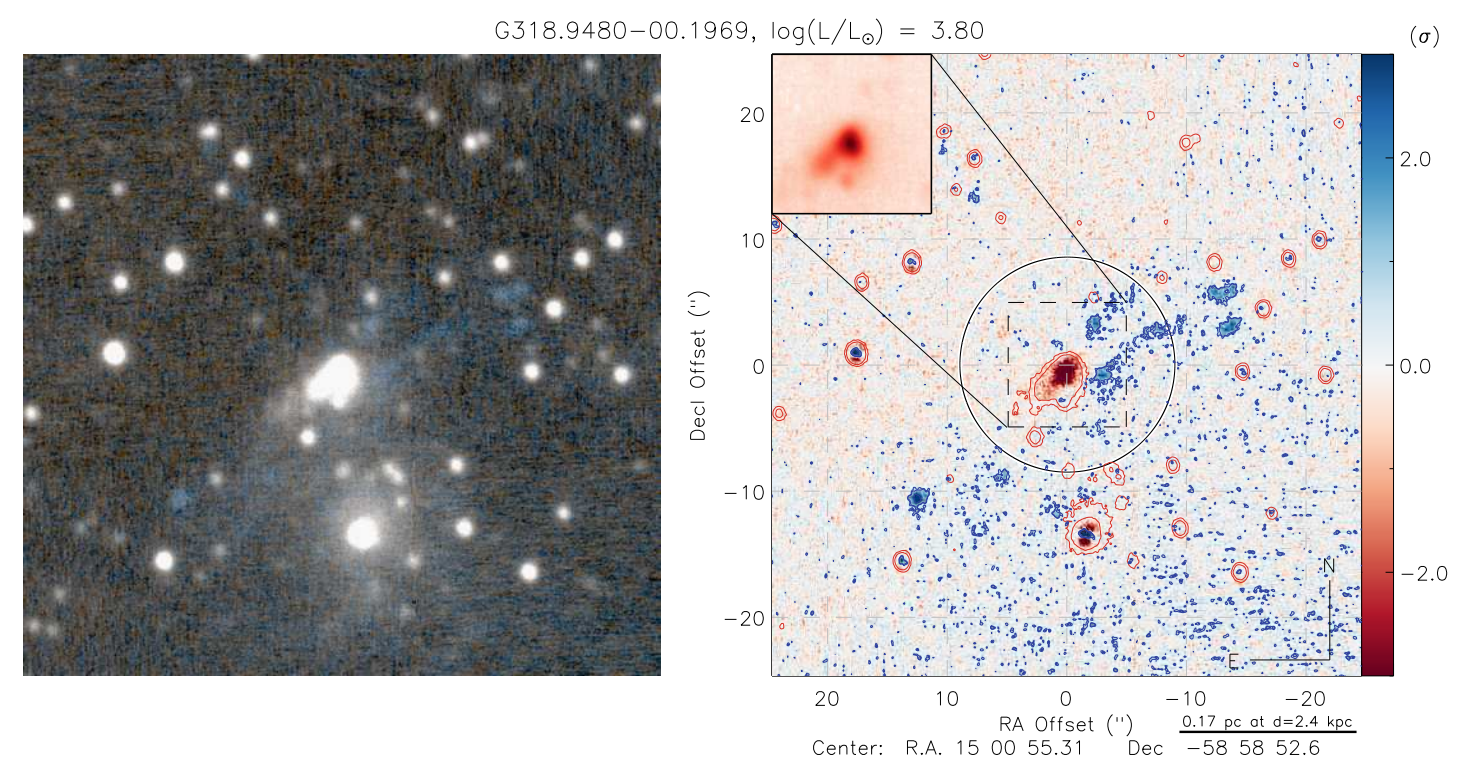

- G326.4755+00.6947 $\left(L=4.4 \times 10^{3}[d(k p c) / 2.8]^{2} \mathrm{~L}_{\odot}, \mathrm{B} 2 \mathrm{~V}_{0}\right)$ : O objeto central apresenta emissão no filtro do contínuo que se estende desde a região central até $\approx 5^{\prime \prime}$ na direção 
SE da fonte. O mapa de emissão em $\mathrm{H}_{2}$ apresenta uma estrutura bipolar, orientada perpendicularmente à emissão no contínuo. A emissão recebeu a classificação BP2. O lóbulo localizado na direção NE corresponde a uma dimensão projetada de $\ell_{\text {proj }} \approx 0.10$ pc e sua razão de aspecto foi estimada em $R=3.2$.

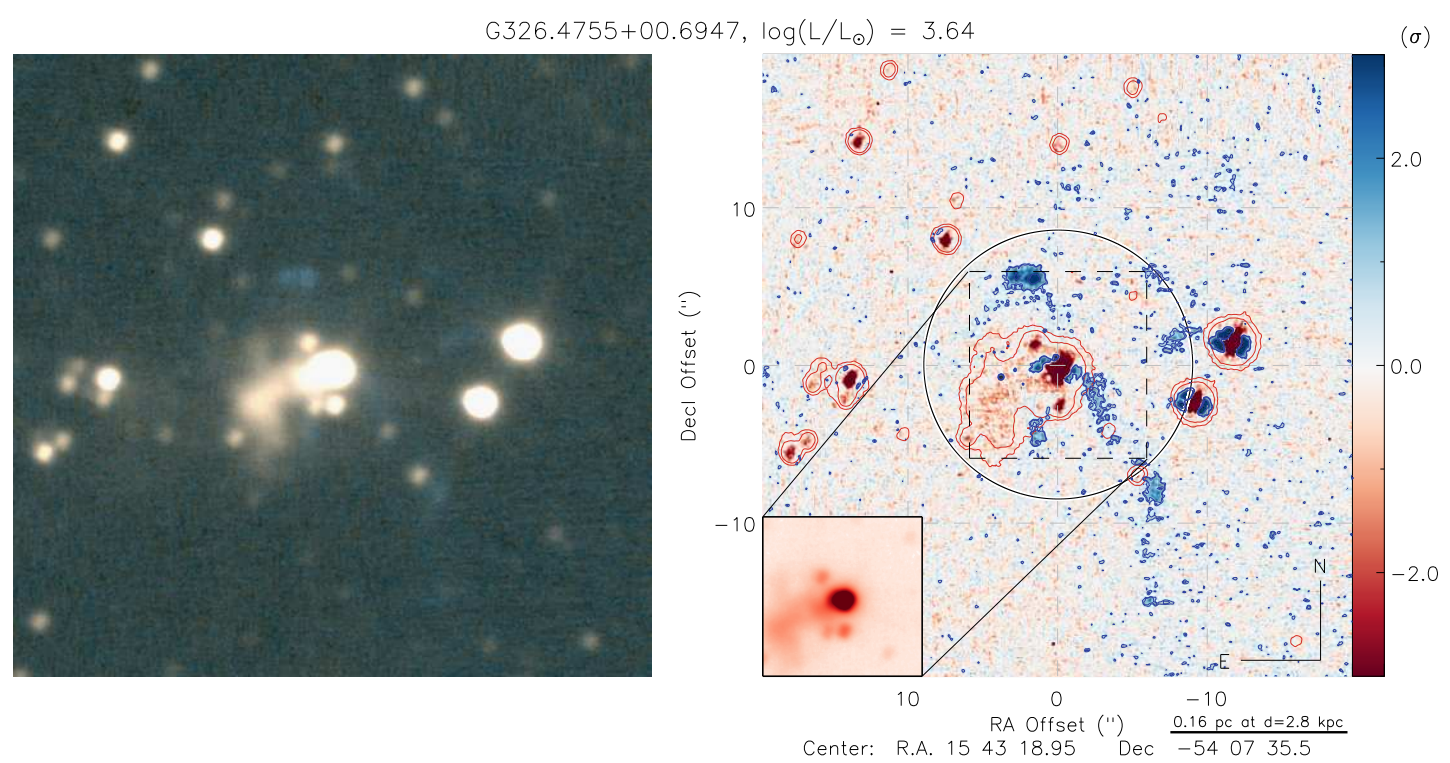

- G326.7249+00.6159B $\left(L=1.6 \times 10^{5}[d(k p c) / 11.4]^{2} \mathrm{~L}_{\odot}, \mathrm{O} 6.5 \mathrm{~V}\right):$ A fonte RMS possui luminosidade bolométrica compatível com uma estrela do tipo O6.5 V. Seu mapa de emissão em $\mathrm{H}_{2}$ apresenta uma estrutura do tipo BP1 com baixo grau de colimação $(R=0.9)$, que se estende desde a região central do campo até $\approx 30^{\prime \prime}$ na direção N. A estrutura corresponde a uma dimensão projetada de $\ell_{\text {proj }}=1.6 \mathrm{pc}$. 


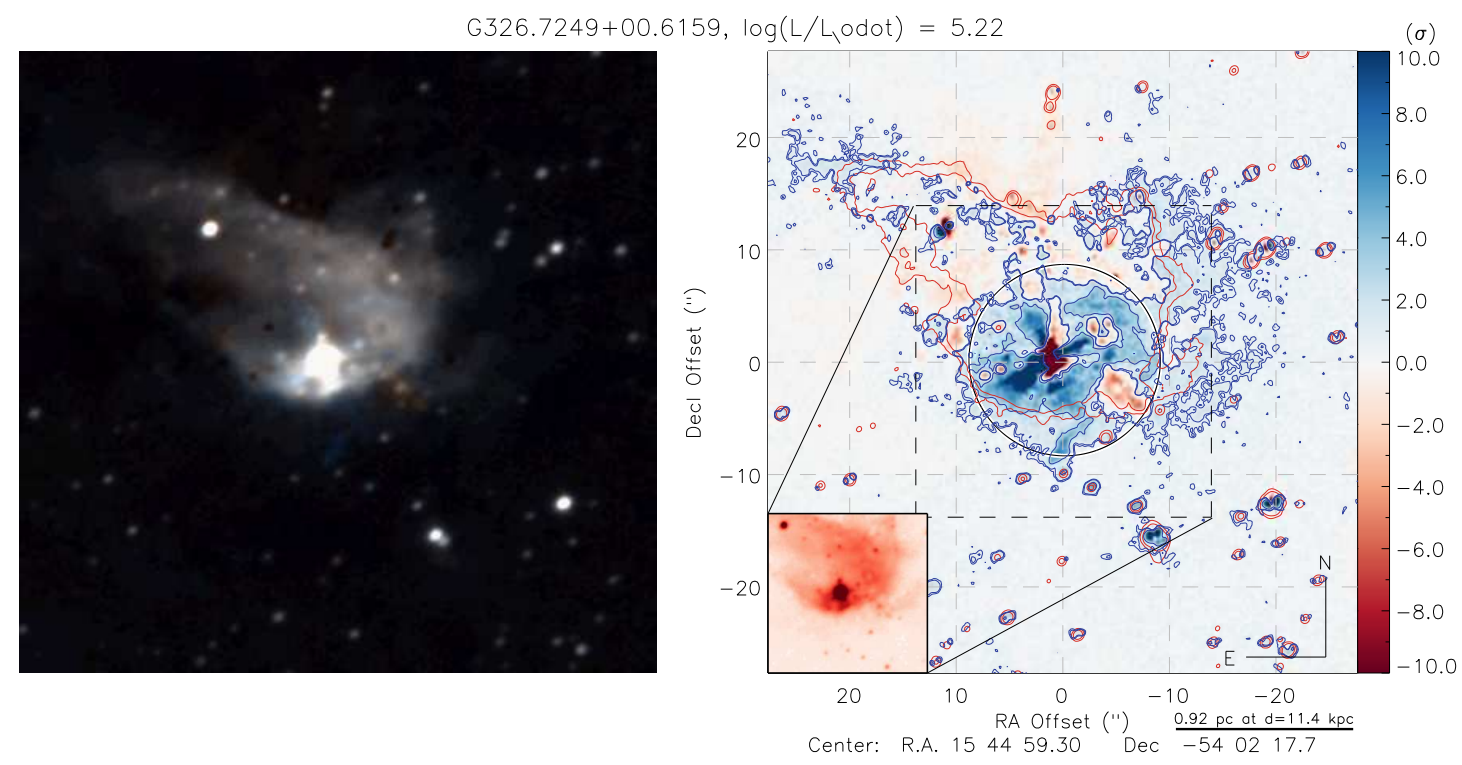

- G328.2523-00.5320 $\left(L=4.6 \times 10^{4}[d(k p c) / 3.1]^{2} \mathrm{~L}_{\odot}, 09.5 \mathrm{~V}_{0}\right):$ O mapa de emissão em $\mathrm{H}_{2}$ apresenta uma estrutura com morfologia do tipo monopolar (BP1), na direção $\mathrm{S}$ do objeto central. A emissão em $\mathrm{H}_{2}$ possui dimensão projetada de $\ell_{\text {proj }}=0.28$ pc e sua razão de aspecto foi estimada em $R=7.0$.

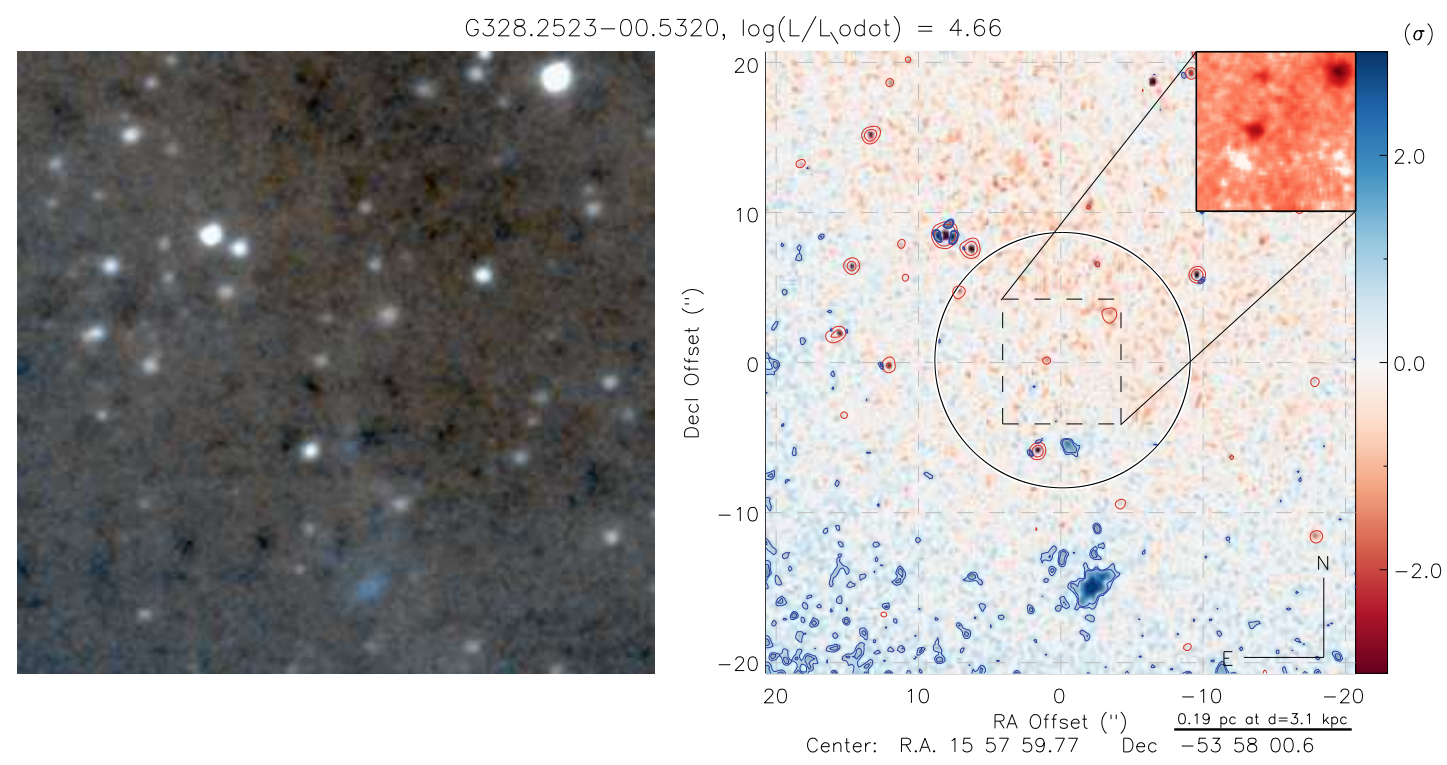

- G328.5487+00.2717 $\left(L=2.1 \times 10^{3}[d(k p c) / 3.9]^{2} \mathrm{~L}_{\odot}, \mathrm{B} 3 \mathrm{~V}_{0}\right):$ O mapa de emissão em $\mathrm{H}_{2}$ apresenta uma estrutura com morfologia do tipo BP2, orientada na direção N-S. 
A diferença na intensidade dos lóbulos permite concluir que a estrutura localizada ao S representa o lóbulo azul da emissão bipolar. O lóbulo S, possui dimensão projetada de $\ell_{\text {proj }}=0.30$ pc e sua razão de aspecto foi estimada em $R=4.0$.

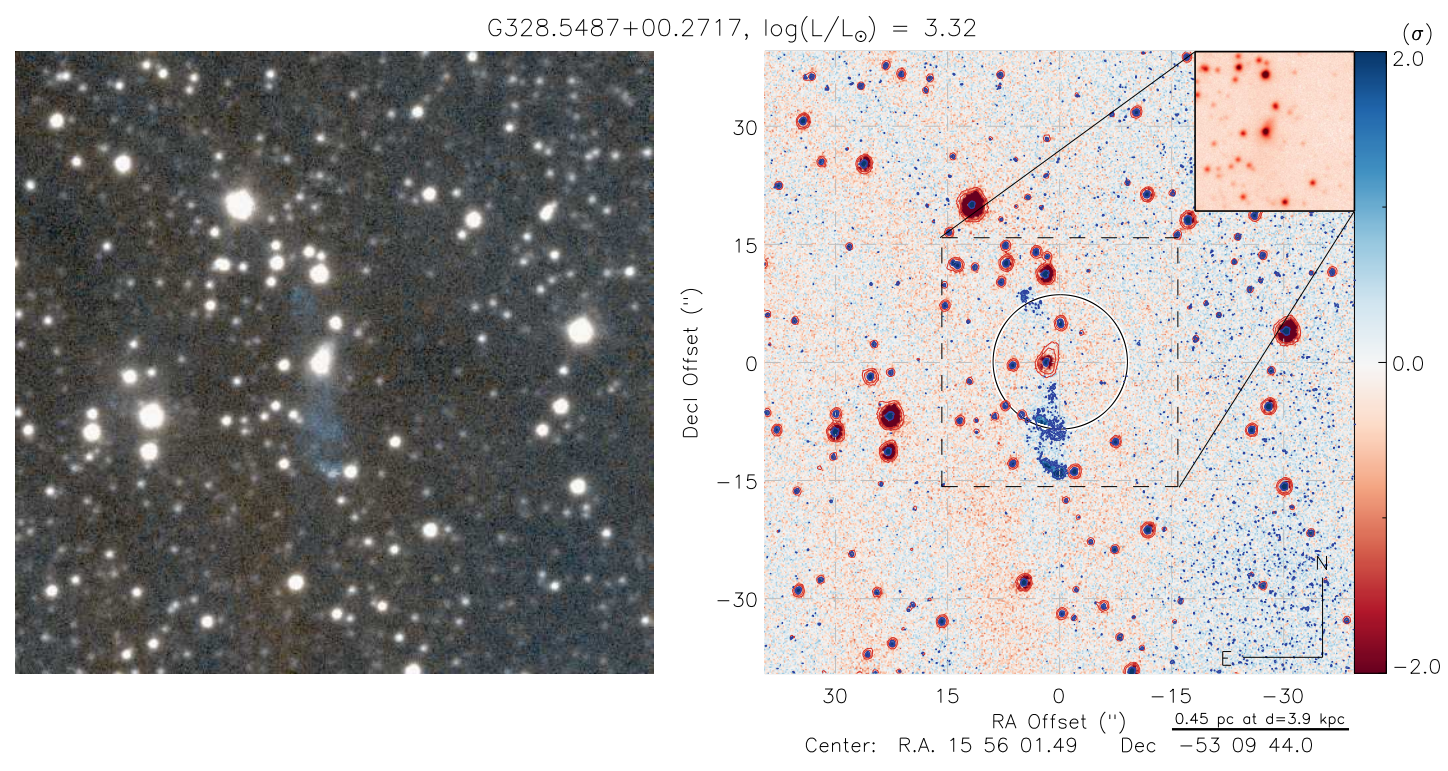

- G331.7318+02.6747 $\left(L=9.5 \times 10^{2}[d(k p c) / 1.9]^{2} \mathrm{~L}_{\odot},<\mathrm{B} 3 \mathrm{~V}_{0}\right)$ : A fonte RMS corresponde a um objeto de luminosidade inferior a estrelas do tipo espectral B3 na SPIZ e está associada a uma estrutura com morfologia do tipo BP4, foi identificada no mapa de emissão em $\mathrm{H}_{2}$. As dimensões da emissão em $\mathrm{H}_{2}$ foram estimadas em $\ell_{\text {proj }} \approx 0.10 \mathrm{pc}$.
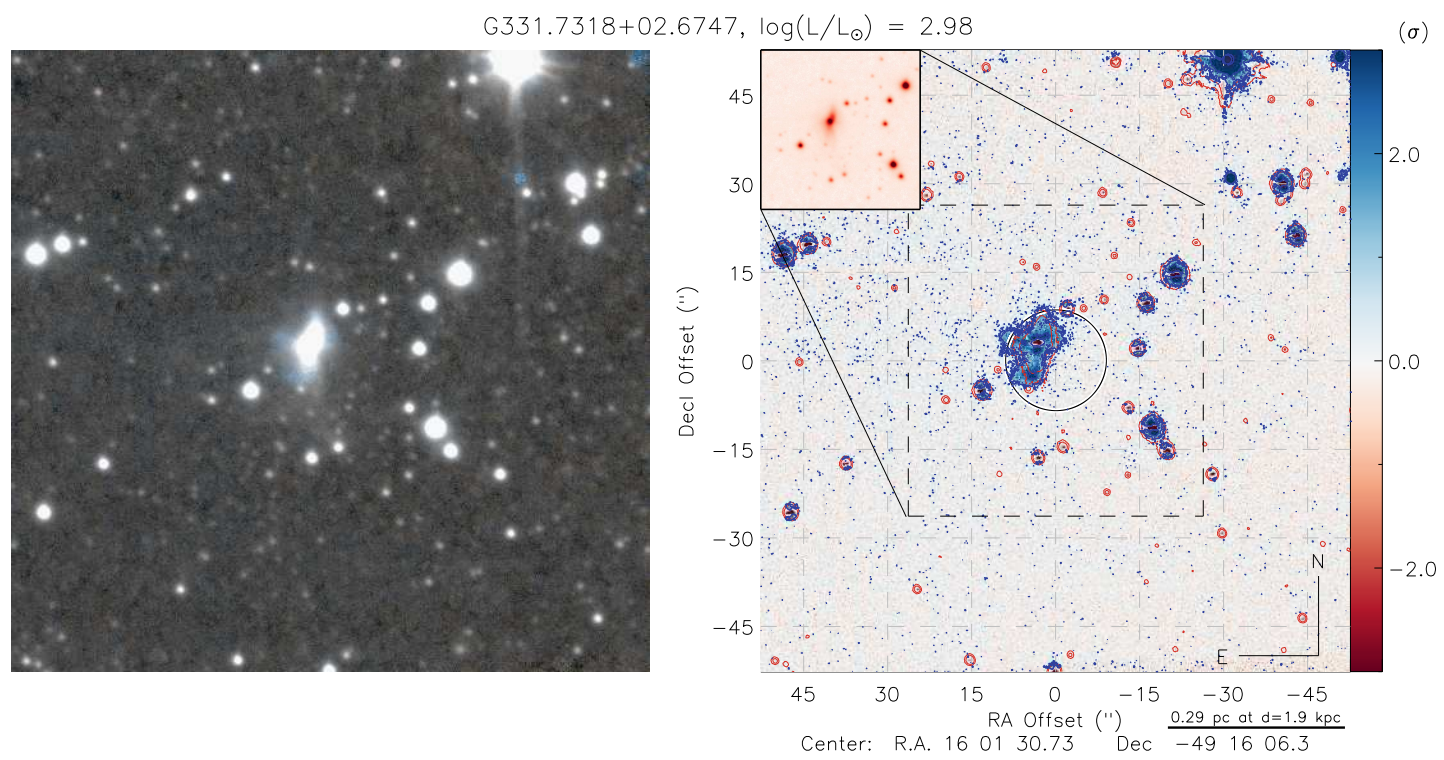
- G333.3151+00.1053 $\left(L=4.7 \times 10^{3}[d(k p c) / 3.3]^{2} \mathrm{~L}_{\odot}, \mathrm{B} 2 \mathrm{~V}_{0}\right)$ : Uma emissão do tipo BP2, identificada no mapa de emissão em $\mathrm{H}_{2}$, parece estar associada à estrutura alongada distante de $\approx 5^{\prime \prime}$ na direção $\mathrm{W}$ do centro do campo. A emissão em $\mathrm{H}_{2}$ é orientada na direção NE-SW e apresenta dimensão projetada de $\ell_{\text {proj }} \approx 0.20$ pc. A razão de aspecto do lóbulo NE foi estimada em $R=3.8$.

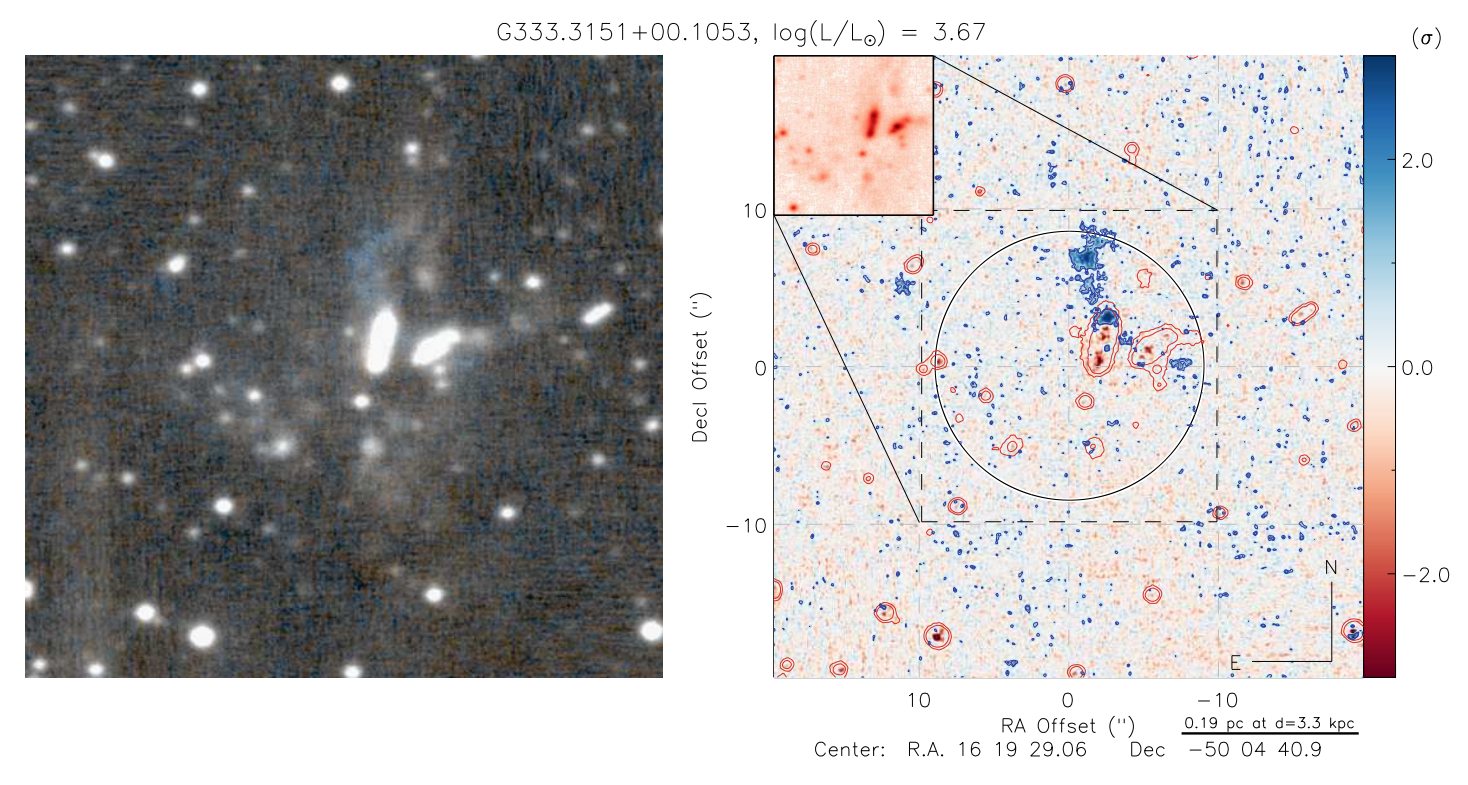

- G338.2801+00.5419 $\left(L=1.8 \times 10^{4}[d(k p c) / 11.5]^{2} \mathrm{~L}_{\odot}, \mathrm{B} 0.5 \mathrm{~V}_{0}\right):$ O mapa de emissão em $\mathrm{H}_{2}$ apresenta uma estrutura com morfologia do tipo BP4. Alguns nós de emissão em $\mathrm{H}_{2}$, posicionados na direção NW-SE, indicam uma emissão do tipo polar associada ao objeto central, com $\ell_{\text {proj }}=1.0$ pc e $R \approx 5.5$. Uma segunda sequência de nós, na direção NE-SW, sugerem a presença de outra estrutura bipolar originada na região central do campo. 


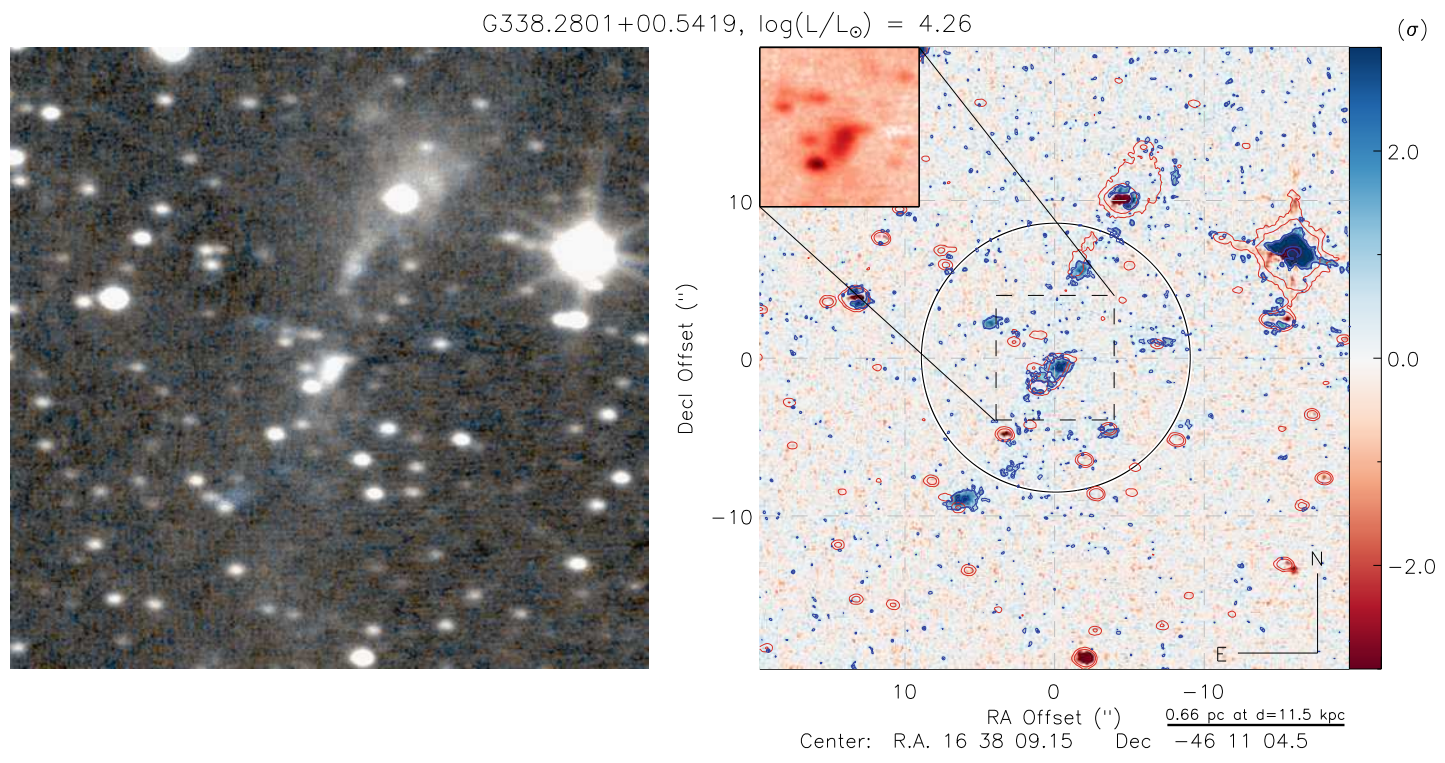

- G338.5459+02.1175 $\left(L=8[d(k p c) / 8.1]^{2} \mathrm{~L}_{\odot},<\right.$ B3 $\left.\mathrm{V}_{0}\right)$ : O objeto central está associado a uma emissão em $\mathrm{H}_{2}$ do tipo BP2, orientada na direção NE-SW. Os lóbulos correspondem a dimensões projetadas de $\ell_{\text {proj }} \approx 0.6 \mathrm{pc}$ e suas razões de aspecto foram estimadas em $R \approx 3.3$.

$G 338.5459+02.1175, \log \left(L / L_{\odot}\right)=0.91$
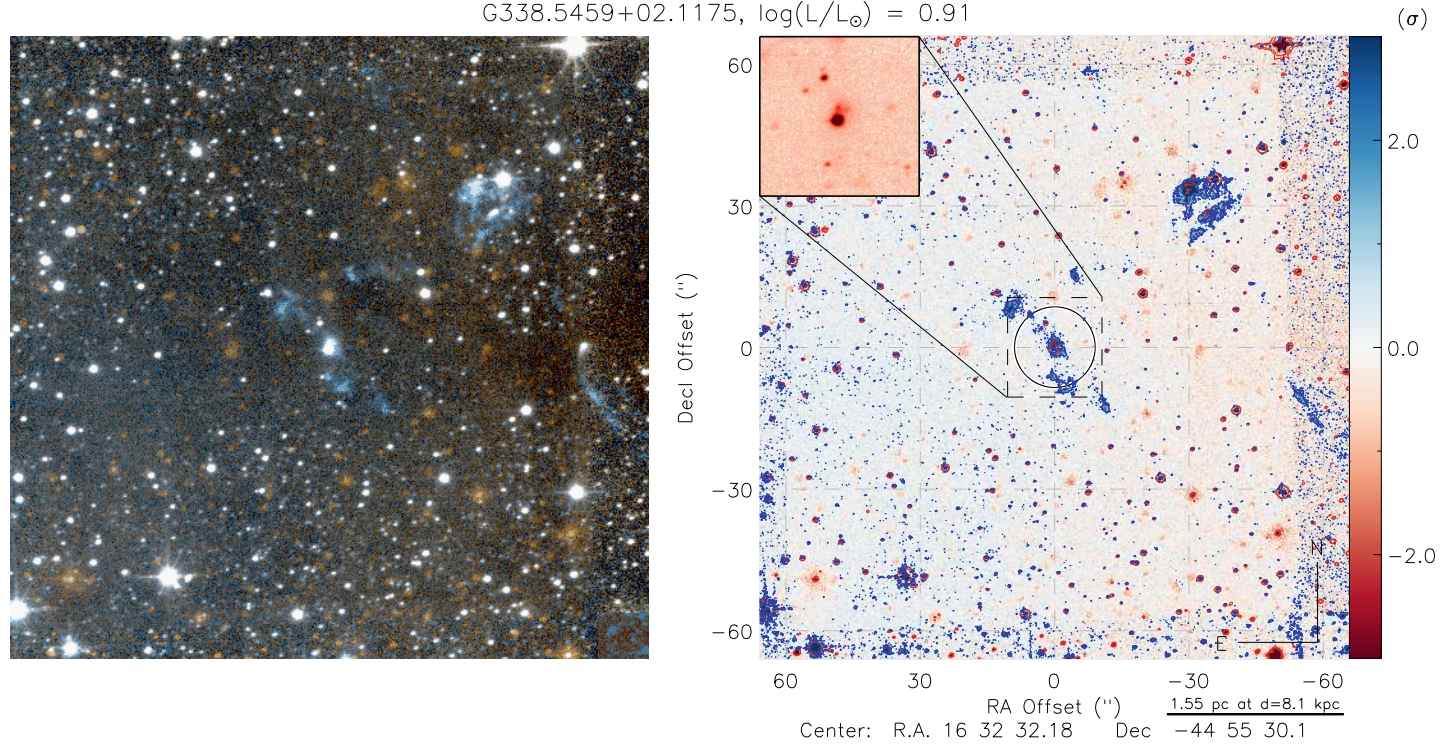
Capítulo 5

\section{Análise e Discussão dos Resultados}

O Capítulo 4 apresentou os resultados observacionais do levantamento de candidatos a MYSOs a partir de observações no infravermelho próximo, conduzido nos telescópios CFHT e SOAR. O presente capítulo irá apresentar a análise e a discussão dos resultados, comparando as características gerais da amostra com demais trabalhos da literatura.

\subsection{Estatísticas Gerais da Amostra}

A Figura 5.1 apresenta as propriedades gerais dos 296 candidatos a MYSOs apresentados nesse trabalho, classificados de acordo com as propriedades observacionais definidas na Seção 4.5. Os Painéis A, B e C da Figura 5.1 apresentam a classificação das fontes de acordo com a morfologia da emissão em $\mathrm{H}_{2}$ identificada em cada um dos campos. O Painel A mostra que $\approx 50 \%$ da amostra apresenta emissão extensa no filtro do $\mathrm{H}_{2}$, sendo $19 \%$ classificada como emissões difusas, $11 \%$ como emissões nodais e $21 \%$ (bi)polares. A análise das emissões com morfologia do tipo BP indica que 40 das fontes estão associadas a emissões bipolares (BP2). Os casos multipolares totalizam 11 fontes e podem representar a superposição de distintos jatos bipolares, gerados por fontes múltiplas ou por uma única fonte geratriz com considerável movimento de precessão. Os últimos 11 objetos apresentam emissão monopolar (BP1). No entanto, o mecanismo da formação dos jatos não permite a existência de estruturas monopolares gerada a partir de estrelas jovens. Nesse caso, é esperado que uma combinação de fatores (tais como a inclinação da estrutura em relação à linha de visada, a extinção e opacidade do meio interestelar nas proximidades da protoestrela) seja responsável pelo obscurecimento da contrapartida mais distante da emissão observada. 


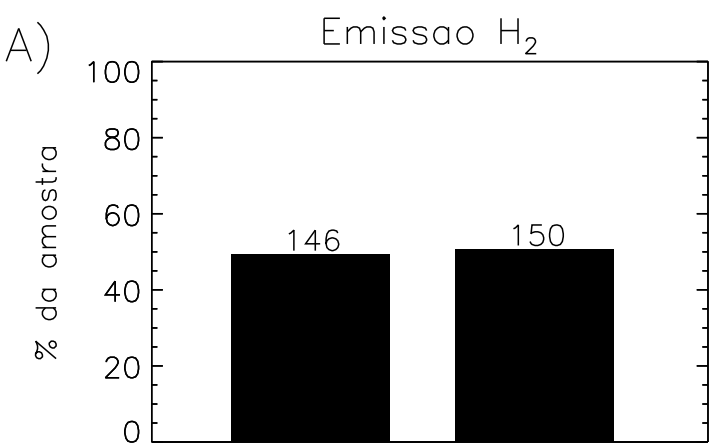

N

B)

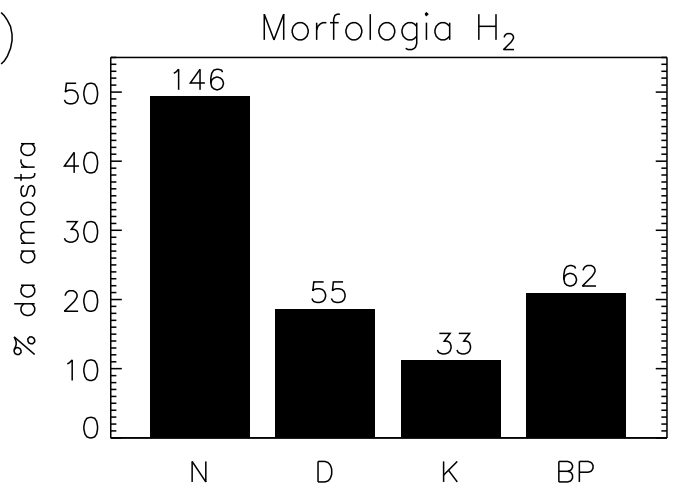

C)

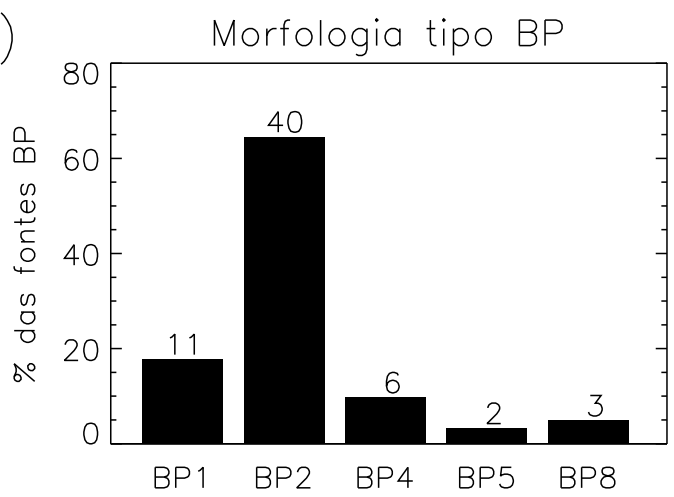

D)

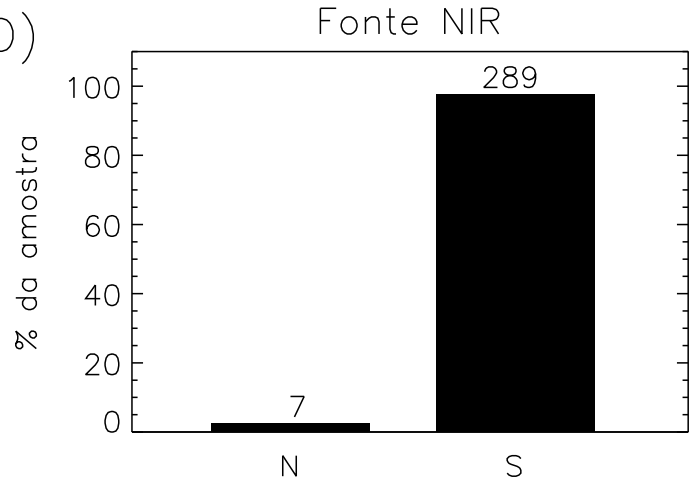

E)

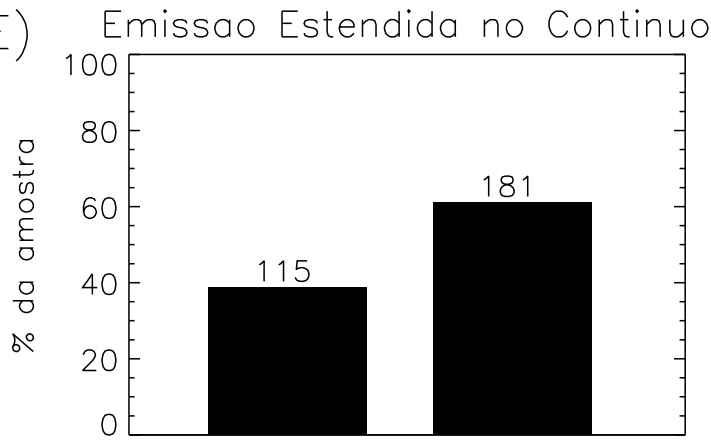

N

S

F

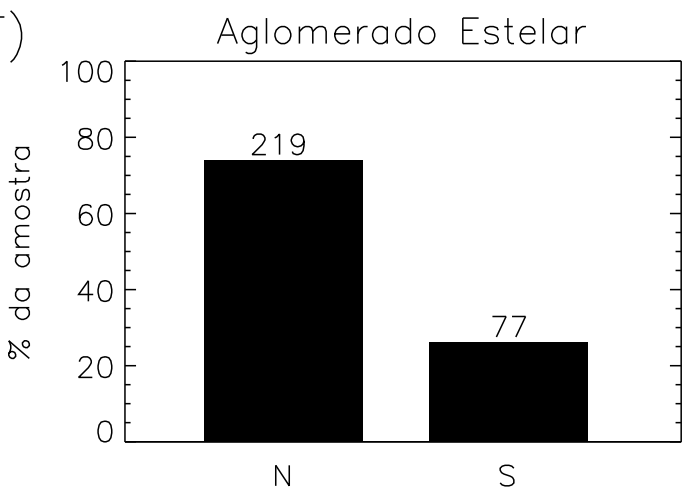

Figura 5.1: Propriedades gerais das fontes RMS, classificadas de acordo com os ítens apresentados no início da seção. Os gráficos de barra são apresentados como percentual do número total de fontes (296; 62 para o Painel C), e o número de fontes representadas por cada barra é mostrado no topo. Painel A: Presença $(\mathrm{S})$ ou ausência $(\mathrm{N})$ de emissão extensa no filtro $\mathrm{H}_{2}$ associada às fontes RMS. Painel B: Morfologia das emissões em $\mathrm{H}_{2}$, classificadas como tipos N, D, K ou BP. Painel C: Subtipos das fontes com emissão em $\mathrm{H}_{2}$ do tipo BP, desde fontes monopolares (BP1) até fontes multipolares com 8 componentes (BP8). Painel D: Presença (S) ou ausência (N) de contrapartida no infravermelho próximo da fonte RMS. Painel E: Presença (S) ou ausência (N) de emissão extensa no filtro do contínuo associada ao objeto central. Painel F: Presença (S) ou ausência $(\mathrm{N})$ de aglomerado estelar associado à fonte RMS. 
O Painel D mostra que apenas 7 das 296 fontes RMS analisadas não apresentam contrapartida no NIR. Isso pode decorrer de fontes em estágios iniciais de formação (análogos aos objetos de classe 0) ou fontes muito distantes, não detectadas devido à sensibilidade das observações. Essas hipóteses serão investigadas mais adiante. Aproximadamente $60 \%$ da amostra está associada a emissões estendidas detectadas no filtro do contínuo e presentes também no filtro do $\mathrm{H}_{2}$. A origem da emissão pode decorrer de dois processos: emissão nebular ou espalhamento pela poeira. As imagens no filtro do contínuo não permitem distinguir qual dos dois processos é responsável pela emissão observada. Observações adicionais em linhas de transições atômicas (tais como o Brackett- $\gamma$ em $2.16 \mu \mathrm{m}$ ) podem evidenciar regiões com emissão nebular. É importante ressaltar que a subtração das imagens deveria eliminar a emissão difusa no contínuo. No entanto, alguns resíduos podem ser eventualmente identificados na imagem resultante devido a efeitos de extinção (a intensidade da emissão estendida associada à região seria maior no filtro com maior comprimento de onda. Finalmente, o Painel F indica que apenas $26 \%$ da amostra está associada a grupos de estrelas ou aglomerados estelares. Esse resultado é importante pois confronta a hipótese de Bonnell et al. (1998), mostrando que estrelas de alta massa não são necessariamente formadas via coalescência e esse cenário não é capaz de explicar a formação de, pelo menos, $\approx 75 \%$ das fontes observadas.

A Figura 5.2 apresenta os mesmos resultados da Figura 5.1, porém separados entre as subamostras observadas com cada um dos instrumentos utilizados (WIRCam, Spartan e OSIRIS). De modo geral, a subamostra observada com o WIRCam apresentou taxas de detecção superiores às taxas encontradas para as fontes observadas no hemisfério Sul, com o SOAR. A diferença entre a sensibilidade instrumental das observações ( $10^{-18} \mathrm{~W} \mathrm{~m}^{-2} \operatorname{arcsec}^{2}$ para o WIRCam e $\sim 10^{-17} \mathrm{~W} \mathrm{~m}^{-2} \operatorname{arcsec}^{2}$ para o Spartan e OSIRIS, ver Seção 4.1) pode ser responsável pela diferença nas taxas de detecção. A maior parte das fontes RMS sem contrapartida no NIR estão contidas na subamostra observada com o WIRCam, ou seja, é pouco provável que as não-detecções decorram devido à sensibilidade das observações. Caso as contrapartidas existam e não tenham sido observadas, suas magnitudes na banda $\mathrm{K}_{s}$ são mais fracas que o limite de deteç̧ão das observações realizadas com o WIRCam $\left(K_{s}<K_{\text {s,limite }}=19.16 \pm 0.10\right.$ mag, Tabela 4.11). A detecção de emissões extensas no filtro do contínuo apresenta um perfil análogo ao observado para 

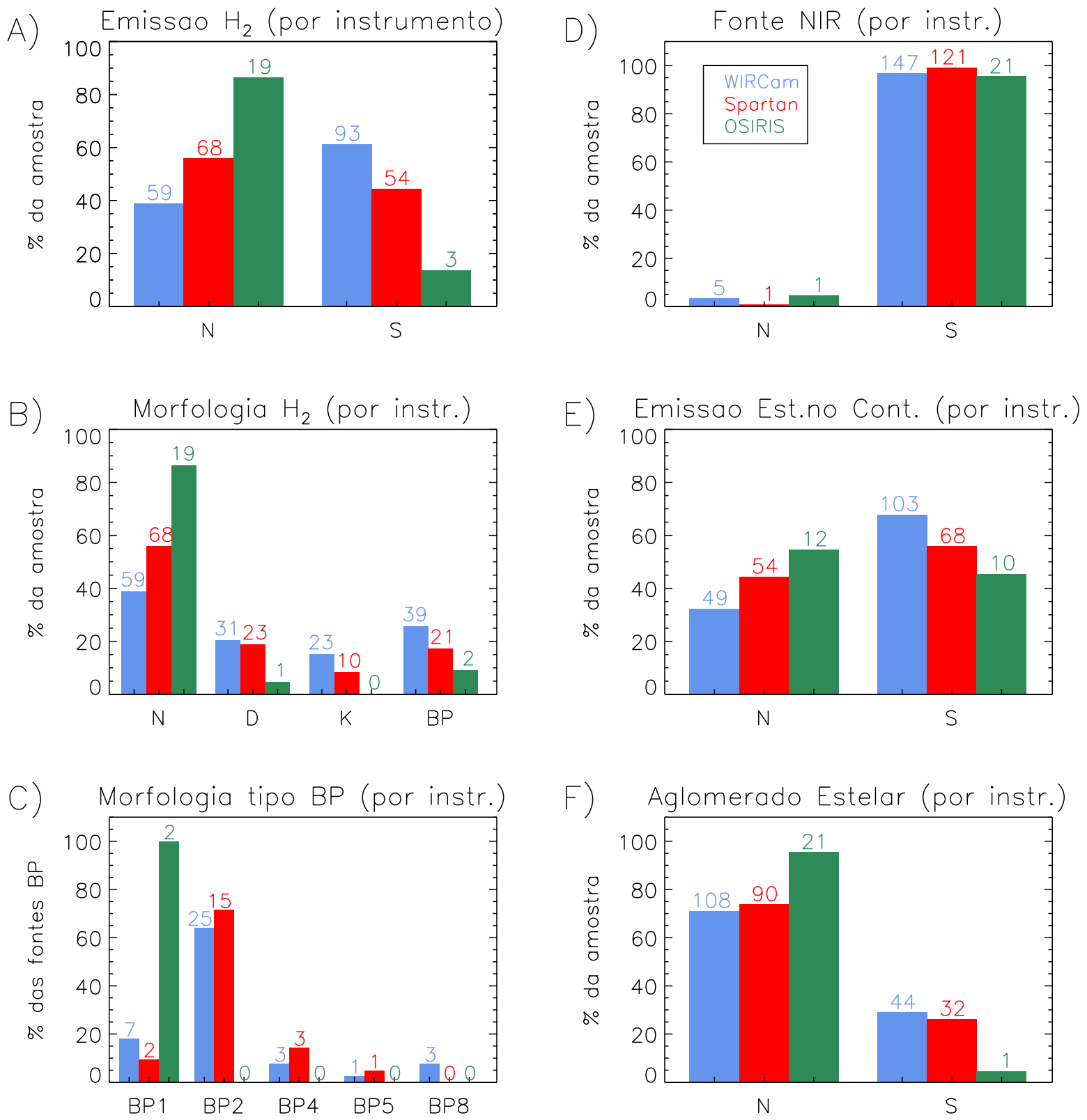

Figura 5.2: Análogo à Figura 5.1 porém em função das subamostras observacas com cada um dos instrumentos utilizados: WIRCam (162 fontes, em azul), Spartan (122 fontes, em vermelho) e OSIRIS (22 fontes, em verde).

as emissões no filtro $\mathrm{H}_{2}$ : suas taxas são mais frequentes para as observações no hemisfério norte do que aquelas observadas para o hemisfério sul. Por fim, com excessão da subamostra observada com o OSIRIS, a associação de fontes RMS com aglomerados estelares apresenta frações similares para as subamostras observadas com as câmeras WIRCam e Spartan. 


\subsubsection{Propriedades em Função da Morfologia das Emissões em $\mathrm{H}_{2}$}

A Figura 5.3 apresenta as propriedades das fontes RMS em função da morfologia da emissão em $\mathrm{H}_{2}$ identificada em cada campo. O Painel B da figura indica que as fontes sem contrapartida no NIR também não apresentam emissão extensa em $\mathrm{H}_{2}$. O Painel C mostra que grande parte das fontes não associadas a emissões estendidas em $\mathrm{H}_{2}$ também não apresentam emissão extensa no contínuo. O Painel D indica uma correlação entre emissões em $\mathrm{H}_{2}$ com morfologia do tipo difusa e presença de aglomerados estelares.

A)

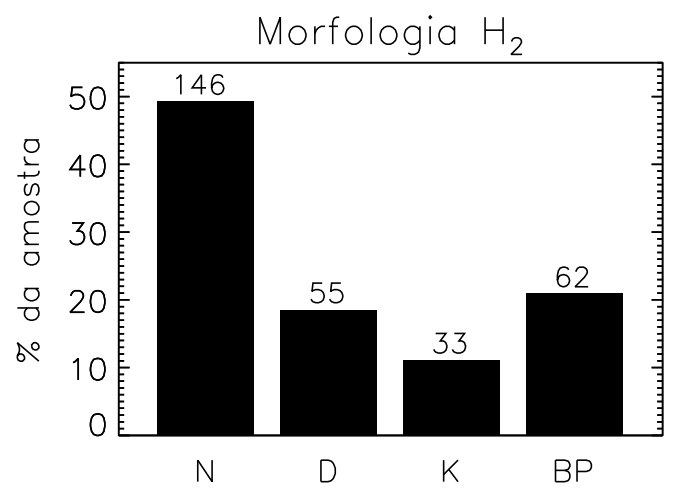

C)

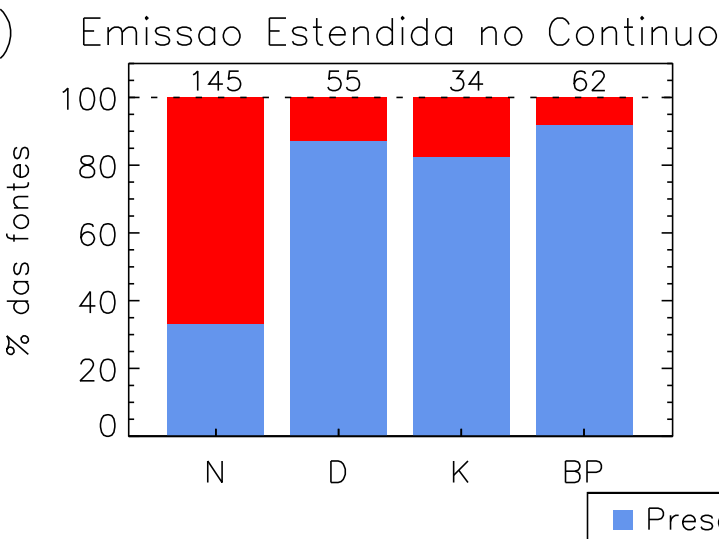

B)

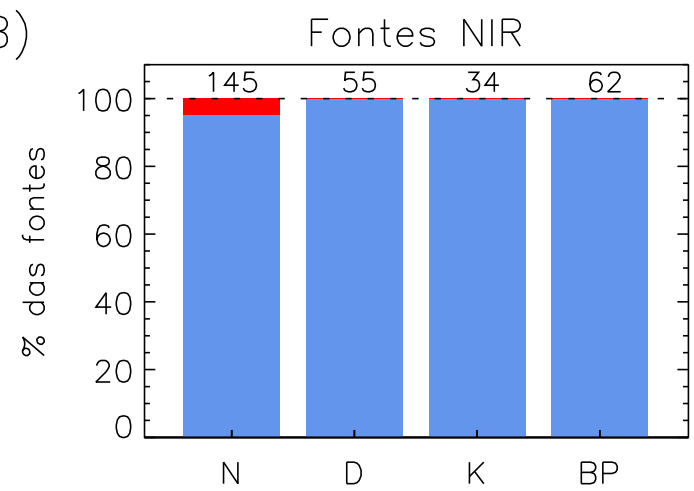

D)

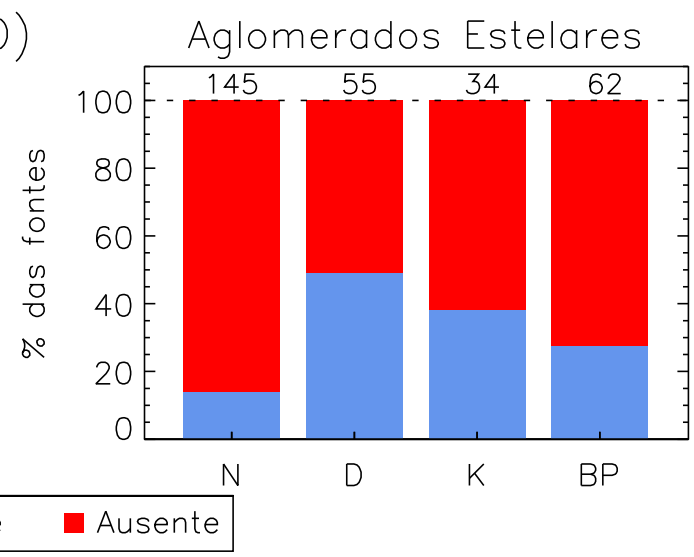

Figura 5.3: Propriedades das fontes RMS em função do tipo morfológico das estruturas identificadas nos mapas de emissão em $\mathrm{H}_{2}$. Painel A: Morfologia das emissões em $\mathrm{H}_{2}$, classificadas como tipos N, D, K ou BP. Painel B: Contrapartida NIR em função da morfologia das emissões em $\mathrm{H}_{2}$. Painel C: Emissão estendida no contínuo Painel D: Associação com aglomerados estelares Os demais paineis apresentam as taxas de detecção (em azul) ou ausência (em vermelho) de contrapartidas NIR (Painel B); emissão estendida no contínuo (Painel C); e associação com aglomerados estelares (Painel D) em função da morfologia das emissões em $\mathrm{H}_{2}$.

A Figura 5.4 apresenta as propriedades das fontes RMS com emissão em $\mathrm{H}_{2}$ do tipo BP. É possível verificar que todas as fontes com emissão polar em $\mathrm{H}_{2}$ possuem contrapartidas no NIR, detectadas nas imagens. O Painel C mostra que $20 \%$ das fontes com emissão 
monopolar e $\approx 10 \%$ das fontes com emissão bipolar não estão associadas a emissões estendidas identificadas no filtro do contínuo. Todas as 11 fontes multipolares estão associadas a emissões extensas no contínuo.

A)

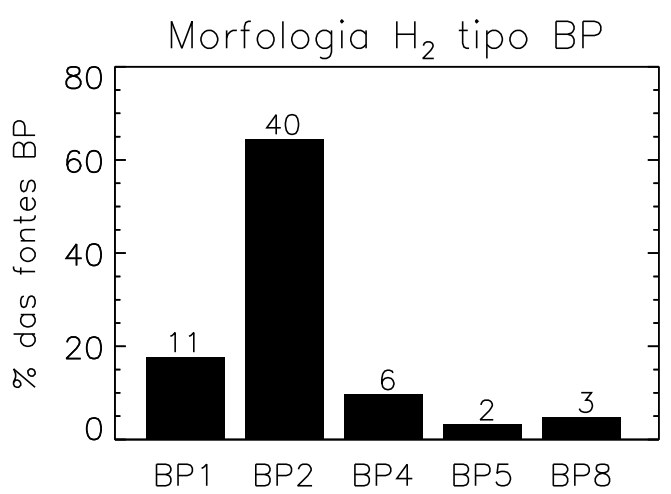

C)

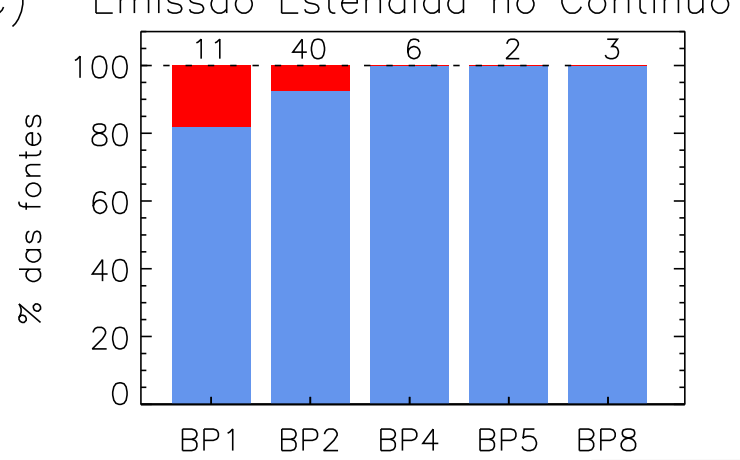

B)

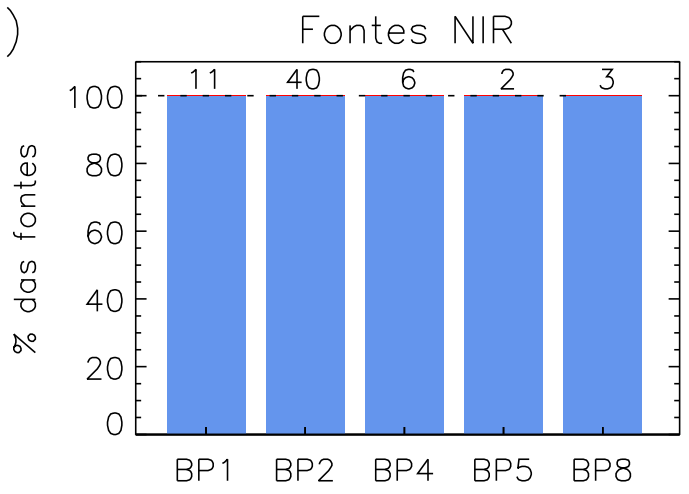

D)

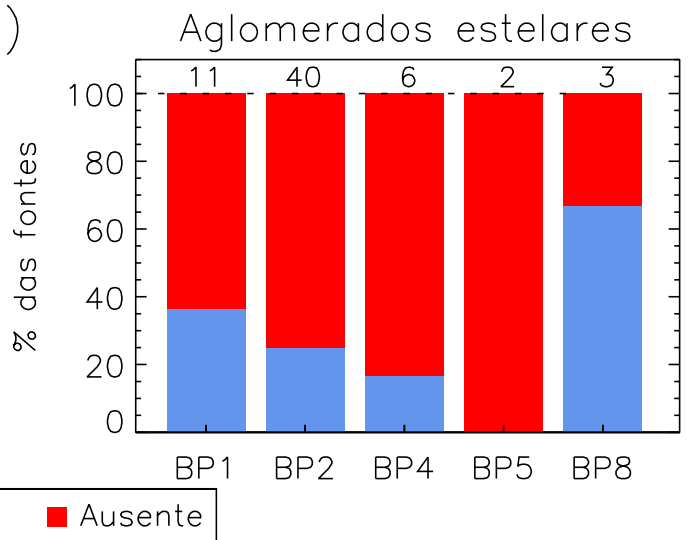

Figura 5.4: Análogo à Figura 5.3. considerando apenas as 62 fontes associadas à emissões em $\mathrm{H}_{2}$ com morfologia do tipo BP.

\subsubsection{Propriedades em Função da Luminosidade e Distância das Fontes RMS}

Outra maneira de analisar as propriedades das fontes é verificar em quais limites de distância cinemática e luminosidade bolométrica estão concentradas as detecções e nãodetecções das emissões em $\mathrm{H}_{2}$, emissões estendidas no contínuo, presença de contrapartidas no NIR e associações com aglomerados estelares.

A Figura 5.5 apresenta os histogramas cumulativos das propriedades investigadas em cada um dos campos como função da distância cinemática das fontes. O Painel A da Figura 5.5 indica que as não-detecções de contrapartidas no NIR (em vermelho) estão preferencialmente localizadas em distâncias menores que o restante da amostra (em azul). Este resultado evidencia que a não-detecção de contrapartida no NIR não é devida a um 
limite observacional. A distribuição das fontes com emissão em $\mathrm{H}_{2}$ em função da distância cinemática (Painel B, Figura 5.5) mostra que as fontes associadas a emissões extensas em $\mathrm{H}_{2}$ apresentam distâncias sistematicamente menores que o restante da amostra $(50 \%$ das fontes com emissão estendida em $\mathrm{H}_{2}$ apresentam distâncias menores que $\approx 4 \mathrm{kpc}$, enquanto a mesma fração das fontes que não estão associadas à emissões em $\mathrm{H}_{2}$ apresenta distâncias $d \lesssim 7 \mathrm{kpc}$ ). O perfil da distribuição de fontes associadas a emissões extensas no filtro do cont́inuo em função da distância cinemática das fontes é análogo ao observado para as emissões em $\mathrm{H}_{2}$, bem como a associação dos objetos com aglomerados estelares. A análise dos Painéis B, C e D indicam que a detecção de emissão extensa e de aglomerados estelares está determinada pelo limite observacional das imagens.

O Painel A da Figura 5.6 mostra que as não-detecções estão preferencialmente associadas a objetos com menor luminosidade bolométrica que os demais objetos da amostra. A análise dos Painéis A das Figuras 5.6 e 5.5 permite concluir que as não-detecções de contrapartidas NIR estão ligadas a fontes de baixa luminosidade e mais próximas. Observa-se uma tendência de que fontes com menor luminosidade bolométrica não estão associadas a emissões extensas tanto no filtro do contínuo quanto no $\mathrm{H}_{2}$. Por fim, a presença de aglomerados estelares não apresenta forte dependência em relação à luminosidade dos objetos.

\subsubsection{Dimensões das Estruturas Identificadas nos Campos}

A Figura 5.7 apresenta a dimensão projetada $\left(\ell_{\text {proj }}\right)$ das estruturas identificadas em cada campo. Por estruturas, entende-se aglomerados estelares, jatos bipolares, nebulosidades e regiões de choque mais afastadas do objeto central. As dimensões das estruturas foram estimadas a partir da distância cinemática da fonte RMS e apresentam um fator geométrico associado à medida, ou seja,

$$
\ell_{\text {real }}=\ell_{\text {proj }} / \operatorname{sen}(i)
$$

onde $i$ é a inclinação da estrutura em relação à linha de visada. Nesse caso, a medida representa um limite inferior do tamanho real da estrutura.

O Painel A da Figura 5.7 apresenta a distribuição da dimensões projetadas das estruturas identificadas nos campos observados e indica que estruturas com $\ell_{\text {proj }} \sim 10^{-0.5}$ pc $\approx$ 0.3 pc são mais frequentes, tanto para o tamanho das emissões polares quanto as demais 

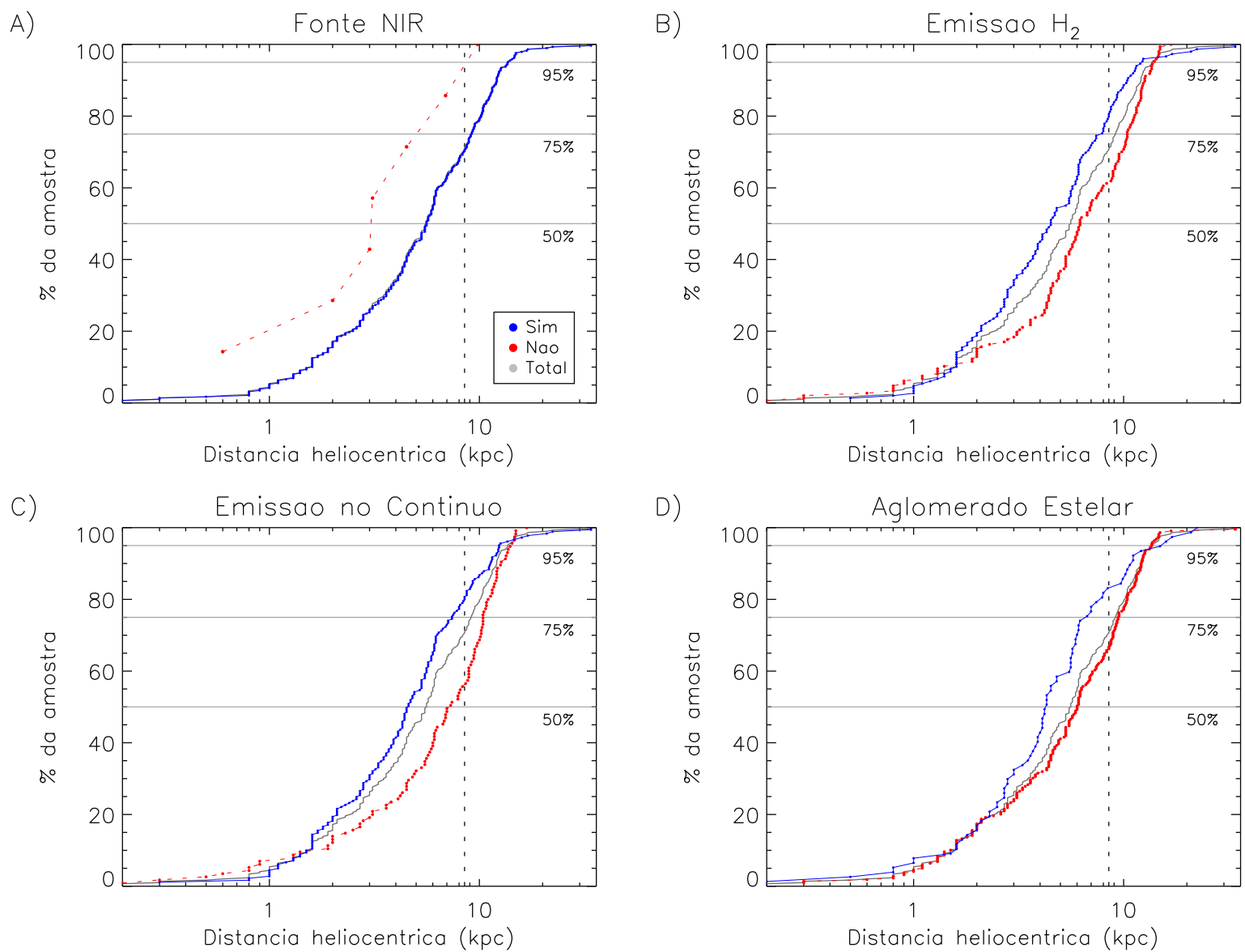

Figura 5.5: Histograma cumulativo das características observacionais associadas às fontes RMS em função da distância heliocêntrica de cada objeto. Painel A: presença de contrapartida no infravermelho próximo (NIR); Painel B: Emissão extensa em $\mathrm{H}_{2}$; Painel C: Emissão extensa no filtro do contínuo; Painel D: fontes RMS associadas a aglomerados estelares. O total de fontes observadas é mostrado em cinza, detecções positivas são mostradas em azul e não-detecções, em vermelho. A linha tracejada vertical corresponde à distância do centro Galático, $d_{C G}=$ $8.5 \mathrm{kpc}$; enquanto as linhas horizontais em cinza indicam 50\%, 75\% e 95\% de completeza de cada subamostra.

estruturas identificadas na amostra. Poucas estruturas apresentam tamanhos maiores que 1 pc. Emissões polares e jatos observados na linha de CO (ou seja, na região mais externa e fria dos jatos moleculares identificados na linha de $\mathrm{H}_{2}$ ) e associados a estrelas jovens apresentam tamanhos típicos entre 0.1 e 5 pc (Bachiller, 1996) e aglomerados de estrelas jovens apresentam raios efetivos $\lesssim 15$ pc (Bastian et al., 2013). Visto que as dimensões estimadas são diretamente proporcionais à distância cinemática adotada, estruturas muito grandes podem indicar erros na determinação de $d$, como é o caso das duas detecções com tamanhos estimados em $\sim 10^{1.5} \mathrm{pc} \sim 30 \mathrm{pc}$. O Painel B da mesma figura mostra a relação entre as medidas das dimensões projetadas e a distância cinemática da fonte RMS pre- 
A)

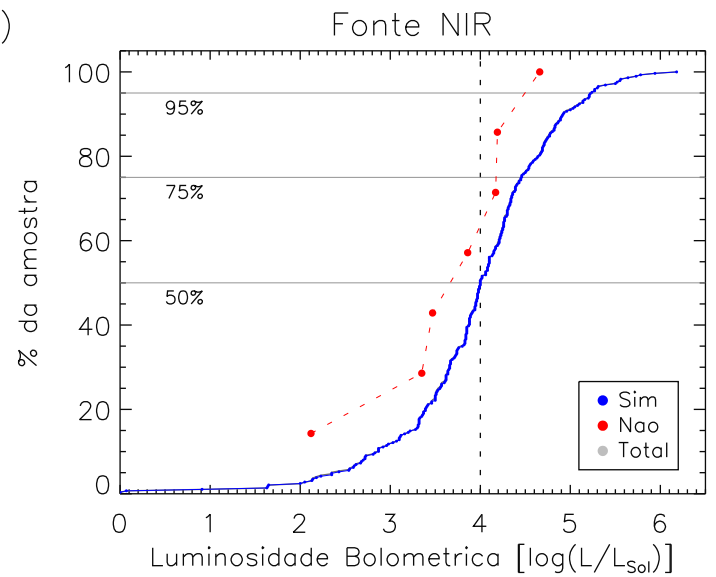

C)

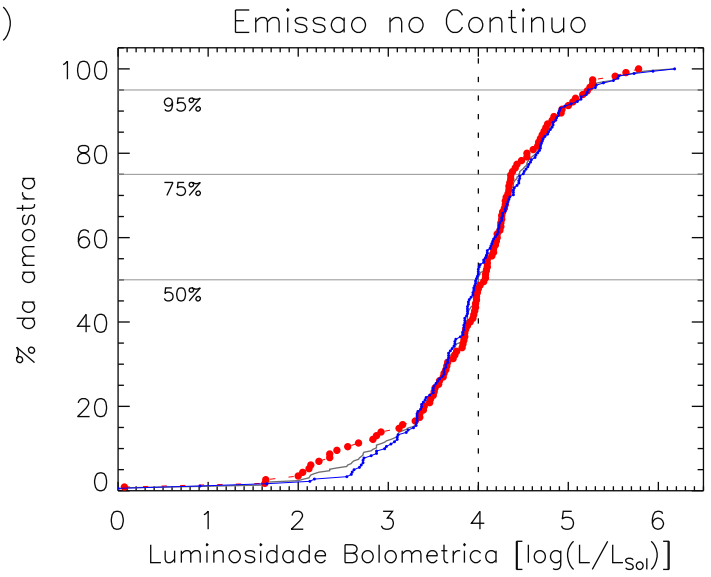

B)

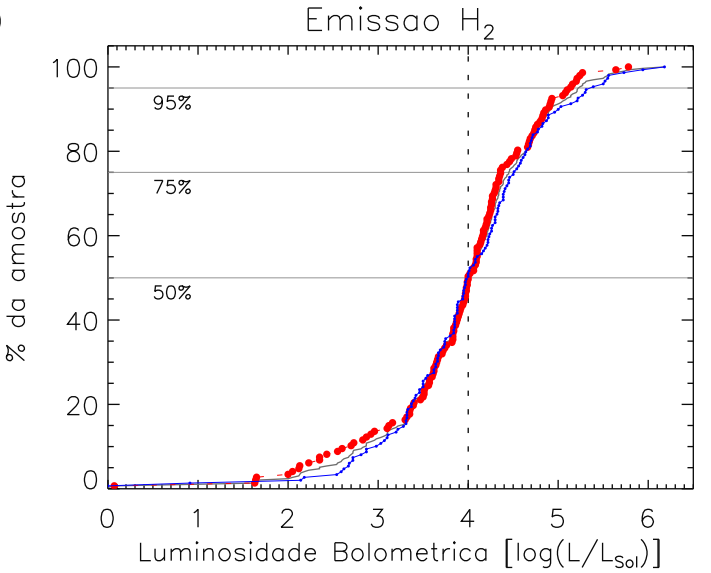

D)

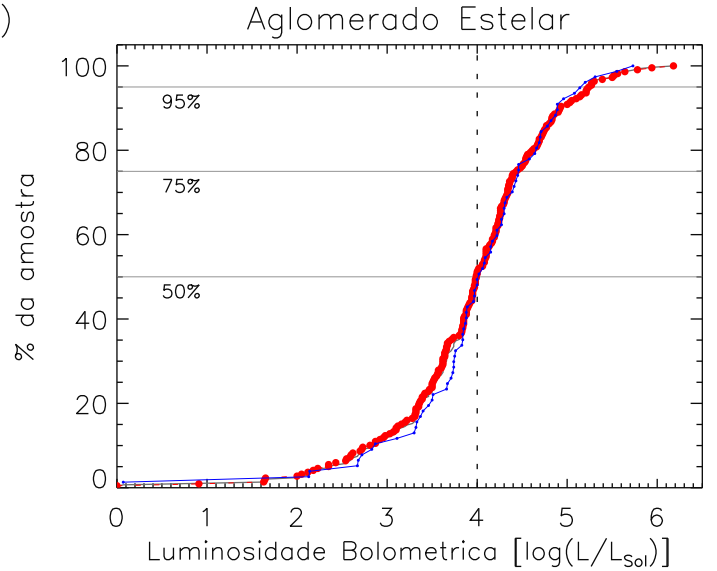

Figura 5.6: Análogo à Figura 5.5. porém em função da luminosidade bolométrica de cada objeto. A linha tracejada vertical corresponde à luminosidade esperada para uma estrela do tipo B0 na SPIZ; enquanto as linhas horizontais indicam 50\%, 75\% e 95\% de completeza de cada subamostra.

sente no campo. É possível verificar um limite inferior para o tamanho das estruturas como função da distância cinemática, tal como mostra a linha pontilhada indicada na curva. Por fim, o Painel C apresenta as dimensões medidas em função da luminosidade bolométrica das fontes RMS. A curva mostra que fontes de baixa luminosidade estão preferencialmente associadas a estruturas menores enquanto objetos com luminosidades mais elevadas estão associadas às maiores estruturas identificadas na amostra.

\subsection{Emissões Polares e Comparação com Outras Amostras}

O levantamento apresentado nesse trabalho resultou em 62 objetos $(\approx 21 \%$ da amostra) associados a emissões em $\mathrm{H}_{2}$, com morfologia do tipo (bi)polar. No trabalho de Varricatt et al. (2010), os autores identificaram que 38 das 50 fontes observadas apresen- 

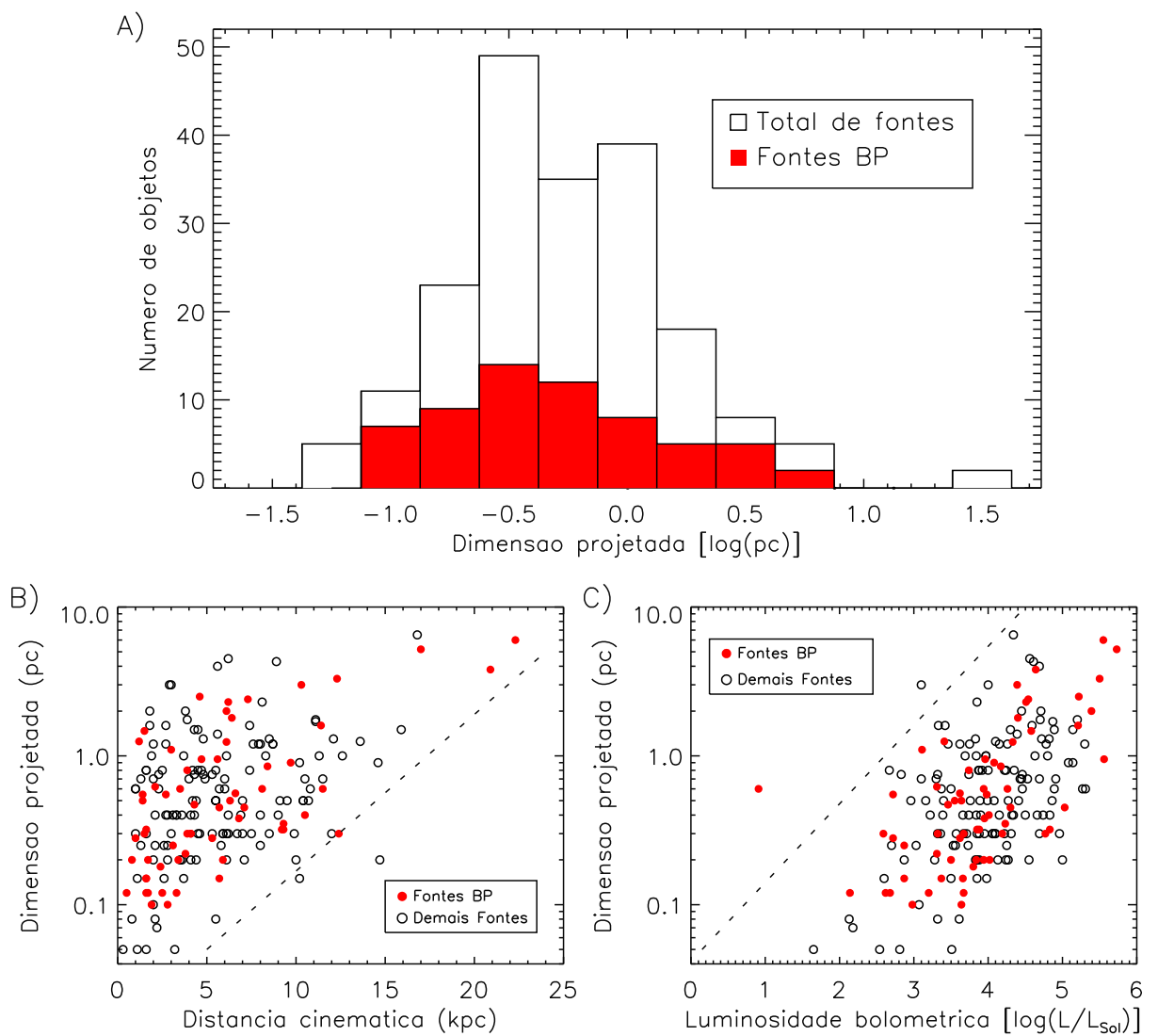

Figura 5.7: Propriedades das estruturas identificadas nos campos observados. Painel A: Distribuição das dimensões projetadas das estruturas associadas às fontes RMS presentes na amostra (barras sem preenchimento), comparadas ao tamanho dos jatos identificados ao redor das fontes com emissão em $\mathrm{H}_{2}$ do tipo BP (barras vermelhas). Painéis B e C: Distribuição das dimensões projetadas em função das distâncias cinemáticas das fontes (Painel B) e da luminosidade bolométrica de cada objeto (Painel C); os círculos vermelhos representam os objetos com emissão em $\mathrm{H}_{2}$ do tipo BP enquanto as demais fontes da amostra estão representadas pelos círculos em pretos. As linhas pontilhadas indicam delineiam os valores limites

tam emissão estendida em $\mathrm{H}_{2}$, correspondendo a $76 \%$ da amostra. Em 25 dos casos (50\%), a emissão apresenta forma polar. A fração de fontes com emissão polar identificadas por aqueles autores é $\approx 2.5$ vezes maior do que a fração encontrada para os objetos do presente trabalho. Esse resultado sugere que a fase de acreção relacionada ao período no qual os objetos apresentam emissões polares esteja fortemente associada aos critérios observacionais utilizados para a seleção das fontes observadas por aqueles autores (emissão de amônia, maser de água ou metanol e jatos identificados em CO).

As propriedades das emissões identificadas por aqueles autores foram comparadas às propriedades das emissões em $\mathrm{H}_{2}$ com morfologia do tipo BP, apresentadas no Capítulo 4 . 
Os resultados gerais são mostrados na Figura 5.8. As propriedades das fontes e das emissões identificadas em ambos os trabalhos são mostradas nos painéis A, B e C da Figura 5.8. Visando facilitar a comparação entre as amostras, os histogramas foram normalizados em relação ao valor do pico da distribuição, mostrado acima e na mesma cor do pico correspondente. Os valores medianos de cada grandezas são indicados na respectiva curva. A relação entre as diferentes propriedades são mostradas nos demais painéis. O Painel A da Figura 5.8 mostra que as fontes associadas à emissões com morfologia do tipo BP pertencem ao mesmo intervalo de luminosidade bolométrica observado para os objetos associados à emissões polares do trabalho de Varricatt et al. (2010). As razões de aspecto determinadas por aqueles autores são sistematicamente maiores que as razões de aspecto associadas às emissões das fontes RMS. A distribuição dos valores de $\mathrm{R}$ medidos por Varricatt et al. (2010) apresenta máxima frequência em $R \approx 5.5$, enquanto os valores de $\mathrm{R}$ determinados nesse trabalho possuem máximo em $R \approx 4$.3. O Painel $\mathrm{C}$ apresenta a comparação entre as dimensões das emissões polares identificadas ao redor das fontes RMS e aquelas identificadas na amostra de Varricatt et al. (2010). Os resultados mostram que ambos os trabalhos identificaram estruturas com tamanhos similares. A distribuição das dimensões projetadas em função da luminosidade do objeto central (Painel D, Figura 5.8) indica que, para ambas as amostras, objetos mais luminosos estão preferencialmente associados à estruturas maiores e que fontes de baixa luminosidade não são capazes de gerar estruturas muito extensas. Este resultado sugere que o tamanho dos jatos depende de características intrínsecas do objeto central. Os demais Painéis (E e F) apresentados na Figura 5.8 não apresentam nenhuma tendência ou relação entre os valores de $\mathrm{R}$ e a luminosidade bolométrica do objeto central, ou a dimensão projetada da emissão em $\mathrm{H}_{2}$.

\subsubsection{Análise Individual das Emissões Bipolares}

A diferença entre os valores de $R$, determinados nesse trabalho e por Varricatt et al. (2010) (Painel B, Figura 5.8), corrobora o fato de que as emissões ao redor de objetos de alta massa apresentam menor grau de colimação do que os jatos associados a fontes com menores massas. Os altos valores de $R$ associados a estrelas de baixa massa são explicados mediante a colimação dos jatos bipolares devido aos alinhamento entre o campo magnético estelar e o eixo de propagação dos jatos, tal como proposto por Shu et al. (1987). Recentemente, 
A)

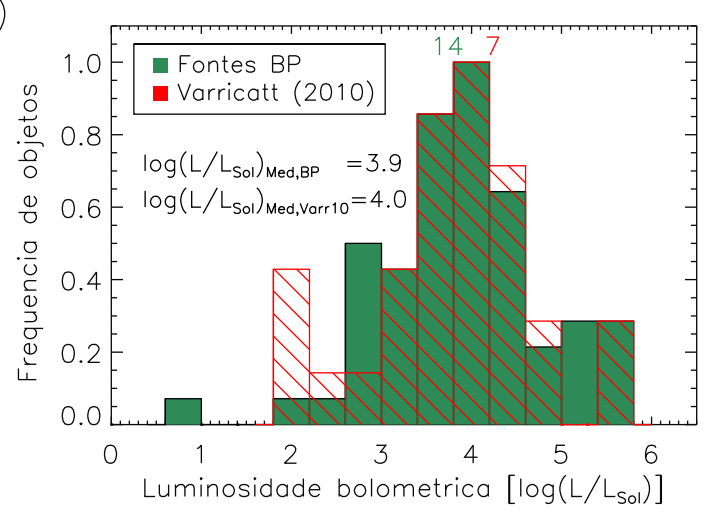

B)

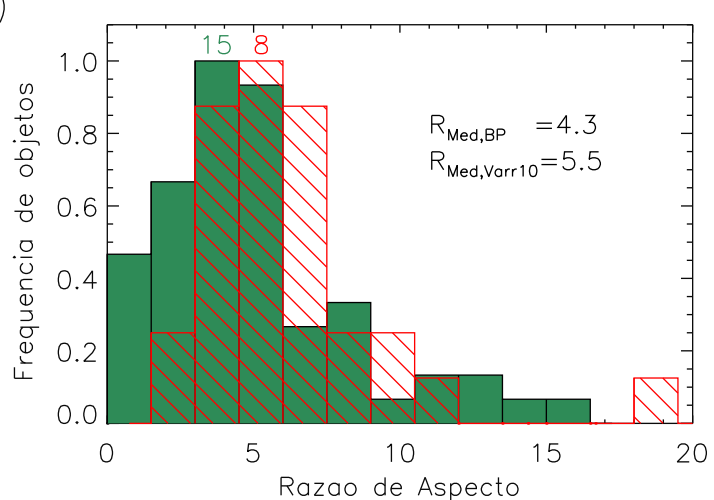

C)

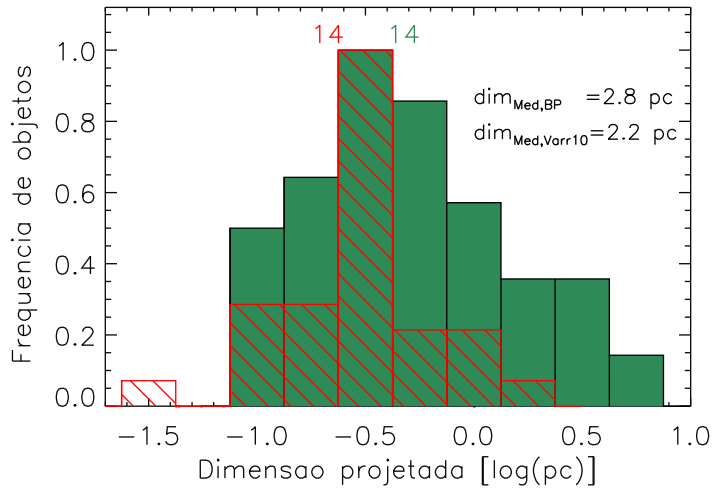

D)

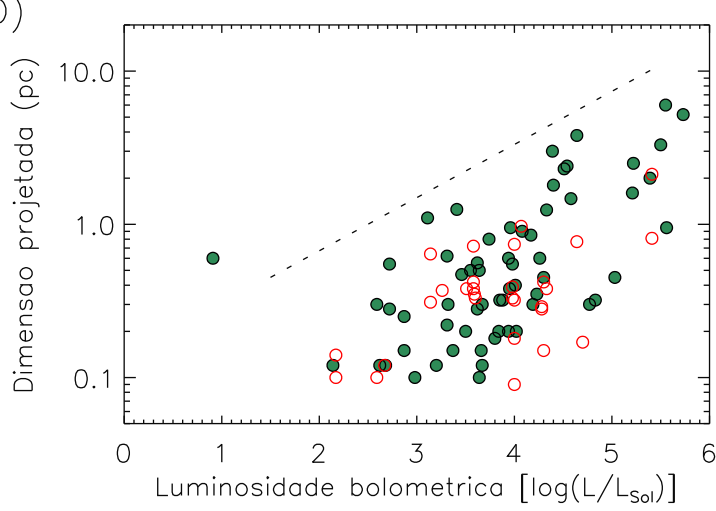

E)

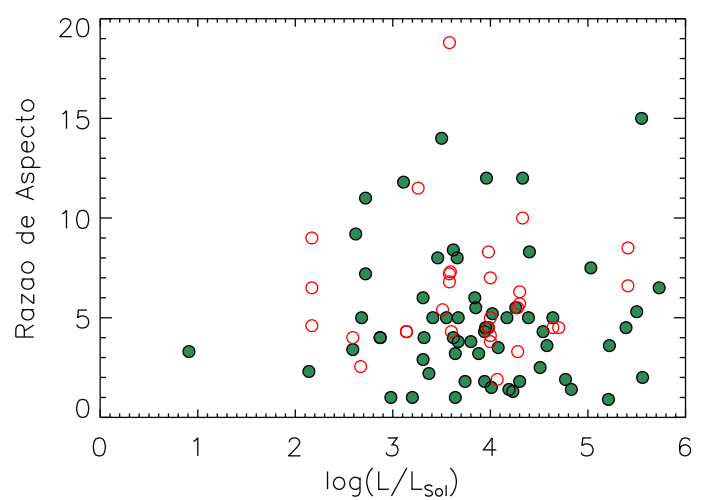

F)

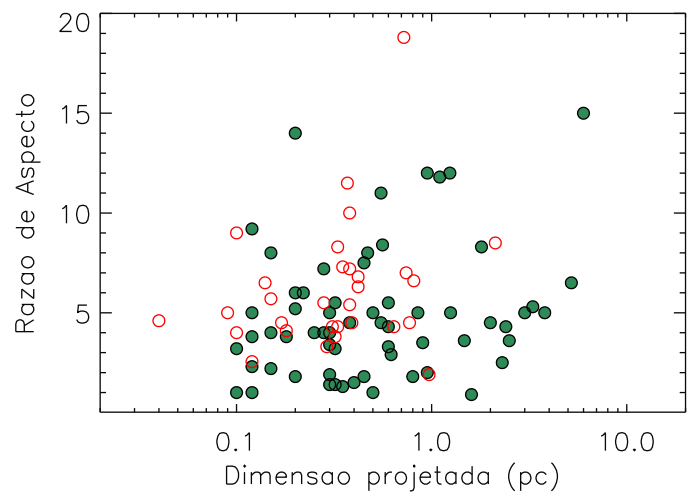

Figura 5.8: Comparação entre as fontes com emissões em $\mathrm{H}_{2}$ com morfologia do tipo BP, identificadas no presente trabalho (em verde) e aquelas contidas em Varricatt et al. (2010, em vermelho). Painel A: Distribuição da luminosidade bolométrica das fontes; Painéis B e C: Distribuição razão de aspecto (B) e das dimensões projetadas (C) das emissões polares associadas às fontes; Painel D: Dimensões das emissões polares em função da luminosidade dos objetos centrais, as linhas pontilhadas indicam os limites da distribuição de cada amostra. Painéis E e F: Distribuição da razão de aspecto das emissões polares em função da luminosidade das fontes centrais (E) e da dimensão projetada da estrutura correspondente $(\mathrm{F})$.

o trabalho de Surcis et al. (2013) identificou emissão maser de metanol (em $6.7 \mathrm{GHz}$ ) ao redor de estrelas de alta massa em formação. Os resultados daqueles autores mostram 
que as emissões maser estão distribuídas em estruturas alinhadas na direção dos jatos bipolares associados aos objetos. Os autores ainda apresentam resultados polarimétricos que indicam um alinhamento do campo magnético na região mais próxima da protoestrela (em escalas entre 10 - 100 UA) com a direção dos jatos em larga escala, tais como as emissões identificadas nesse trabalho e em Varricatt et al. (2010). Nesse cenário, é esperado que os lóbulos dos jatos bipolares apresentem propriedades e morfologias semelhantes.

Uma segunda hipótese sugere que as emissões bipolares associadas a estrelas de alta massa em formação sejam originadas a partir da pressão de radiação do próprio disco de acreção (Drew et al., 1998). Nesse caso, os jatos apresentariam baixo grau de colimação e os lóbulos poderiam apresentar propriedades distintas, tais como diferenças no valor da razão de aspecto e assimetrias na morfologia das estruturas.

A Figura 5.9 apresenta as medidas individuais da razão de aspecto dos lóbulos mais bem definidos e associados às emissões bipolares (BP2) identificadas nesse trabalho. O Painel A dessa figura indica um decréscimo no valor de $\mathrm{R}$ em função da luminosidade do objeto central. Esse é um resultado bastante relevante para diferenciar as emissões associadas aos YSOs de alta e baixa massa. O Painel B mostra que estruturas com alto grau de colimação são encontradas em menores distâncias enquanto emissões com baixo grau de colimação estão situadas em distâncias maiores. Não foi possível estabelecer uma relação entre os valores de $\mathrm{R}$ e a dimensão projetada de cada emissão (Painel C). 


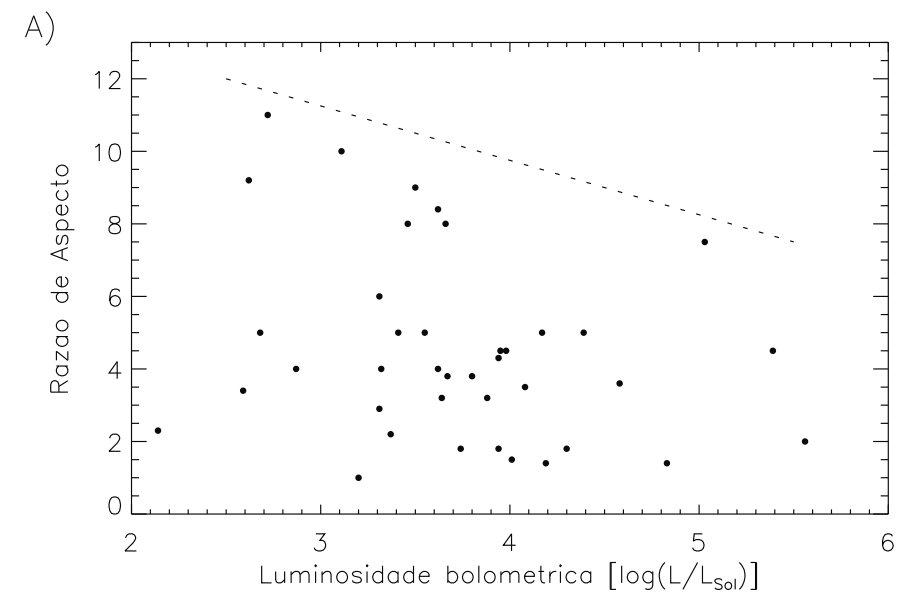

B)

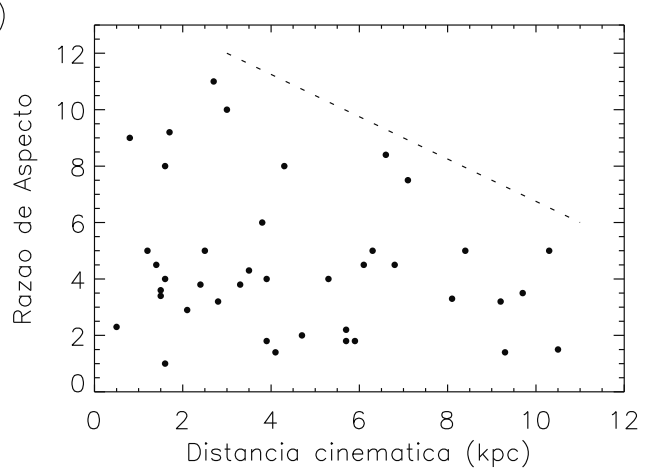

C)

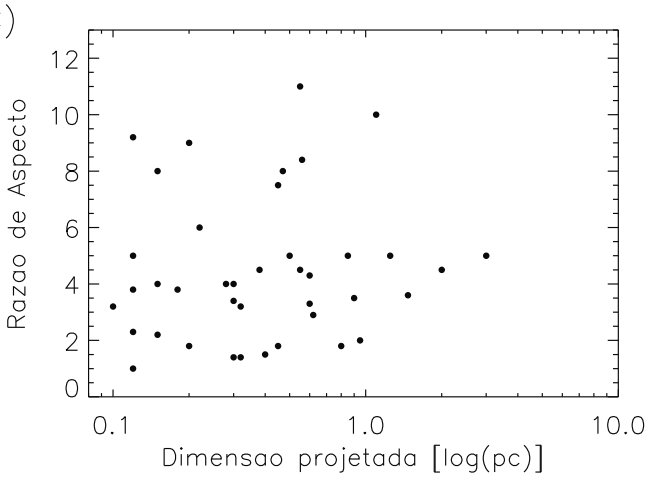

Figura 5.9: Razões de aspecto das emissões classificadas como BP2 As razões de aspecto são mostradas como função do logaritmo da luminosidade bolométrica do objeto central (Painel A), da distância cinemática (Painel B) e da dimensão projetada da emissão em $\mathrm{H}_{2}$ (Painel C). 
Capítulo 6

\section{Considerações Finais}

\subsection{Conclusões}

O presente trabalho apresentou um levantamento de candidatos a MYSOs, selecionados a partir do levantamento Red MSX Source e observados nos filtros estreitos do $\mathrm{H}_{2}$ e de um contínuo adjacente. Observações de 296 campos ao redor de objetos RMS foram realizadas nos telescópios CFHT e SOAR e processadas utilizando o pacote THELI. A análise dos mapas de emissão em $\mathrm{H}_{2}$ e das imagens RGB apresentadas nesse trabalho, permitiram concluir que

1. $\approx 50 \%$ da amostra apresenta emissão extensa no filtro do $\mathrm{H}_{2}$, sendo $19 \%$ classificadas como emissões difusas, $11 \%$ como emissões nodais ou floculares e $21 \%$ polares;

2. Dentre as emissões polares, 40 objetos apresentaram morfologia bipolar, 11 correspondem a emissões multipolares e 11 delas representam os casos monopolares. Para esses casos, é esperado que exista uma contrapartida mais distante associada aos jatos monopolares, provavelmente obscurecida por fatores ligados ao ângulo de inclinação da estrutura e à elevada extinção circunstelar das regiões de formação estelar;

3. Existe uma correlação entre emissões extensas em $\mathrm{H}_{2}$ e no filtro do contínuo. A origem da emissão no contínuo pode ser devida à emissão nebular ou espalhamento pela poeira circunstelar e nem sempre a subtração das imagens é capaz de eliminar completamente sua contribuição;

4. A fração de objetos RMS associados a aglomerados estelares totaliza apenas $\approx 25 \%$ da amostra. Comparando as diferentes classes morfológicas de emissão em $\mathrm{H}_{2}$, a 
fração de fontes associadas a aglomerados é maior para aquelas que apresentam emissão em $\mathrm{H}_{2}$ do tipo difusa $(\approx 50 \%)$;

As fontes associadas a emissões do tipo polar foram analisadas individualmente e comparadas à amostra de Varricatt et al. (2010). Os principais resultados mostram que:

1. $\approx 76 \%$ das fontes observadas por aqueles autores apresentam emissão extensa em $\mathrm{H}_{2}$, sendo $50 \%$ delas classificadas como emissões polares;

2. As propriedades das fontes e das emissões do tipo polar são similares para ambas as amostras de candidatos a MYSOs;

3. As fontes associadas a emissões polares estão contidas no mesmo intervalo de luminosidades;

4. A comparação entre a razão de aspecto das emissões de ambas as amostras indica que os valores de $\mathrm{R}$ determinados por aqueles autores são ligeiramente maiores que os medidos no presente trabalho; e

5. As dimensões projetadas das emissões polares estão distribuídas entre 0.1 e 3.0 pc;

6. A análise da razão de aspecto das emissões em função da luminosidade bolométrica do objeto central permitiu verificar a existência de um limite superior para os valores de R: quanto maior a luminosidade do objeto, menor o grau de colimação das emissões polares. Esse resultado é favorável à idéia de que os jatos de MYSOs sejam originados a partir de ventos produzidos pela pressão de radiação dos discos e não devido a efeitos magnéticos, como é o caso das estrelas de baixa massa.

A identificação de estruturas bipolares associadas aos candidatos a MYSOs é uma evidência observacional do cenário de formação via disco circunstelar. Suas baixas taxas de detecção podem indicar que o tempo de vida das estruturas é relativamente curto ( milhões de anos) quando comparados ao tempo de formação das estrelas de alta massa. Apenas $\approx 25 \%$ das fontes RMS estão associadas a aglomerados estelares, mostrando que o cenário de formação via coalescência, proposto por Bonnell et al. (2001), não é capaz de explicar a formação de todas as estrelas de alta massa. 


\subsection{Perspectivas e Trabalhos Futuros}

As principais perspectivas para a continuidade desse trabalho são:

1. A determinação da massa dinâmica dos objetos com discos de acreção, através de movimentos Keplerianos do gás circunstelar resolvido espacialmente em observações de alta resolução $\left(\leq 0.1^{\prime \prime}\right)$, realizadas com espectrógrafos de campo integral (como o NIFS no Gemini Norte) ou mapas em ondas milimétricas, obtidos com o ALMA ou APEX no hemisfério sul, e com o VLA no hemisfério norte. Sete objetos do hemisfério norte foram observados com o NIFS e serão processados no início do doutorado.

2. O aprofundamento da parte teórica da formação de estrelas de alta massa, a partir de um estágio no exterior através de uma colaboração com o Dr. Mark R. Krumholz (Universidade da Califórnia), reconhecido pela sua grande contribuição teórica na área de formação de estrelas de alta massa. A proposta seria realizar simulações MHDs análogas àquelas apresentadas em Krumholz et al. (2009), incluindo a presença dos jatos bipolares e modelar alguns dos resultados observacionais obtidos no presente trabalho.

Como perspectivas secundárias, temos:

1. O término da redução e análise dos demais $\approx 80$ campos que apresentaram problemas durante o seu processamento.

2. A busca bibliográfica das fontes RMS, relacionando a presença de emissão em $\mathrm{H}_{2}$ com demais propriedades observacionais, tais como emissão maser e outras linhas moleculares. O uso de ferramentas relacionadas aos Observatórios Virtuais terá papel decisivo para coleta de informações na literatura e levantamentos de emissão maser poderão indicar o estágio das fontes. 


\section{Referências Bibliográficas}

André P., Montmerle T., From T Tauri stars to protostars: Circumstellar material and young stellar objects in the rho Ophiuchi cloud, ApJ, 1994, vol. 420, p. 837

Andre P., Ward-Thompson D., Motte F., Probing the initial conditions of star formation: the structure of the prestellar core L 1689B., A\&A, 1996, vol. 314, p. 625

Anglada G., Estalella R., Pastor J., Rodriguez L. F., Haschick A. D., A CS and $\mathrm{NH}_{3}$ Survey of Regions with $\mathrm{H}_{2} \mathrm{O}$ Maser Emission, ApJ, 1996, vol. 463, p. 205

Bacciotti F., Mundt R., Ray T. P., Eislöffel J., Solf J., Camezind M., Hubble Space Telescope STIS Spectroscopy of the Optical Outflow from DG Tauri: Structure and Kinematics on Subarcsecond Scales, ApJL, 2000, vol. 537, p. L49

Bachiller R., Bipolar Molecular Outflows from Young Stars and Protostars, ARA\&A, 1996, vol. 34 , p. 111

Bacmann A., Andre P., Abergel A., Bernard J. P., Puget J. L., Bontemps S., WardThompson D., An ISOCAM Absorption Study of Dense Cloud Cores. In Star Formation with the Infrared Space Observatory, vol. 132 of Astronomical Society of the Pacific Conference Series, 1998, p. 307

Bally J., Zinnecker H., The Birth of High-Mass Stars: Accretion and/or Mergers?, AJ, 2005, vol. 129, p. 2281

Bastian N., Schweizer F., Goudfrooij P., Larsen S. S., Kissler-Patig M., Luminosity profiles and sizes of massive star clusters in NGC 7252, MNRAS, 2013, vol. 431, p. 1252 
Baumgardt H., Klessen R. S., The role of stellar collisions for the formation of massive stars, MNRAS, 2011, vol. 413, p. 1810

Beck T. L., McGregor P. J., Takami M., Pyo T.-S., Spatially Resolved Molecular Hydrogen Emission in the Inner 200 AU Environments of Classical T Tauri Stars, ApJ, 2008, vol. 676 , p. 472

Beichman C. A., Neugebauer G., Habing H. J., Clegg P. E., Chester T. J., eds,, 1988 Infrared astronomical satellite (IRAS) catalogs and atlases. Volume 1: Explanatory supplement vol. 1

Beltrán M. T., Brand J., Cesaroni R., Fontani F., Pezzuto S., Testi L., Molinari S., Search for massive protostar candidates in the southern hemisphere. II. Dust continuum emission, A\&A, 2006, vol. 447, p. 221

Benjamin R. A., Churchwell E., Babler B. L., Bania T. M., Clemens D. P., Cohen M., et al., GLIMPSE. I. An SIRTF Legacy Project to Map the Inner Galaxy, PASP, 2003, vol. 115 , p. 953

Beuther H., Leurini S., Schilke P., Wyrowski F., Menten K. M., Zhang Q., Interferometric multi-wavelength (sub)millimeter continuum study of the young high-mass protocluster IRAS 05358+3543, A\&A, 2007, vol. 466, p. 1065

Beuther H., Schilke P., Gueth F., Massive Molecular Outflows at High Spatial Resolution, ApJ, 2004, vol. 608, p. 330

Beuther H., Schilke P., Sridharan T. K., Menten K. M., Walmsley C. M., Wyrowski F., Massive molecular outflows, A\&A, 2002, vol. 383, p. 892

Beuther H., Zhang Q., Sridharan T. K., Chen Y., Testing the Massive Disk Scenario for IRAS 18089-1732, ApJ, 2005, vol. 628, p. 800

Bik A., Thi W. F., Evidence for an inner molecular disk around massive Young Stellar Objects, AAp, 2004, vol. 427, p. L13

Blum R. D., Barbosa C. L., Damineli A., Conti P. S., Ridgway S., Accretion Signatures from Massive Young Stellar Objects, ApJ, 2004, vol. 617, p. 1167 
Blum R. D., Damineli A., Conti P. S., The Stellar Content of Obscured Galactic Giant H II Regions. III. W31, AJ, 2001, vol. 121, p. 3149

Bonnell I. A., Bate M. R., Clarke C. J., Pringle J. E., Competitive accretion in embedded stellar clusters, MNRAS, 2001, vol. 323, p. 785

Bonnell I. A., Bate M. R., Zinnecker H., On the formation of massive stars, MNRAS, 1998, vol. 298 , p. 93

Brand J., Blitz L., The Velocity Field of the Outer Galaxy, A\&A, 1993, vol. 275, p. 67

Cao Y., Terebey S., Prince T. A., Beichman C. A., The High-Resolution IRAS Galaxy Atlas, ApJS, 1997, vol. 111, p. 387

Carey S. J., et al., MIPSGAL: A Survey of the Inner Galactic Plane at 24 and $70 \mu \mathrm{m}$, PASP, 2009, vol. 121, p. 76

Cesaroni R., Disks and jets in high-mass young stellar objects, Highlights of Astronomy, 2002, vol. 12 , p. 156

Cesaroni R., Felli M., Jenness T., Neri R., Olmi L., Robberto M., Testi L., Walmsley C. M., Unveiling the disk-jet system in the massive (proto)star IRAS 20126+4104, A\&A, 1999, vol. 345 , p. 949

Cesaroni R., Felli M., Testi L., Walmsley C. M., Olmi L., The disk-outflow system around the high-mass (proto)star IRAS 20126+4104., A\&A, 1997, vol. 325, p. 725

Cesaroni R., Neri R., Olmi L., Testi L., Walmsley C. M., Hofner P., A study of the Keplerian accretion disk and precessing outflow in the massive protostar IRAS 20126+4104, A\&A, 2005, vol. 434, p. 1039

Chrysostomou A., Bacciotti F., Nisini B., Ray T. P., Eislöffel J., Davis C. J., Takami M., Investigating the transport of angular momentum from young stellar objects. Do H2 jets from class I YSOs rotate?, A\&A, 2008, vol. 482, p. 575

Churchwell E., Massive Star Formation. In NATO ASIC Proc. 540: The Origin of Stars and Planetary Systems , 1999, p. 515 
Churchwell E., Ultra-Compact HII Regions and Massive Star Formation, ARA\&A, 2002, vol. 40 , p. 27

Cohen M., Wheaton W. A., Megeath S. T., Spectral Irradiance Calibration in the Infrared. XIV. The Absolute Calibration of 2MASS, AJ, 2003, vol. 126, p. 1090

Cohen R. J., Baart E. E., Jonas J. L., OH masers associated wth IRAS far-infrared sources, MNRAS, 1988, vol. 231, p. 205

Corcoran M., Ray T. P., Spectroscopic discovery of a bipolar jet from the Herbig Ae/Be star LkH $\alpha$ 233, A\&A, 1998, vol. 336, p. 535

Cyganowski C. J., Brogan C. L., Hunter T. R., Churchwell E., Zhang Q., Bipolar Molecular Outflows and Hot Cores in Glimpse Extended Green Objects (EGOs), ApJ, 2011, vol. 729 , p. 124

Davies B., Lumsden S. L., Hoare M. G., Oudmaijer R. D., de Wit W., The circumstellar disc, envelope and bipolar outflow of the massive young stellar object W33A, MNRAS, 2010, vol. 402, p. 1504

De Buizer J. M., Testing the circumstellar disc hypothesis: a search for $\mathrm{H}_{2}$ outflow signatures from massive young stellar objects with linearly distributed methanol masers, MNRAS, 2003, vol. 341, p. 277

de Wit W. J., et al., Resolved 24.5 micron emission from massive young stellar objects, A\&A, 2009, vol. 494, p. 157

de Wit W. J., Hoare M. G., Oudmaijer R. D., Lumsden S. L., The origin of mid-infrared emission in massive young stellar objects: multi-baseline VLTI observations of W33A, A\&A, 2010, vol. 515, p. A45+

Di Francesco J., Johnstone D., Kirk H., MacKenzie T., Ledwosinska E., The SCUBA Legacy Catalogues: Submillimeter-Continuum Objects Detected by SCUBA, ApJS, 2008a, vol. 175 , p. 277

Di Francesco J., Johnstone D., Kirk H., MacKenzie T., Ledwosinska E., The SCUBA Legacy Catalogues: Submillimeter-Continuum Objects Detected by SCUBA, ApJS, 2008b, vol. 175 , p. 277 
Diolaiti E., Bendinelli O., Bonaccini D., Close L., Currie D., Parmeggiani G., Analysis of isoplanatic high resolution stellar fields by the StarFinder code, A\&AS, 2000, vol. 147, p. 335

Draine B. T., Interstellar shock waves with magnetic precursors, ApJ, 1980, vol. 241, p. 1021

Draine B. T., Roberge W. G., Dalgarno A., Magnetohydrodynamic shock waves in molecular clouds, ApJ, 1983, vol. 264, p. 485

Drew J. E., Proga D., Stone J. M., A radiation-driven disc wind model for massive young stellar objects, MNRAS, 1998, vol. 296, p. L6

Dutrey A., Guilloteau S., Bachiller R., Successive SiO shocks along the L1448 jet axis., A\&A, 1997, vol. 325, p. 758

Edris K. A., Fuller G. A., Cohen R. J., A survey of OH masers towards high mass protostellar objects, A\&A, 2007, vol. 465, p. 865

Egan M. P., et al., MSX6C Infrared Point Source Catalog. The Midcourse Space Experiment Point Source Catalog Version 2.3 (October 2003), VizieR Online Data Catalog, 2003, vol. 5114, p. 0

Egan M. P., Price S. D., Shipman R. F., Gugliotti G. M., Tedesco E. F., Moshir M., Cohen M., The MSX Infrared Point Source Catalog, Version 1. 0. In Astrophysics with Infrared Surveys: A Prelude to SIRTF , vol. 177 of Astronomical Society of the Pacific Conference Series, 1999, p. 404

Eislöffel J., Morphology and Kinematics of Jets from Young Stars. In Reviews in Modern Astronomy, vol. 13 of Reviews in Modern Astronomy, 2000, p. 81

Ellingsen S. P., von Bibra M. L., McCulloch P. M., Norris R. P., Deshpande A. A., Phillips C. J., A survey of the Galactic plane for 6.7-GHz methanol masers - I. l=325 deg-335 $\operatorname{deg} b=-0 .{ }^{\circ} 53-0{ }^{\circ} 53$, MNRAS, 1996, vol. 280, p. 378

Elmegreen B. G., Scalo J., Interstellar Turbulence I: Observations and Processes, ARA\&A, 2004, vol. 42, p. 211 
Erben T., Schirmer M., Dietrich J. P., Cordes O., Haberzettl L., Hetterscheidt M., Hildebrandt H., et al., GaBoDS: The Garching-Bonn Deep Survey. IV. Methods for the image reduction of multi-chip cameras demonstrated on data from the ESO Wide-Field Imager, Astronomische Nachrichten, 2005, vol. 326, p. 432

Evans II N. J., Physical Conditions in Regions of Star Formation, ARA\&A, 1999, vol. 37, p. 311

Faúndez S., Bronfman L., Garay G., Chini R., Nyman L., May J., SIMBA survey of southern high-mass star forming regions. I. Physical parameters of the $1.2 \mathrm{~mm} / \mathrm{IRAS}$ sources, A\&A, 2004, vol. 426, p. 97

Fontani F., Beltrán M. T., Brand J., Cesaroni R., Testi L., Molinari S., Walmsley C. M., Search for massive protostellar candidates in the southern hemisphere. I. Association with dense gas, AAp, 2005, vol. 432, p. 921

Fontani F., Cesaroni R., Furuya R. S., Class I and Class II methanol masers in high-mass star-forming regions, A\&A, 2010, vol. 517, p. A56+

Furuya R. S., Kitamura Y., Wootten A., Claussen M. J., Kawabe R., Water Maser Survey toward Low-Mass Young Stellar Objects in the Northern Sky with the Nobeyama 45 Meter Telescope and the Very Large Array, ApJS, 2003, vol. 144, p. 71

Garmany C. D., Conti P. S., Chiosi C., The initial mass function for massive stars, ApJ, 1982, vol. 263 , p. 777

Goddi C., Moscadelli L., Sanna A., Cesaroni R., Minier V., Associations of H_2O and CH_3OH masers at milli-arcsec angular resolution in two high-mass YSOs, A\&A, 2007, vol. 461, p. 1027

Goodson A. P., Böhm K.-H., Winglee R. M., Jets from Accreting Magnetic Young Stellar Objects. I. Comparison of Observations and High-Resolution Simulation Results, ApJ, 1999, vol. 524, p. 142

Goodson A. P., Winglee R. M., Boehm K.-H., Time-dependent Accretion by Magnetic Young Stellar Objects as a Launching Mechanism for Stellar Jets, ApJ, 1997, vol. 489, p. 199 
Grave J. M. C., Kumar M. S. N., Spitzer-IRAC GLIMPSE of high mass protostellar objects. II. SED modelling of a bona fide sample, A\&A, 2009, vol. 498, p. 147

Guarcello M. G., Drake J. J., Wright N. J., Drew J. E., Gutermuth R. A., et al., The Protoplanetary Disks in the Nearby Massive Star-forming Region Cygnus OB2, ApJ, 2013, vol. 773 , p. 135

Guesten R., Mezger P. G., Star formation and abundance gradients in the galaxy, Vistas in Astronomy, 1982, vol. 26, p. 159

Harju J., Lehtinen K., Booth R. S., Zinchenko I., A survey of SiO emission towards interstellar masers. I. SiO line characteristics, A\&AS, 1998, vol. 132, p. 211

Harwit M., Neufeld D. A., Melnick G. J., Kaufman M. J., Thermal Water Vapor Emission from Shocked Regions in Orion, ApJL, 1998, vol. 497, p. L105

Henning T., Friedemann C., Guertler J., Dorschner J., A catalogue of extremely young, massive and compact infrared objects, Astronomische Nachrichten, 1984, vol. 305, p. 67

Hill T., Burton M. G., Minier V., Thompson M. A., Walsh A. J., Hunt-Cunningham M., Garay G., Millimetre continuum observations of southern massive star formation regions - I. SIMBA observations of cold cores, MNRAS, 2005, vol. 363, p. 405

Hoare M. G., et al., The RMS survey: Massive young stars throughout the galaxy. In Massive Star Birth: A Crossroads of Astrophysics, vol. 227 of IAU Symposium, 2005, p. 370

Hughes V. A., MacLeod G. C., An analysis of IRAS-identified H II regions and their radio properties, ApJ, 1994, vol. 427, p. 857

Hunter T. R., Churchwell E., Watson C., Cox P., Benford D. J., Roelfsema P. R., 350 Micron Images of Massive Star Formation Regions, AJ, 2000, vol. 119, p. 2711

Jijina J., Adams F. C., Infall Collapse Solutions in the Inner Limit: Radiation Pressure and Its Effects on Star Formation, ApJ, 1996, vol. 462, p. 874

Jijina J., Myers P. C., Adams F. C., Dense Cores Mapped in Ammonia: A Database, ApJS, 1999, vol. 125, p. 161 
Keto E., On the Evolution of Ultracompact H II Regions, ApJ, 2002, vol. 580, p. 980

Keto E., The Formation of Massive Stars by Accretion through Trapped Hypercompact H II Regions, ApJ, 2003, vol. 599, p. 1196

Kroupa P., The initial mass function of simple and composite stellar populations, ArXiv Astrophysics e-prints, 2007

Krumholz M. R., Klein R. I., McKee C. F., Offner S. S. R., Cunningham A. J., The Formation of Massive Star Systems by Accretion, Science, 2009, vol. 323, p. 754

Kuiper R., Klahr H., Beuther H., Henning T., Radiation pressure feedback in the formation of massive stars, Bulletin de la Societe Royale des Sciences de Liege, 2011a, vol. 80, p. 211

Kuiper R., Klahr H., Beuther H., Henning T., Three-dimensional Simulation of Massive Star Formation in the Disk Accretion Scenario, ApJ, 2011b, vol. 732, p. 20

Kumar M. S. N., Grave J. M. C., Spitzer-IRAC GLIMPSE of high-mass protostellar objects. I. Infrared point sources and nebulae, A\&A, 2007, vol. 472, p. 155

Kurtz S., Hypercompact HII regions. In Massive Star Birth: A Crossroads of Astrophysics , vol. 227 of IAU Symposium, 2005, p. 111

Kurtz S., Cesaroni R., Churchwell E., Hofner P., Walmsley C. M., Hot Molecular Cores and the Earliest Phases of High-Mass Star Formation, Protostars and Planets IV, 2000, pp 299-326

Kwan J. H., Gatley I., Merrill K. M., Probst R., Weintraub D. A., On the molecular hydrogen emission at the Orion Nebula, ApJ, 1977, vol. 216, p. 713

Lada C. J., Cold outflows, energetic winds, and enigmatic jets around young stellar objects, ARA\&A, 1985, vol. 23, p. 267

Lada C. J., Wilking B. A., The nature of the embedded population in the Rho Ophiuchi dark cloud - Mid-infrared observations, ApJ, 1984, vol. 287, p. 610 
Loh E. D., Biel J. D., Davis M. W., Laporte R., Loh O. Y., Verhanovitz N. J., Spartan Infrared Camera, a High-Resolution Imager for the SOAR Telescope: Design, Tests, and On-Telescope Performance, PASP, 2012, vol. 124, p. 343

Loup C., Forveille T., Omont A., Paul J. F., CO and HCN observations of circumstellar envelopes. A catalogue - Mass loss rates and distributions, A\&AS, 1993, vol. 99, p. 291

Lumsden S. L., Hoare M. G., Oudmaijer R. D., Richards D., The population of the Galactic plane as seen by MSX, MNRAS, 2002, vol. 336, p. 621

MacLow M., Turbulence in the Interstellar Medium, Ap\&SS, 2004, vol. 289, p. 323

Martins F., Schaerer D., Hillier D. J., A new calibration of stellar parameters of Galactic O stars, A\&A, 2005, vol. 436, p. 1049

Mason B. D., Gies D. R., Hartkopf W. I., Bagnuolo Jr. W. G., ten Brummelaar T., McAlister H. A., ICCD speckle observations of binary stars. XIX - an astrometric/spectroscopic survey of O stars, AJ, 1998, vol. 115, p. 821

Mathis J. S., Interstellar dust and extinction. In The Evolution of the Interstellar Medium , vol. 12 of Astronomical Society of the Pacific Conference Series, 1990, p. 63

Matzner C. D., Protostellar Outflow-driven Turbulence, ApJ, 2007, vol. 659, p. 1394

McCaughrean M. J., et al., High-Resolution Near-Infrared Imaging of the Orion 114-426 Silhouette Disk, ApJL, 1998, vol. 492, p. L157+

McKee C. F., Tan J. C., Massive star formation in 100,000 years from turbulent and pressurized molecular clouds, Nature, 2002, vol. 416, p. 59

McKee C. F., Tan J. C., The Formation of Massive Stars from Turbulent Cores, ApJ, 2003, vol. 585 , p. 850

Meisenheimer K., Roeser H.-J., Schloetelburg M., The synchrotron spectrum of the jet in M87., A\&A, 1996, vol. 307, p. 61

Menten K. M., The discovery of a new, very strong, and widespread interstellar methanol maser line, ApJL, 1991, vol. 380, p. L75 
Moeckel N., Clarke C. J., Collisional formation of very massive stars in dense clusters, MNRAS, 2011, vol. 410, p. 2799

Molinari S., Brand J., Cesaroni R., Palla F., A search for precursors of ultracompact HII regions in a sample of luminous IRAS sources. I. Association with ammonia cores., A\&A, 1996, vol. 308 , p. 573

Molinari S., Brand J., Cesaroni R., Palla F., Palumbo G. G. C., A search for precursors of ultracompact H II regions in a sample of luminous IRAS sources. II. VLA observations, A\&A, 1998, vol. 336, p. 339

Mottram J. C., The Luminosity Function of Massive Young Stellar Objects in the Milky Way Galaxy, University of Leeds (UK, 2008, Tese de Doutorado

Mottram J. C., et al., The Red MSX Source survey: the bolometric fluxes and luminosity distributions of young massive stars, A\&A, 2011, vol. 525, p. A149+

Mottram J. C., Hoare M. G., Lumsden S. L., Oudmaijer R. D., Urquhart J. S., Meade M. R., Moore T. J. T., Stead J. J., The RMS survey: far-infrared photometry of young massive stars, AAp, 2010, vol. 510, p. A89+

Mottram J. C., Hoare M. G., Lumsden S. L., Oudmaijer R. D., Urquhart J. S., Sheret T. L., Clarke A. J., Allsopp J., The RMS survey: mid-infrared observations of candidate massive YSOs in the southern hemisphere, A\&A, 2007, vol. 476, p. 1019

Mundt R., Eislöffel J., T Tauri Stars Associated with Herbig-Haro Objects and Jets, AJ, 1998, vol. 116, p. 860

Navarete F., Figueredo E., Damineli A., Moisés A. P., Blum R. D., Conti P. S., The Stellar Content of Obscured Galactic Giant H II Regions. VII. W3, AJ, 2011, vol. 142, p. 67

Nisini B., Kaas A. A., van Dishoeck E. F., Ward-Thompson D., ISO Observations of Pre-Stellar Cores and Young Stellar Objects, SSRv, 2005, vol. 119, p. 159

Onishi T., Mizuno A., Kawamura A., Ogawa H., Fukui Y., A C 180 Survey of Dense Cloud Cores in Taurus: Core Properties, ApJ, 1996, vol. 465, p. 815 
Osorio M., Lizano S., D'Alessio P., Hot Molecular Cores and the Formation of Massive Stars, ApJ, 1999, vol. 525, p. 808

Palla F., Brand J., Comoretto G., Felli M., Cesaroni R., Water masers associated with dense molecular clouds and ultracompact H II regions, AAp, 1991, vol. 246, p. 249

Palla F., Stahler S. W., The Pre-Main-Sequence Evolution of Intermediate-Mass Stars, ApJ, 1993, vol. 418, p. 414

Panagia N., Some Physical parameters of early-type stars, AJ, 1973, vol. 78, p. 929

Patel N. A., et al., A disk of dust and molecular gas around a high-mass protostar, Nature, 2005, vol. 437, p. 109

Pesenti N., Dougados C., Cabrit S., Ferreira J., Casse F., Garcia P., O’Brien D., Predicted rotation signatures in MHD disc winds and comparison to DG Tau observations., A\&A, 2004, vol. 416, p. L9

Pestalozzi M. R., Minier V., Booth R. S., A general catalogue of 6.7-GHz methanol masers. I. Data., A\&A, 2005, vol. 432, p. 737

Plambeck R. L., Menten K. M., 95 GHz methanol masers near DR 21 and DR 21(OH), ApJ, 1990, vol. 364, p. 555

Qiu K., Leurini W., Molecular outflows in young stellar objects, MemSAI, 2011, vol. 82, p. 158

Richer J. S., Shepherd D. S., Cabrit S., Bachiller R., Churchwell E., Molecular Outflows from Young Stellar Objects, Protostars and Planets IV, 2000, pp 867-+

Robitaille T. P., Whitney B. A., Indebetouw R., Wood K., Interpreting Spectral Energy Distributions from Young Stellar Objects. II. Fitting Observed SEDs Using a Large Grid of Precomputed Models, ApJS, 2007, vol. 169, p. 328

Rodriguez L. F., Garay G., Curiel S., Ramirez S., Torrelles J. M., Gomez Y., Velazquez A., Cepheus A HW2: A powerful thermal radio jet, ApJL, 1994, vol. 430, p. L65 
Rosero V., Hofner P., Kurtz S., Bieging J., Araya E. D., Methyl Cyanide Observations toward Massive Protostars, ApJS, 2013, vol. 207, p. 12

Salas L., Cruz-Gonzalez I., Porras A., S187 : SCP 1 (H2): A Curved Molecular Hydrogen Outflow, ApJ, 1998, vol. 500, p. 853

Salas L., Cruz-González I., Rosado M., Velocity Structure in the Curved Jet S187:SCP 1 (H2):, RMxAA, 2000, vol. 36, p. 113

Salpeter E. E., The Luminosity Function and Stellar Evolution., ApJ, 1955, vol. 121, p. 161

Shepherd D. S., Churchwell E., Bipolar Molecular Outflows in Massive Star Formation Regions, ApJ, 1996, vol. 472, p. 225

Shepherd D. S., Testi L., Stark D. P., Clustered Star Formation in W75 N, ApJ, 2003, vol. 584, p. 882

Shu F. H., Adams F. C., Lizano S., Star formation in molecular clouds - Observation and theory, ARA\&A, 1987, vol. 25, p. 23

Sobolev A. M., Cragg D. M., Ellingsen S. P., Gaylard M. J., Goedhart S., Henkel C., Kirsanova M. S., Ostrovskii A. B., Pankratova N. V., Shelemei O. V., van der Walt D. J., Vasyunina T. S., Voronkov M. A., How do methanol masers manage to appear in the youngest star vicinities and isolated molecular clumps?. In IAU Symposium , vol. 242 of IAU Symposium, 2007, p. 81

Solf J., Bipolar Outflows and Jets from Central Stars of Planetary Nebulae. In Stellar Jets and Bipolar Outflows, vol. 186 of Astrophysics and Space Science Library, 1993, p. 145

Sridharan T. K., Beuther H., Schilke P., Menten K. M., Wyrowski F., High-Mass Protostellar Candidates. I. The Sample and Initial Results, ApJ, 2002, vol. 566, p. 931

Stahler S. W., Shu F. H., Taam R. E., The evolution of protostars. I - Global formulation and results, ApJ, 1980, vol. 241, p. 637 
Surcis G., Vlemmings W. H. T., van Langevelde H. J., Hutawarakorn Kramer B., QuirogaNuñez L. H., EVN observations of $6.7 \mathrm{GHz}$ methanol maser polarization in massive star-forming regions. II. First statistical results, A\&A, 2013, vol. 556, p. A73

Tan J. C., Theories of Massive Star Formation: Collisions, Accretion and the View from the "I" of Orion (Invited Review). In Galactic Star Formation Across the Stellar Mass Spectrum, vol. 287 of Astronomical Society of the Pacific Conference Series, 2003, p. 207

Thomas H. S., Fuller G. A., The circumstellar environment of high-mass protostellar objects. IV. $\mathrm{C}^{17} \mathrm{O}$ observations and depletion, A\&A, 2008, vol. 479, p. 751

Torrelles J. M., Gómez J. F., Rodríguez L. F., Curiel S., Anglada G., Ho P. T. P., Radio Continuum-H_2O Maser Systems in NGC 2071: H_2O Masers Tracing a Jet (IRS 1) and a Rotating Proto-planetary Disk of Radius 20 AU (IRS 3), ApJ, 1998, vol. 505, p. 756

Torrelles J. M., Gomez J. F., Rodriguez L. F., Curiel S., Ho P. T. P., Garay G., The Thermal Radio Jet of Cepheus A HW2 and the Water Maser Distribution at 0 -8pt. Scale (60 AU), ApJL, 1996, vol. 457, p. L107+

Trinidad M. A., Rodríguez T., Rodríguez L. F., Radio Jets and Disks in the IntermediateMass Star-Forming Region NGC2071IR, ApJ, 2009, vol. 706, p. 244

Urquhart J. S., Busfield A. L., Hoare M. G., Lumsden S. L., Clarke A. J., Moore T. J. T., Mottram J. C., Oudmaijer R. D., The RMS survey. Radio observations of candidate massive YSOs in the southern hemisphere, A\&A, 2007, vol. 461, p. 11

Urquhart J. S., et al., The RMS survey. ${ }^{13} \mathrm{CO}$ observations of candidate massive YSOs in the southern Galactic plane, A\&A, 2007, vol. 474, p. 891

Urquhart J. S., et al., The RMS survey. ${ }^{13} \mathrm{CO}$ observations of candidate massive YSOs in the northern Galactic plane, A\&A, 2008, vol. 487, p. 253

Urquhart J. S., et al., The RMS survey. $6 \mathrm{~cm}$ continuum VLA observations towards candidate massive YSOs in the northern hemisphere, A\&A, 2009a, vol. 501, p. 539

Urquhart J. S., et al., The RMS survey. H_2O masers towards a sample of southern hemisphere massive YSO candidates and ultra compact HII regions, A\&A, 2009b, vol. 507, p. 795 
Urquhart J. S., Hoare M. G., Lumsden S. L., Oudmaijer R. D., Moore T. J. T., The RMS Survey: A Galaxy-wide Sample of Massive Young Stellar Objects. In Massive Star Formation: Observations Confront Theory, vol. 387 of Astronomical Society of the Pacific Conference Series, 2008, p. 381

Urquhart J. S., Morgan L. K., Figura C. C., Moore T. J. T., Lumsden S. L., Hoare M. G., et al., The Red MSX Source survey: ammonia and water maser analysis of massive star-forming regions, MNRAS, 2011, vol. 418, p. 1689

Vacca W. D., Garmany C. D., Shull J. M., The Lyman-Continuum Fluxes and Stellar Parameters of O and Early B-Type Stars, ApJ, 1996, vol. 460, p. 914

van Dishoeck E. F., Black J. H., Boogert A. C. A., Boonman A. M. S., Ehrenfreund P., Gerakines P. A., de Graauw T., Helmich F. P., et al., ISO spectroscopy of young stellar objects. In The Universe as Seen by ISO , vol. 427 of ESA Special Publication, 1999, p. 437

Varricatt W. P., Davis C. J., Ramsay S., Todd S. P., A near-IR imaging survey of intermediate- and high-mass young stellar outflow candidates, MNRAS, 2010, vol. 404, p. 661

Vigroux L. G., Cesarsky C. J., Boulade O., Rio Y., Perault M., Abergel A., Desert F. X., Rouan D., Lacombe F., ISOCAM-the Infrared Space Observatory camera: results of testing and calibrations. In Society of Photo-Optical Instrumentation Engineers (SPIE) Conference Series, vol. 1946 of Society of Photo-Optical Instrumentation Engineers (SPIE) Conference Series, 1993, p. 281

Walsh A. J., Burton M. G., Hyland A. R., Robinson G., Studies of ultracompact HII regions - II. High-resolution radio continuum and methanol maser survey, MNRAS, 1998, vol. 301, p. 640

Ward-Thompson D., André P., Lay O. P., Observations of YSO Circumstellar Discs. In Planetary Systems in the Universe, vol. 202 of IAU Symposium, 2004, p. 393 
Ward-Thompson D., Andre P., Motte F., ISOPHOT Observations of Pre-stellar Cores. In Star Formation with the Infrared Space Observatory, vol. 132 of Astronomical Society of the Pacific Conference Series, 1998, p. 195

Ward-Thompson D., Scott P. F., Hills R. E., Andre P., A Submillimetre Continuum Survey of Pre Protostellar Cores, MNRAS, 1994, vol. 268, p. 276

Wood D. O. S., Churchwell E., Massive stars embedded in molecular clouds - Their population and distribution in the galaxy, ApJ, 1989, vol. 340, p. 265

Wu Y., Wei Y., Zhao M., Shi Y., Yu W., Qin S., Huang M., Catalogue of high velocity molecular outflows (Update) $(\mathrm{Wu}+2004)$, VizieR Online Data Catalog, 2004, vol. 342, p. 60503

Wynn-Williams C. G., The search for infrared protostars, ARA\&A, 1982, vol. 20, p. 587

Yang J., Jiang Z., Wang M., Ju B., Wang H., A Large-Scale Molecular Line Survey for Cold IRAS Sources in the Galaxy. I. The CO ( $J=1-0)$ Data, ApJS, 2002, vol. 141, p. 157

Yonekura Y., Asayama S., Kimura K., Ogawa H., Kanai Y., Yamaguchi N., Barnes P. J., Fukui Y., High-Mass Cloud Cores in the $\eta$ Carinae Giant Molecular Cloud, ApJ, 2005, vol. 634, p. 476

Yorke H. W., Welz A., Photoevaporation of protostellar disks. I. The evolution of disks around early B stars., A\&A, 1996, vol. 315, p. 555

Zhang Q., Hunter T. R., Sridharan T. K., A Rotating Disk around a High-Mass Young Star, ApJL, 1998, vol. 505, p. L151

Zhang Q., Hunter T. R., Sridharan T. K., Ho P. T. P., A Disk/Jet System toward the High-Mass Young Star in AFGL 5142, ApJ, 2002, vol. 566, p. 982

Zinnecker H., Yorke H. W., Toward Understanding Massive Star Formation, ARA\&A, 2007, vol. 45 , p. 481 
Apêndice 

Apêndice $\mathrm{A}$

Imagens RGB e Mapas de Emissão em $\mathrm{H}_{2}$

A.1 Fontes RMS com Emissão $H_{2}$ Não-polar
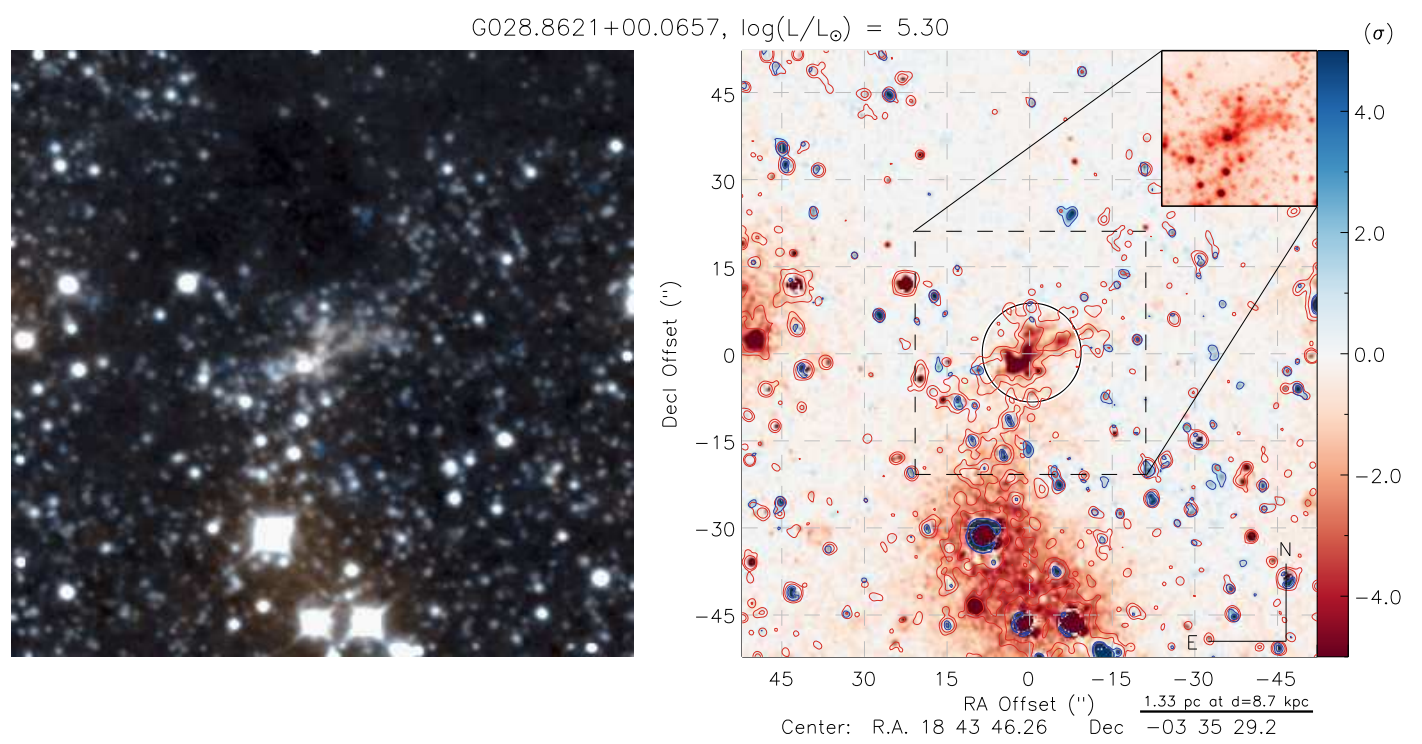

G034.7123-00.5946, $\log \left(L / L_{\odot}\right)=3.95$
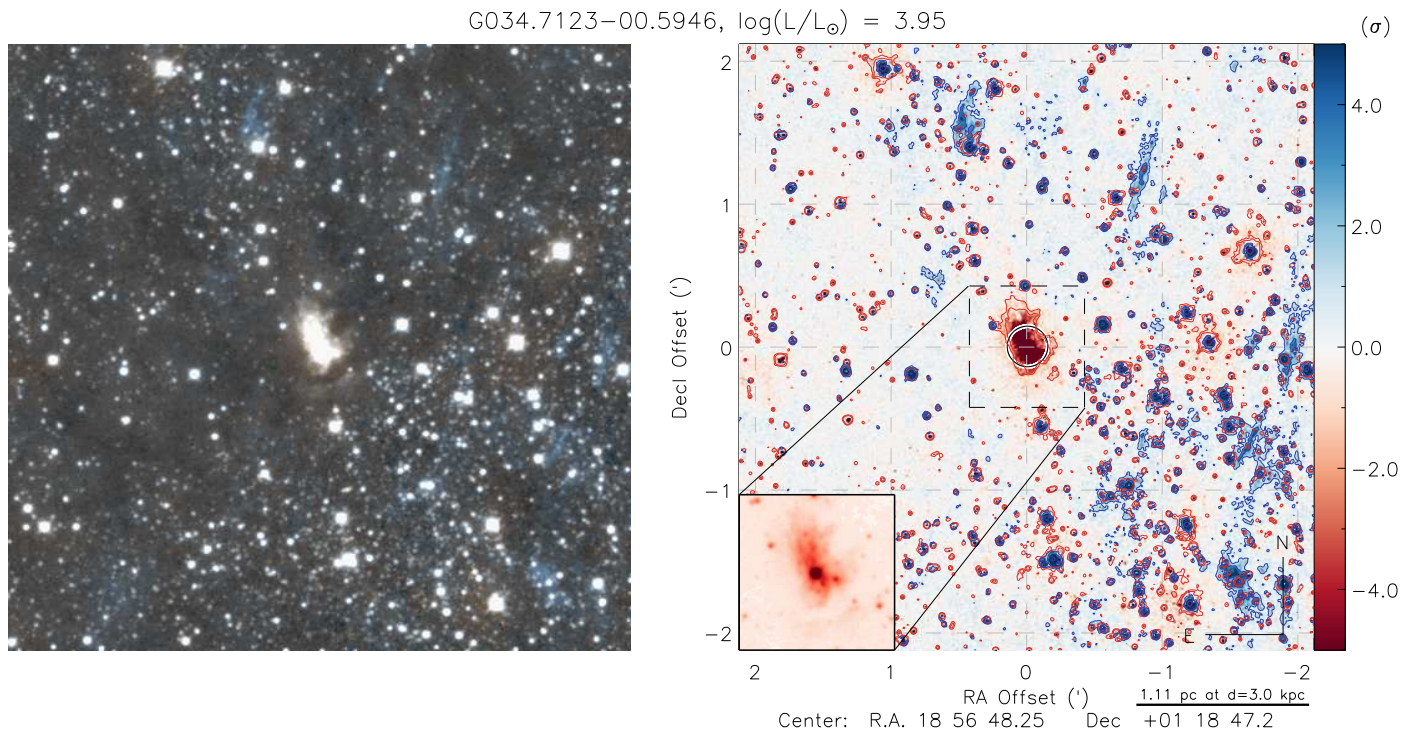

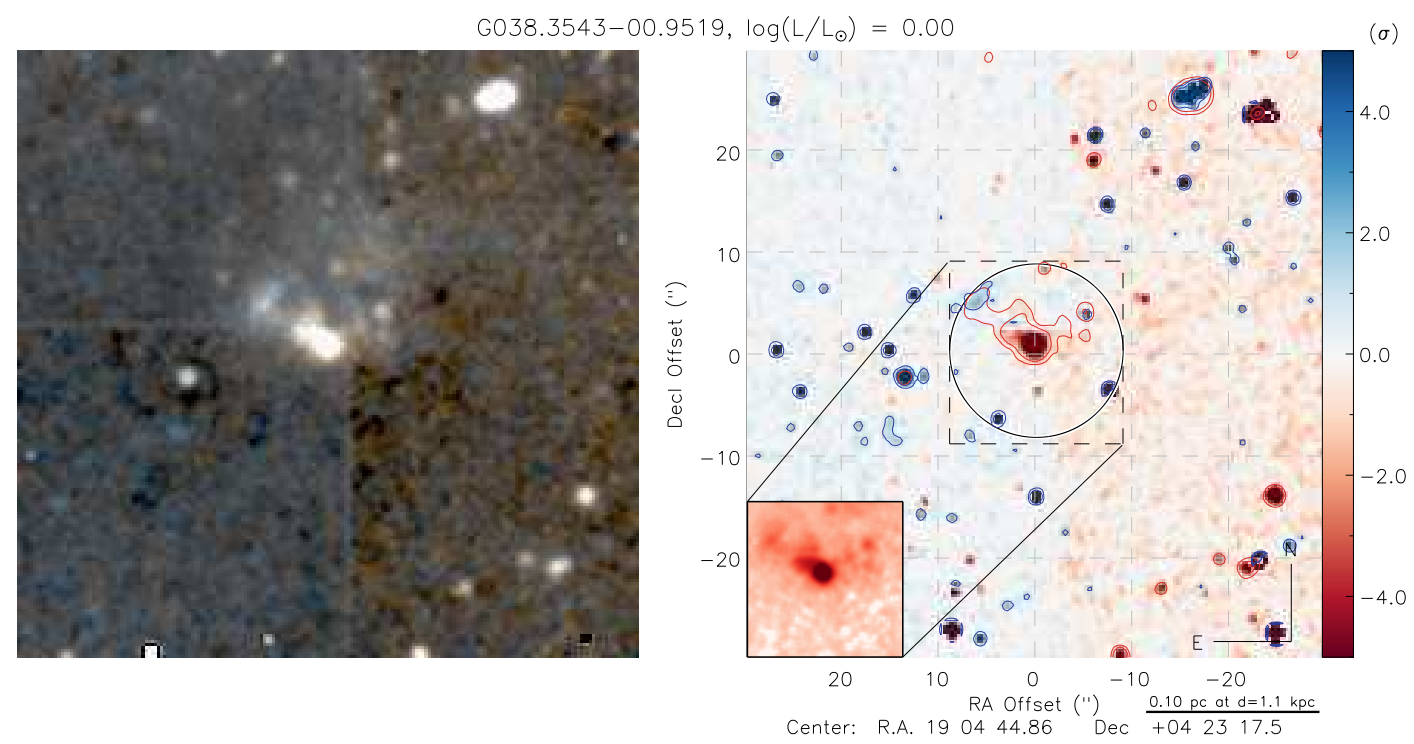

G043.9956-00.0111, $\log \left(L / L_{\odot}\right)=4.32$
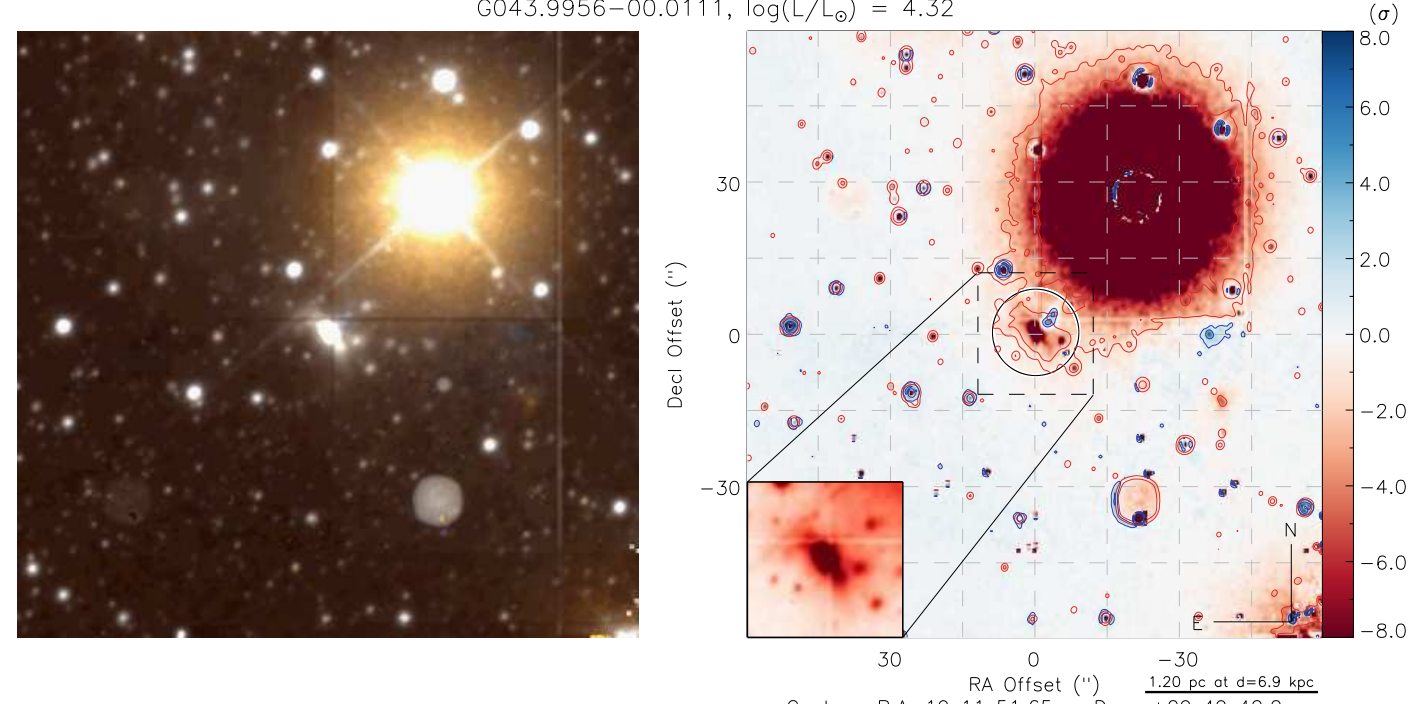

$\mathrm{G} 044.2836-00.5249, \log \left(L / L_{\odot}\right)=3.88$
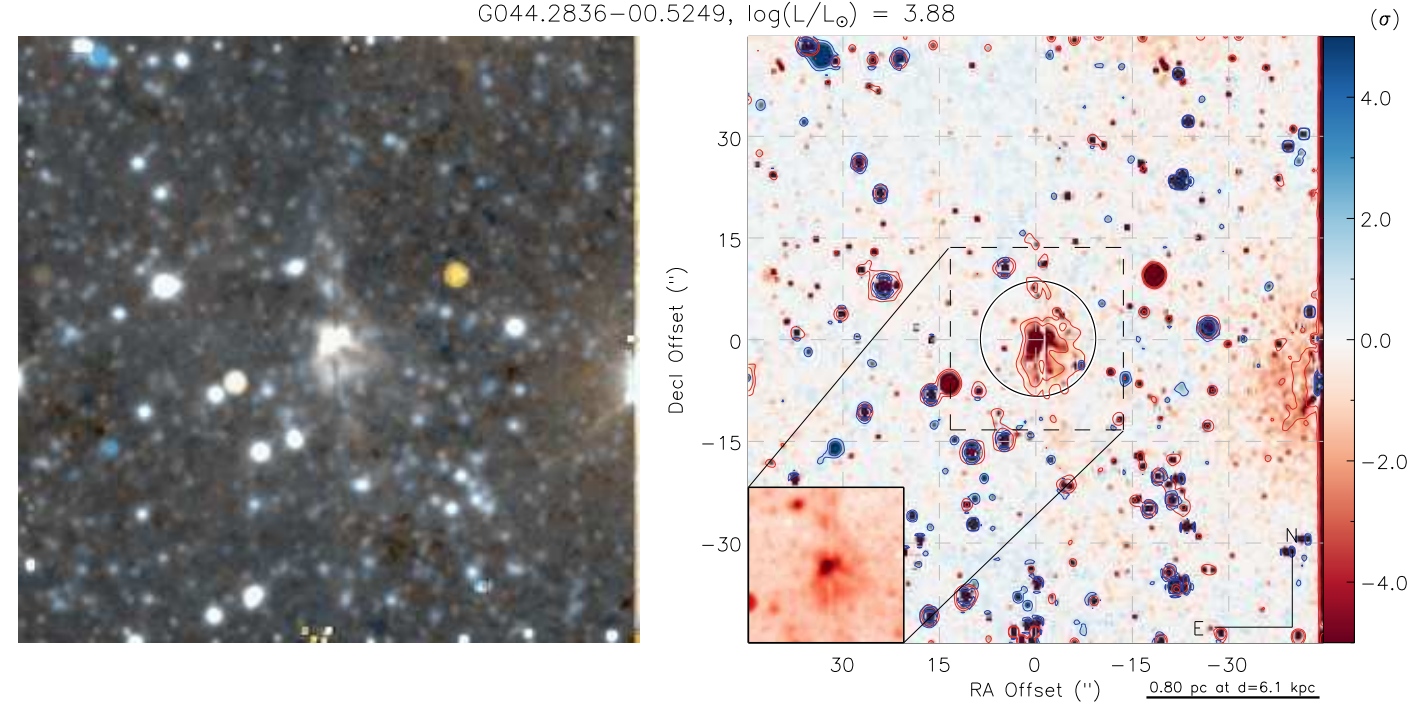

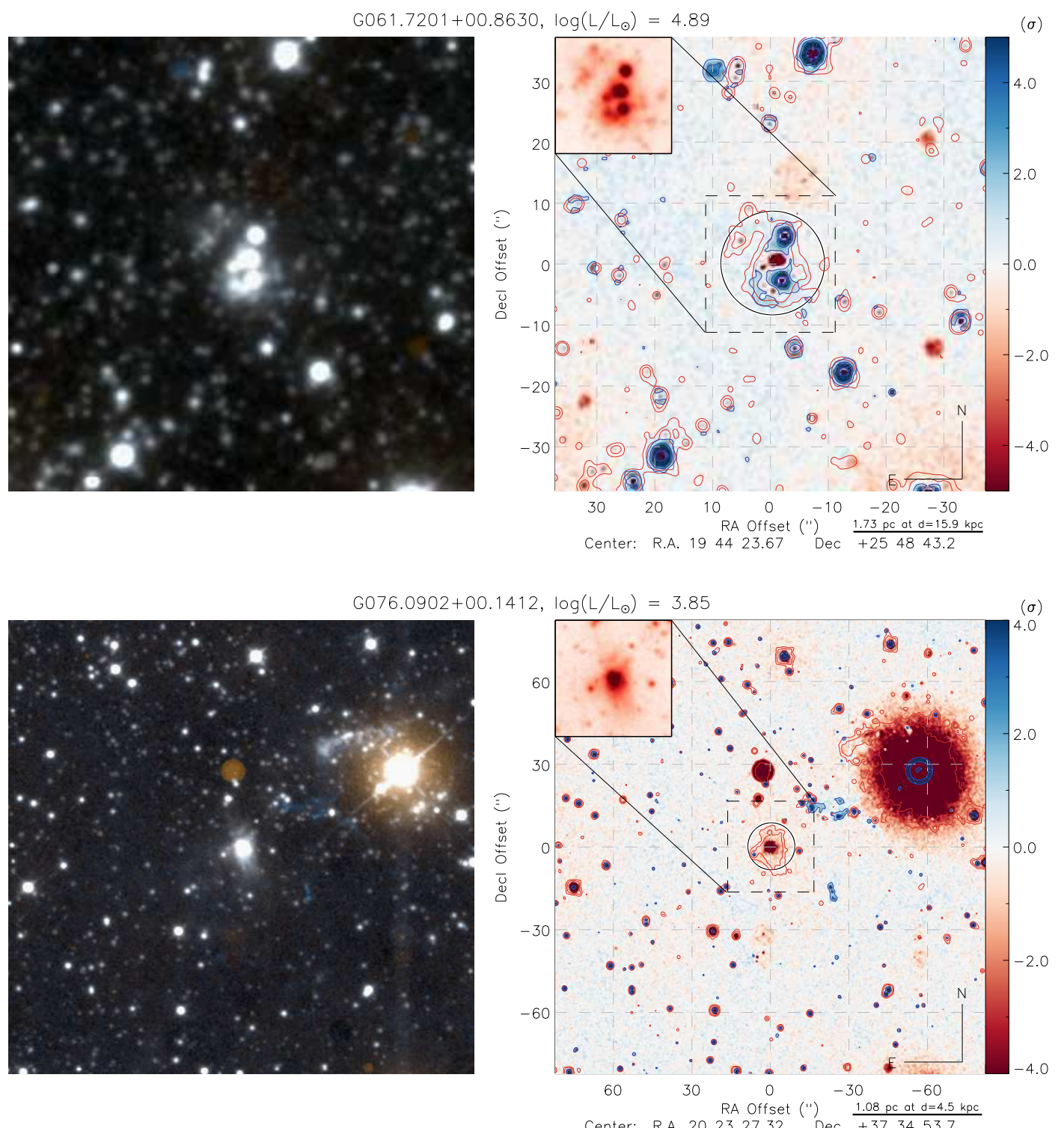

$\mathrm{G} 077.8999+01.7678, \log \left(L / L_{\odot}\right)=3.88$
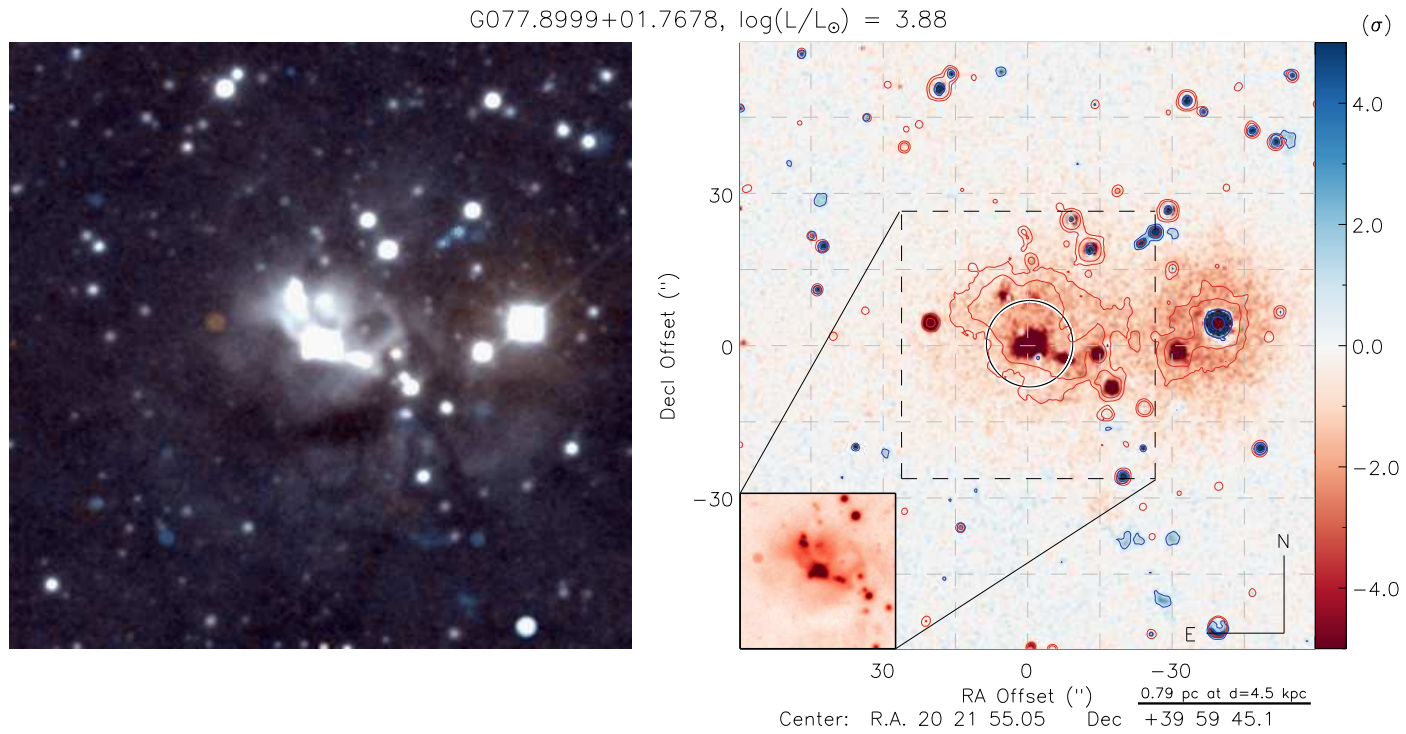
$\mathrm{G} 077.9550+00.0058, \log \left(\mathrm{L} / \mathrm{L}_{\odot}\right)=4.24$
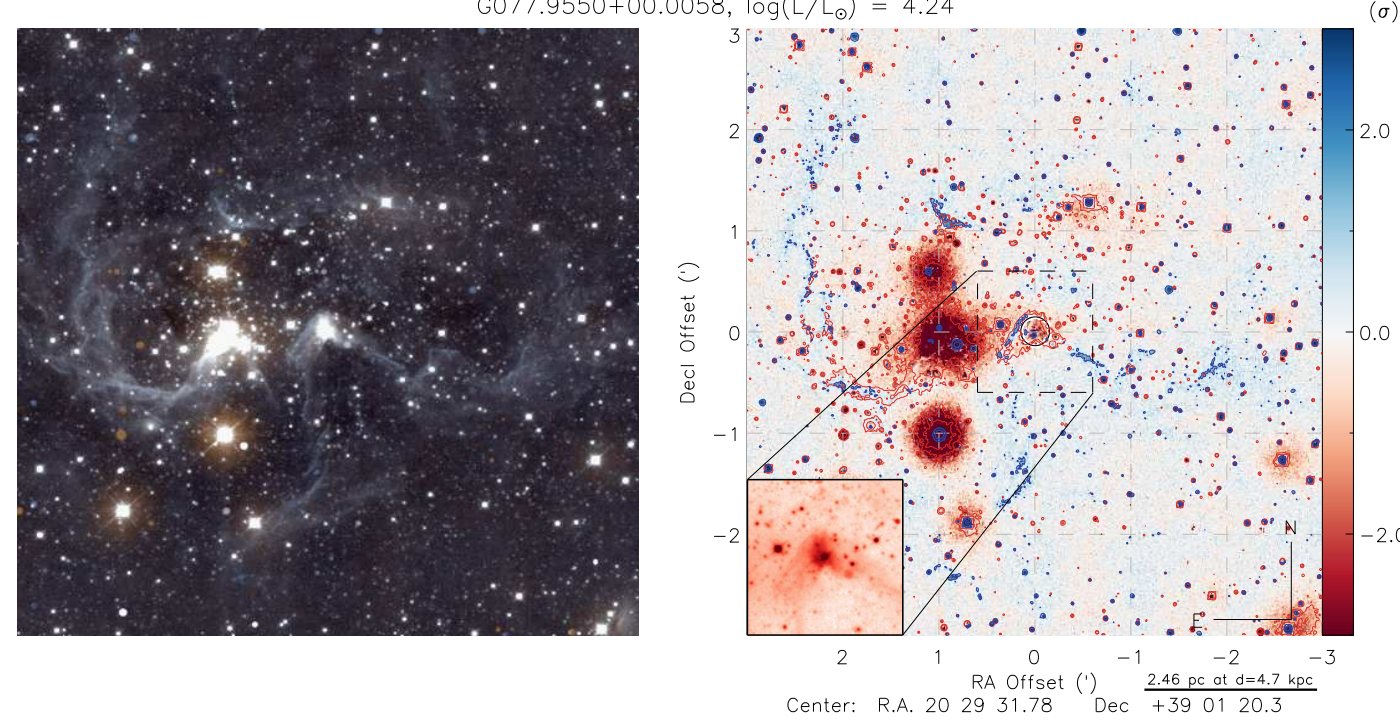

G077.9637-00.0075, $\log \left(L / L_{\odot}\right)=5.14$
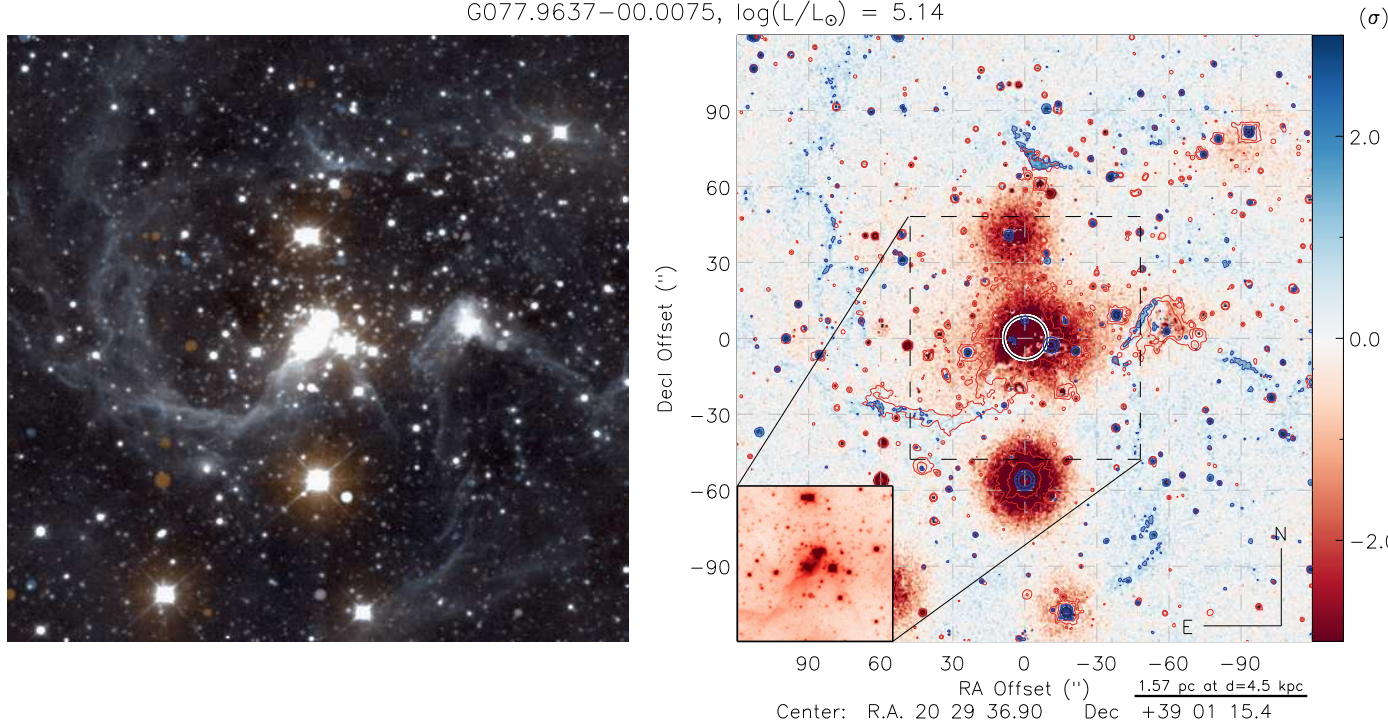

$\mathrm{G} 078.4373+02.6584, \log \left(\mathrm{L} / \mathrm{L}_{\odot}\right)=4.71$
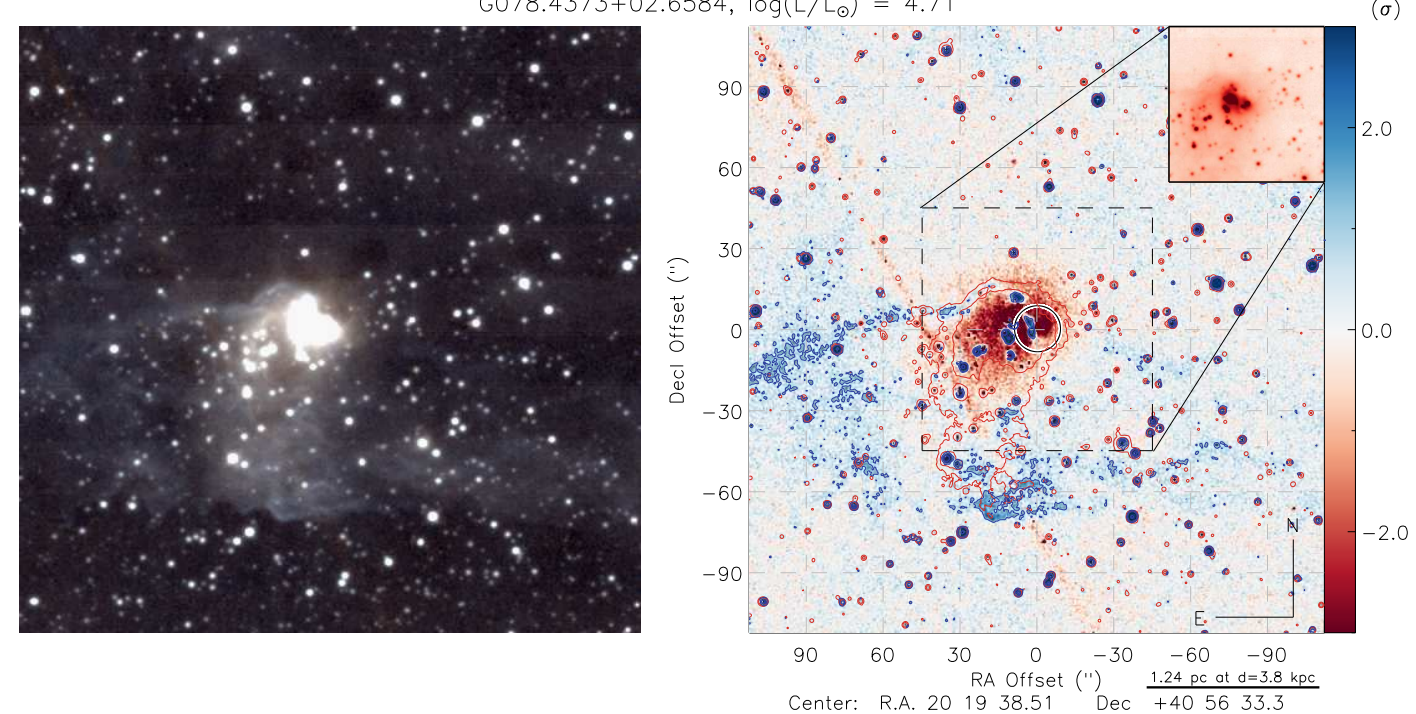

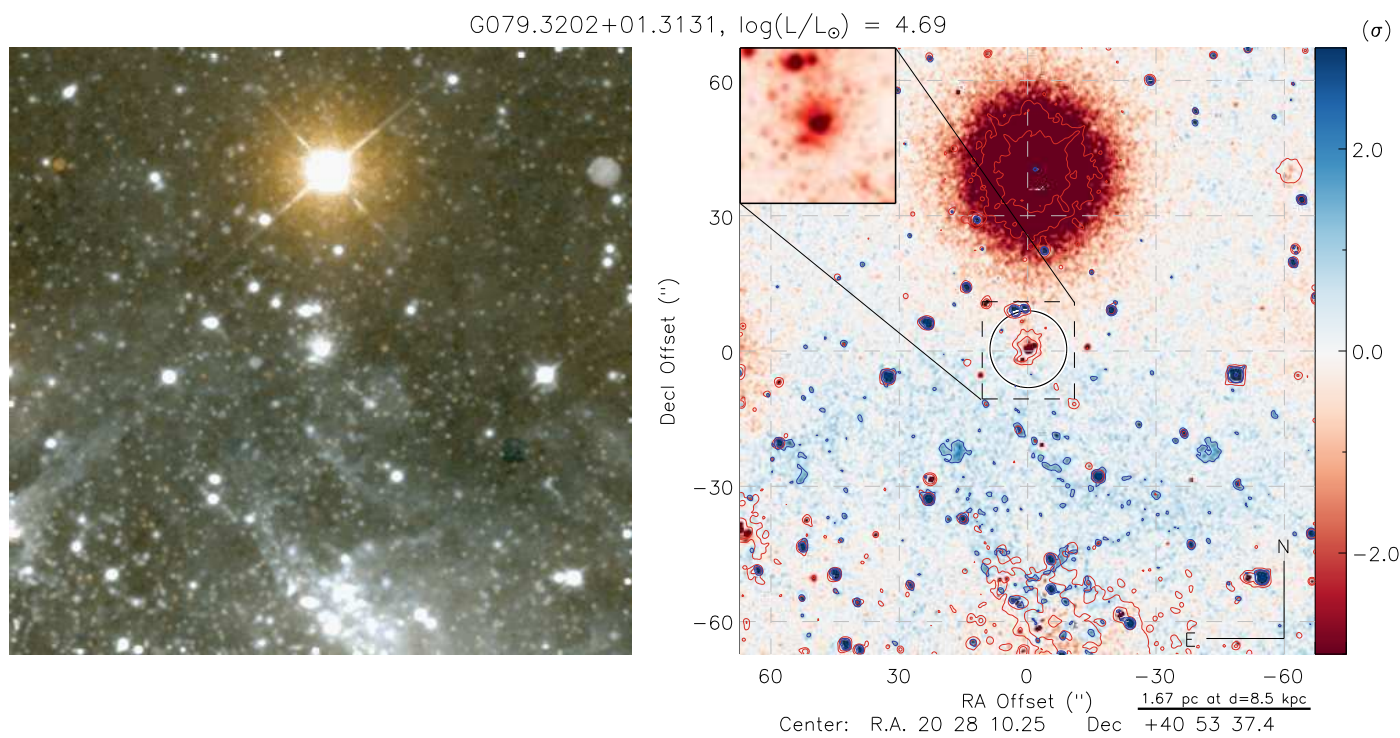

G079.3248+01.2901, $\log \left(L / L_{\odot}\right)=4.72$
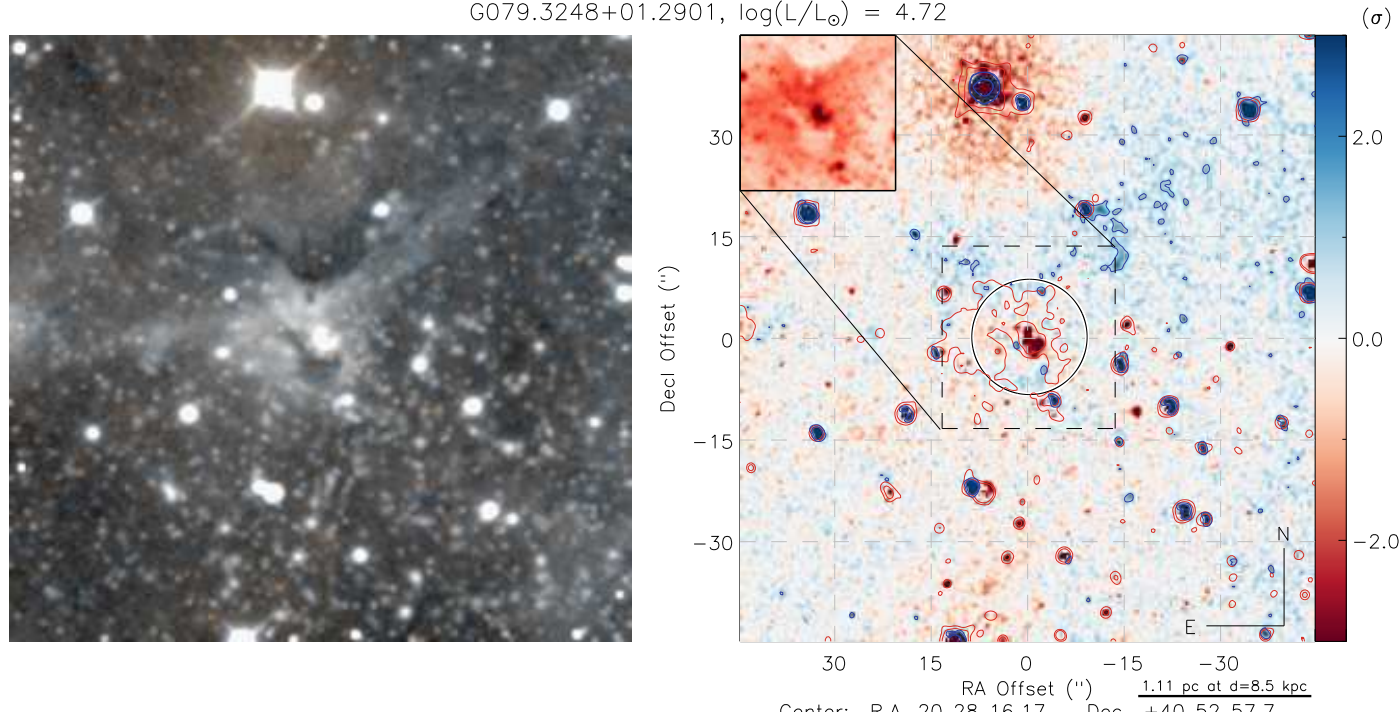

G079.3398+00.3417, $\log \left(L / L_{\odot}\right)=3.28$
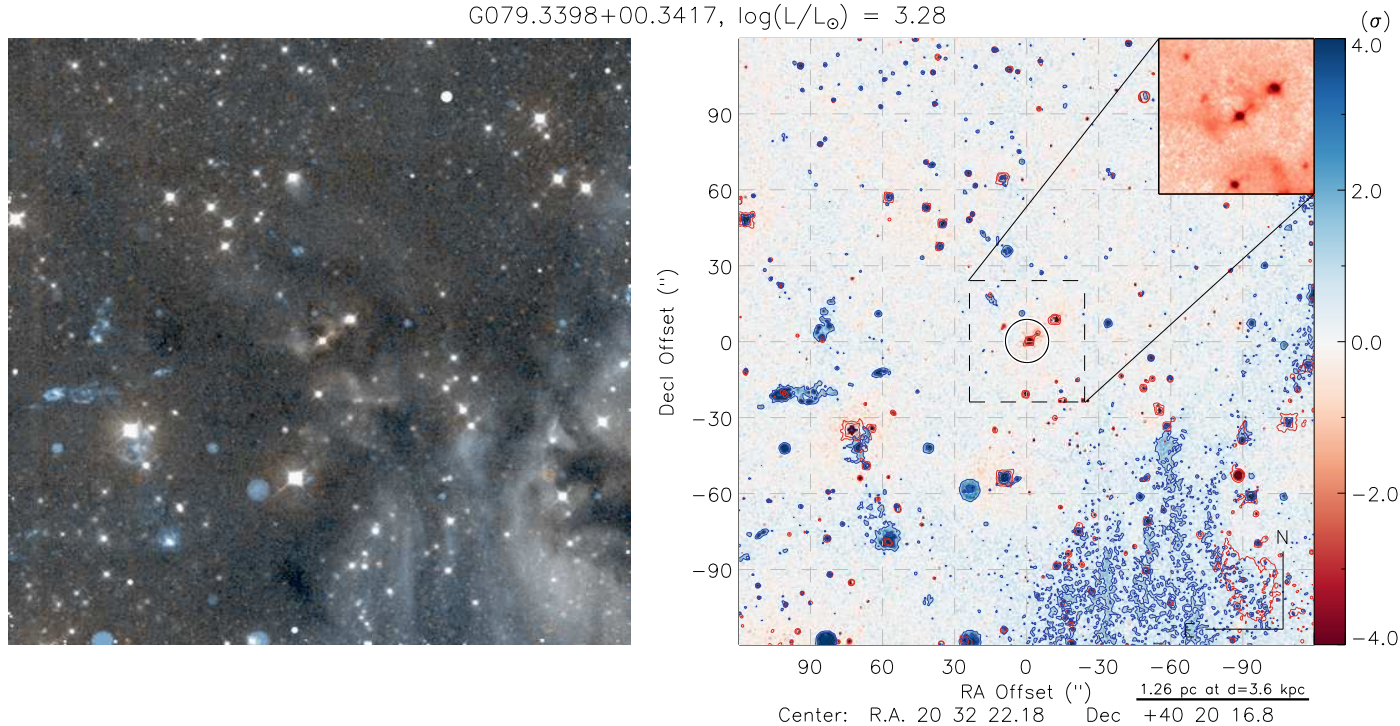

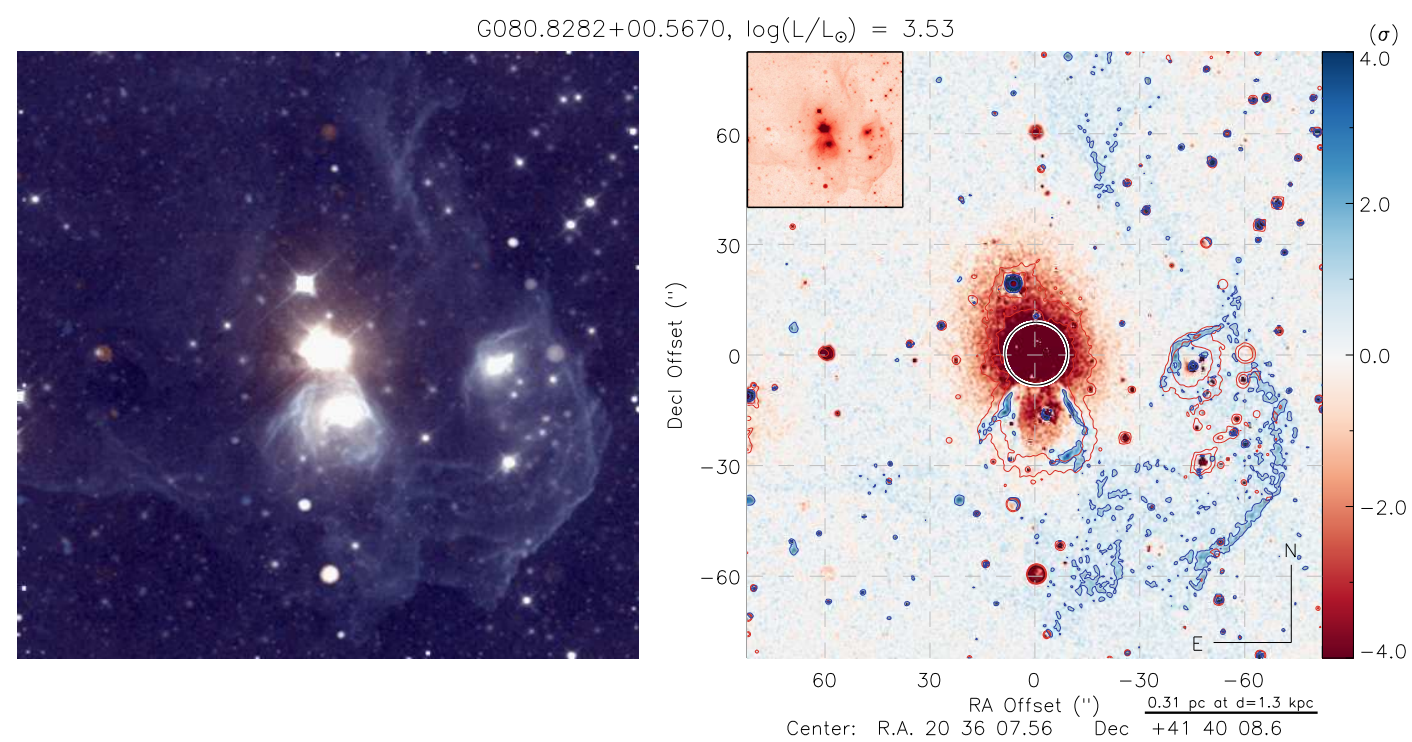

$\mathrm{G} 082.0333+02.3249, \log \left(\mathrm{L}_{\mathrm{C}} \mathrm{L}_{\odot}\right)=4.00$
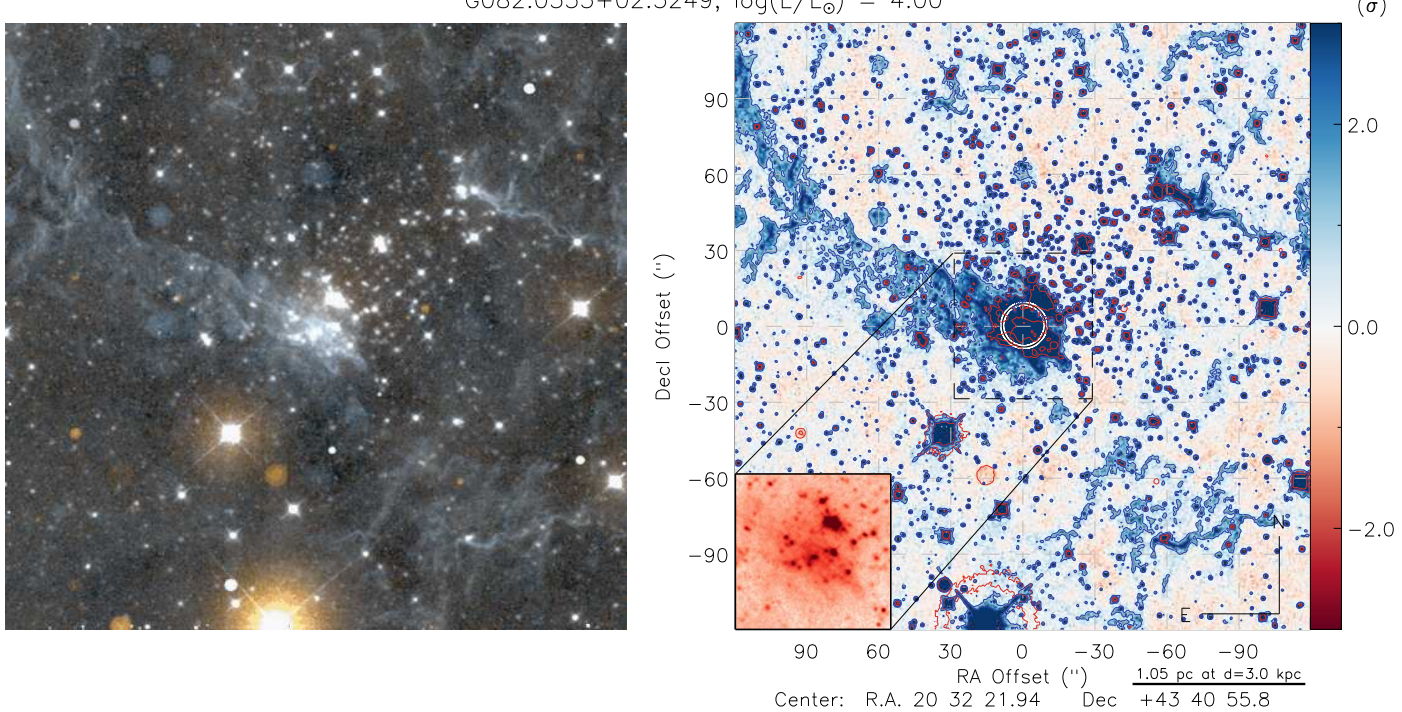

$\mathrm{G} 082.5682+00.4040, \log \left(L^{\prime} L_{\odot}\right)=3.32$
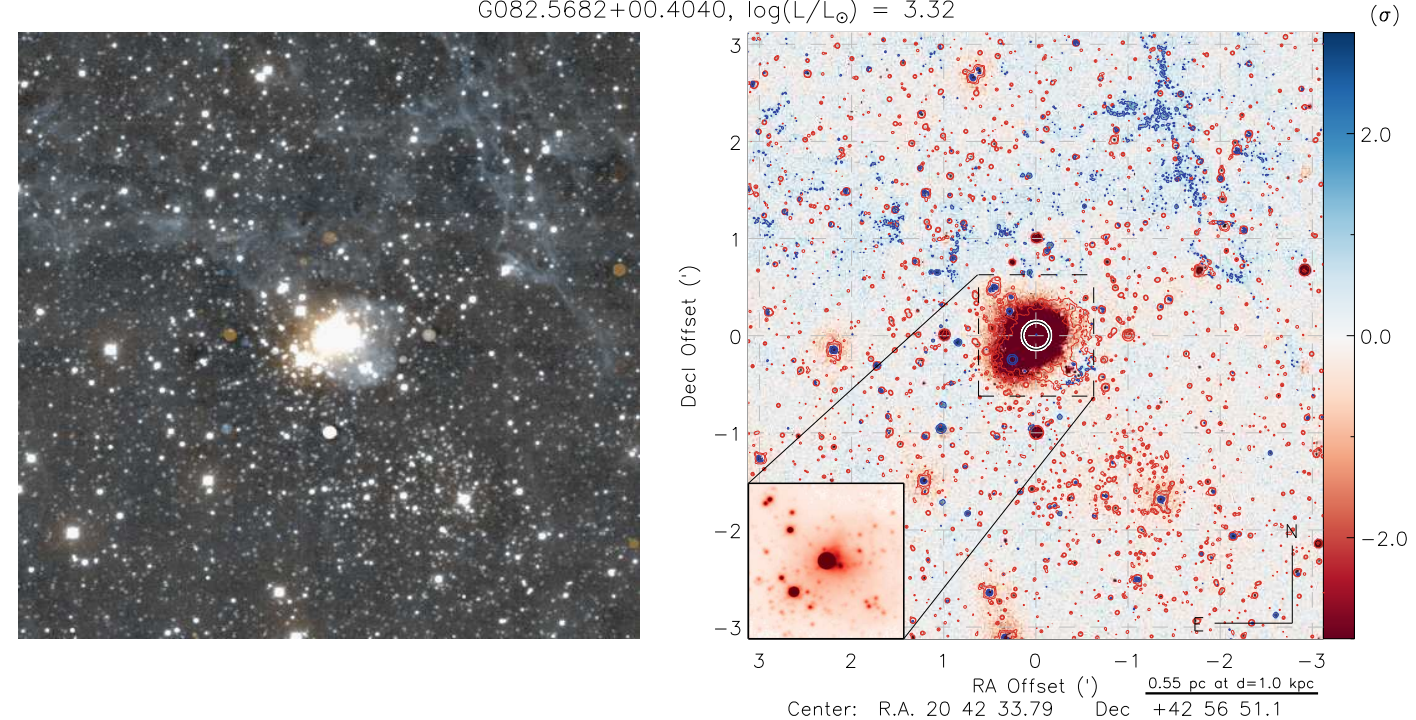
$\mathrm{G} 084.5978+00.1408, \log \left(\mathrm{L} / \mathrm{L}_{\odot}\right)=3.10$
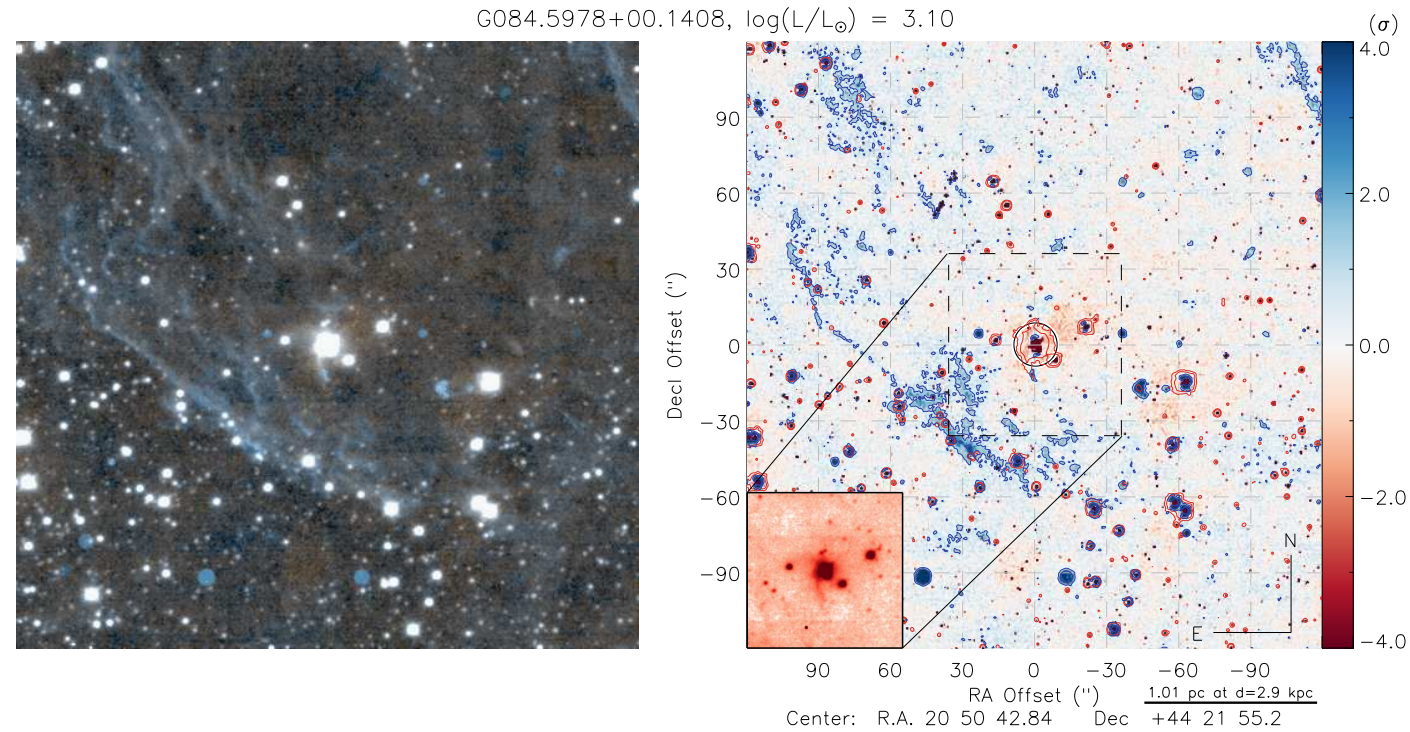

G085.0331+00.3629, $\log \left(L / L_{\odot}\right)=3.22$
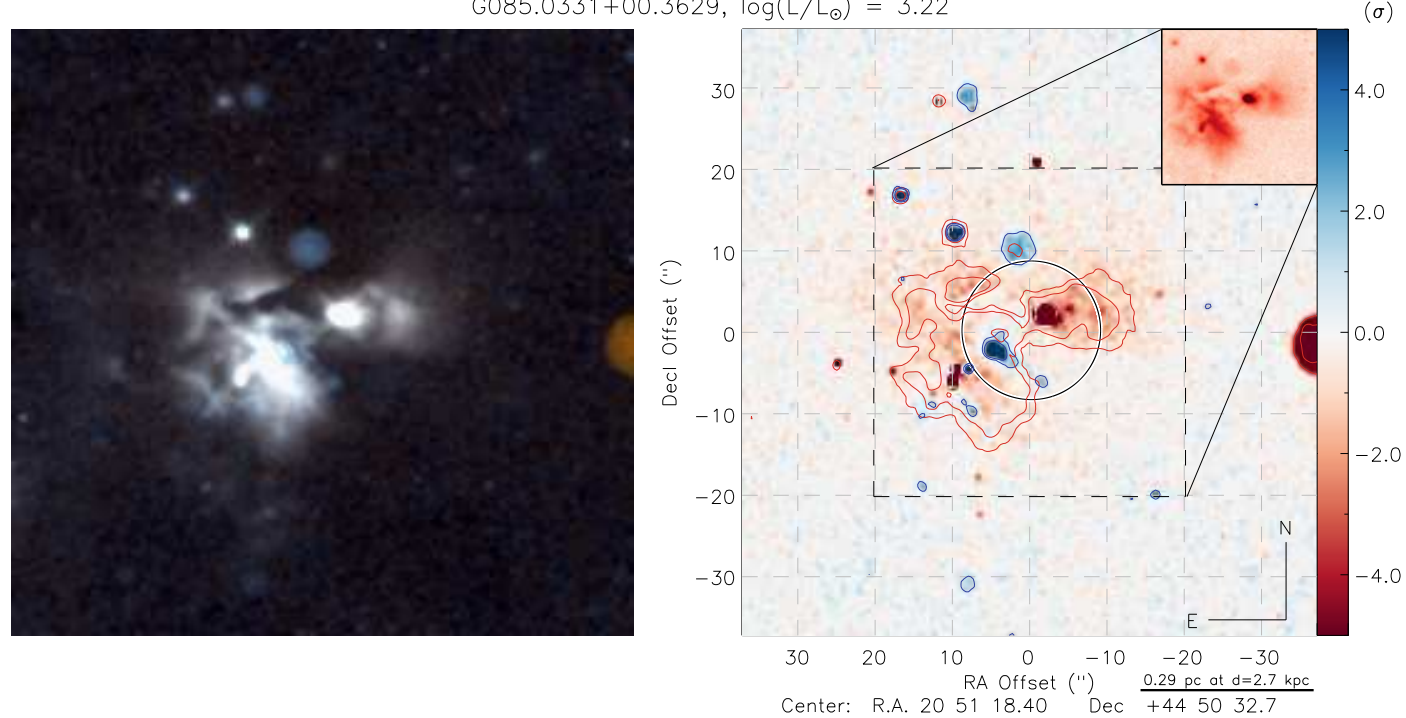

$\mathrm{G} 090.7764+02.8281, \log \left(L / L_{\odot}\right)=3.39$
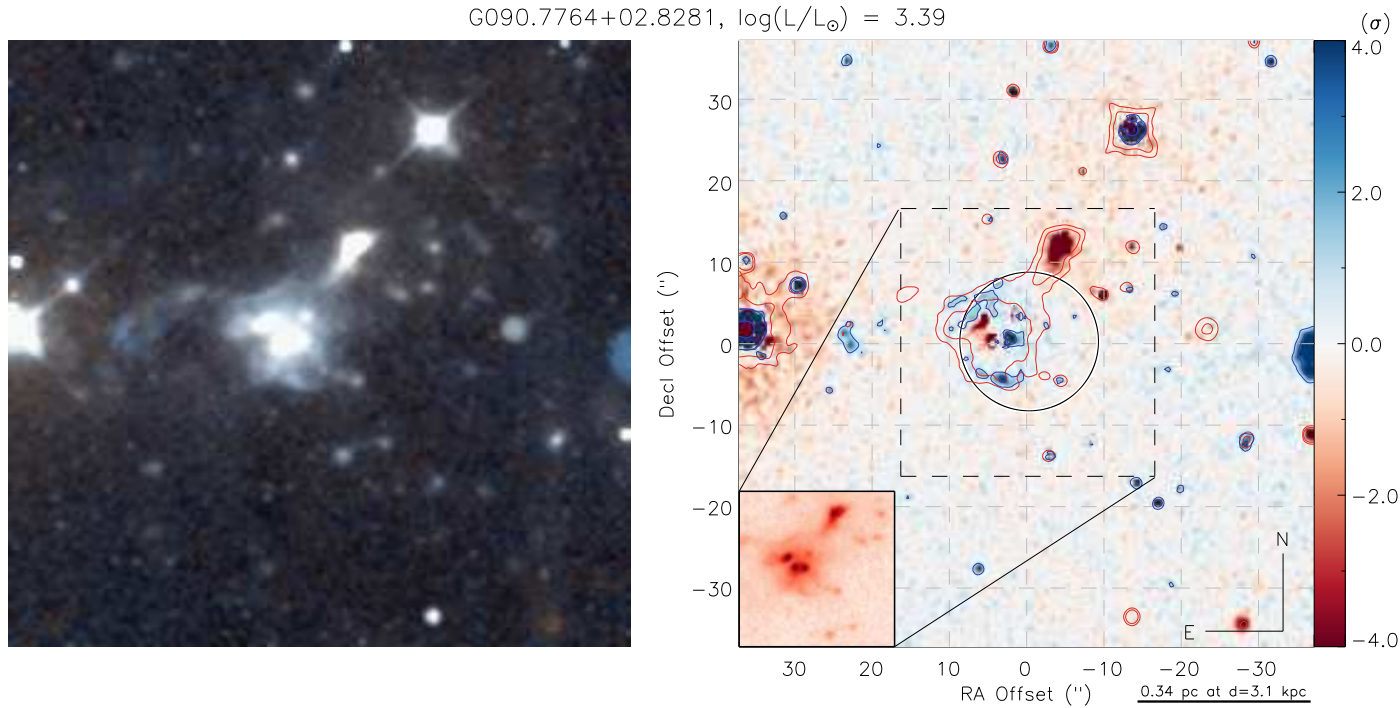

$\begin{array}{ccc}\text { RA Offset (") } & 0.34 \mathrm{pc} \text { at } \mathrm{d}=3.1 \mathrm{kpc} \\ \text { Center: R.A. } 210221.54 & \text { Dec } & \text { (50 48 34.2 }\end{array}$ 
G096.3597+01.2982, $\log \left(L / L_{\odot}\right)=4.34$
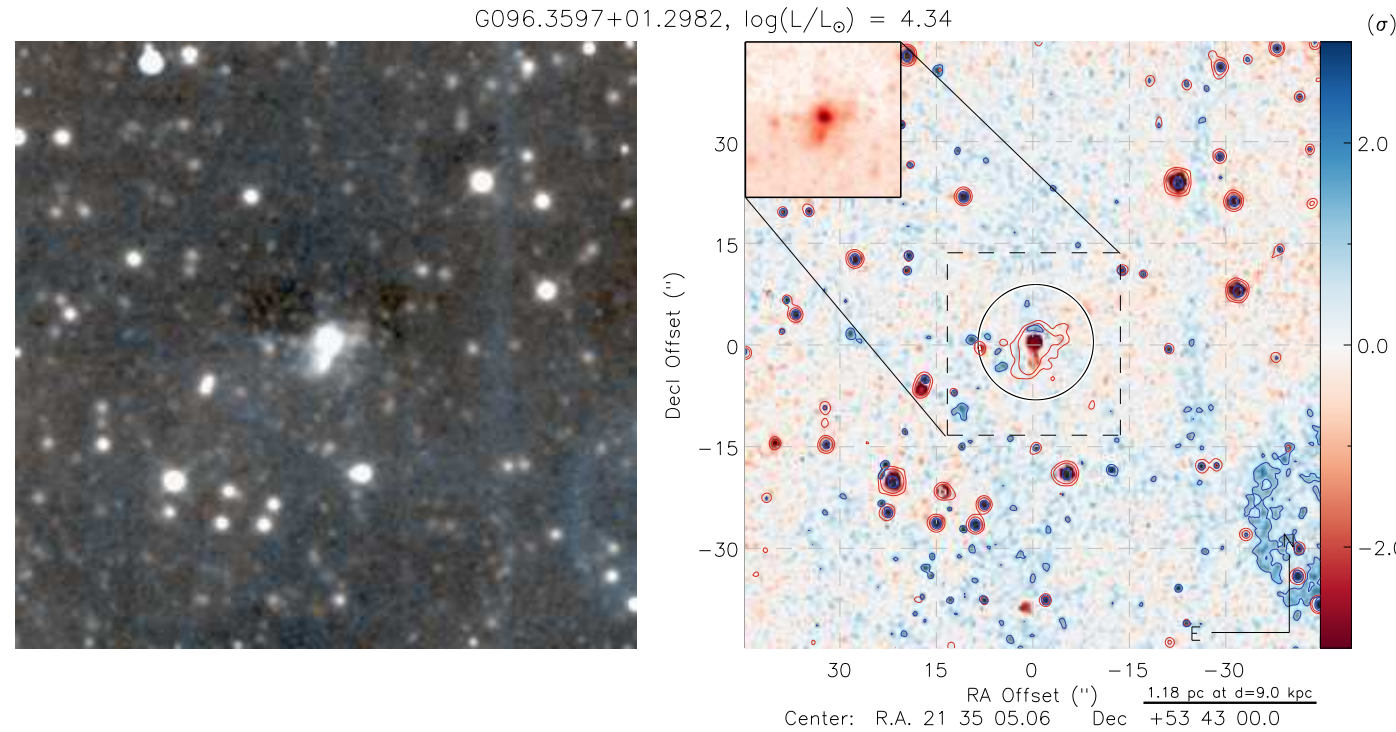

$\mathrm{G} 096.4353+01.3233, \log \left(\mathrm{L} / \mathrm{L}_{\odot}\right)=4.26$
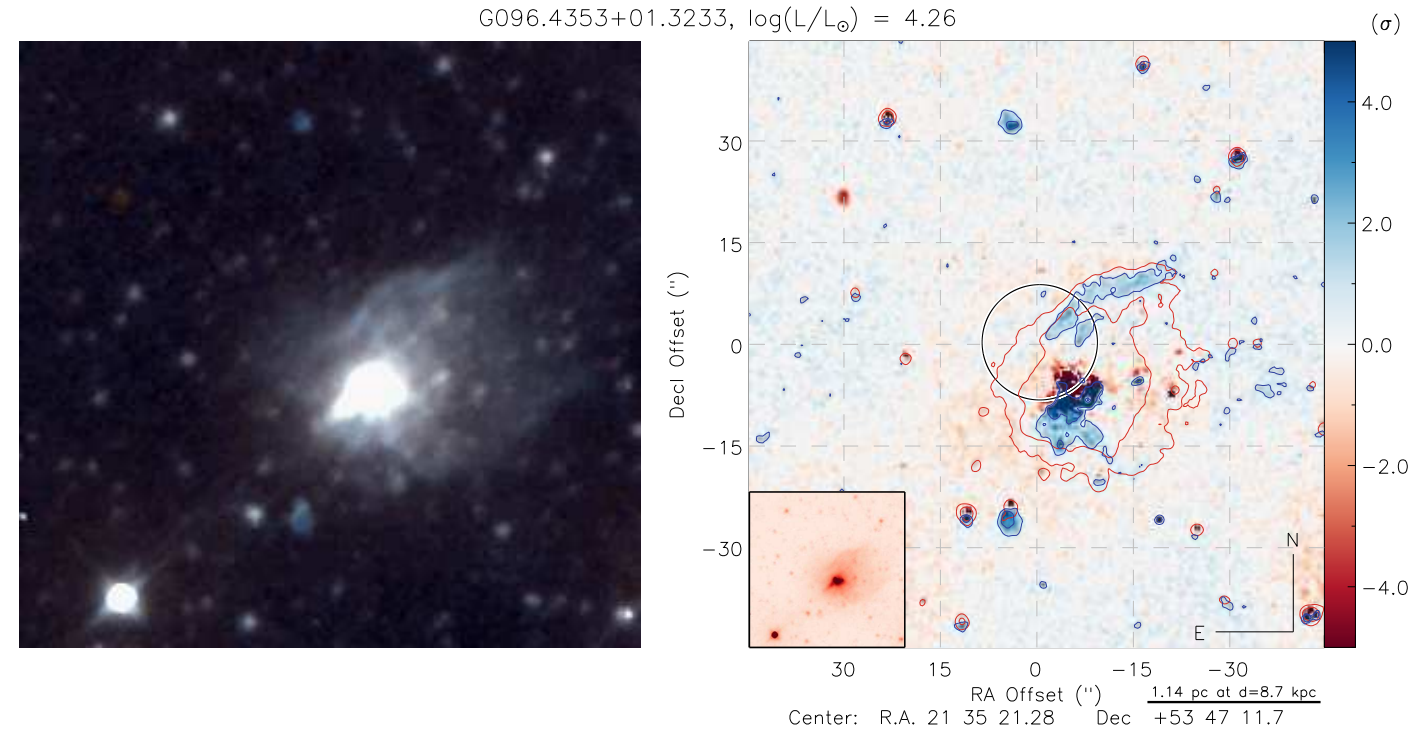

G097.9978+01.4688, $\log \left(L_{/} / L_{\odot}\right)=3.85$
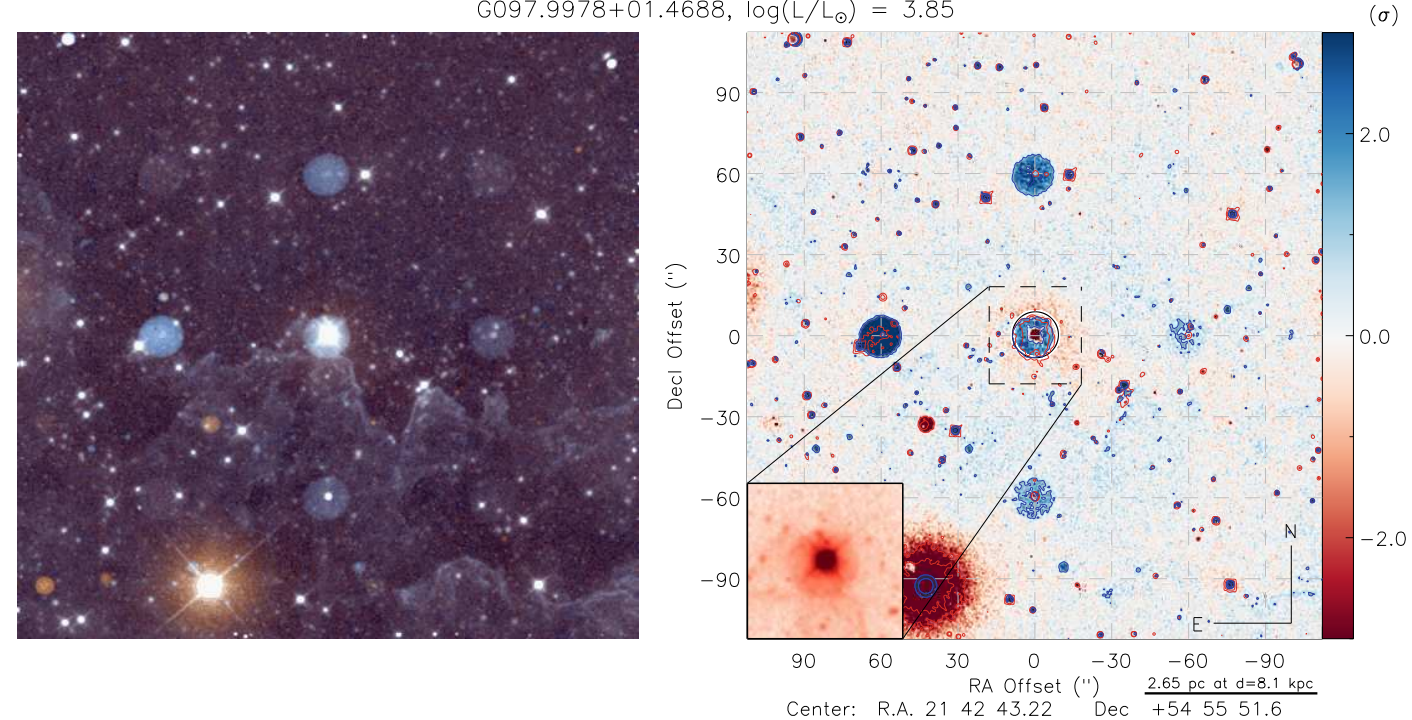

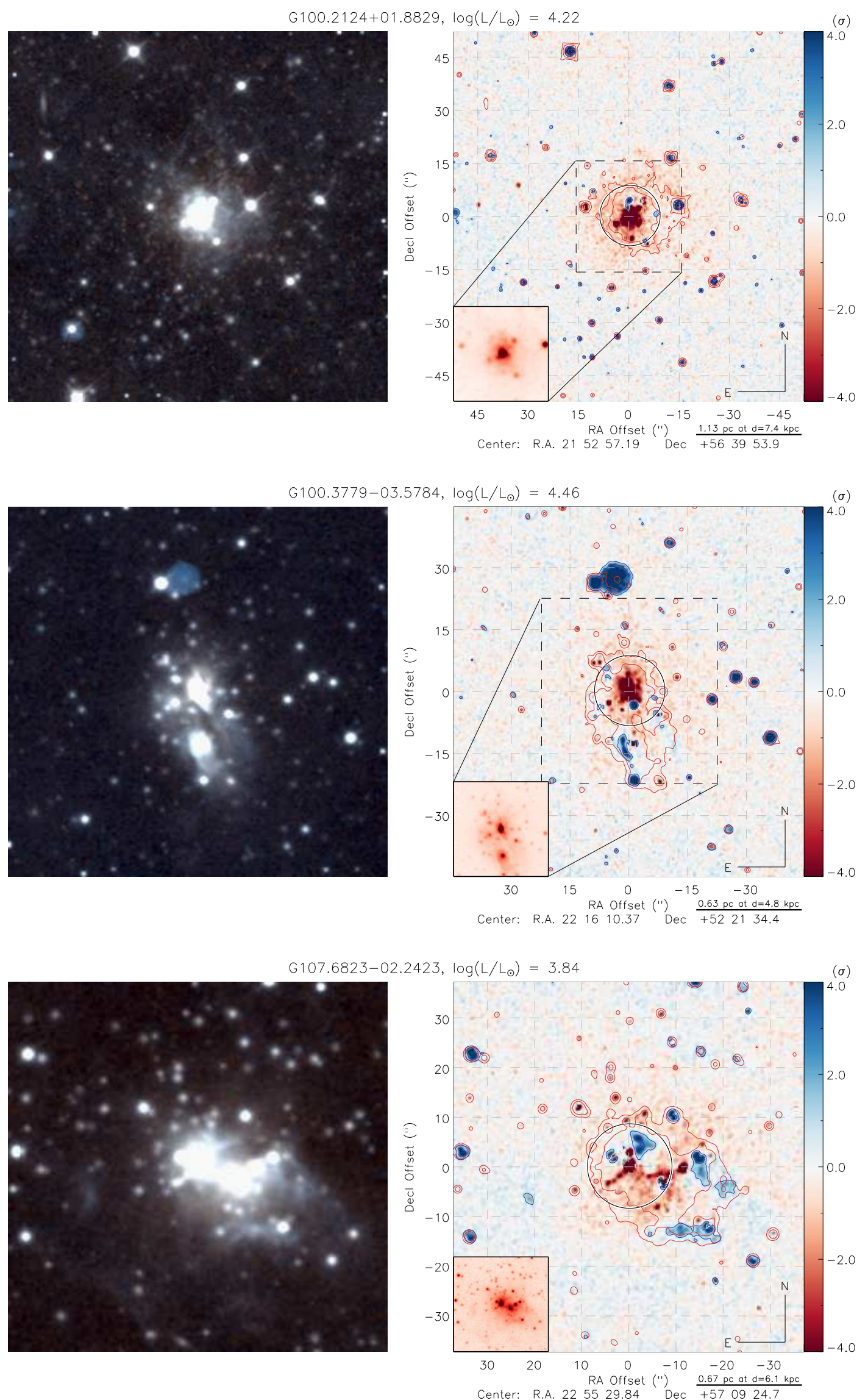
G108.7575-00.9863, $\log \left(L / L_{\odot}\right)=4.34$
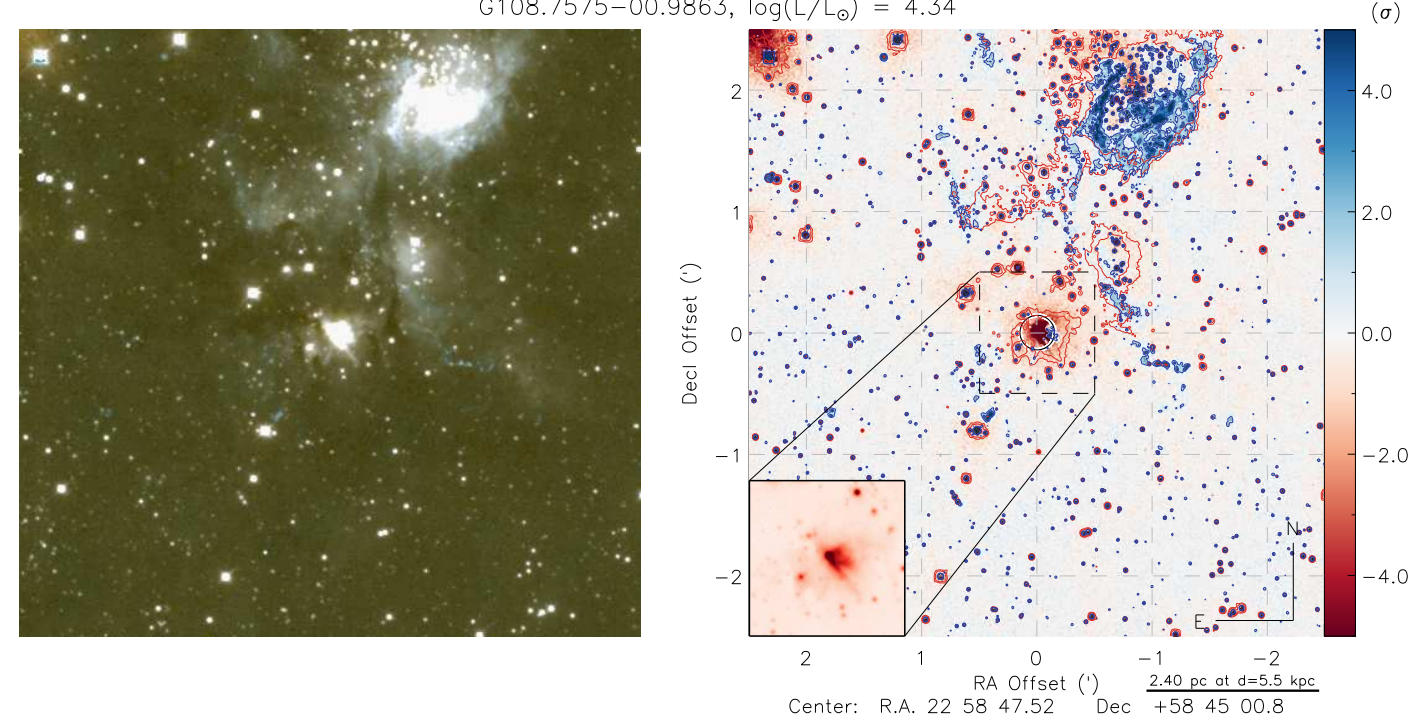

G110.1082+00.0473, $\log \left(L / L_{\odot}\right)=4.68$
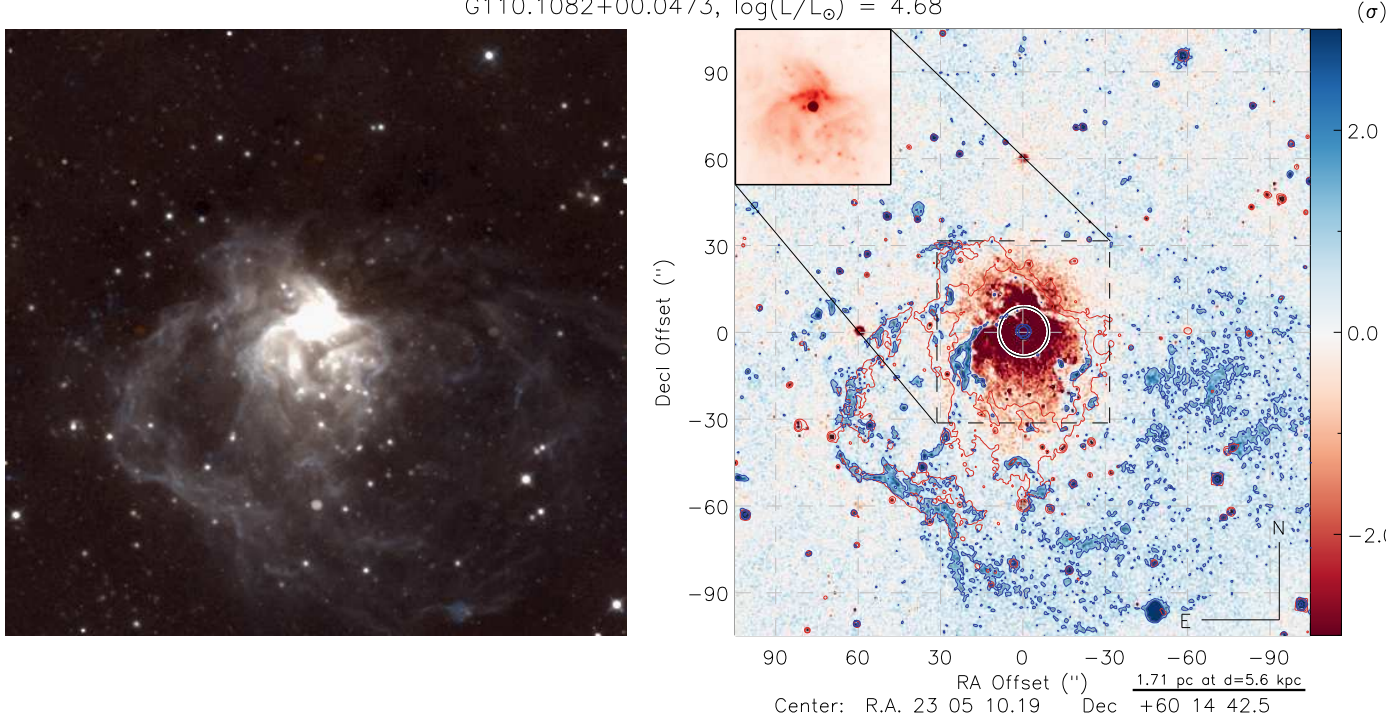

$\mathrm{G} 111.5234+00.8004, \log \left(\mathrm{L} / \mathrm{L}_{\odot}\right)=4.56$
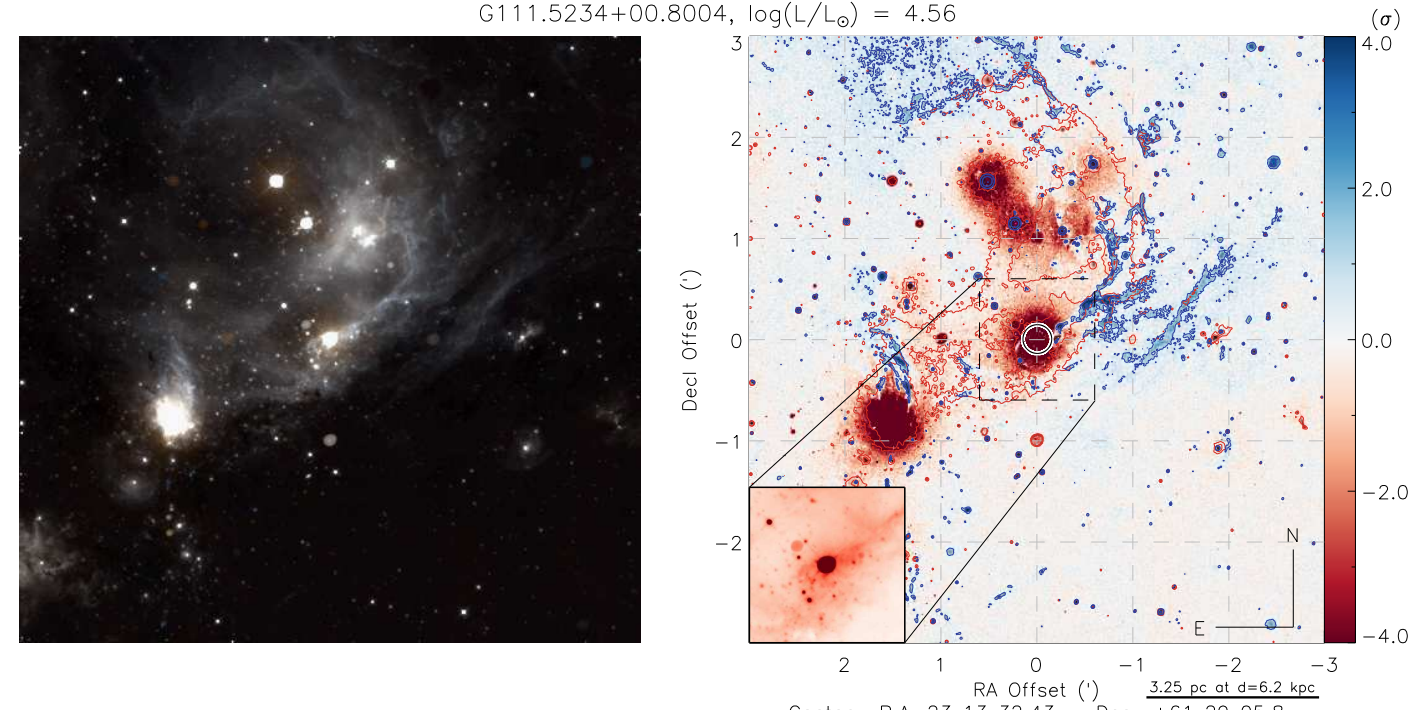

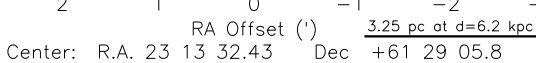


$G 111.5851+00.7976, \log \left(L / L_{\odot}\right)=4.45$
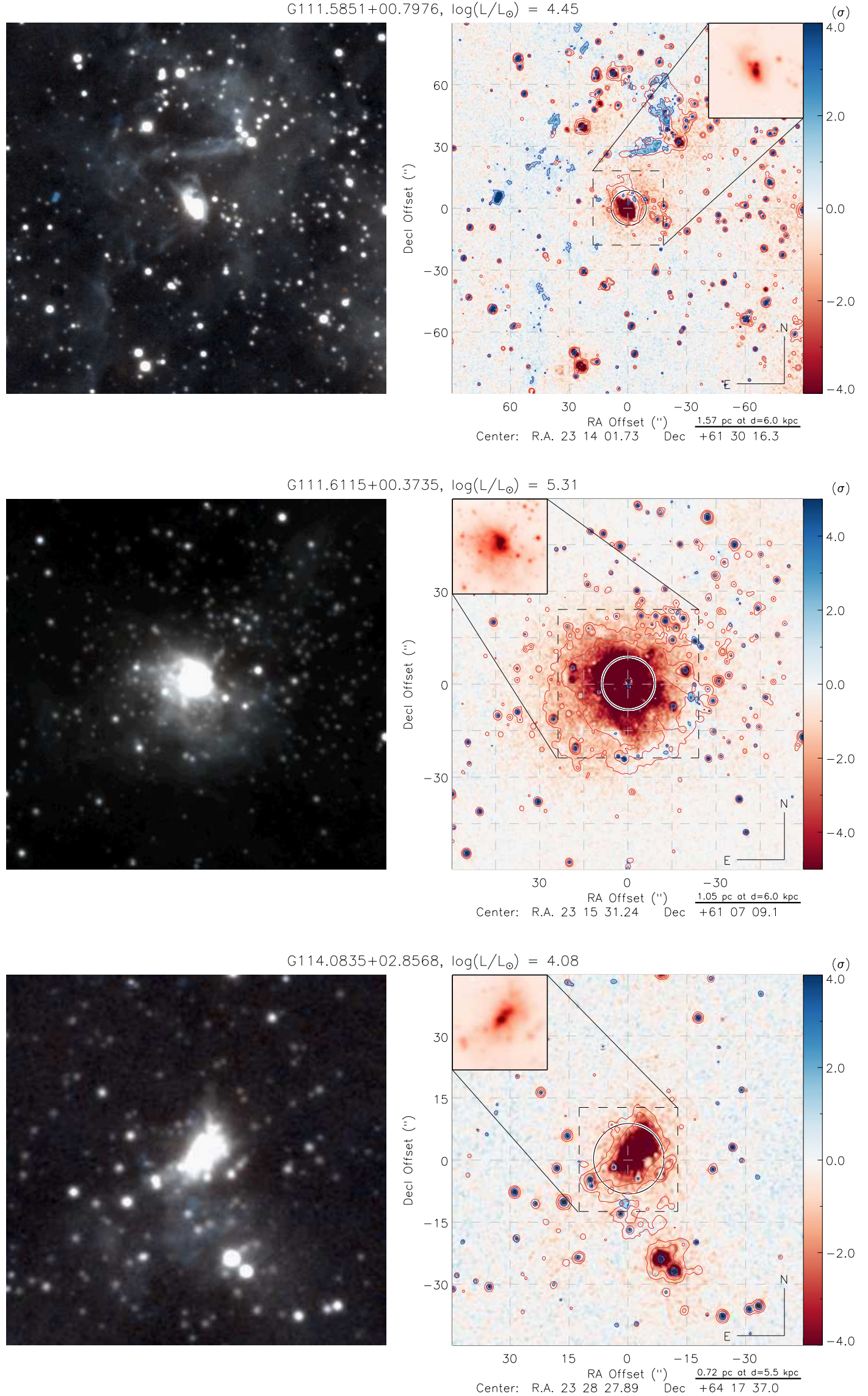
$G 125.6045+02.1038, \log \left(L / L_{\odot}\right)=3.88$
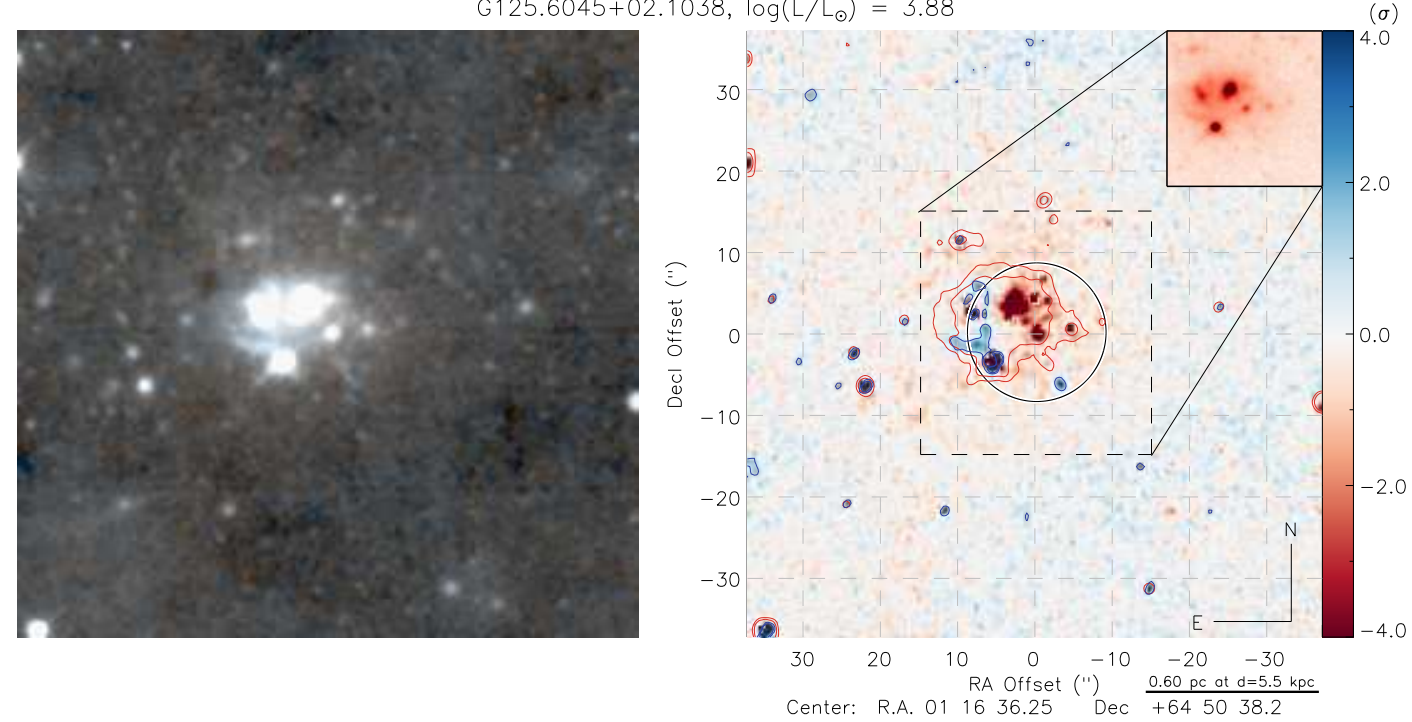

$G 134.2792+00.8561, \log \left(L / L_{\odot}\right)=4.39$
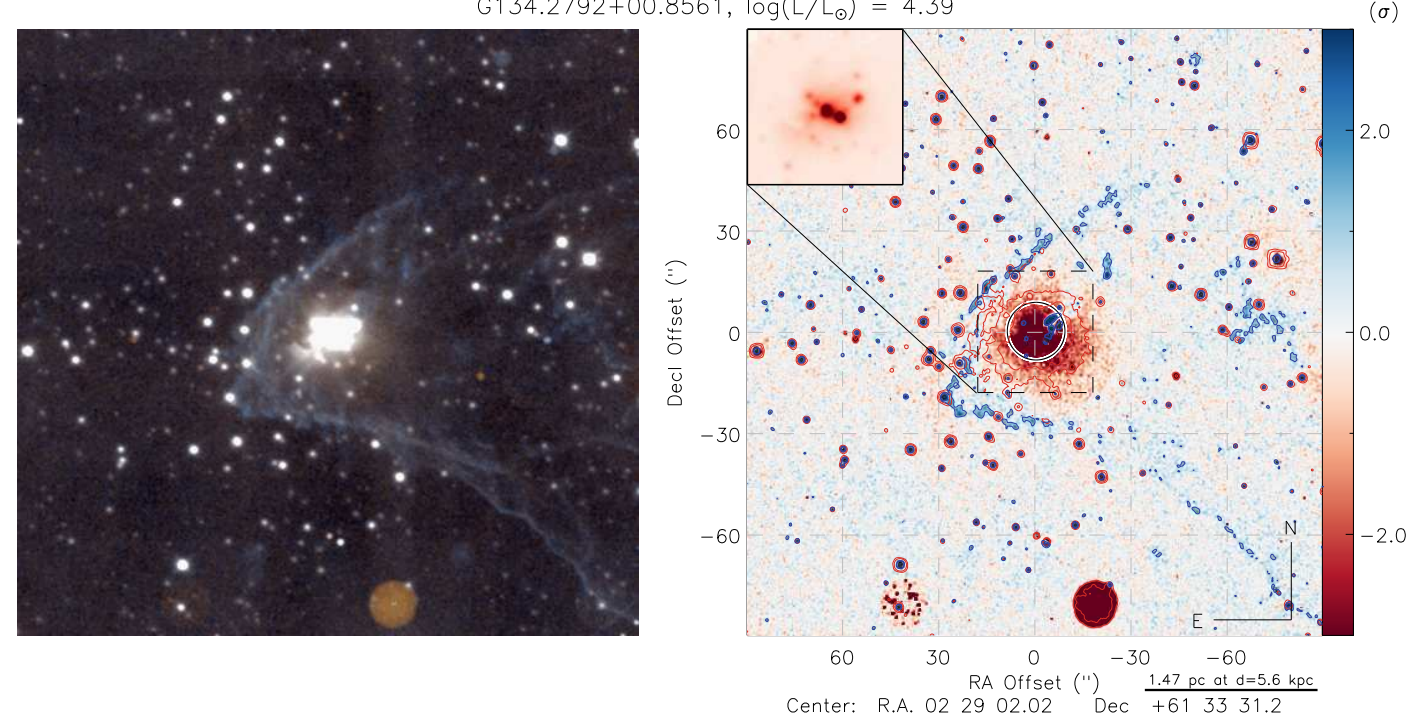

G136.3542+00.9543, $\log \left(L / L_{\odot}\right)=4.06$
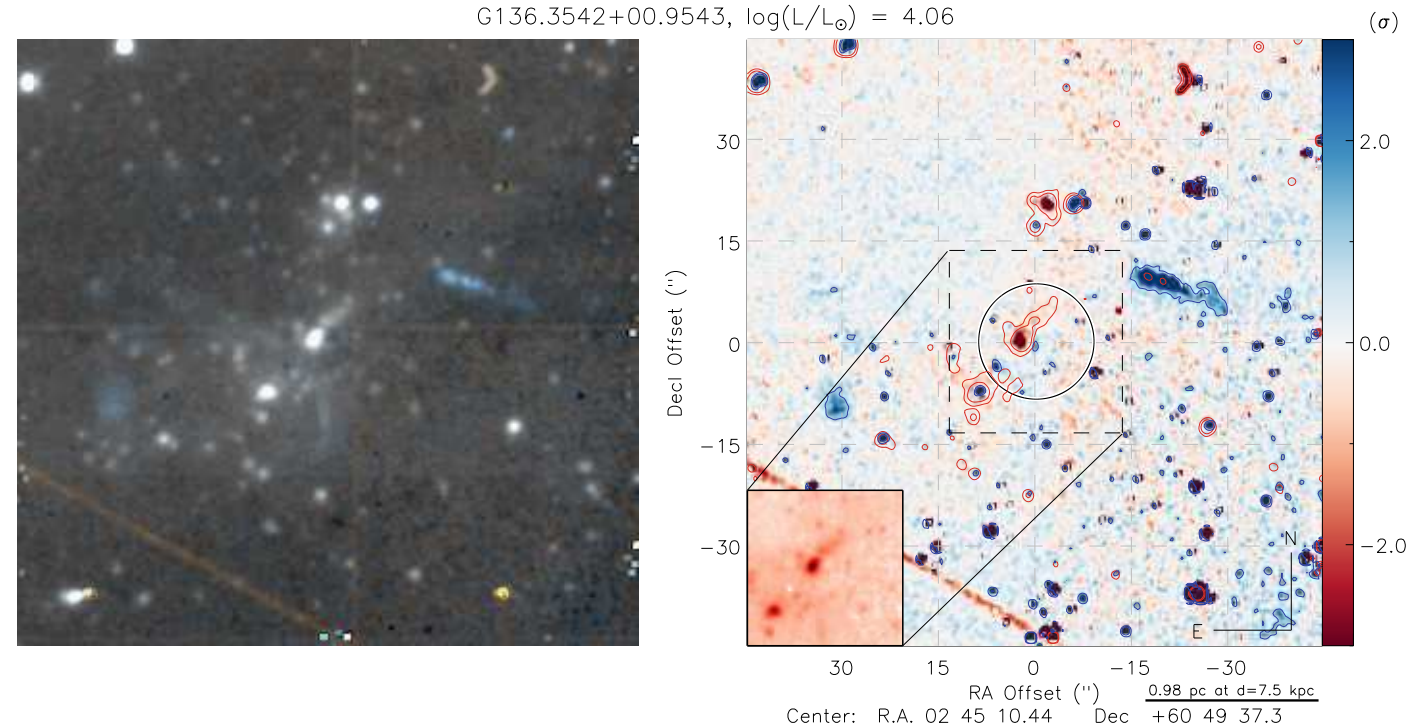
$G 138.2957+01.5552, \log \left(L / L_{\odot}\right)=4.43$
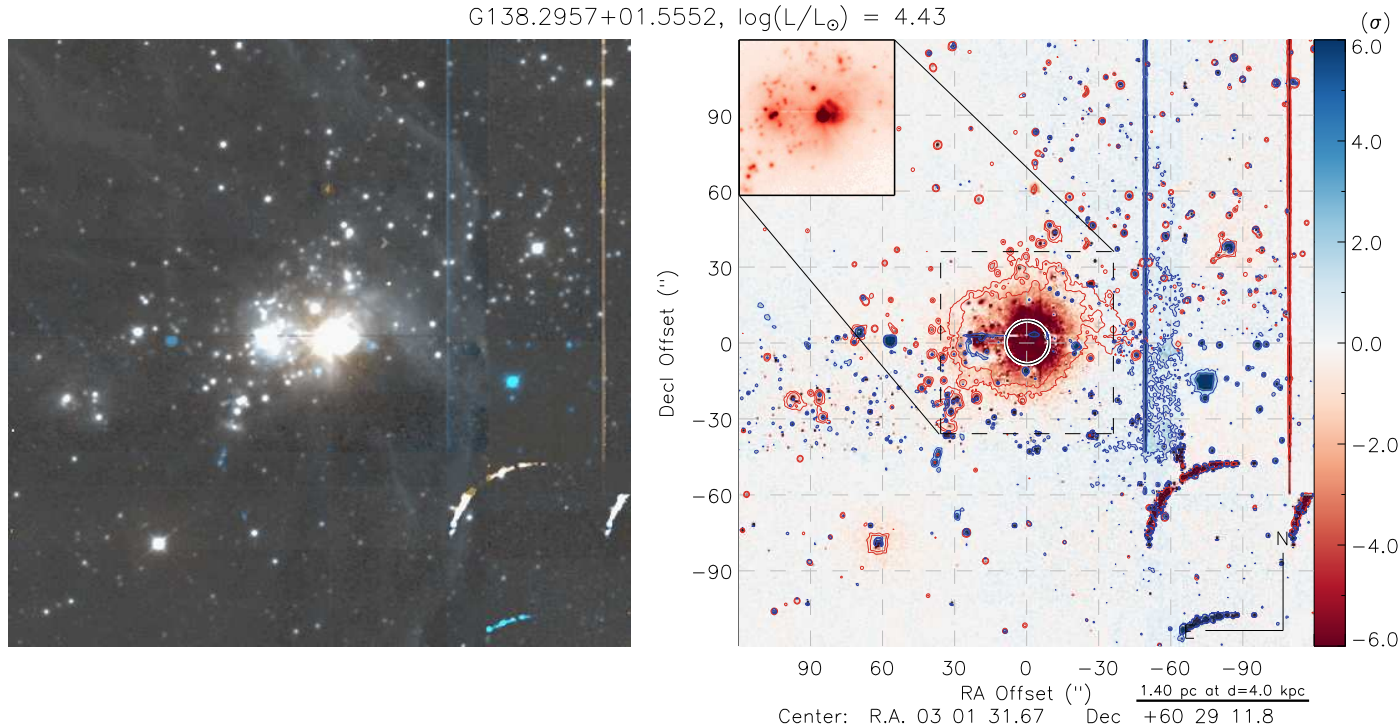

$G 139.9091+00.1969, \log \left(L / L_{\odot}\right)=4.30$
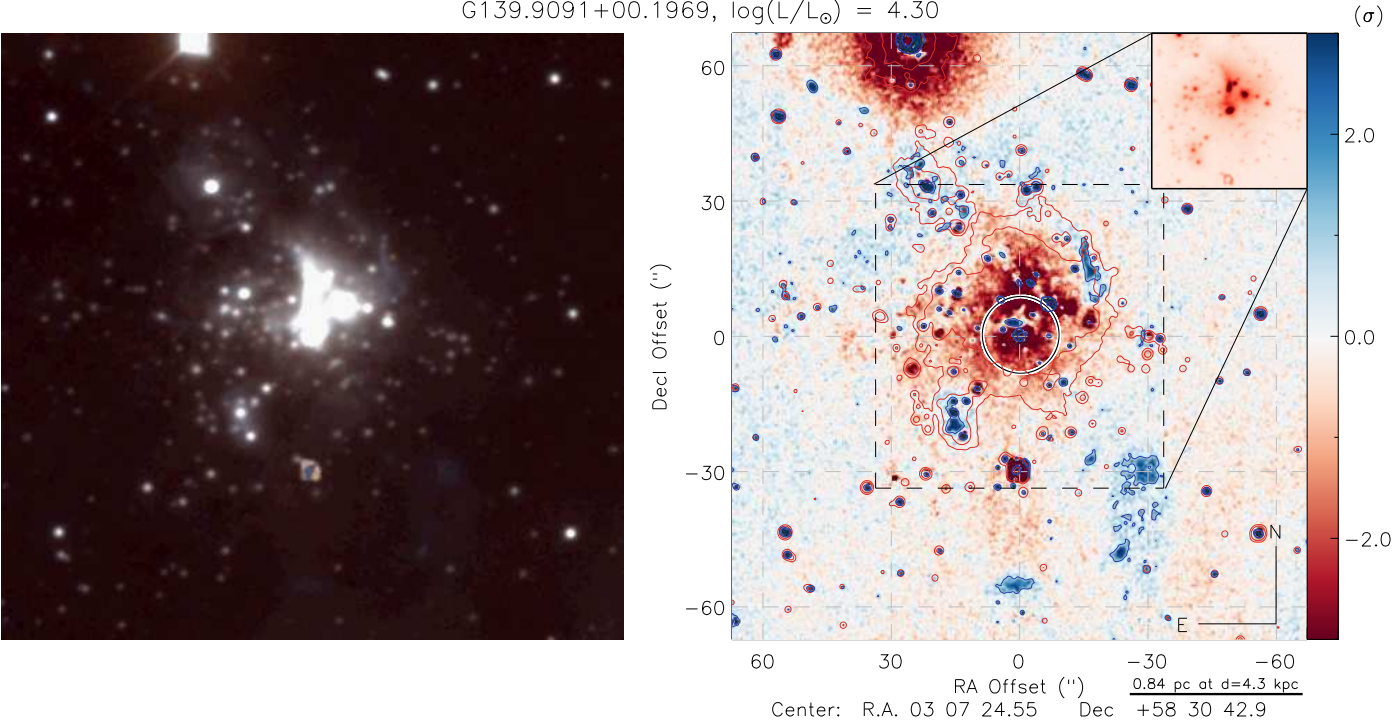

G143.8118-01.5699, $\log \left(L / L_{\odot}\right)=4.27$
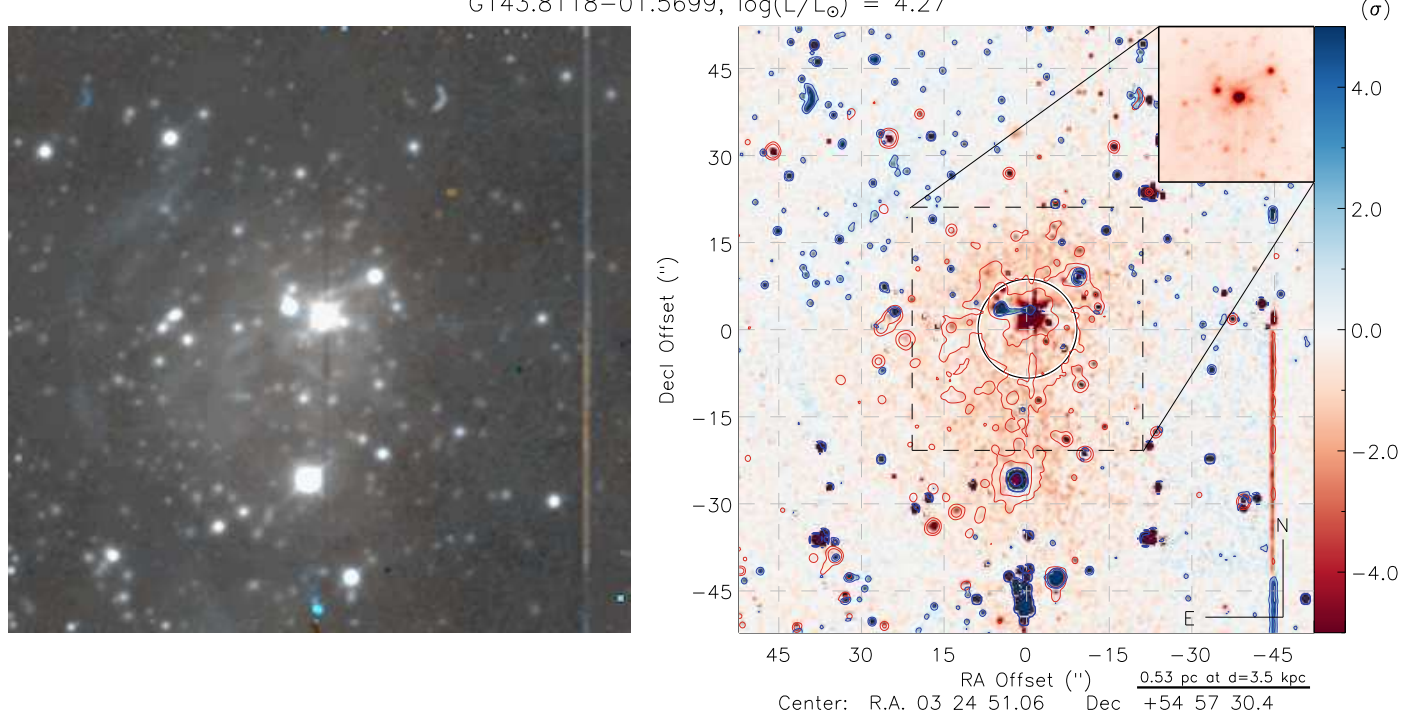
G144.6678-00.7136, $\log \left(L / L_{\odot}\right)=2.87$
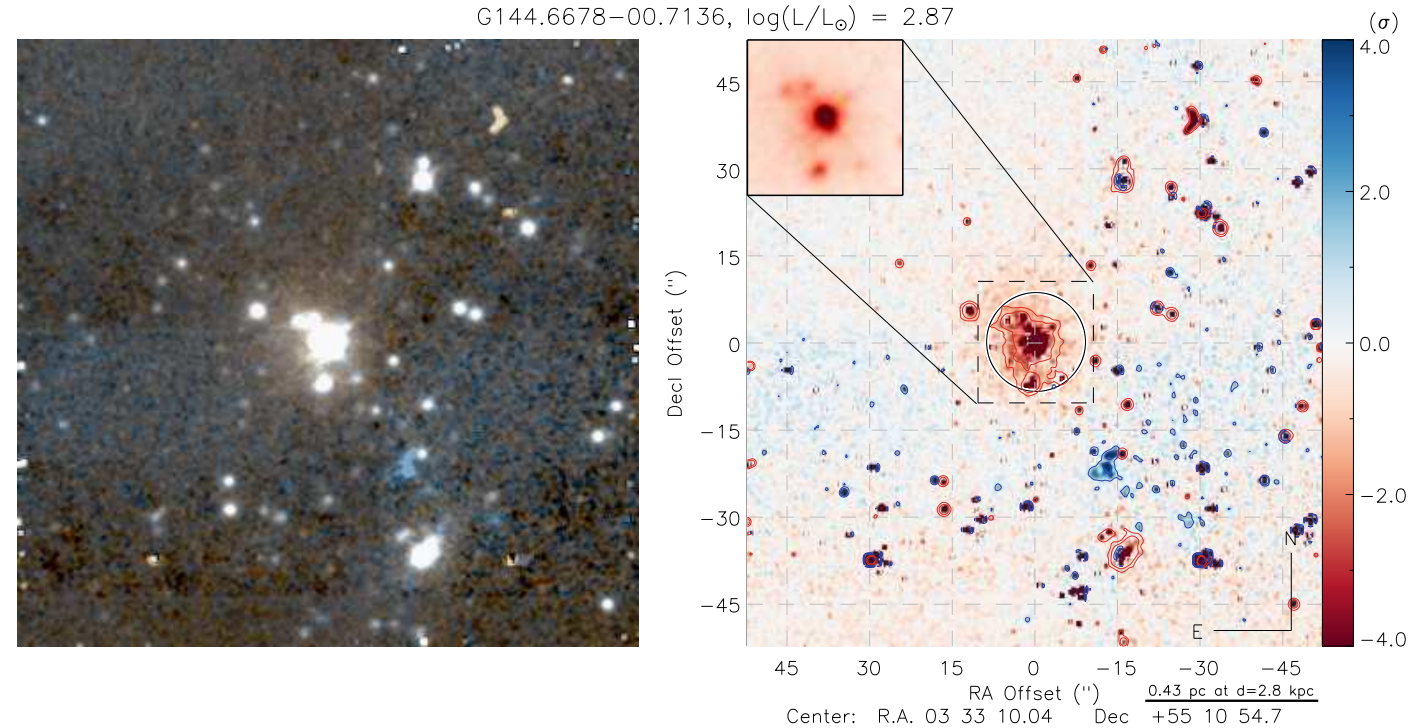

$\mathrm{G} 151.6120-00.4575, \underline{\log \left(L / L_{\odot}\right)=4.61}$
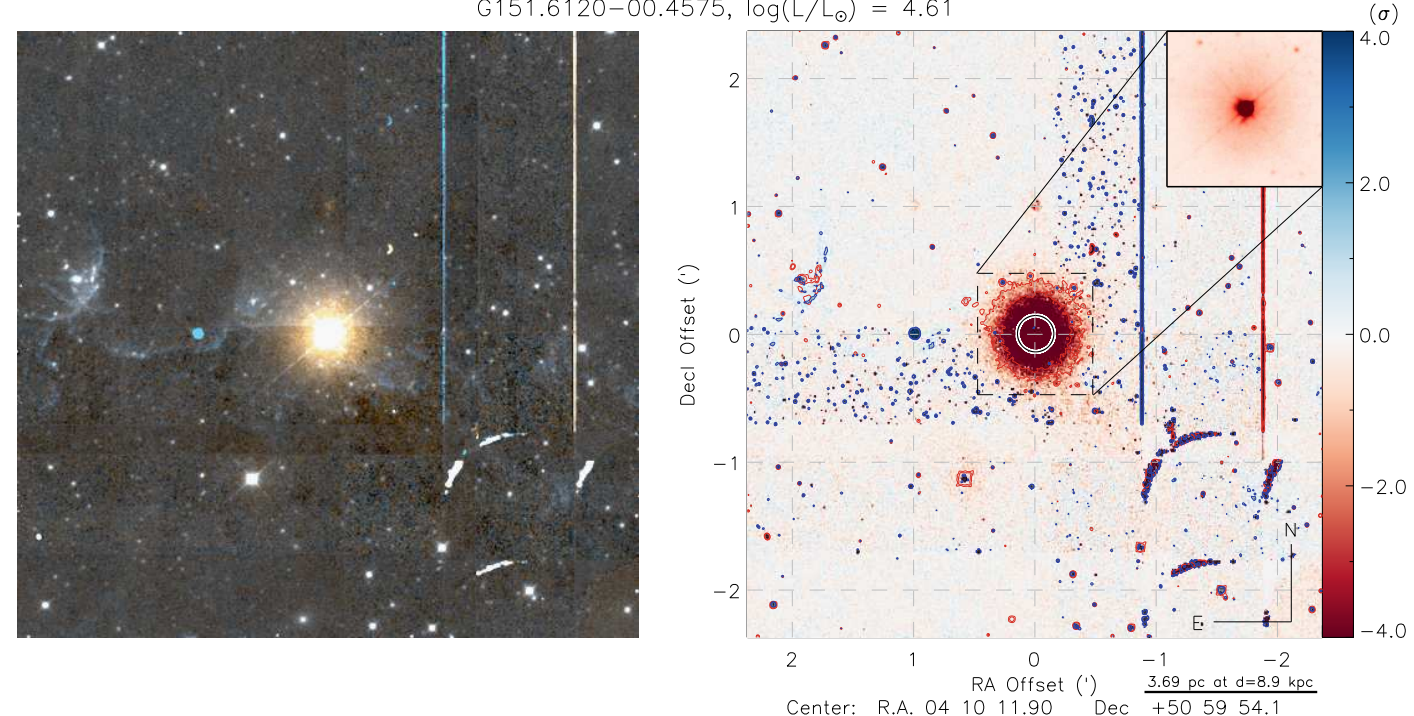

$G 173.6328+02.8064, \log \left(L / L_{\odot}\right)=5.94$
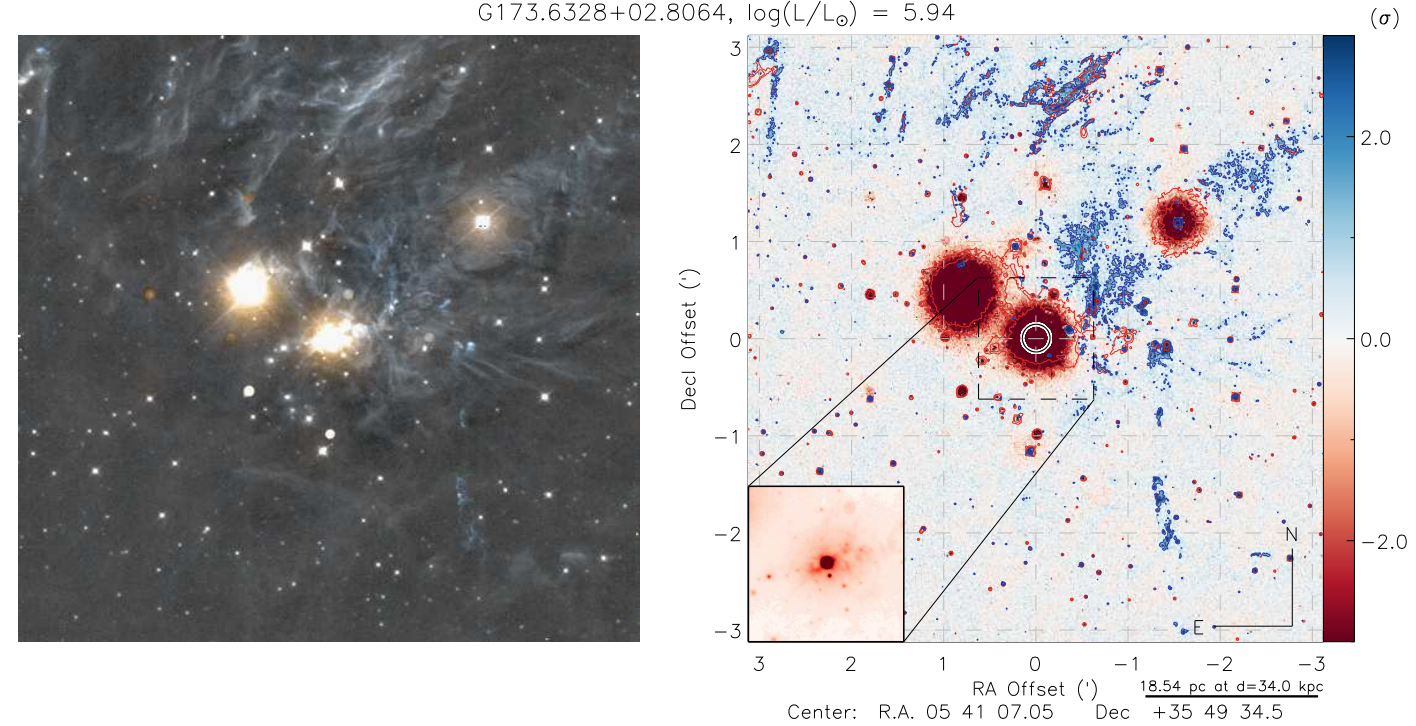
$G 173.6339+02.8218, \log \left(L / L_{\odot}\right)=6.18$
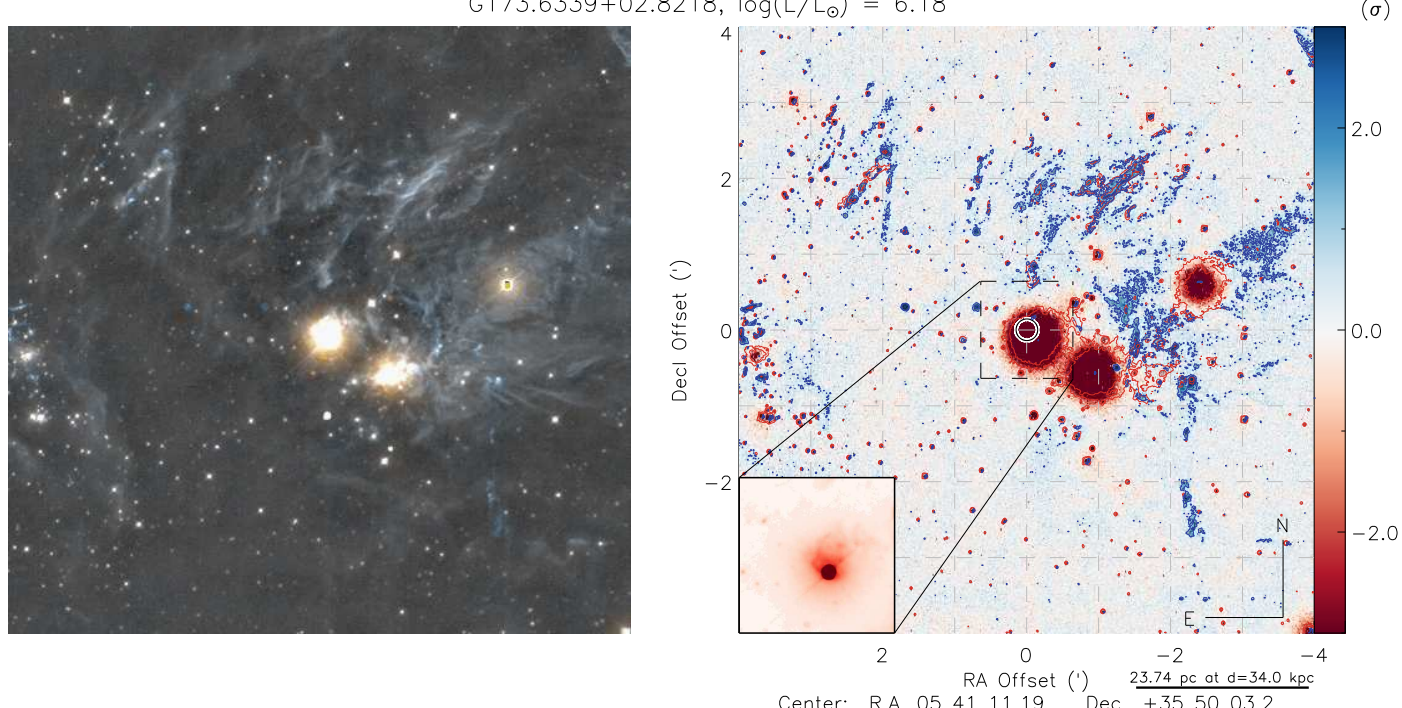

$G 188.9479+00.8871, \log \left(L / L_{\odot}\right)=3.37$
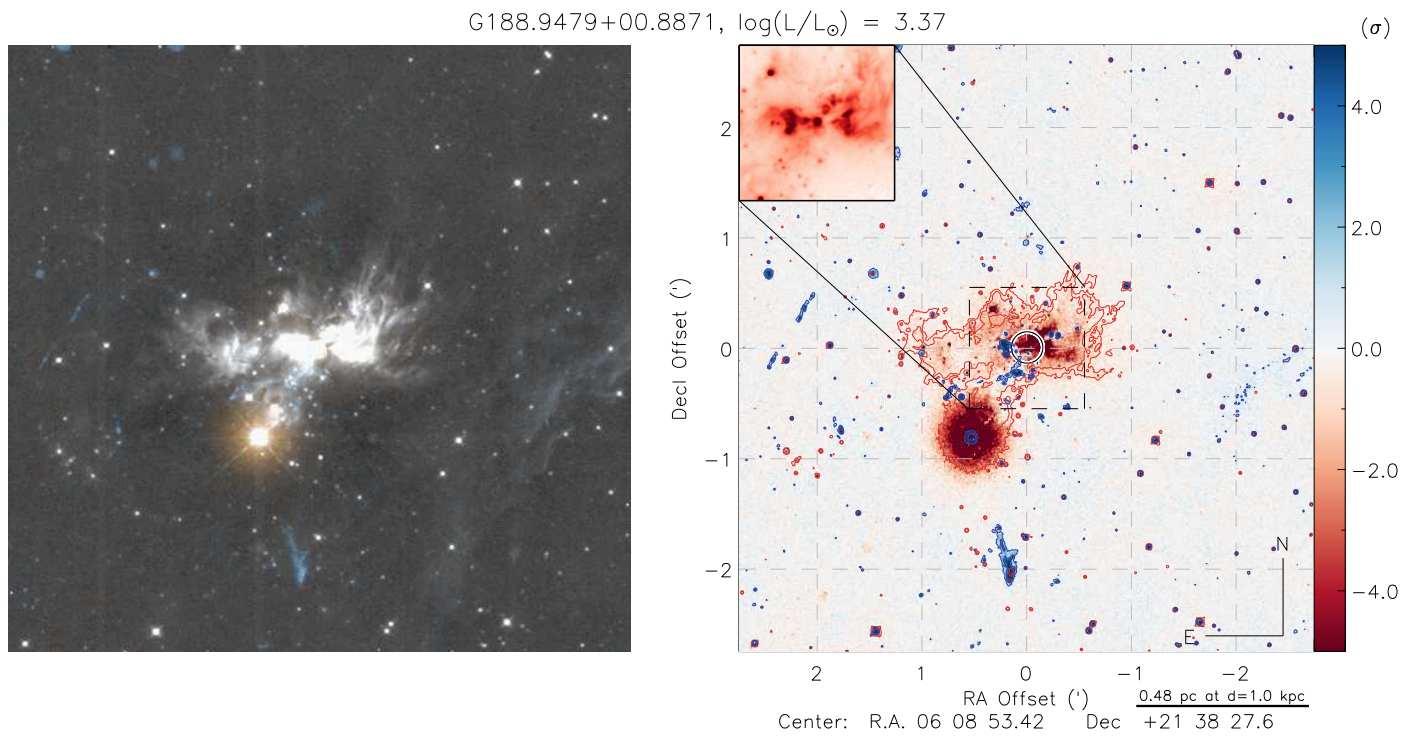

$G 189.8557+00.5011, \log \left(L / L_{\odot}\right)=3.33$
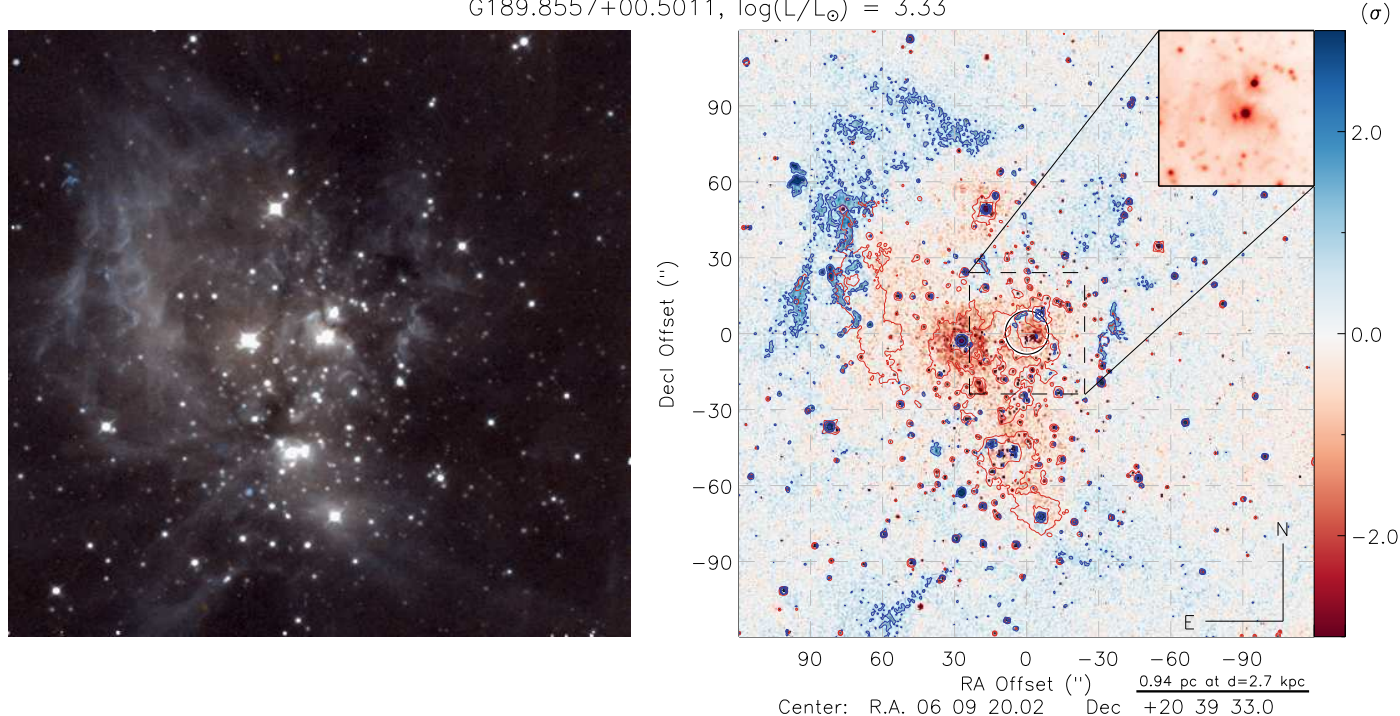
G192.6005-00.0479, $\log \left(L / L_{\odot}\right)=4.45$
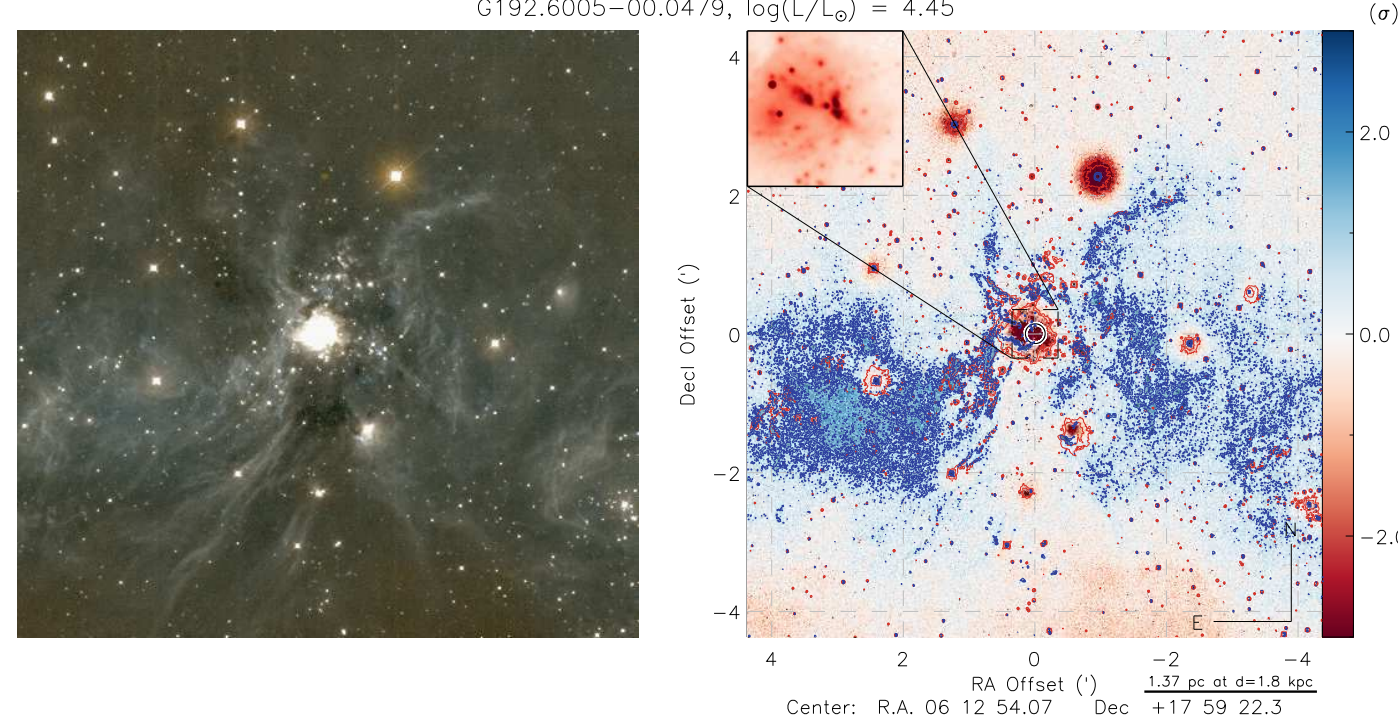

G192.9089-00.6259, $\log \left(L / L_{\odot}\right)=4.78$
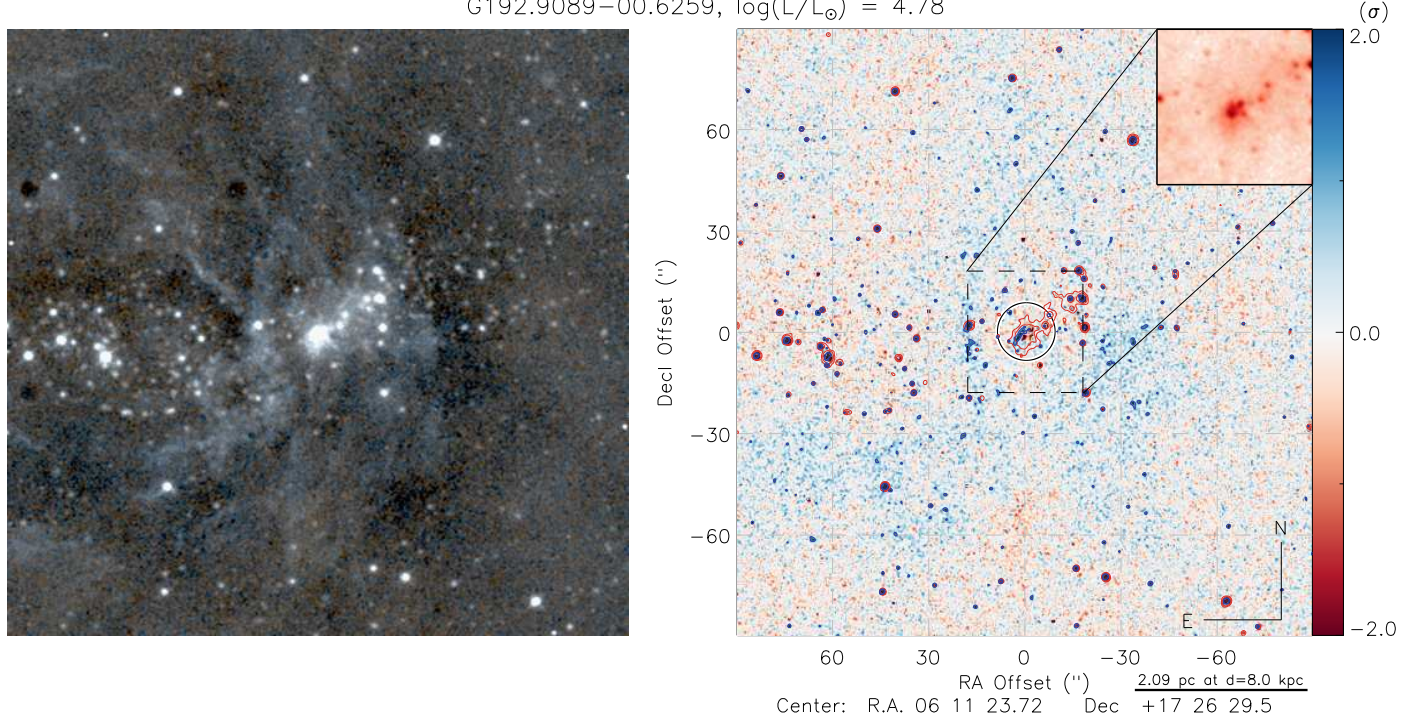

G194.9349-01.2224, $\log \left(L / L_{\odot}\right)=3.97$
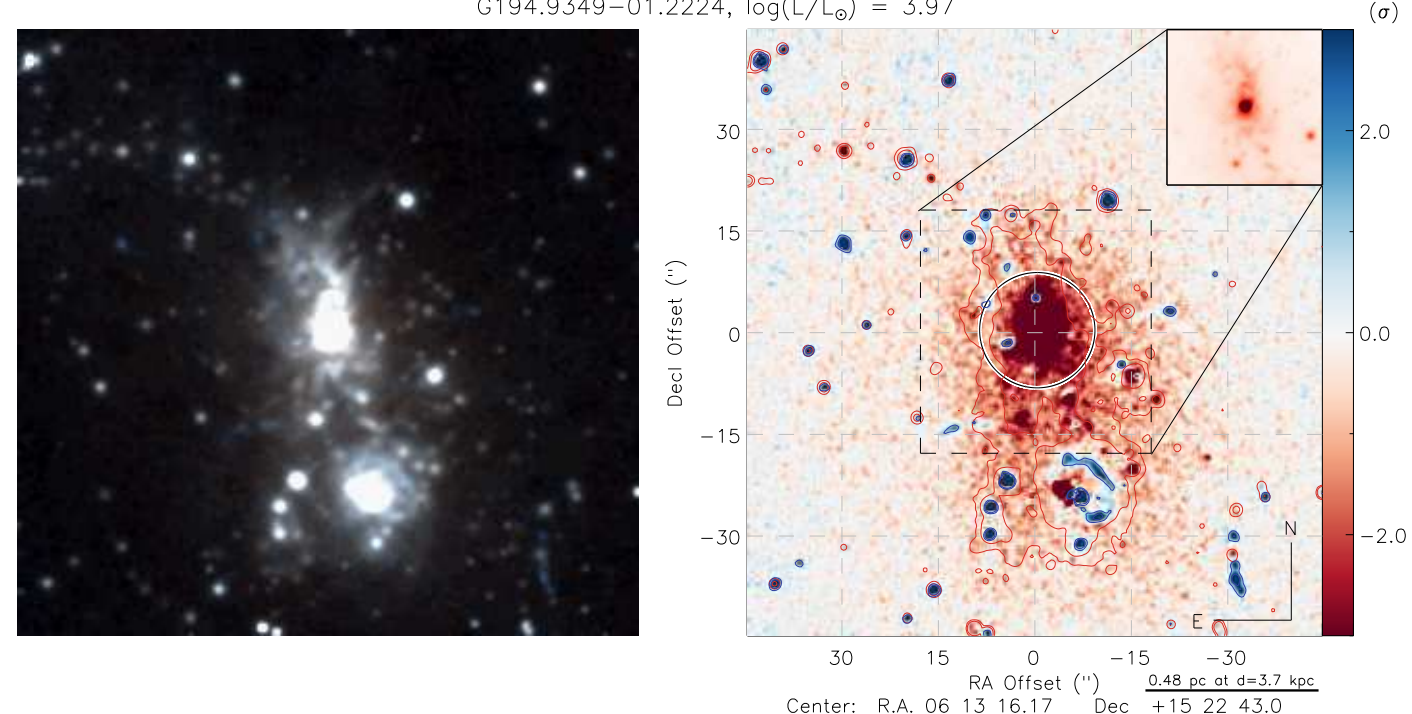
G196.1620-01.2546, $\log \left(\mathrm{L} / \mathrm{L}_{\odot}\right)=3.32$
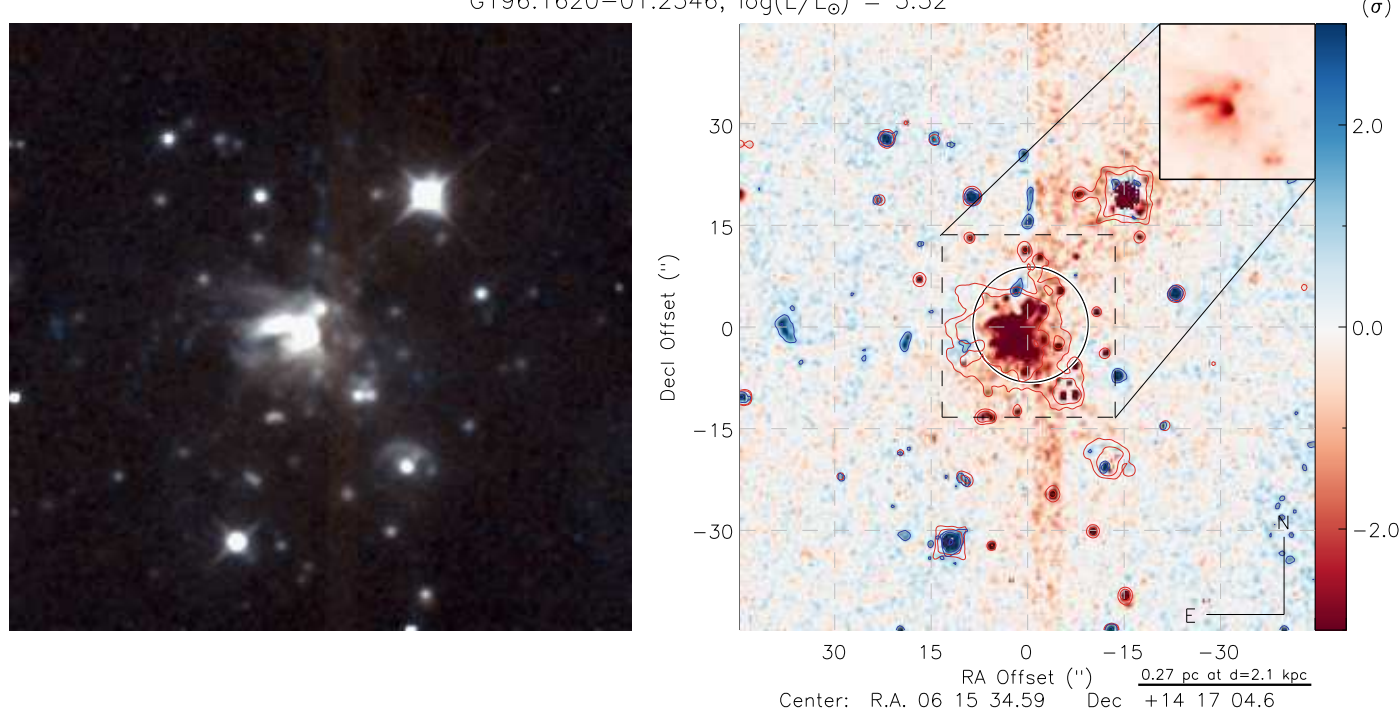

G196.4542-01.6777, $\log \left(L / L_{\odot}\right)=4.70$
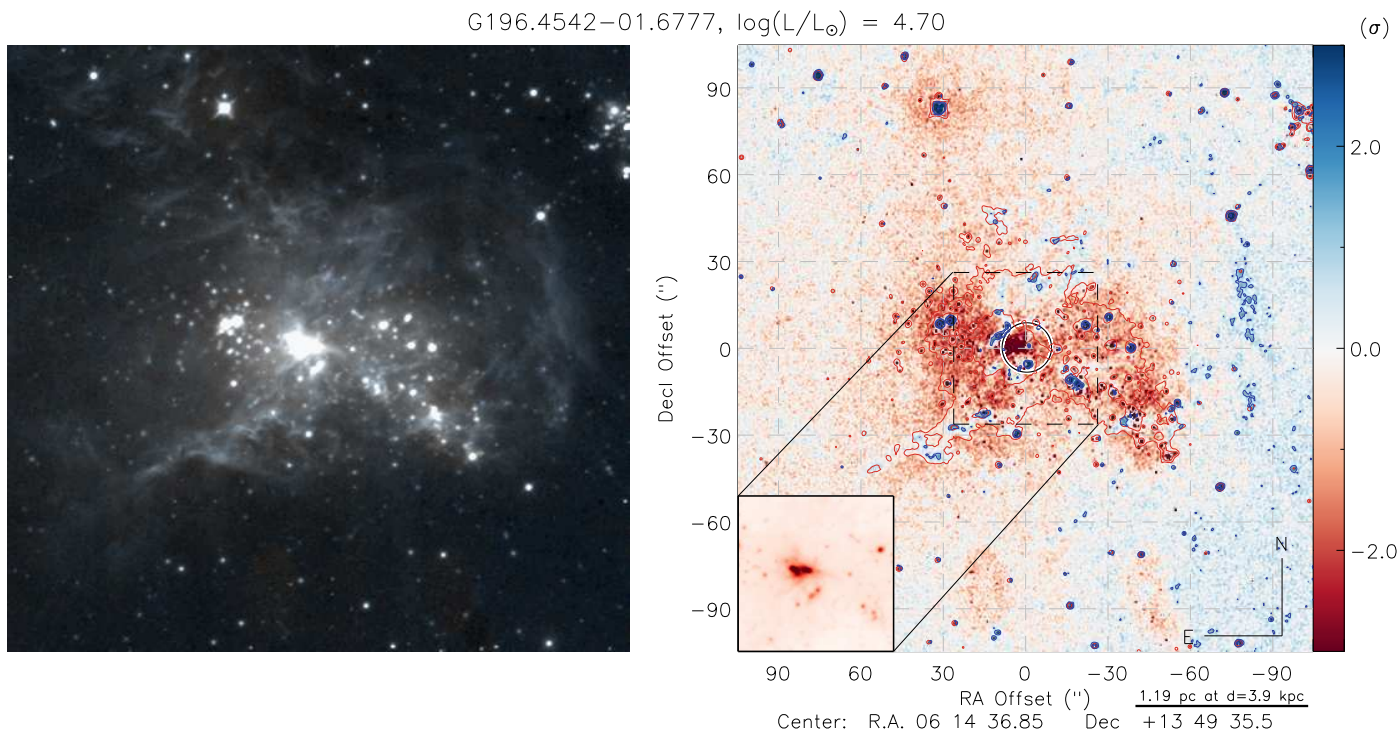

G200.0789-01.6323, $\log \left(L / L_{\odot}\right)=4.15$
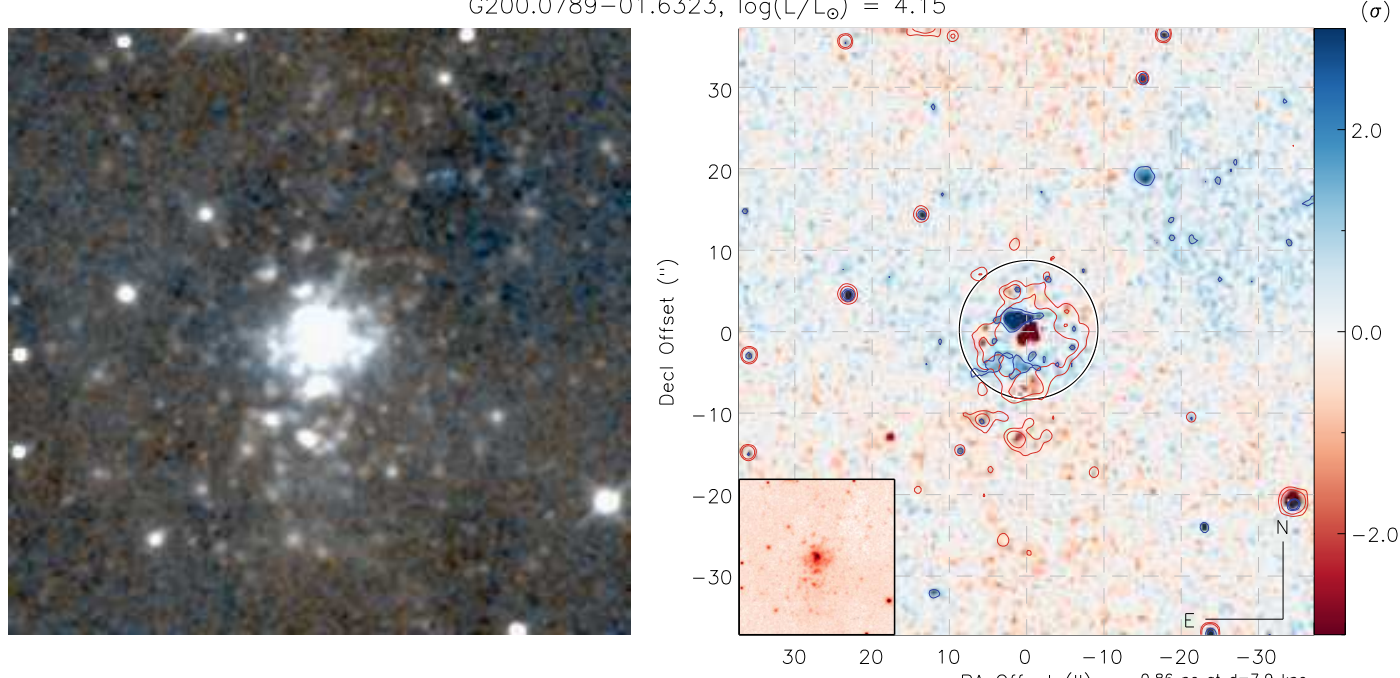

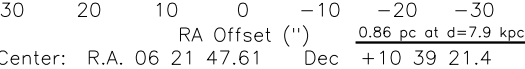


$G 203.3166+02.0564, \log \left(L / L_{\odot}\right)=3.50$
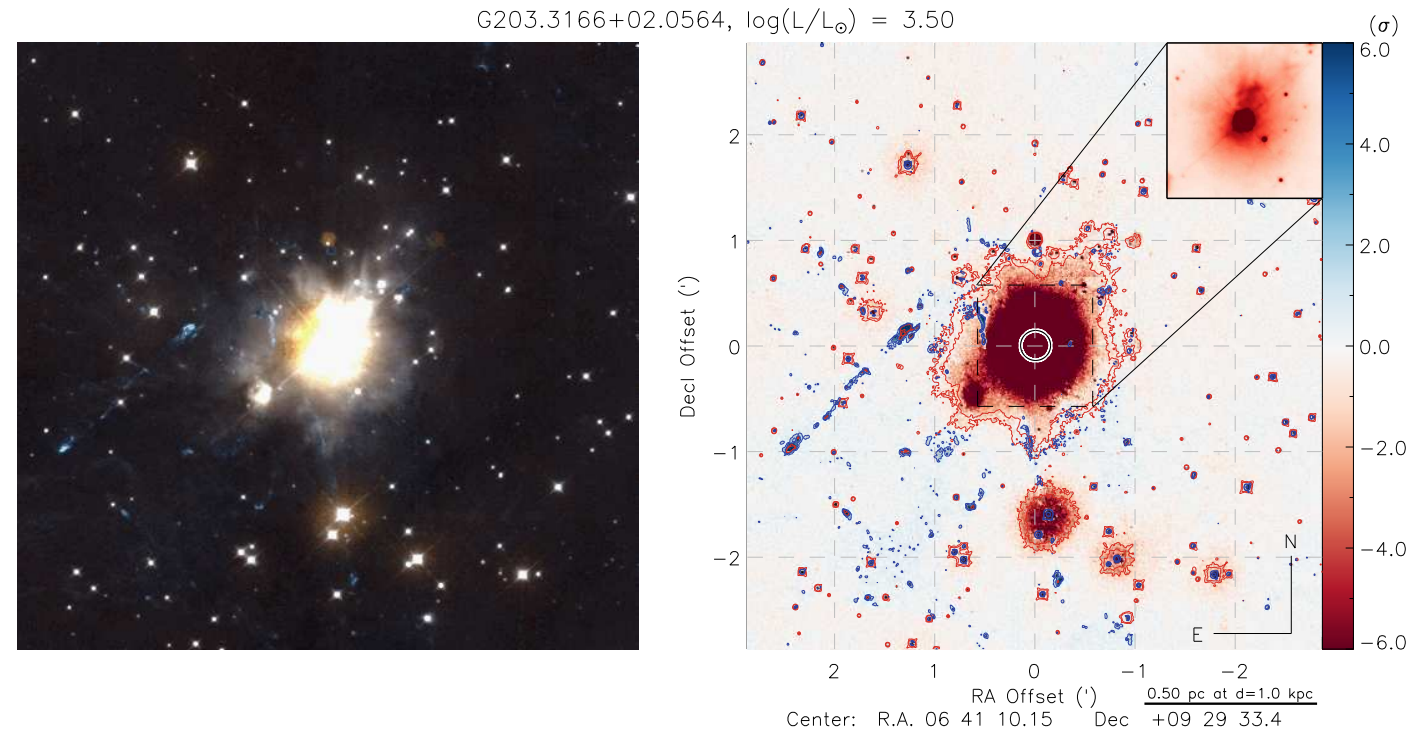

G206.7804-01.9395, $\log \left(L / L_{\odot}\right)=3.42$
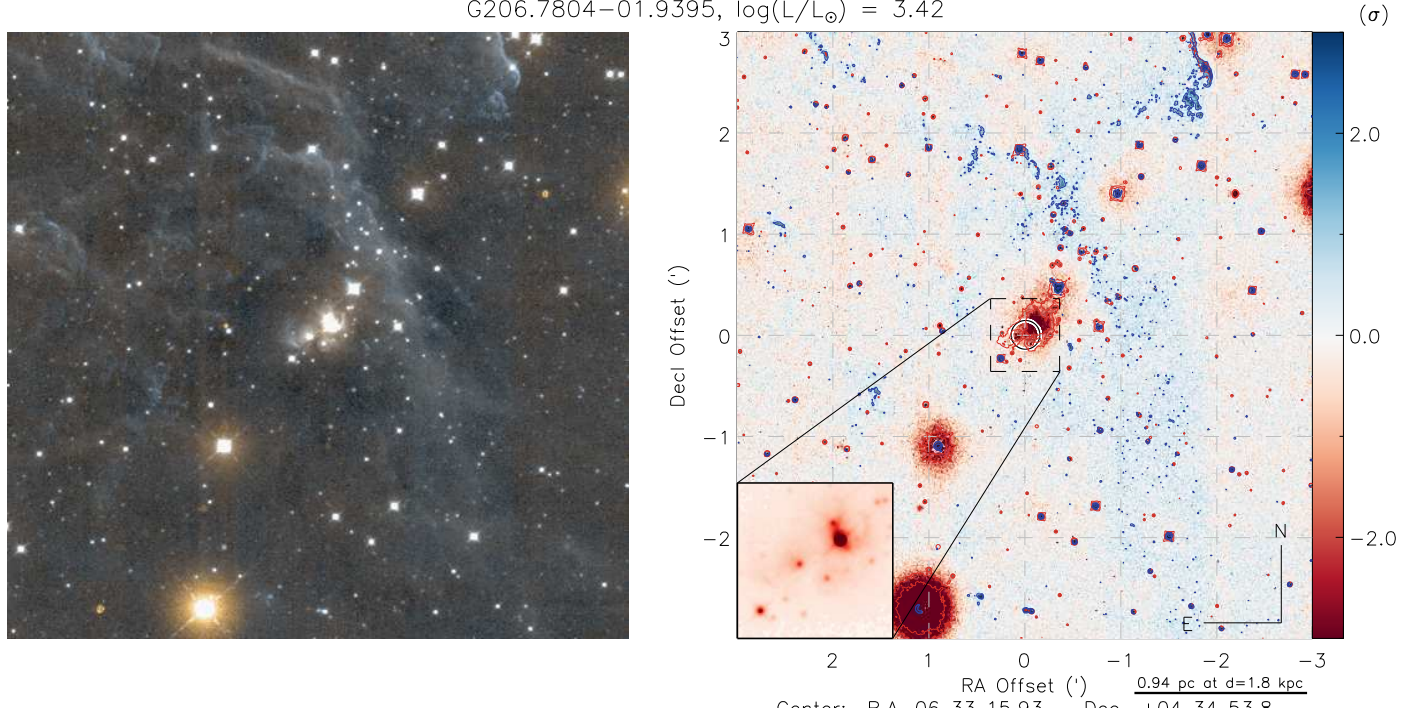

G215.8902-02.0094, $\log \left(L / L_{\odot}\right)=3.69$
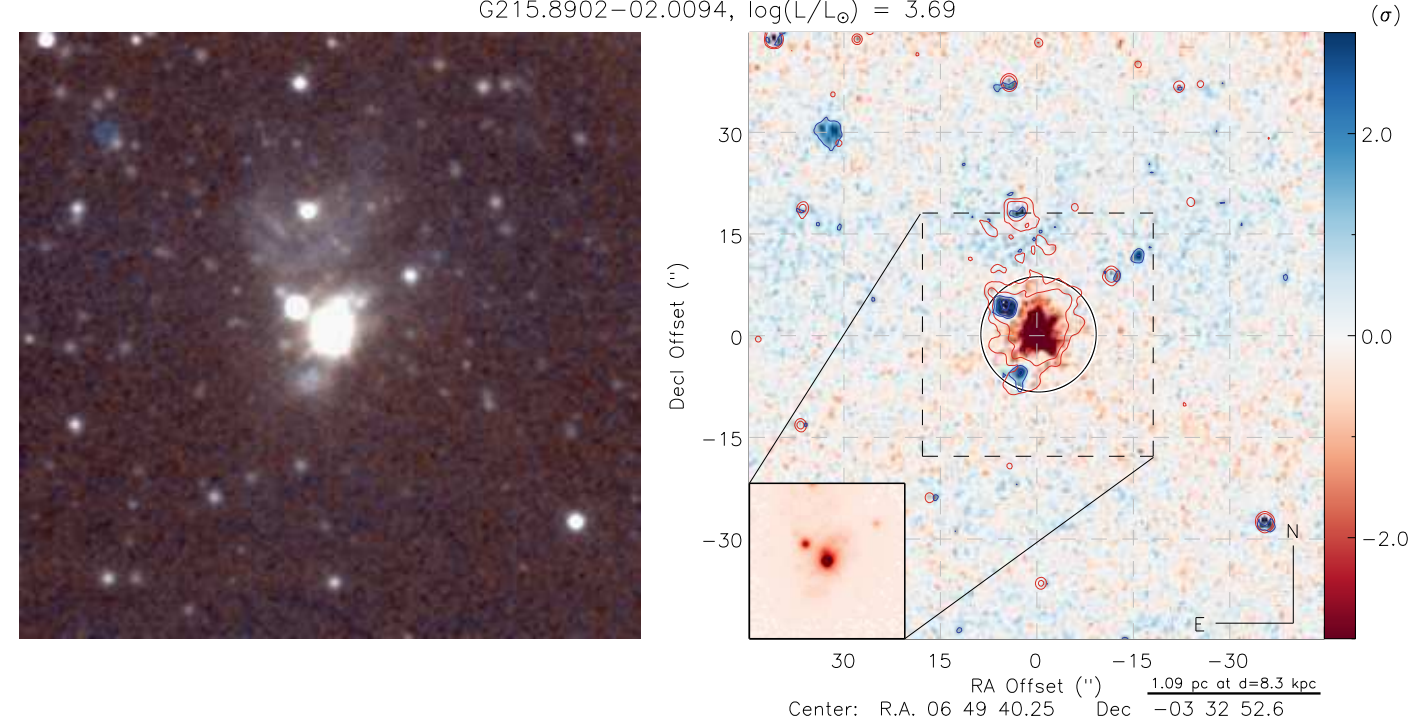
$\mathrm{G} 232.6207+00.9959, \log \left(\mathrm{L} / \mathrm{L}_{\odot}\right)=4.00$
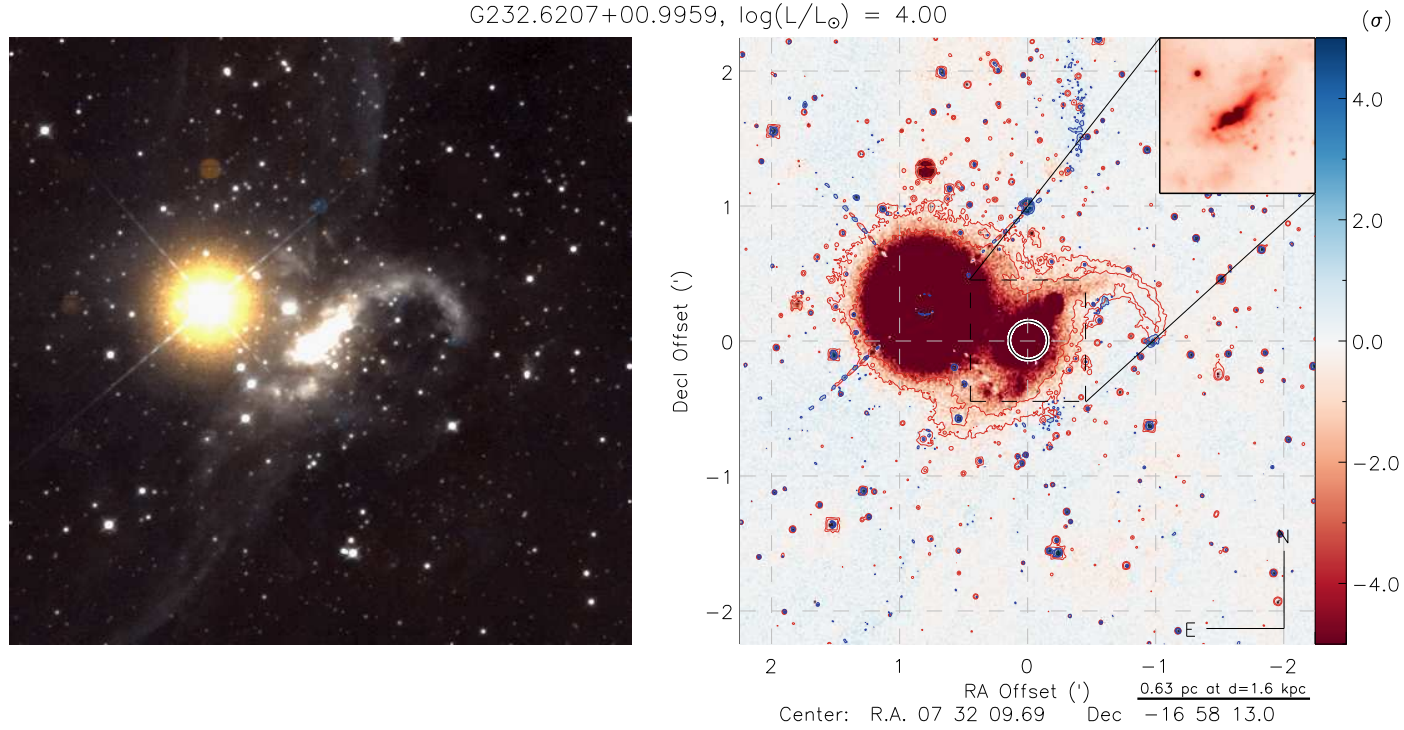

$G 254.0491-00.5615, \log \left(L / L_{\odot}\right)=3.85$
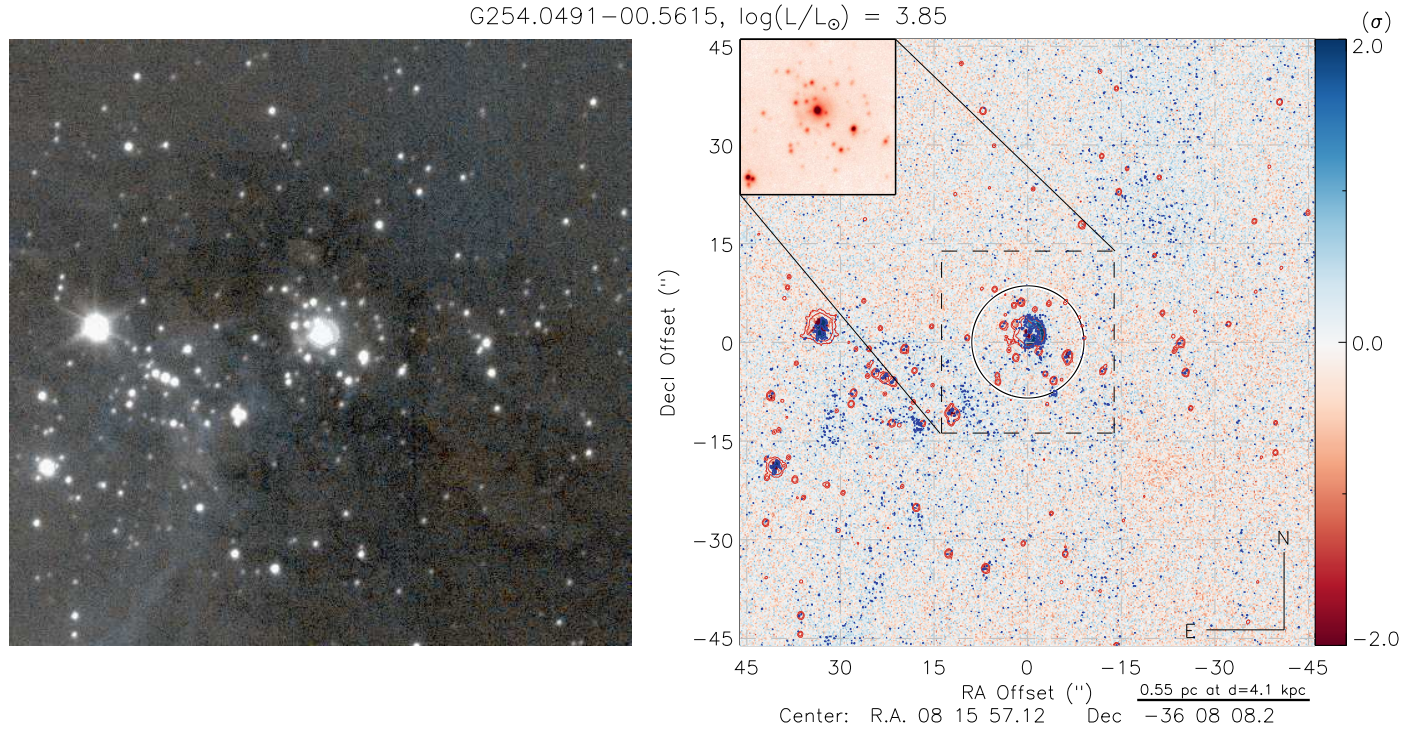

G259.0453-01.5559, $\log \left(L / L_{\odot}\right)=4.06$
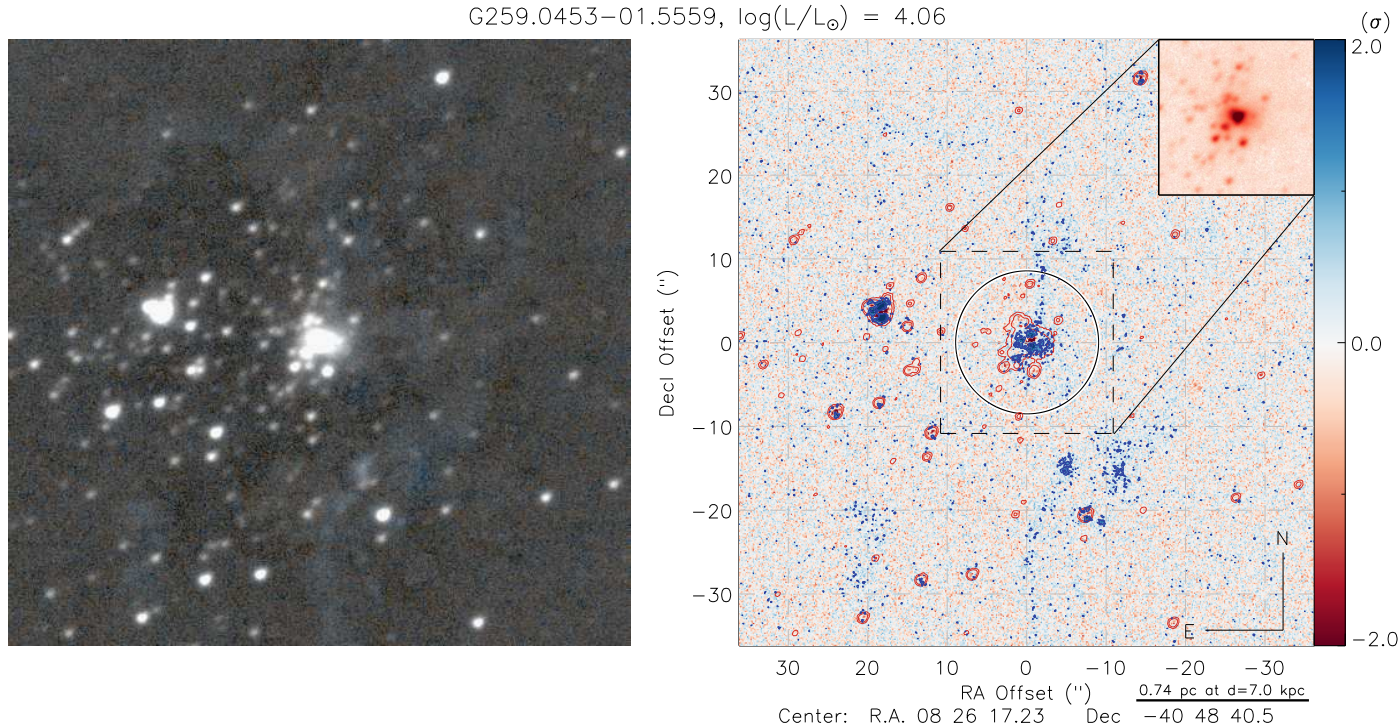
G259.0459-01.9107, $\log \left(L / L_{\odot}\right)=2.18$
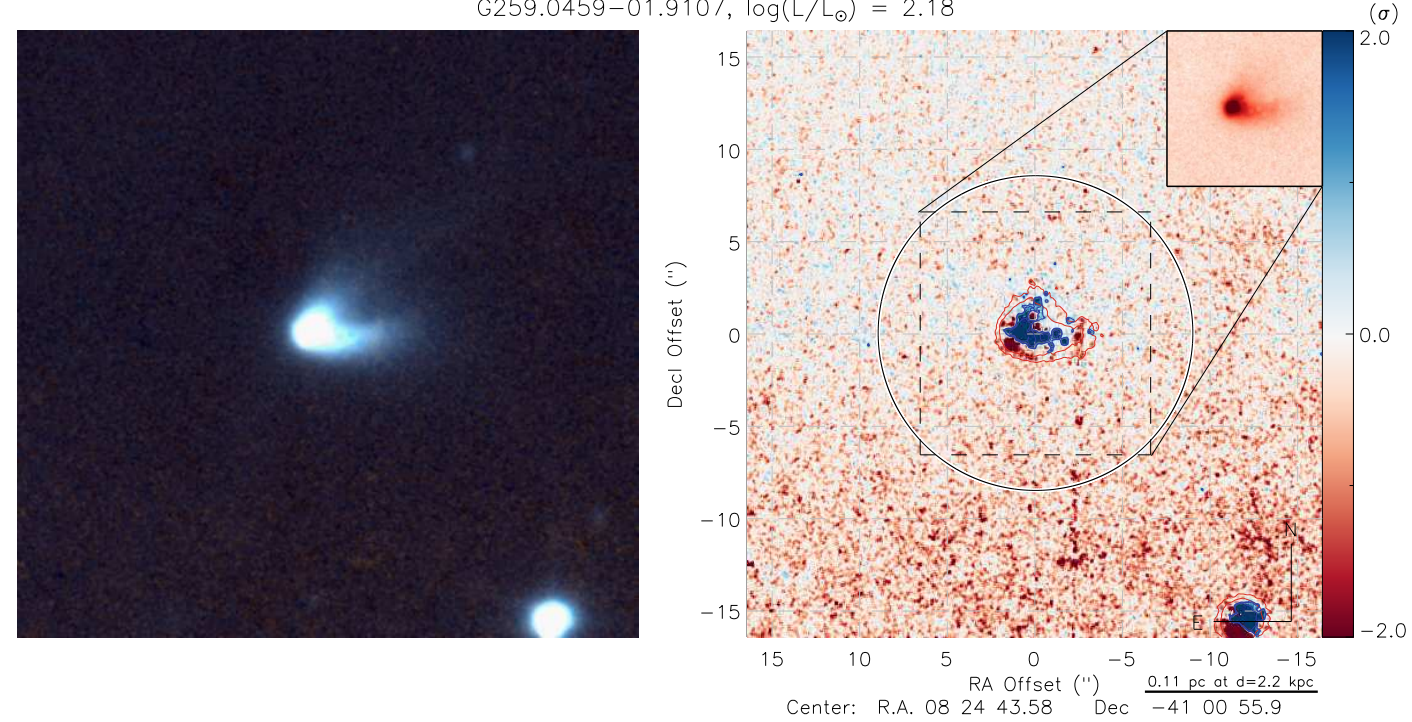

$\mathrm{G} 260.9252+00.1149, \log \left(\mathrm{L} / \mathrm{L}_{\odot}\right)=3.07$
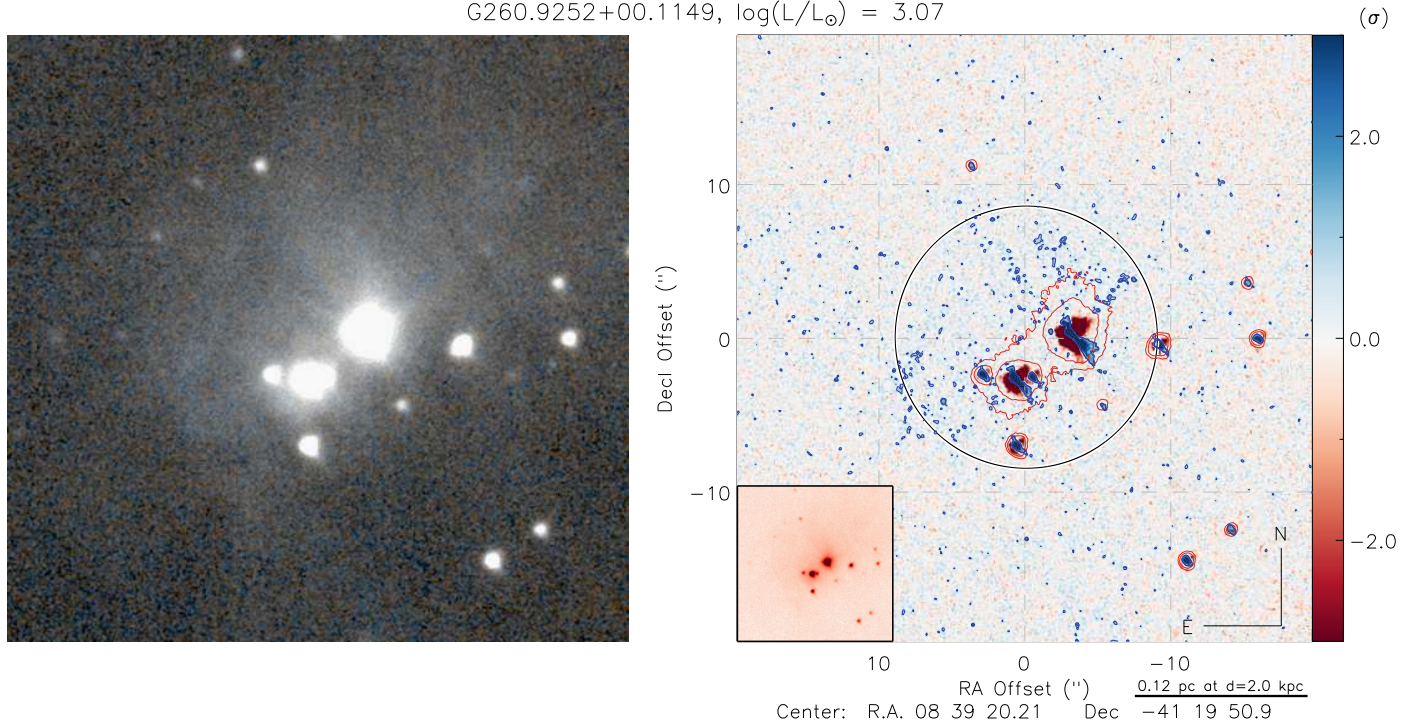

$G 263.7434+00.1161, \log \left(L / L_{\odot}\right)=3.85$
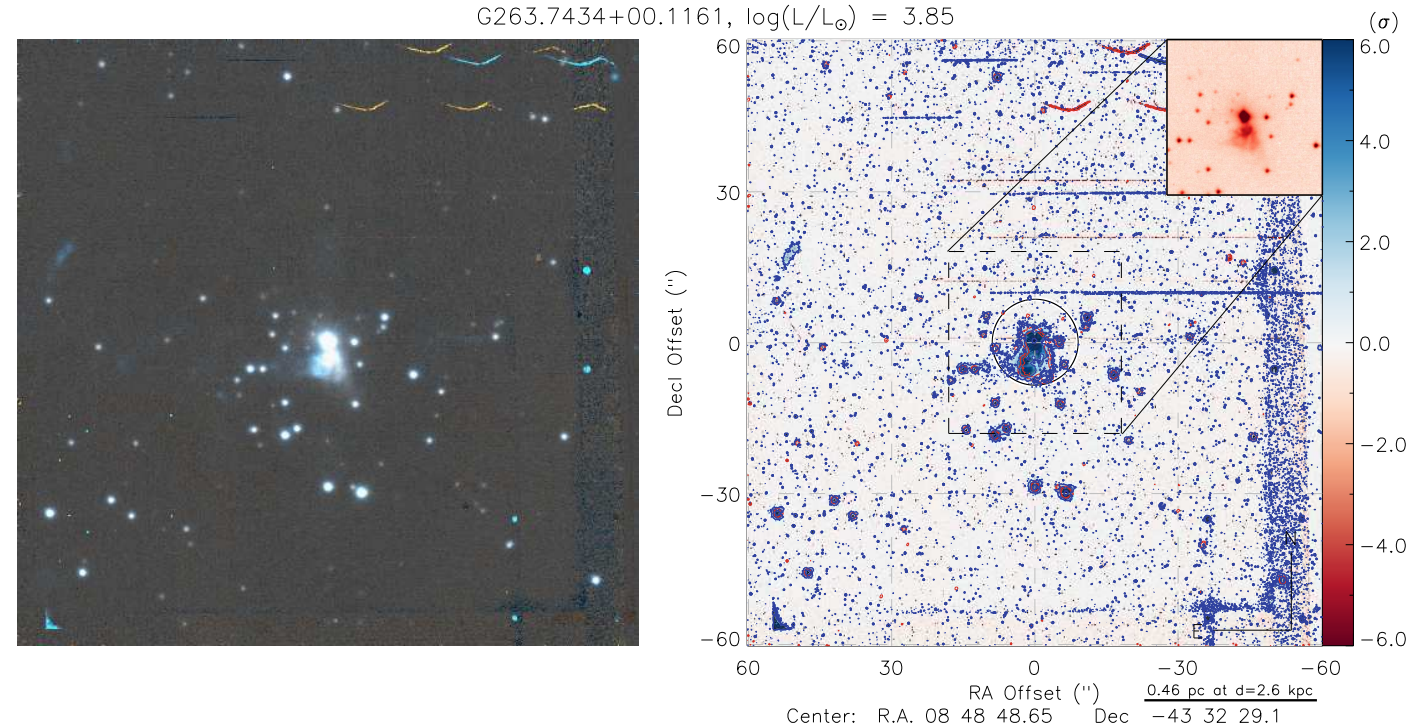
$G 264.2918+01.4700, \log \left(L / L_{\odot}\right)=3.97$
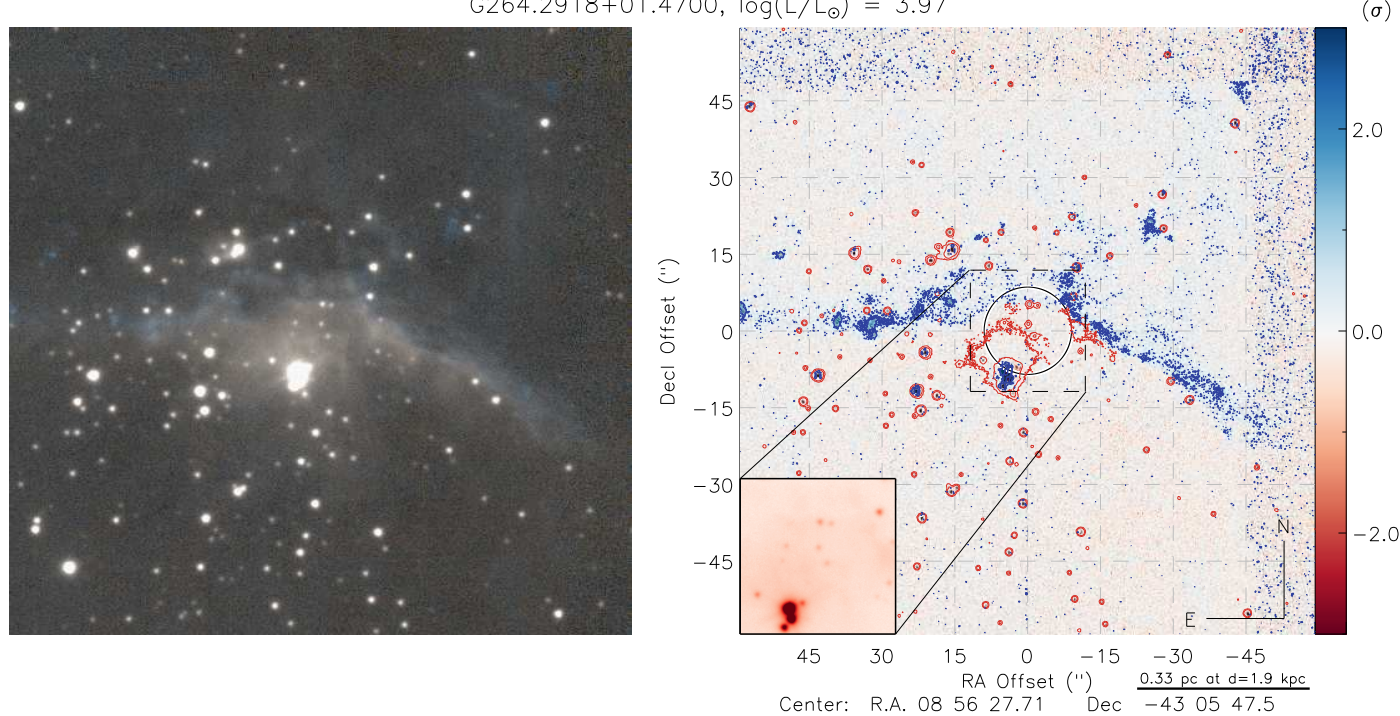

$\mathrm{G} 265.1438+01.4548, \log \left(\mathrm{L} / \mathrm{L}_{\odot}\right)=3.75$
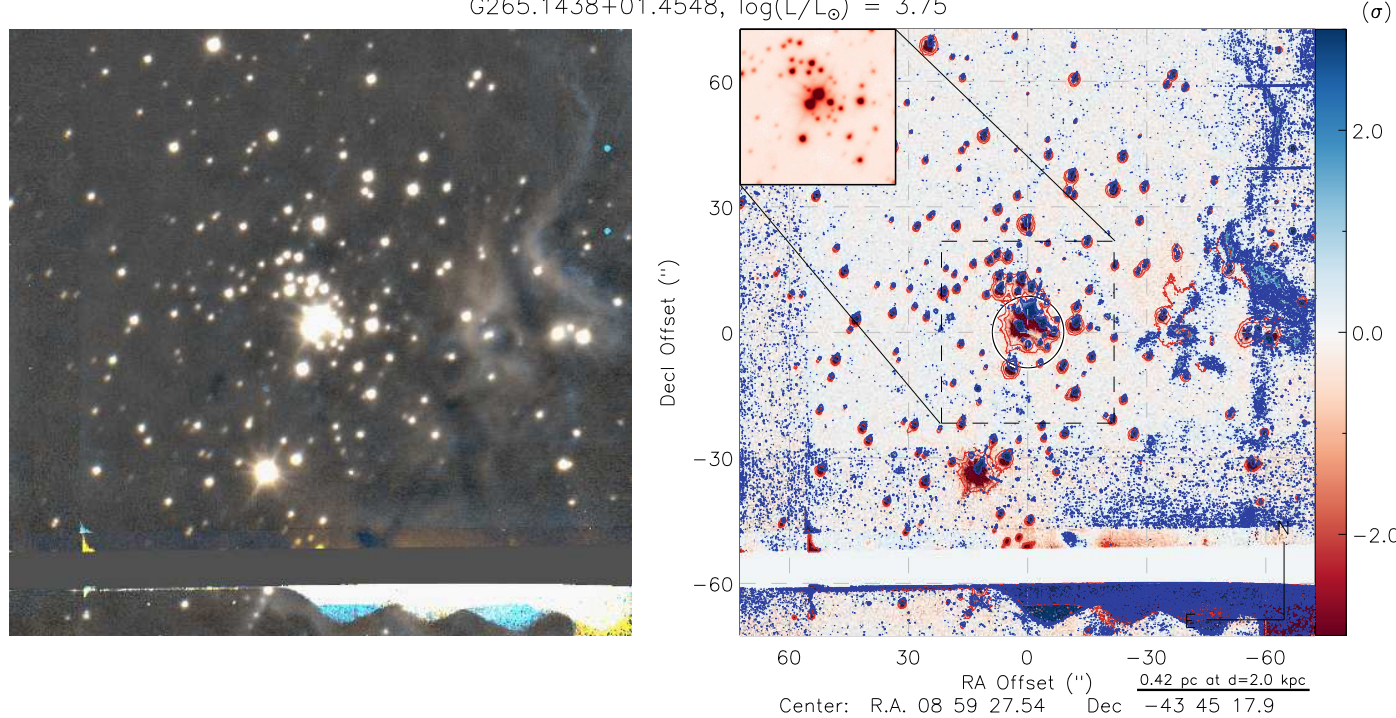

$G 267.7336-01.1058, \log \left(L / L_{\odot}\right)=3.66$
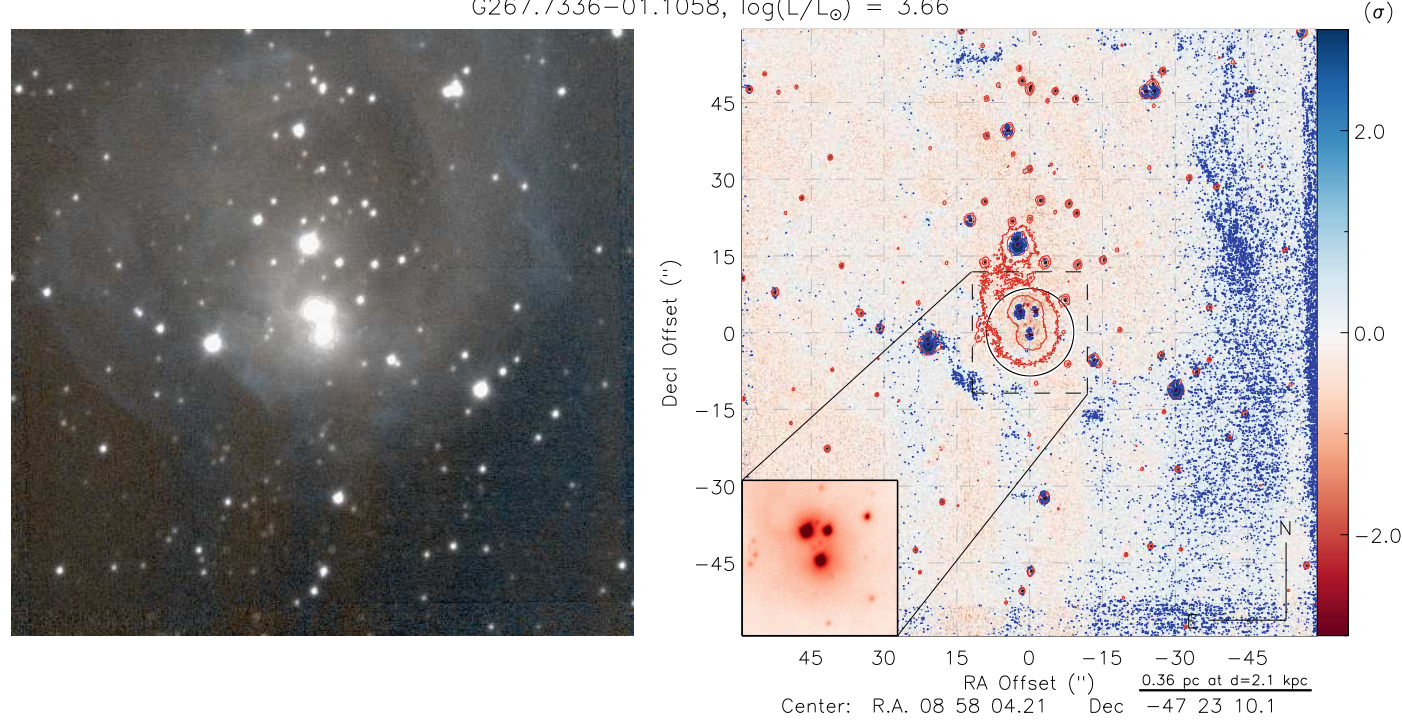
$\mathrm{G} 268.3921-03.0659, \log \left(\mathrm{L} / \mathrm{L}_{\odot}\right)=2.54$
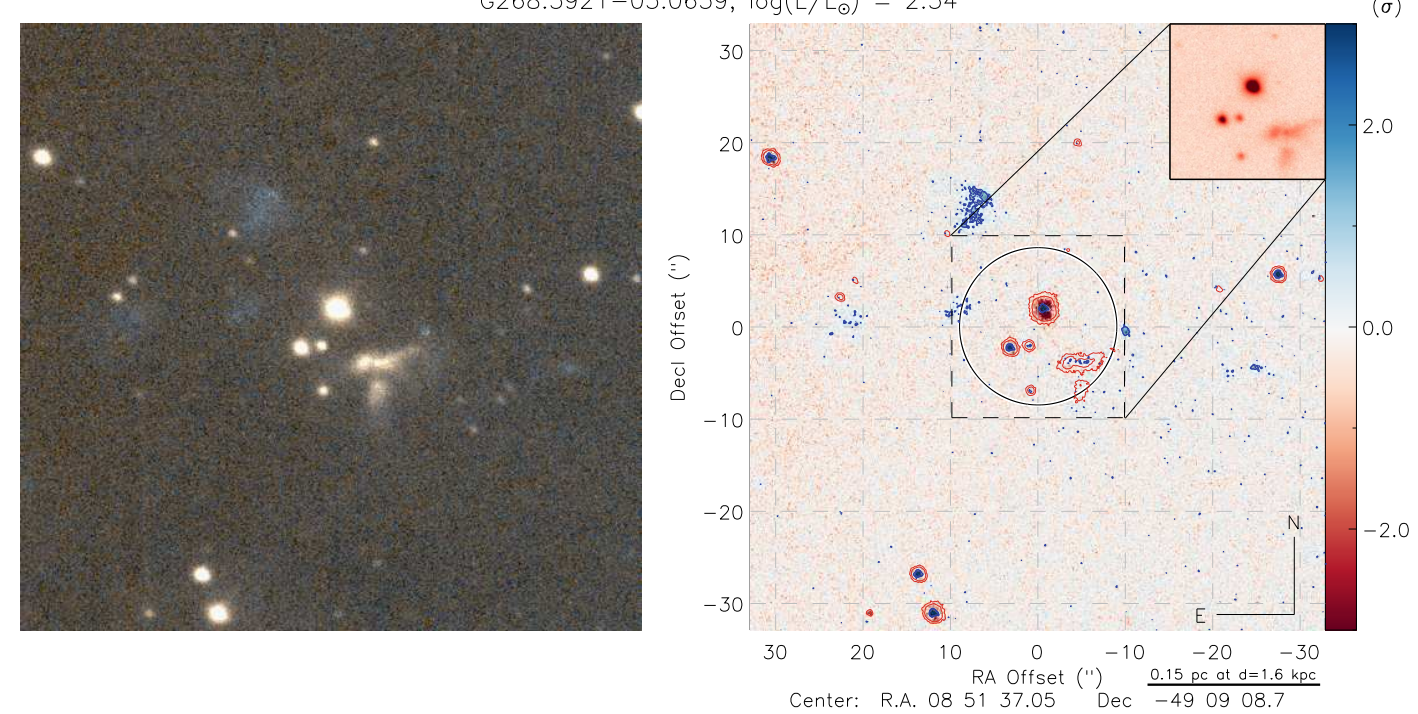

$\mathrm{G} 281.0472-01.5432, \log \left(L_{/} L_{\odot}\right)=3.88$
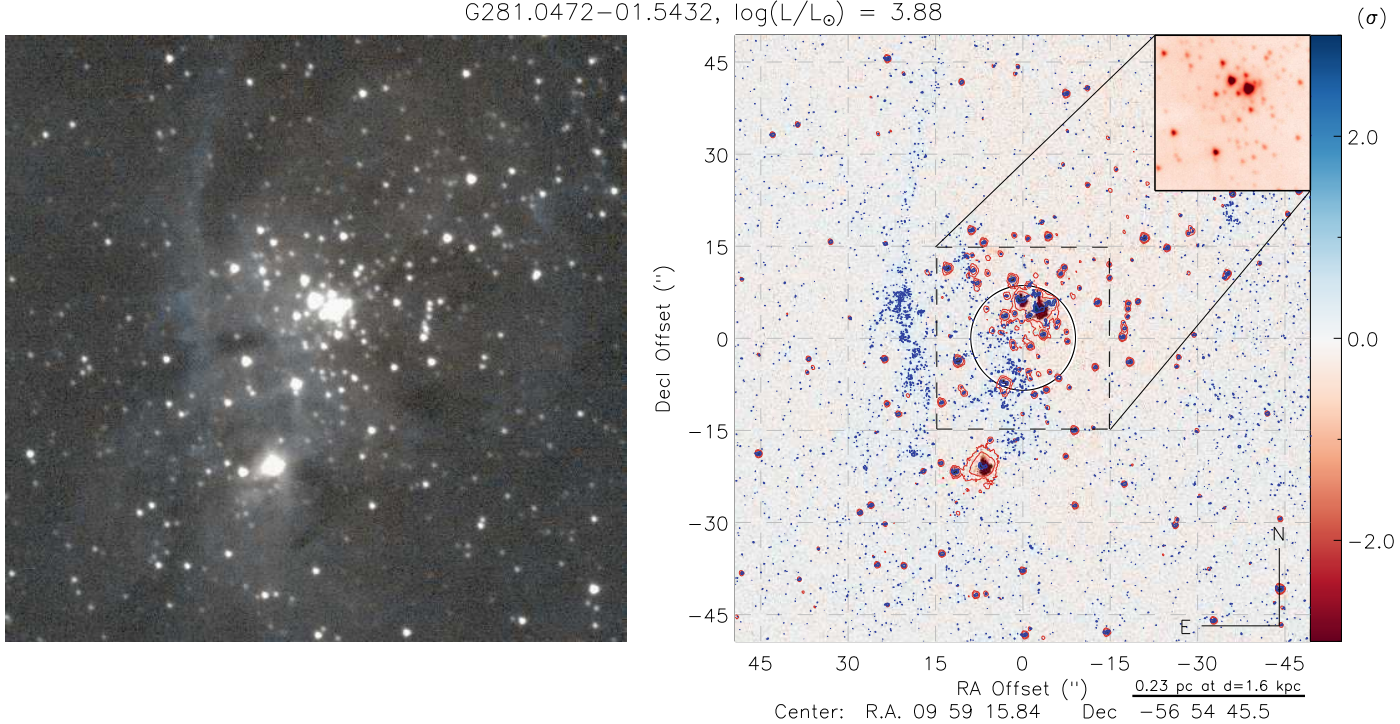

$\mathrm{G} 282.8969-01.2727, \log \left(L / L_{\odot}\right)=0.00$
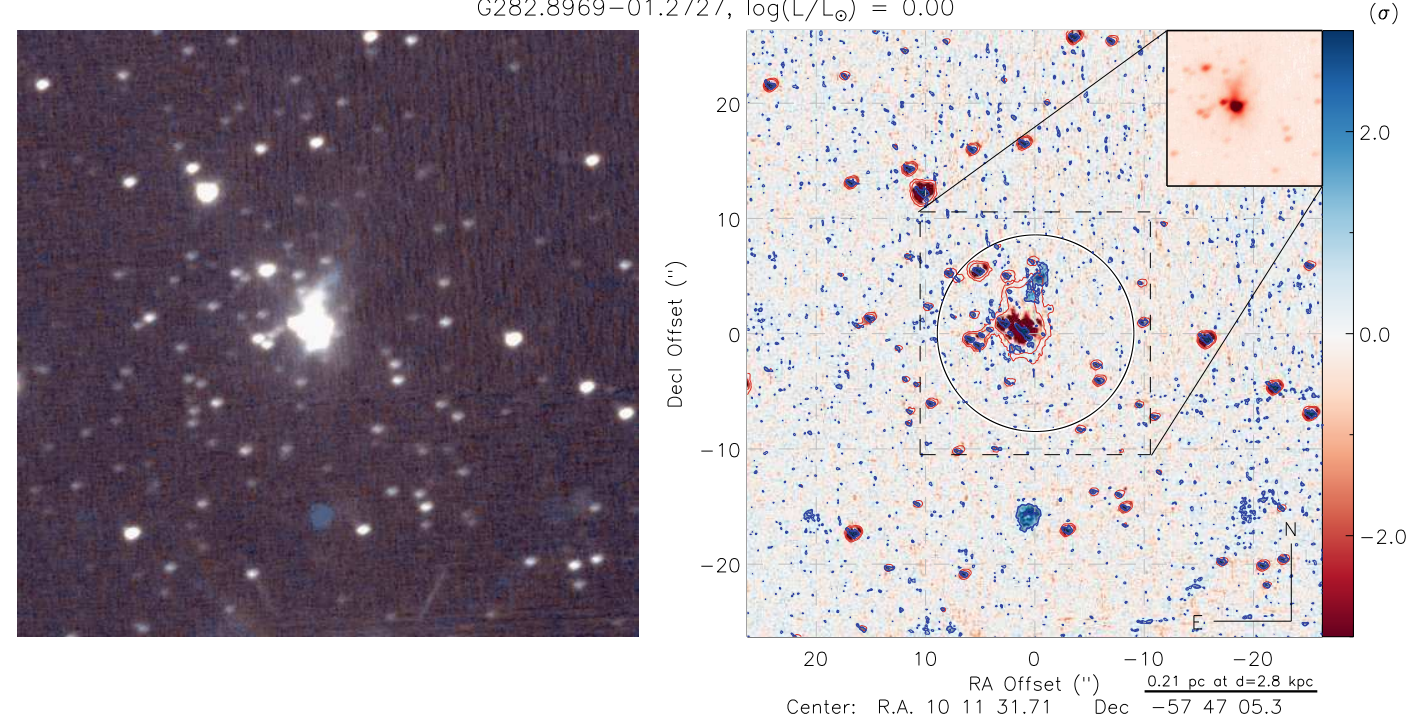
$\mathrm{G} 286.2086+00.1694, \log \left(\mathrm{L} / \mathrm{L}_{\odot}\right)=4.89$
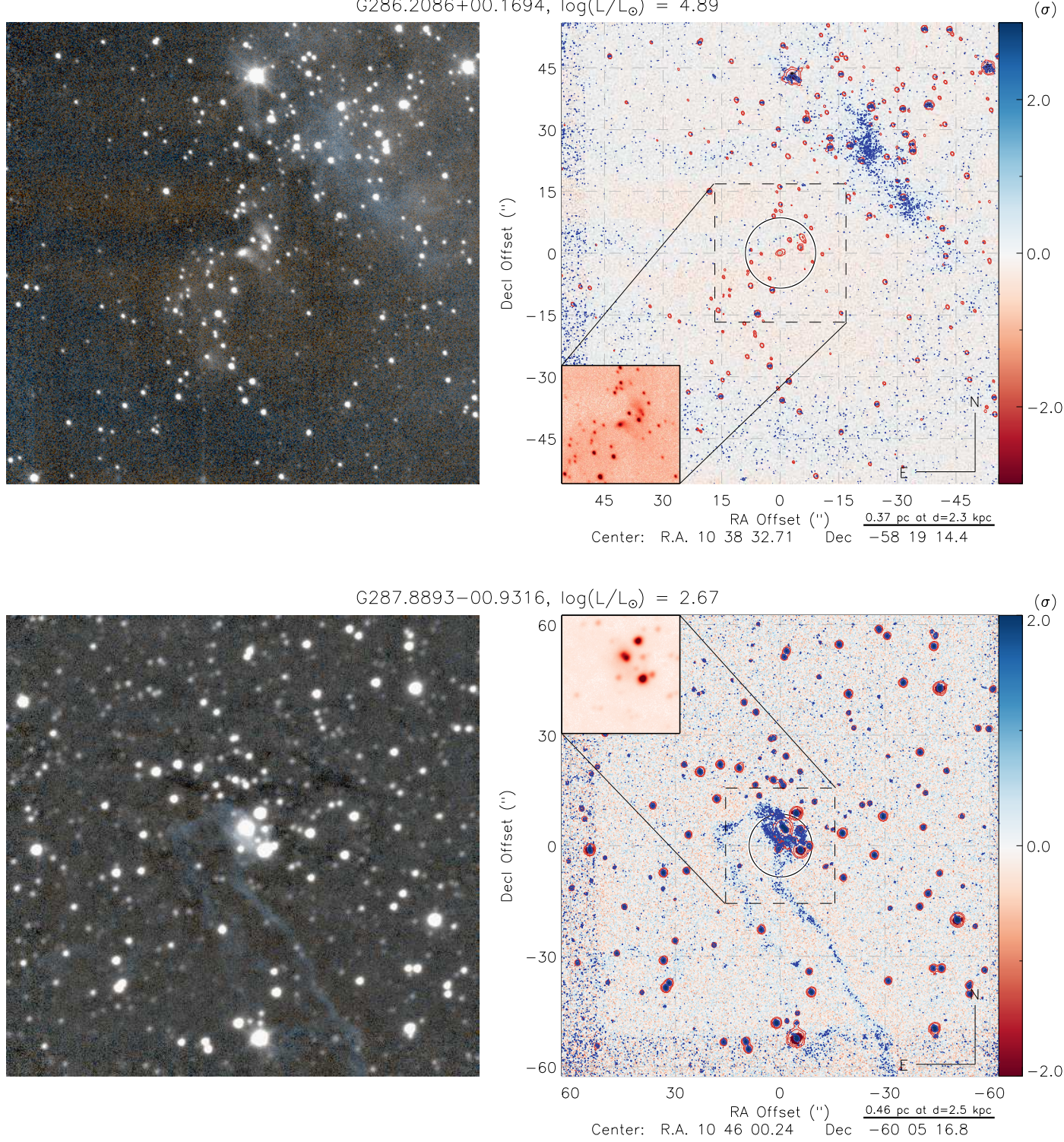

G288.9862+00.2533, $\log \left(L / L_{\odot}\right)=0.00$
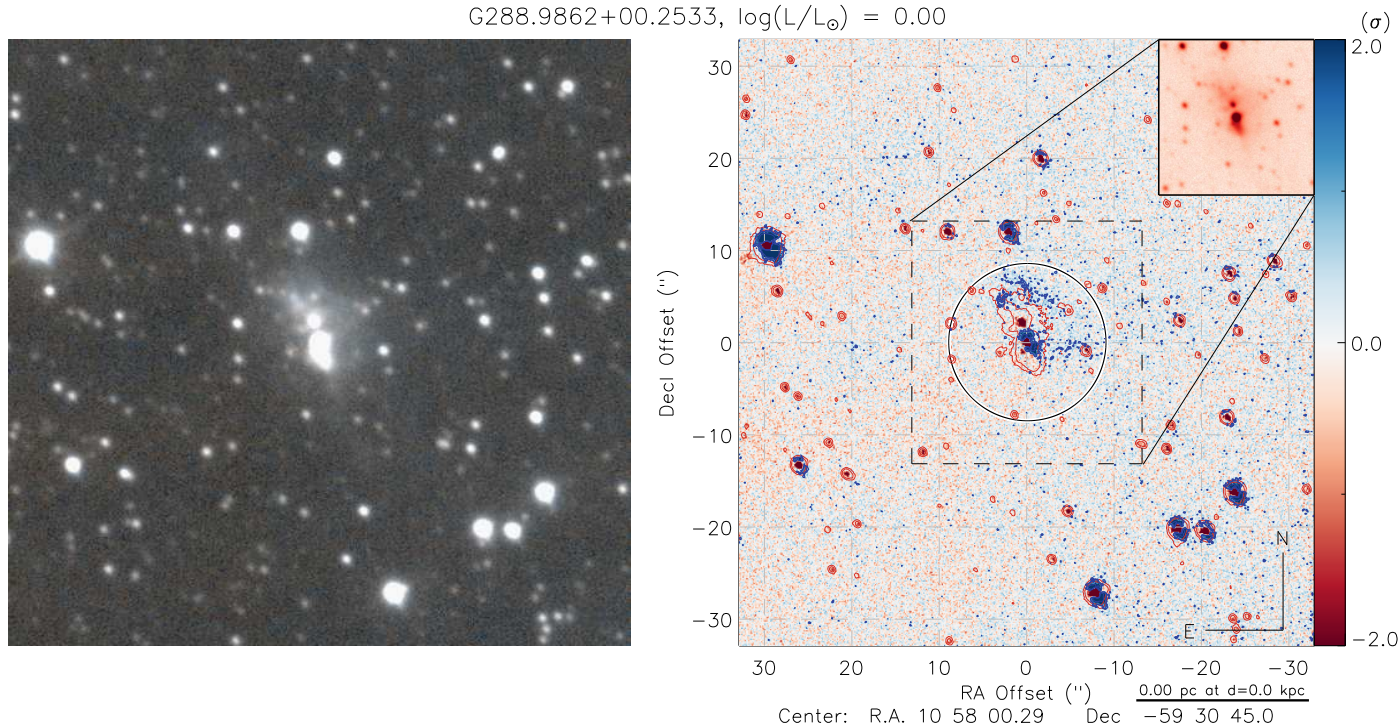
G289.9446-00.8909, $\log \left(L / L_{\odot}\right)=5.52$
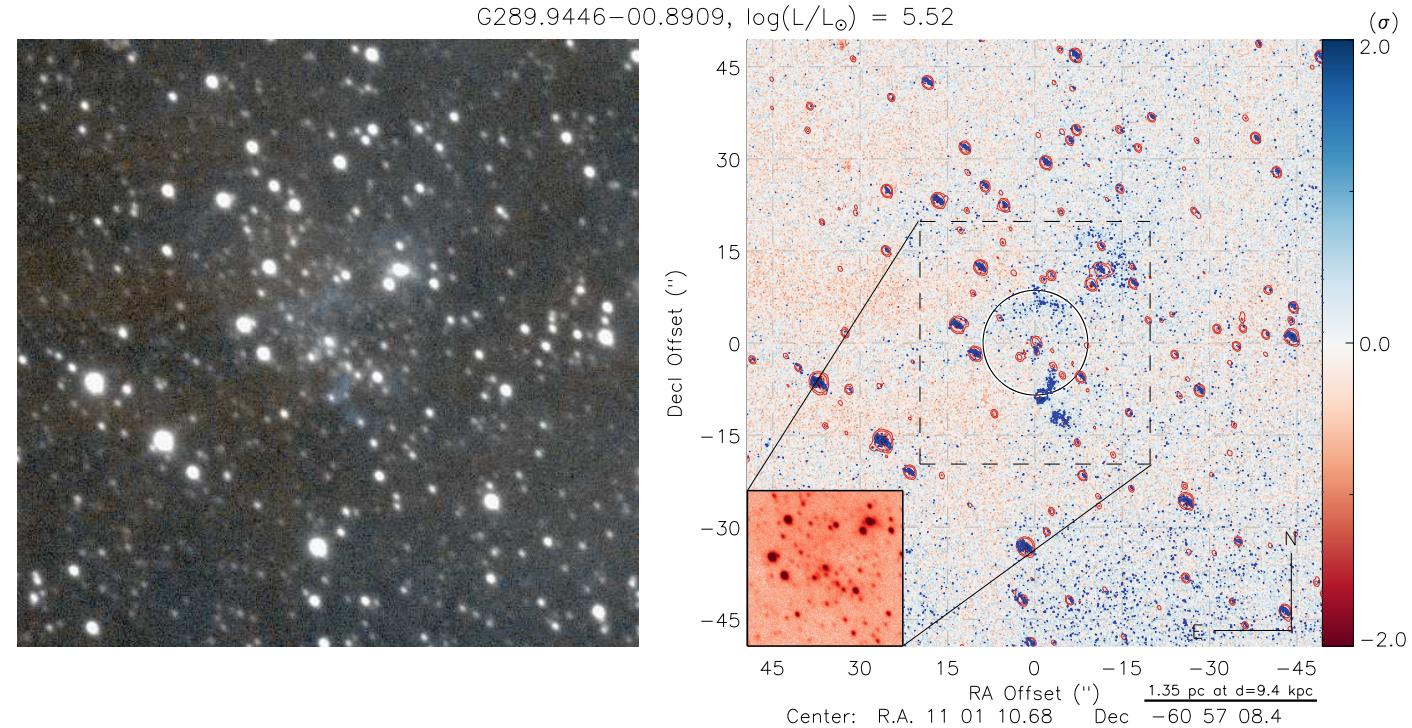

$\mathrm{G} 290.8768-01.2170, \log \left(\mathrm{L} / \mathrm{L}_{\odot}\right)=4.50$
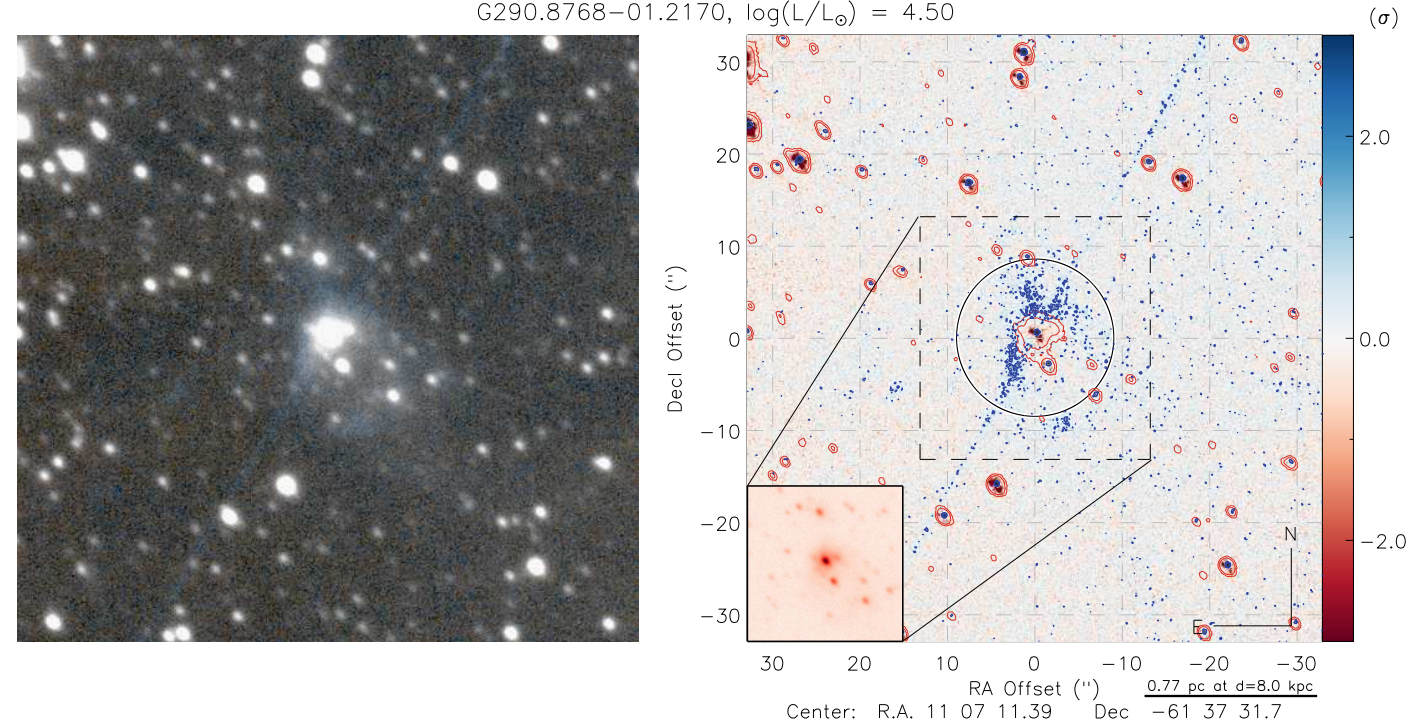

G293.5607-00.6703, $\log \left(L / L_{\odot}\right)=4.66$
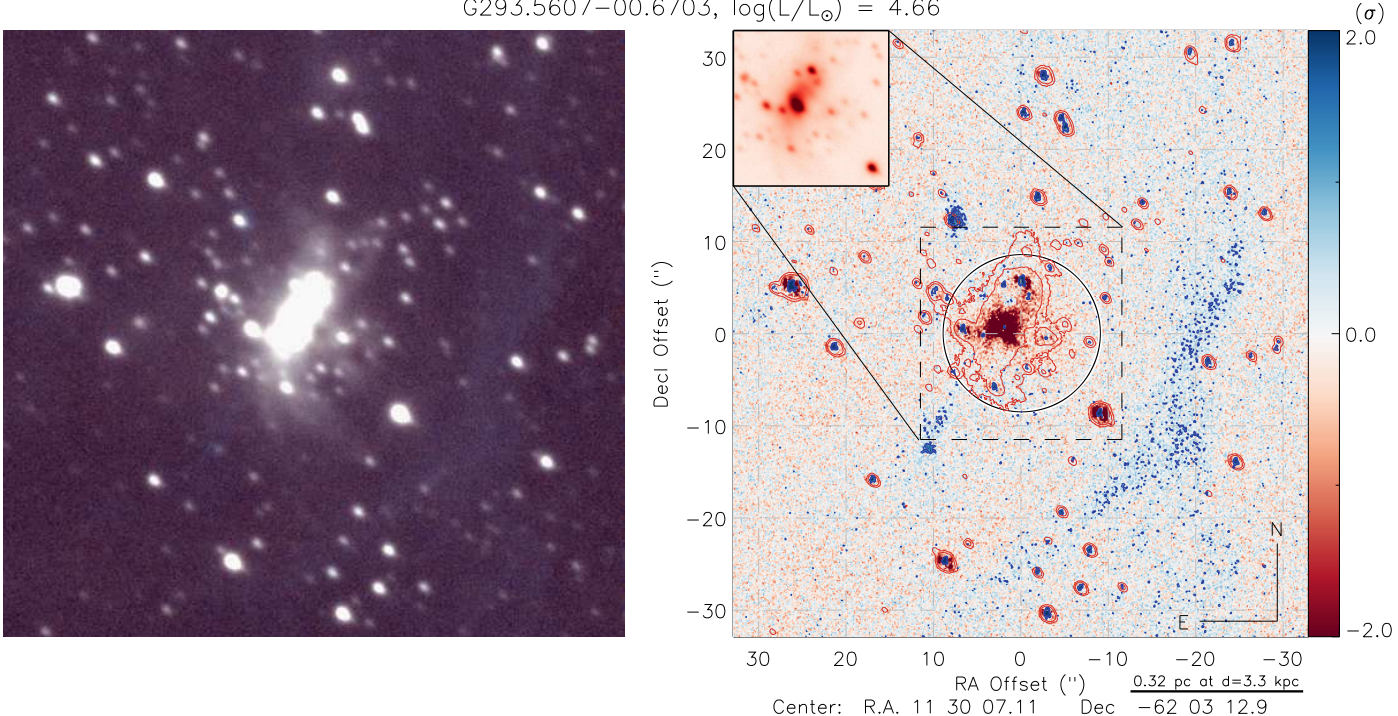
G295.1523-00.5890, $\log \left(L / L_{\odot}\right)=5.27$
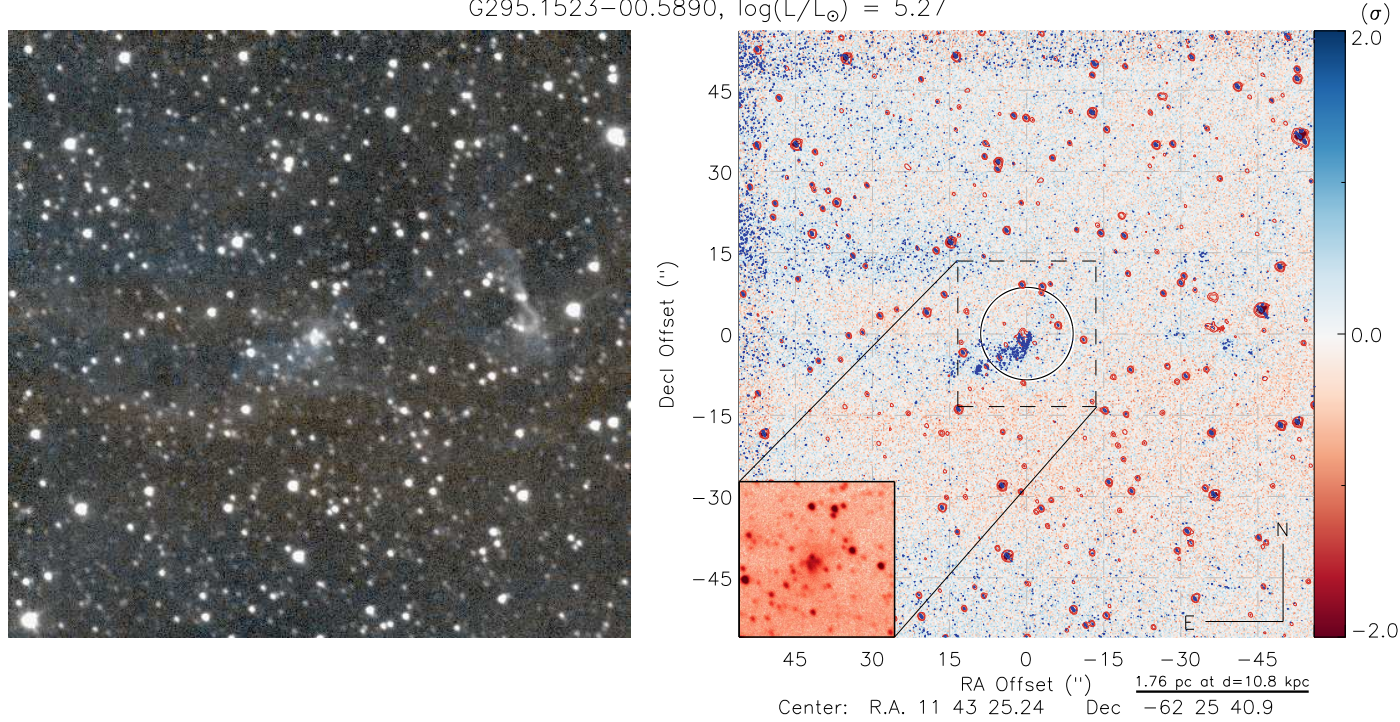

$G 295.5570-01.3787, \log \left(L / L_{\odot}\right)=4.87$
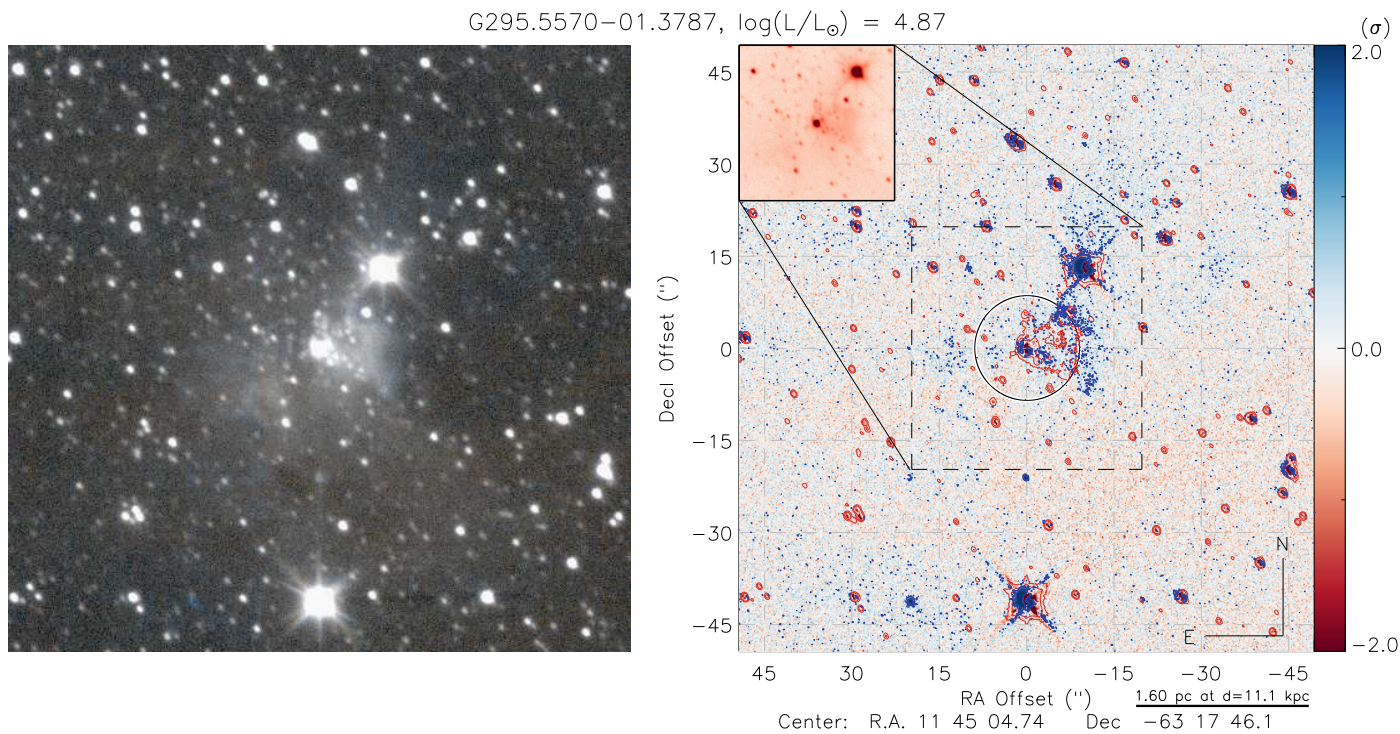

G296.4036-01.0185, $\log \left(L / L_{\odot}\right)=4.41$
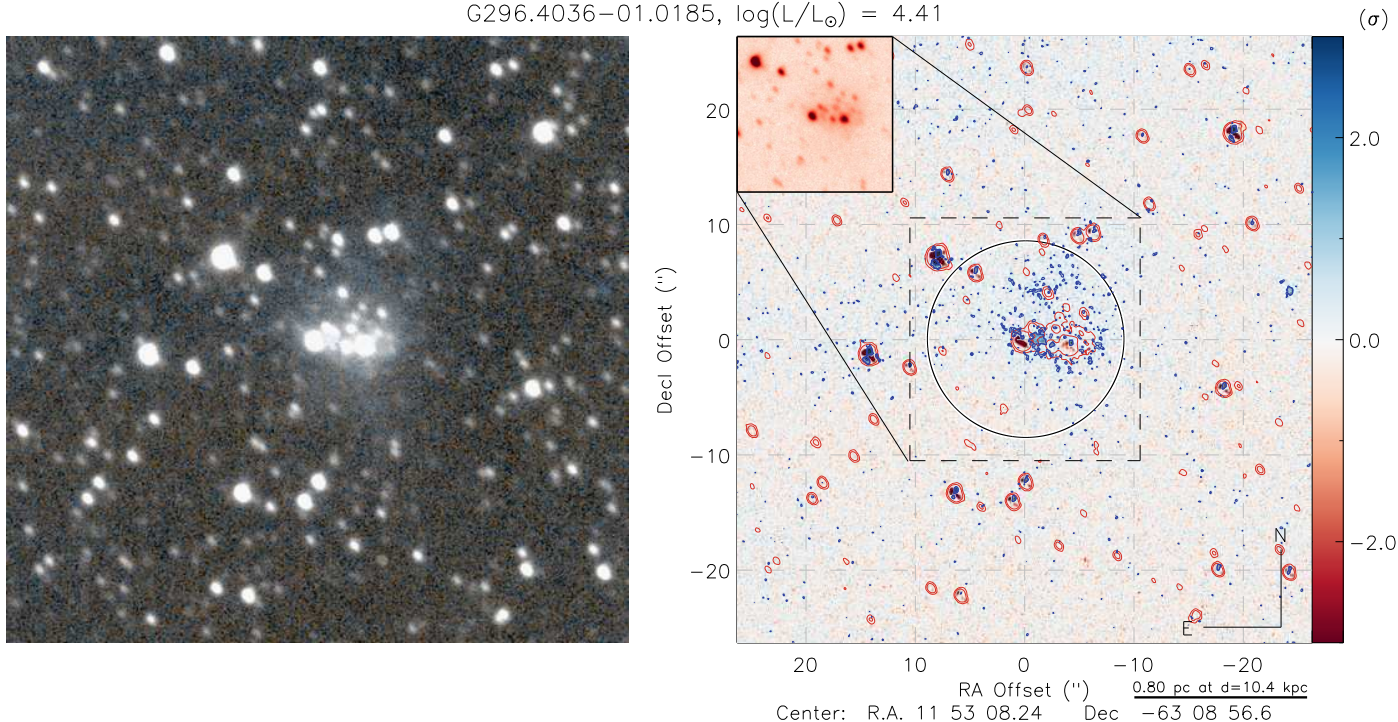
$G 296.7256-01.0382, \log \left(L / L_{\odot}\right)=5.00$
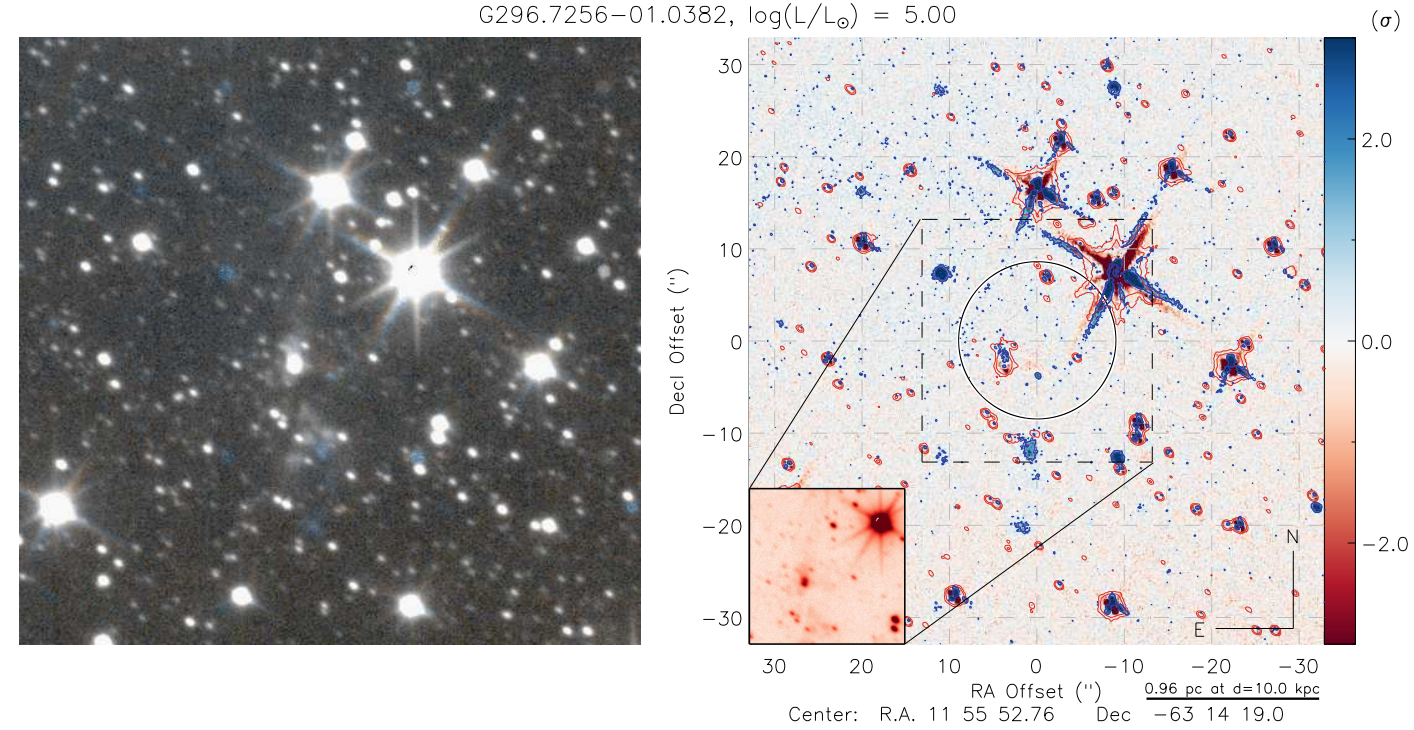

G296.8926-01.3050, $\log \left(L / L_{\odot}\right)=4.22$
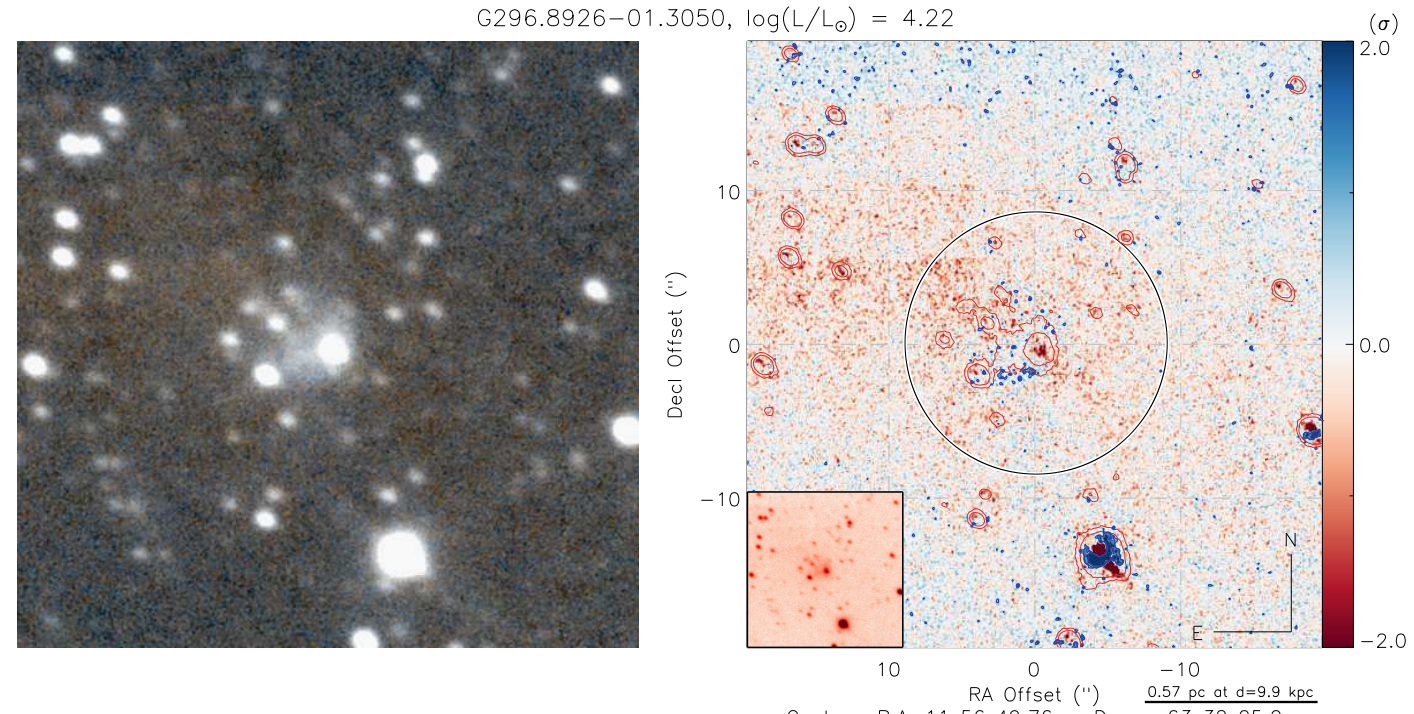

$\mathrm{G} 301.8147+00.7808, \log \left(\mathrm{L} / \mathrm{L}_{\odot}\right)=4.33$
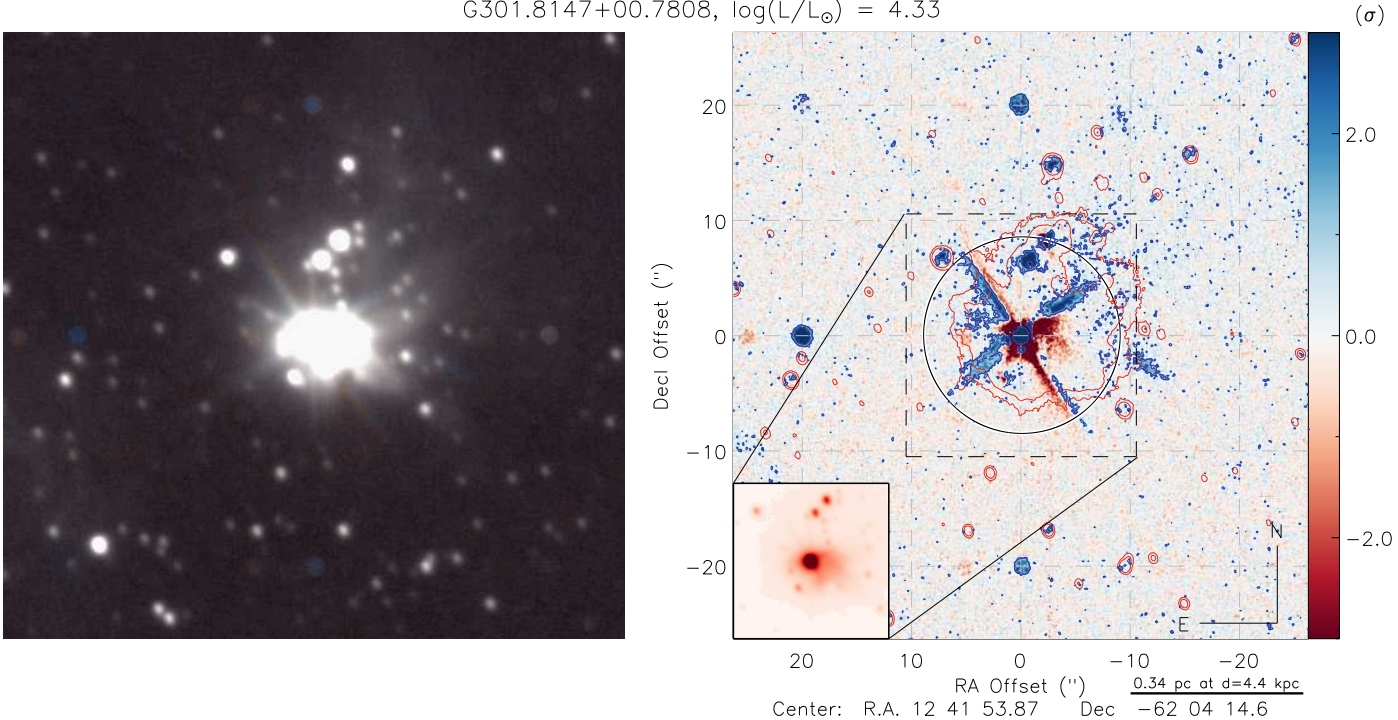
$G 305.5610+00.0124, \log \left(L / L_{\odot}\right)=4.95$
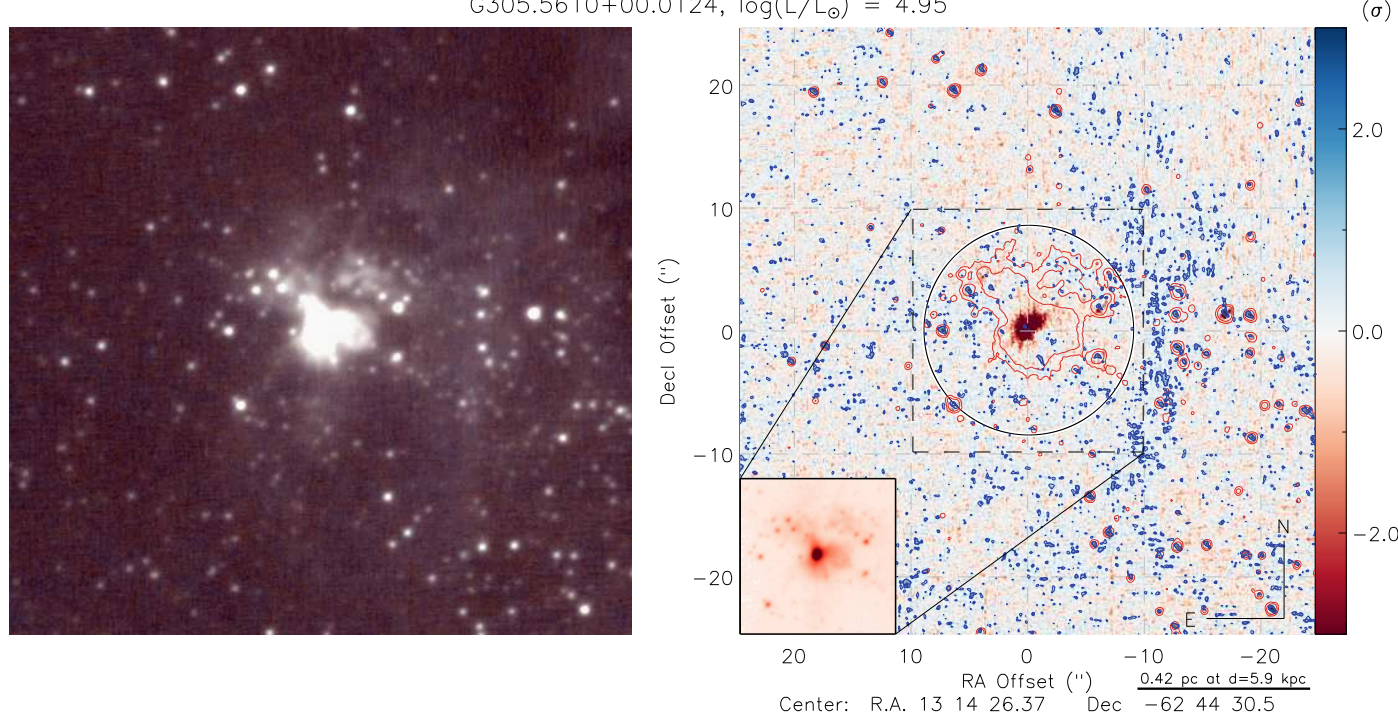

$G 306.1160+00.1386, \log \left(L / L_{\odot}\right)=4.39$
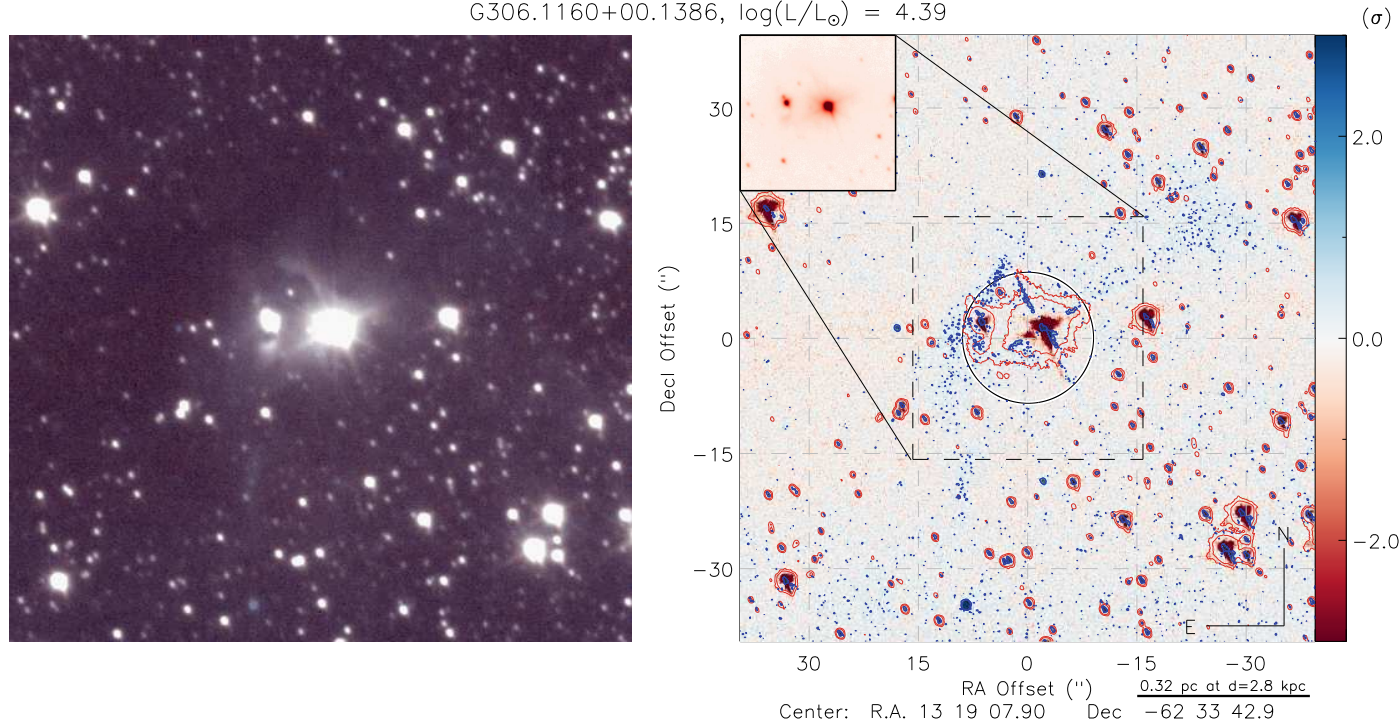

G307.6138-00.2559, $\log \left(L / L_{\odot}\right)=4.59$
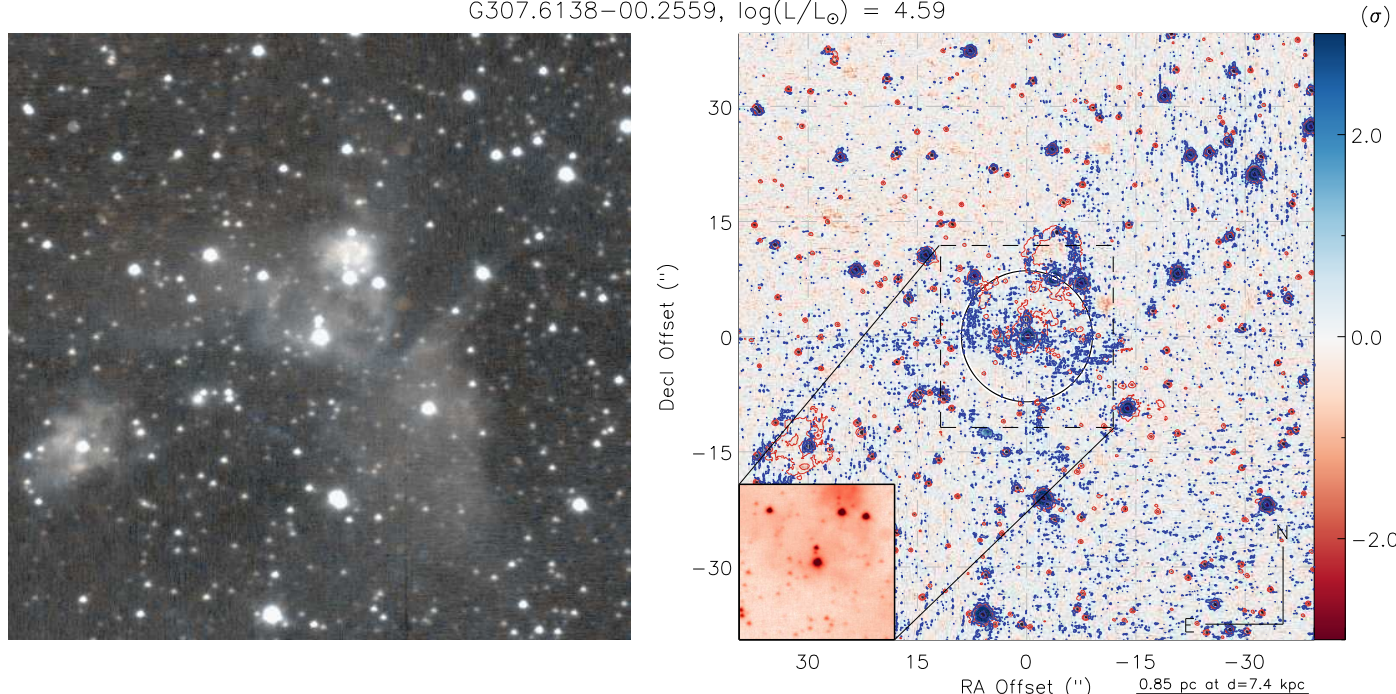

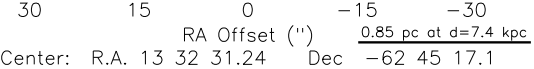


$G 308.6480+00.6469, \log \left(L / L_{\odot}\right)=4.30$
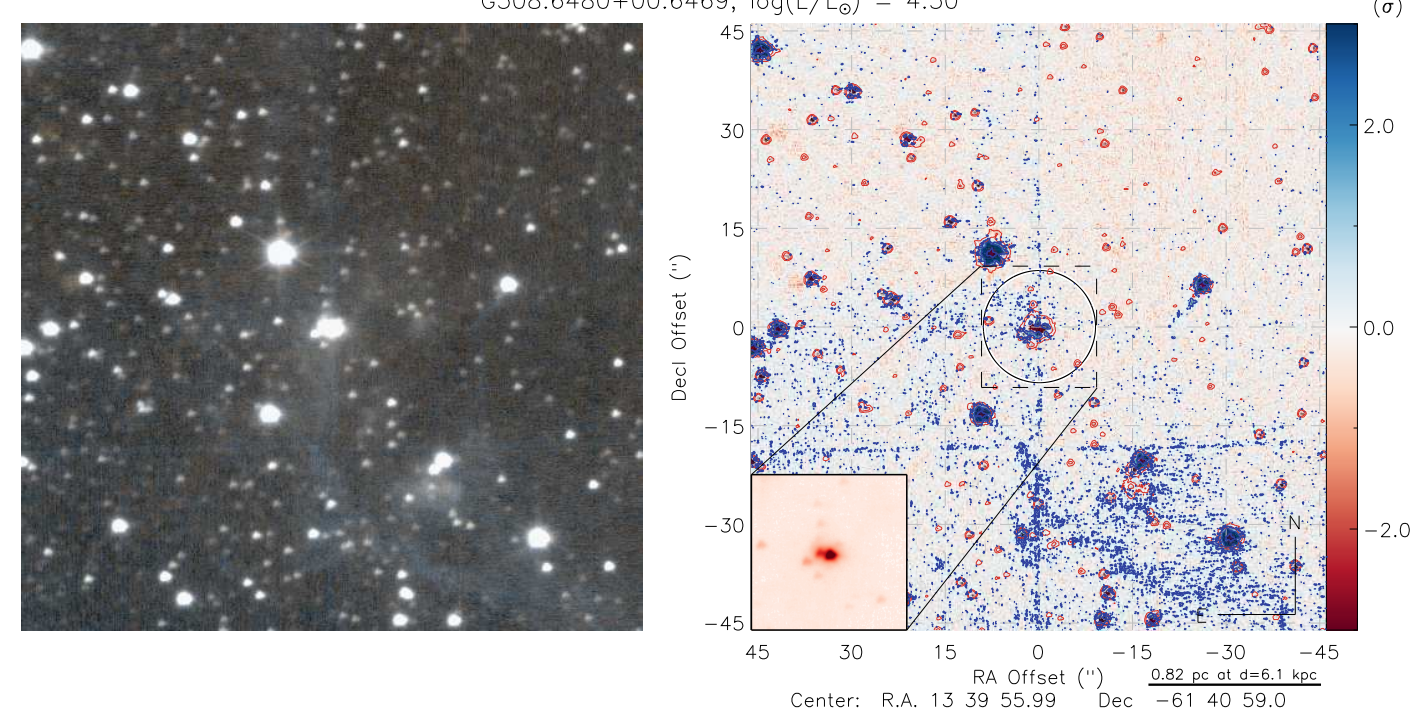

$G 320.1750+00.8001, \log \left(L / L_{\odot}\right)=3.46$
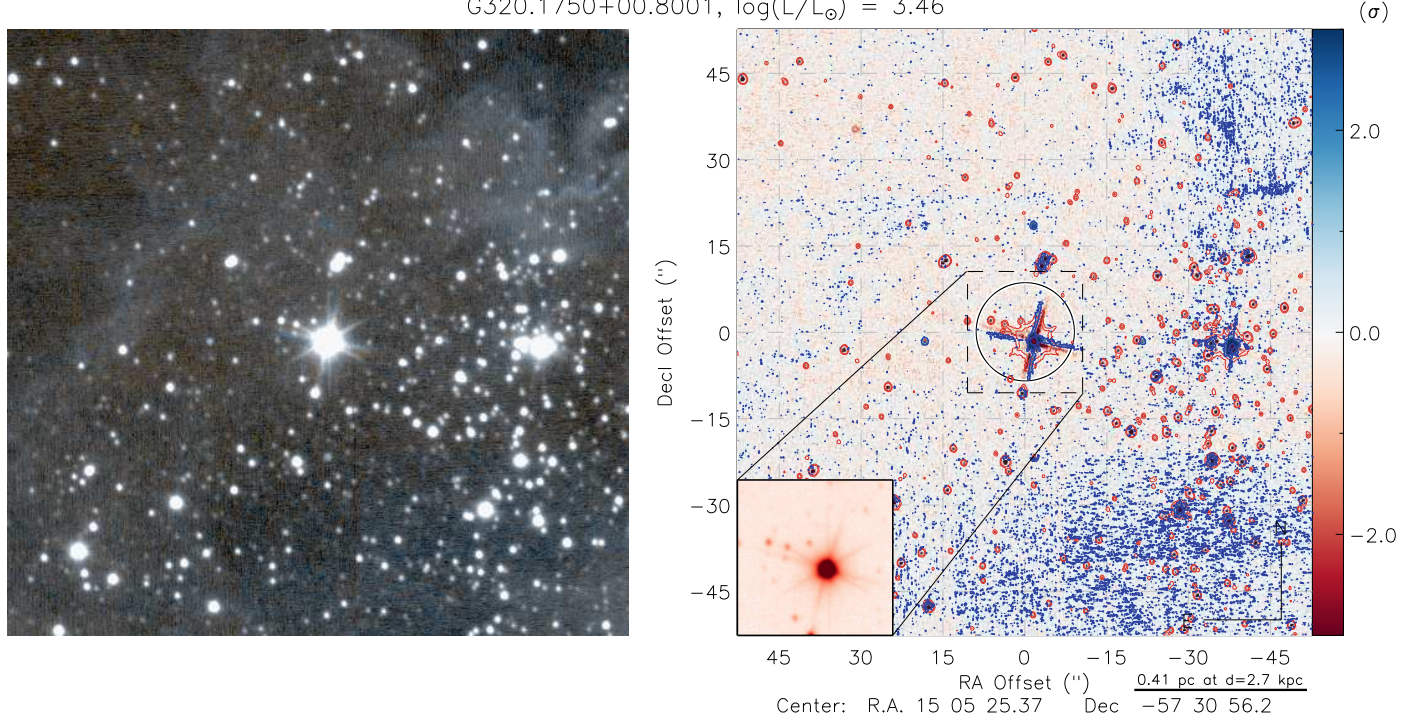

$G 320.2046+00.8626, \log \left(L / L_{\odot}\right)=3.74$
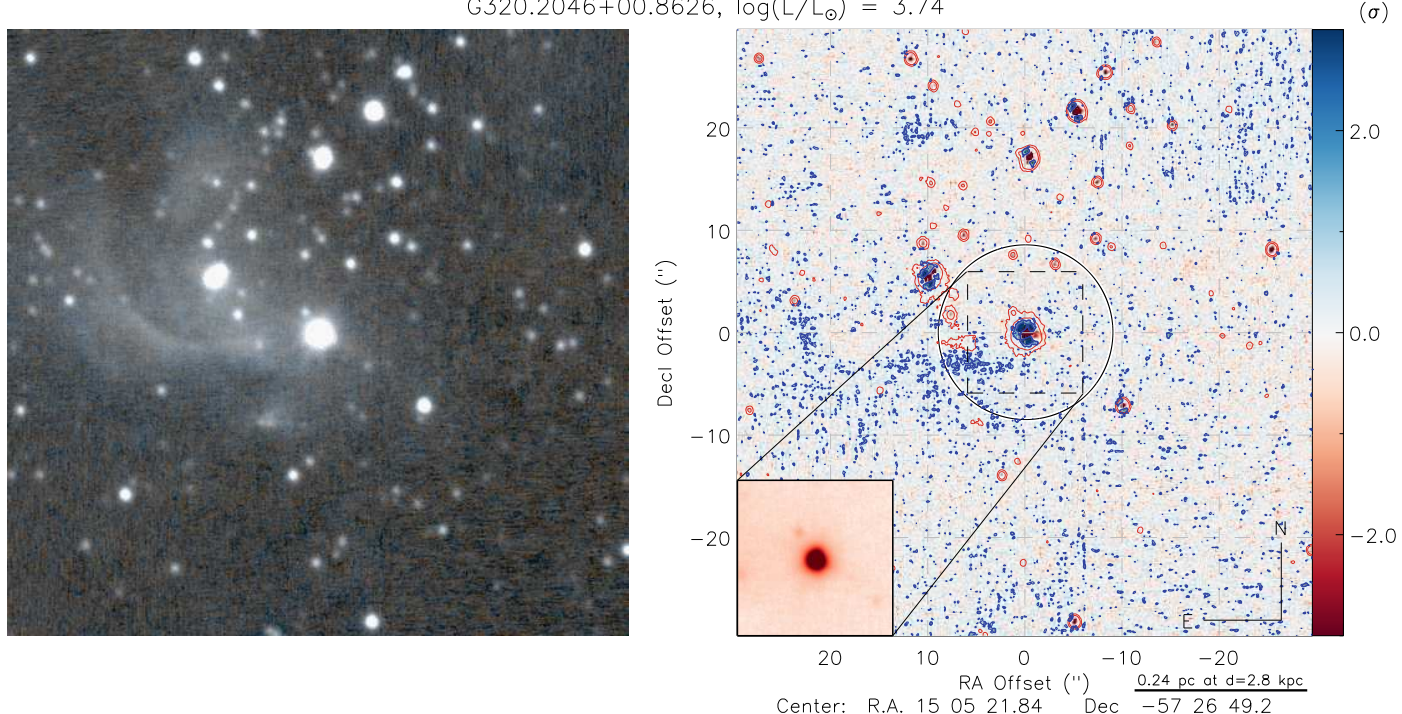
G320.2878-00.3069, $\log \left(\mathrm{L} / \mathrm{L}_{\odot}\right)=4.21$
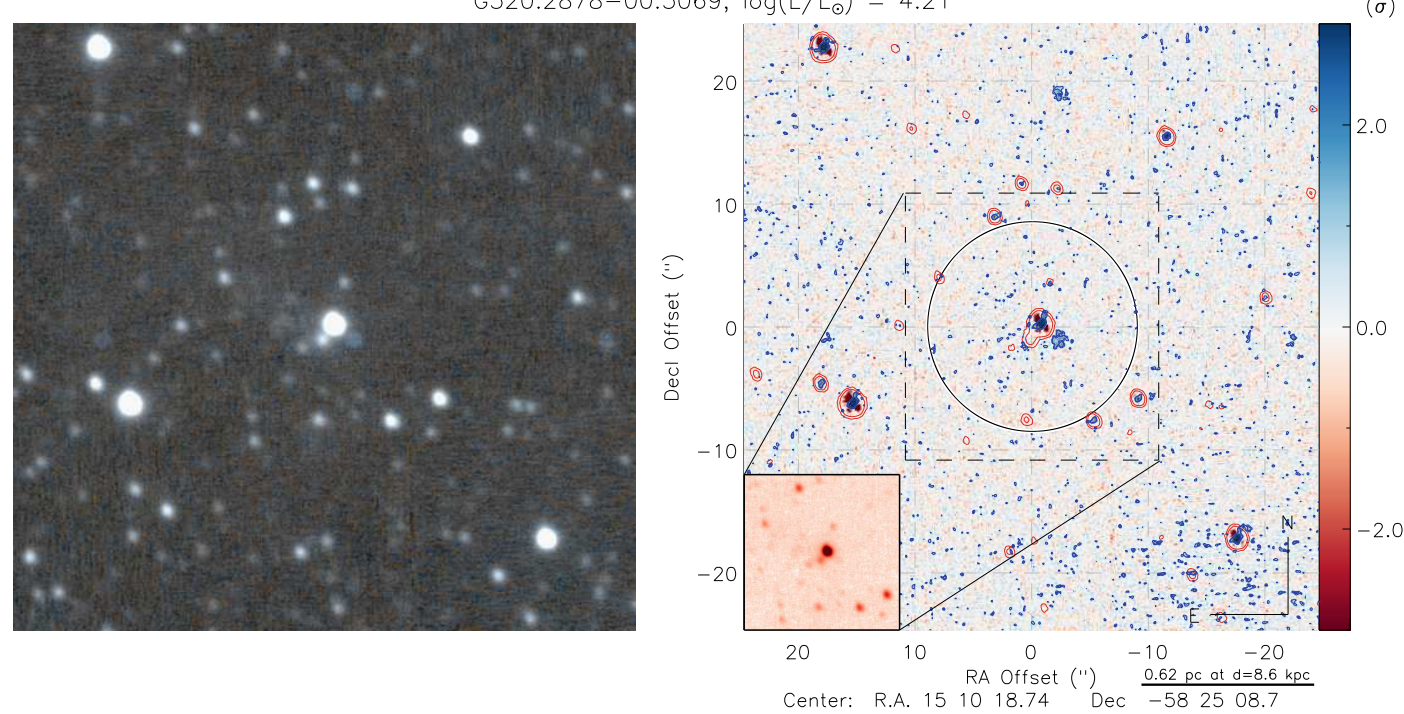

G323.7410-00.2552, $\log \left(L / L_{1}\right.$ odot $)=5.24$
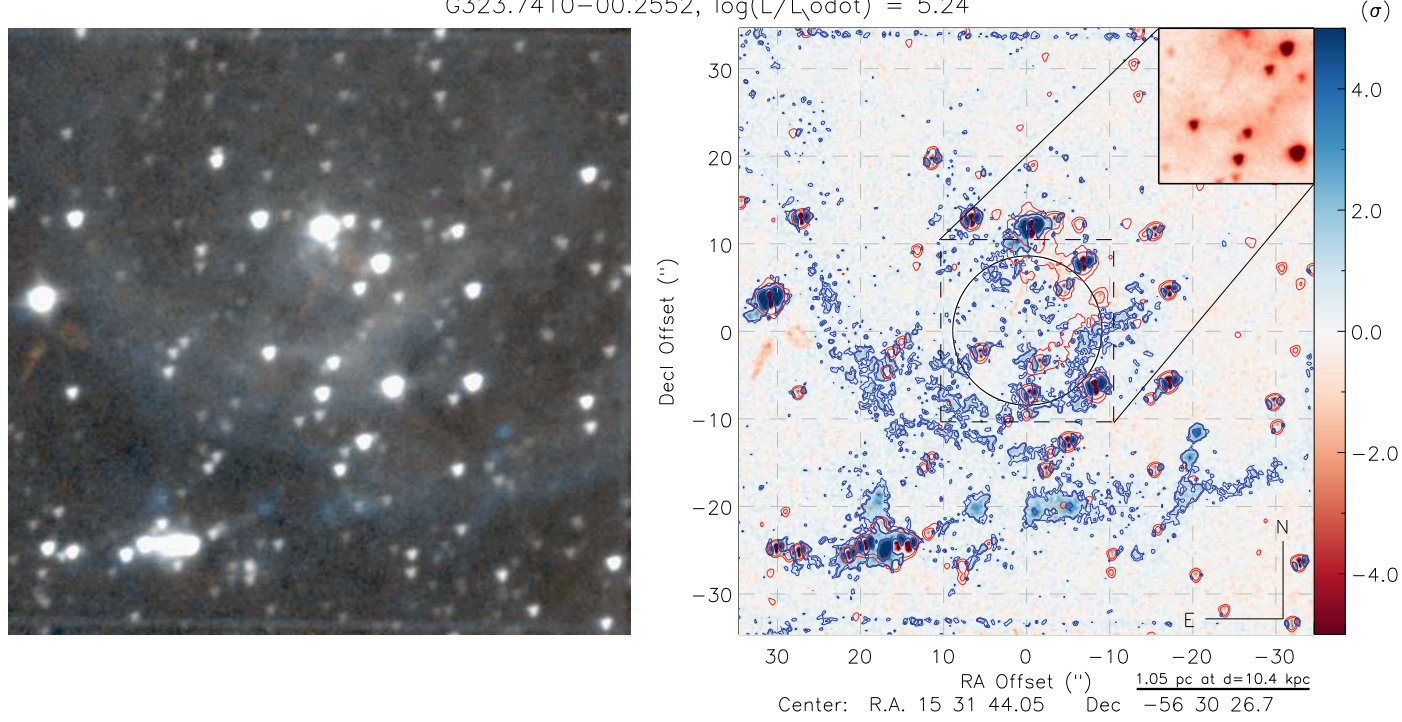

$G 331.3546+01.0638, \log \left(L_{/} L_{1}\right.$ odot $)=4.82$
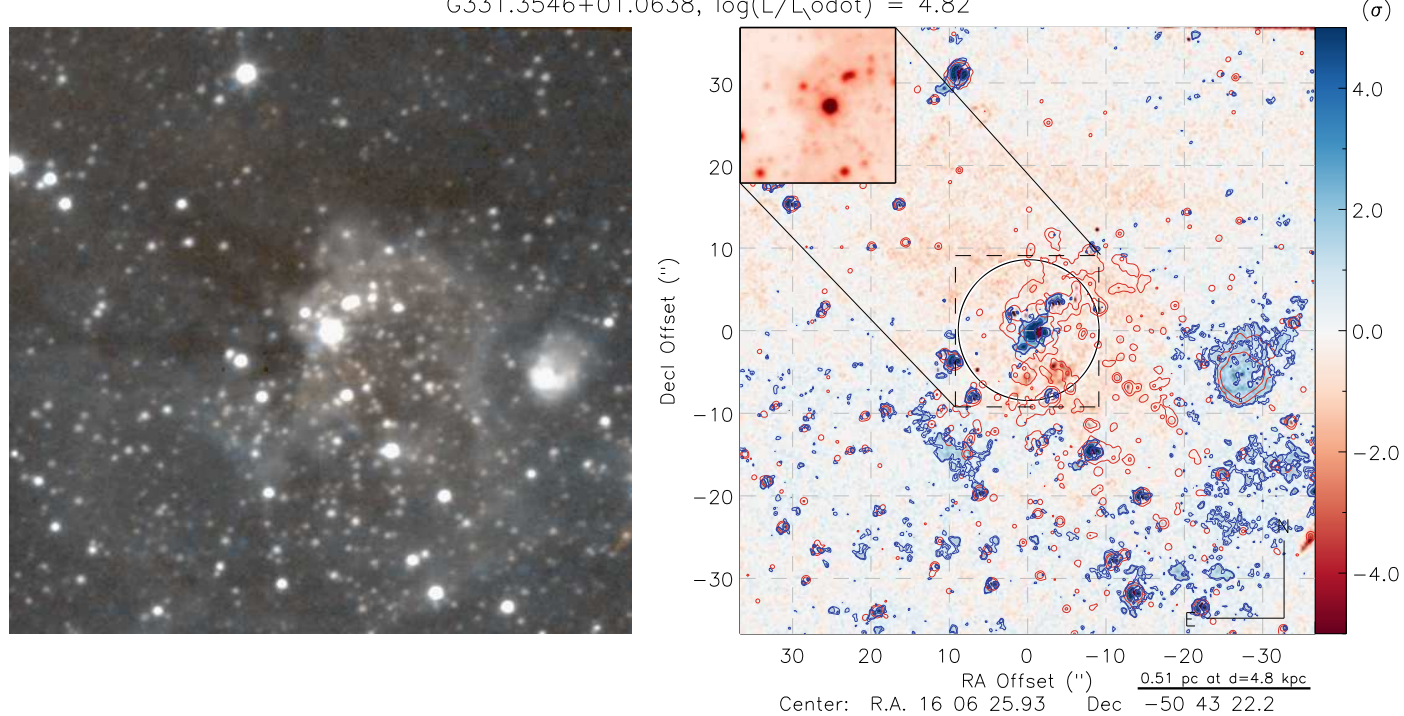
G333.1075-00.5020, $\log \left(L / L_{\odot}\right)=3.50$
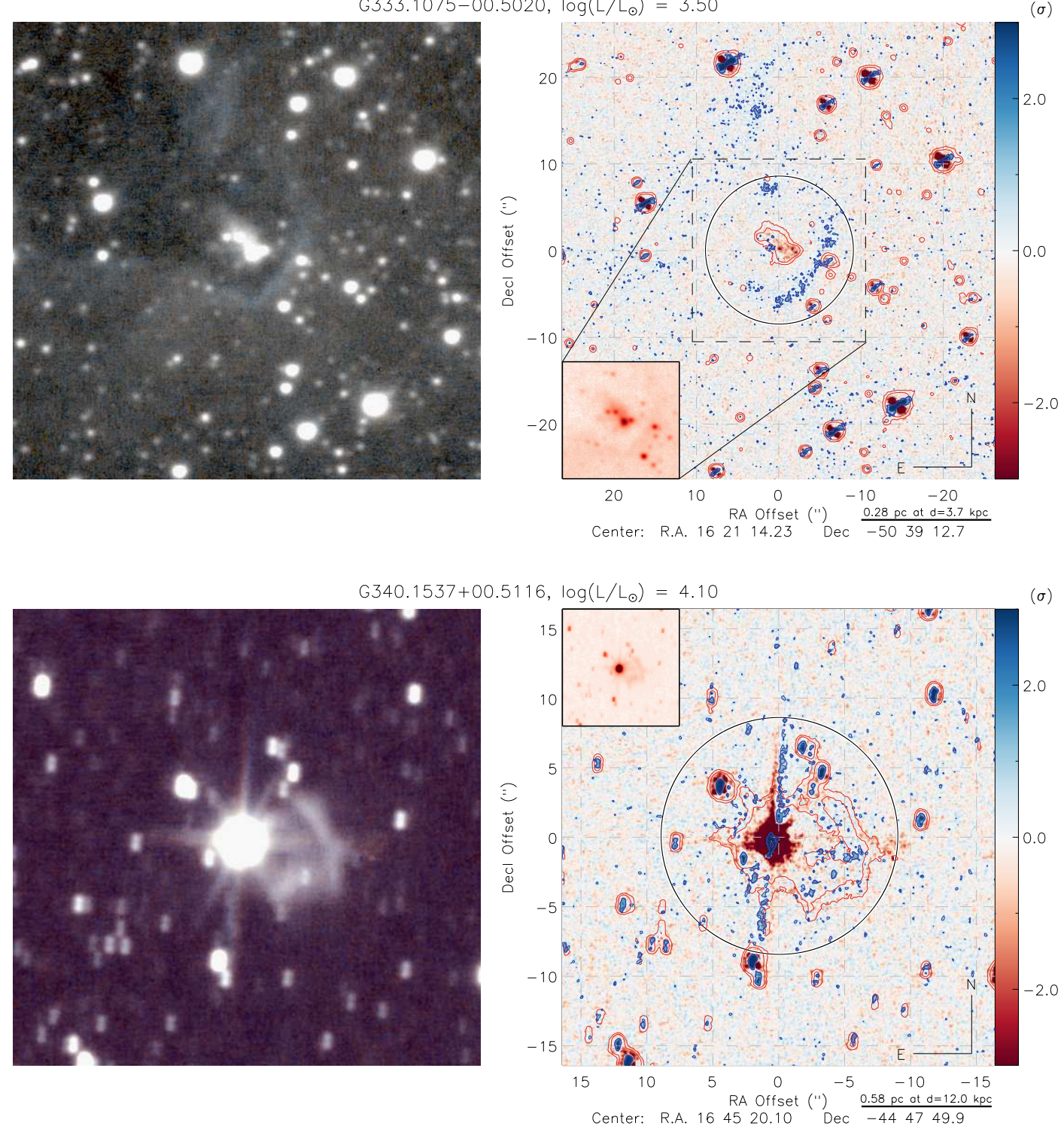

G343.8354-00.1058, $\log \left(L / L_{\odot}\right)=3.03$
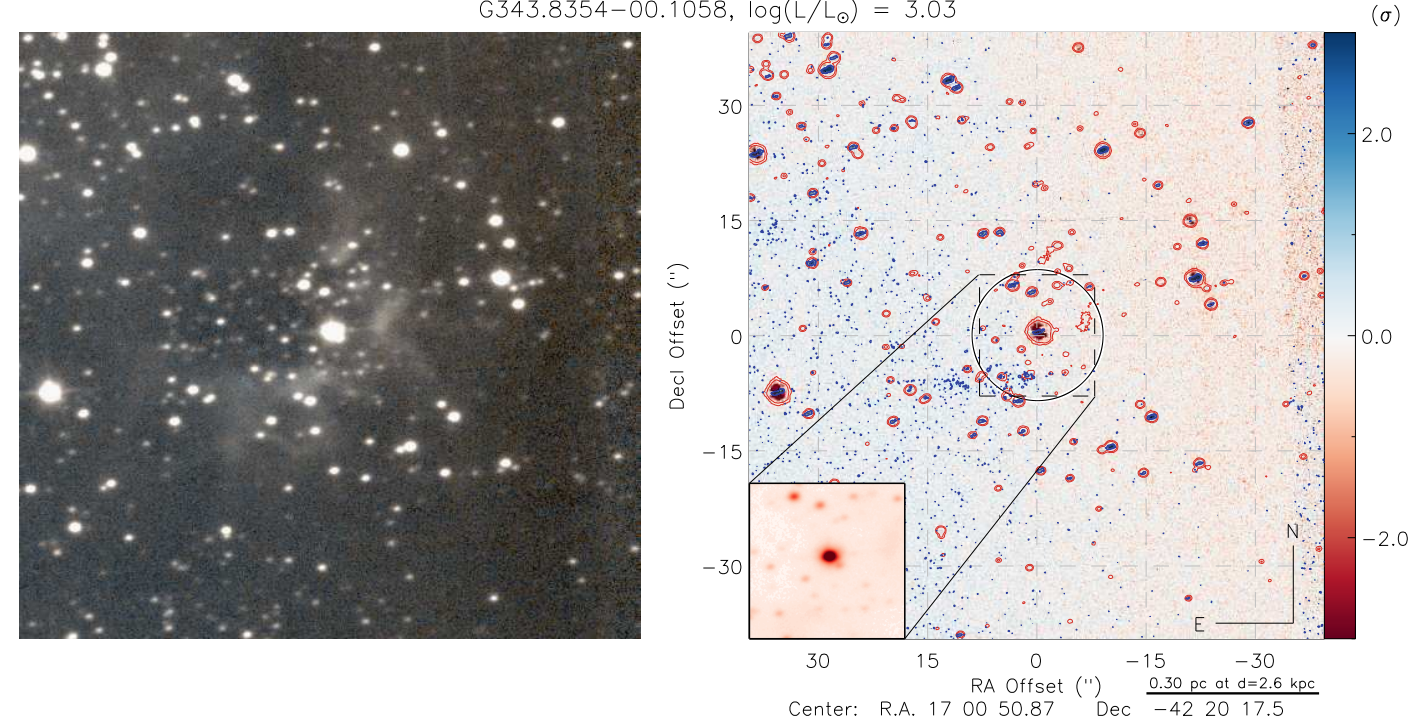
A.2 Fontes RMS sem Emissão Extensa em $\mathrm{H}_{2}$

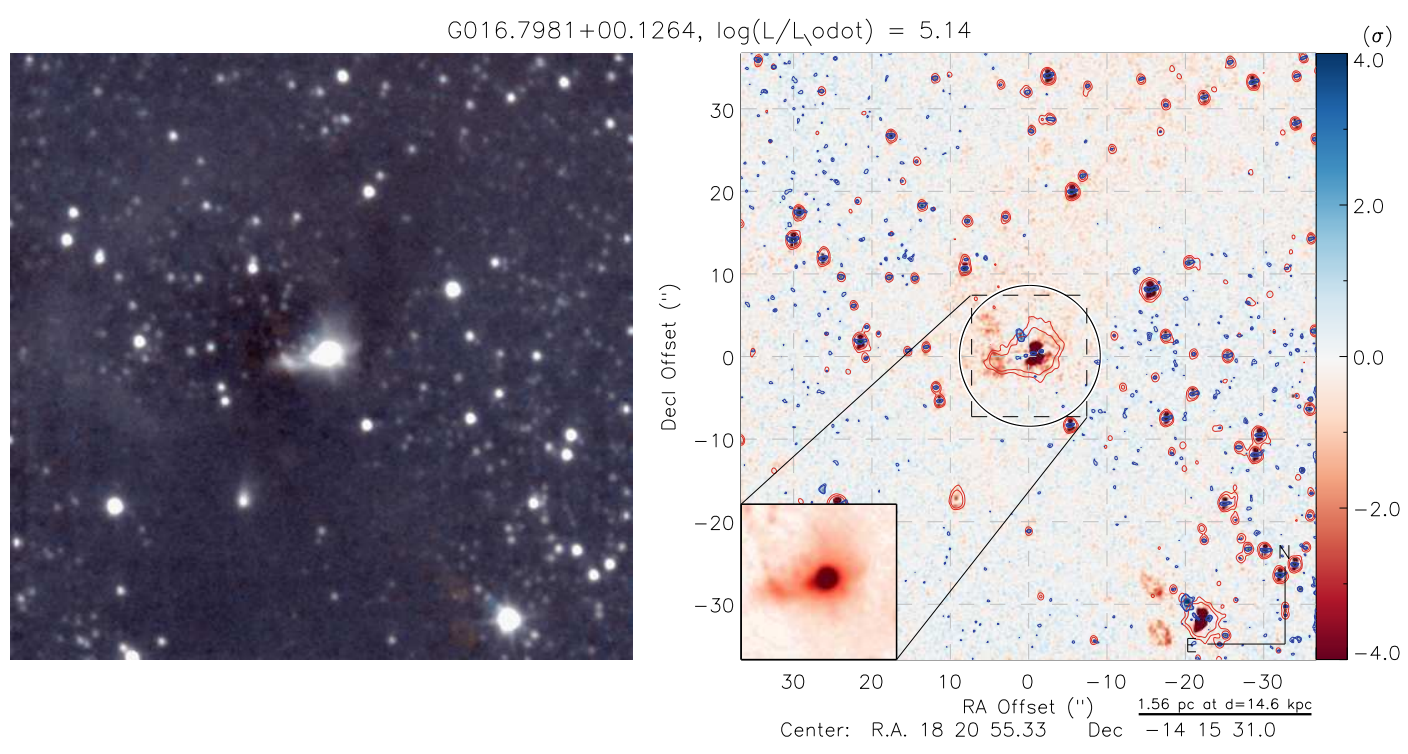

$\mathrm{G} 018.6608+00.0372, \log \left(L / L_{\odot}\right)=4.29$
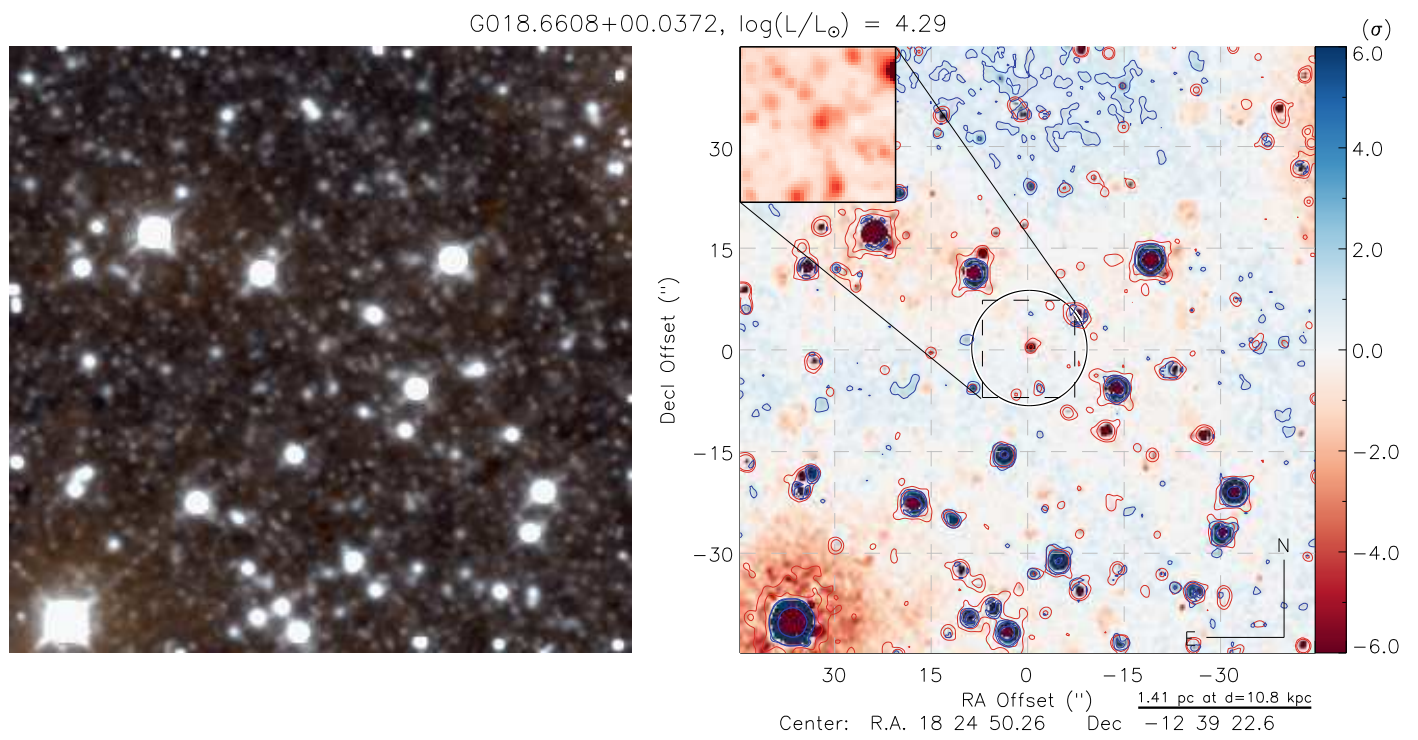

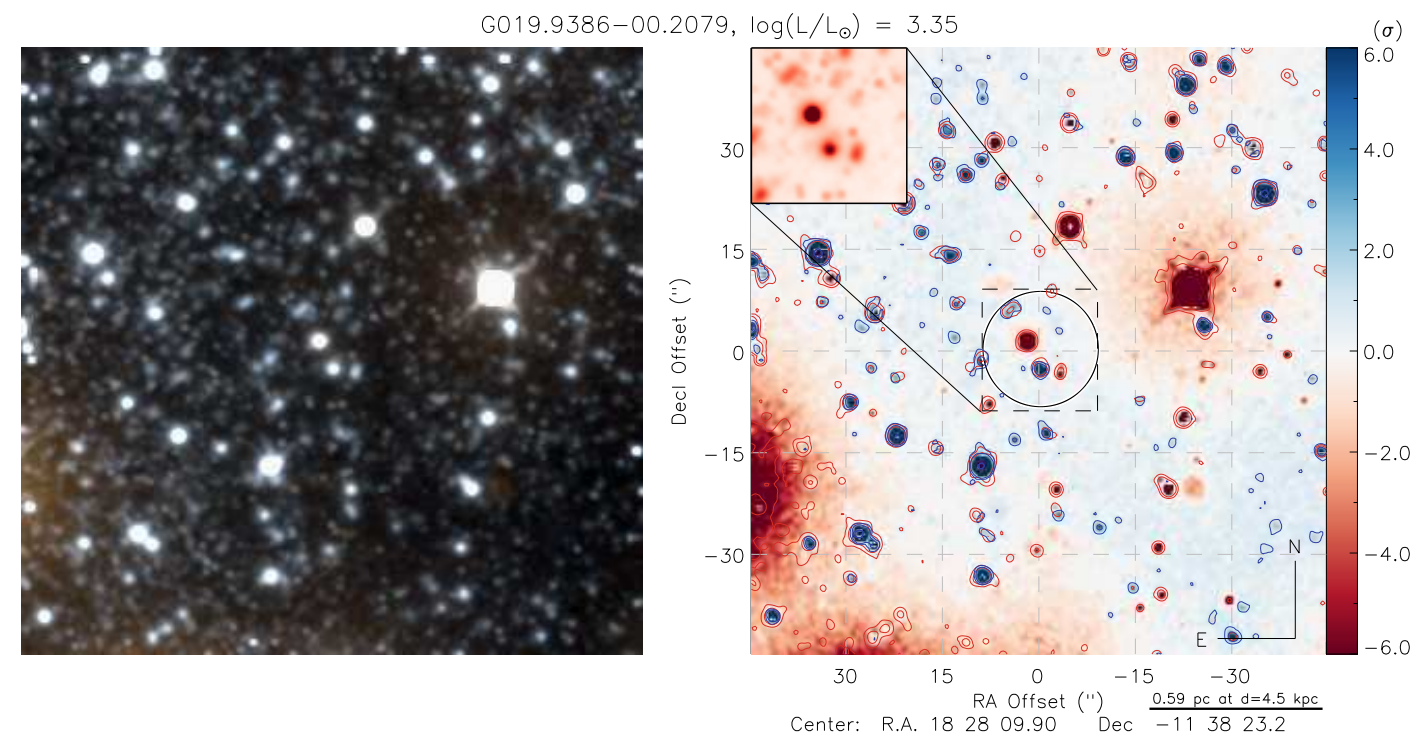

$\mathrm{G} 020.5143+00.4936, \log \left(L / L_{\odot}\right)=4.10$
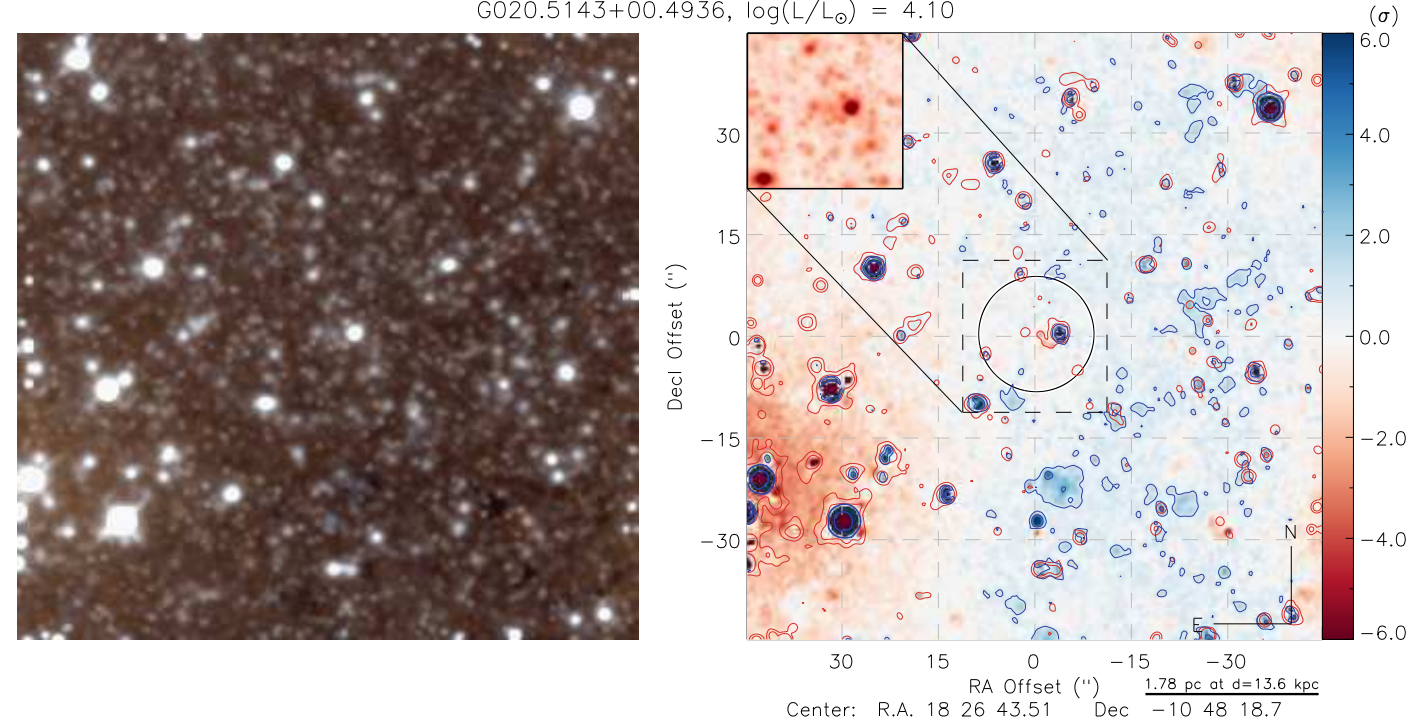

G022.3554+00.0655, $\log \left(L / L_{\odot}\right)=4.23$
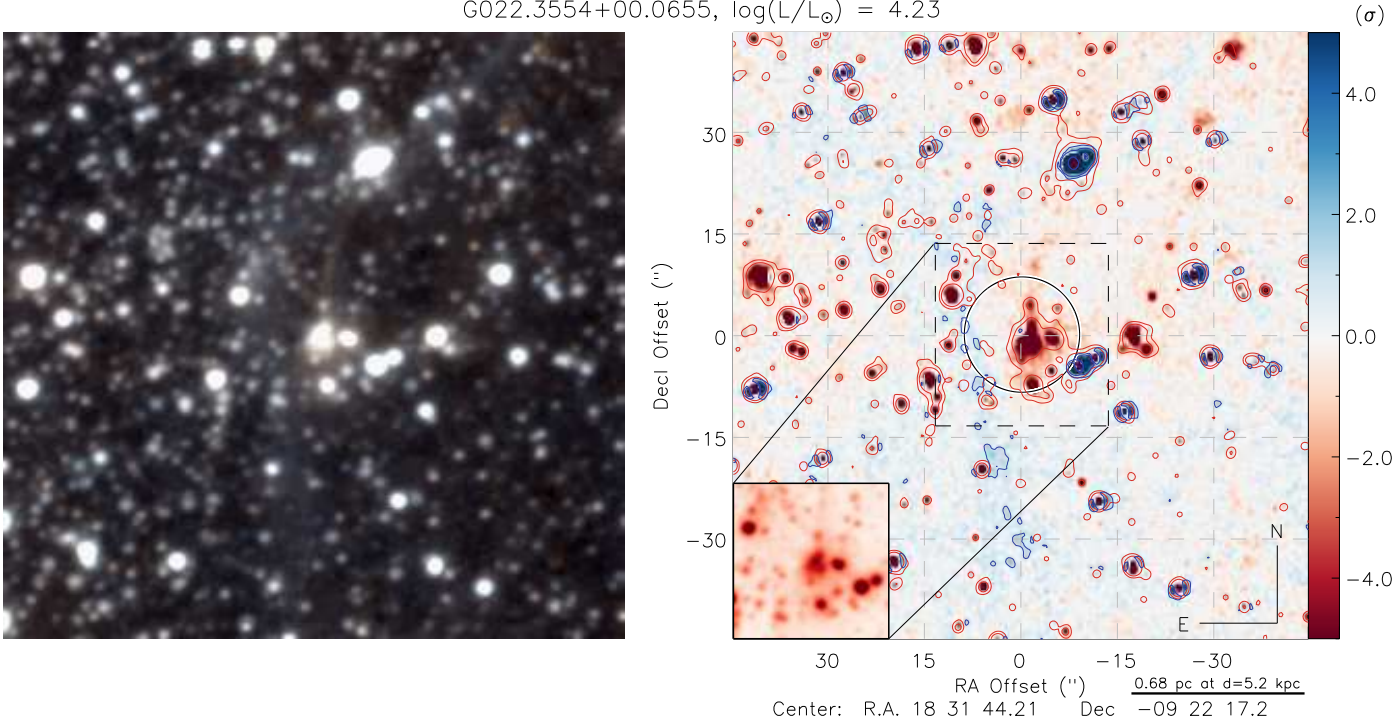

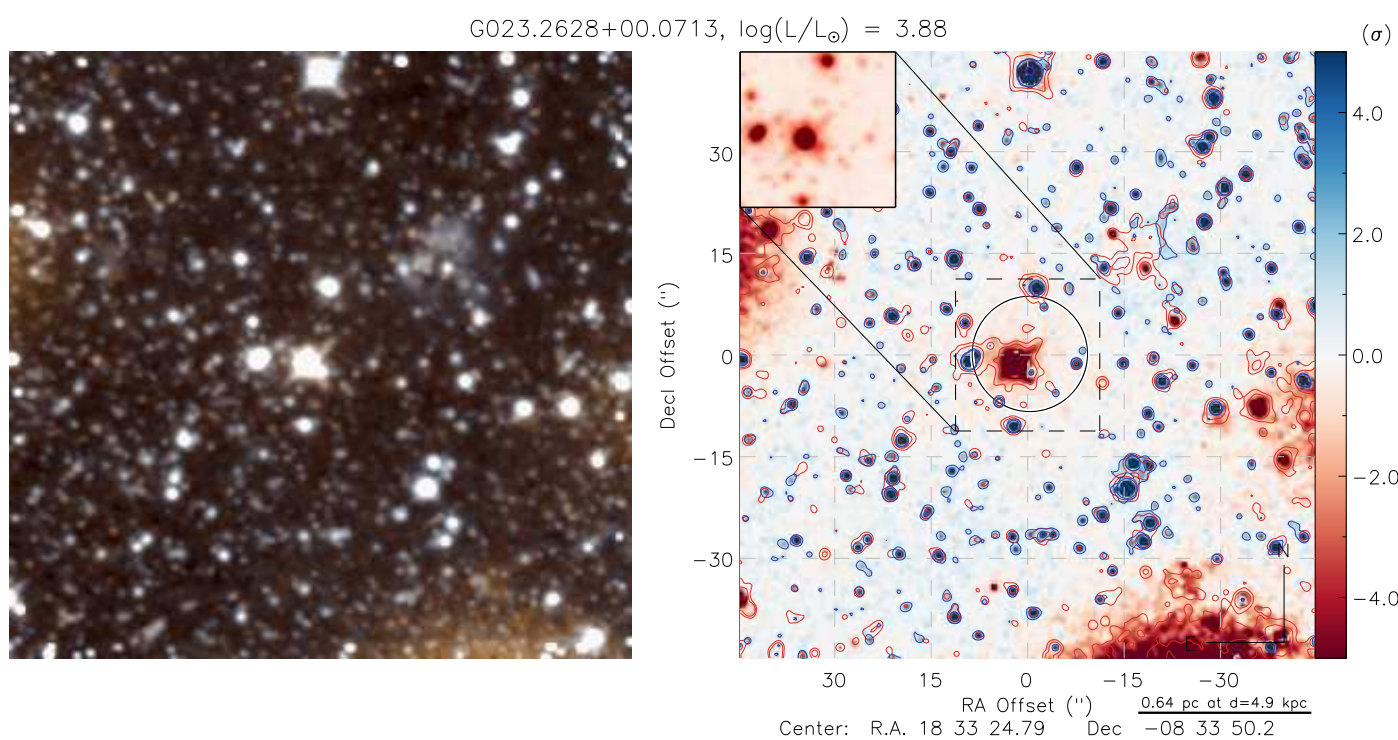

G023.4394-00.2394, $\log \left(L / L_{\odot}\right)=4.36$
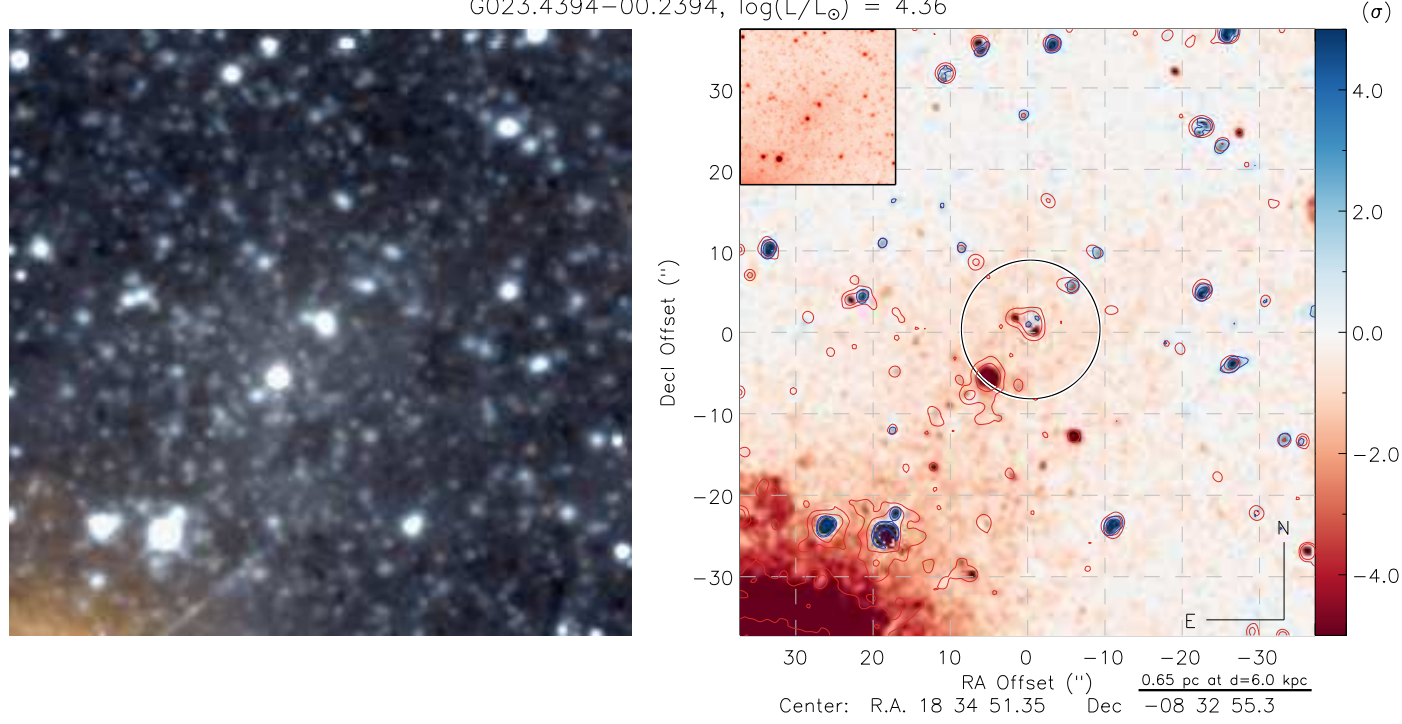

G023.6566-00.1273, $\log \left(L / L_{\odot}\right)=4.17$
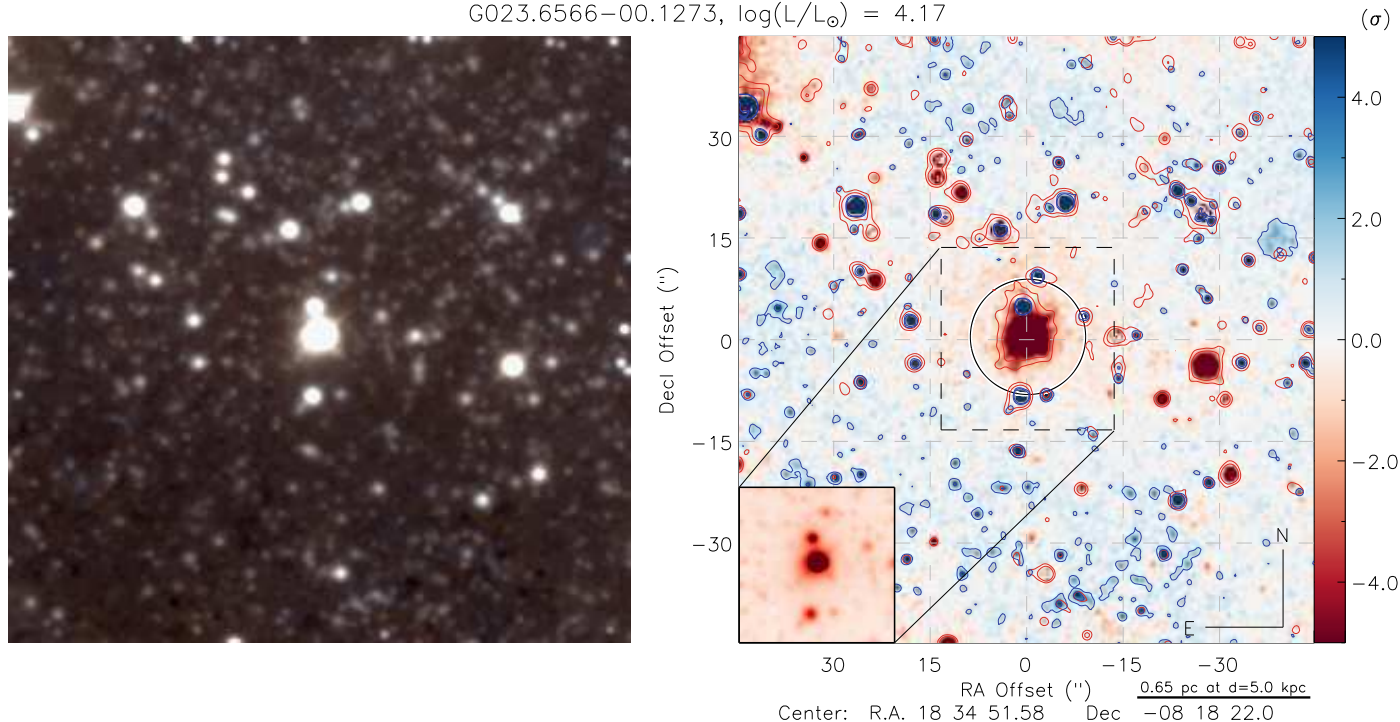

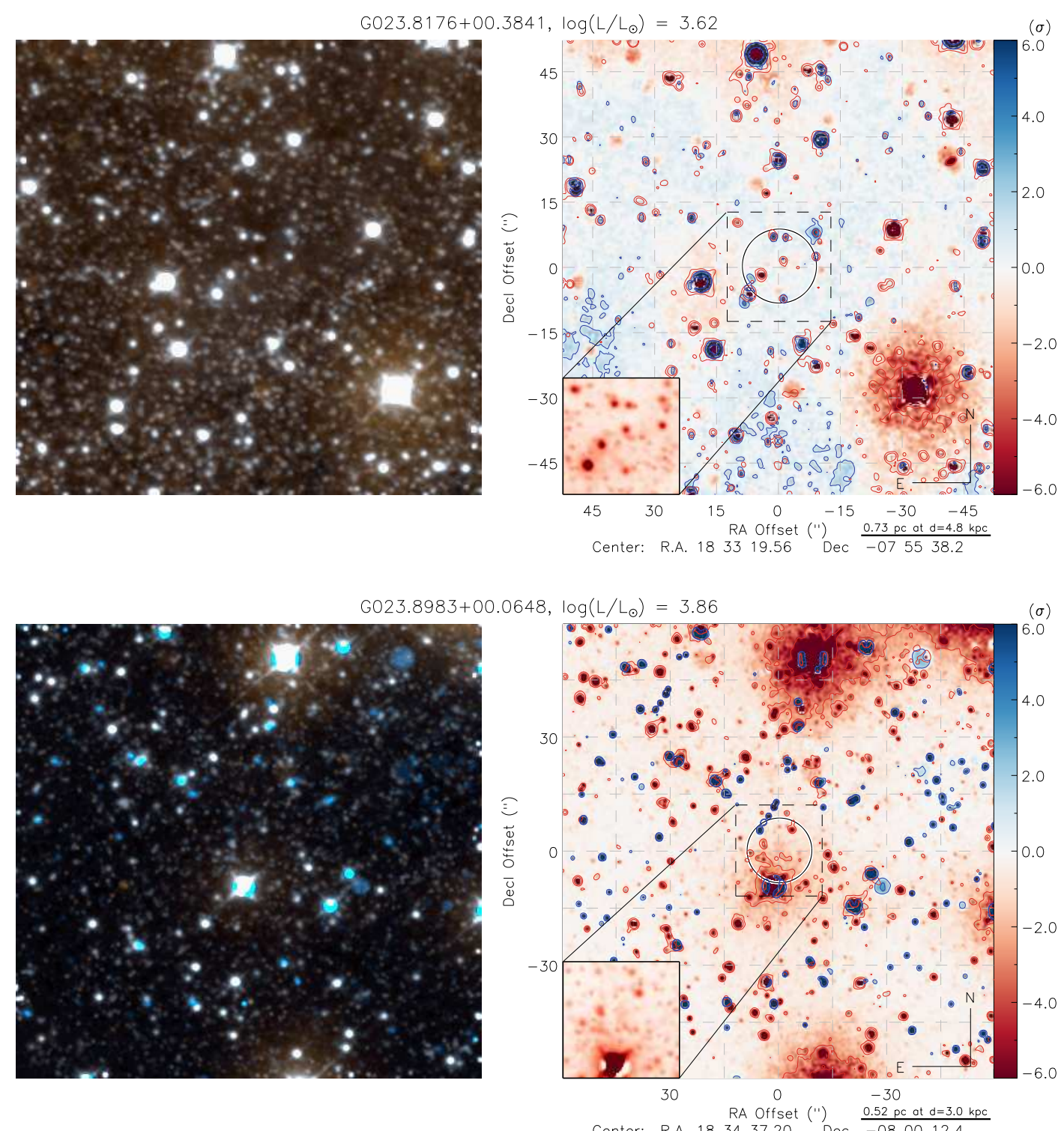

$6024.0946+00.4565, \log \left(L / L_{\odot}\right)=3.50$
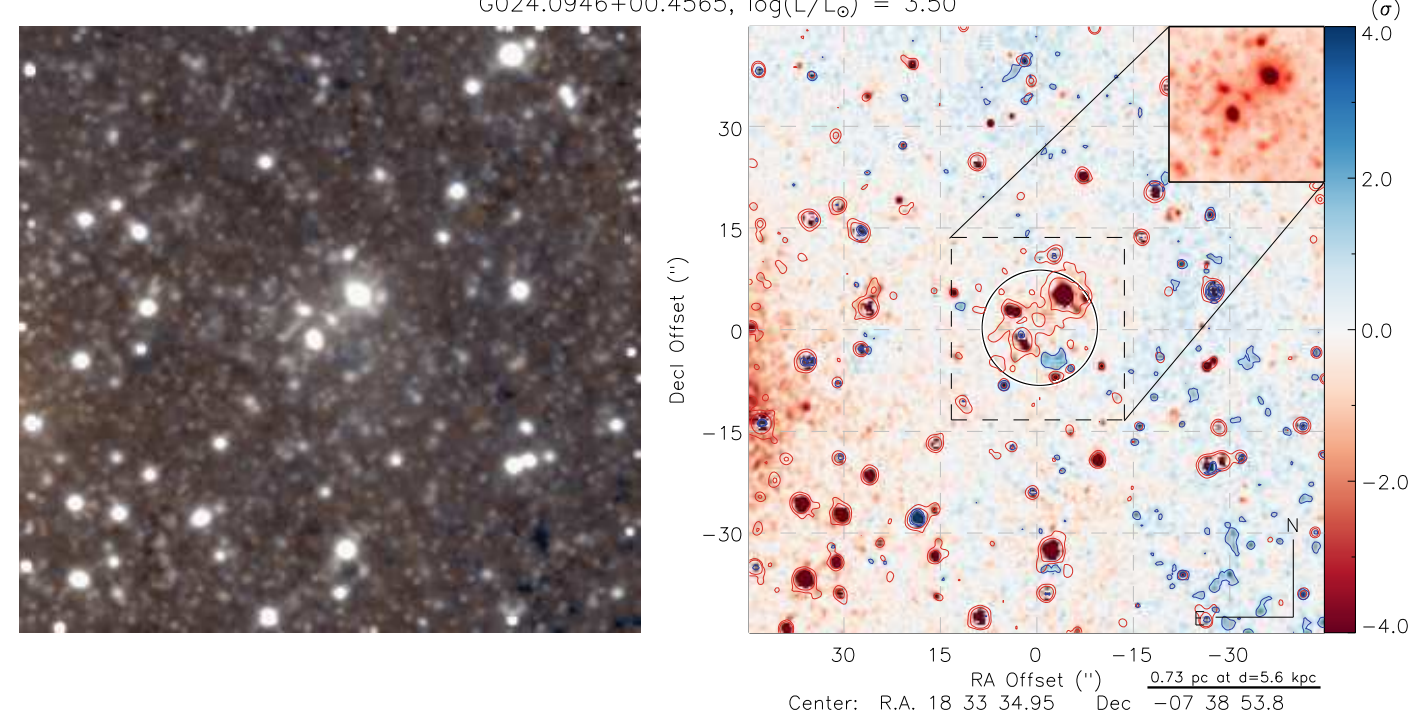
G024.6343-00.3233, $\log \left(L / L_{\odot}\right)=4.90$
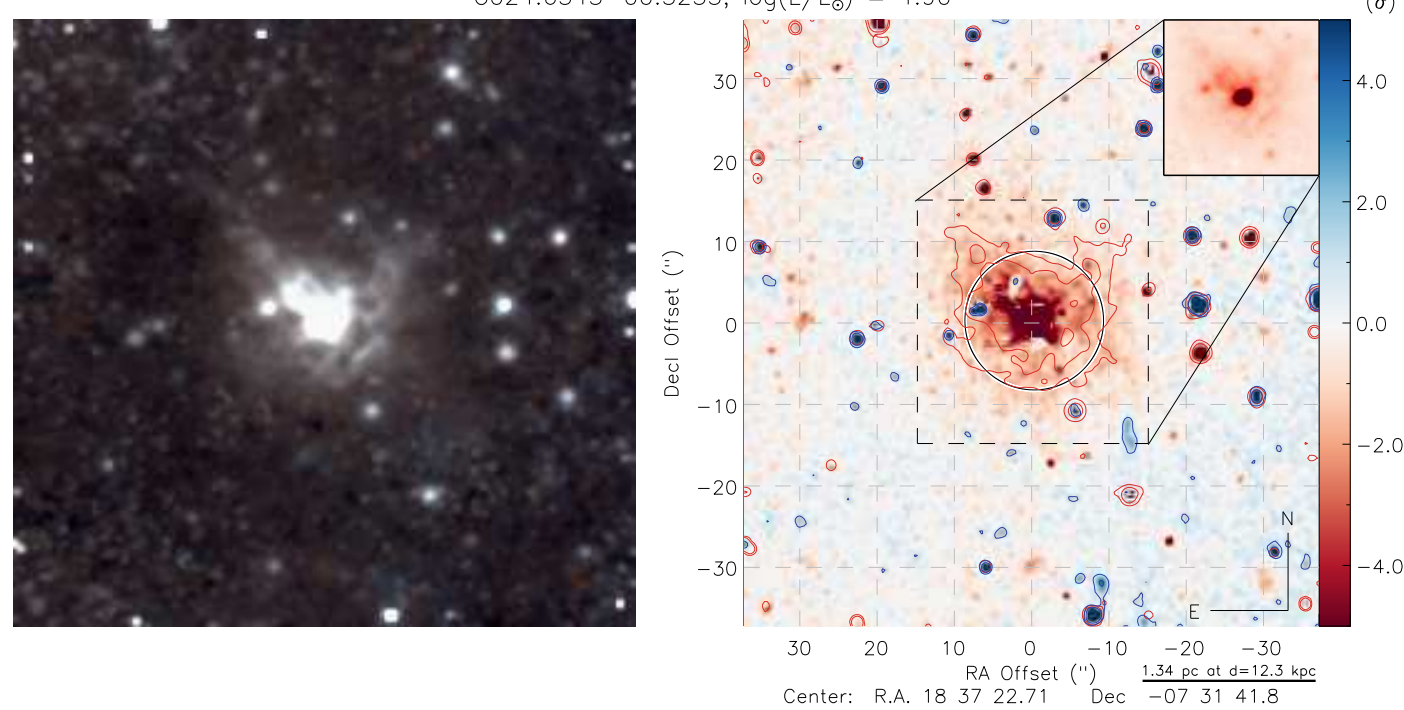

G024.7320+00.1530, $\log \left(L / L_{\odot}\right)=4.26$
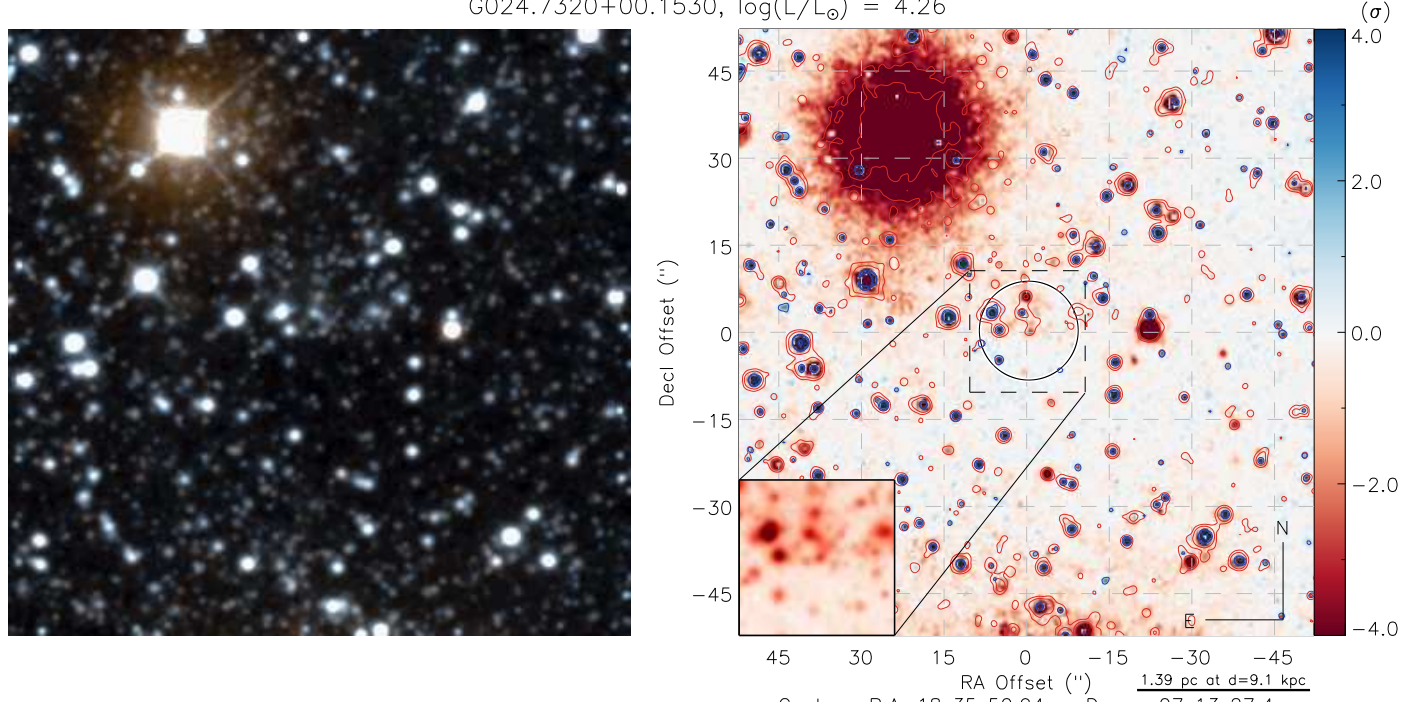

G025.4118+00.1052, $\log \left(L / L_{\odot}\right)=3.97$
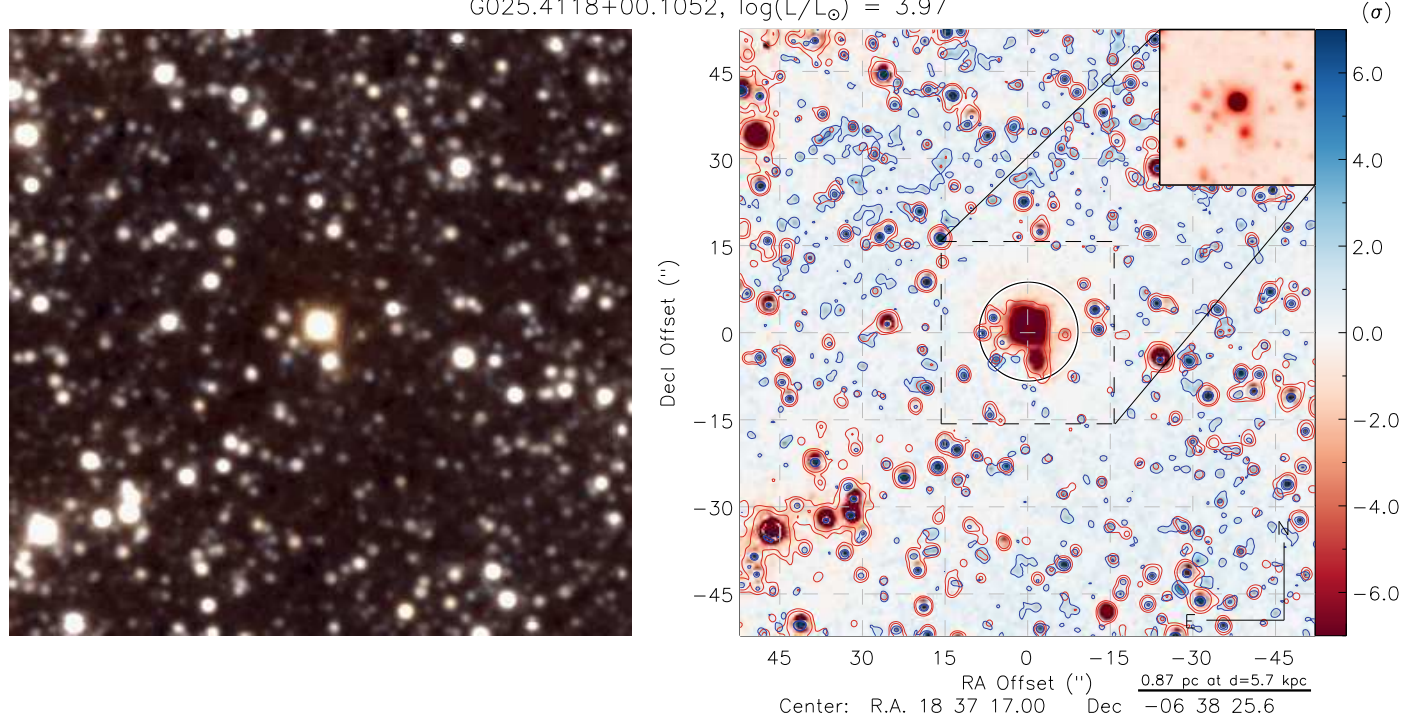

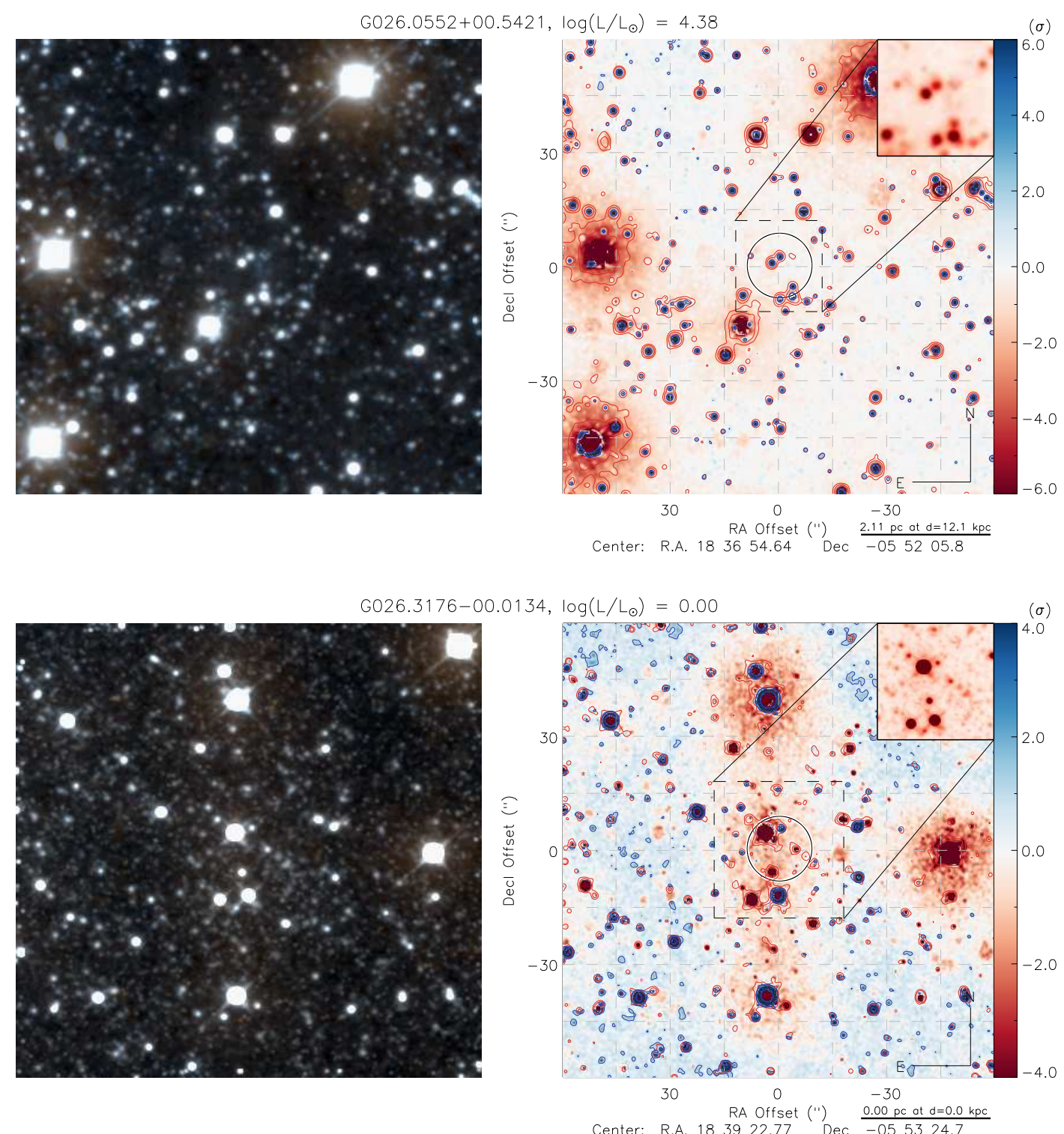

G026.5254-00.2667, $\log \left(L / L_{\odot}\right)=3.72$
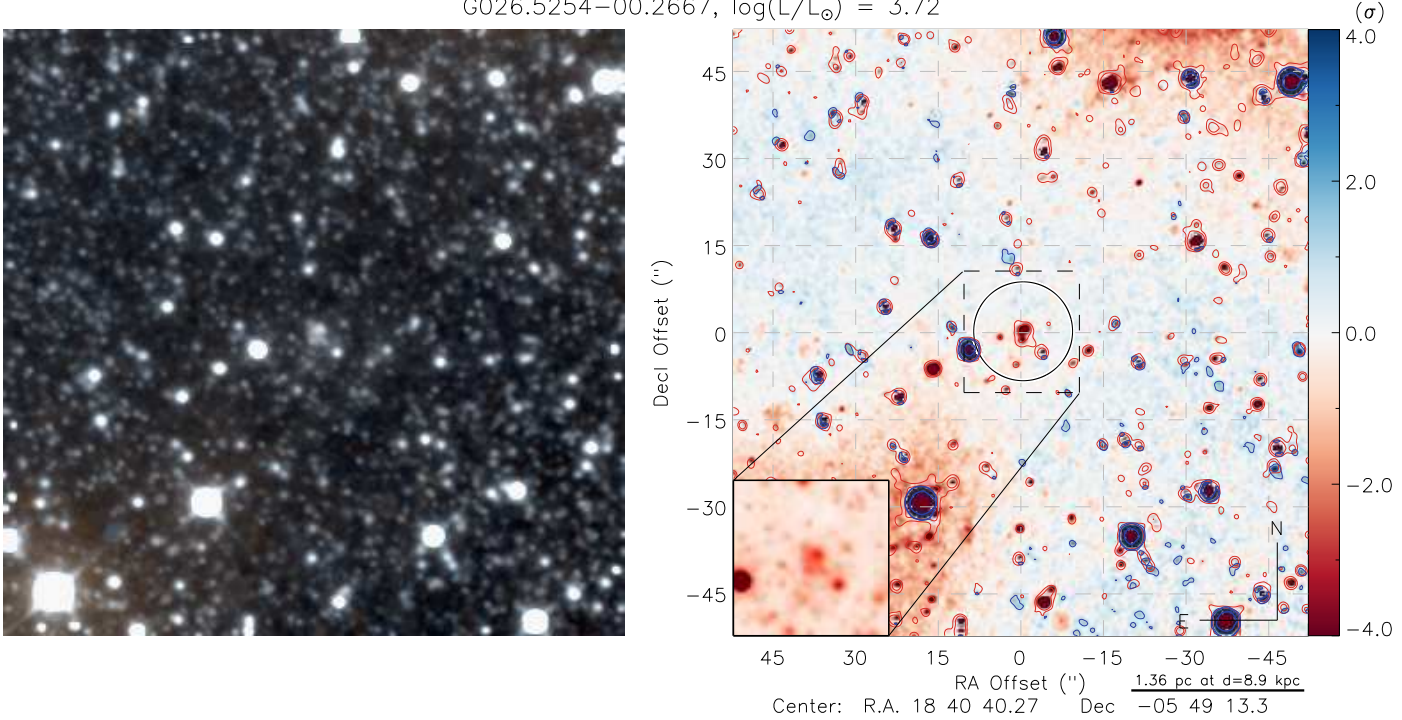
G026.6085-00.2122, $\log \left(\mathrm{L} / \mathrm{L}_{\odot}\right)=4.48$
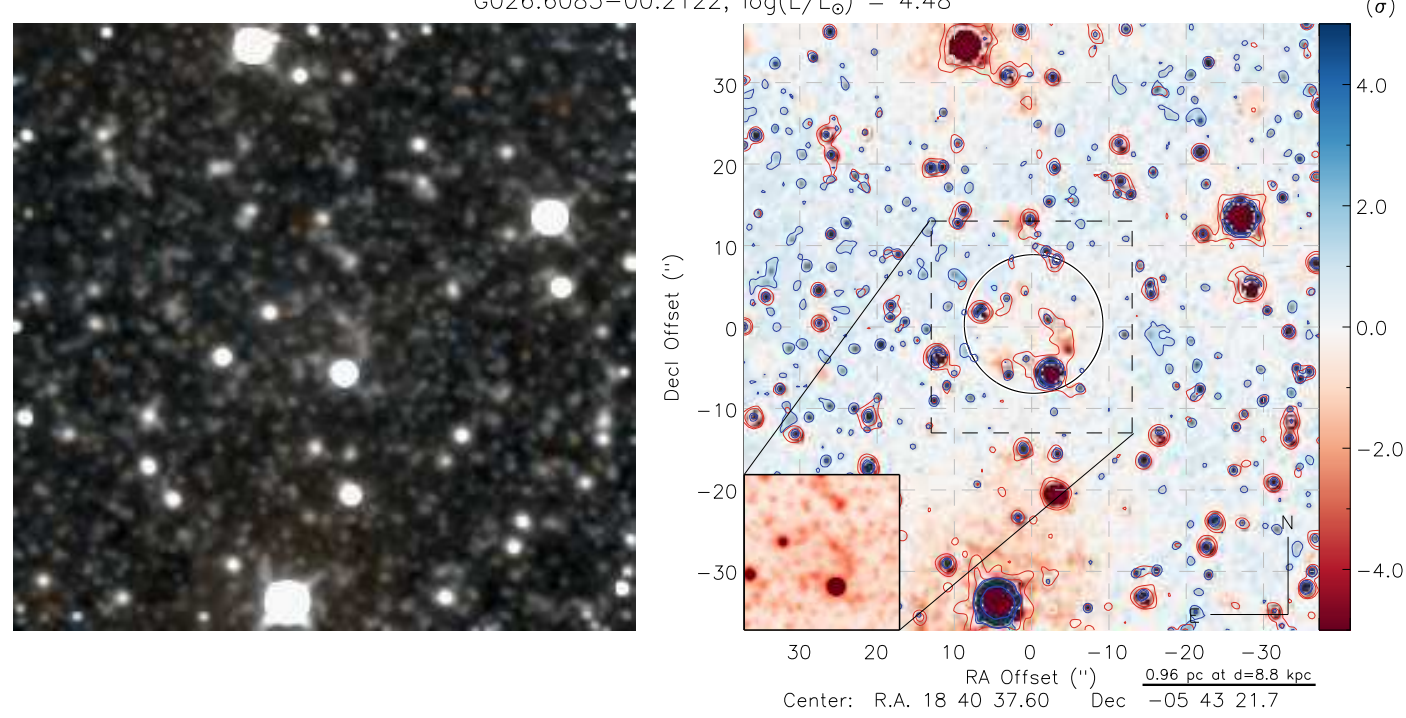

G027.1852-00.0812, $\log \left(L / L_{\odot}\right)=3.35$
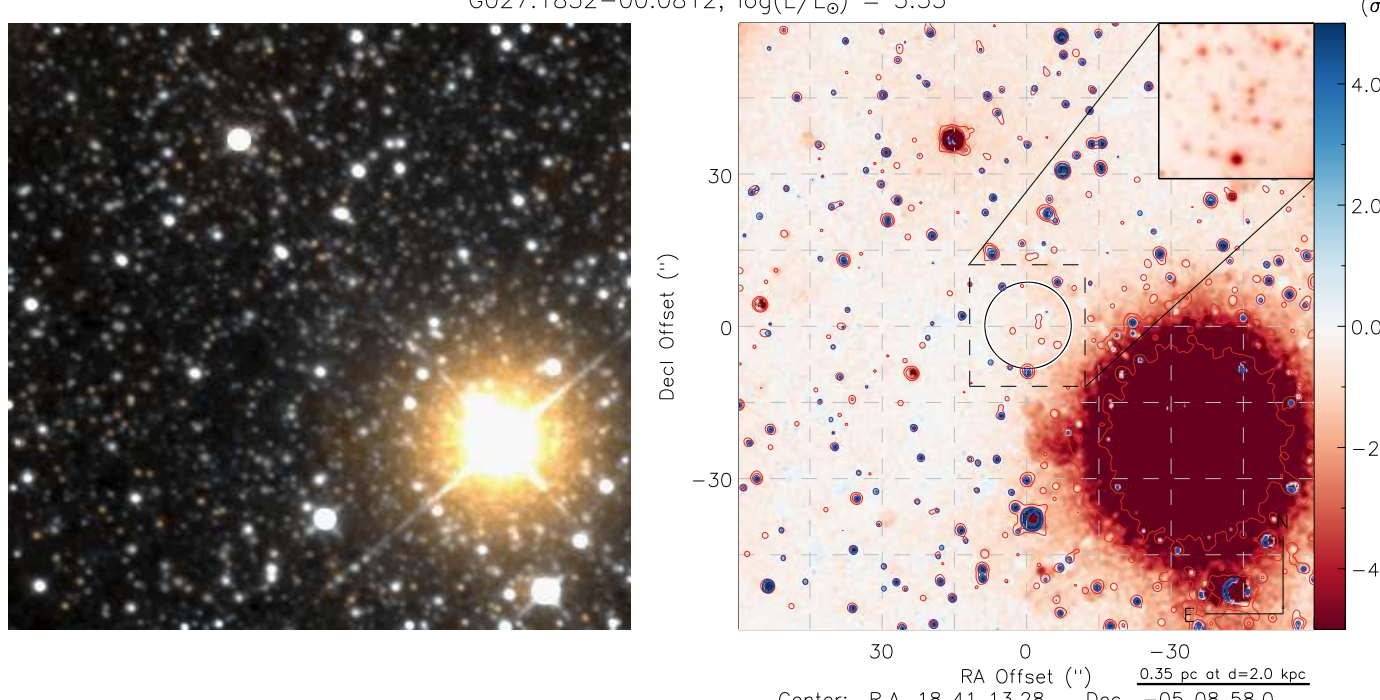

G029.5904-00.6144, $\log \left(L / L_{\odot}\right)=4.25$
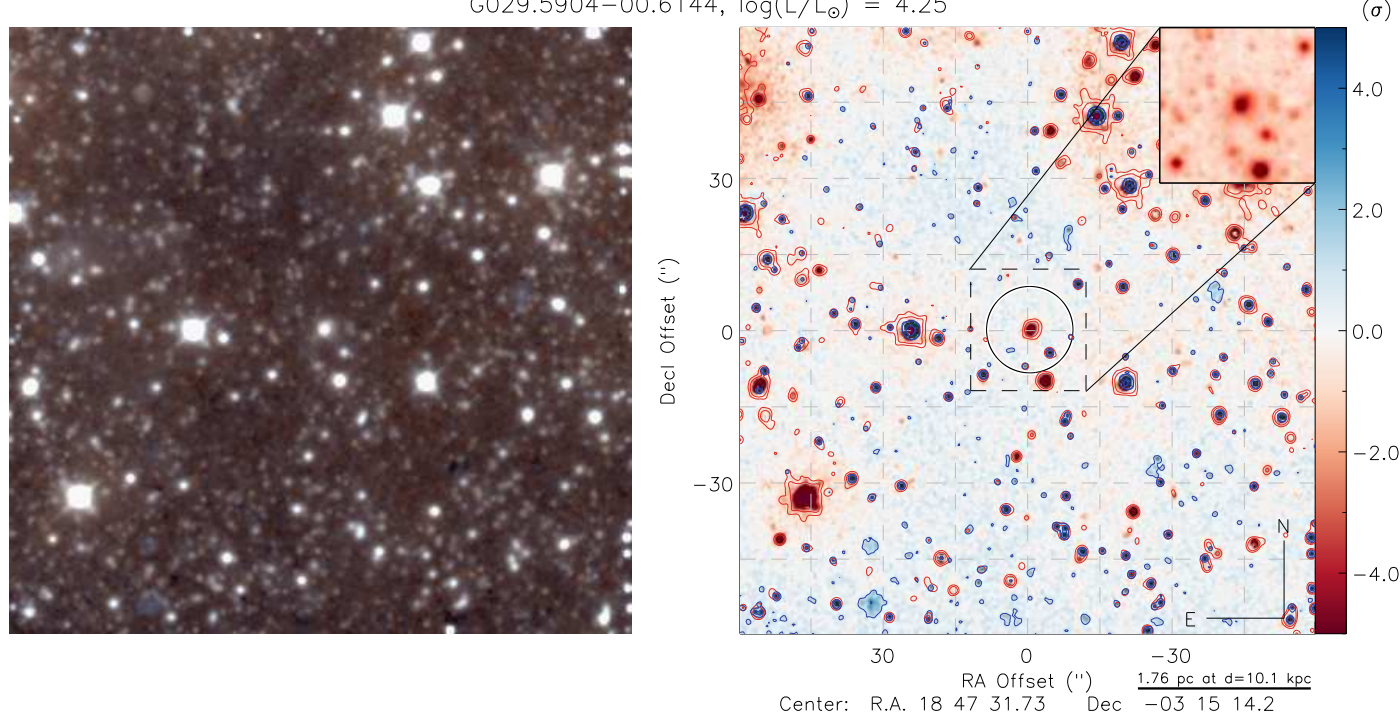
$\mathrm{G} 030.2971+00.0549, \log \left(L / L_{\odot}\right)=4.31$
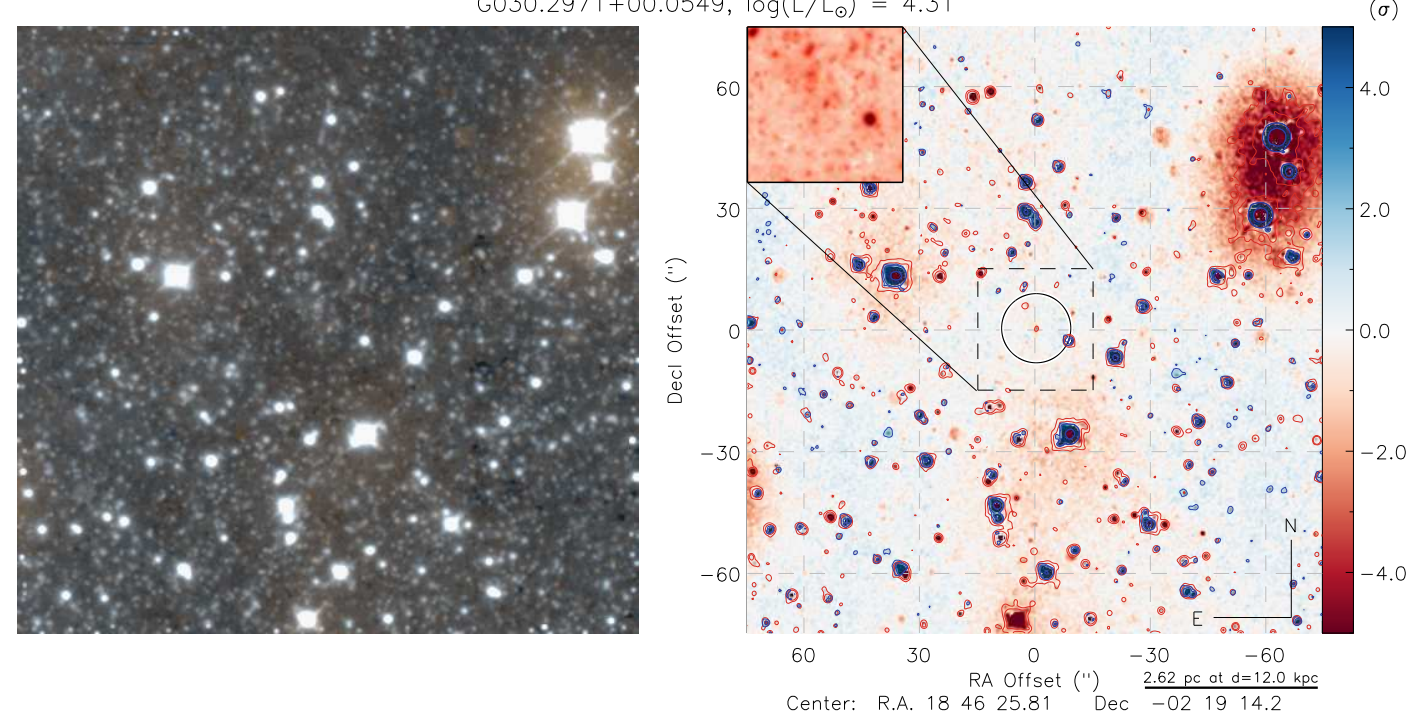

$\mathrm{G} 030.8185+00.2729, \log \left(\mathrm{L} / \mathrm{L}_{\odot}\right)=4.09$
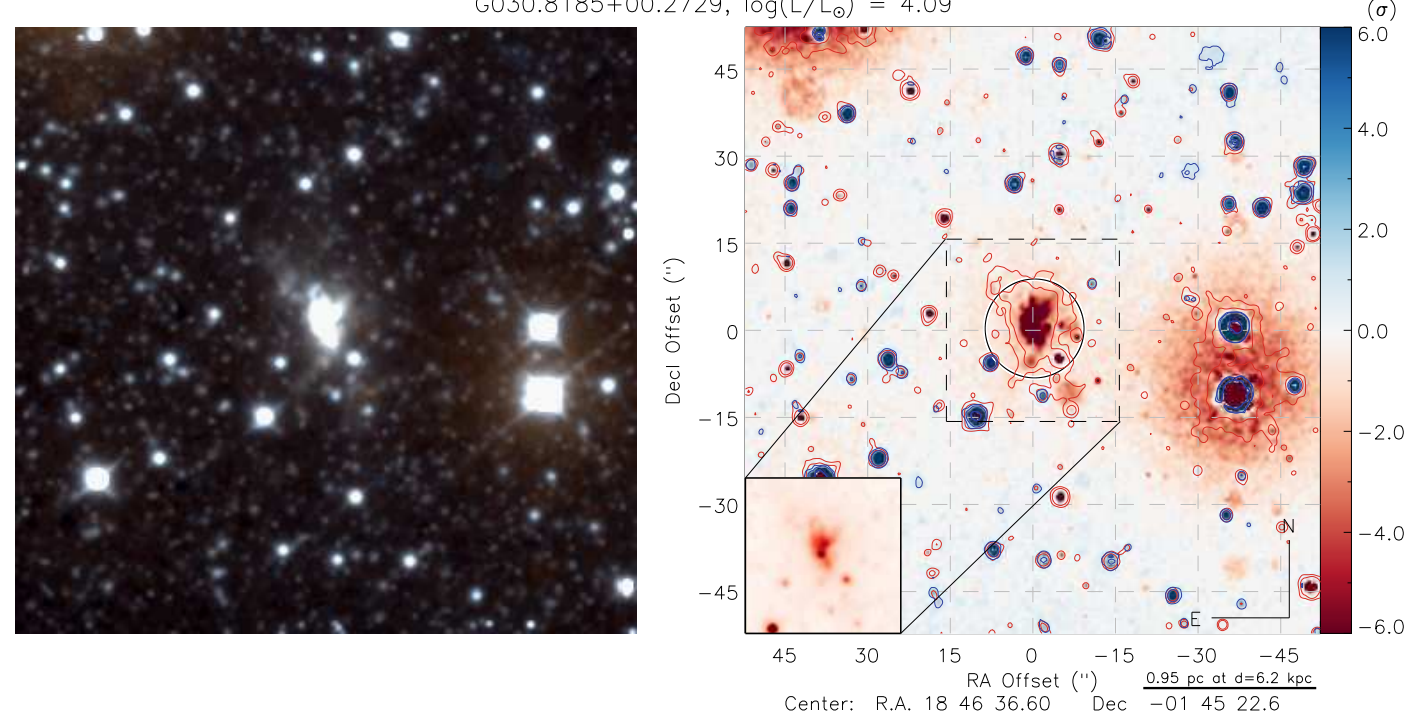

G030.9959-00.0771, $\log \left(L / L_{\odot}\right)=4.21$
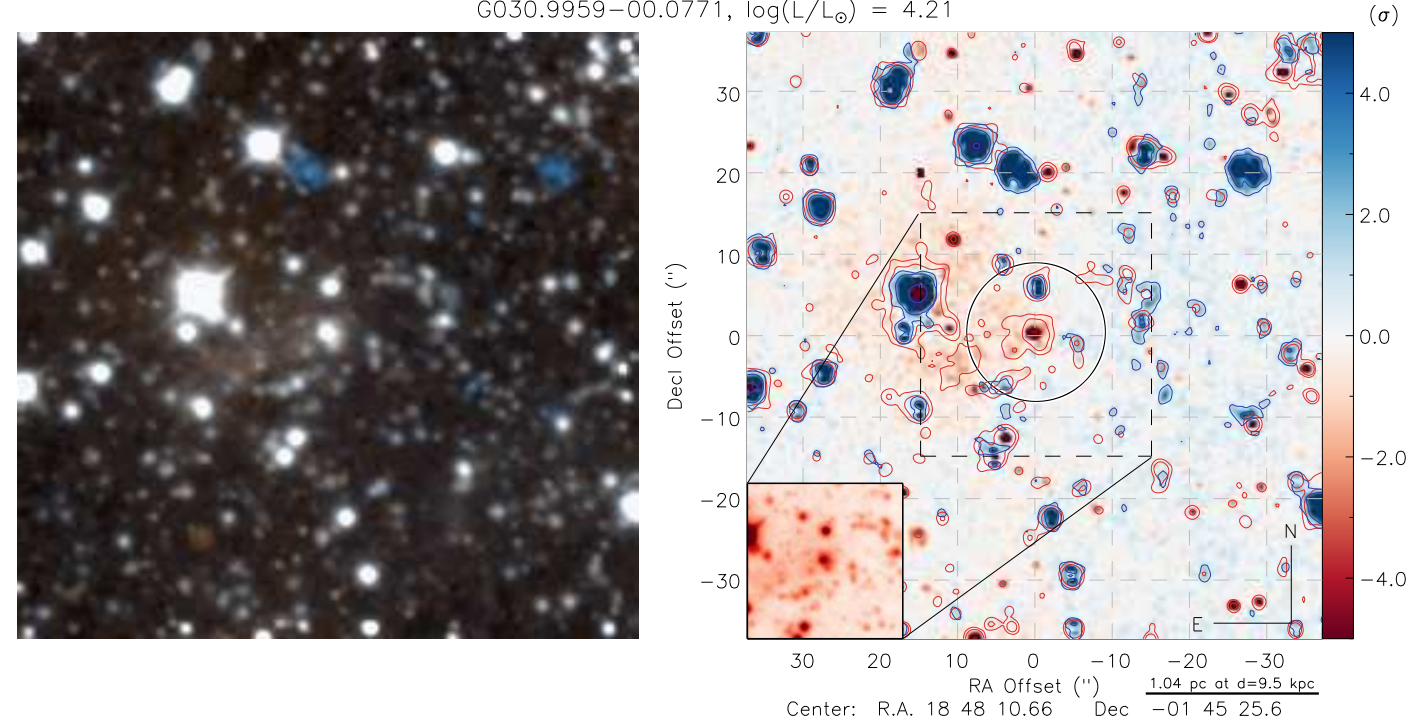
$\mathrm{G} 031.1593+00.0456, \log \left(\mathrm{L} / \mathrm{L}_{\odot}\right)=4.06$
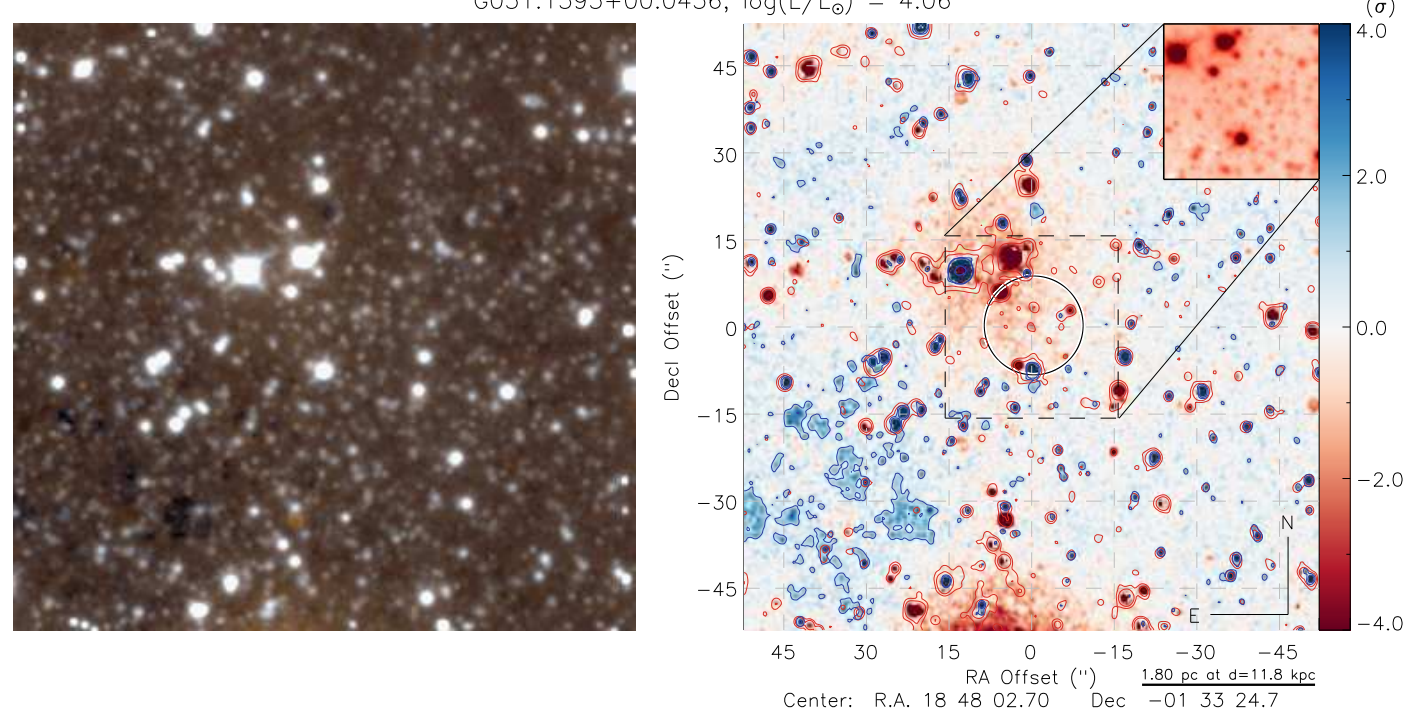

G033.3891+00.1989, $\log \left(L / L_{\odot}\right)=4.08$
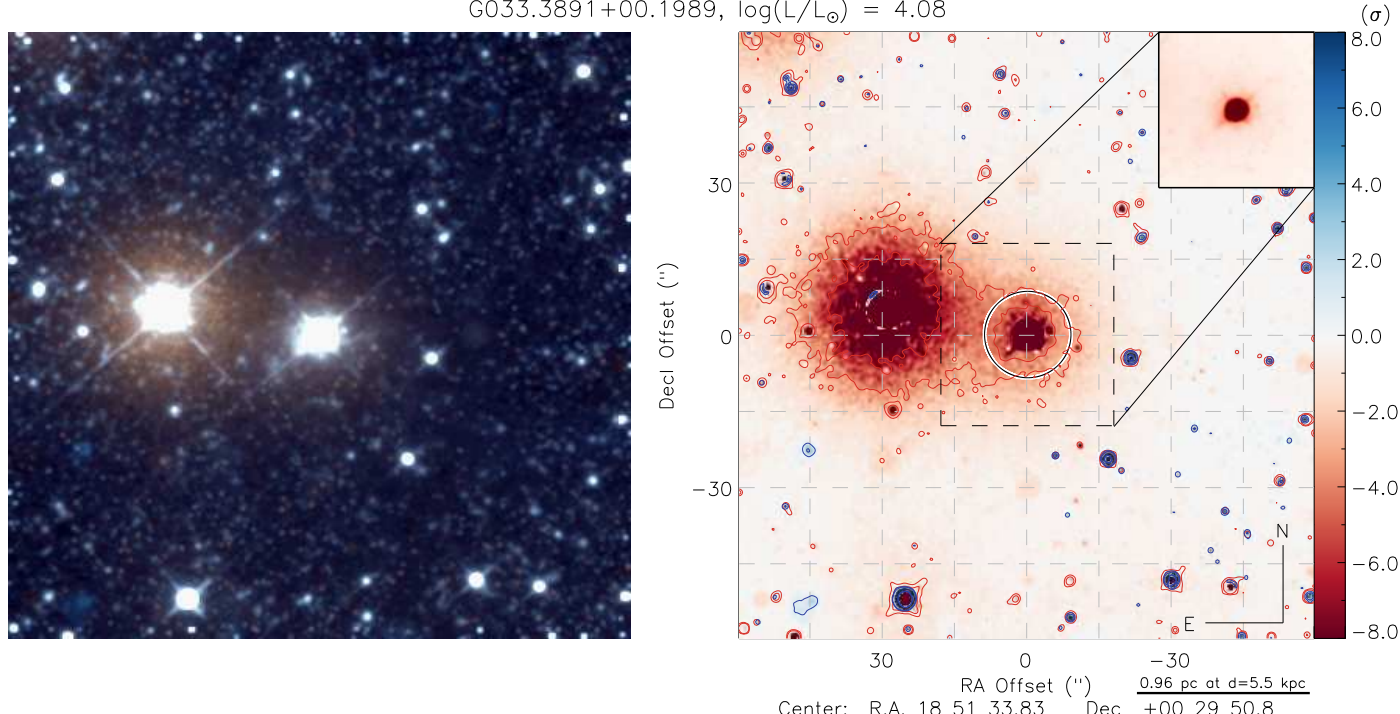

$\mathrm{G} 033.3933+00.0100, \log \left(\mathrm{L} / \mathrm{L}_{\odot}\right)=4.17$
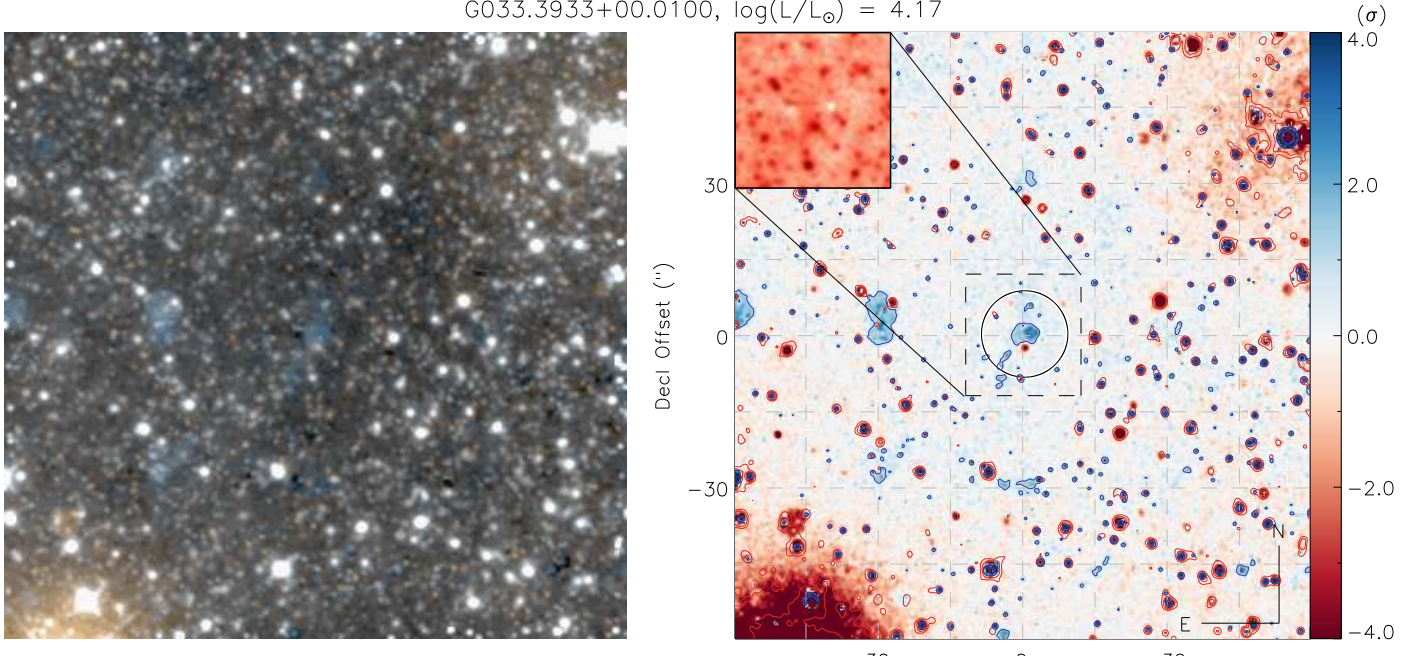

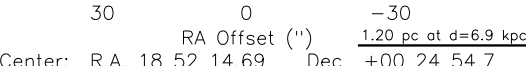


$6033.5237+00.0198, \log \left(L / L_{\odot}\right)=3.98$
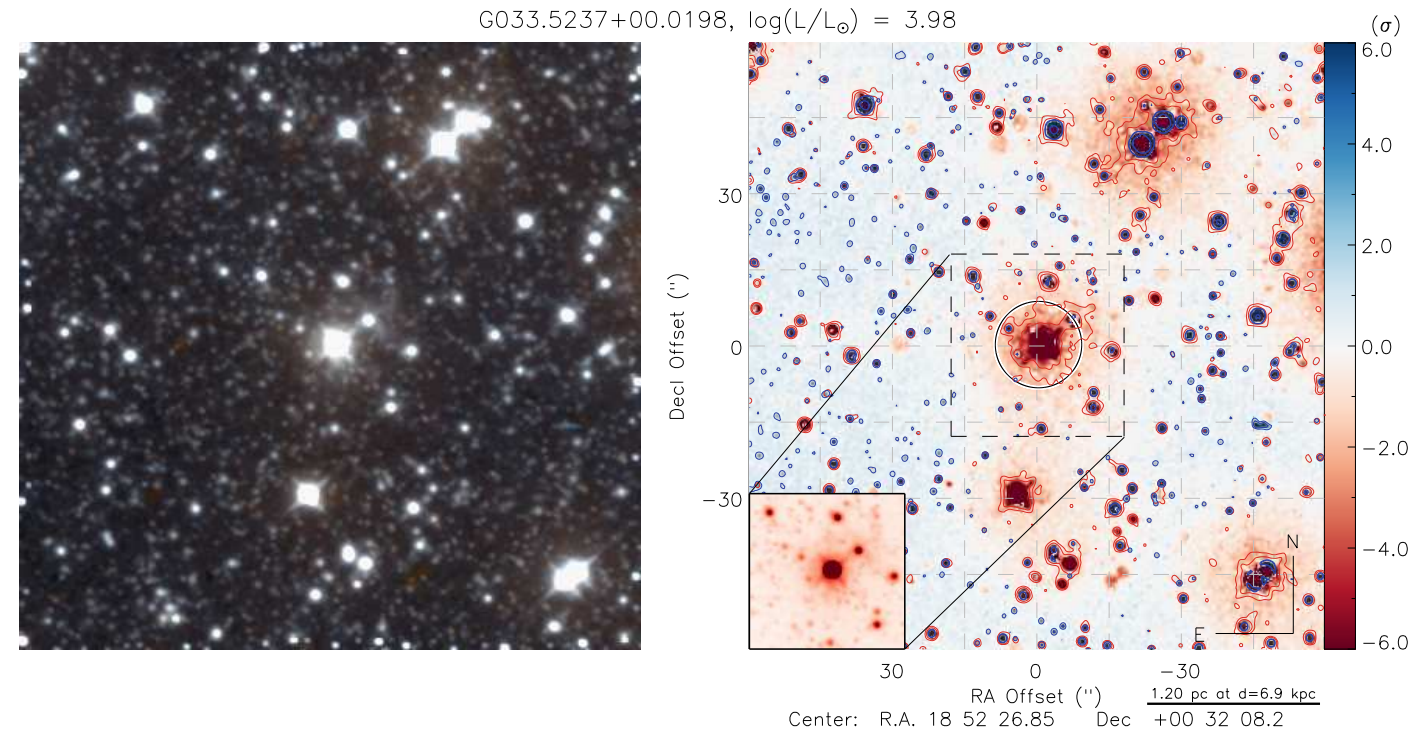

G035.8546+00.2663, $\log \left(L / L_{\odot}\right)=3.12$
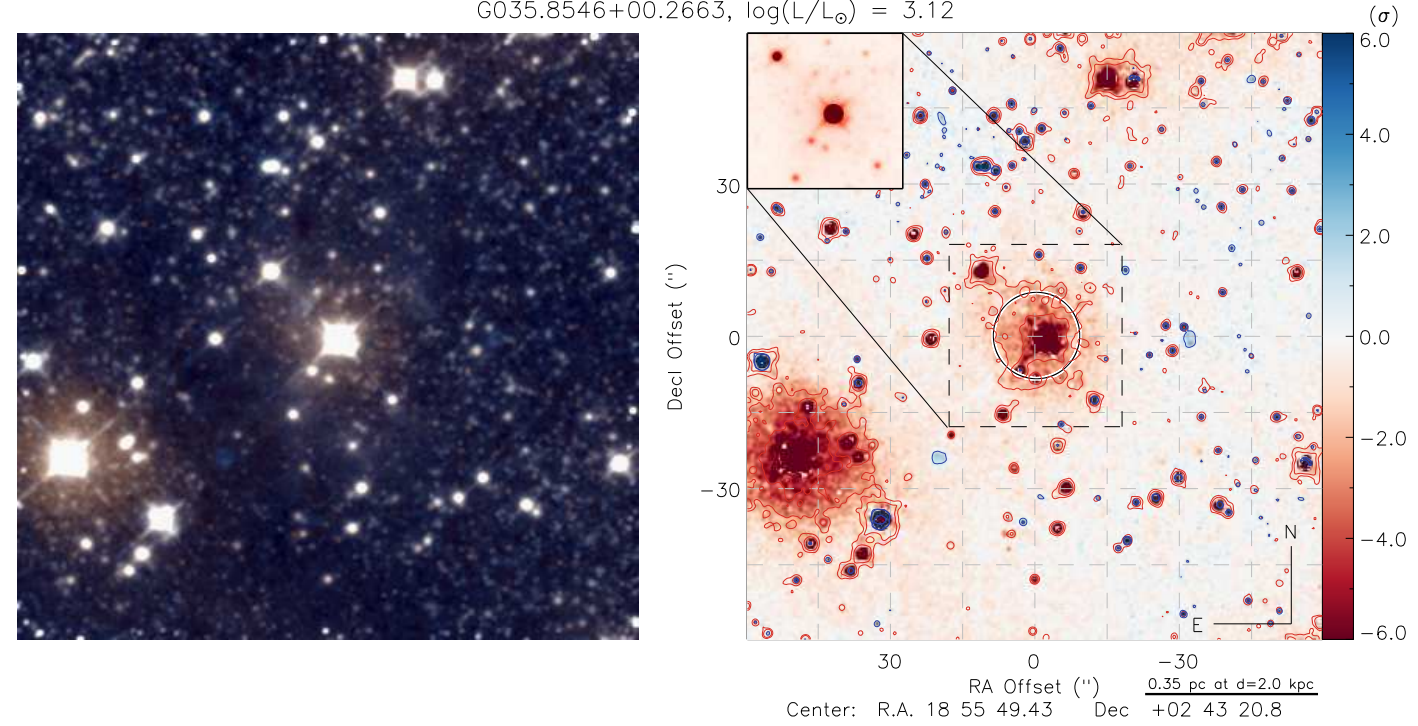

$\mathrm{G} 036.9194+00.4825, \log \left(L / L_{\odot}\right)=4.00$
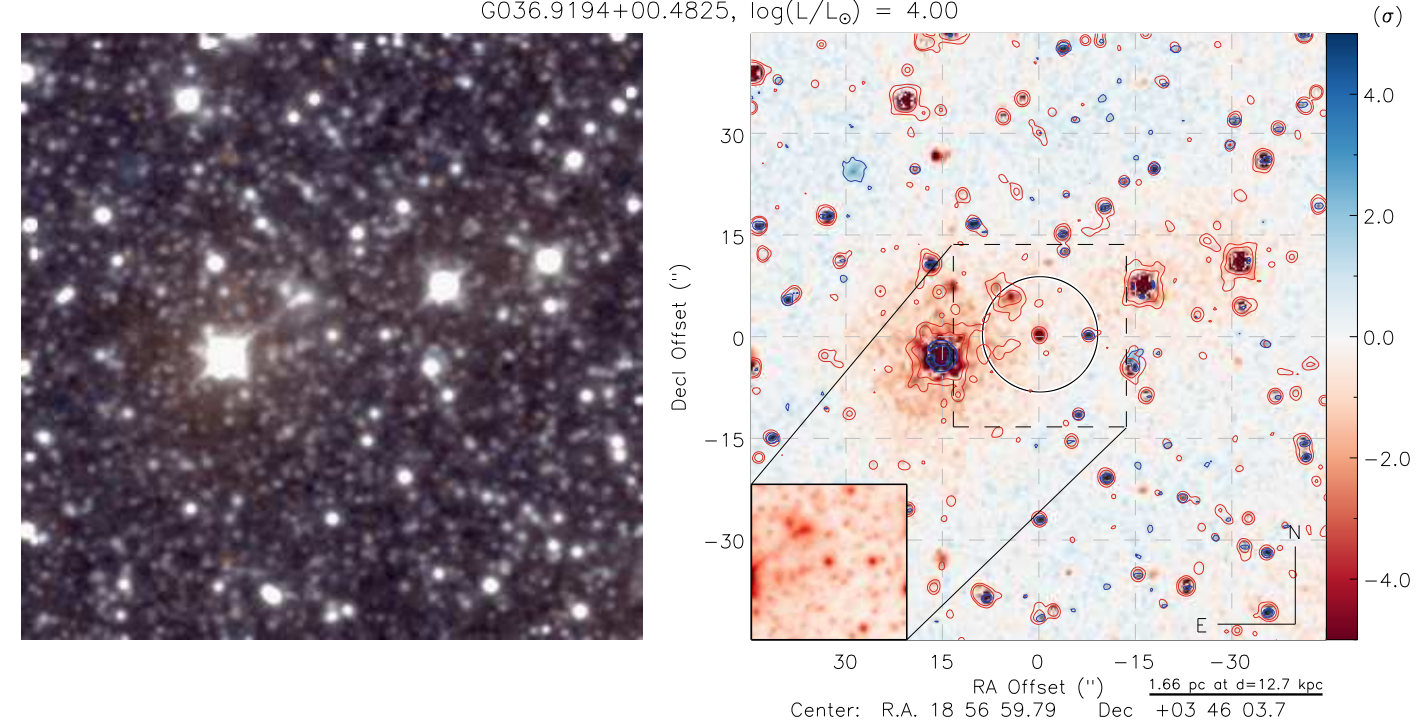
G037.3412-00.0600, $\log \left(L / L_{\odot}\right)=4.19$
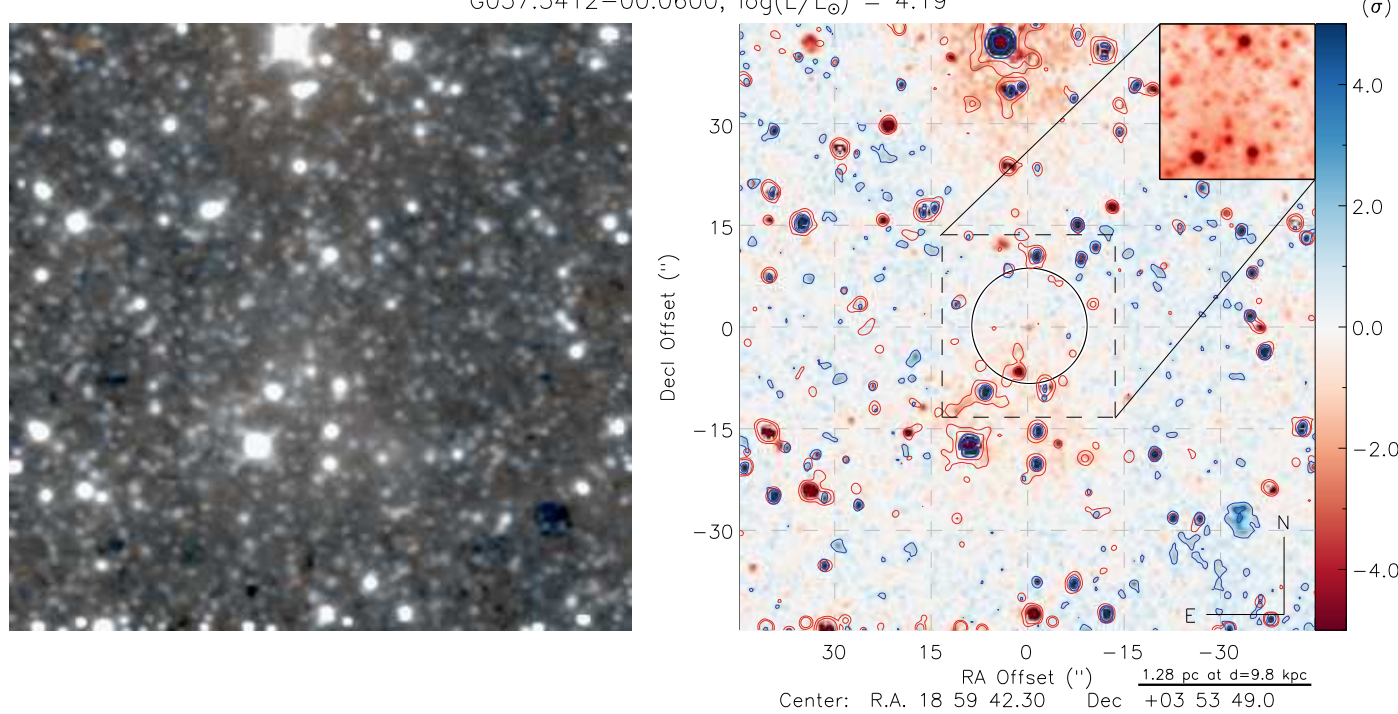

G037.4974+00.5301, $\log \left(L / L_{\odot}\right)=2.12$
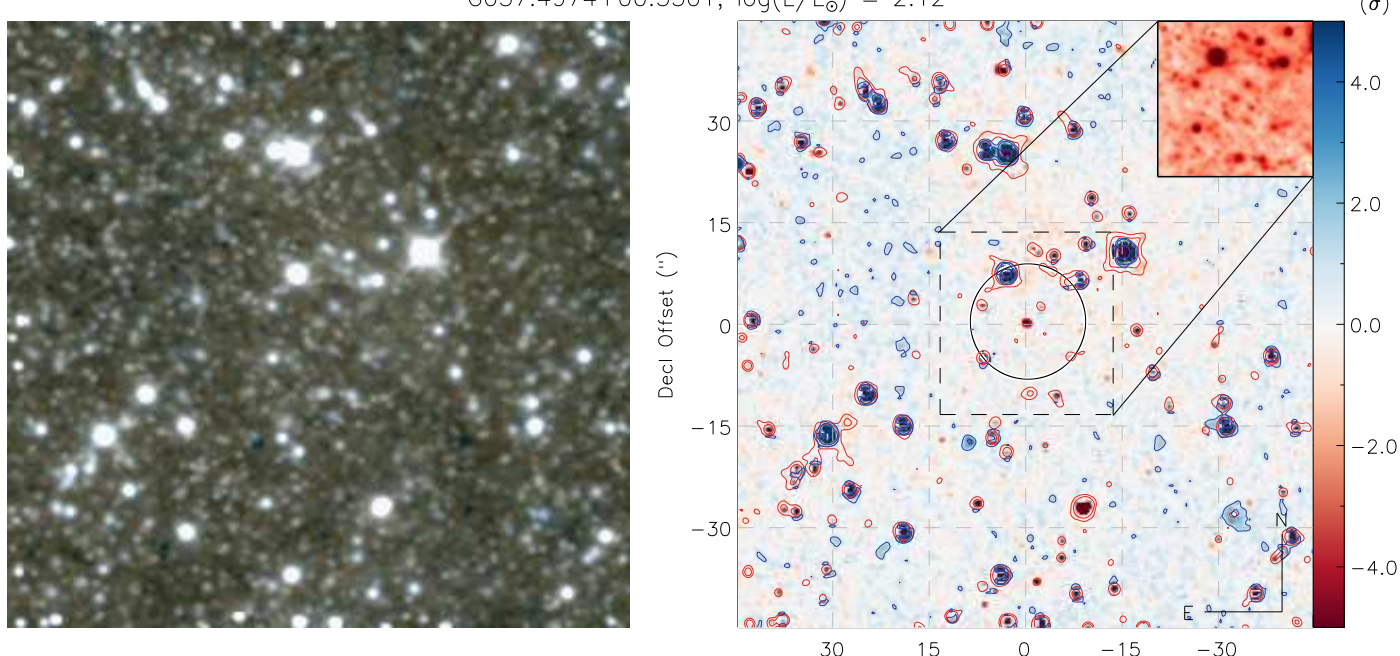

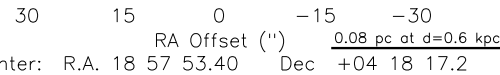

G039.3880-00.1421, $\log \left(\mathrm{L} / \mathrm{L}_{\odot}\right)=3.38$
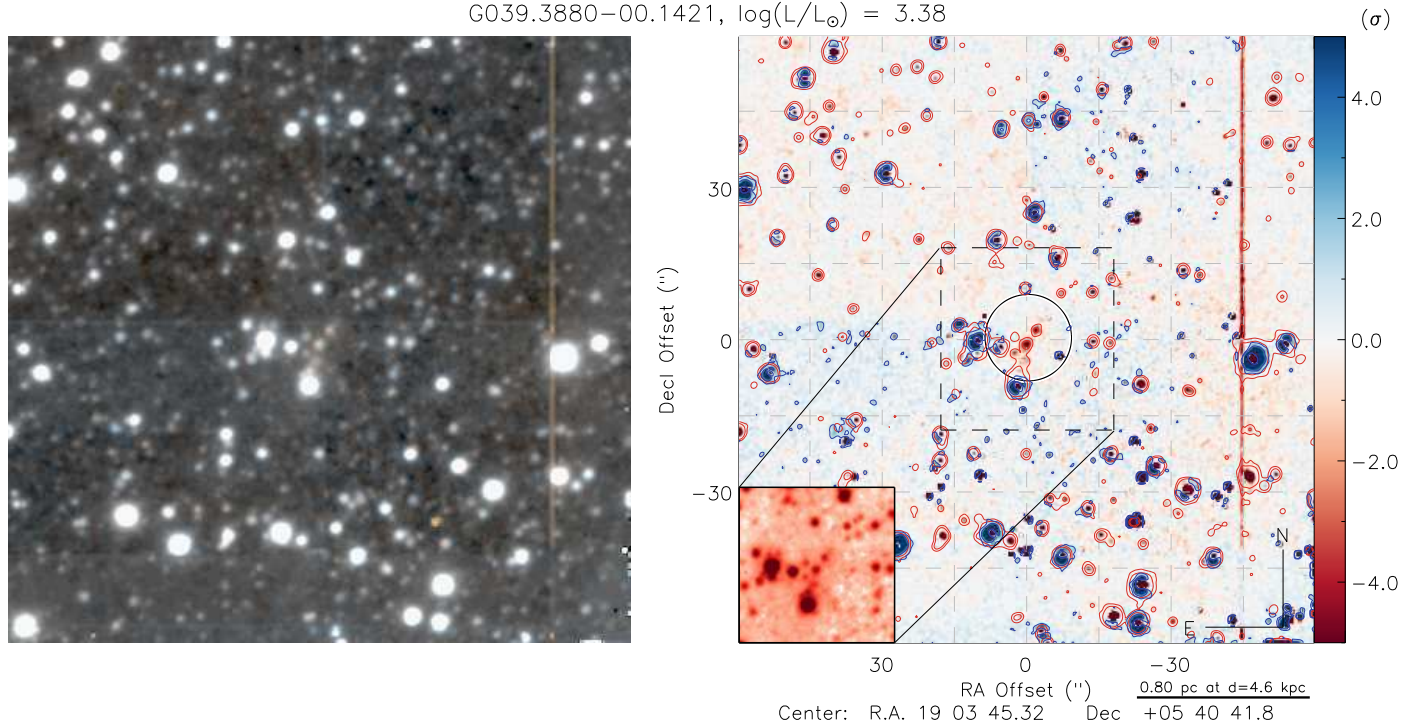
G039.4943-00.9933, $\log \left(L / L_{\odot}\right)=3.90$
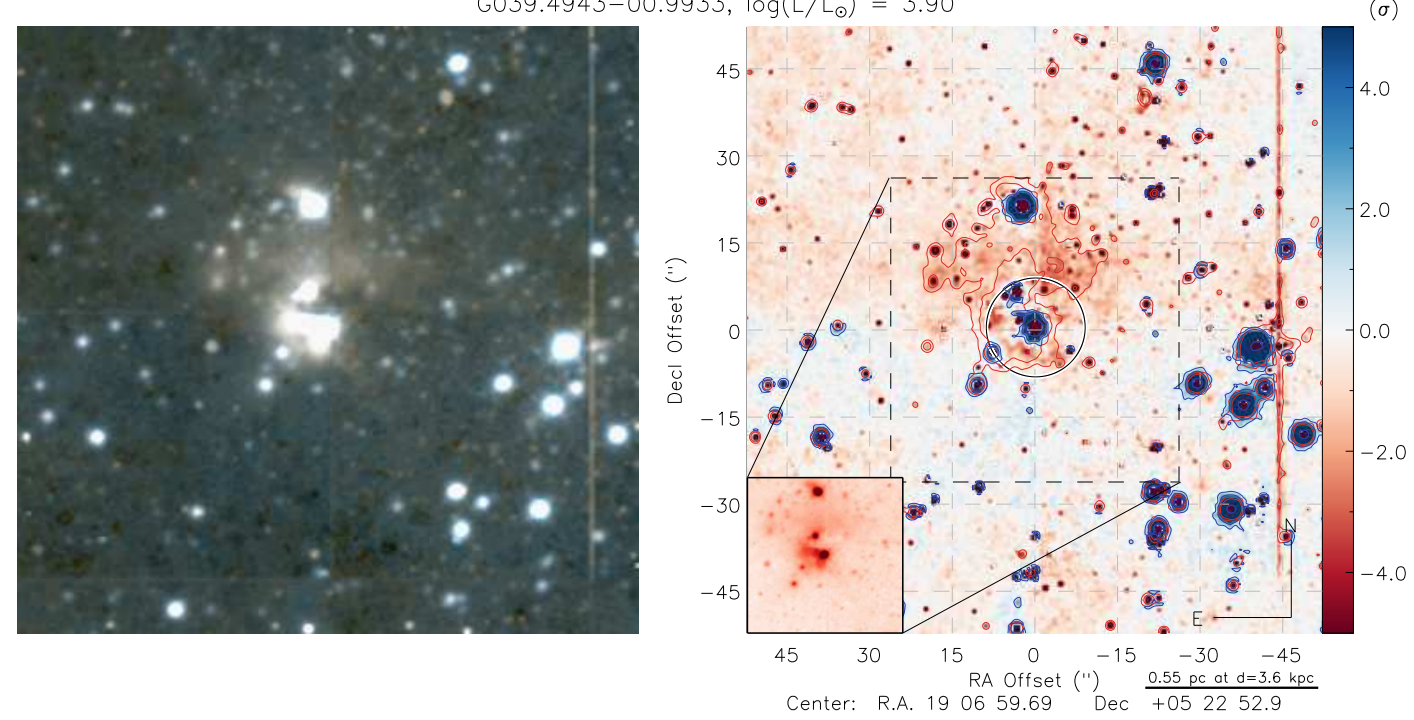

G039.9284-00.3741, $\log \left(L / L_{\odot}\right)=3.82$
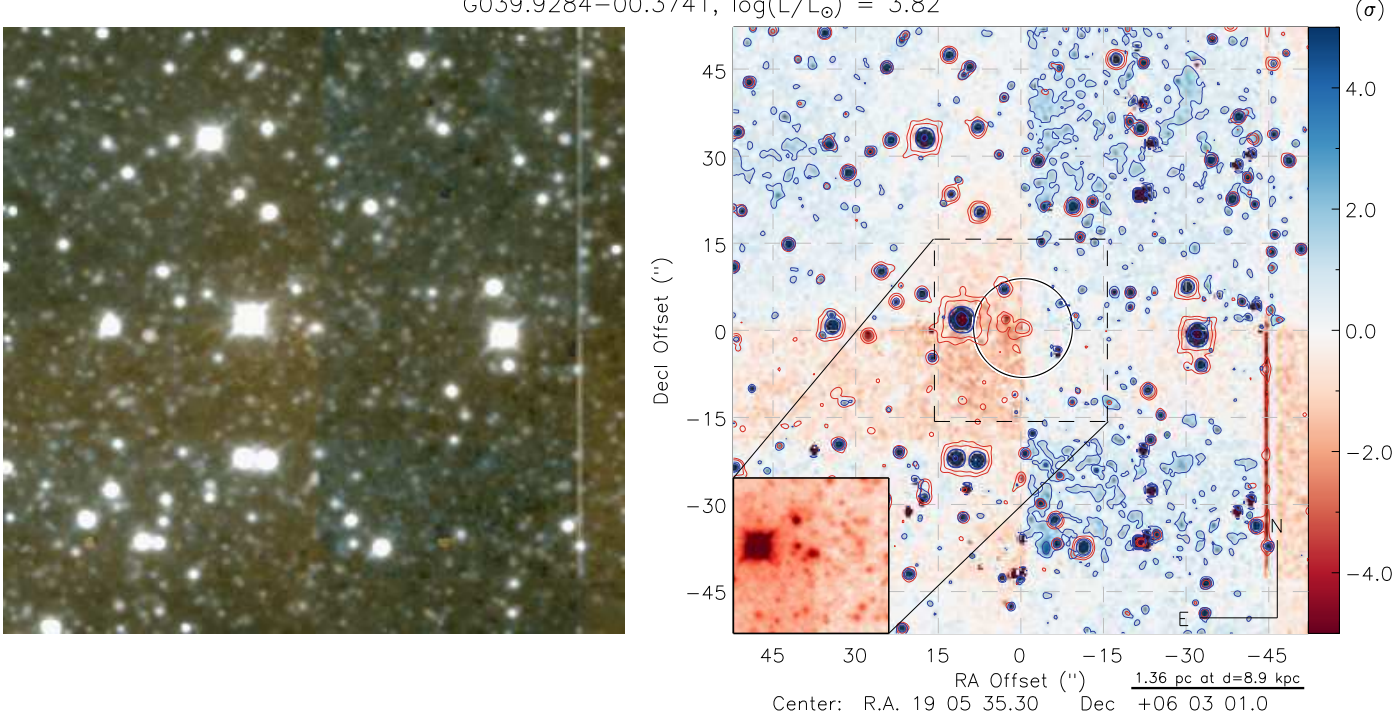

$\mathrm{G} 040.4247+00.6989, \log \left(L / L_{\odot}\right)=1.64$
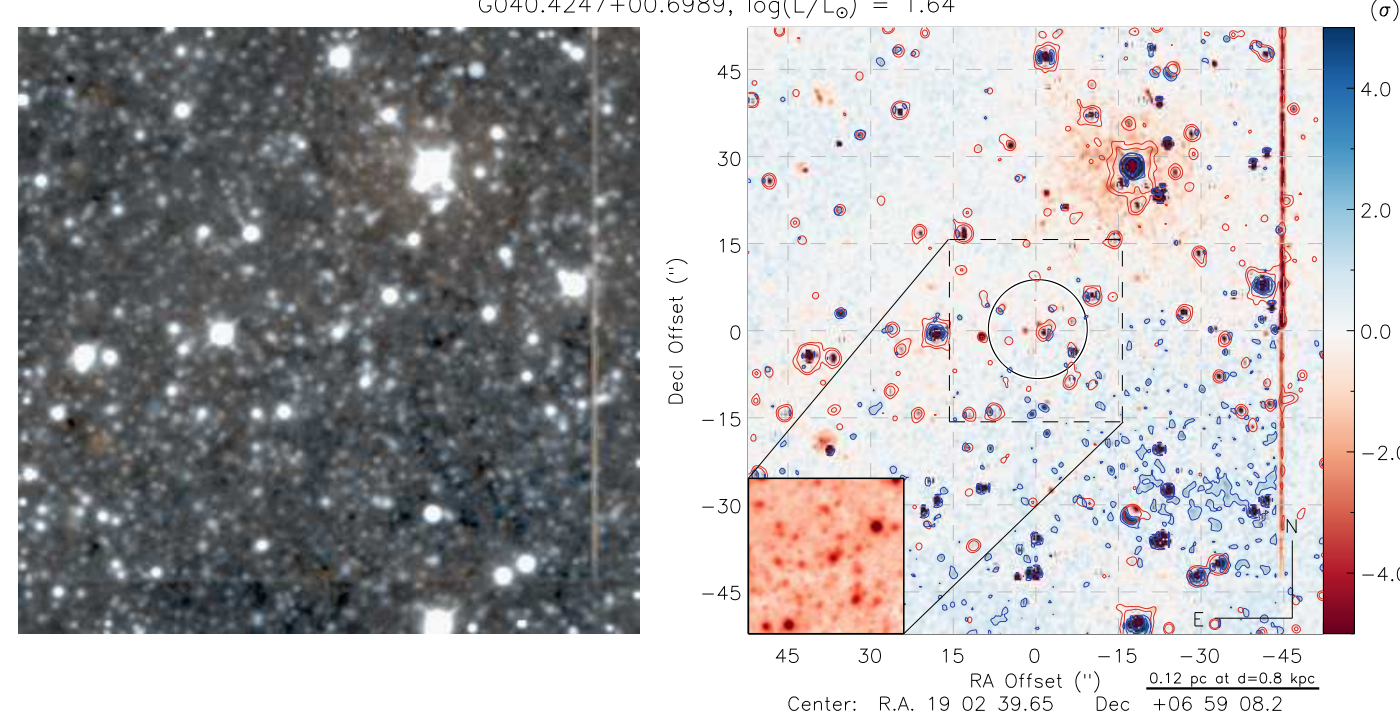
G041.0780-00.6365, $\log \left(L / L_{\odot}\right)=3.57$
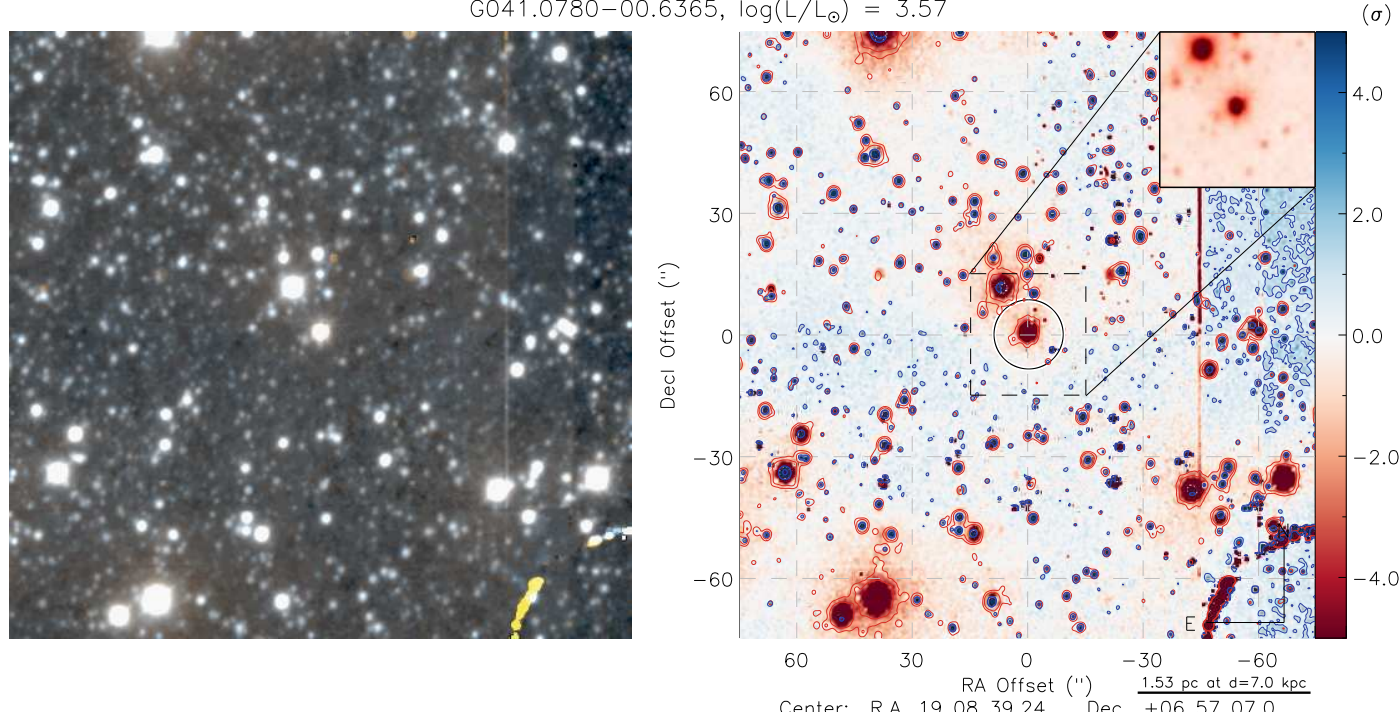

G042.1099-00.4466, $\log \left(L / L_{\odot}\right)=3.95$
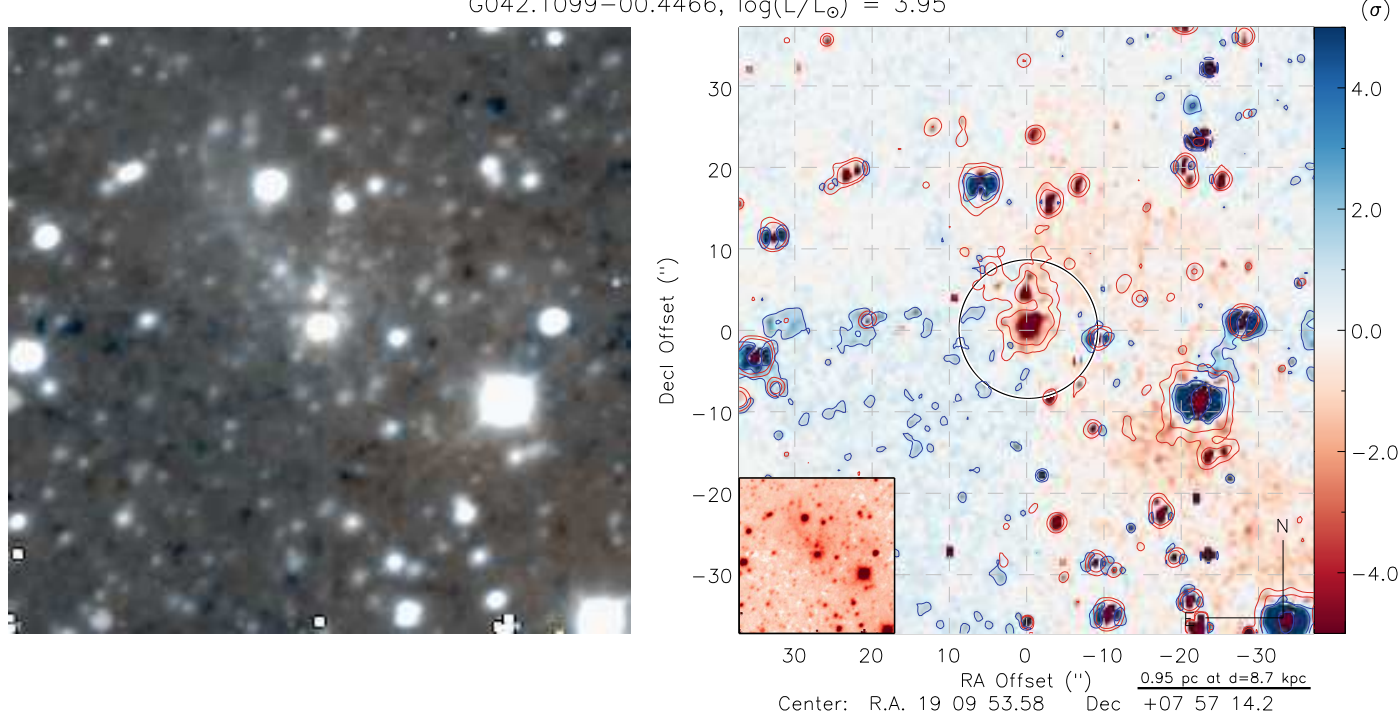

$G 043.0786+00.0033, \log \left(L / L_{\odot}\right)=1.63$
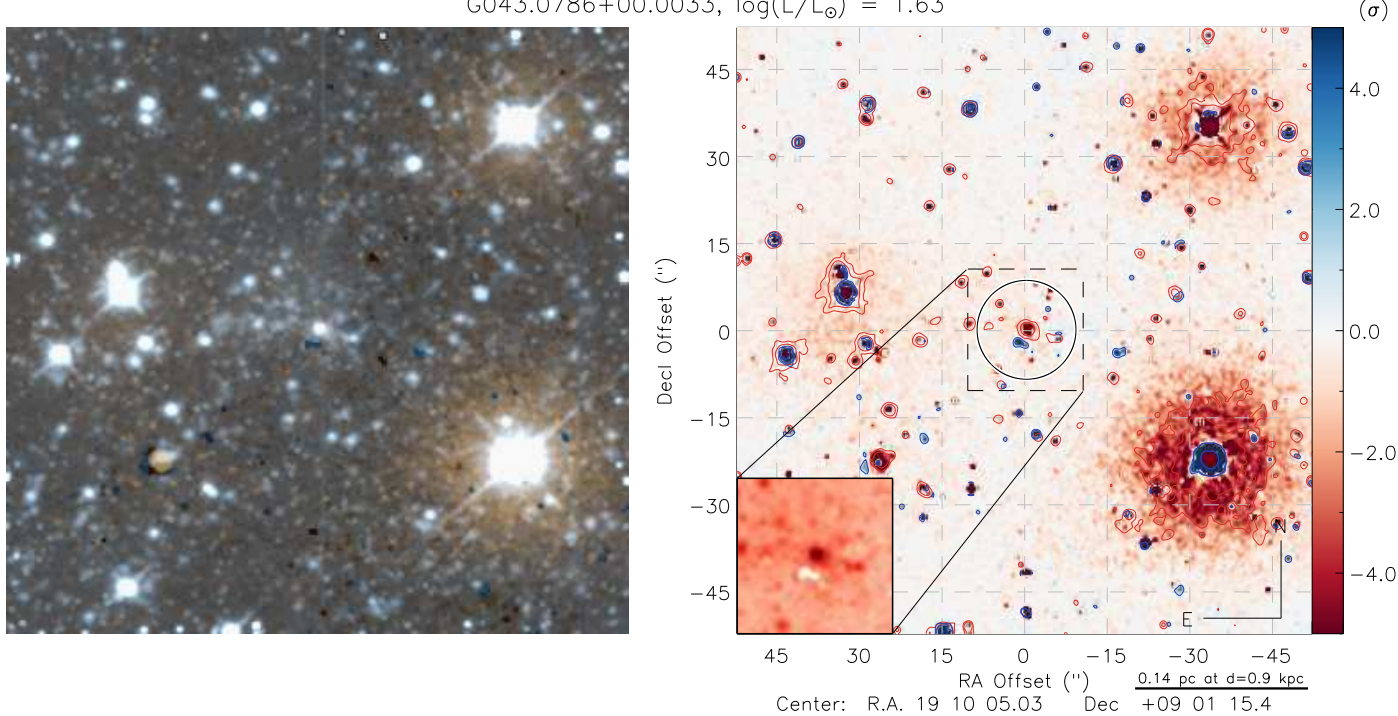
G043.7955-00.1275, $\log \left(L / L_{\text {odot }}\right)=5.16$
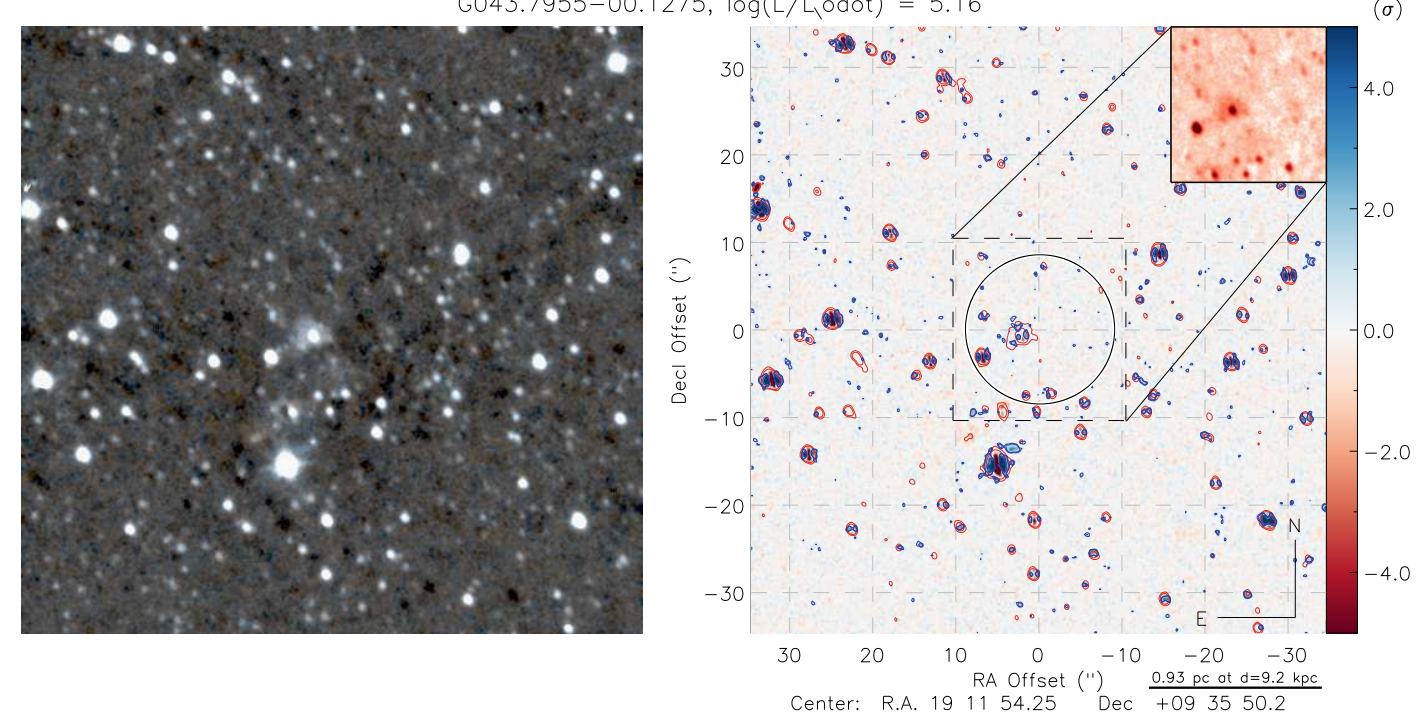

$\mathrm{G} 043.8152-00.1172, \log \left(\mathrm{L} / \mathrm{L}_{\odot}\right)=3.99$
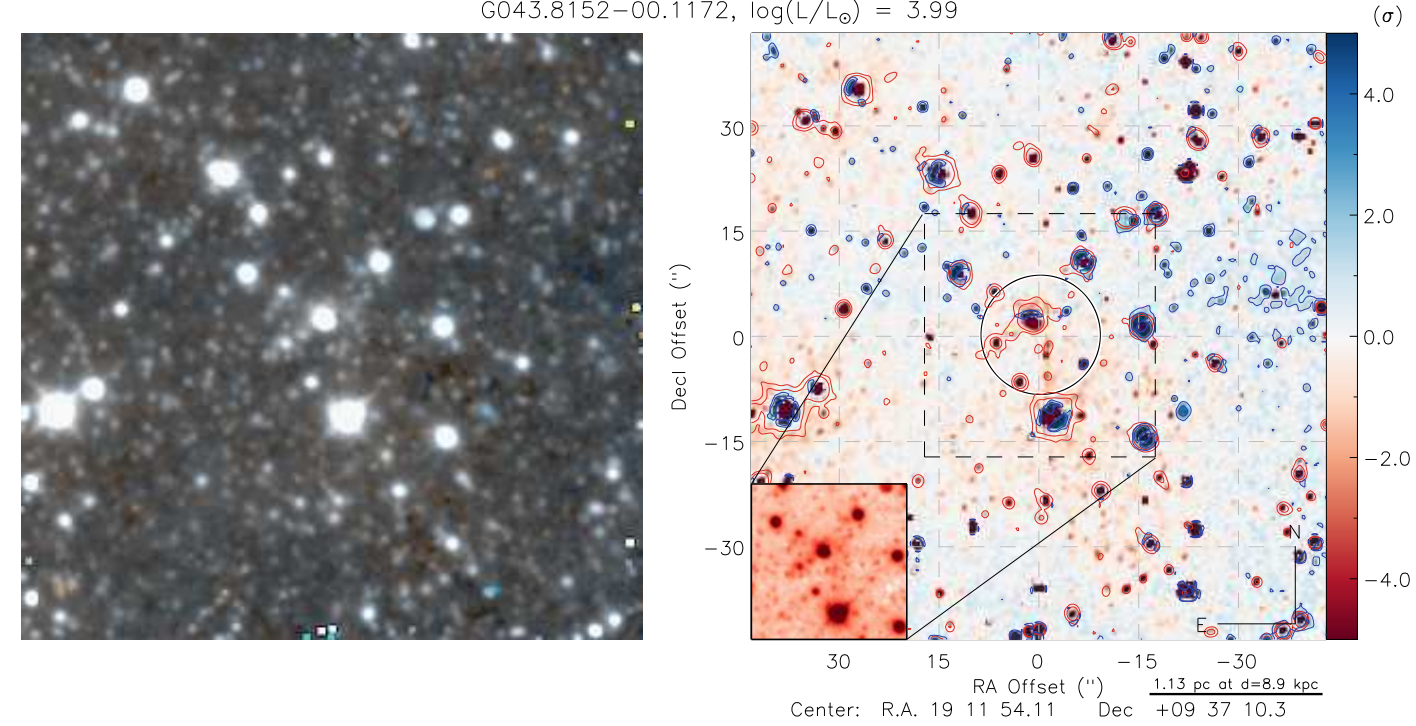

G045.1894-00.4387, $\log \left(L / L_{\odot}\right)=3.84$
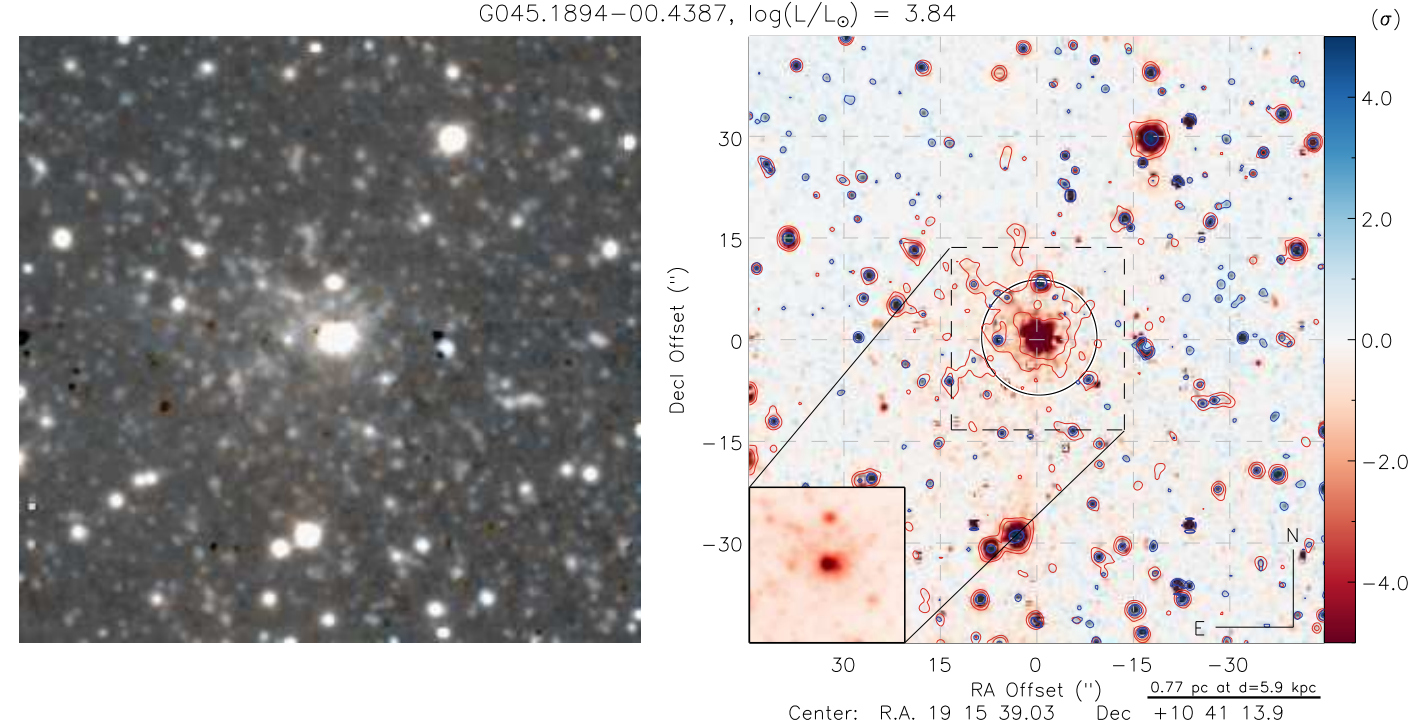
$6053.0366+00.1110, \log \left(L / L_{\odot}\right)=3.60$
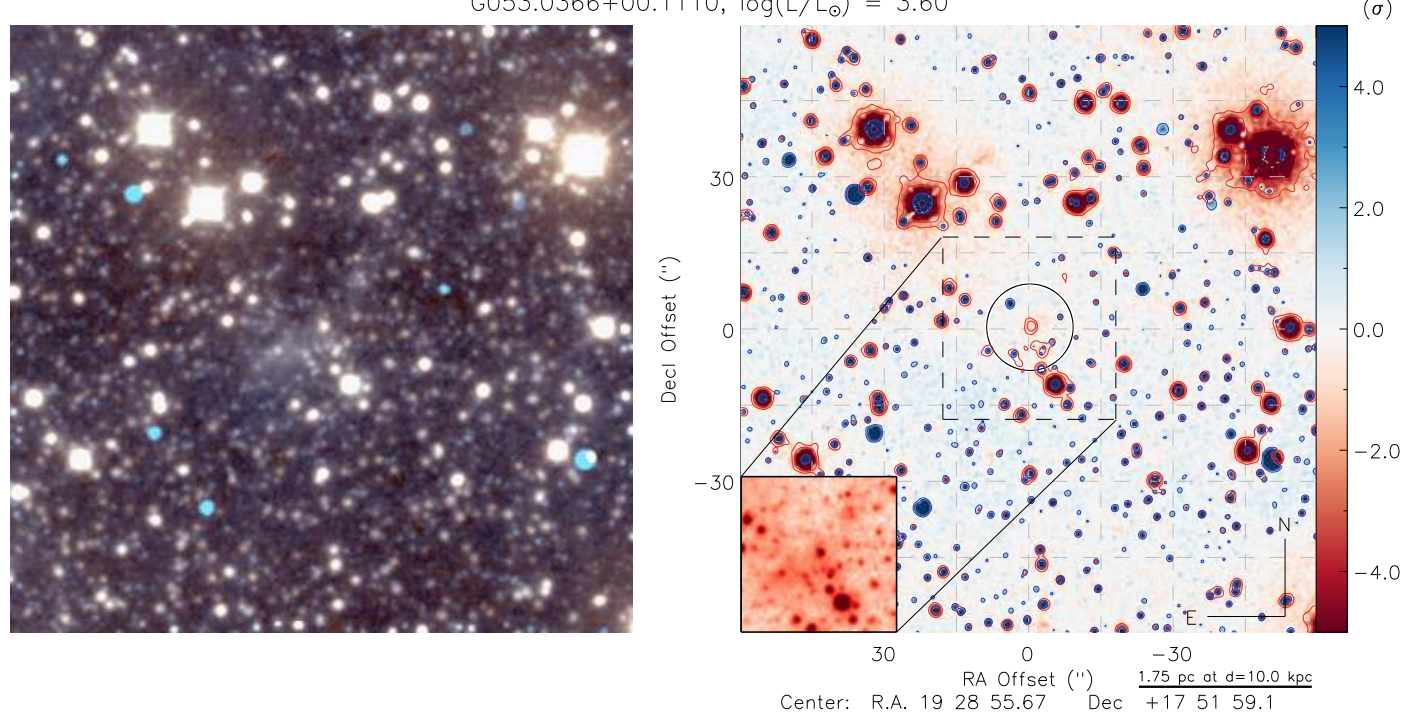

$\mathrm{G} 076.1877+00.0974, \log \left(\mathrm{L} / \mathrm{L}_{\odot}\right)=4.91$
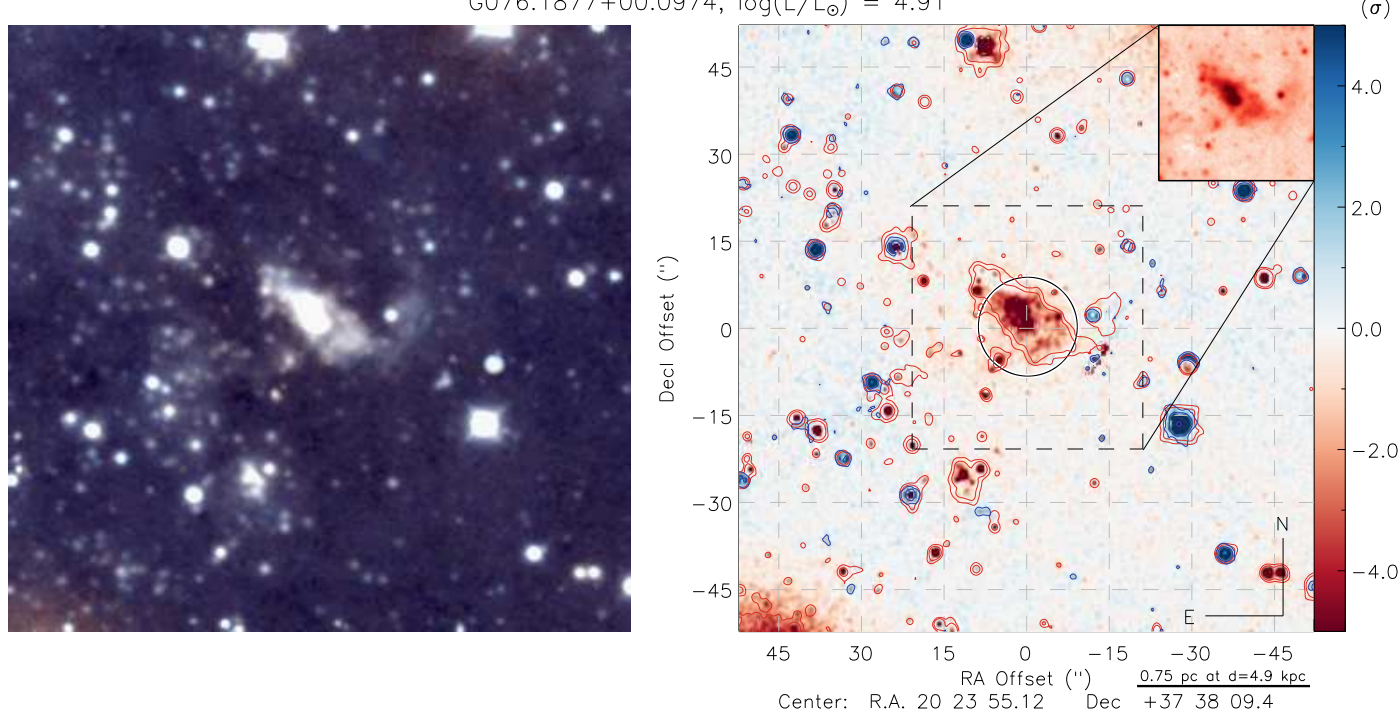

G077.4052-01.2136, $\log \left(L / L_{\odot}\right)=3.67$
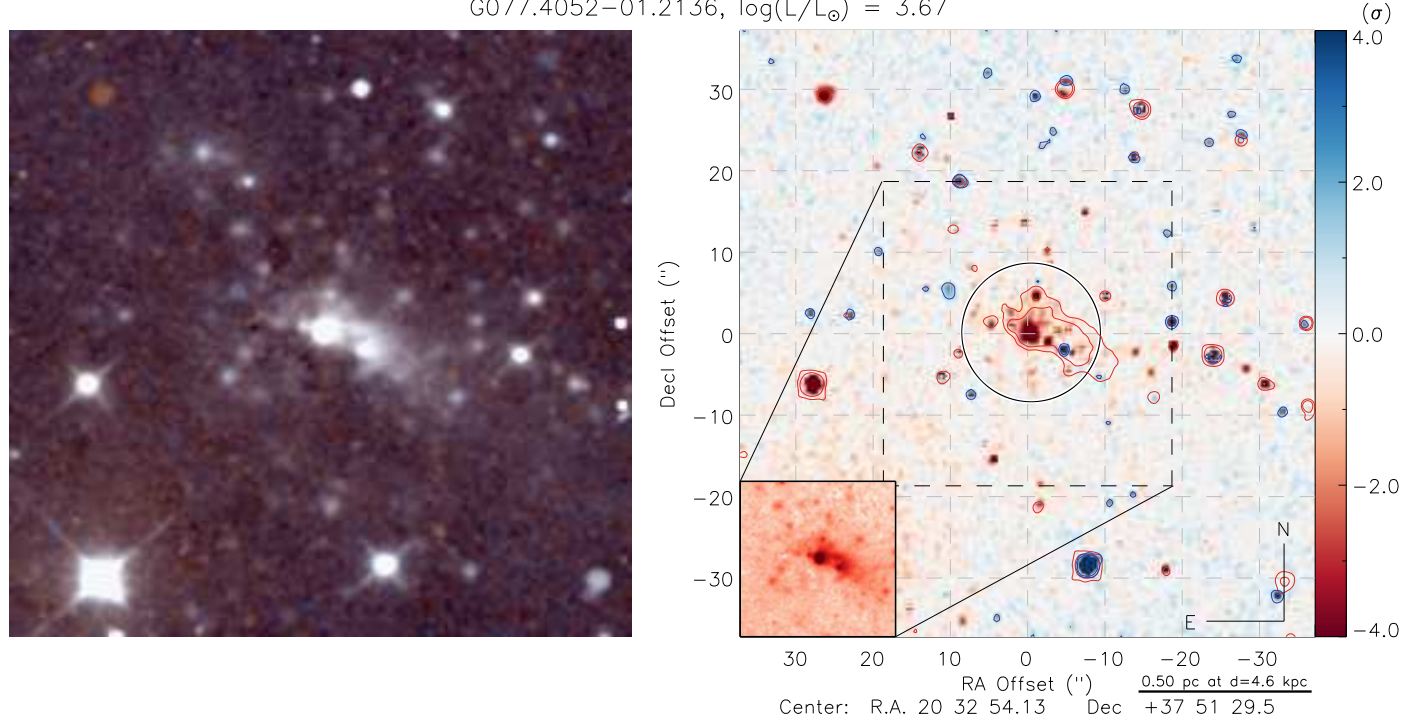
$\mathrm{G} 078.0515+00.6180, \log \left(L / L_{\odot}\right)=3.87$
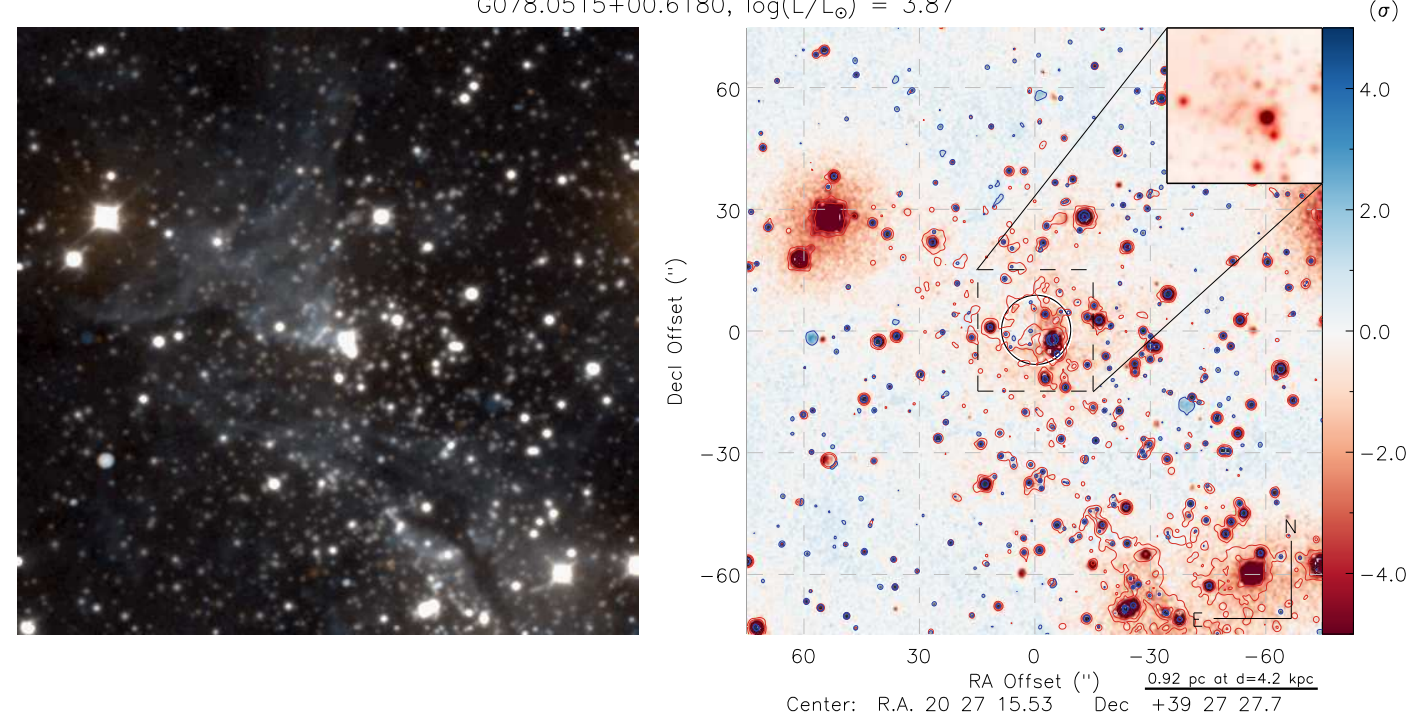

$\mathrm{G} 078.8699+02.7602, \log \left(\mathrm{L} / \mathrm{L}_{\odot}\right)=3.92$
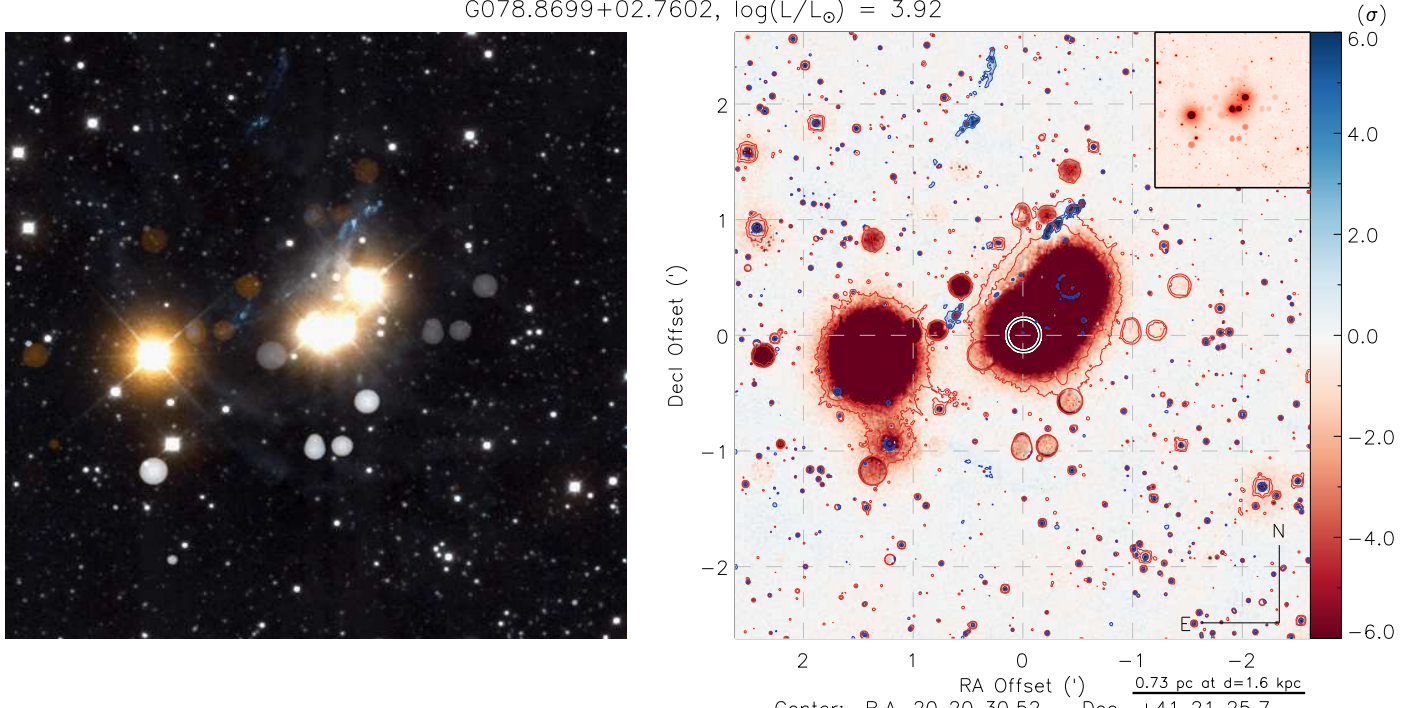

G094.6028-01.7966, $\log \left(L / L_{\odot}\right)=4.84$
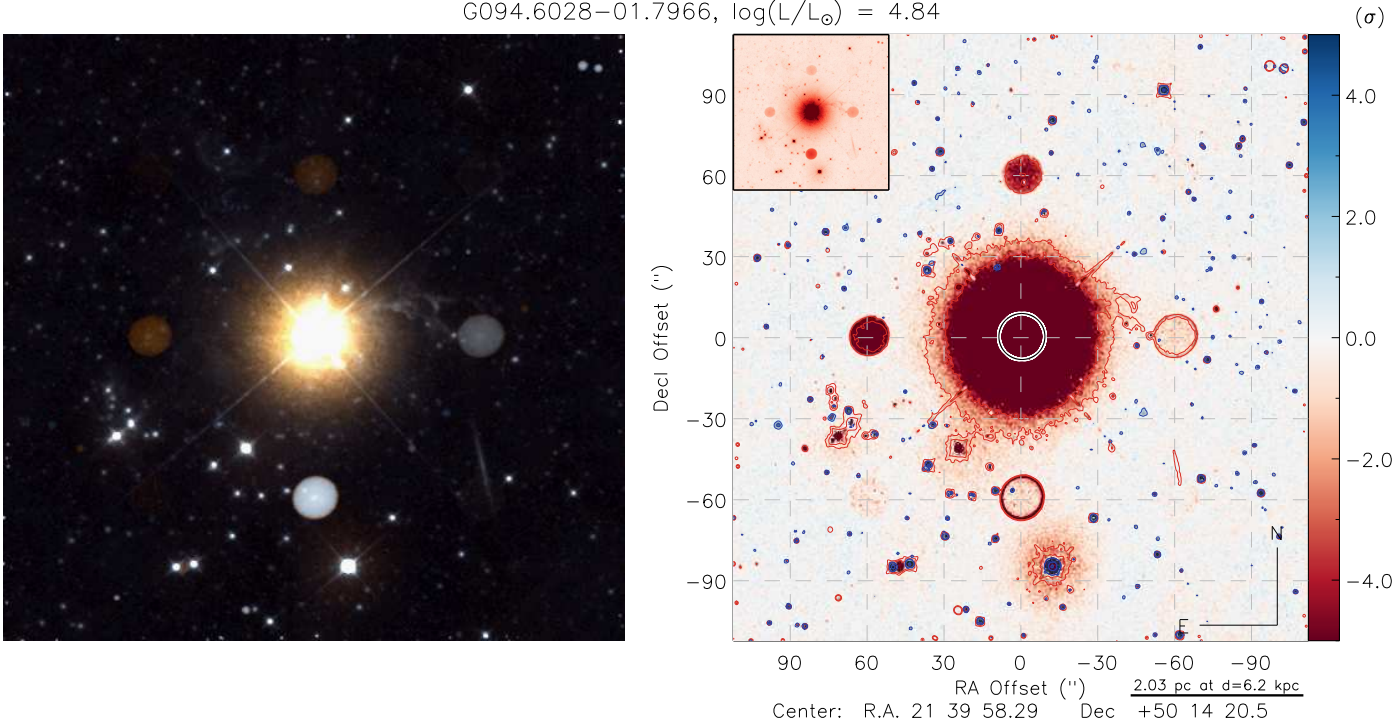

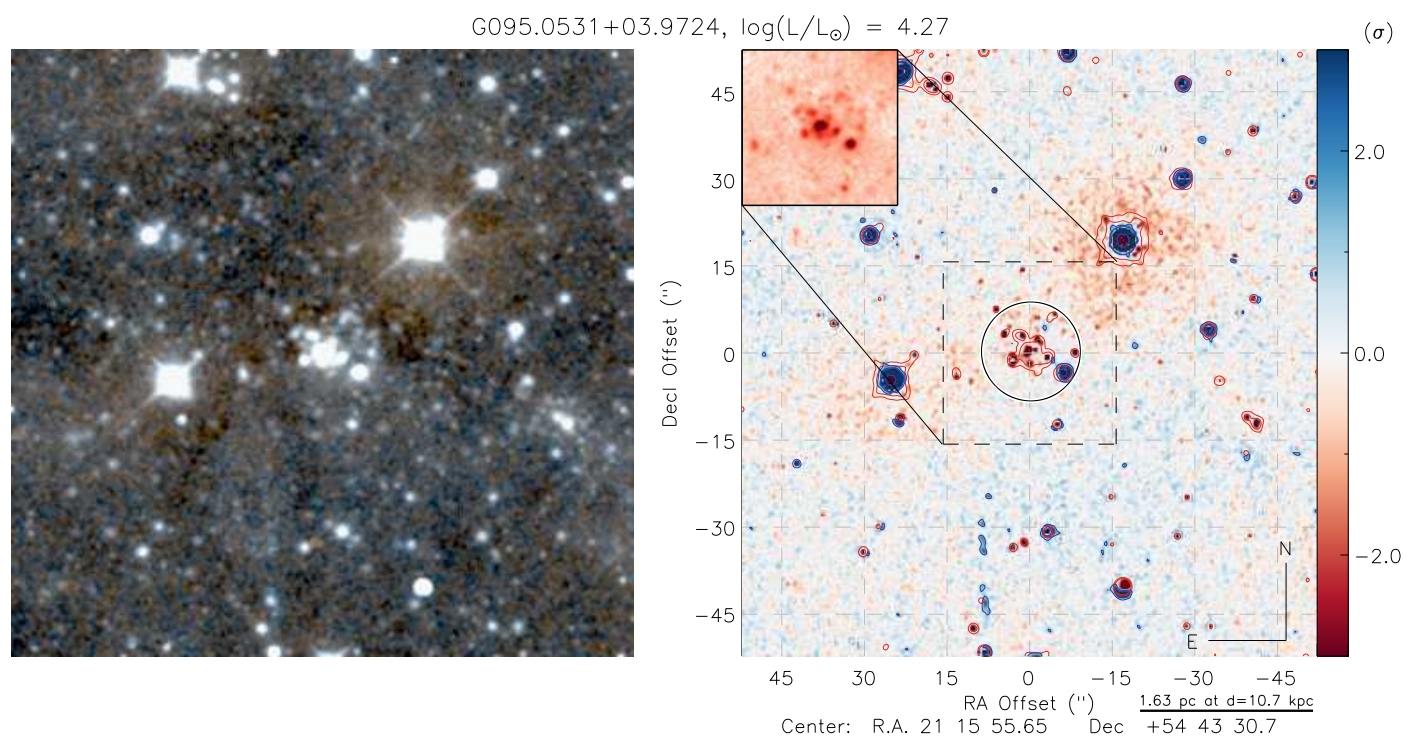

G126.4274-01.2348, $\log \left(L / L_{\odot}\right)=2.23$
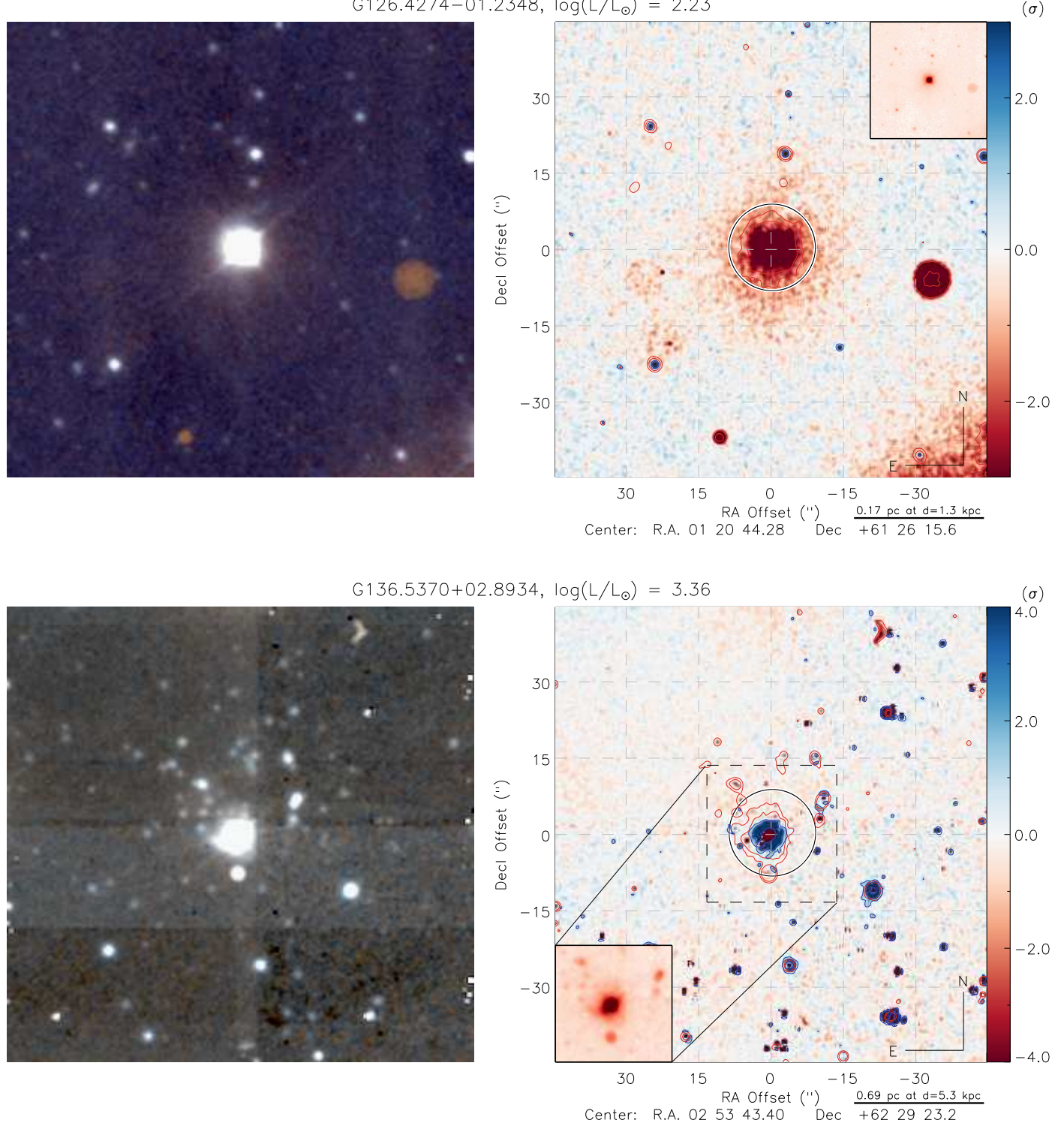
$G 142.2446+01.4299, \log \left(L / L_{\odot}\right)=4.46$
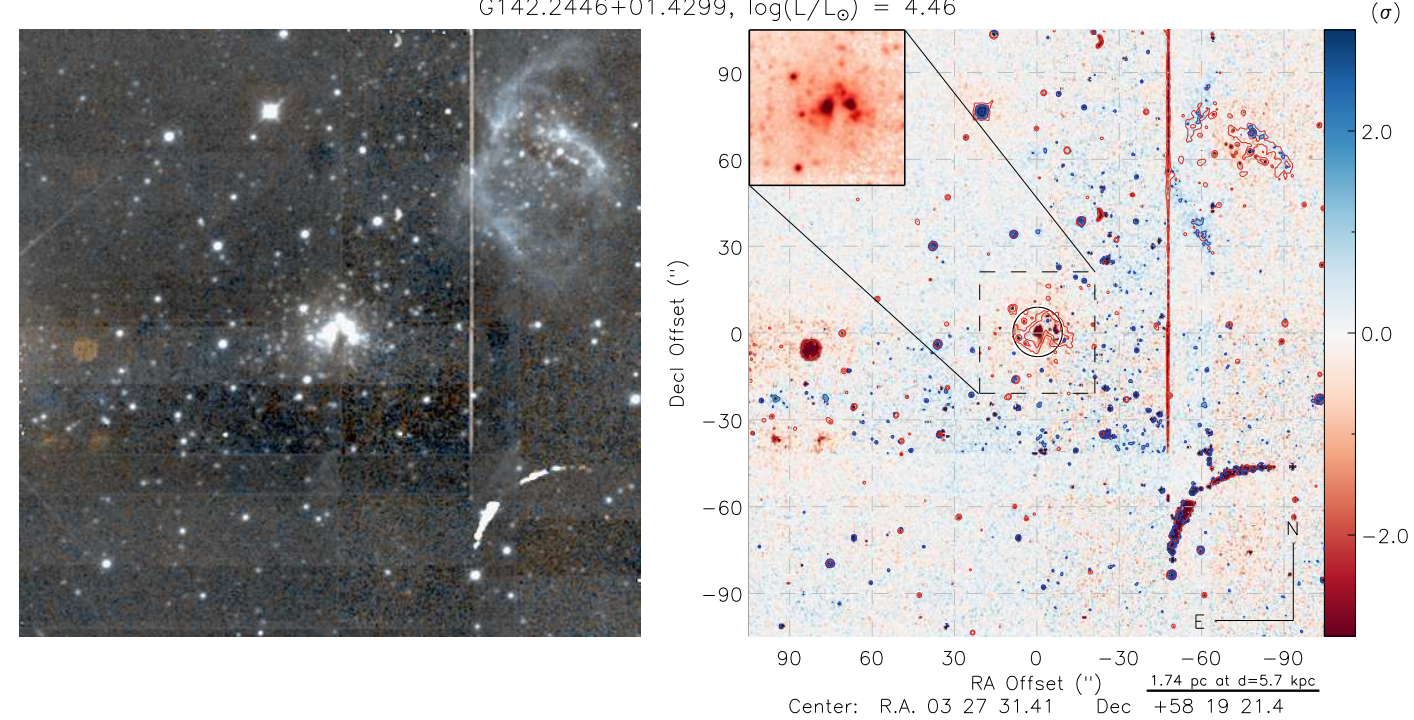

$G 148.1201+00.2928, \log \left(L / L_{\odot}\right)=3.84$
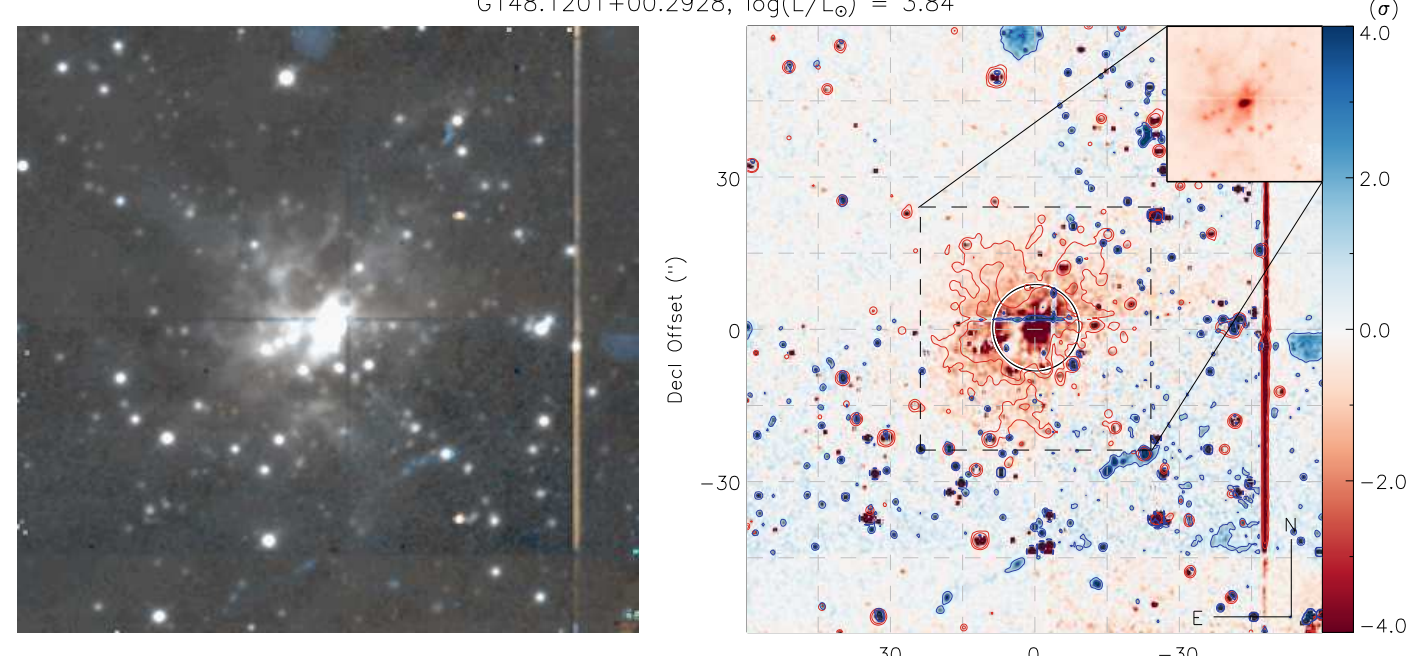

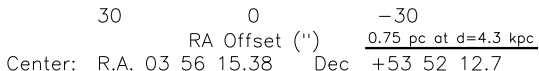

$G 172.8742+02.2687, \log \left(L / L_{\odot}\right)=4.34$
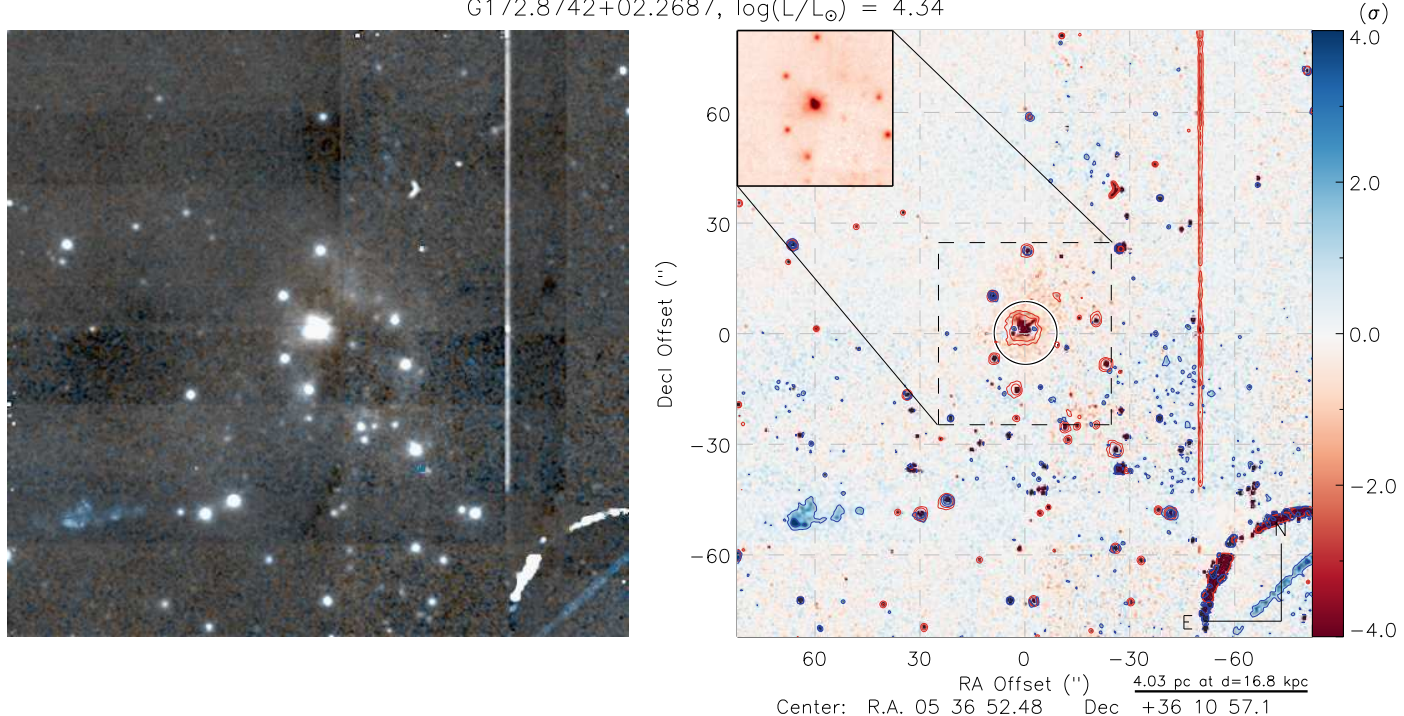
$\mathrm{G} 203.7637+01.2705, \log \left(\mathrm{L} / \mathrm{L}_{\odot}\right)=3.10$
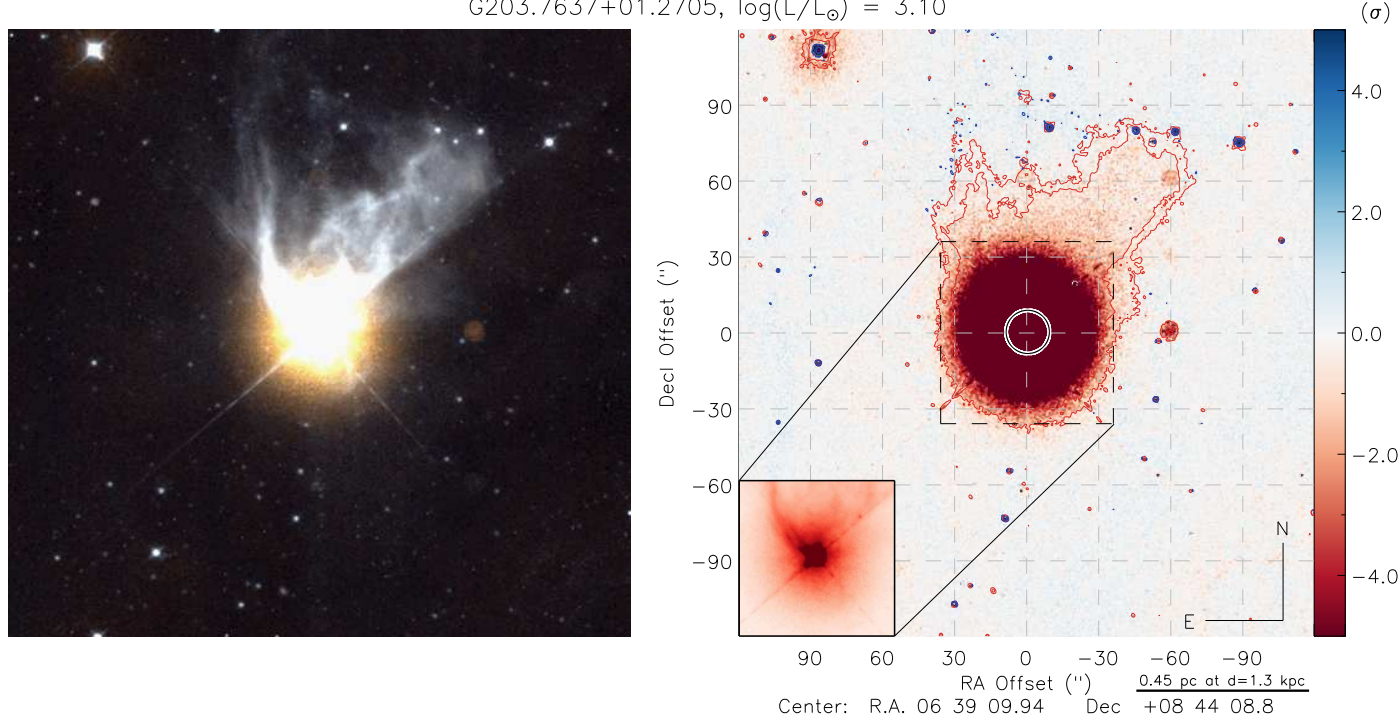

$G 212.2344-03.5038, \log \left(L / L_{\odot}\right)=3.65$
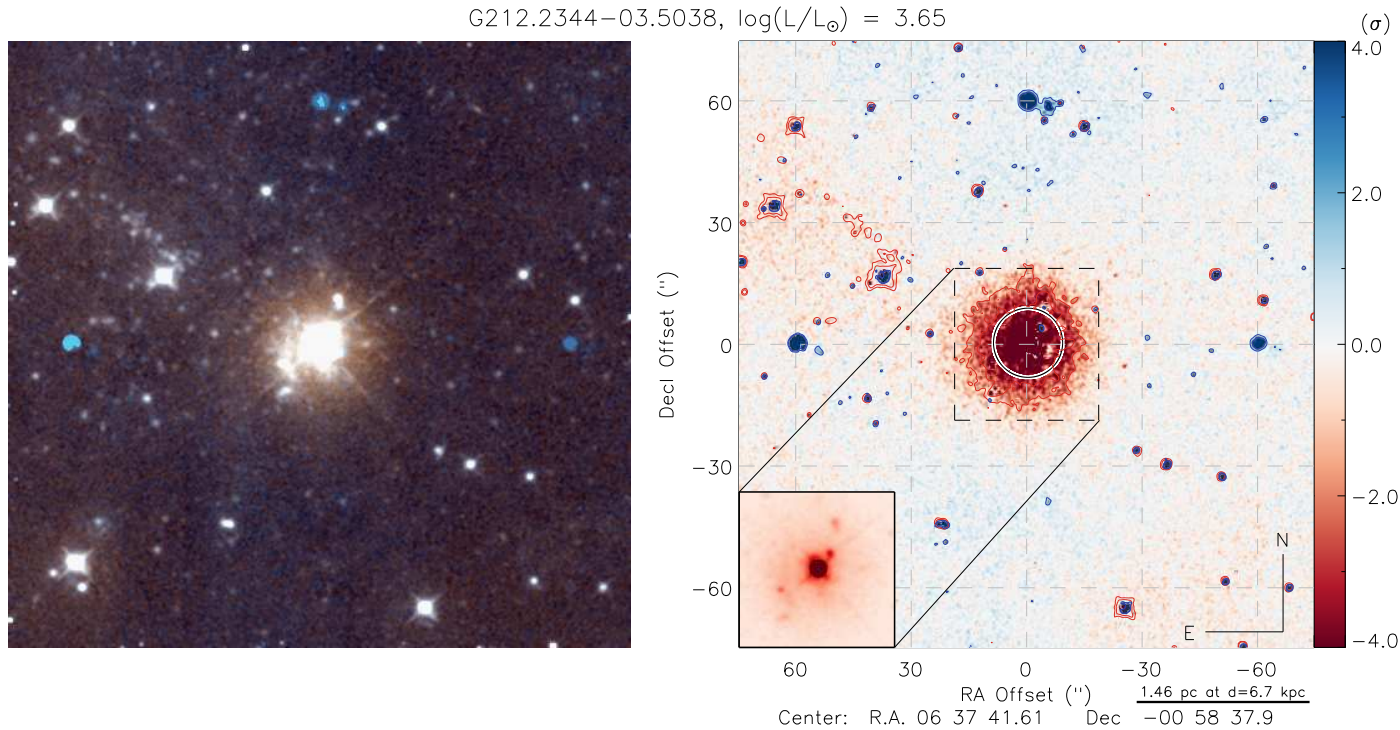

$G 213.9180+00.3786, \log \left(L / L_{\odot}\right)=3.32$
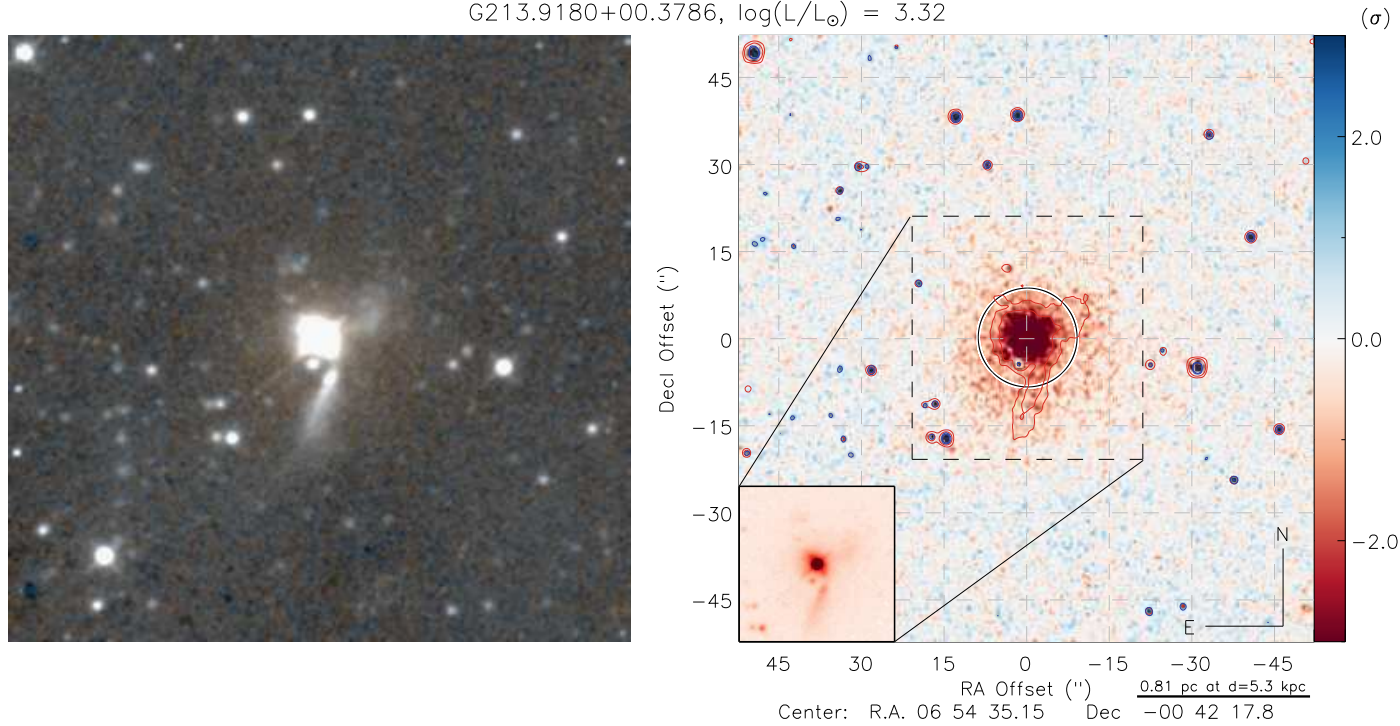
$G 222.4278-03.1357, \log \left(L / L_{\odot}\right)=2.73$
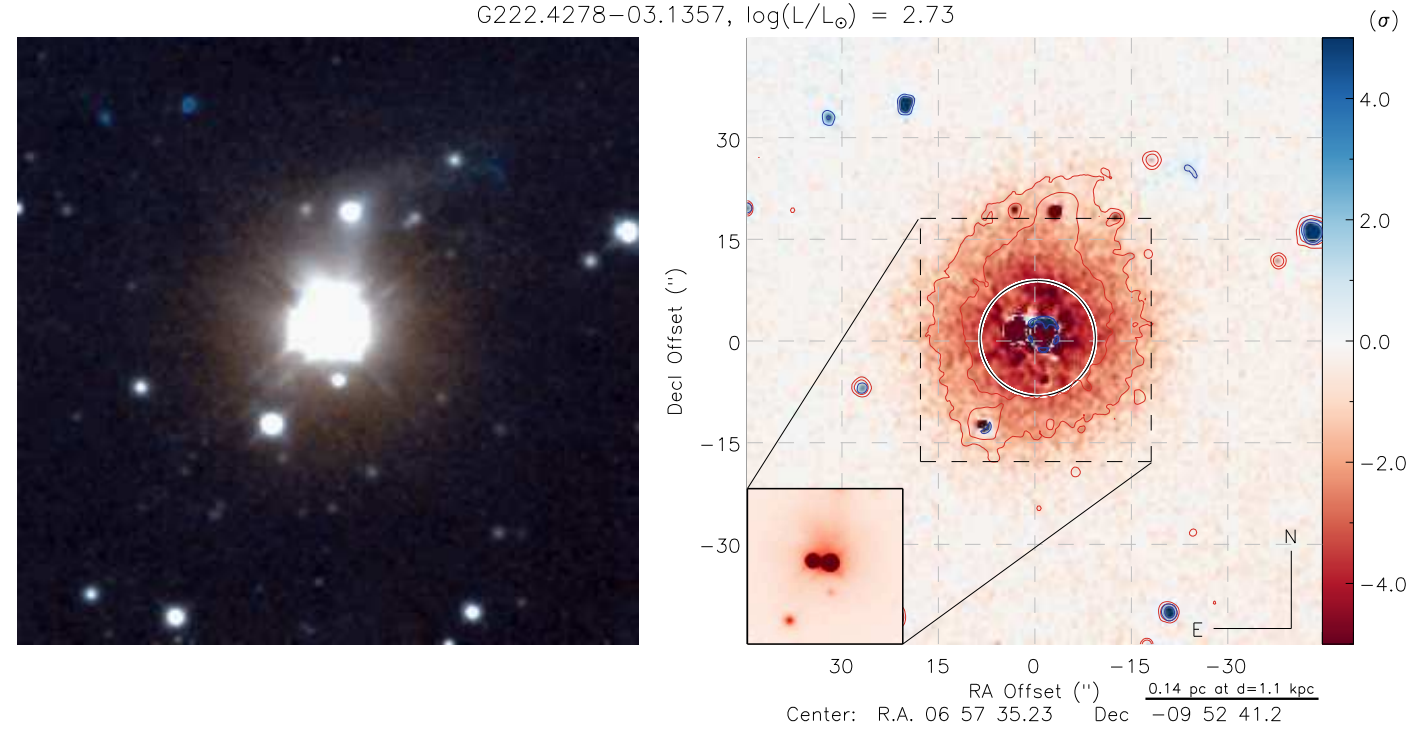

G224.6065-02.5563, $\log \left(L / L_{\odot}\right)=3.52$
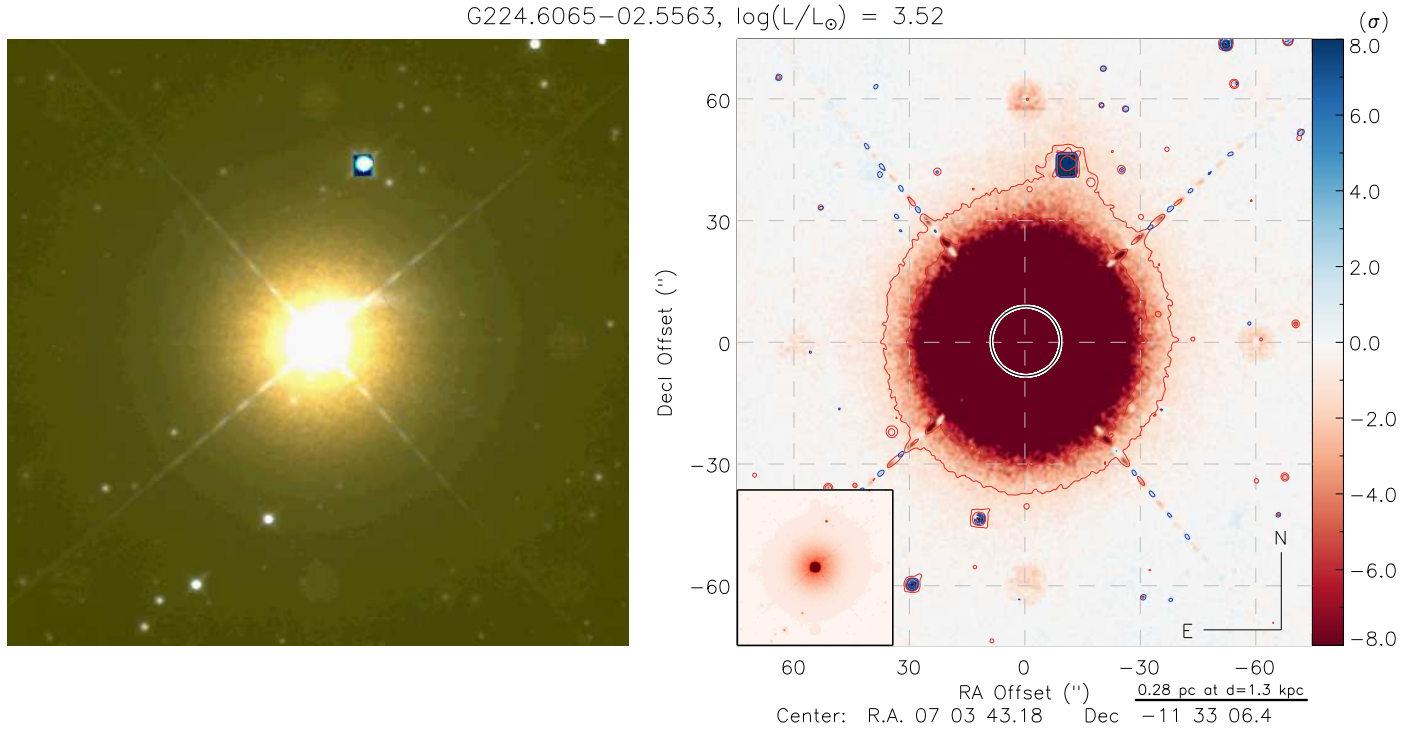

$G 231.7986-01.9682, \log \left(L / L_{\odot}\right)=3.74$
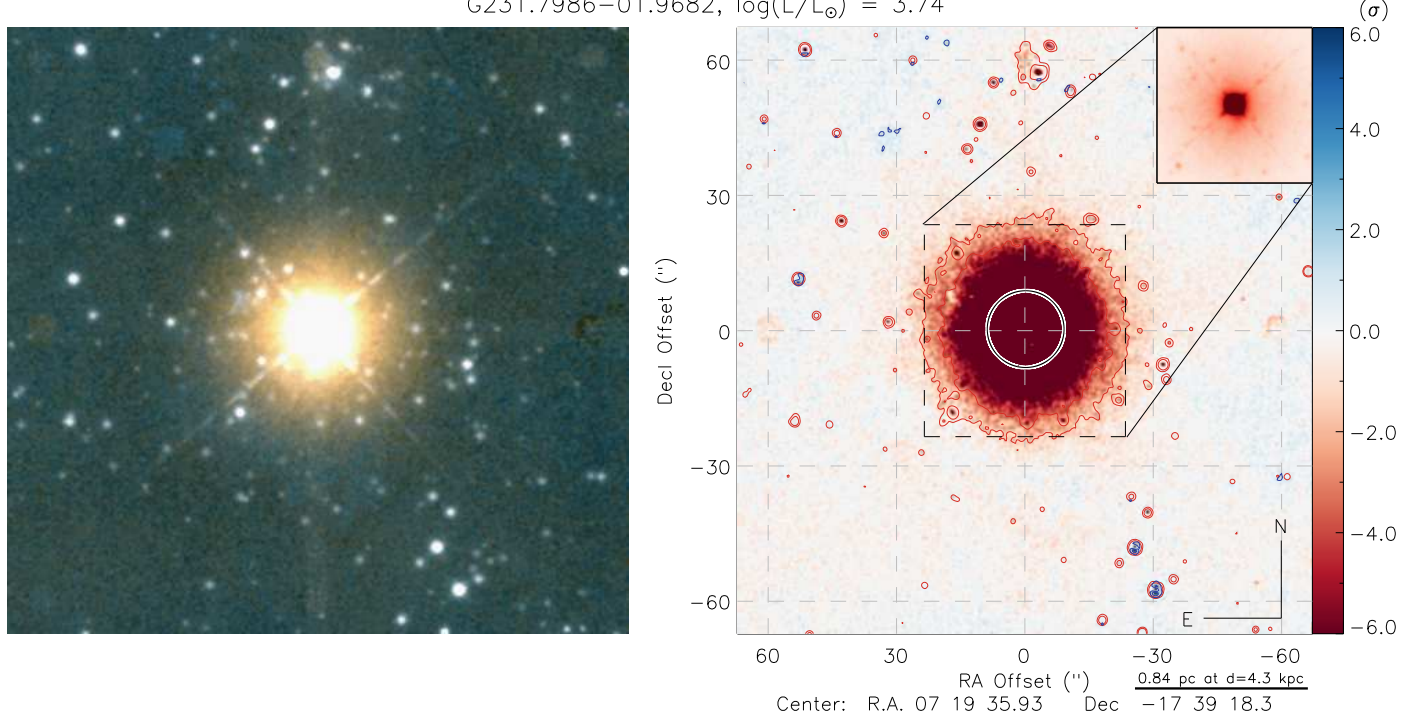
G231.9005-02.1378, $\log \left(L / L_{\odot}\right)=2.96$
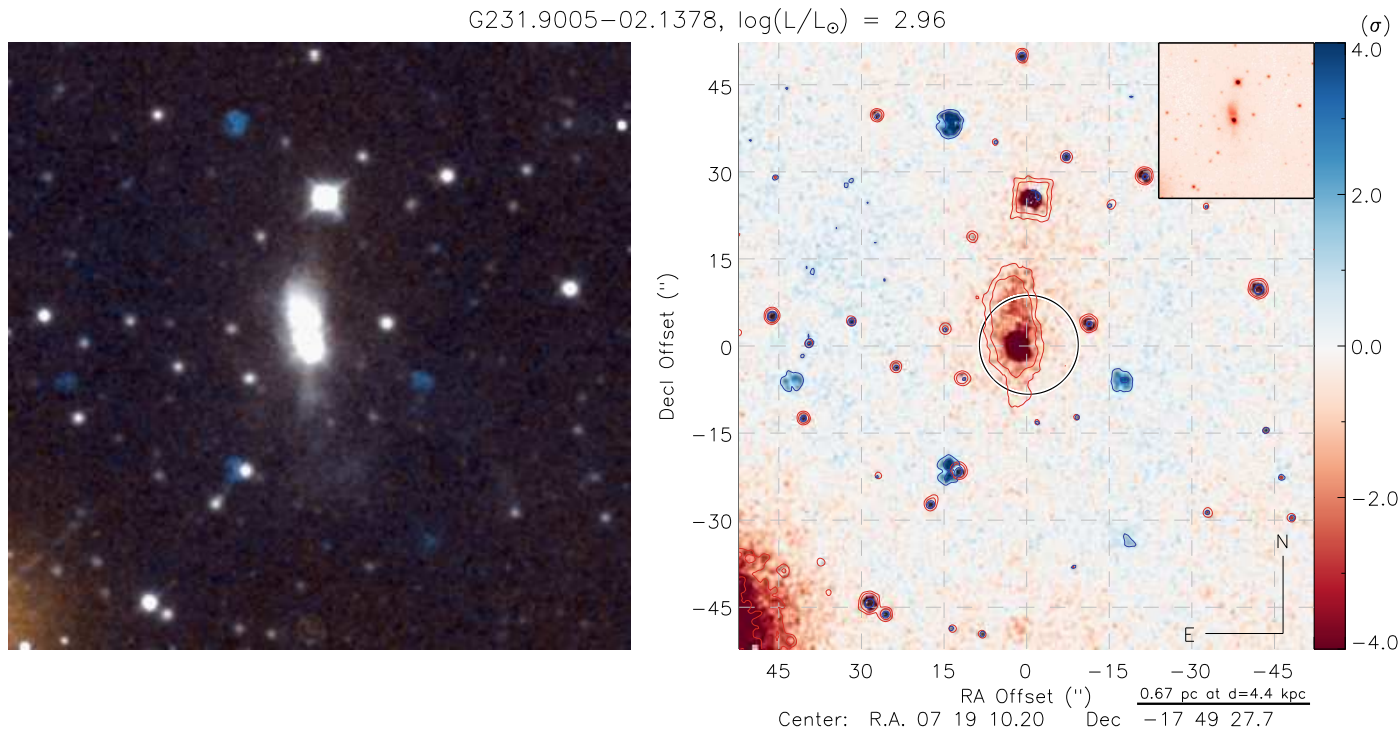

G233.8306-00.1803, $\log \left(L / L_{\odot}\right)=4.27$
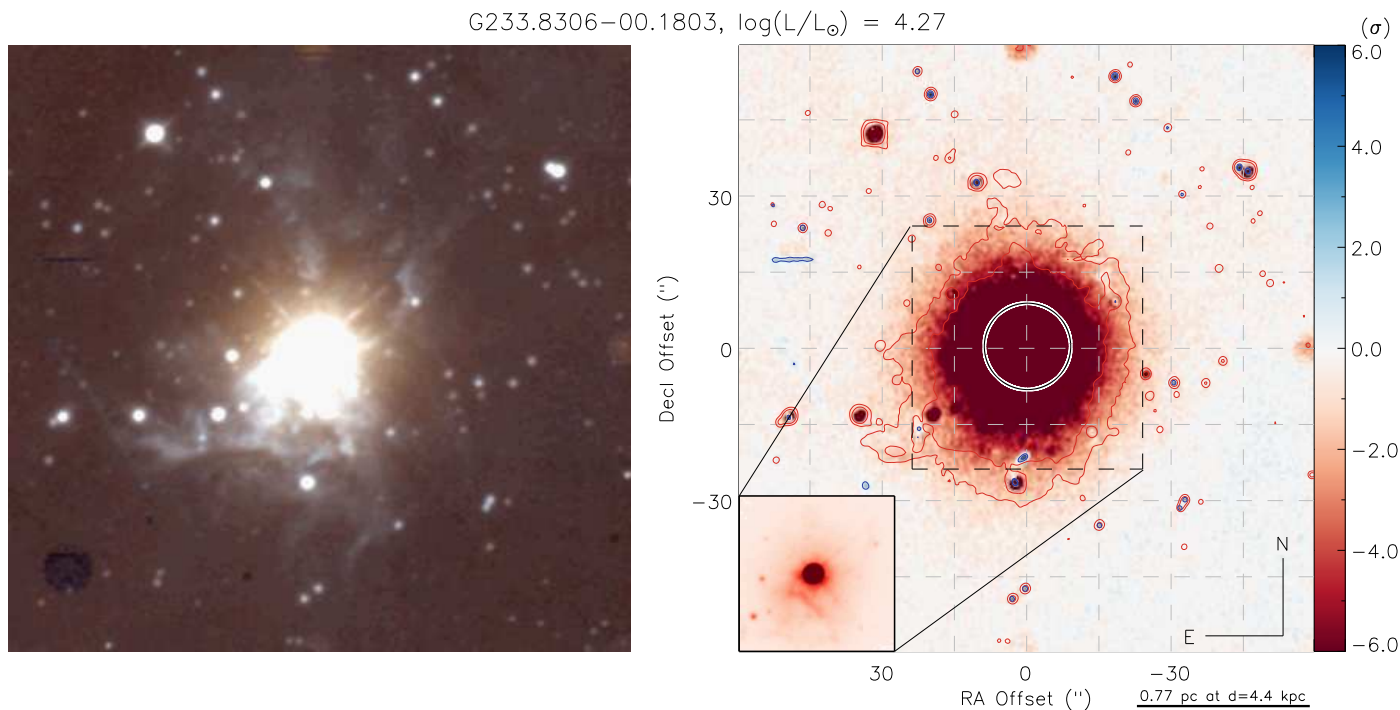

$G 242.9402-00.4501, \log \left(L / L_{\odot}\right)=3.71$
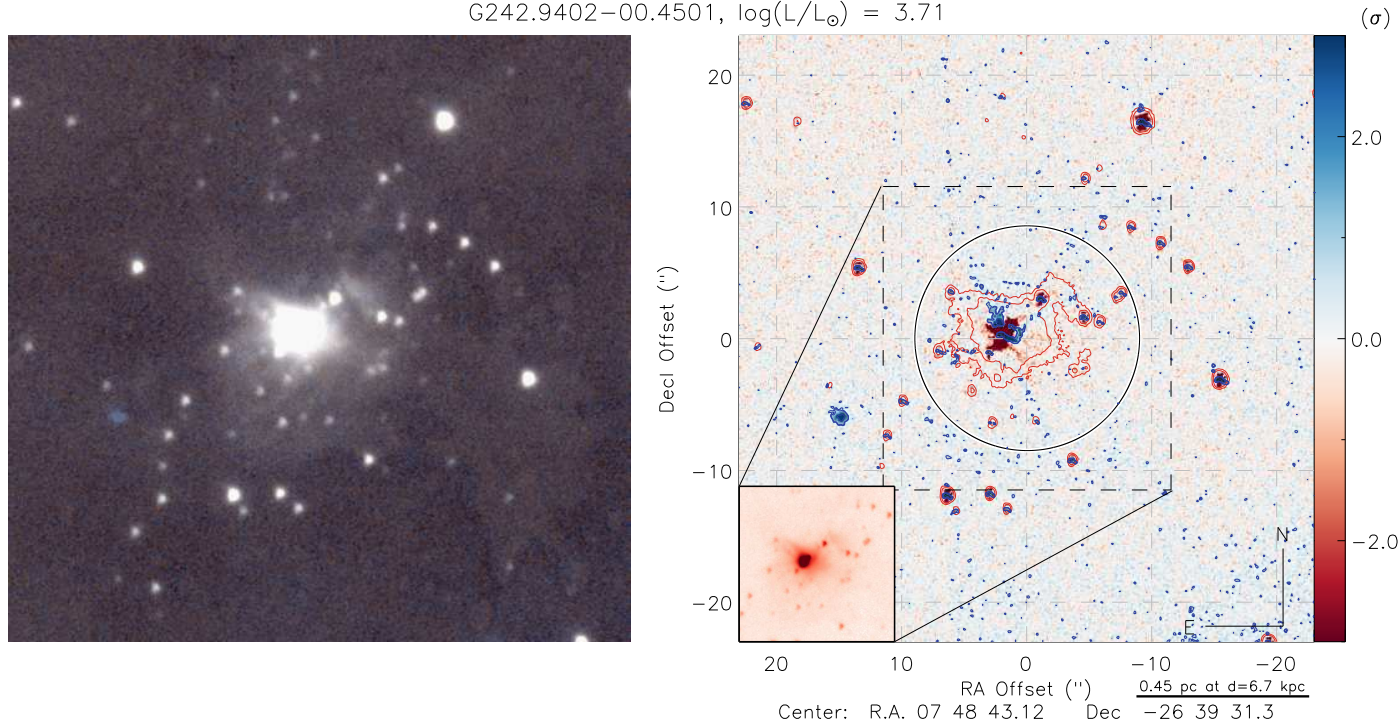


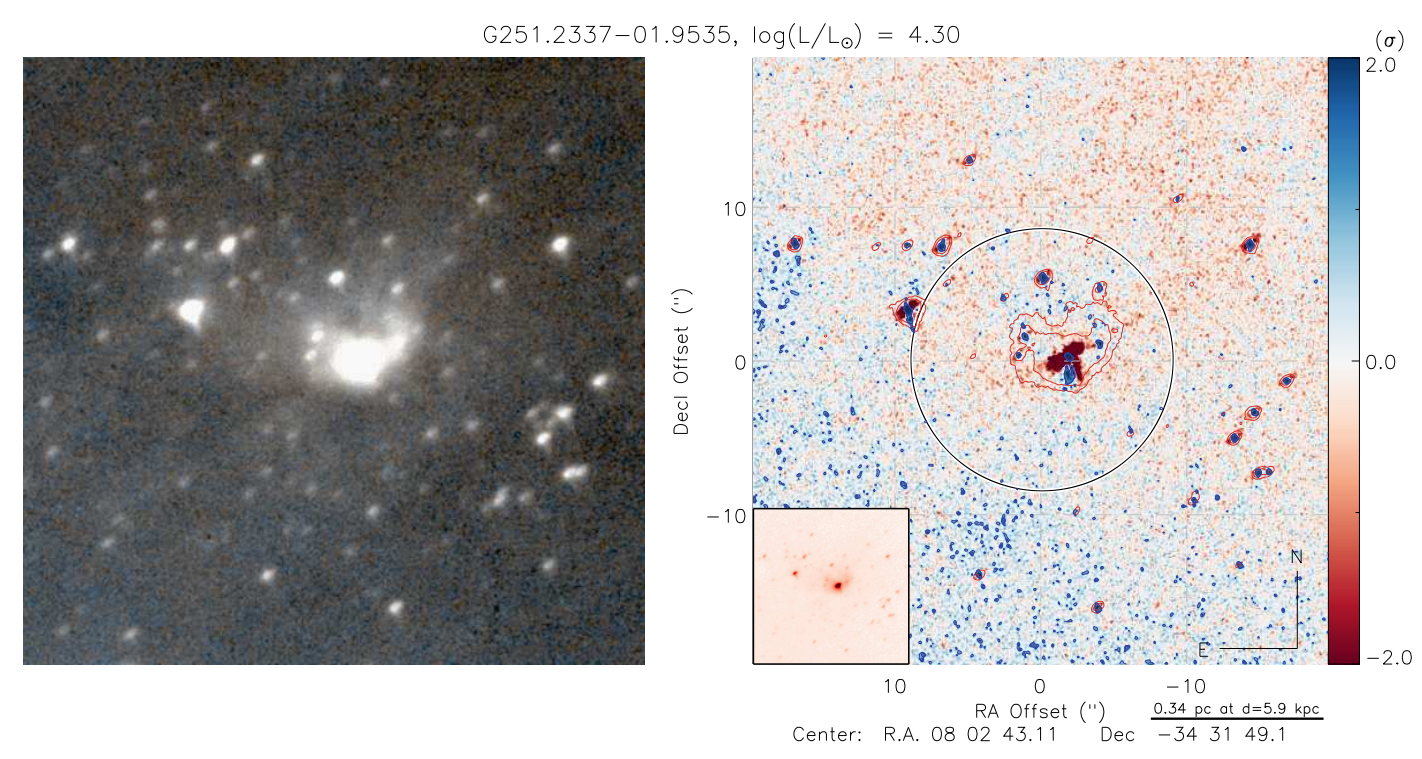

$\mathrm{G} 259.6695-01.3181, \log \left(\mathrm{L} / \mathrm{L}_{\odot}\right)=3.40$
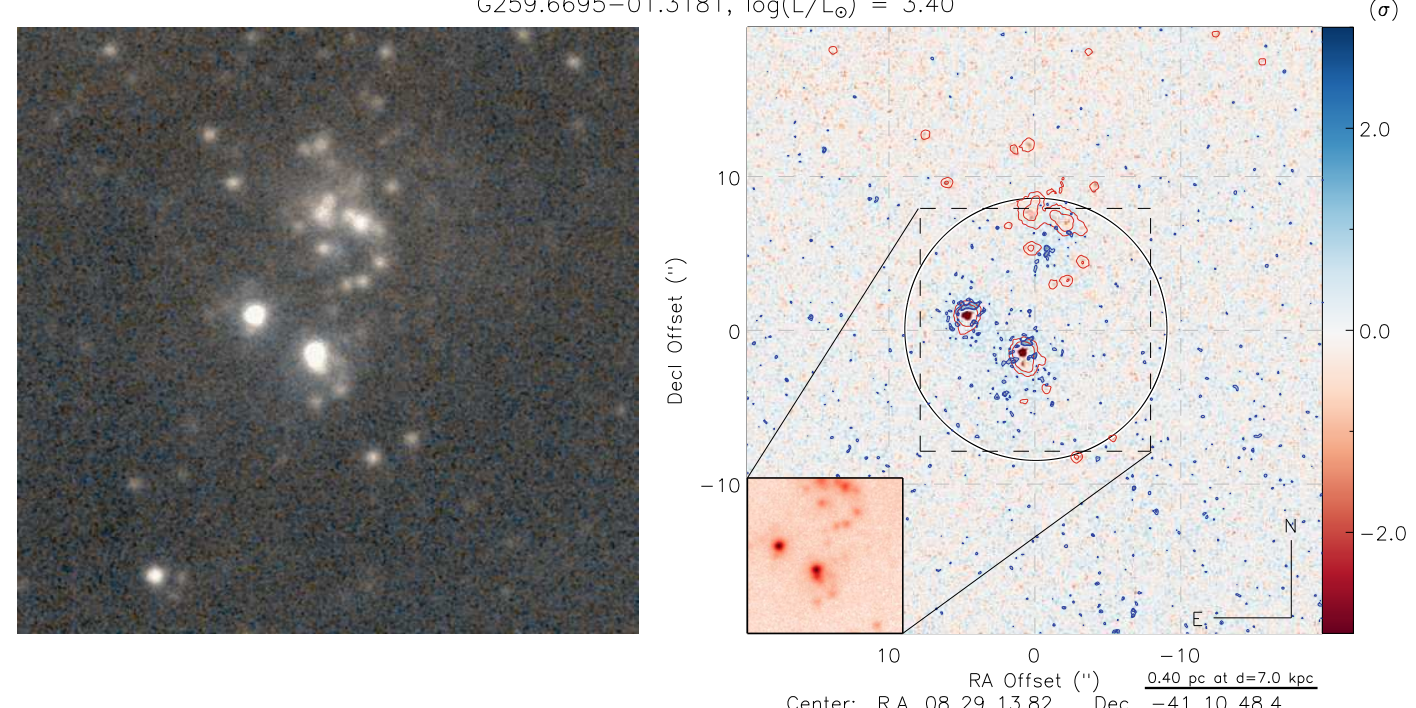

G263.5846-03.9973, $\log \left(L / L_{\odot}\right)=3.97$
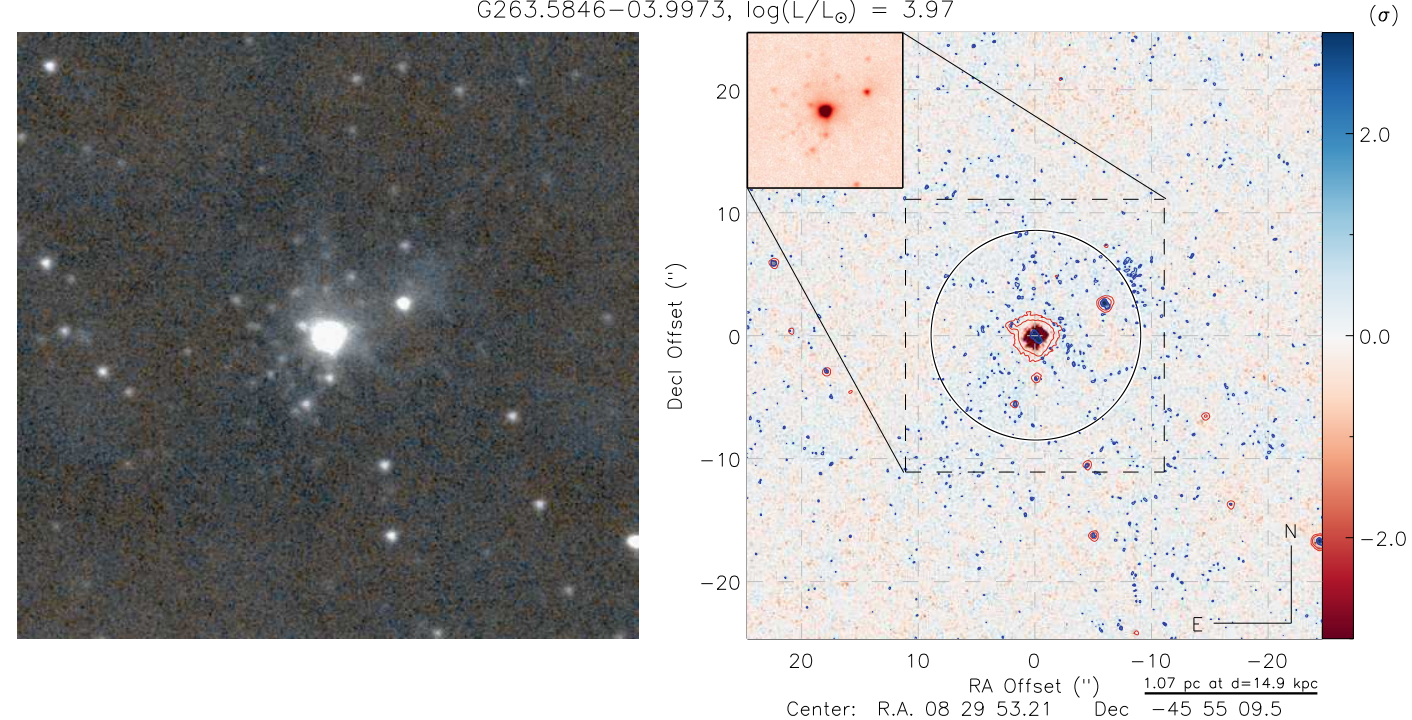
$\mathrm{G} 264.1444+02.0190, \log \left(\mathrm{L} / \mathrm{L}_{\odot}\right)=3.83$
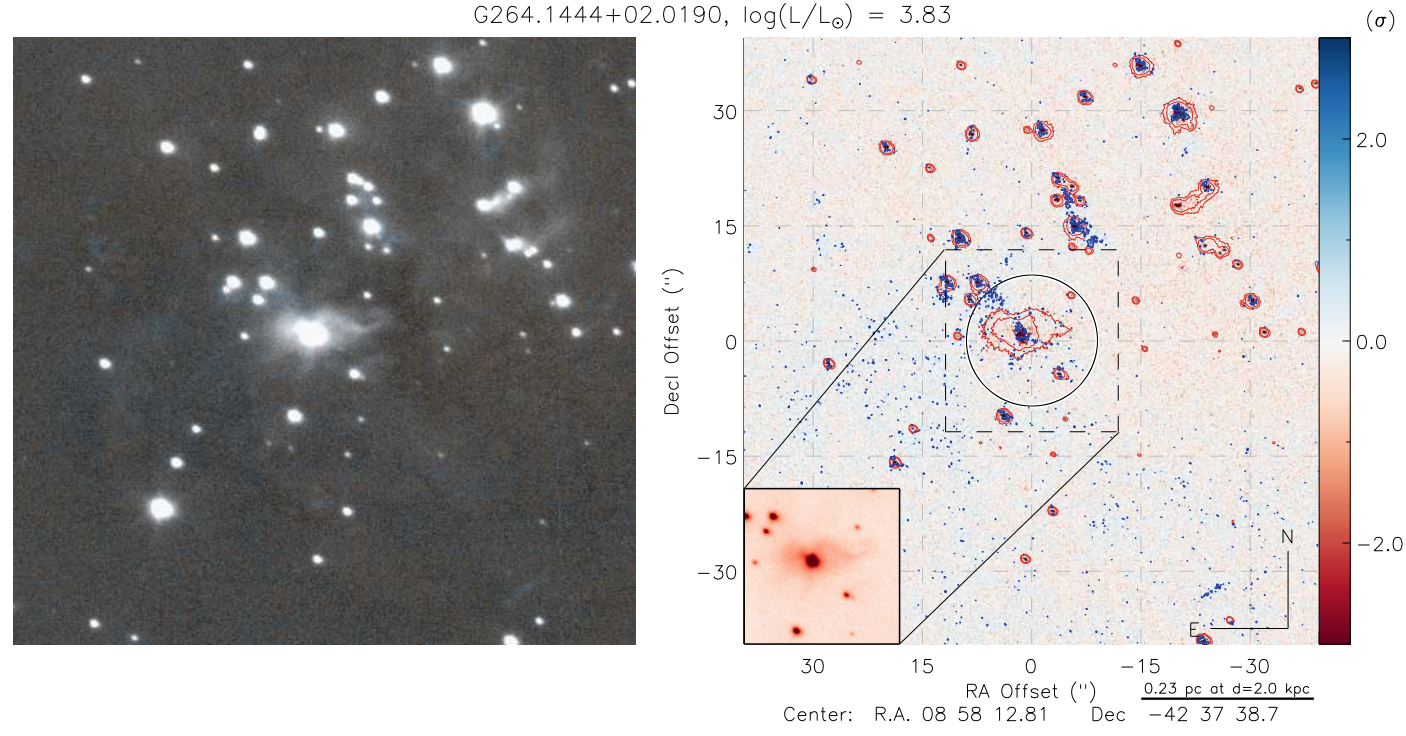

$G 265.3344+01.3916, \log \left(L / L_{\odot}\right)=2.55$
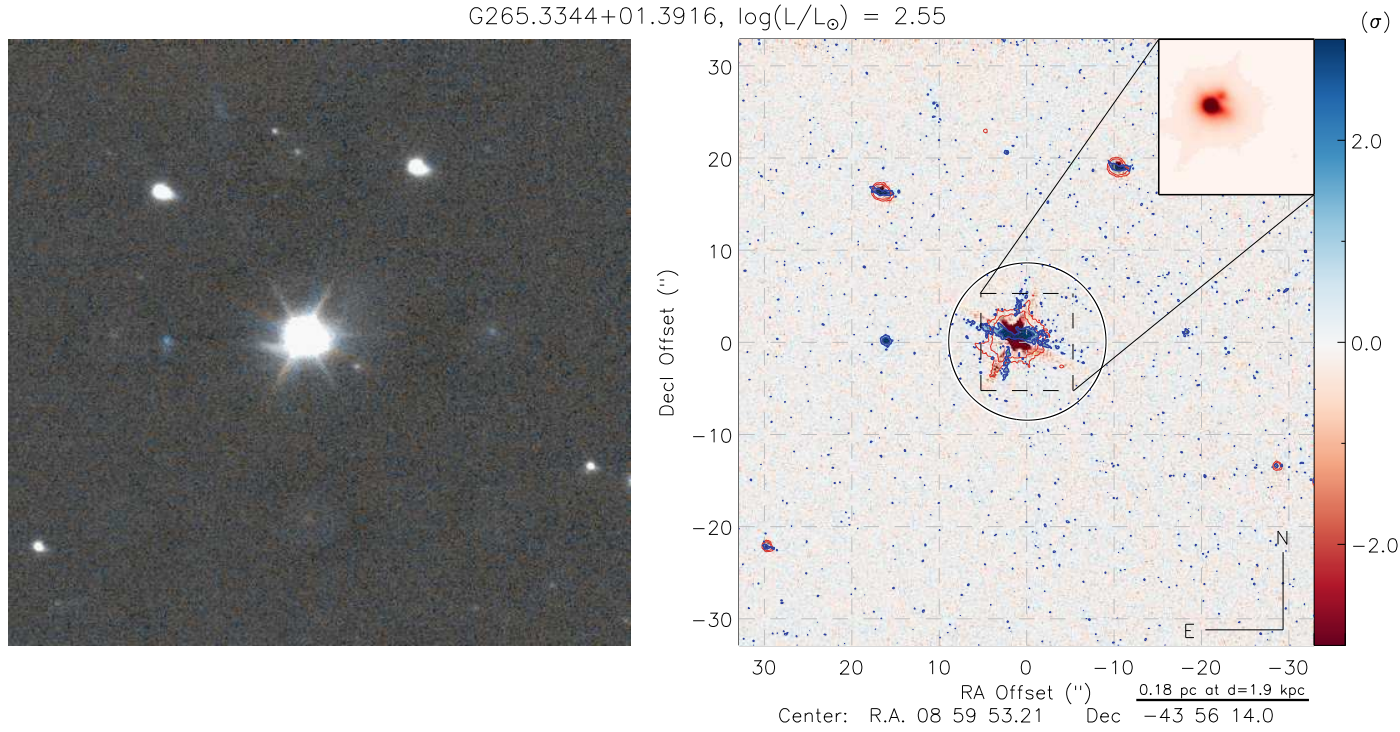

G267.9094+01.7816, $\log \left(L / L_{\odot}\right)=2.60$
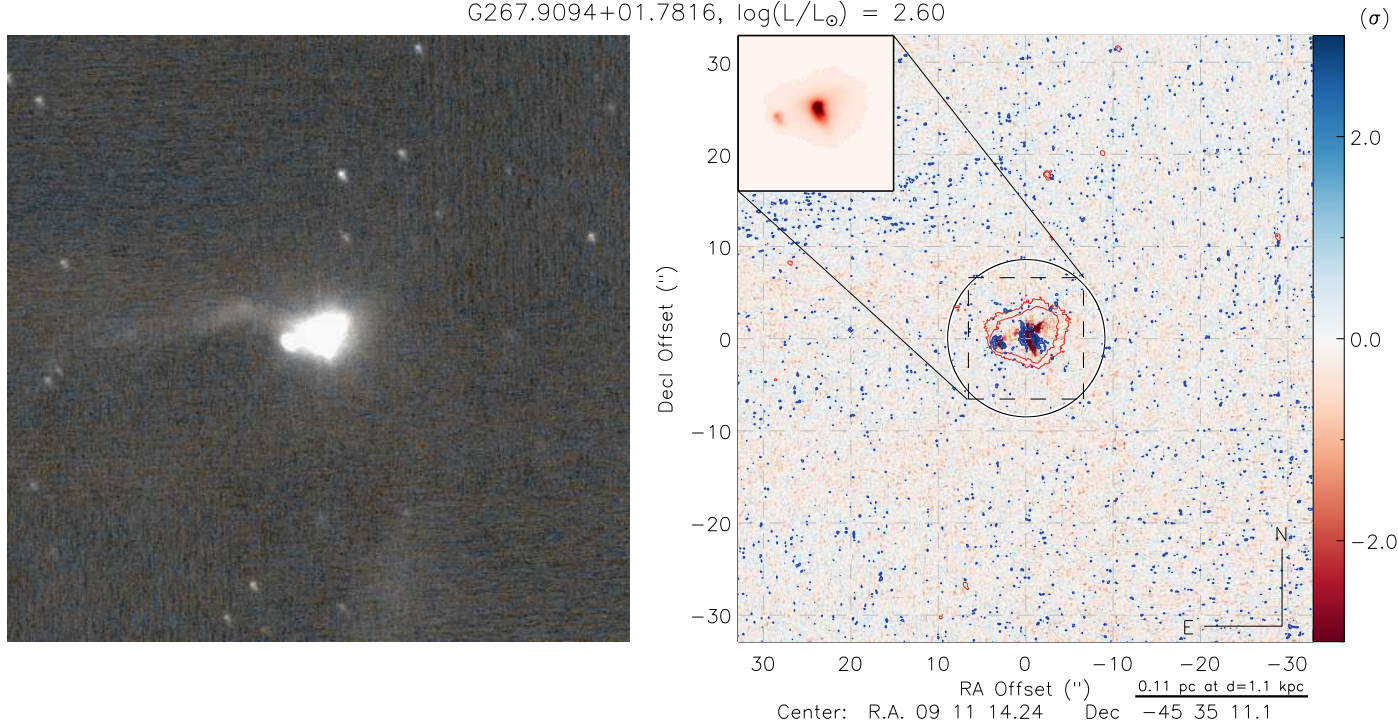
$\mathrm{G} 268.0594-00.8040, \log \left(\mathrm{L} / \mathrm{L}_{\odot}\right)=2.70$
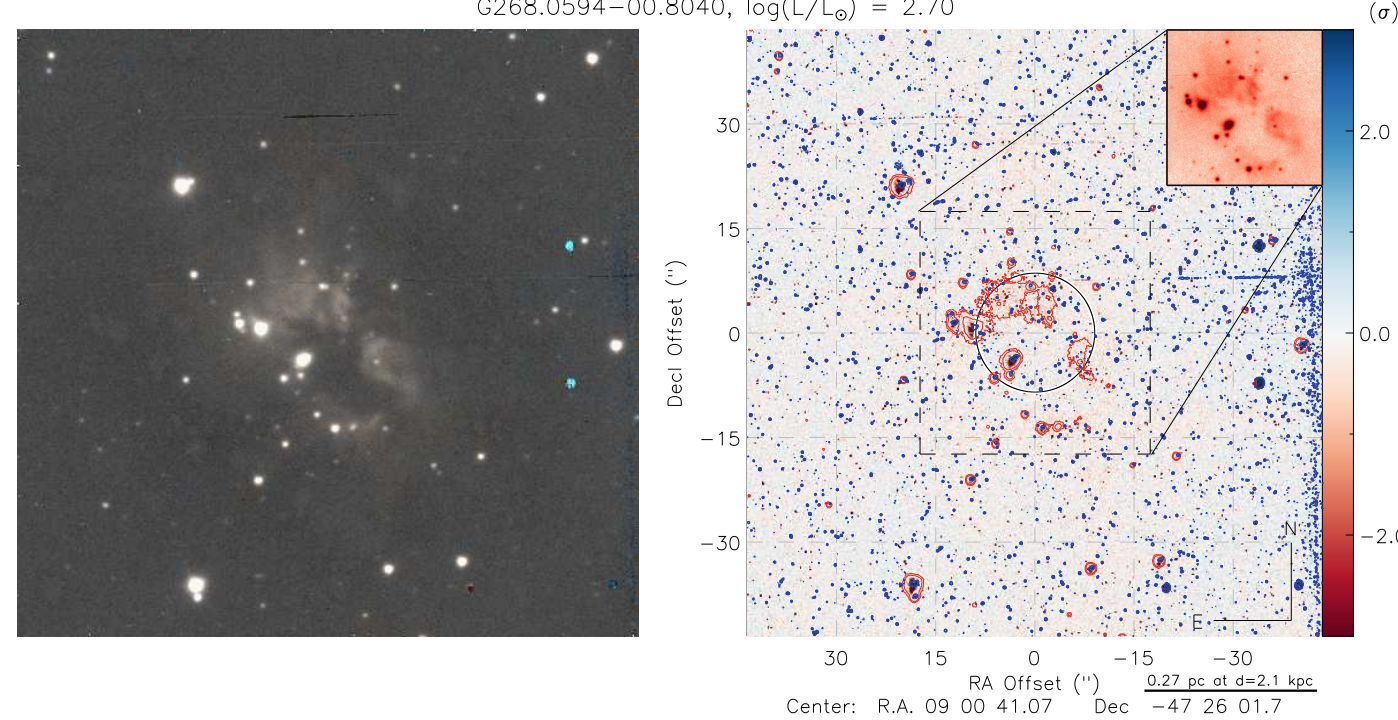

$\mathrm{G} 268.3957-00.4842, \log \left(\mathrm{L} / \mathrm{L}_{\odot}\right)=3.91$
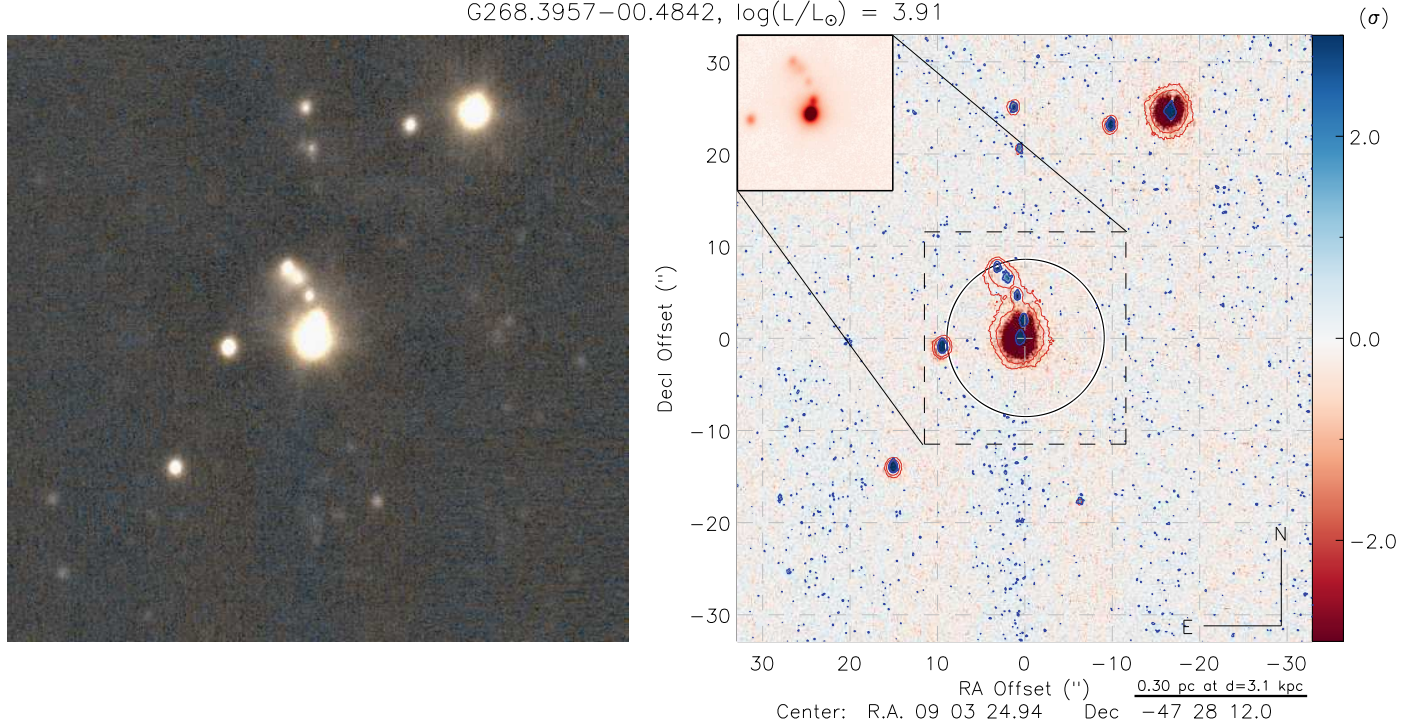

$\mathrm{G} 268.4452-00.8442, \log \left(\mathrm{L} / \mathrm{L}_{\odot}\right)=2.35$
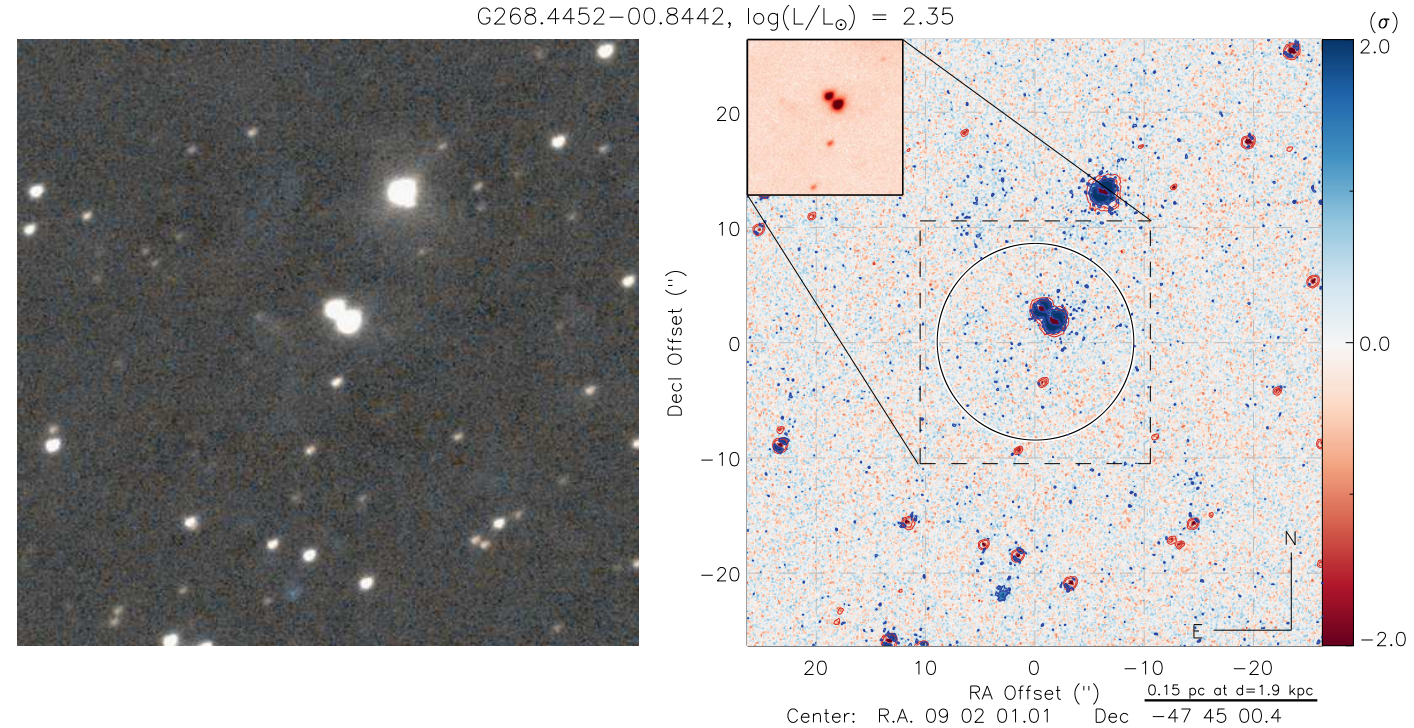
G269.5205-01.2510, $\log \left(L / L_{\odot}\right)=2.83$
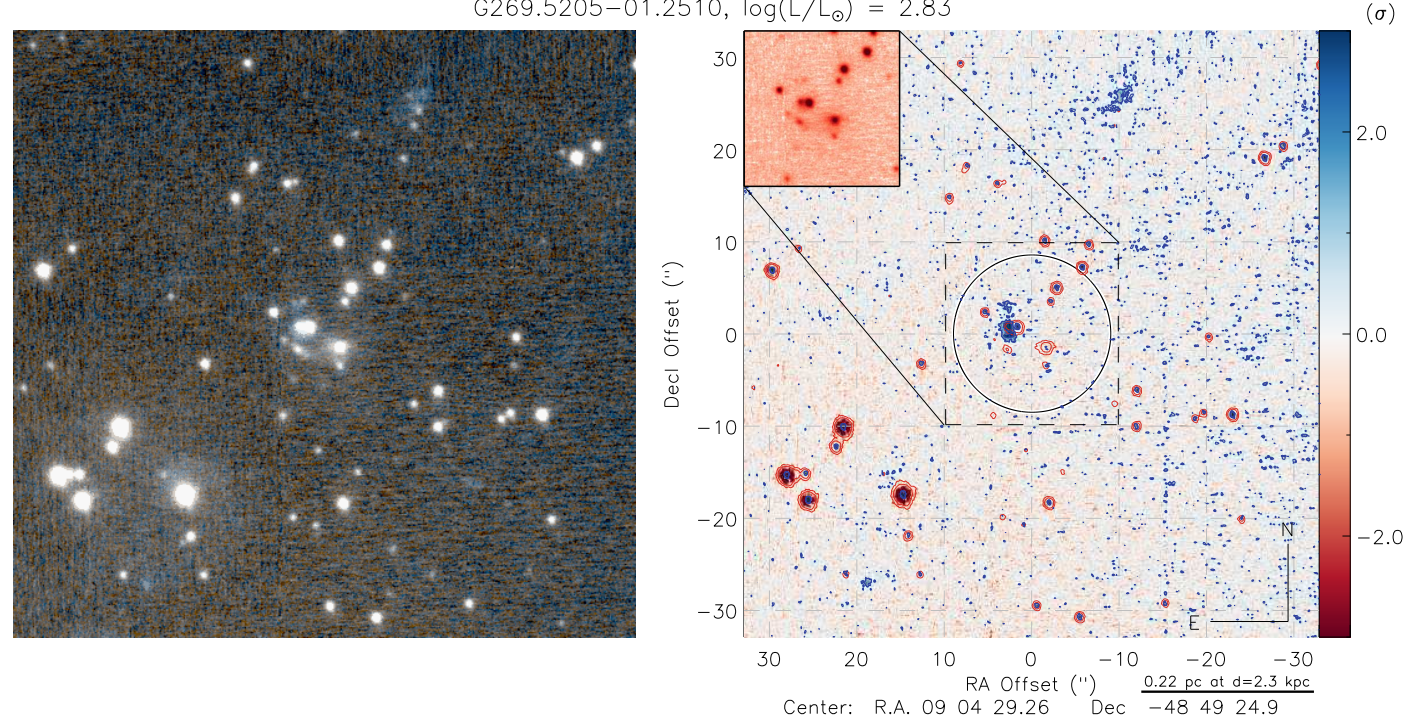

G269.7431-00.3193, $\log \left(L / L_{\odot}\right)=4.93$
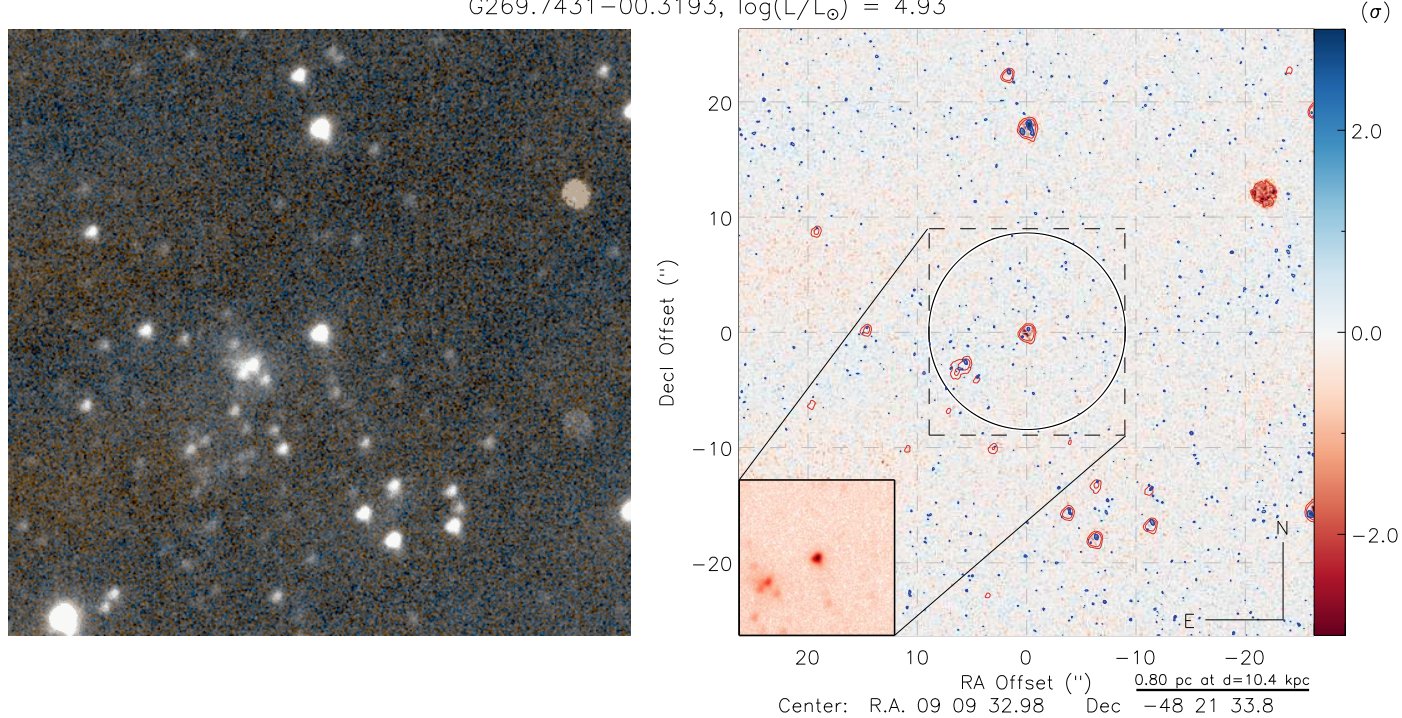

G269.8539-00.0630, $\log \left(L / L_{\odot}\right)=5.08$
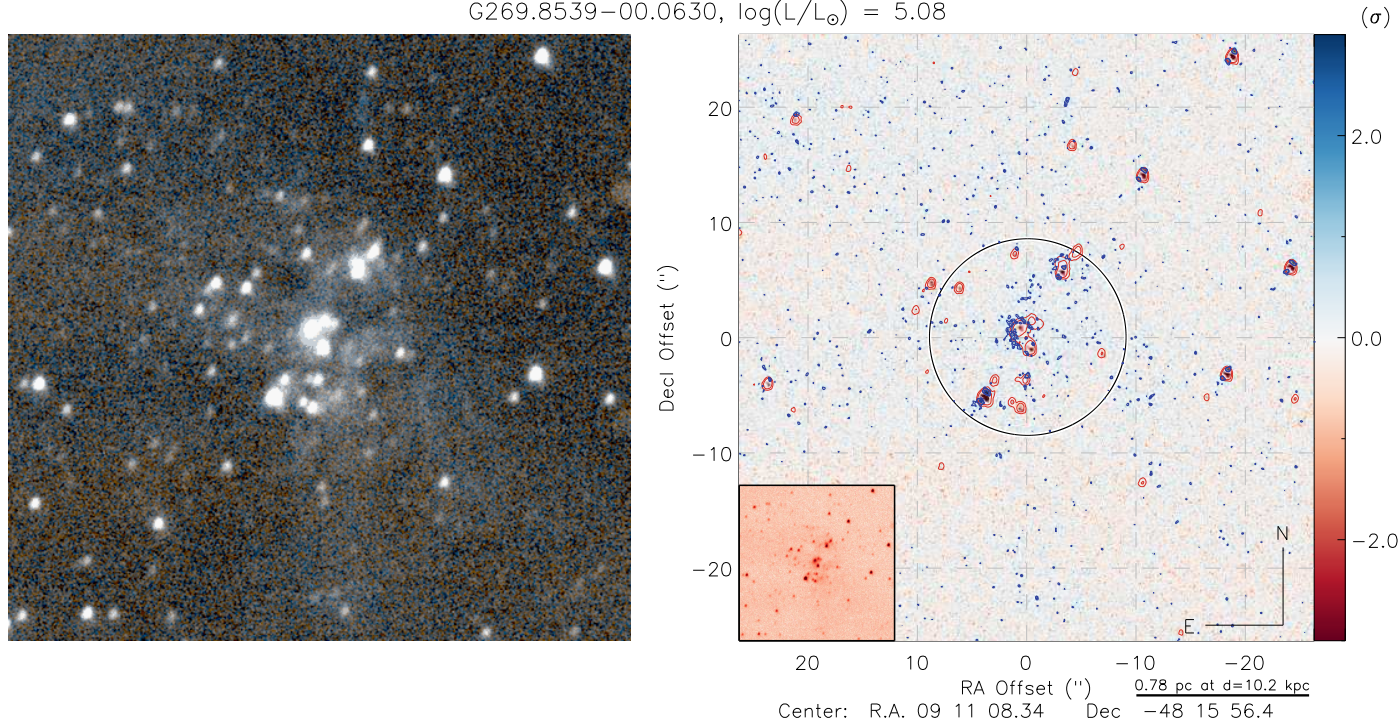

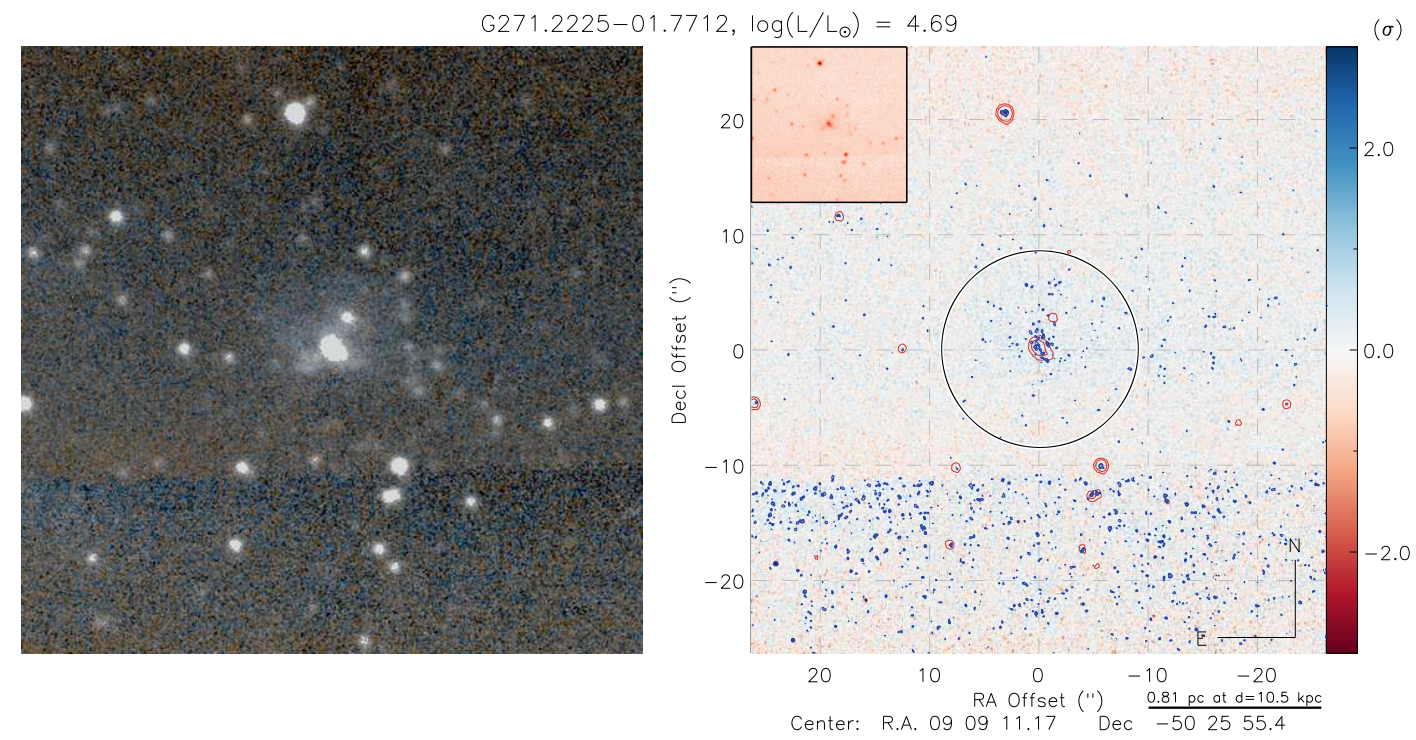

$\mathrm{G} 271.6511-02.1492, \log \left(\mathrm{L} / \mathrm{L}_{\odot}\right)=4.75$
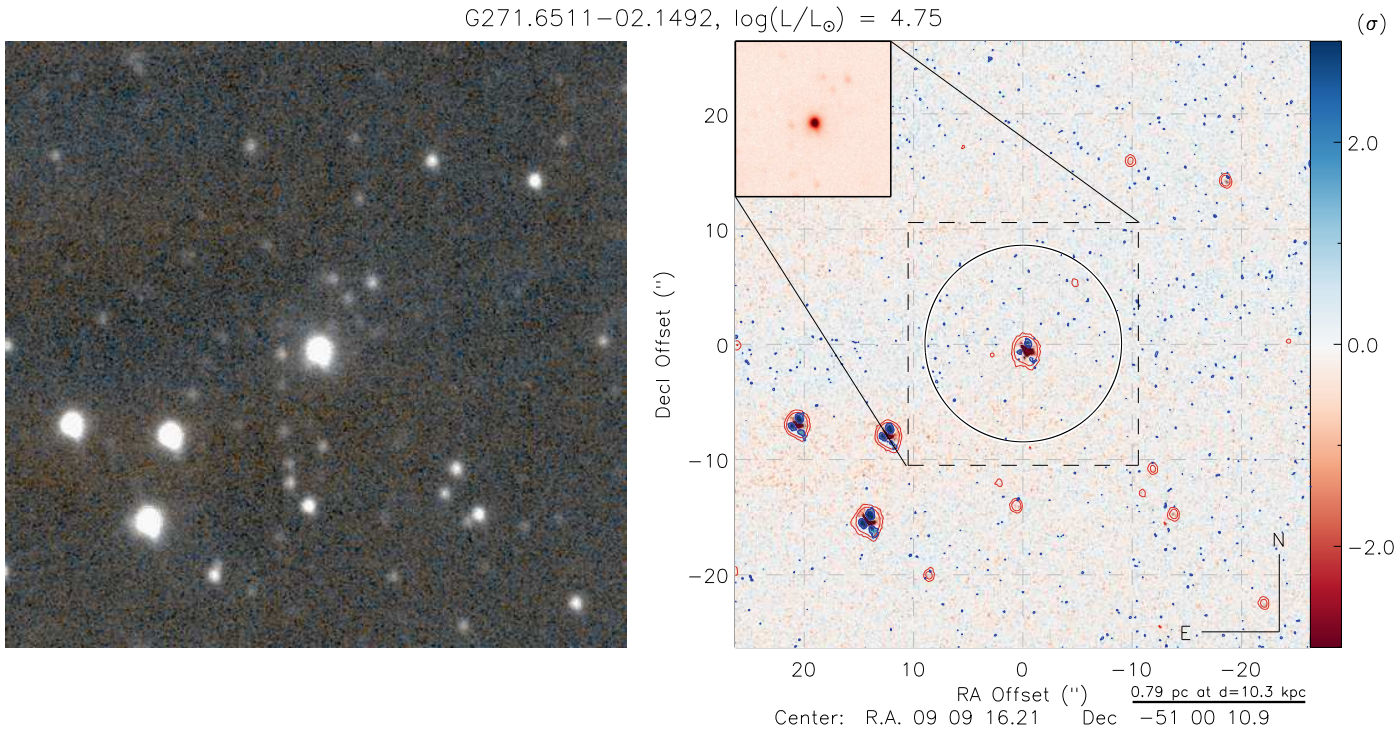

$G 281.2206-01.2556, \log \left(L / L_{\odot}\right)=0.07$
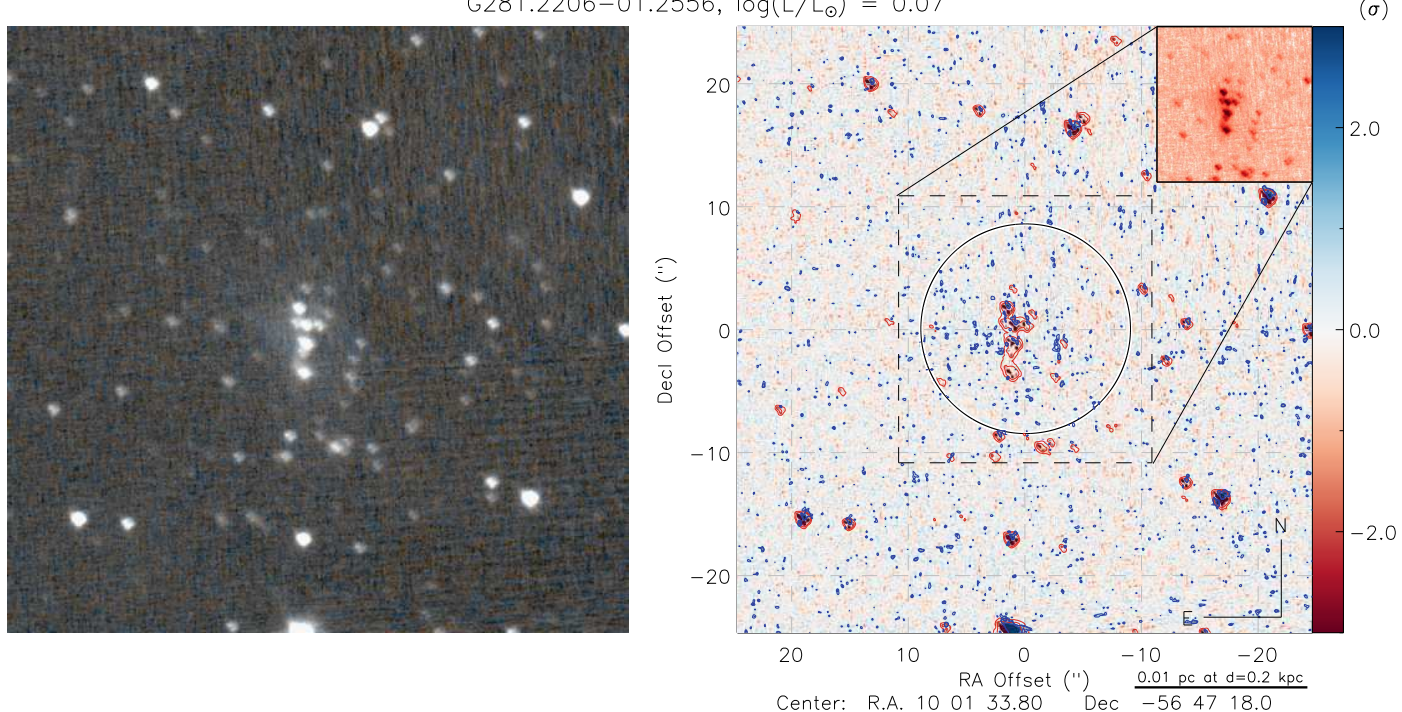
$\mathrm{G} 282.7848-01.2869, \log \left(\mathrm{L} / \mathrm{L}_{\odot}\right)=0.00$
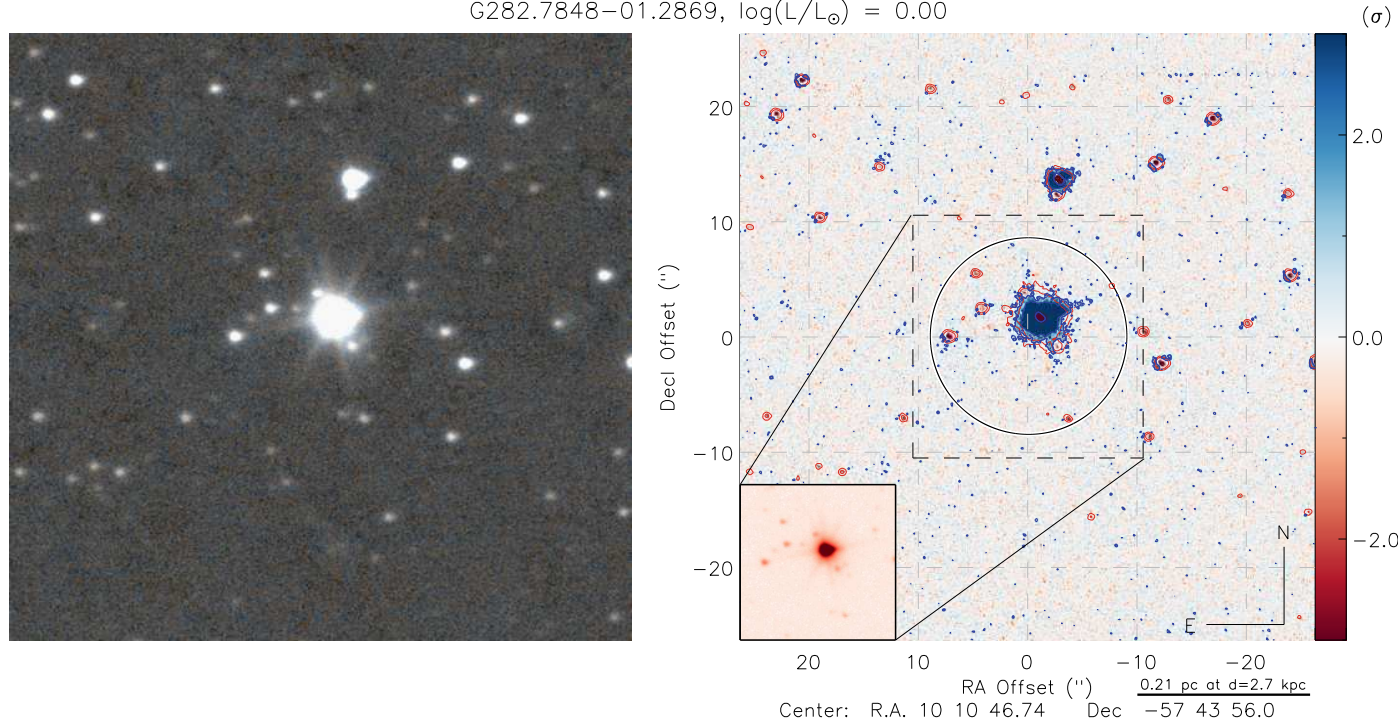

$\mathrm{G} 284.6942-00.3600, \log \left(L / L_{\odot}\right)=4.83$
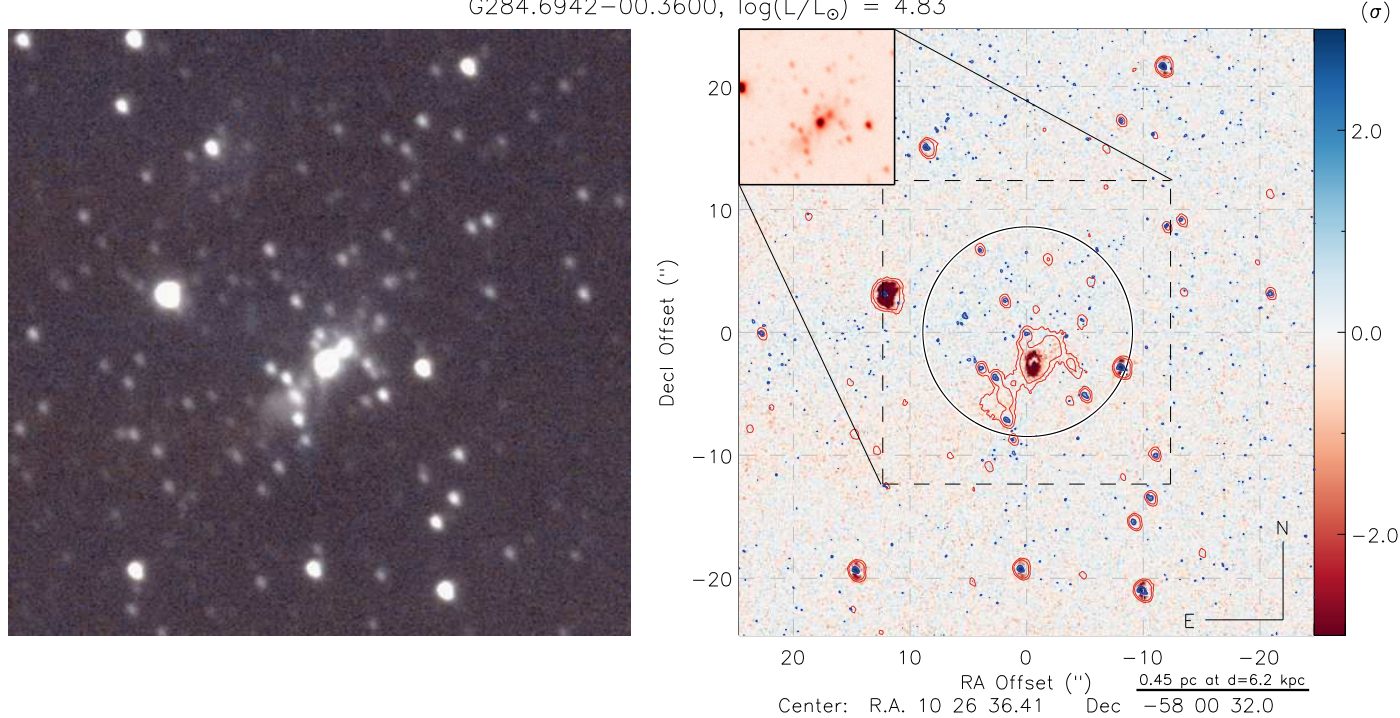

$G 288.1760-00.8351, \log \left(L / L_{\odot}\right)=4.77$
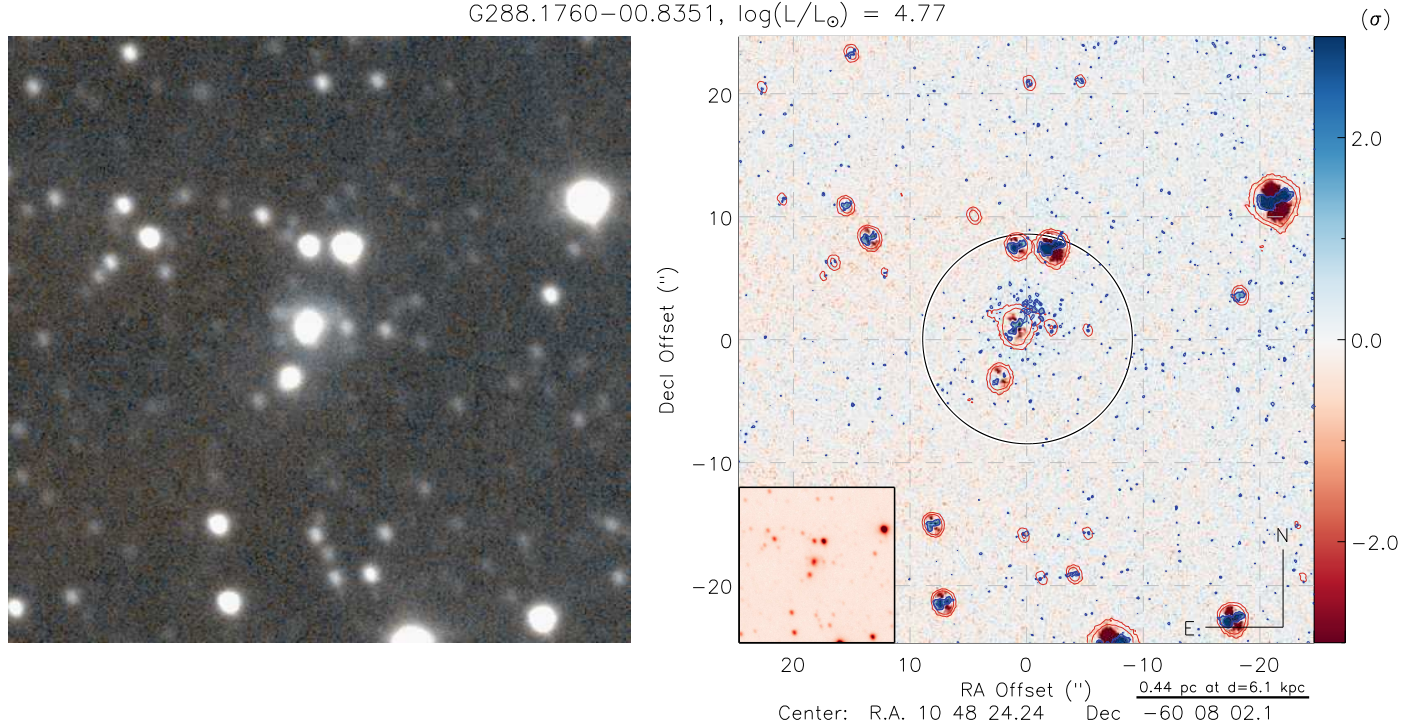
$\mathrm{G} 291.5765-00.4310, \log \left(L / L_{\odot}\right)=5.64$
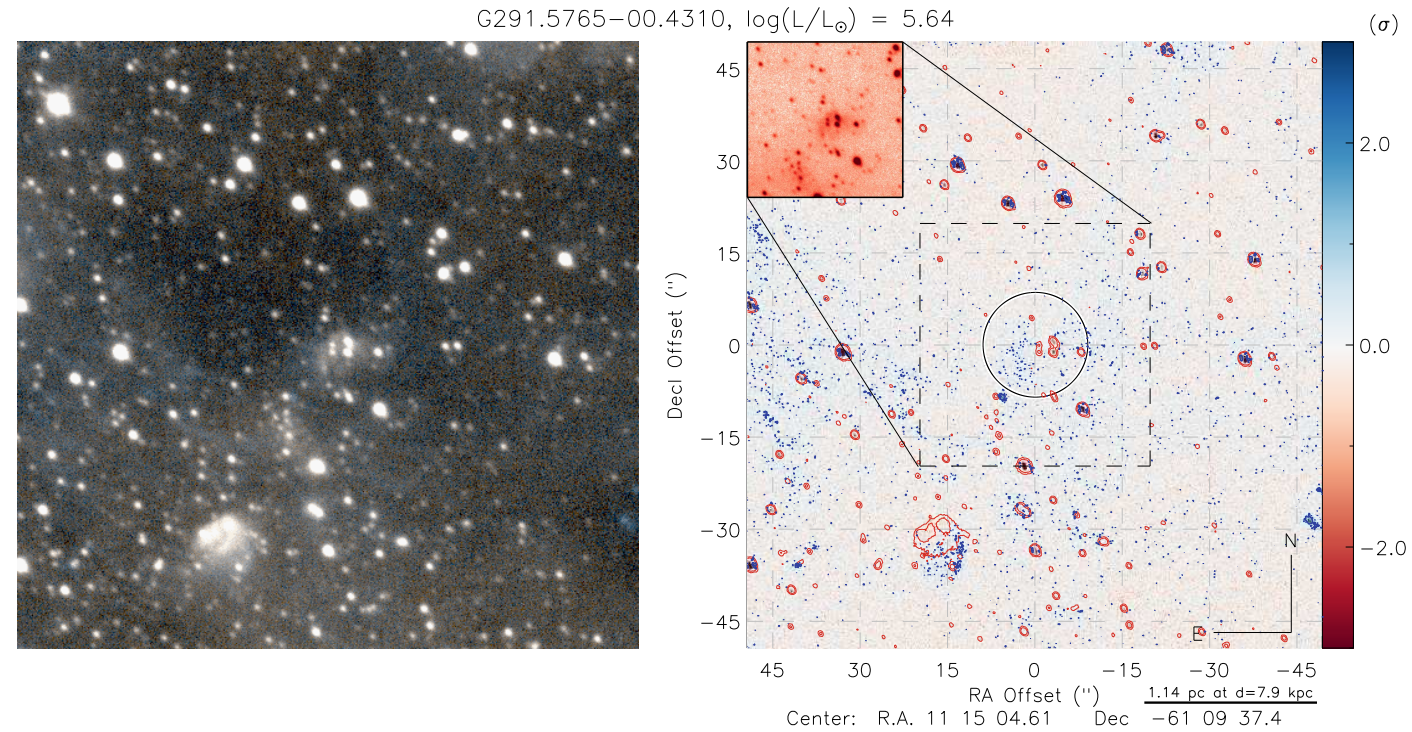

$\mathrm{G} 294.6168-02.3440, \log \left(\mathrm{L} / \mathrm{L}_{\odot}\right)=2.12$
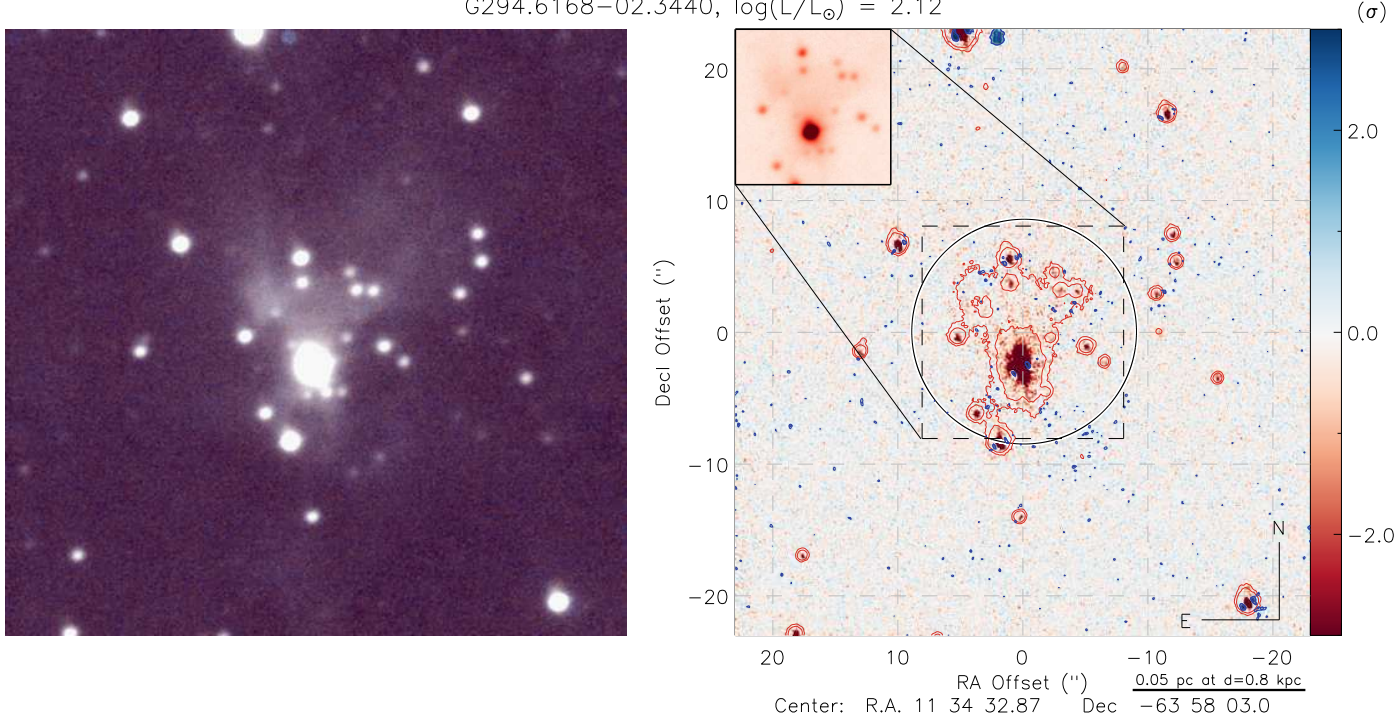

G298.8591-00.4372, $\log \left(L / L_{\odot}\right)=5.20$
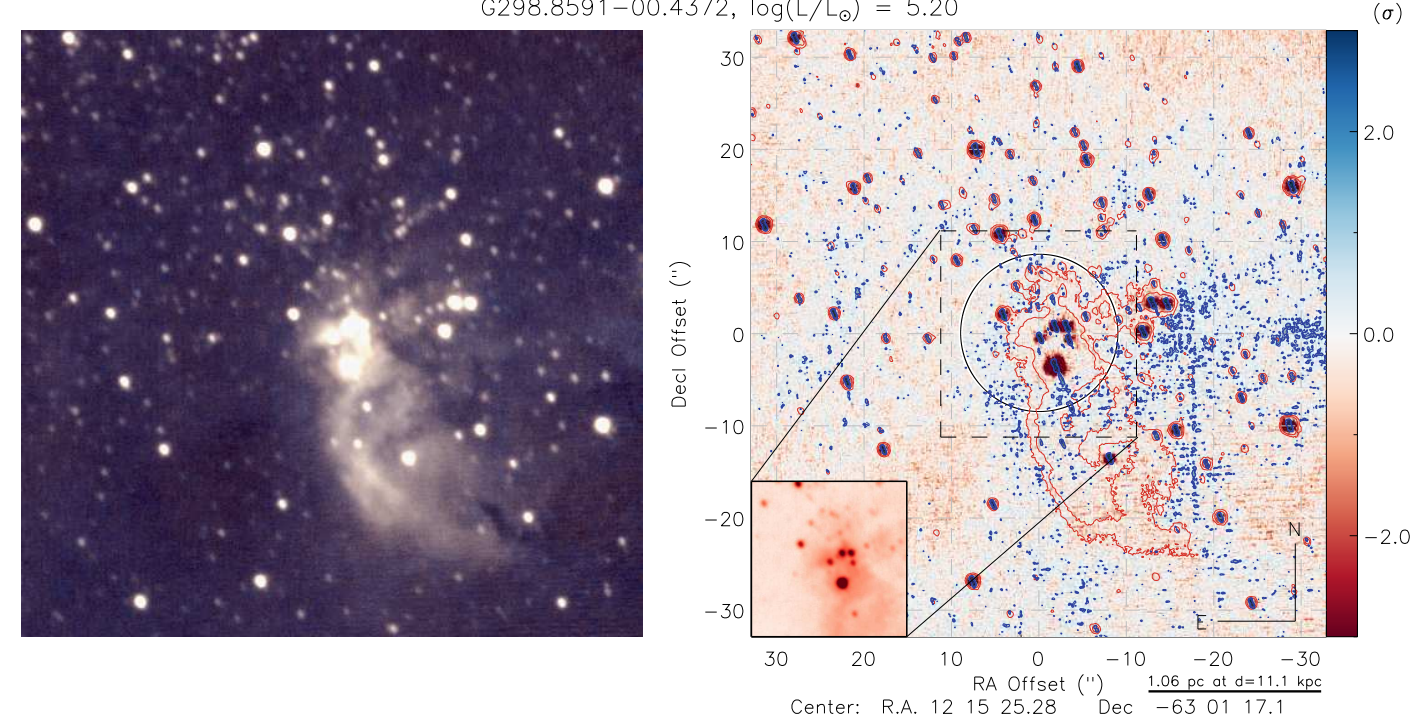
G300.3412-00.2190, $\log \left(L / L_{\odot}\right)=3.76$
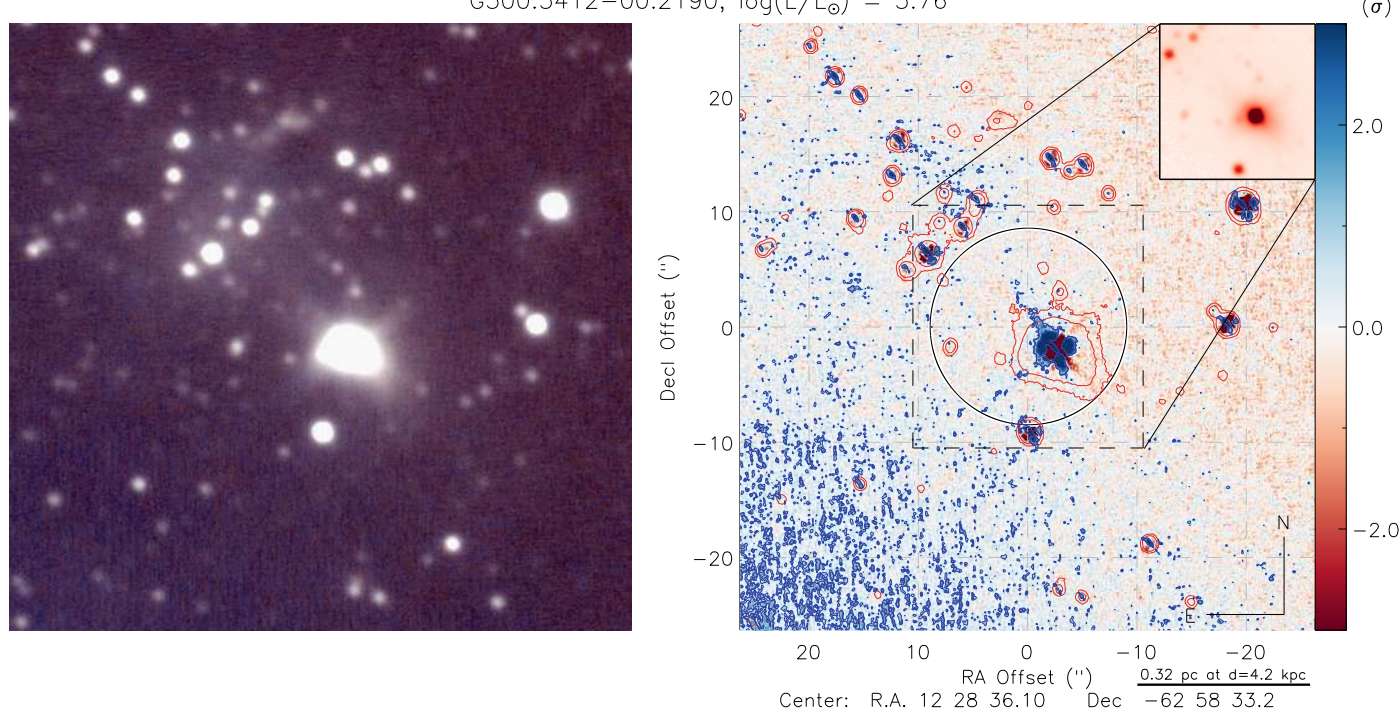

$G 300.7221+01.2007, \log \left(L / L_{\odot}\right)=4.15$
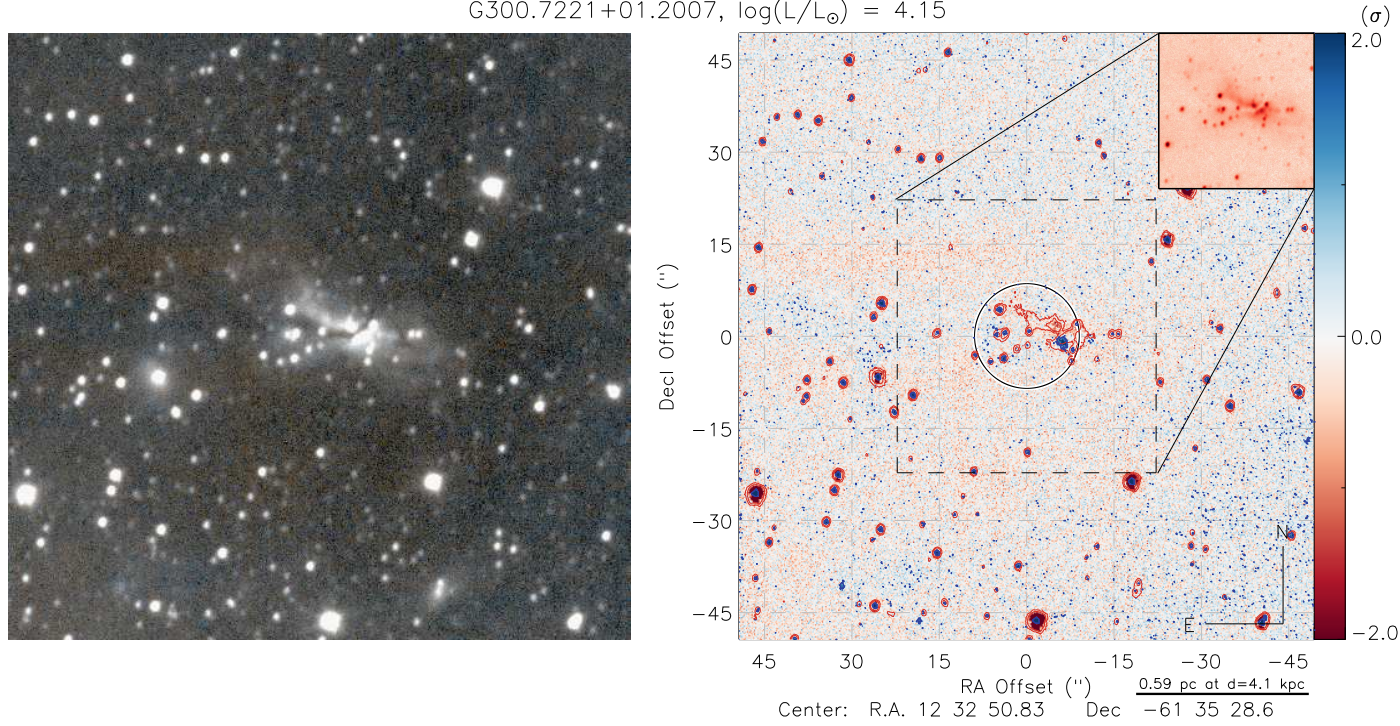

$G 301.1726+01.0034, \log \left(L / L_{\odot}\right)=4.14$
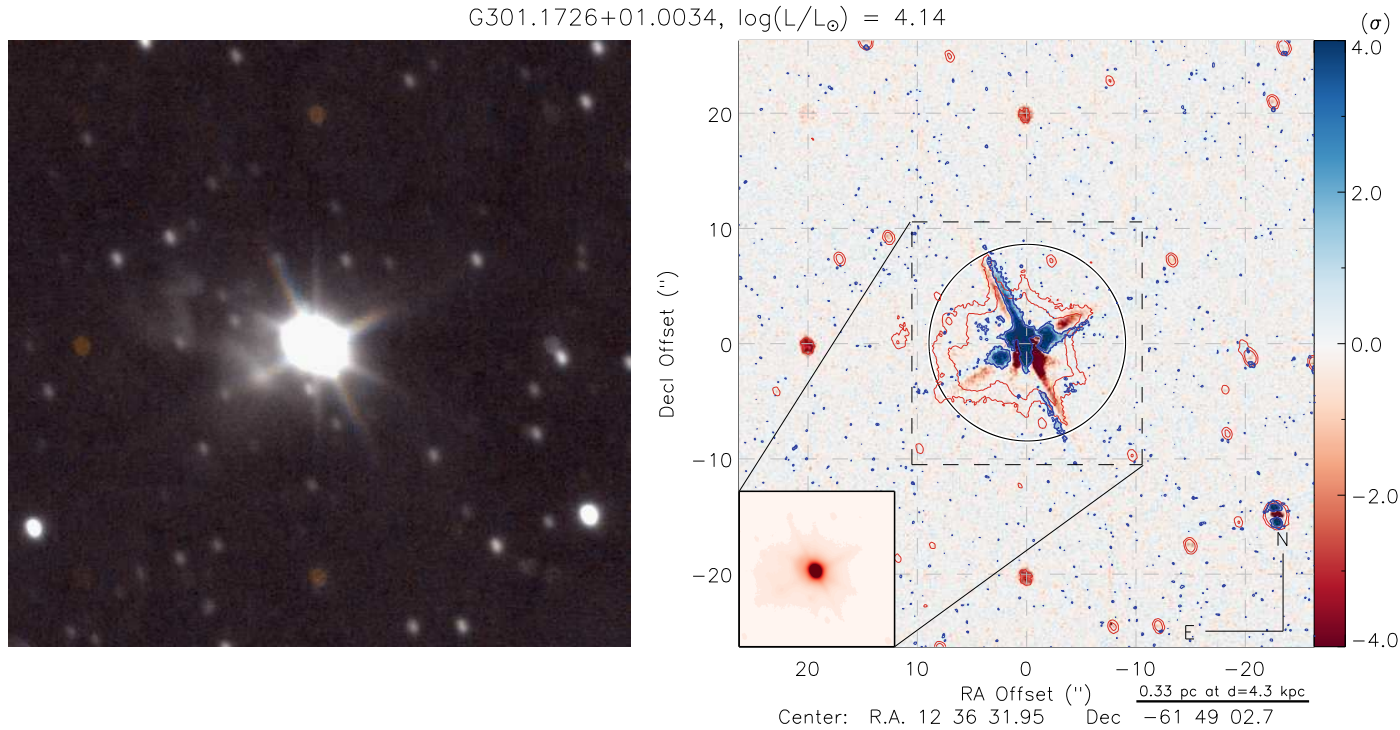
$G 302.1515-00.9488, \log \left(L / L_{\odot}\right)=3.83$
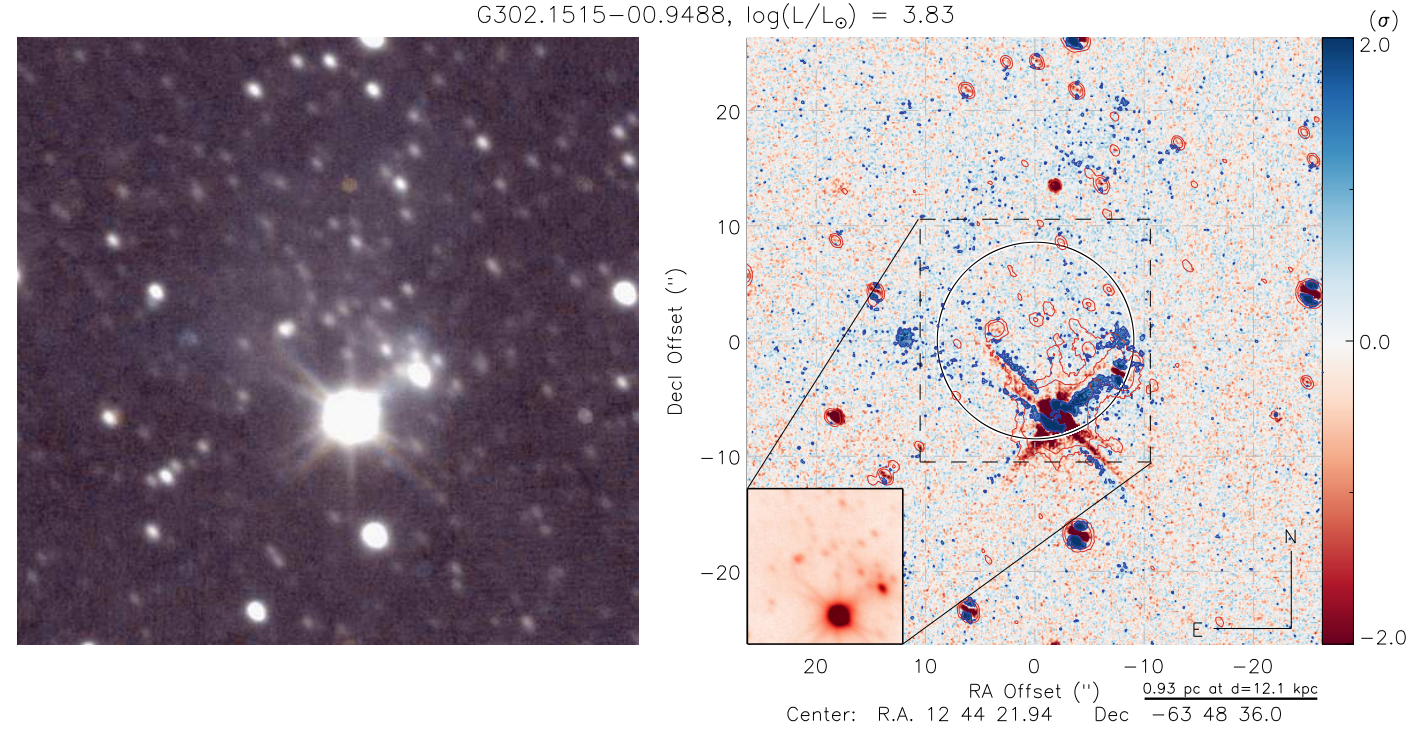

$G 302.4546-00.7401, \log \left(L / L_{\odot}\right)=4.36$
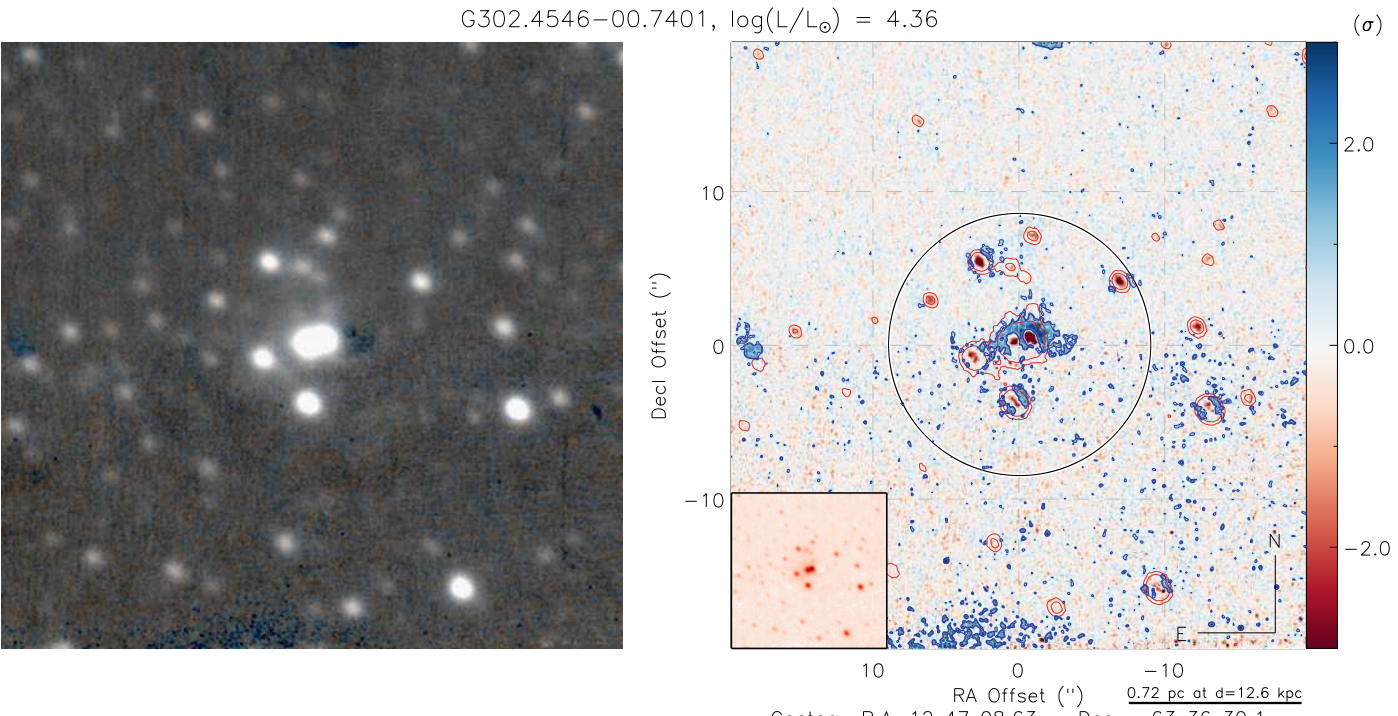

G302.4867-00.0308, $\log \left(L / L_{\odot}\right)=4.10$
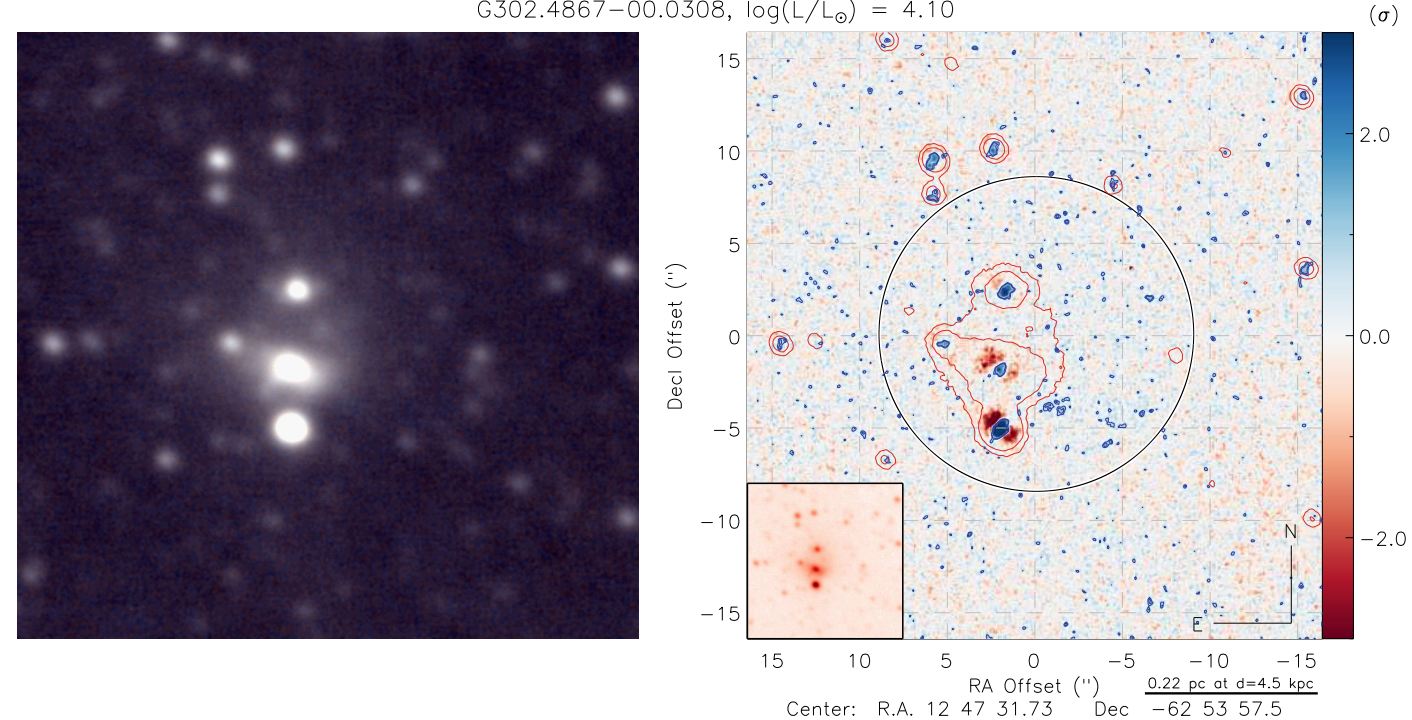
$G 302.5005-00.7701, \log \left(L / L_{\odot}\right)=3.94$
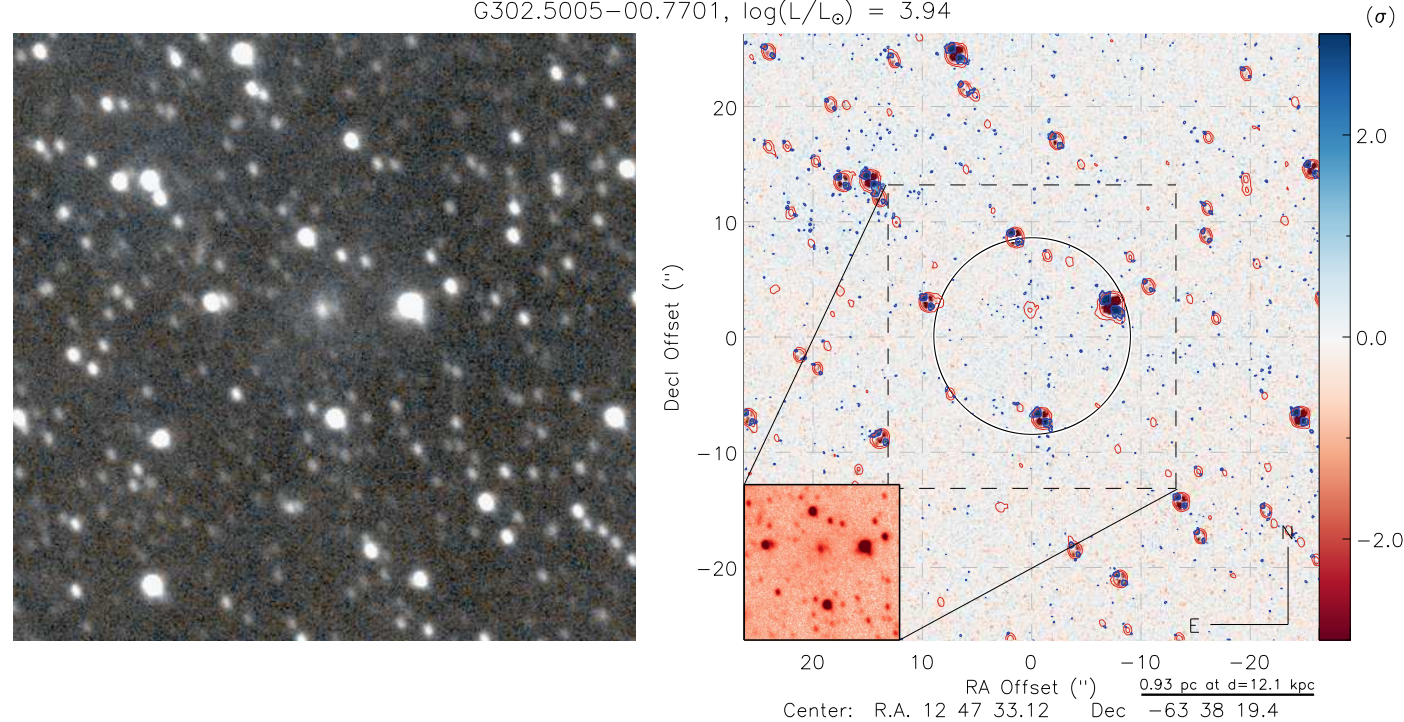

G304.7592-00.6299, $\log \left(L / L_{\odot}\right)=3.64$
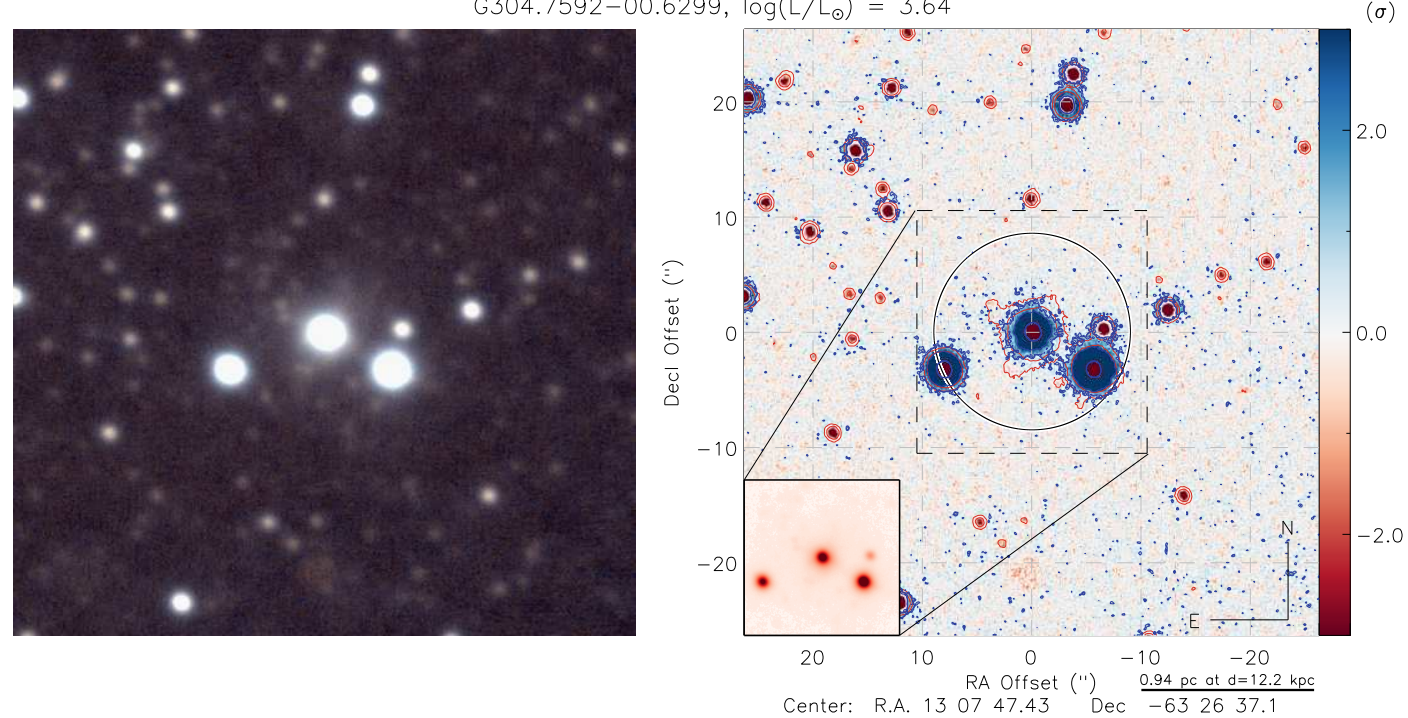

G305.4748-00.0961, $\log \left(L / L_{\odot}\right)=3.57$
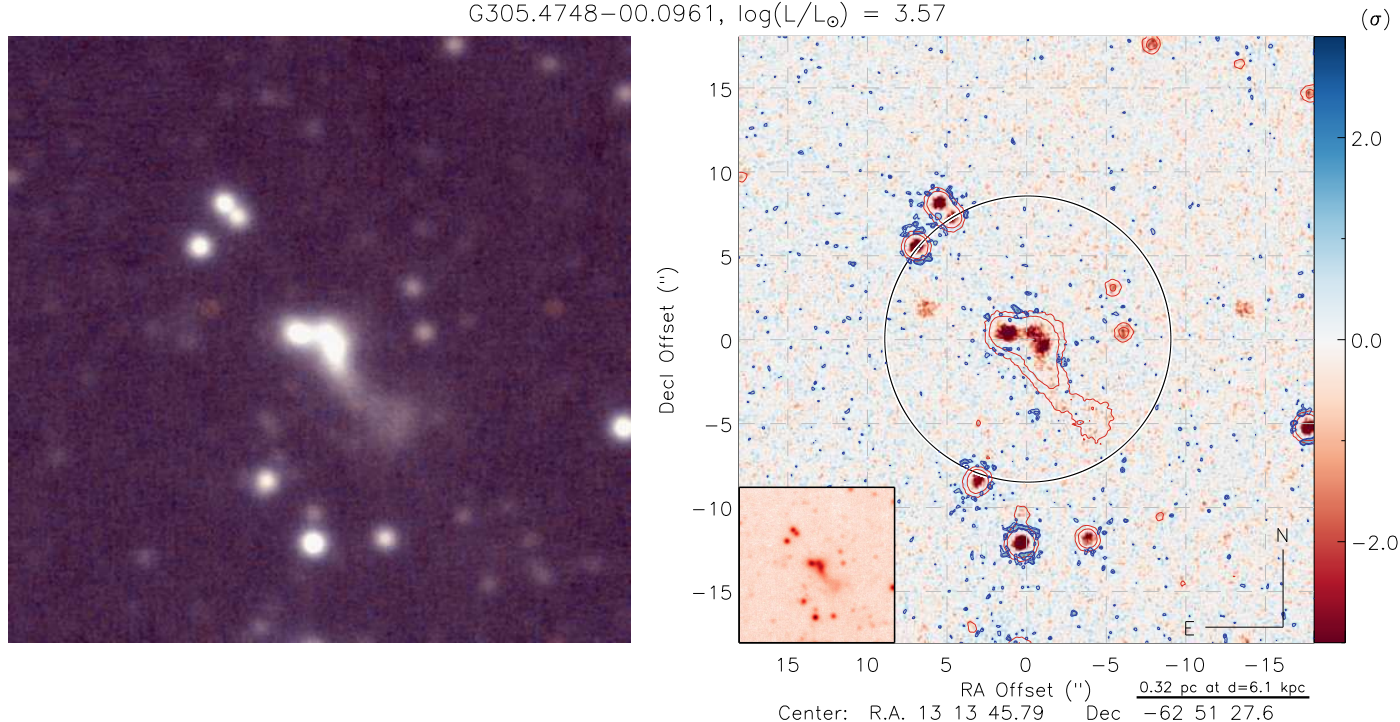
$G 305.4840+00.2248, \log \left(L / L_{\odot}\right)=3.89$
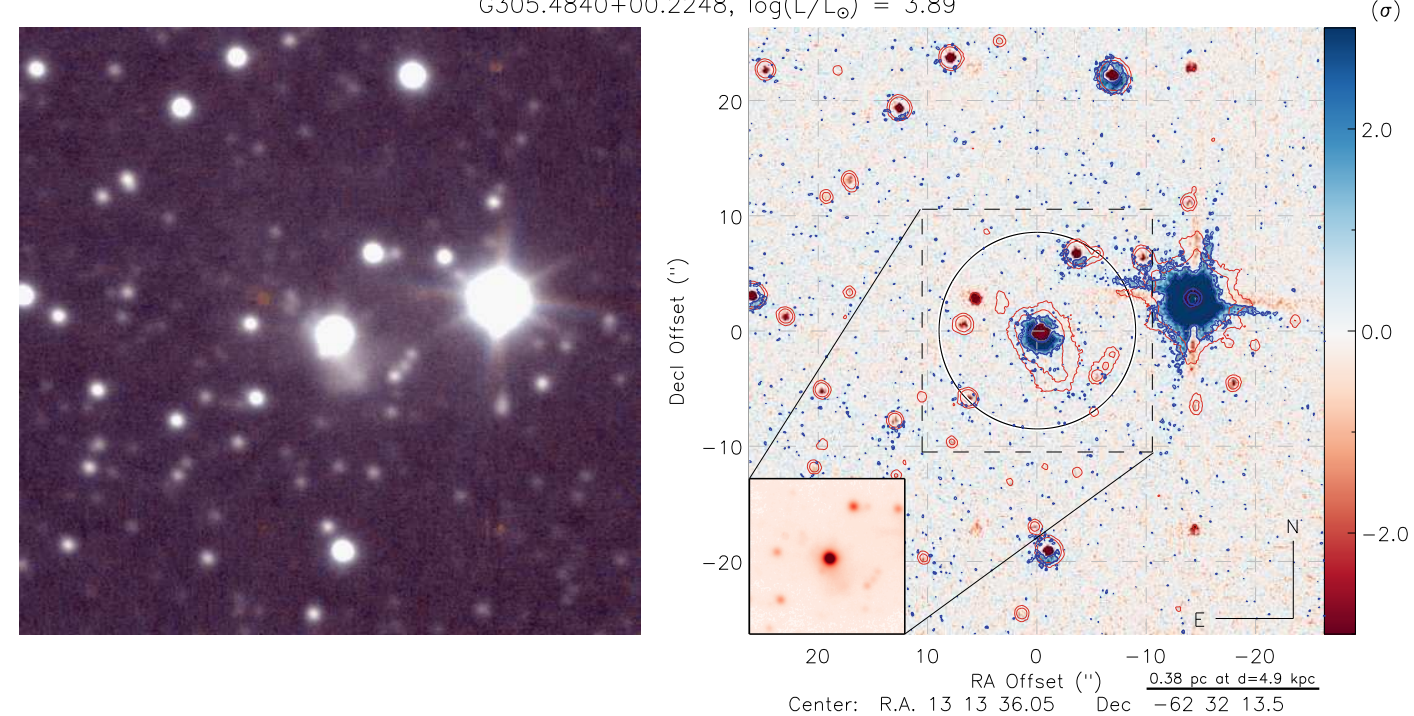

$G 305.5393+00.3394, \log \left(L / L_{\odot}\right)=3.51$
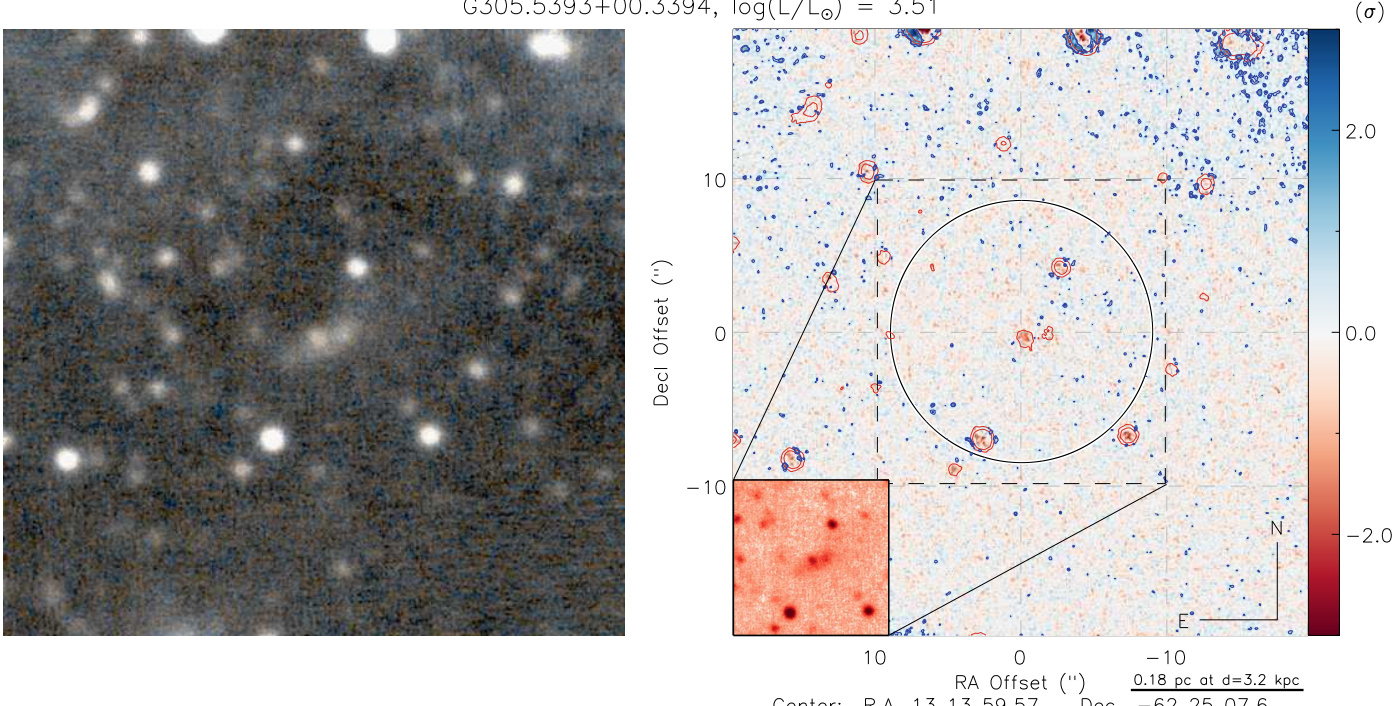

G307.3950-00.5838, $\log \left(L / L_{\odot}\right)=4.10$
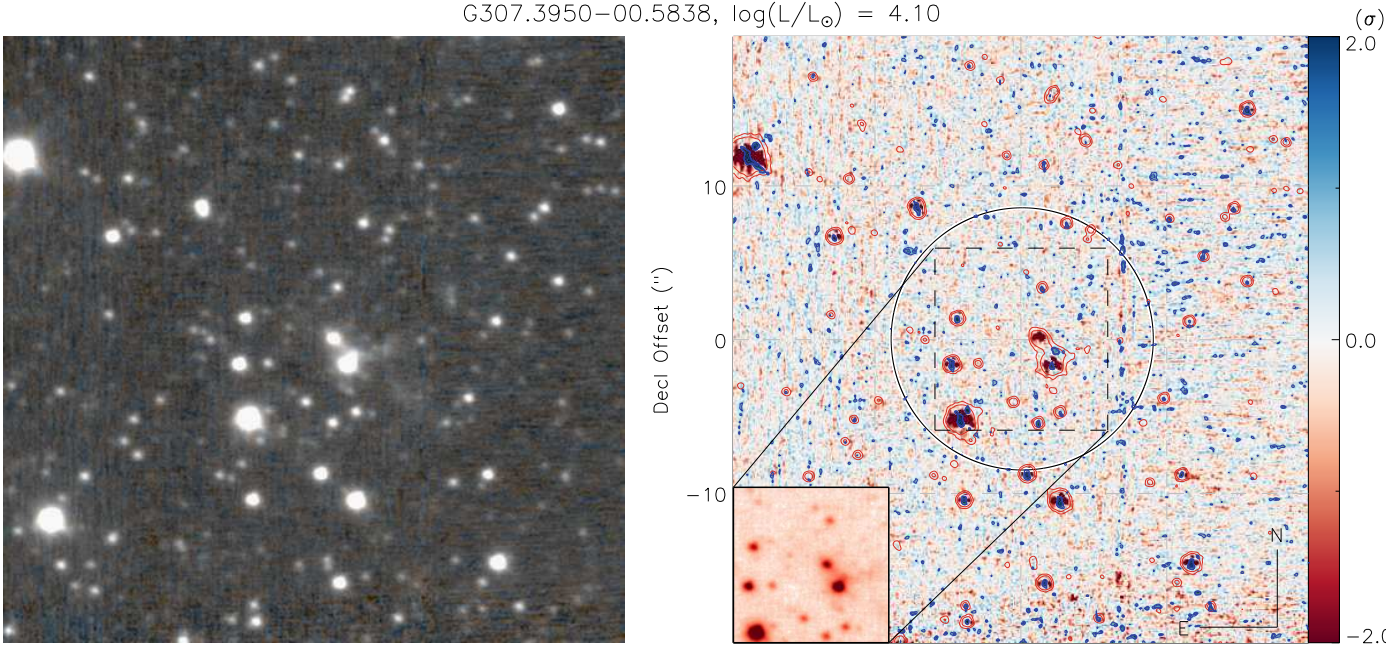

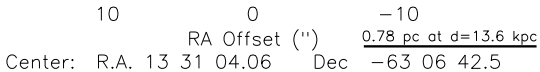


$G 307.7359-00.5945, \log \left(L / L_{\odot}\right)=4.30$
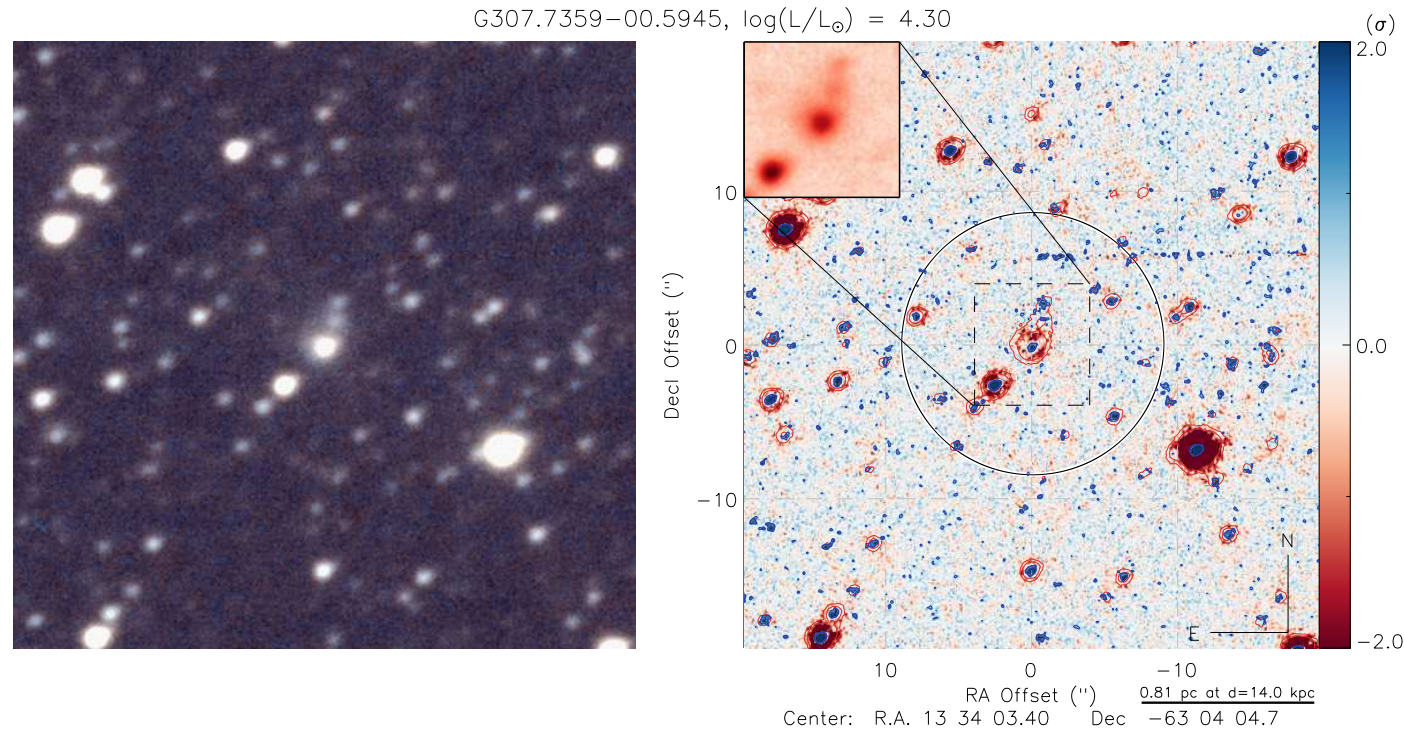

$G 308.0049-00.3868, \log \left(L / L_{\odot}\right)=3.96$
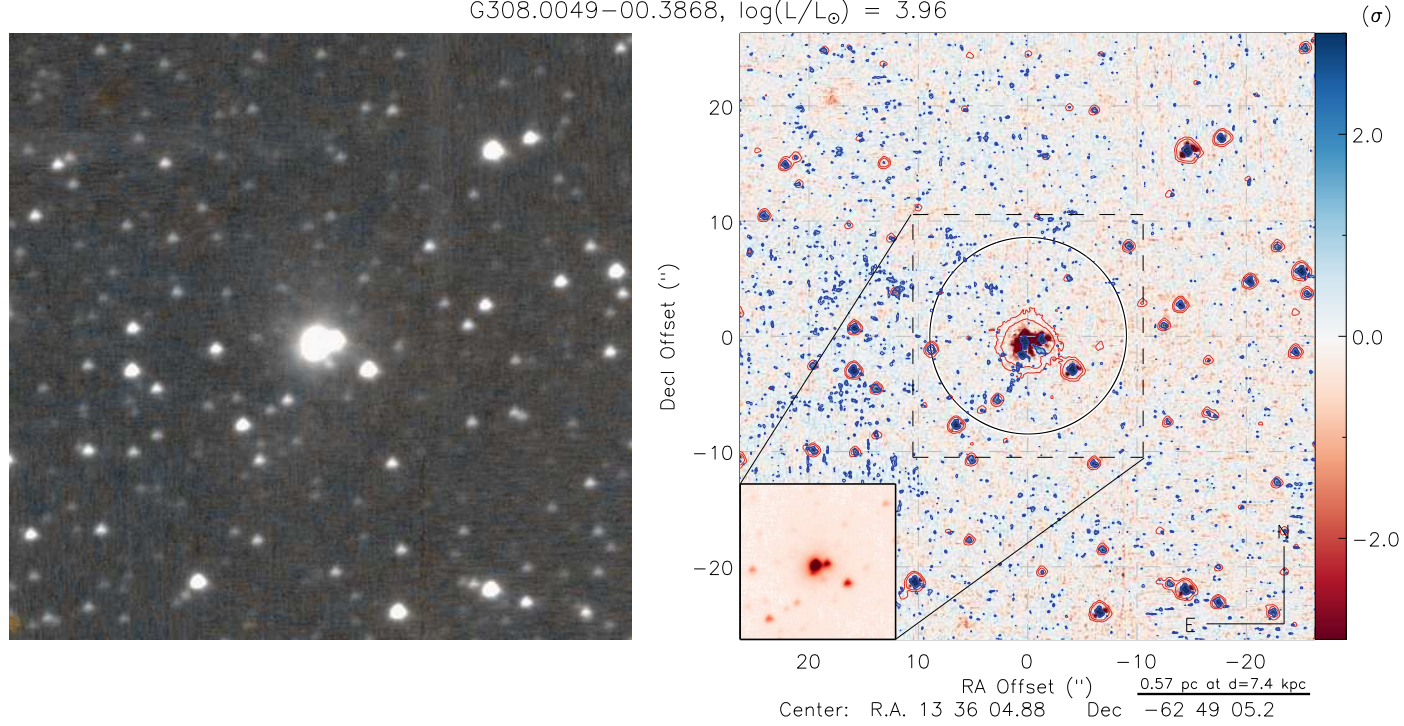

$G 308.7008+00.5312, \log \left(L / L_{\odot}\right)=3.66$
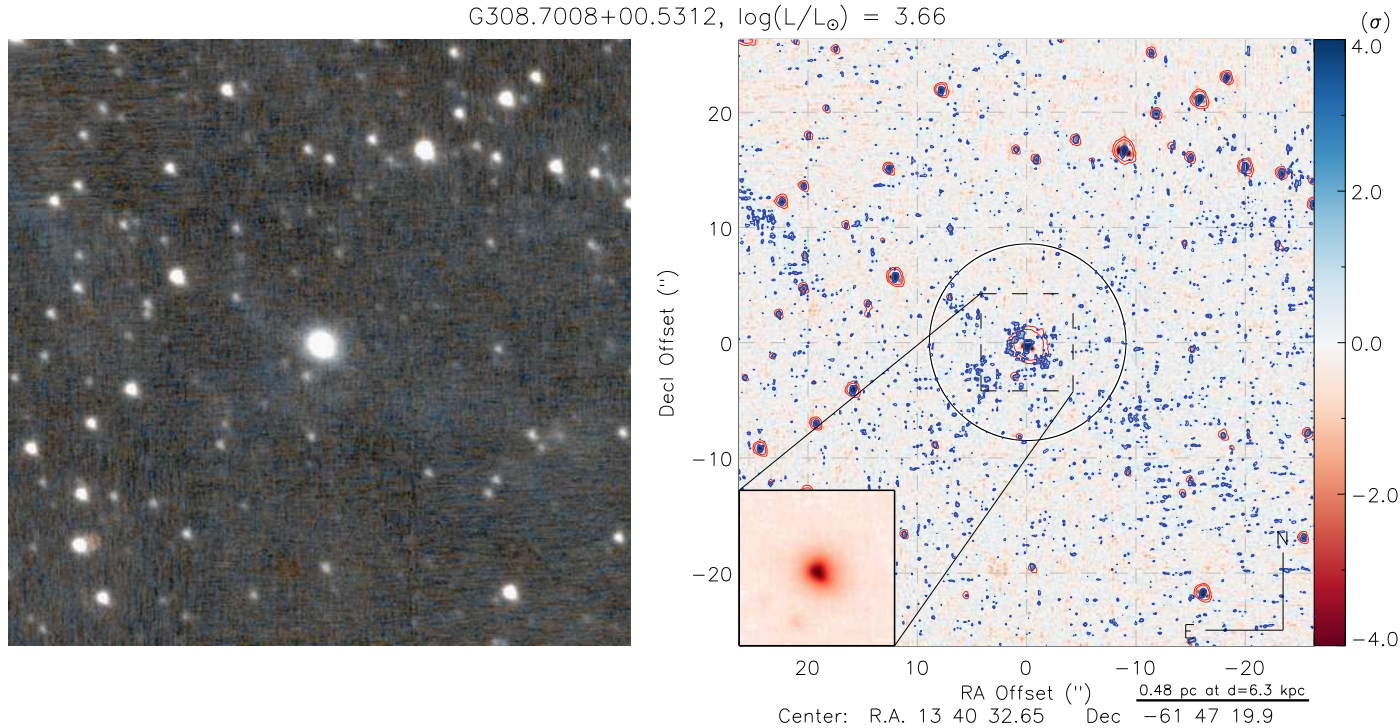

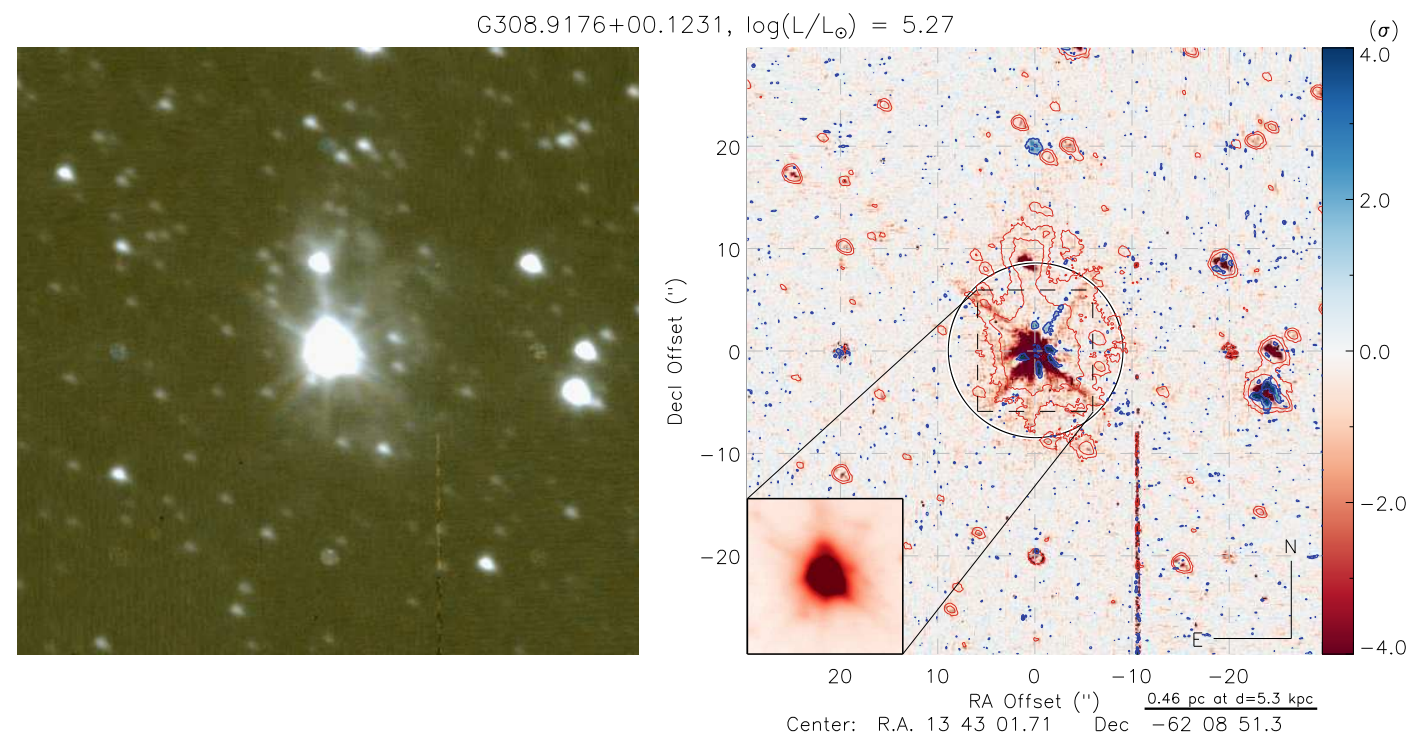

$\mathrm{G} 309.4230-00.6208, \log \left(\mathrm{L} / \mathrm{L}_{\odot}\right)=3.51$
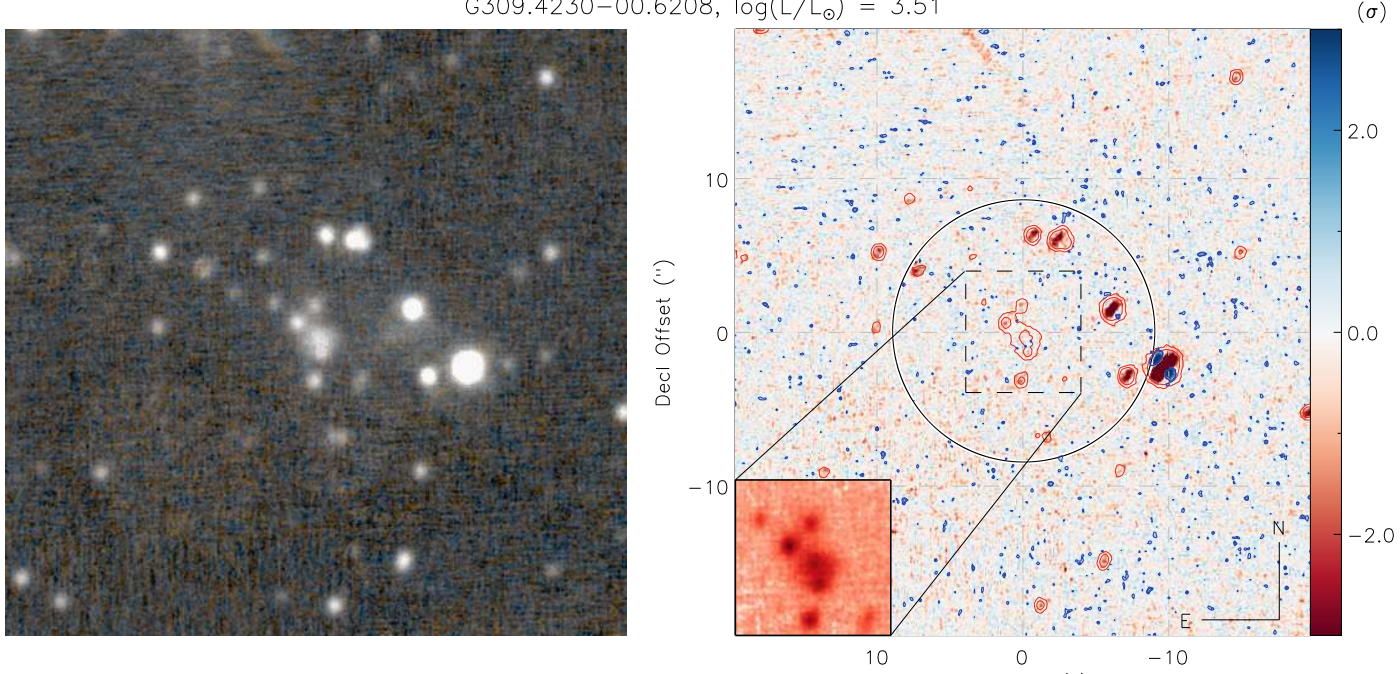

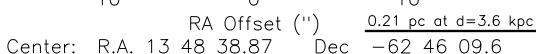

$G 309.9206+00.4790, \log \left(L / L_{\odot}\right)=5.10$
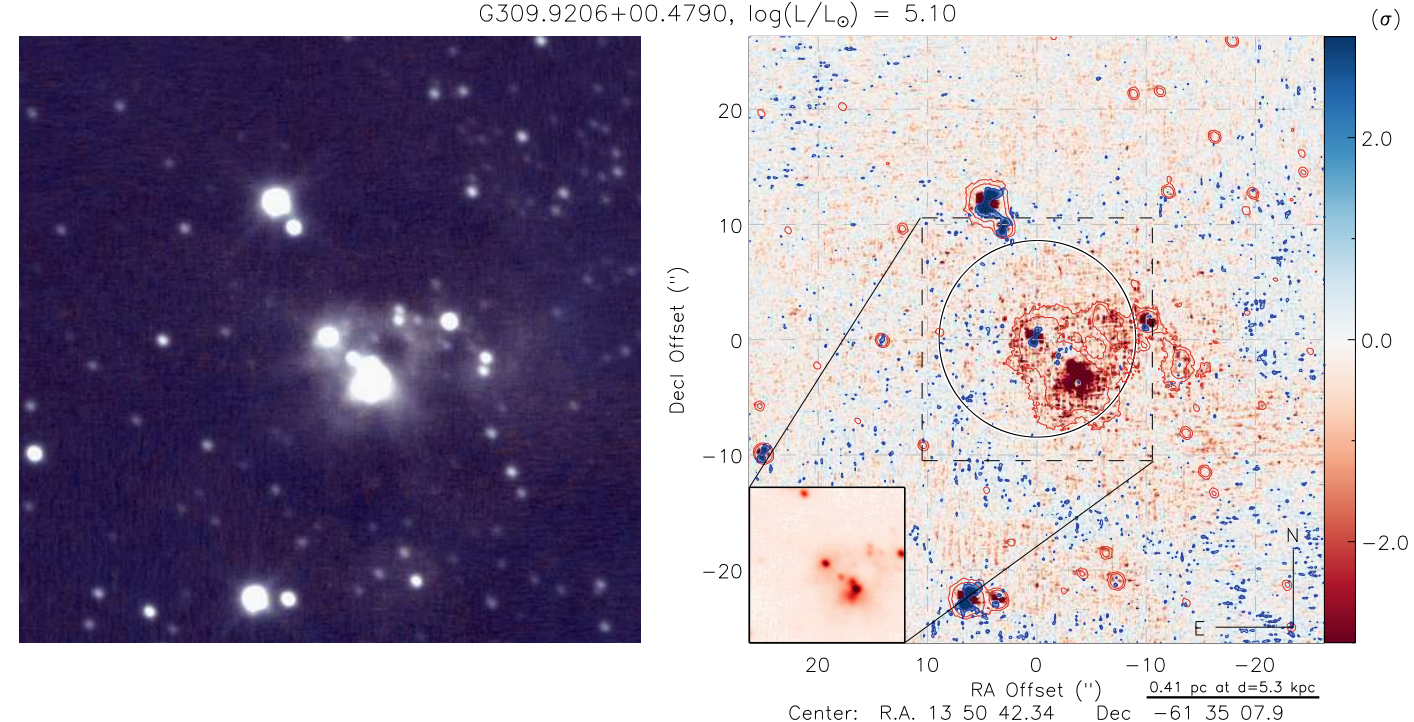
$G 310.0135+00.3892, \log \left(L / L_{\odot}\right)=4.74$
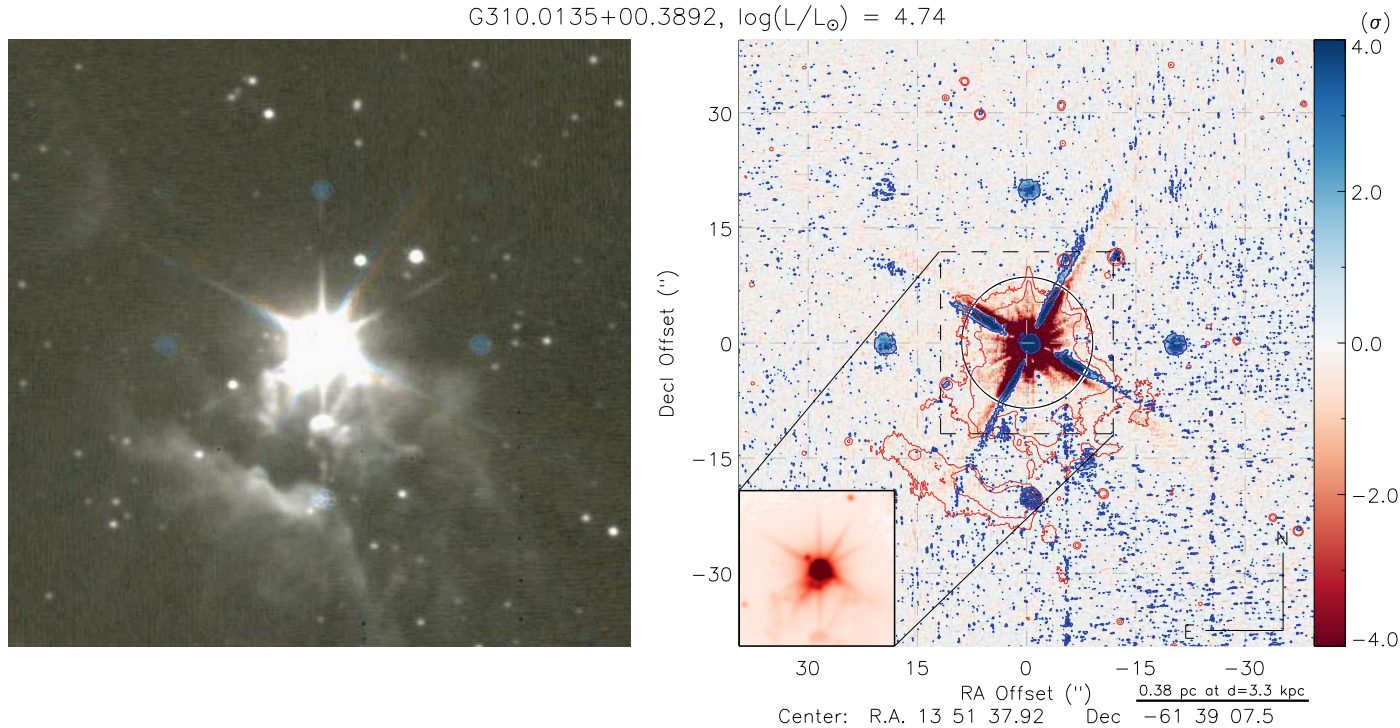

G311.1359-00.2372, $\log \left(L / L_{\odot}\right)=4.09$
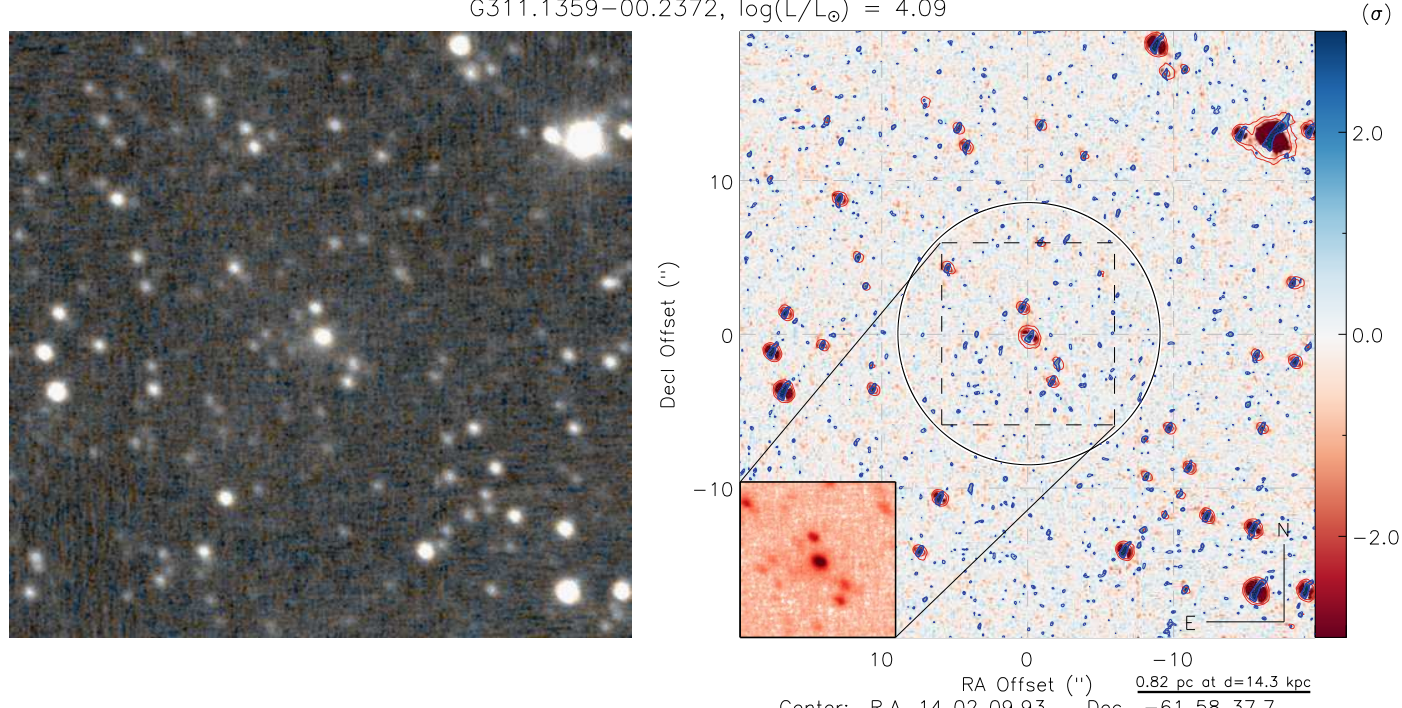

$G 311.4925+00.4021, \log \left(L / L_{\odot}\right)=3.61$
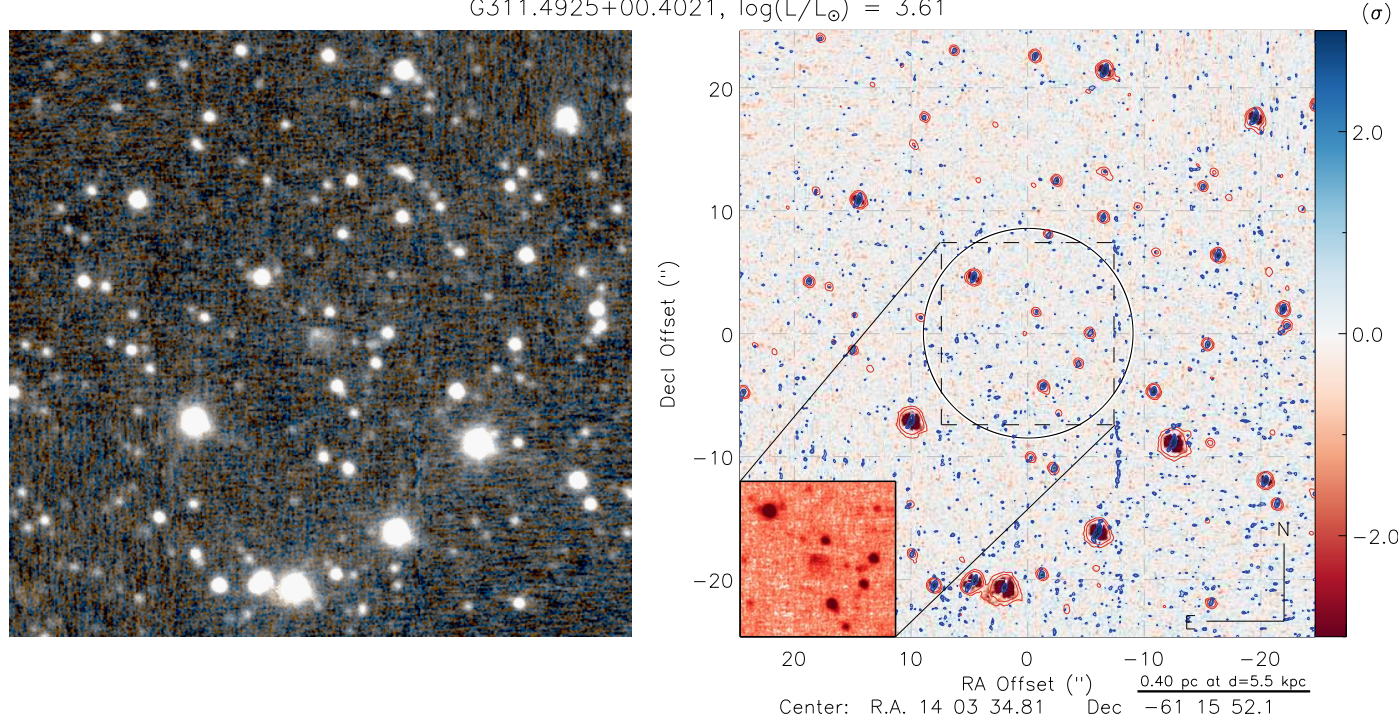

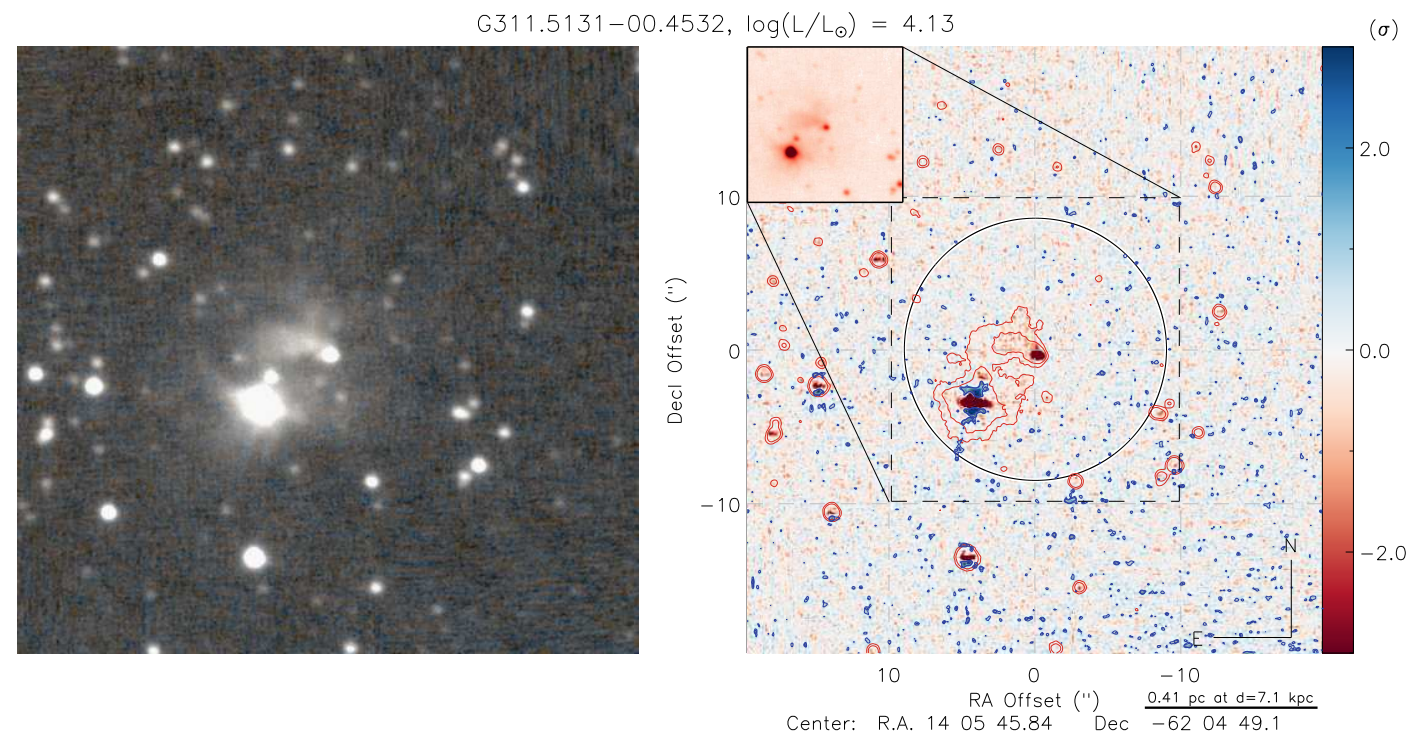

$\mathrm{G} 311.6050-00.6369, \log \left(\mathrm{L} / \mathrm{L}_{\odot}\right)=4.34$
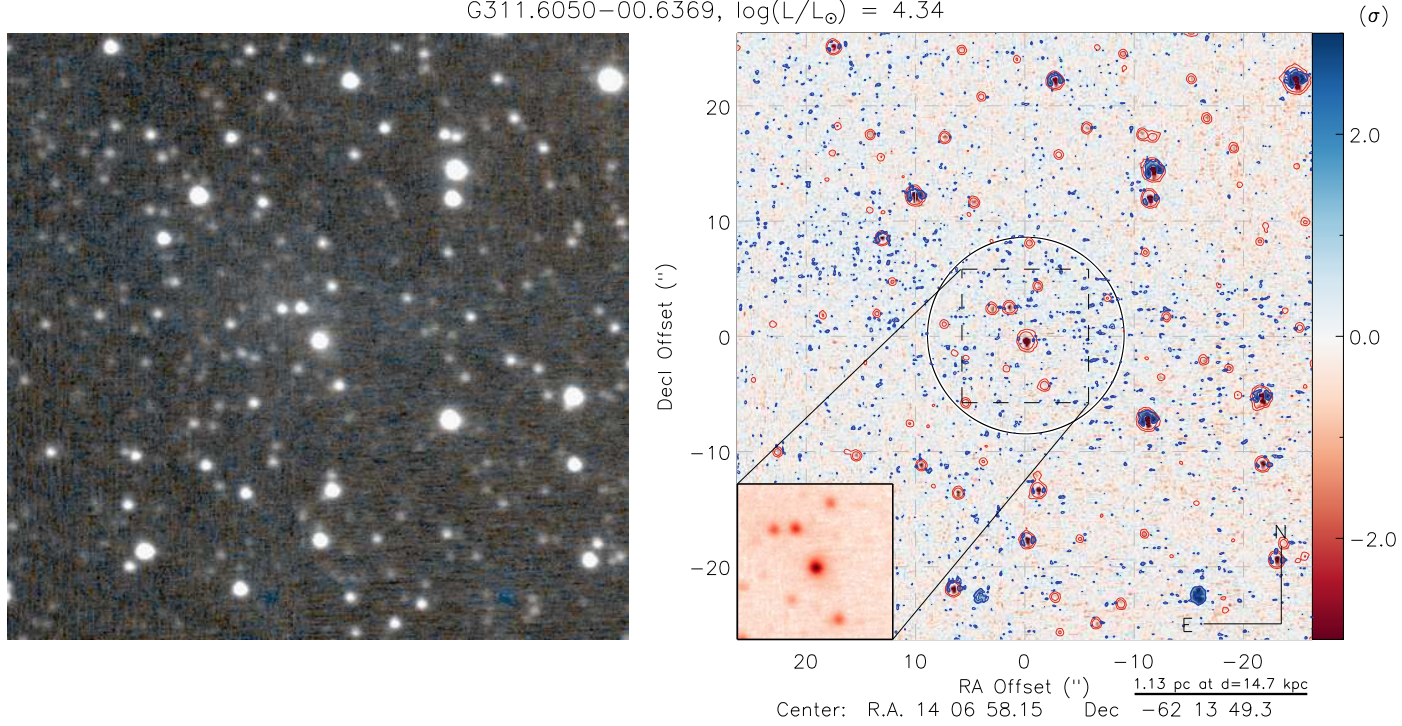

$\mathrm{G} 314.3197+00.1125, \log \left(L / L_{\odot}\right)=4.10$
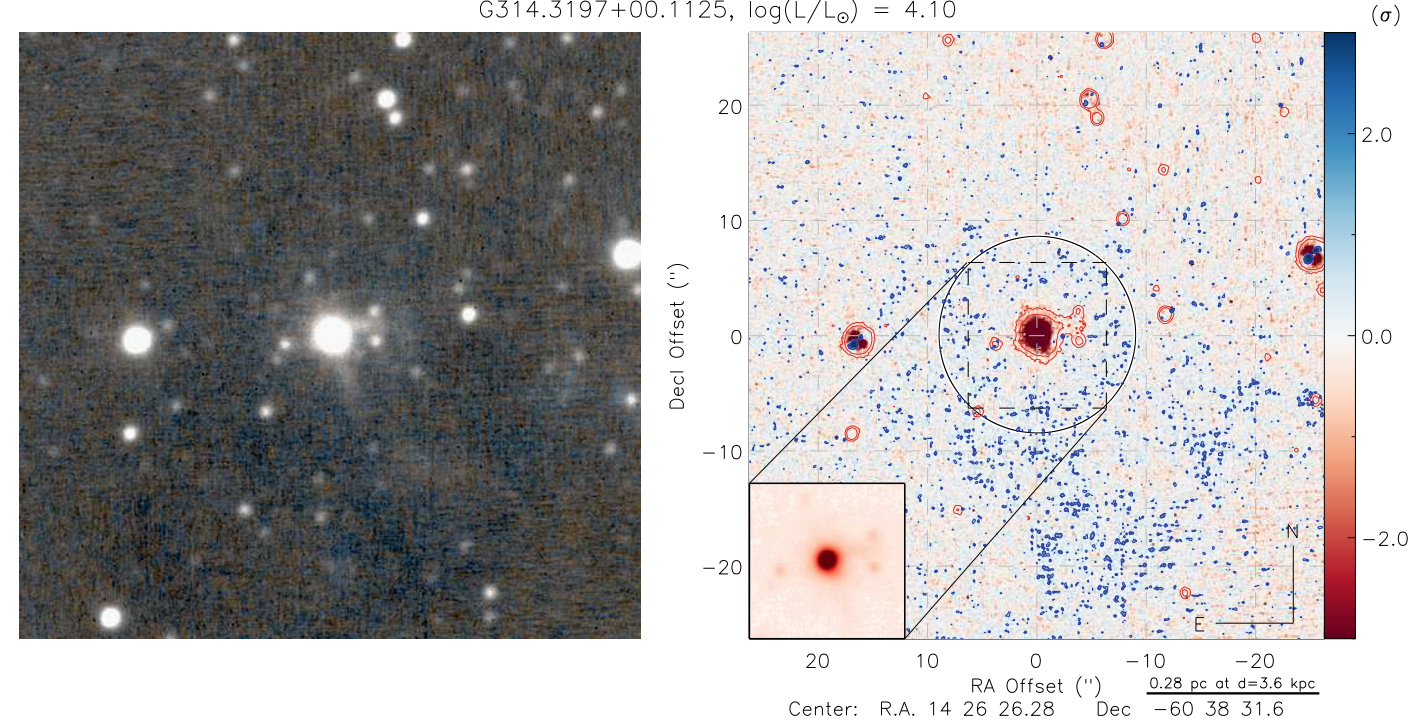
G316.1386-00.5009, $\log \left(\mathrm{L} / \mathrm{L}_{\odot}\right)=3.62$
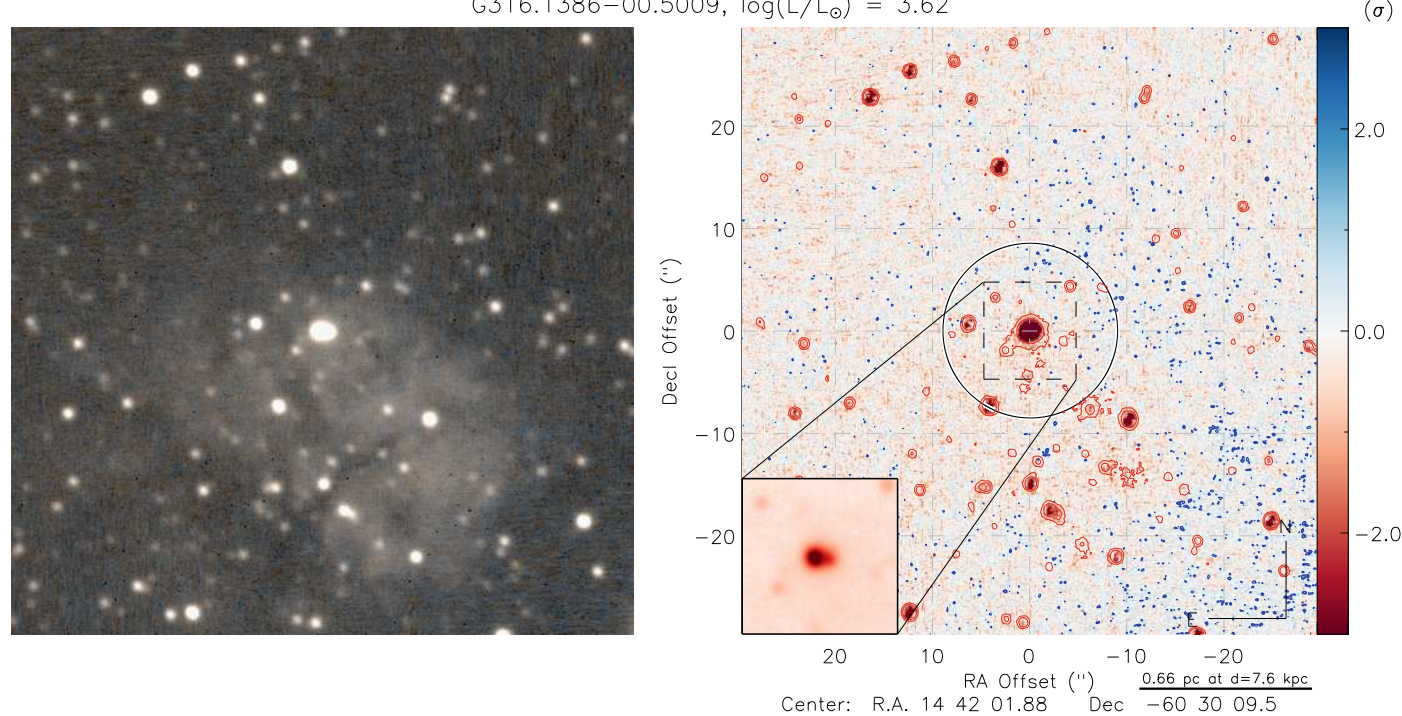

G316.6412-00.0867, $\log \left(L / L_{\text {odot }}\right)=4.92$
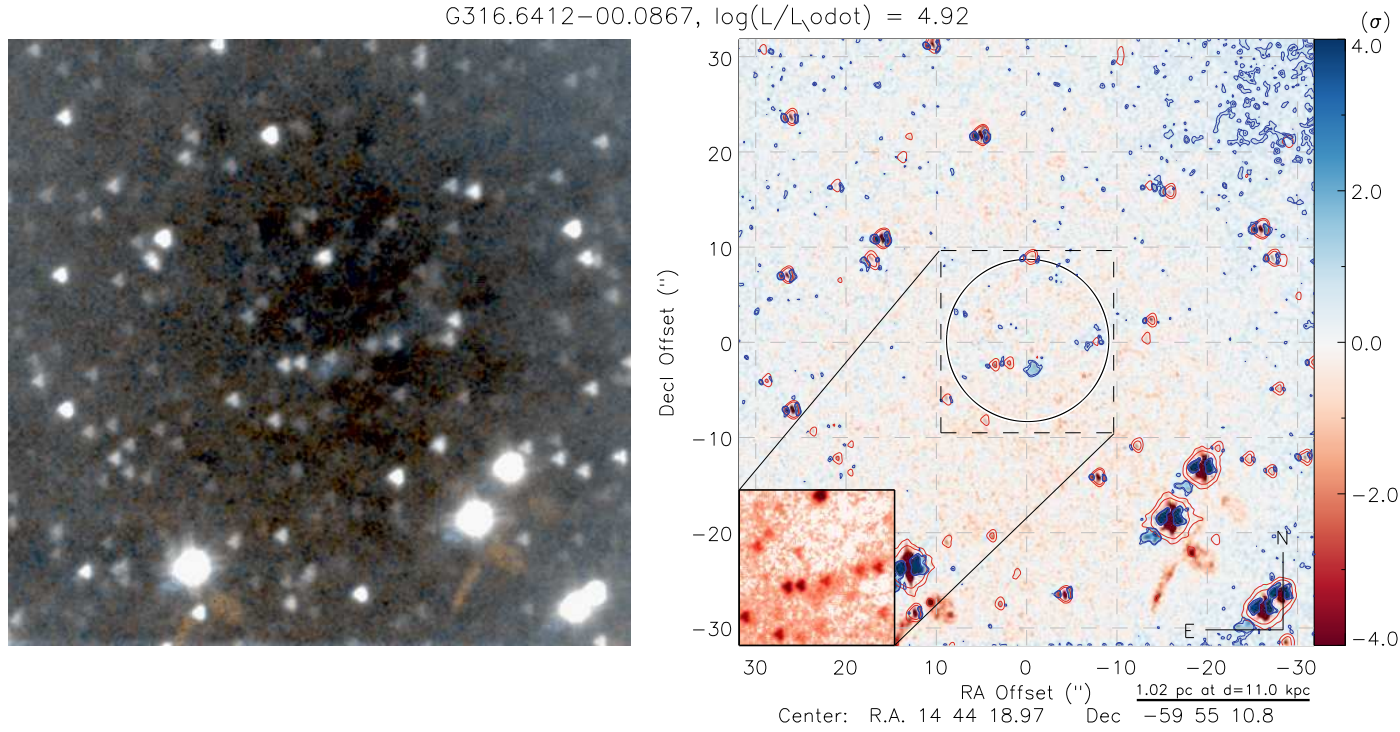

$G 316.9386-03.8102, \log \left(L / L_{\odot}\right)=2.00$
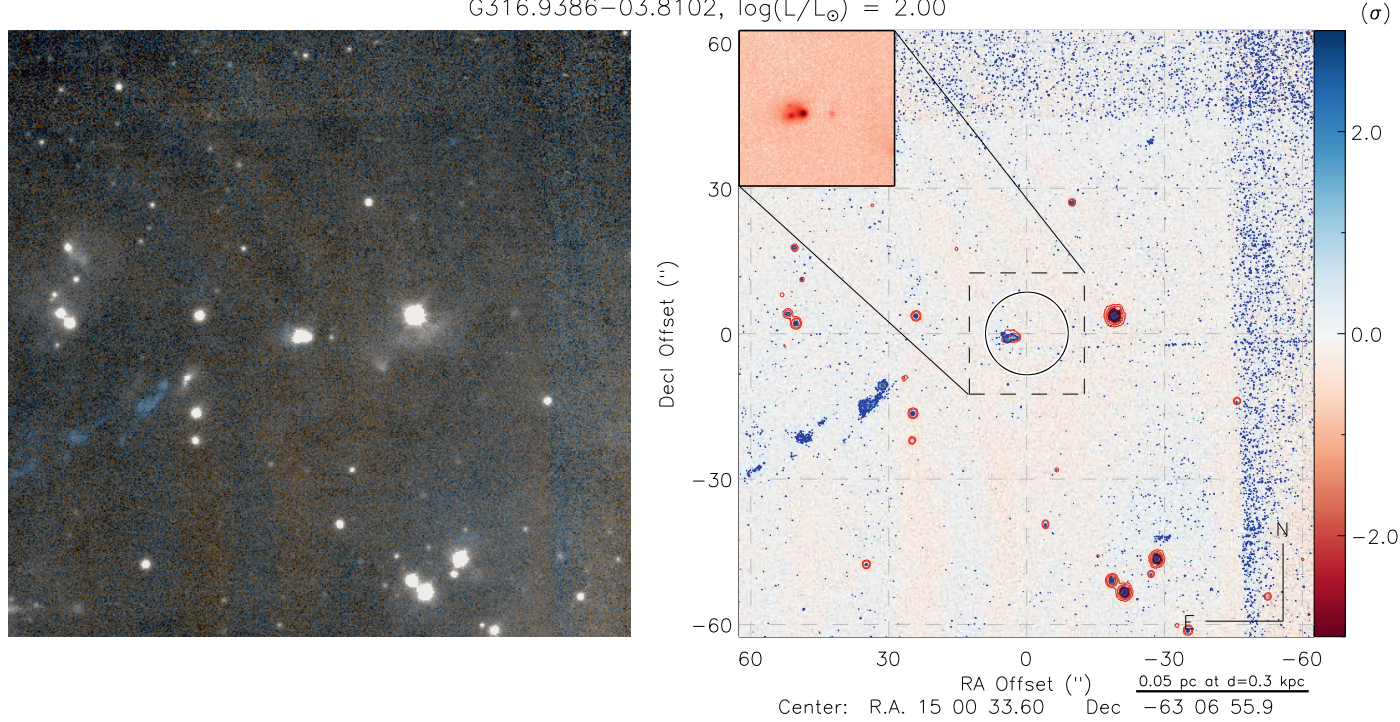

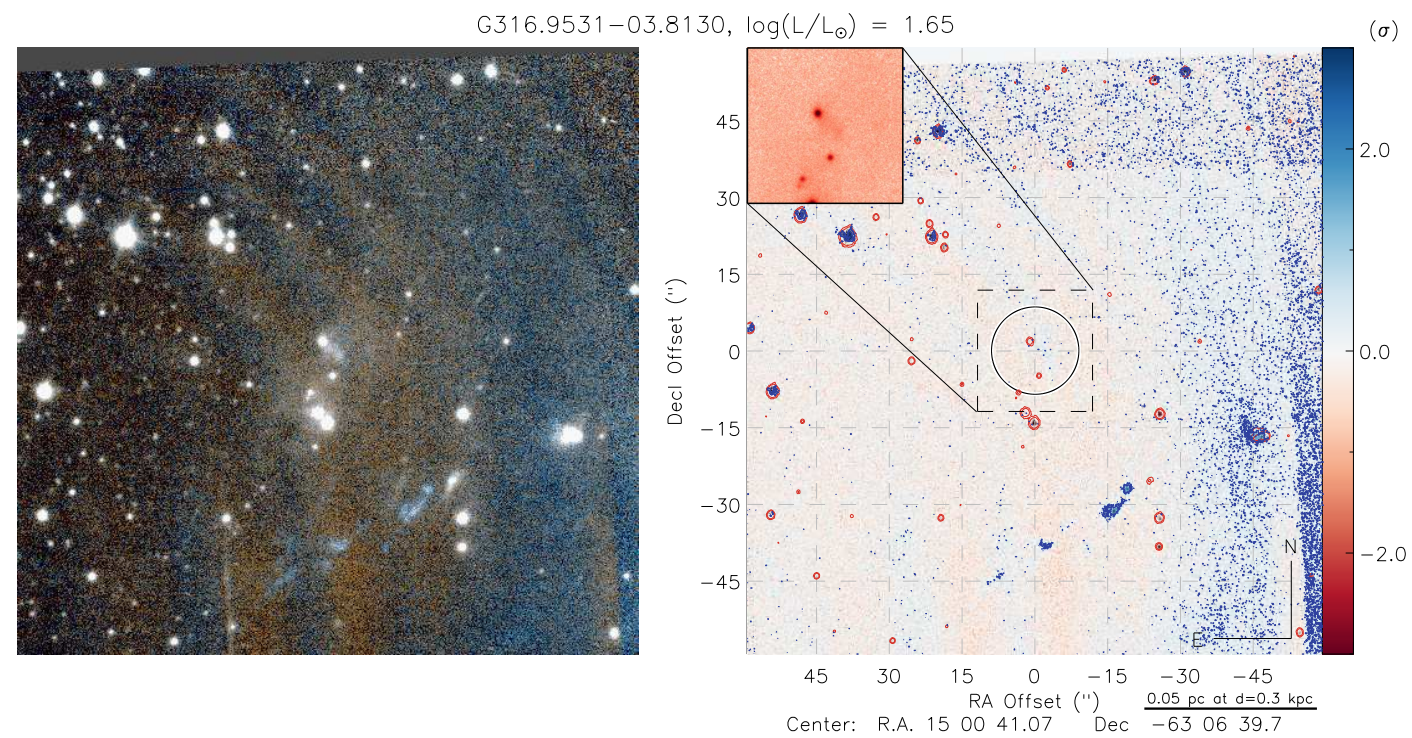

$\mathrm{G} 317.7477+00.0112, \log \left(L_{/} L_{\odot}\right)=4.24$
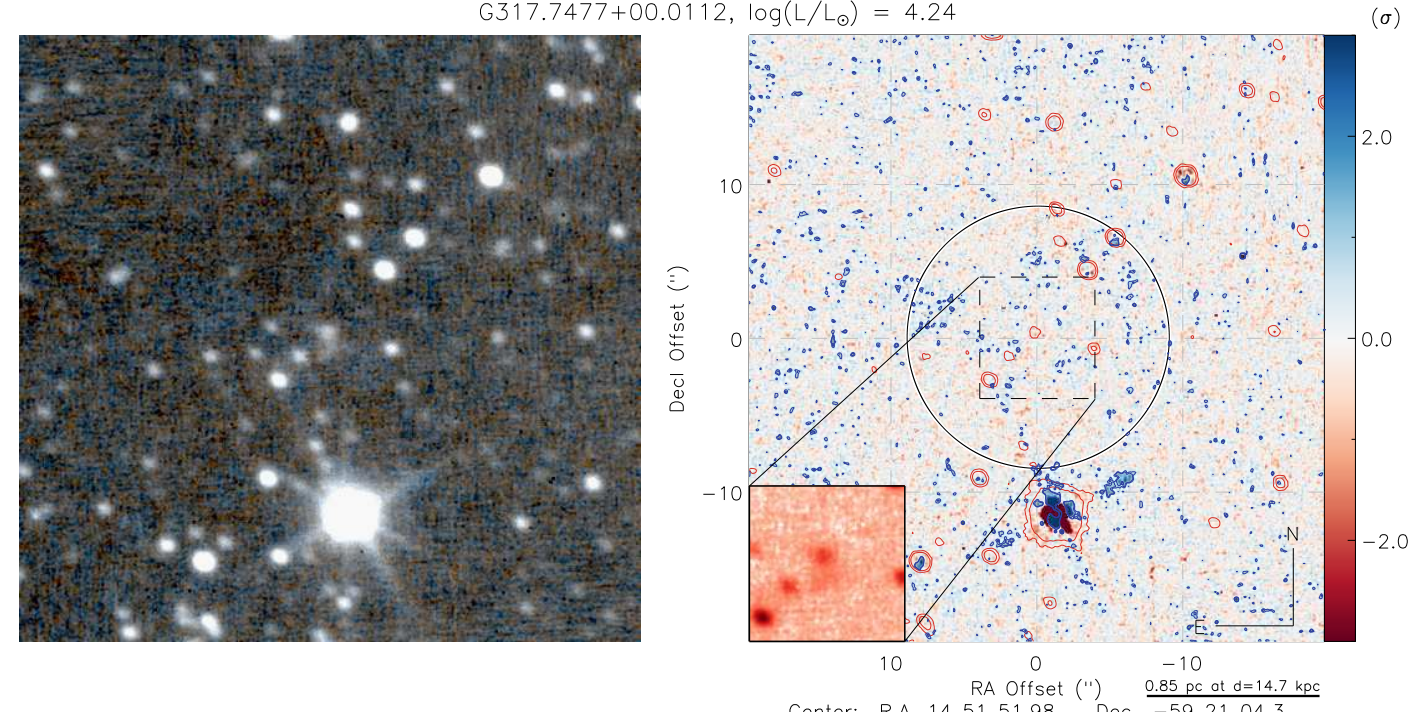

G319.8366-00.1963, $\log \left(L / L_{\odot}\right)=2.35$
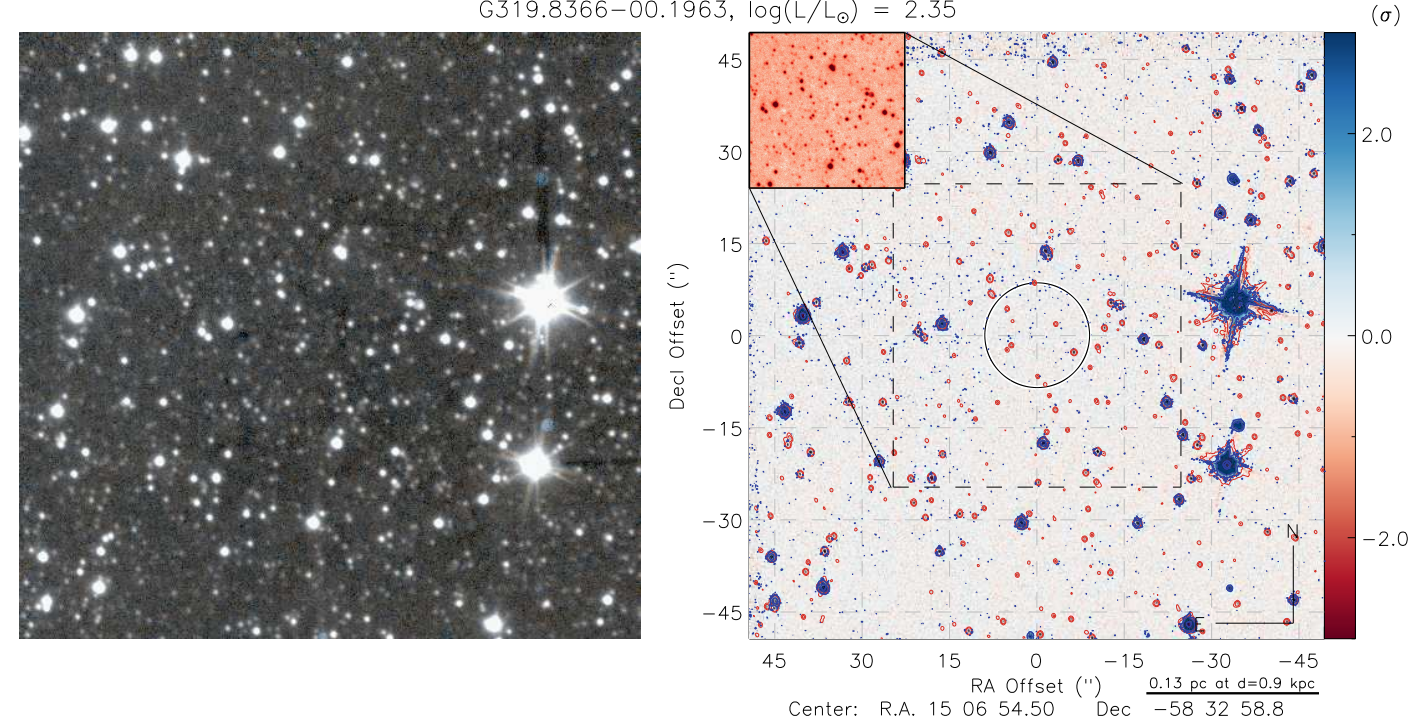
G320.2437-00.5619, $\log \left(L / L_{\odot}\right)=4.26$
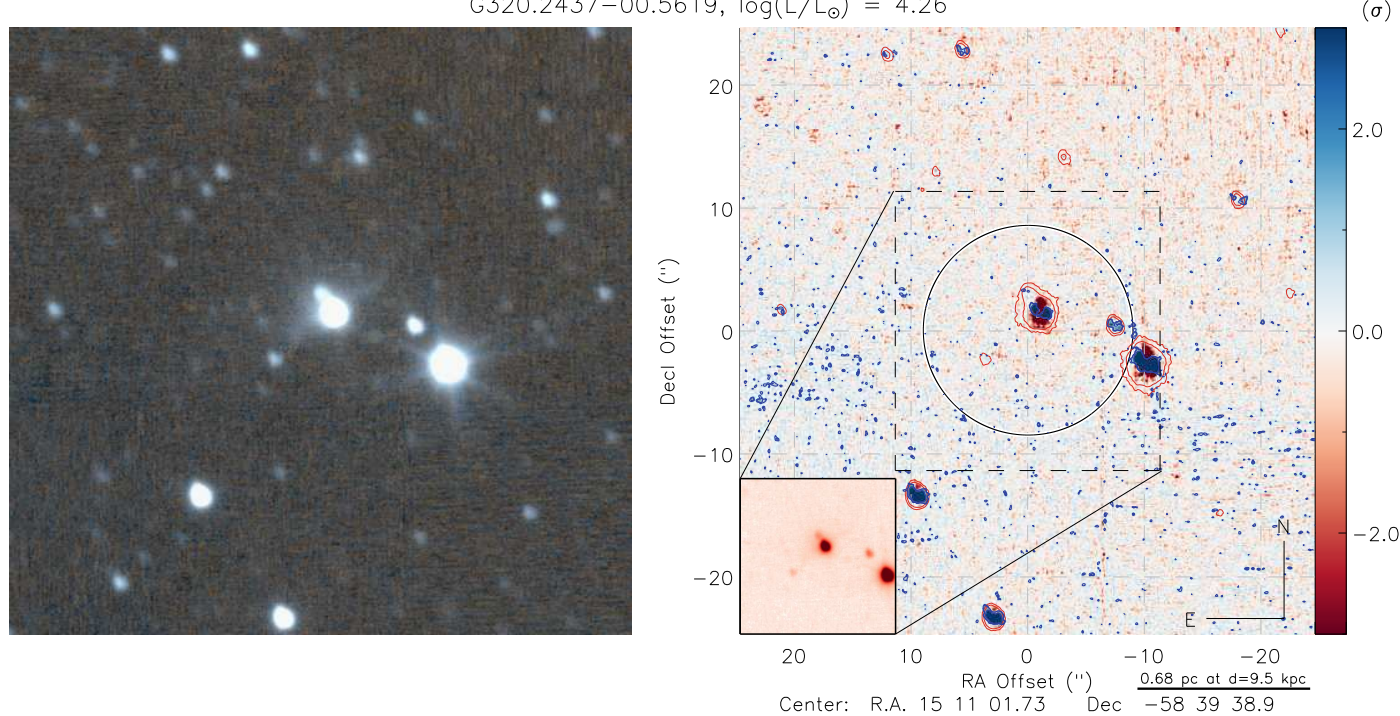

G321.0523-00.5070, $\log \left(L_{/} / L_{\text {odot }}\right)=4.86$
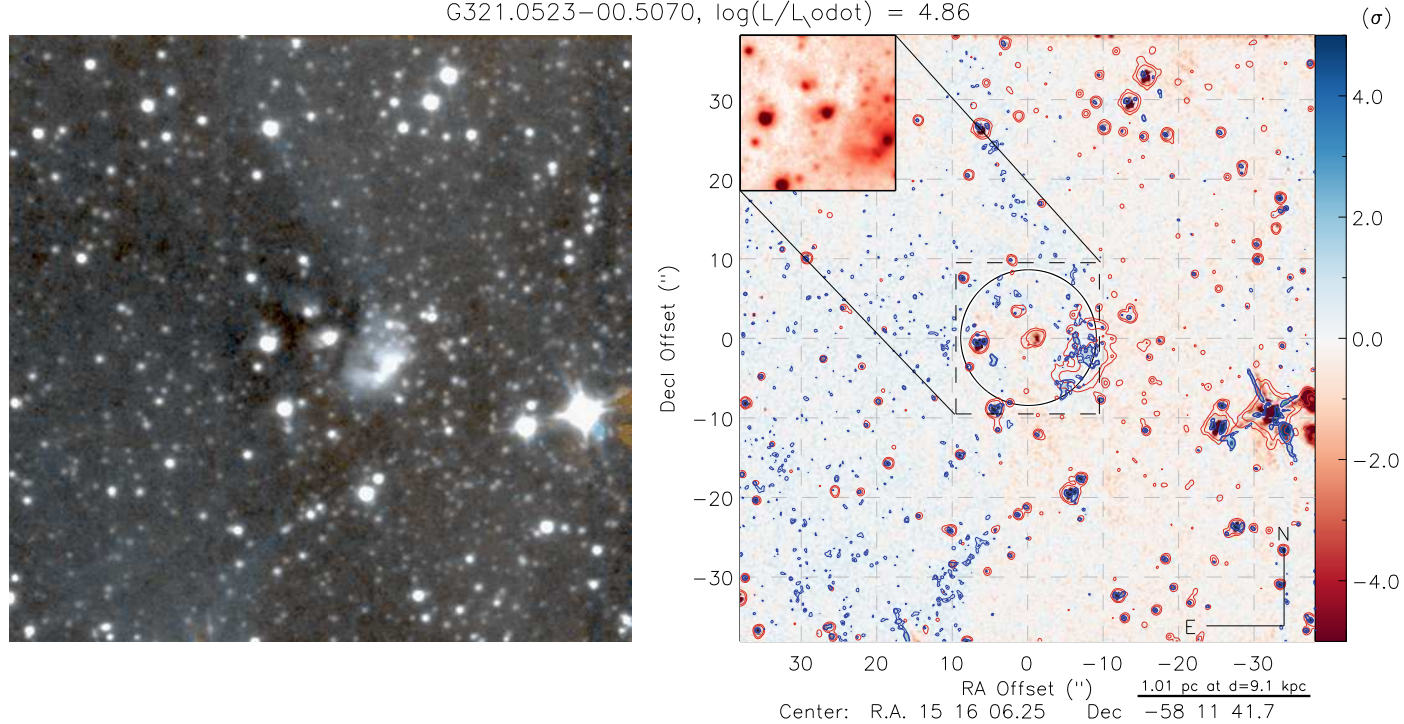

$G 321.3803-00.3016, \log \left(L / L_{\odot}\right)=4.35$
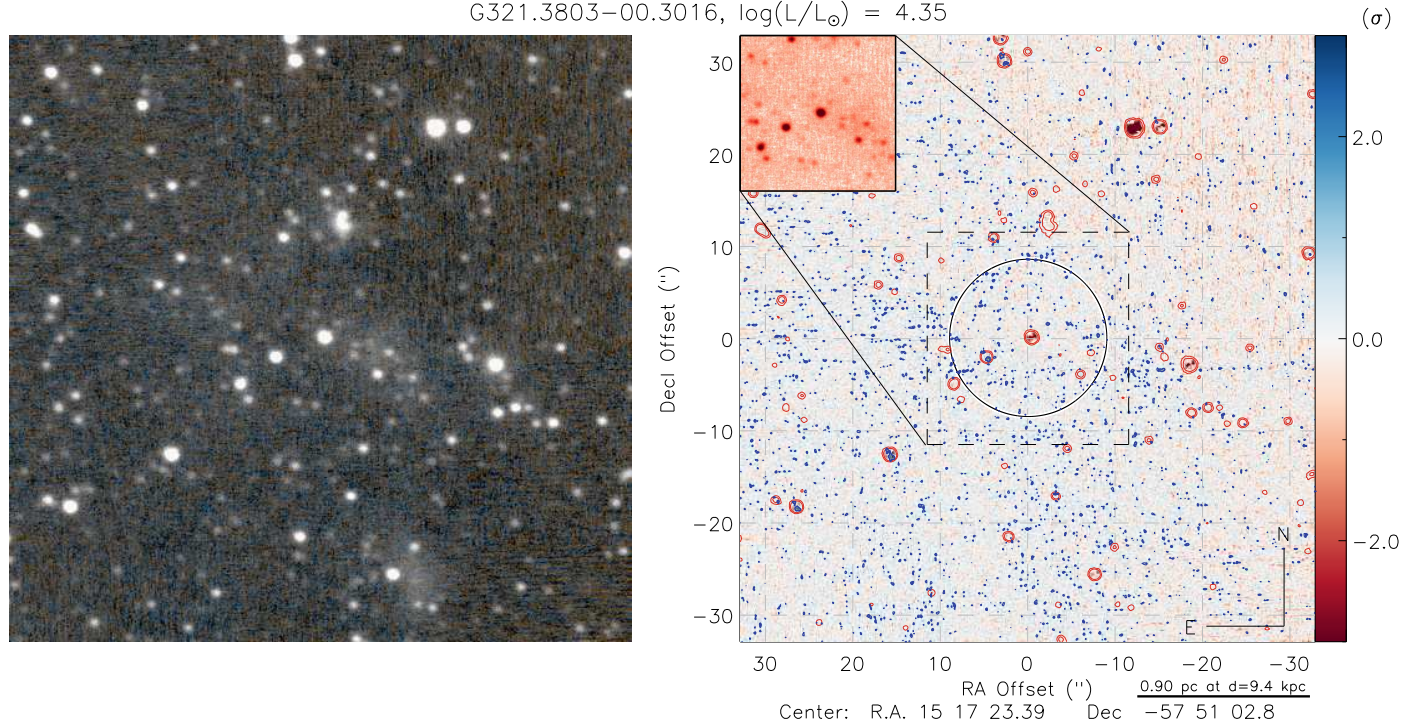
$G 322.1729+00.6442, \log \left(L / L_{\odot}\right)=4.02$
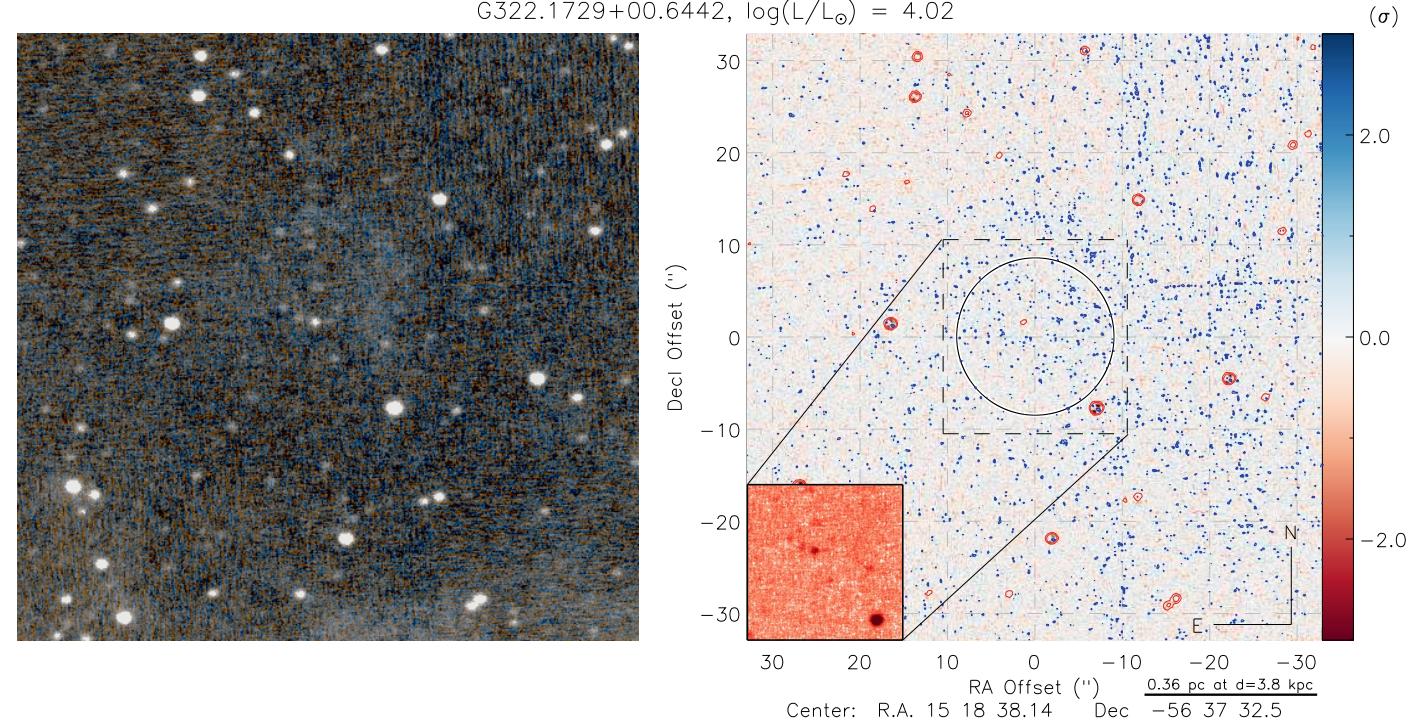

$G 324.1594+00.2622, \log \left(L / L_{\odot}\right)=4.25$
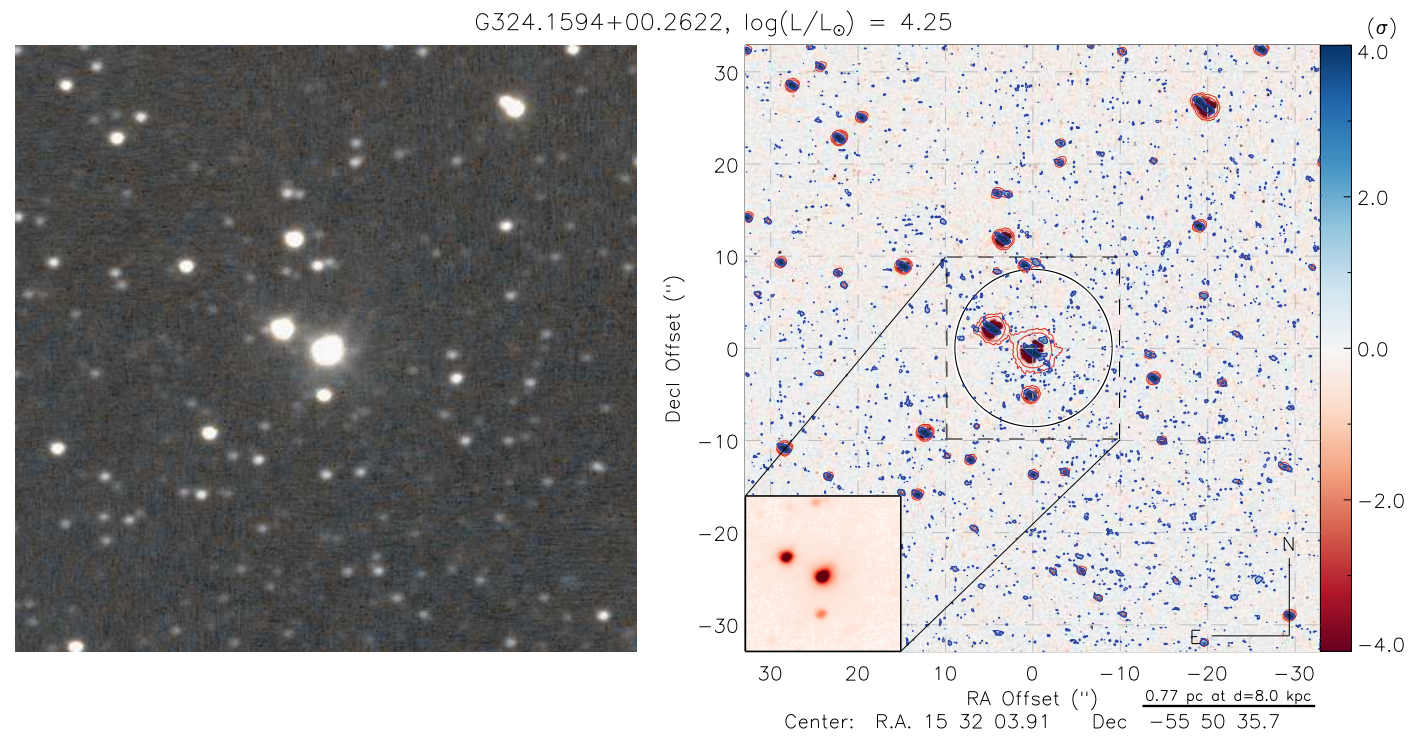

$G 326.5437+00.1684, \log \left(L / L_{\odot}\right)=3.98$
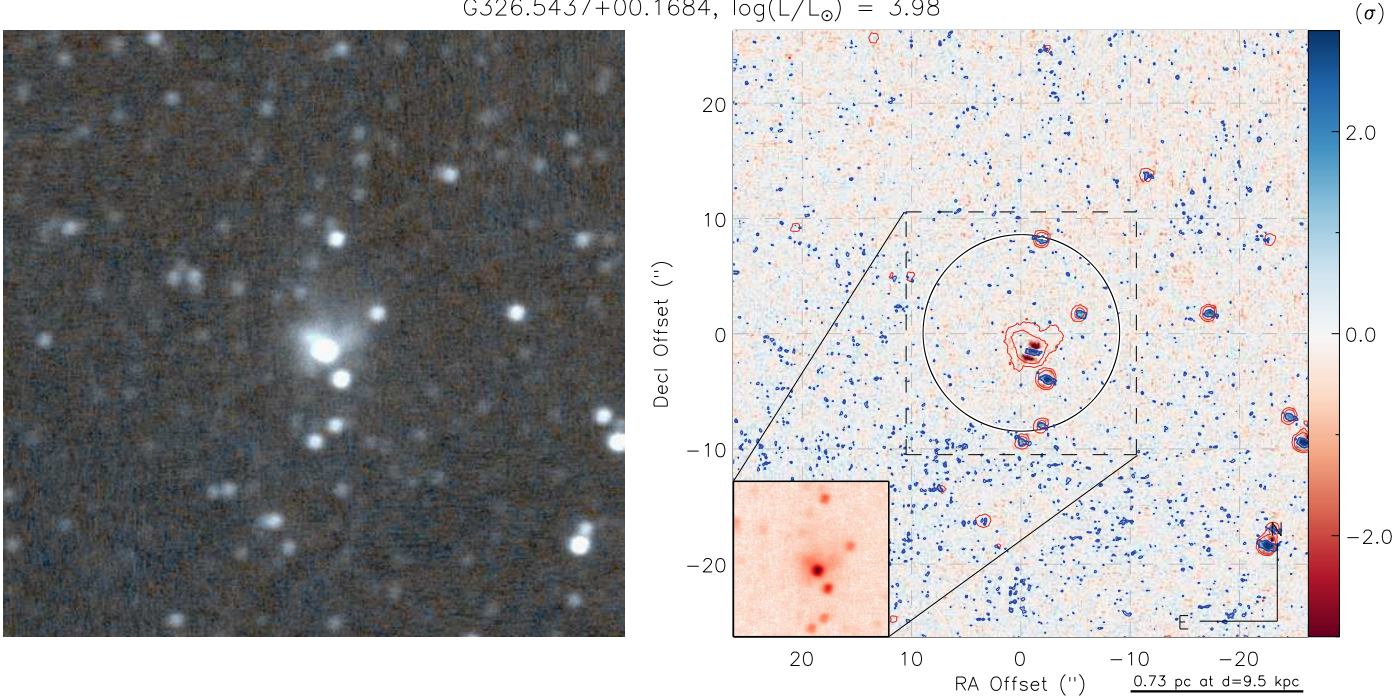

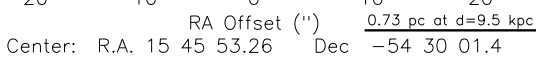


$G 326.6618+00.5207, \log \left(L / L_{1}\right.$ odot $)=5.78$
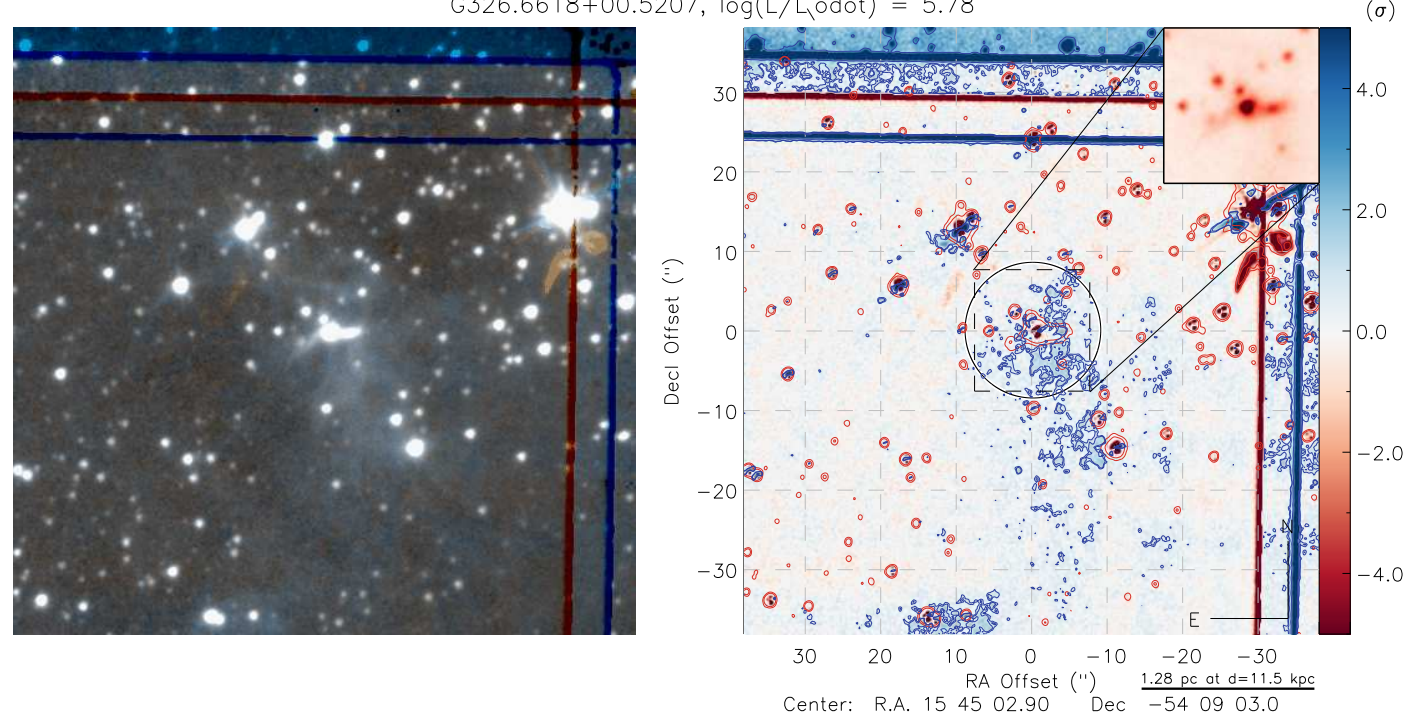

$G 327.1192+00.5103, \log \left(L_{L} L_{1}\right.$ odot $)=4.68$
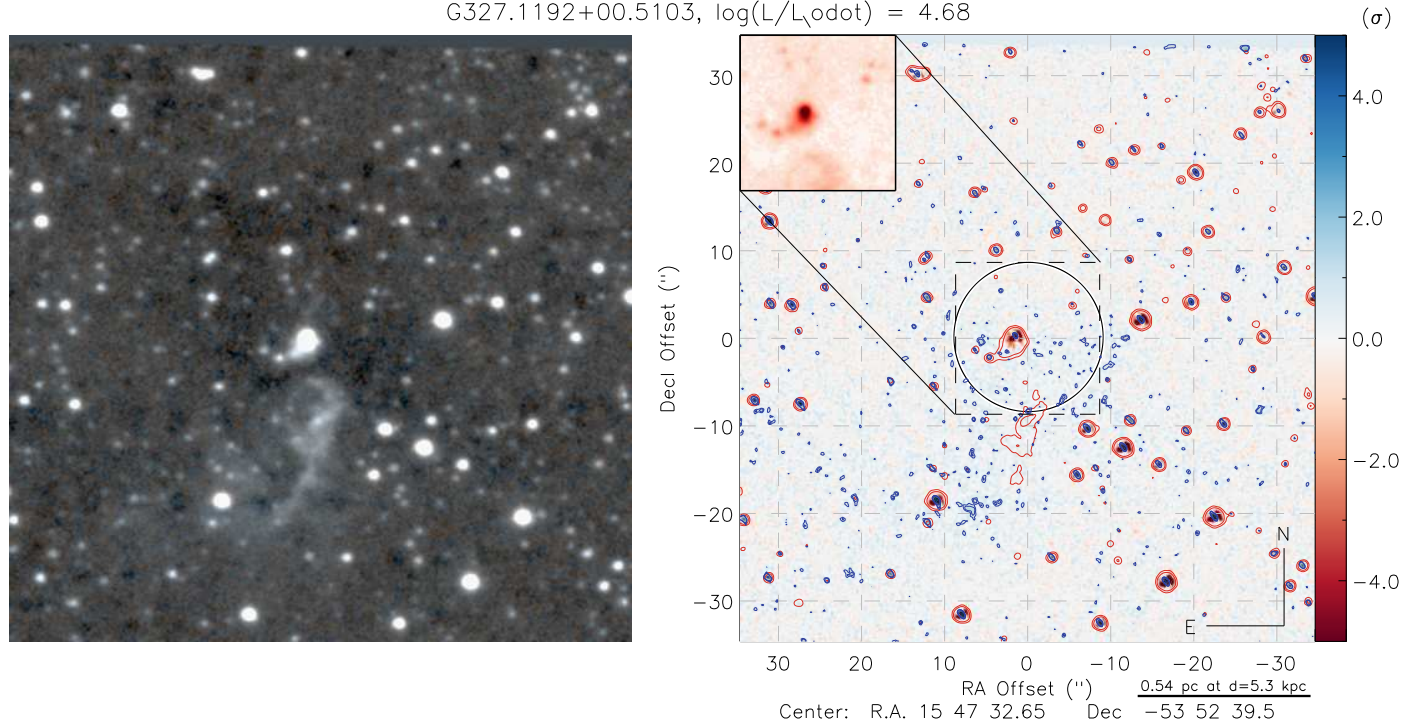

G328.3442-00.4629, $\log \left(L_{/} L_{1}\right.$ odot $)=4.73$
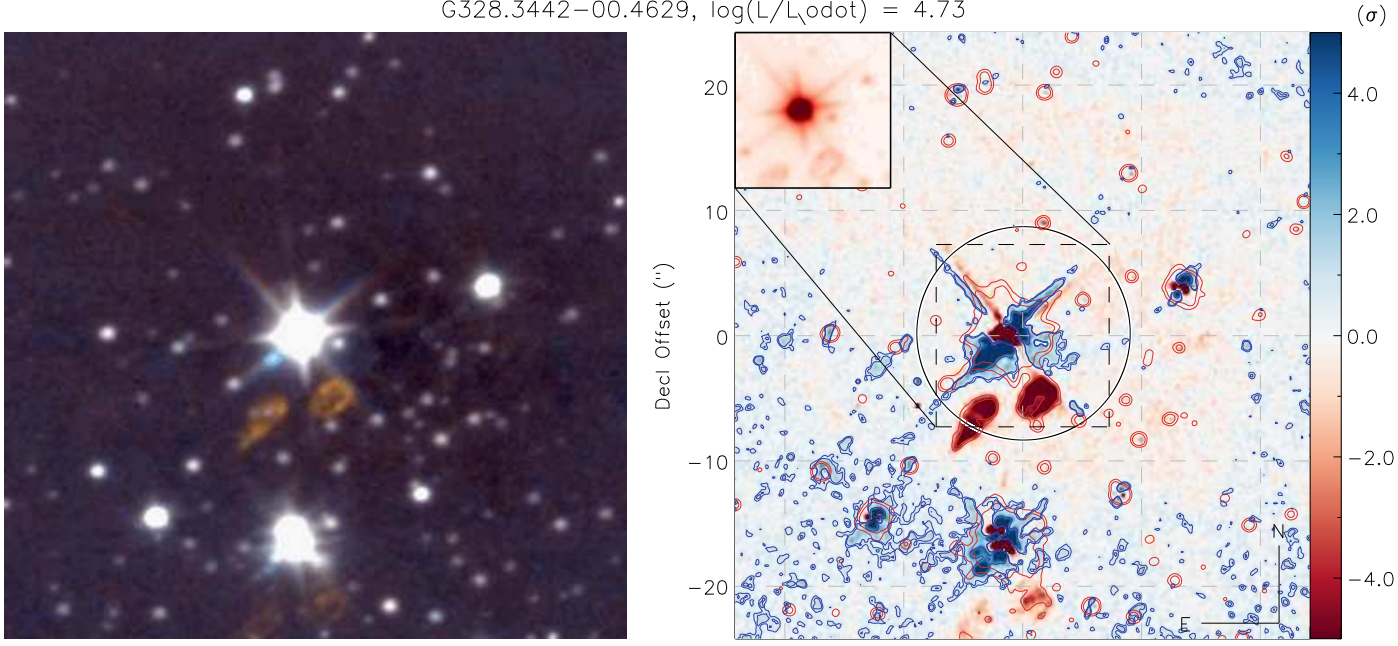

$\begin{array}{lcccc}20 & 10 & 0 & -10 & -20 \\ & \text { RA Offset (") } & \frac{0.81 \mathrm{pc} \text { at } d=11.5 \mathrm{kp}}{}\end{array}$ 
G329.0663-00.3081, $\log \left(L / L_{1}\right.$ odot $)=4.82$
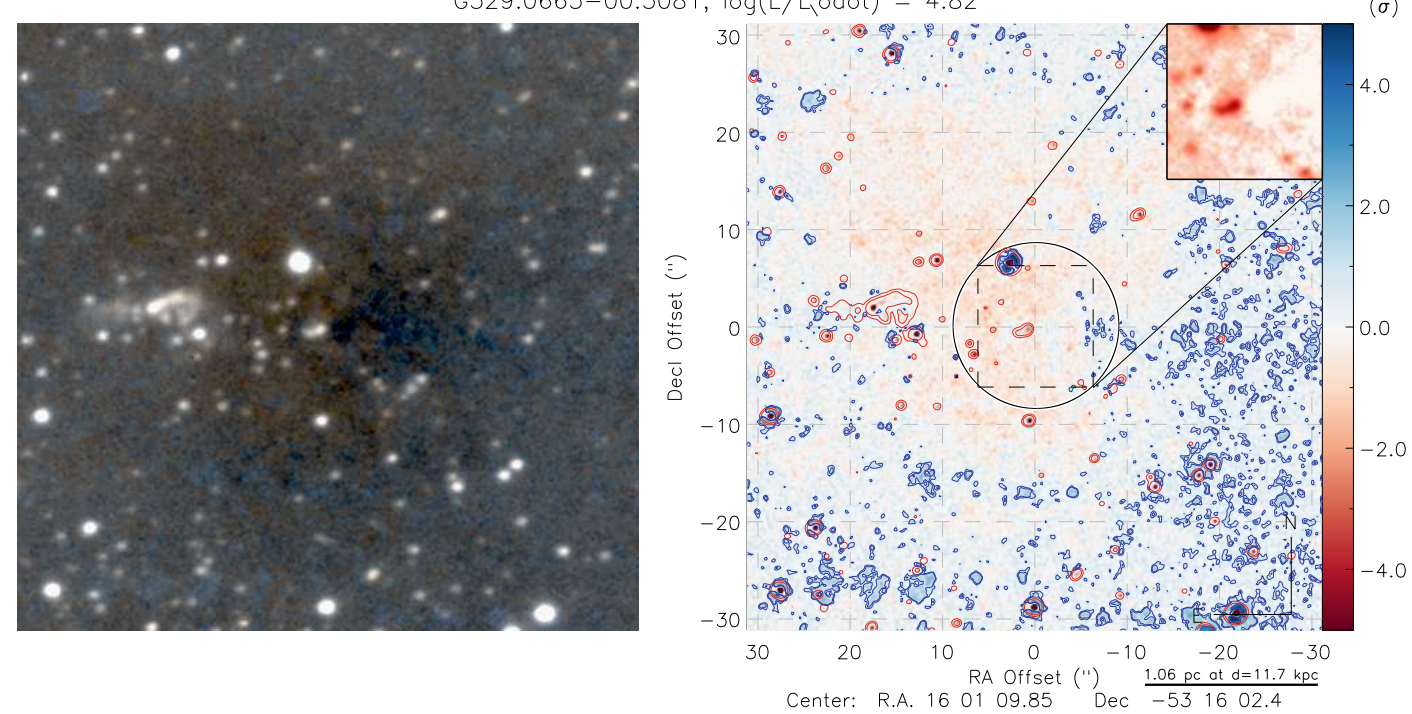

$\mathrm{G} 331.0890+00.0163, \log \left(\mathrm{L} / \mathrm{L}_{\odot}\right)=3.56$
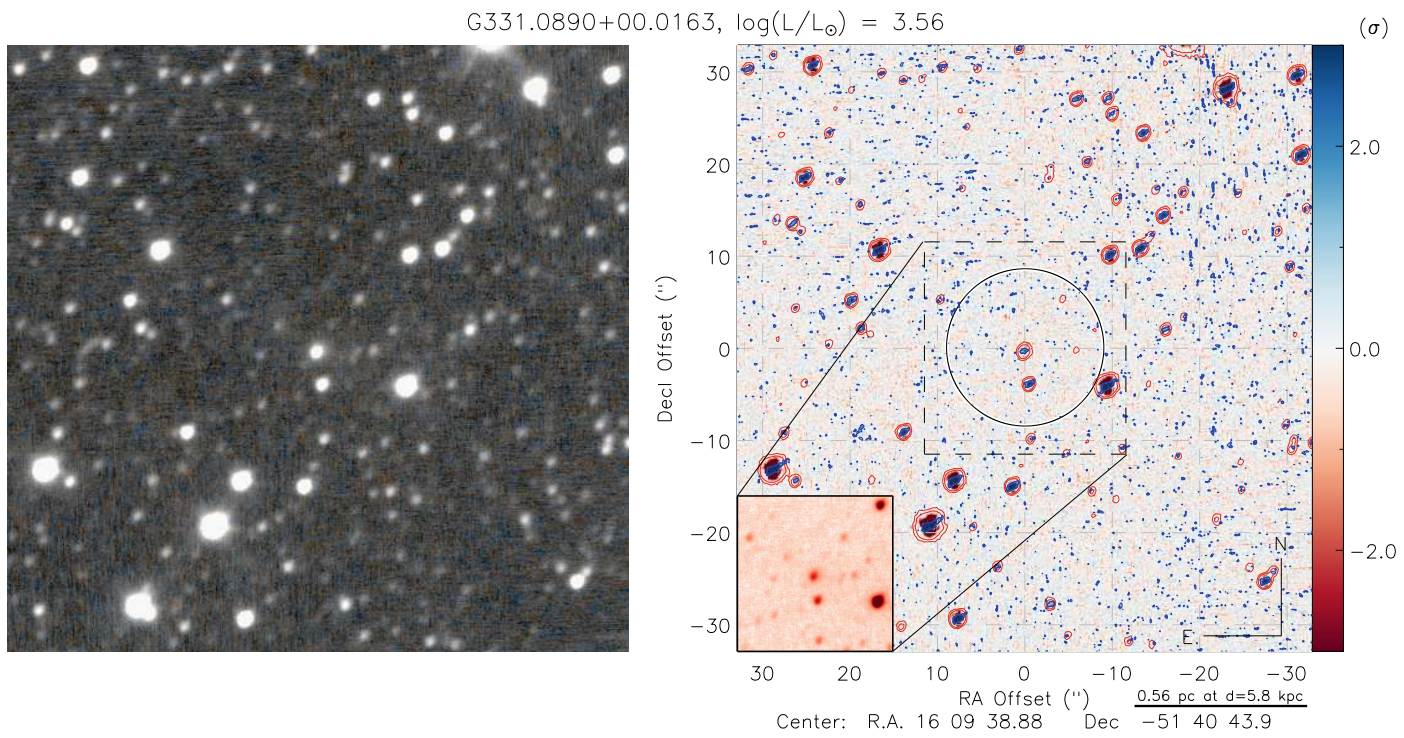

$G 331.5651+00.2883, \log \left(L / L_{\odot}\right)=4.00$
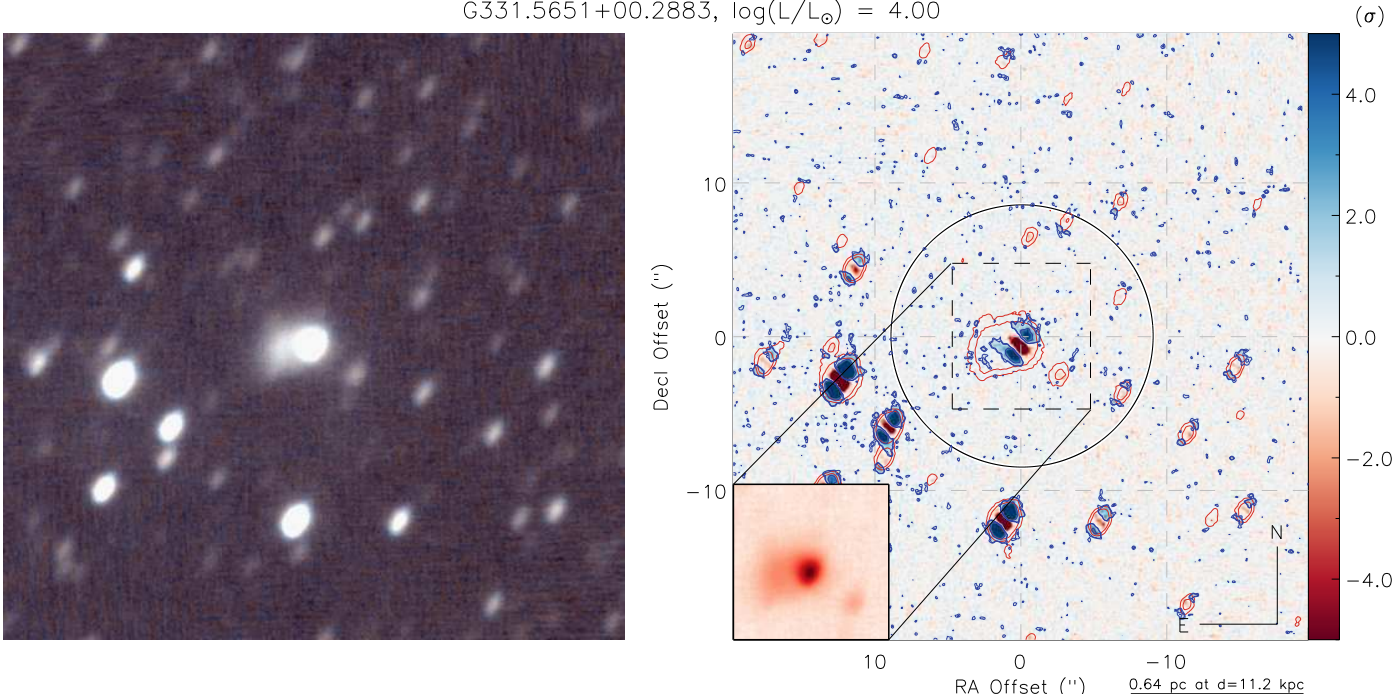

$\begin{array}{ccc}\text { RA Offset (") } & 0.64 \mathrm{pc} \text { at } \mathrm{d}=11.2 \mathrm{kpc} \\ \text { Center: R.A. } 16 & 1042.38 & \text { Dec } \\ -510919.8\end{array}$ 
$\mathrm{G} 331.6191-00.0442, \log \left(\mathrm{L} / \mathrm{L}_{\odot}\right)=3.98$
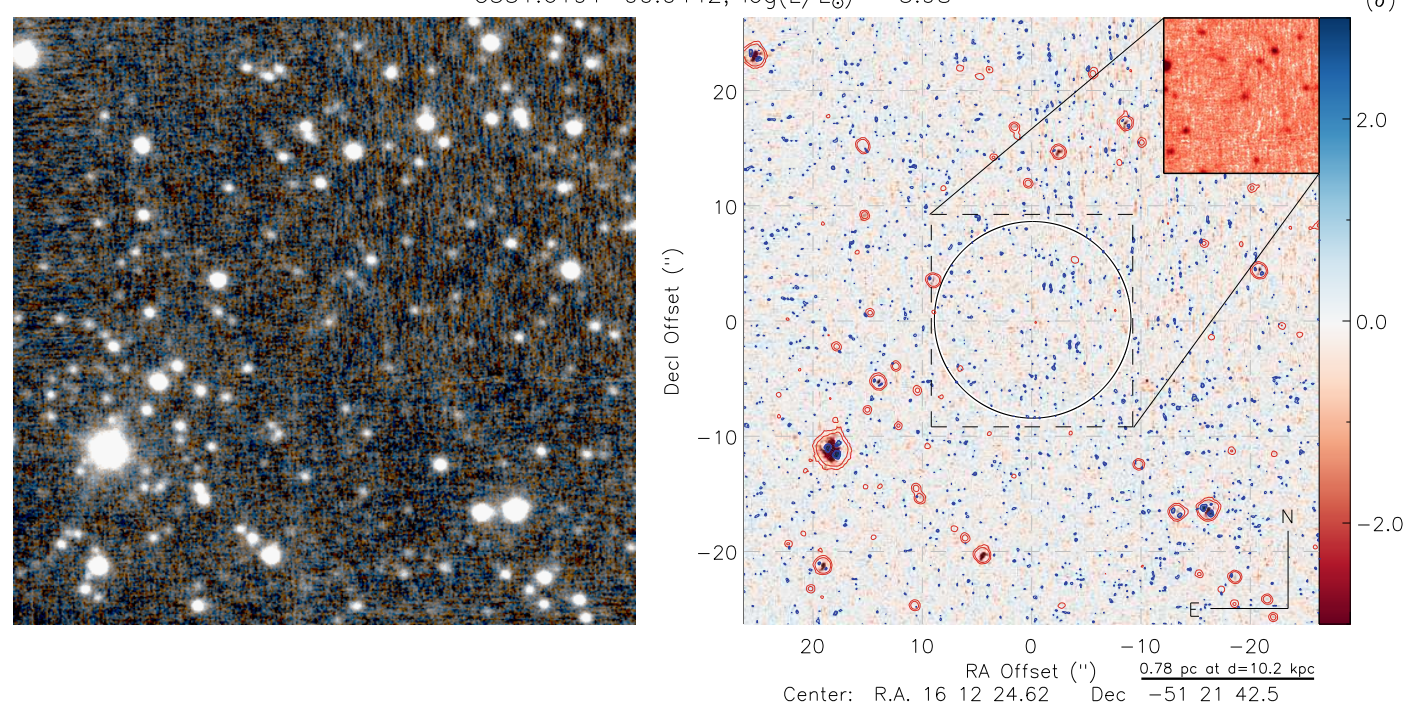

G332.4683-00.5228, $\log \left(L / L_{1}\right.$ odot $)=4.53$
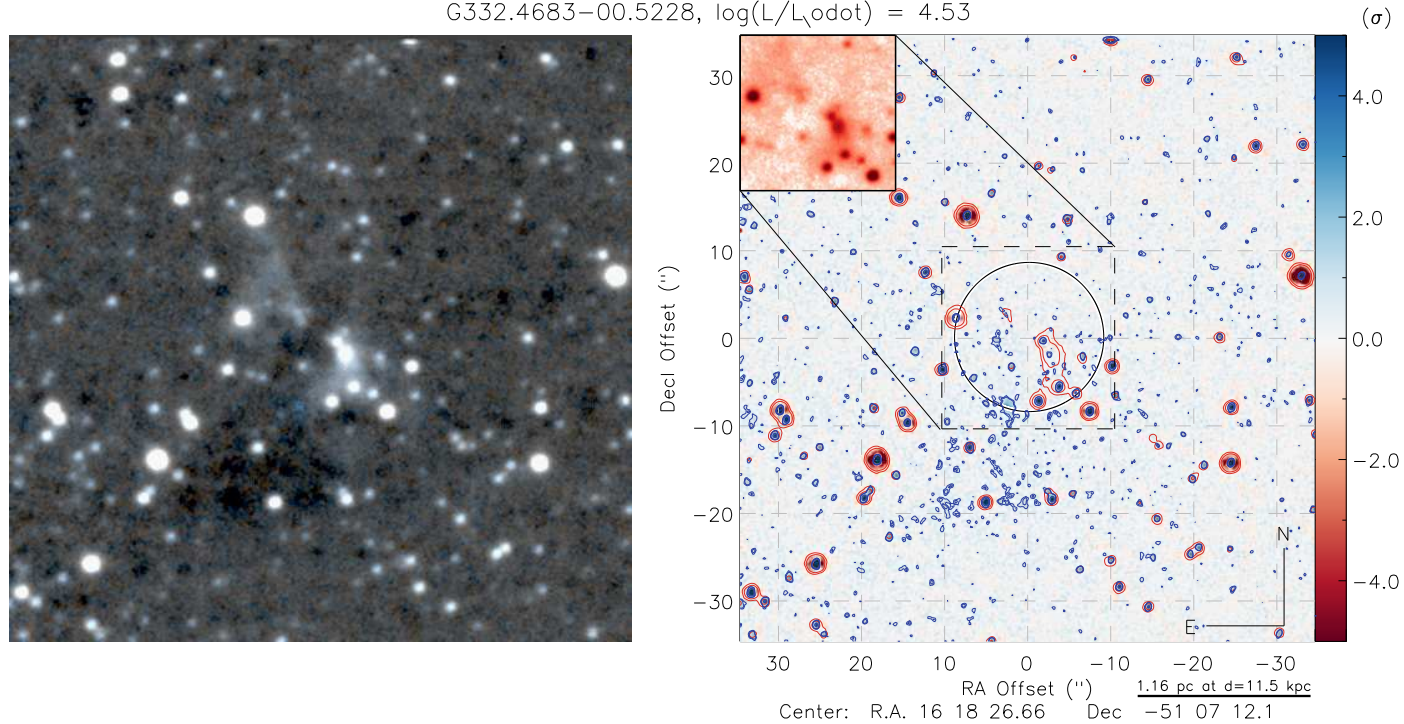

G332.7013-00.5874, $\log \left(L / L_{1}\right.$ odot $)=4.63$
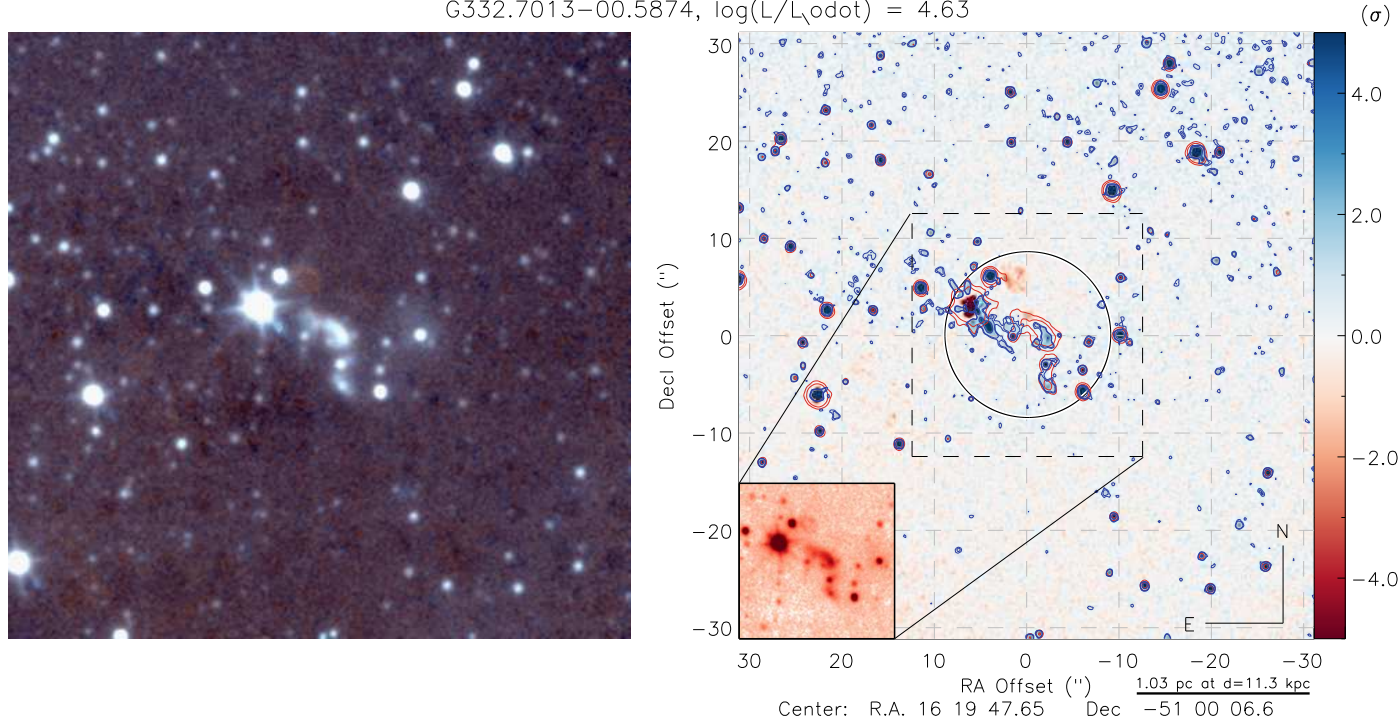
$\mathrm{G} 334.8438+00.2095, \log \left(L / L_{\odot}\right)=3.16$
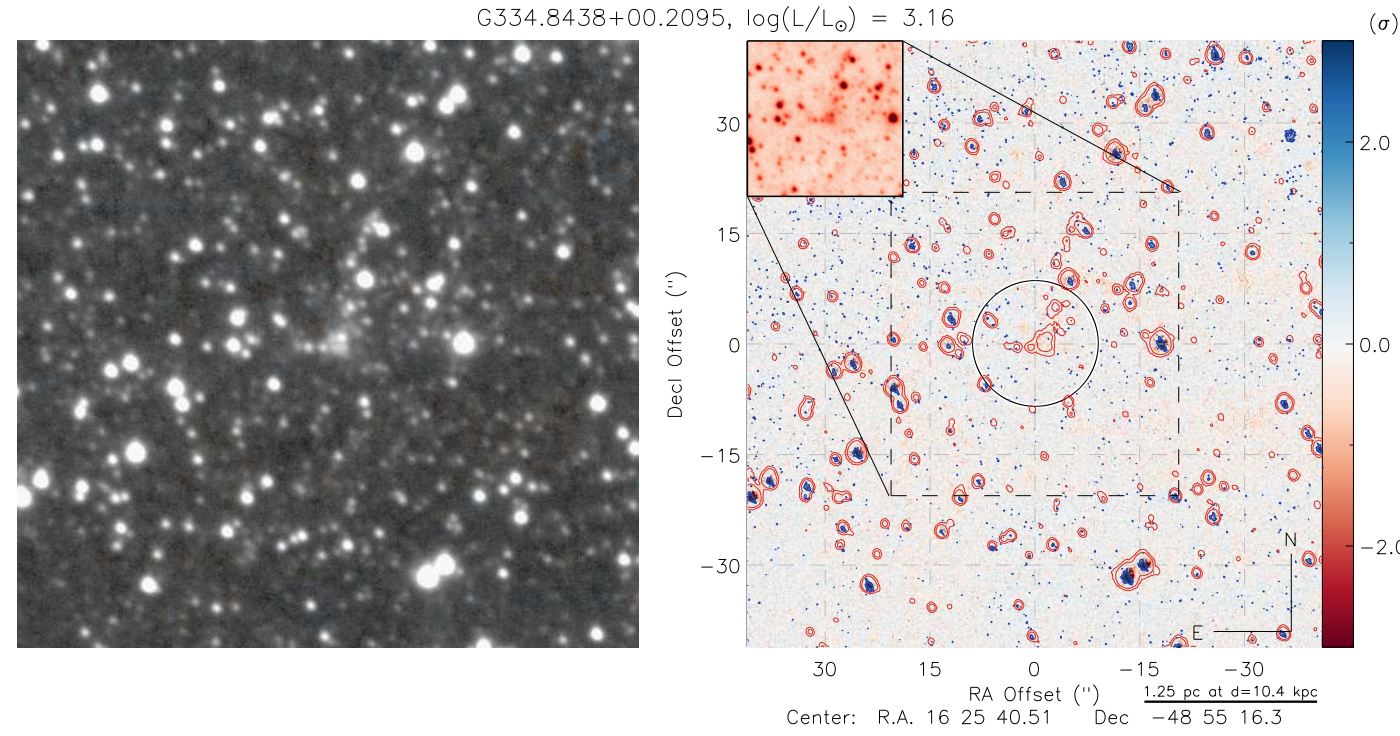

G336.3684-00.0033, $\log \left(L / L_{\odot}\right)=4.21$
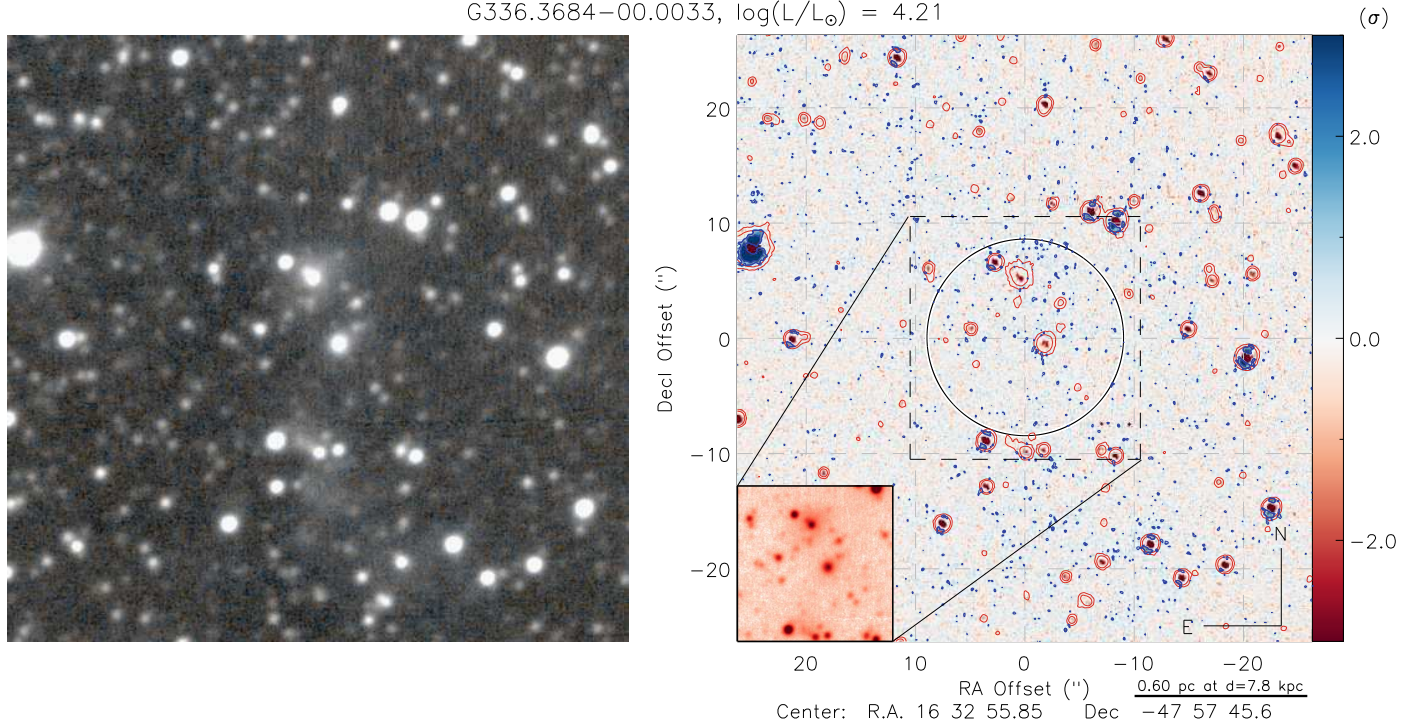

G336.8308-00.3752, $\log (L / L$, odot $)=4.71$
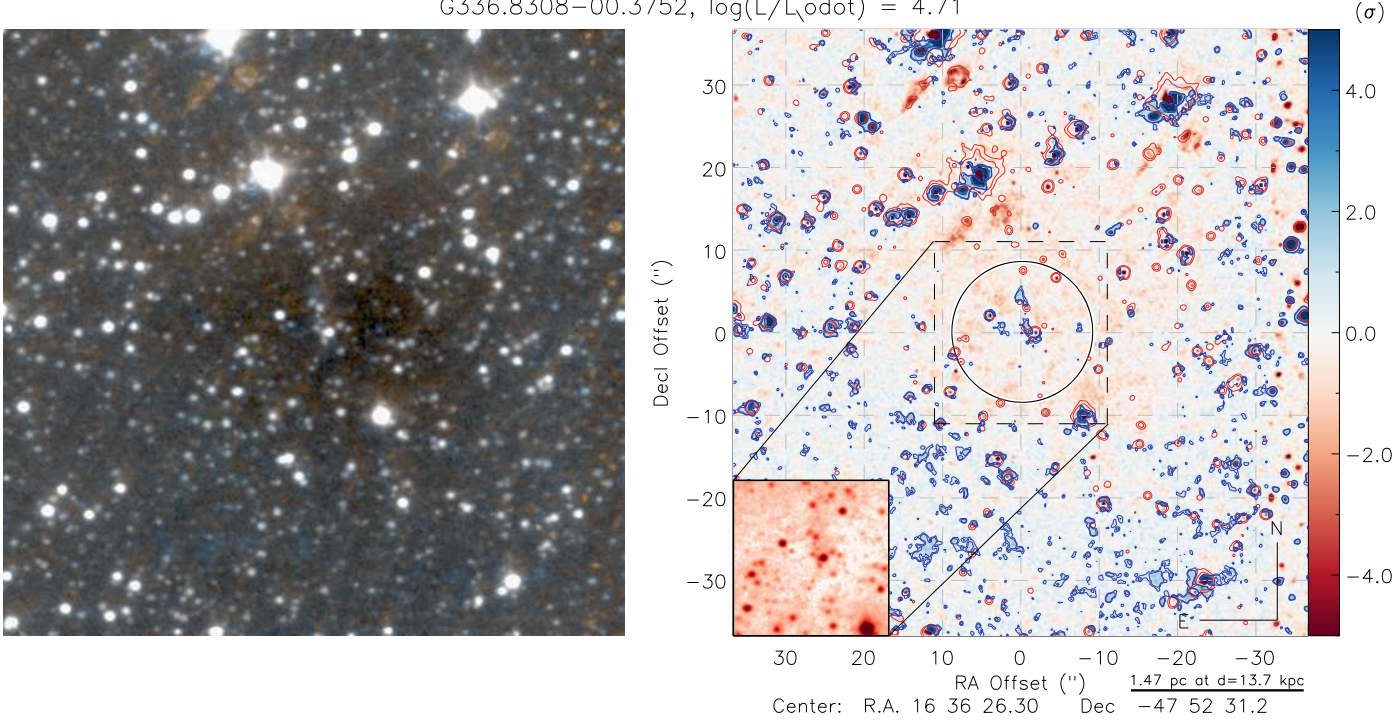
G337.0963-00.9291, $\log \left(L / L_{\odot}\right)=4.16$
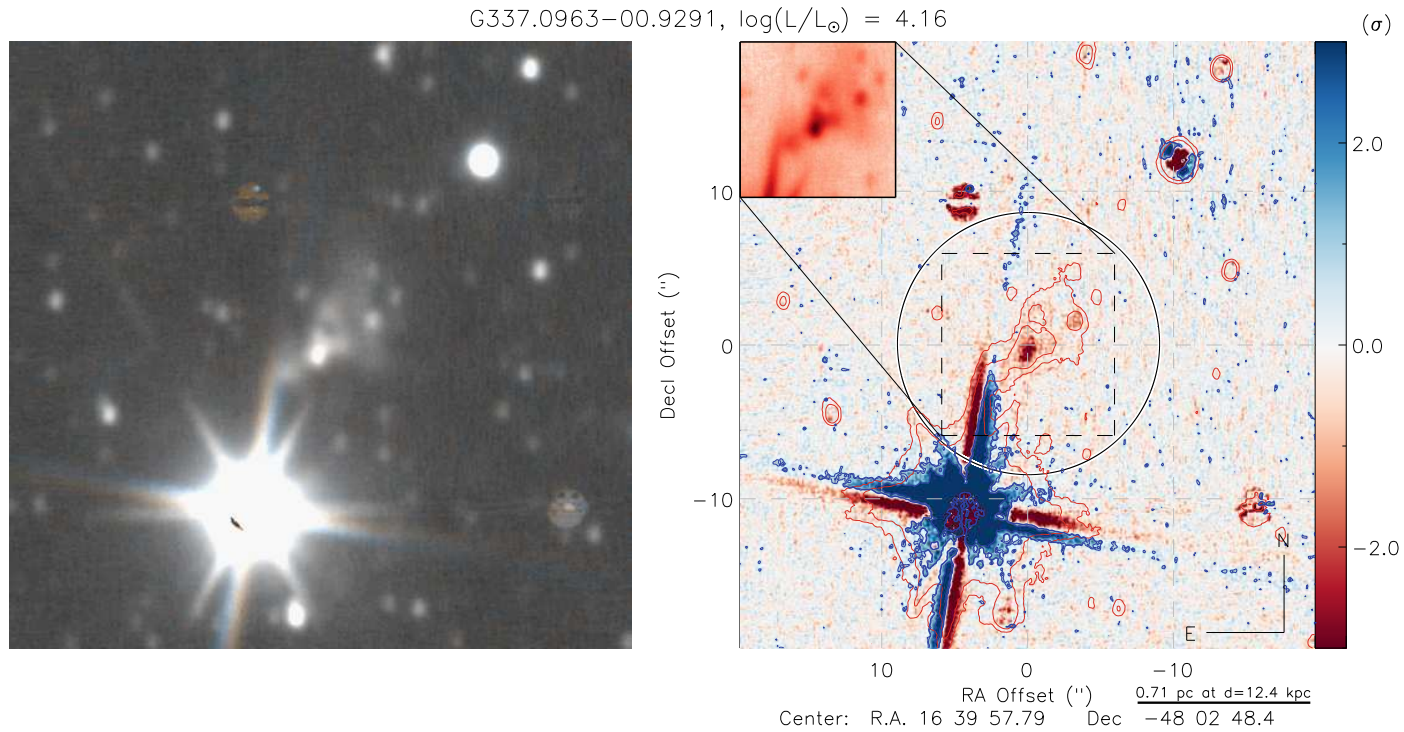

G337.3071-00.1521, $\log \left(L / L_{\odot}\right)=3.47$
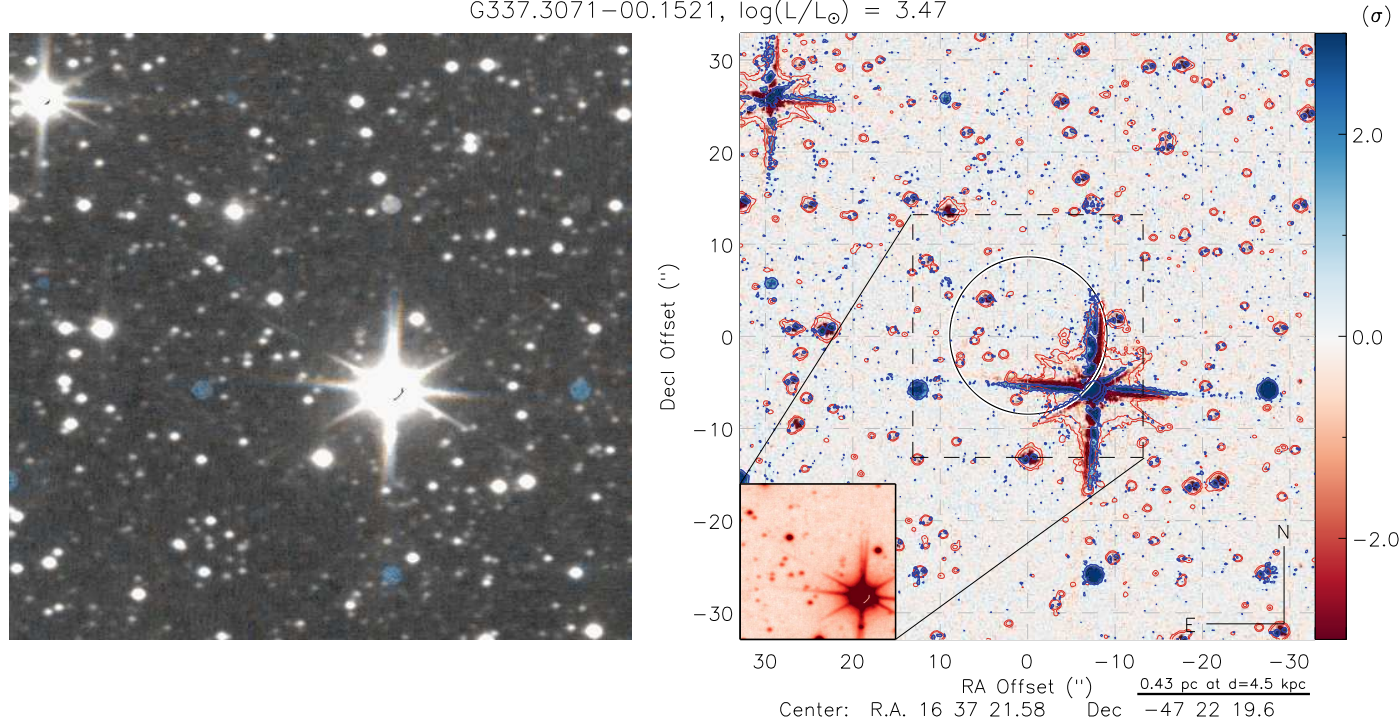

G338.0008-00.1498, $\log \left(L / L_{1}\right.$ odot $)=4.54$
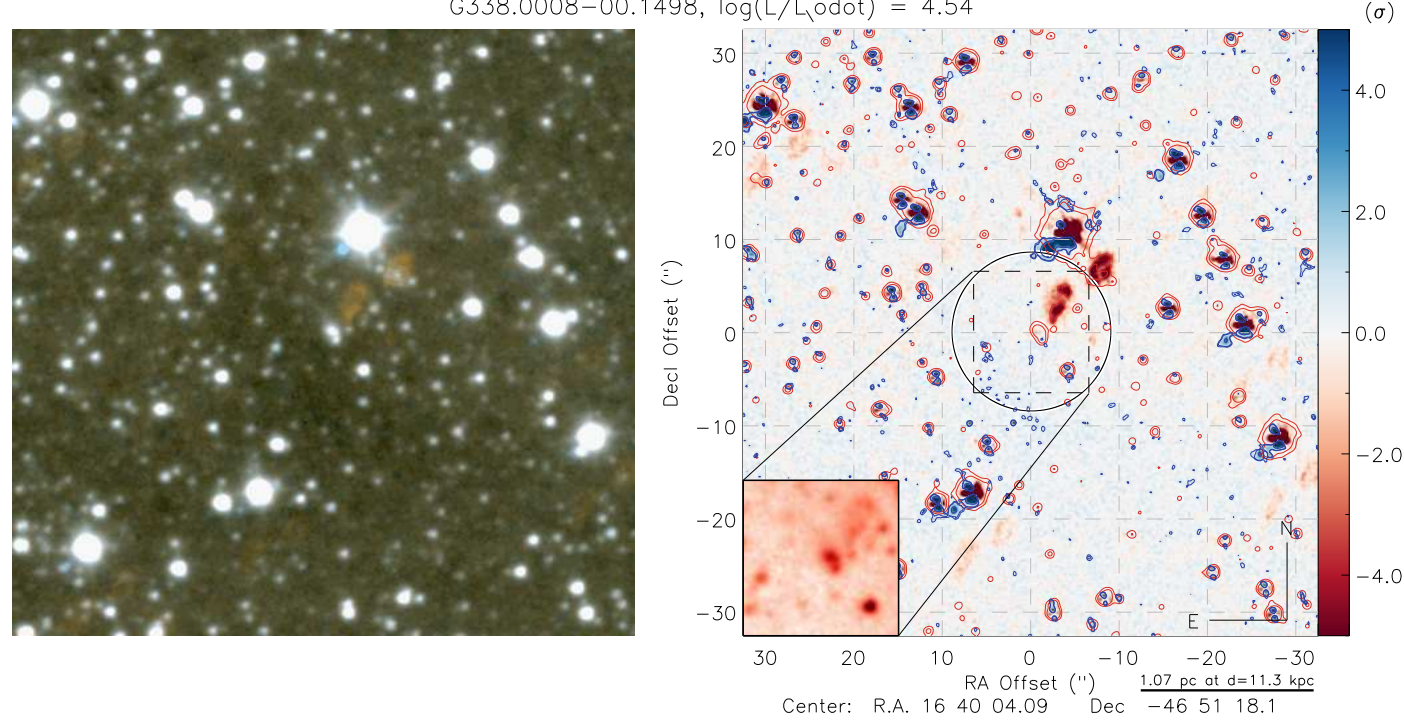
G338.1127-00.1905, $\log \left(L / L_{\odot}\right)=3.83$
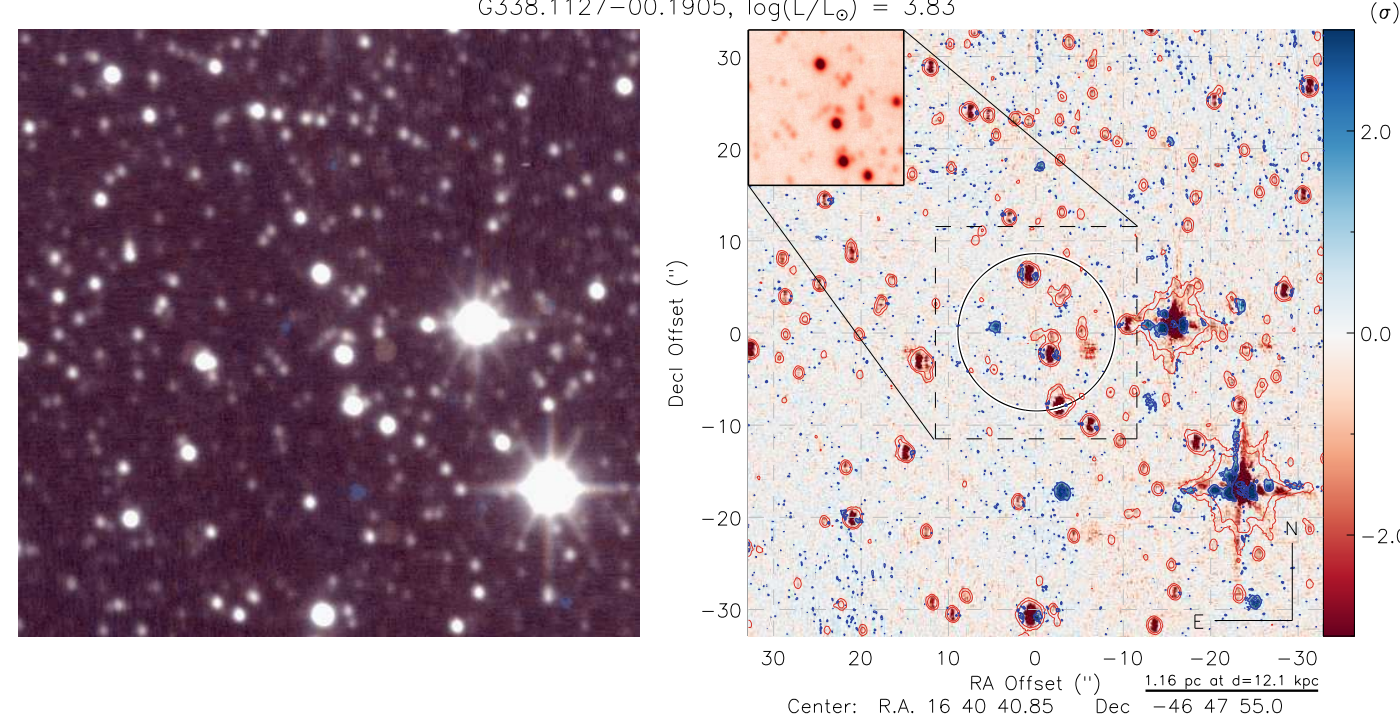

$G 338.9196+00.5495, \log (L / L$, odot $)=4.55$
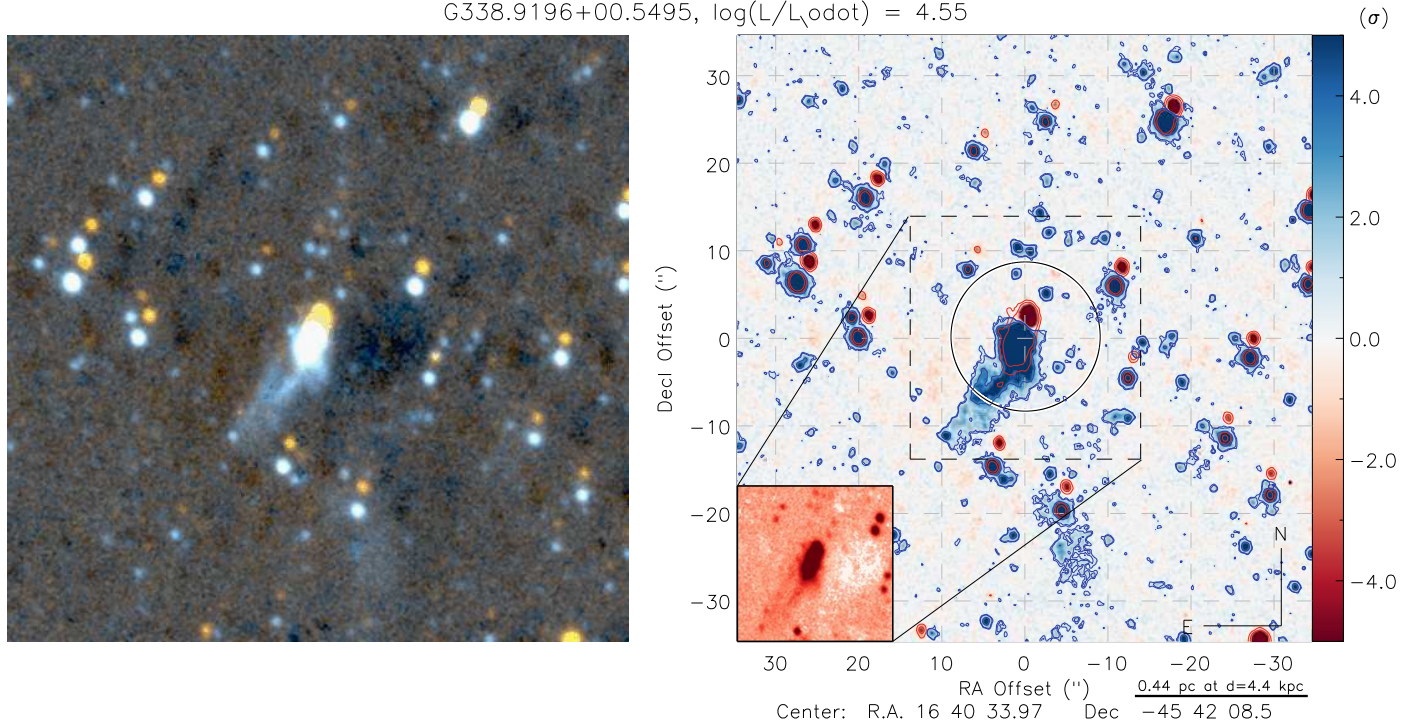

G340.7455-01.0021, $\log \left(L / L_{1}\right.$ odot $)=5.05$
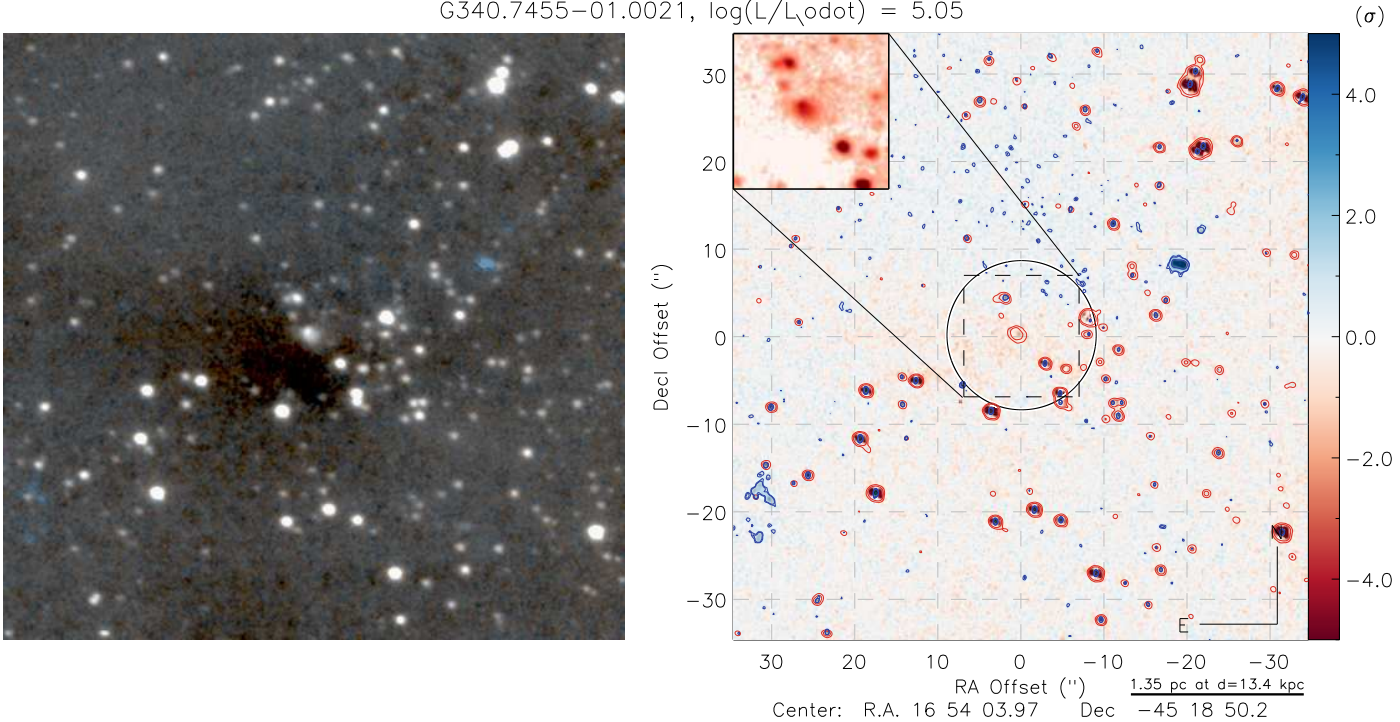

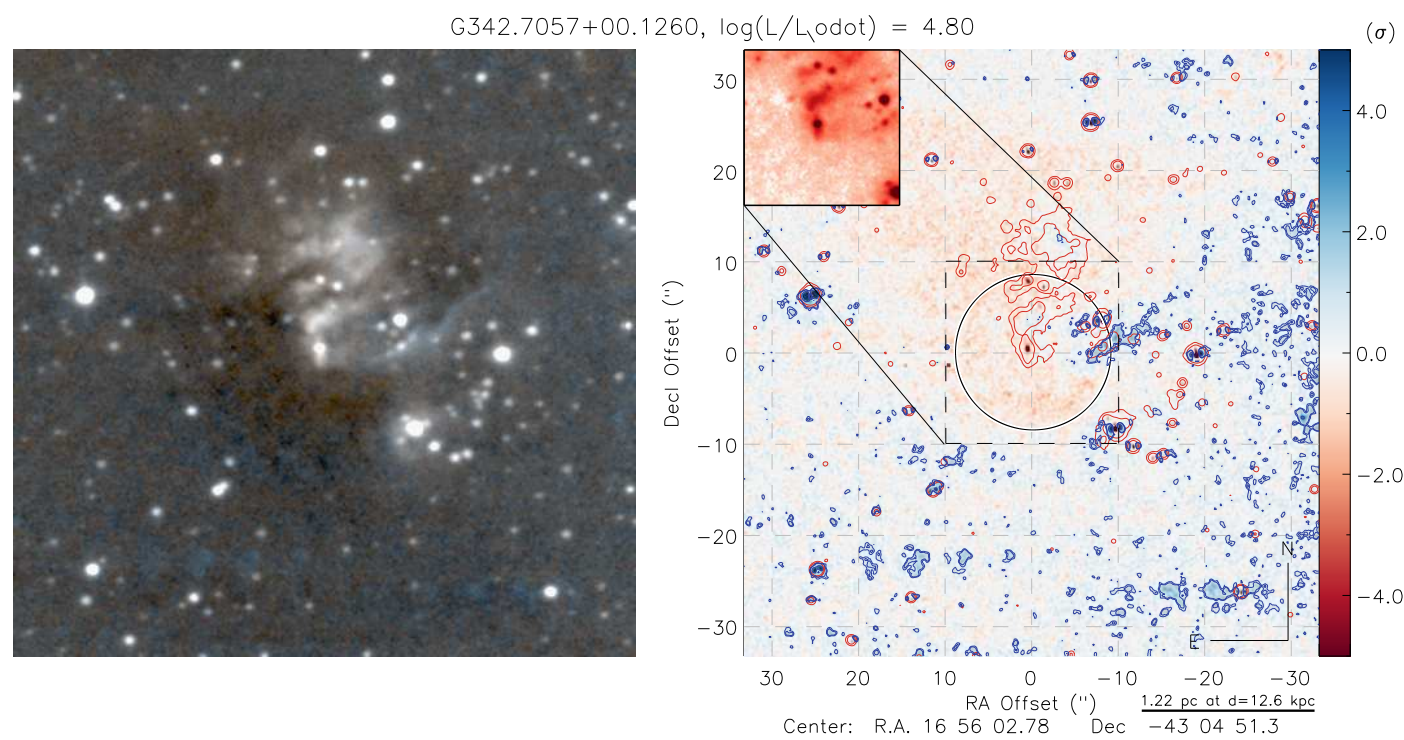

$G 345.1876+01.0308, \log \left(L / L_{\odot}\right)=3.30$
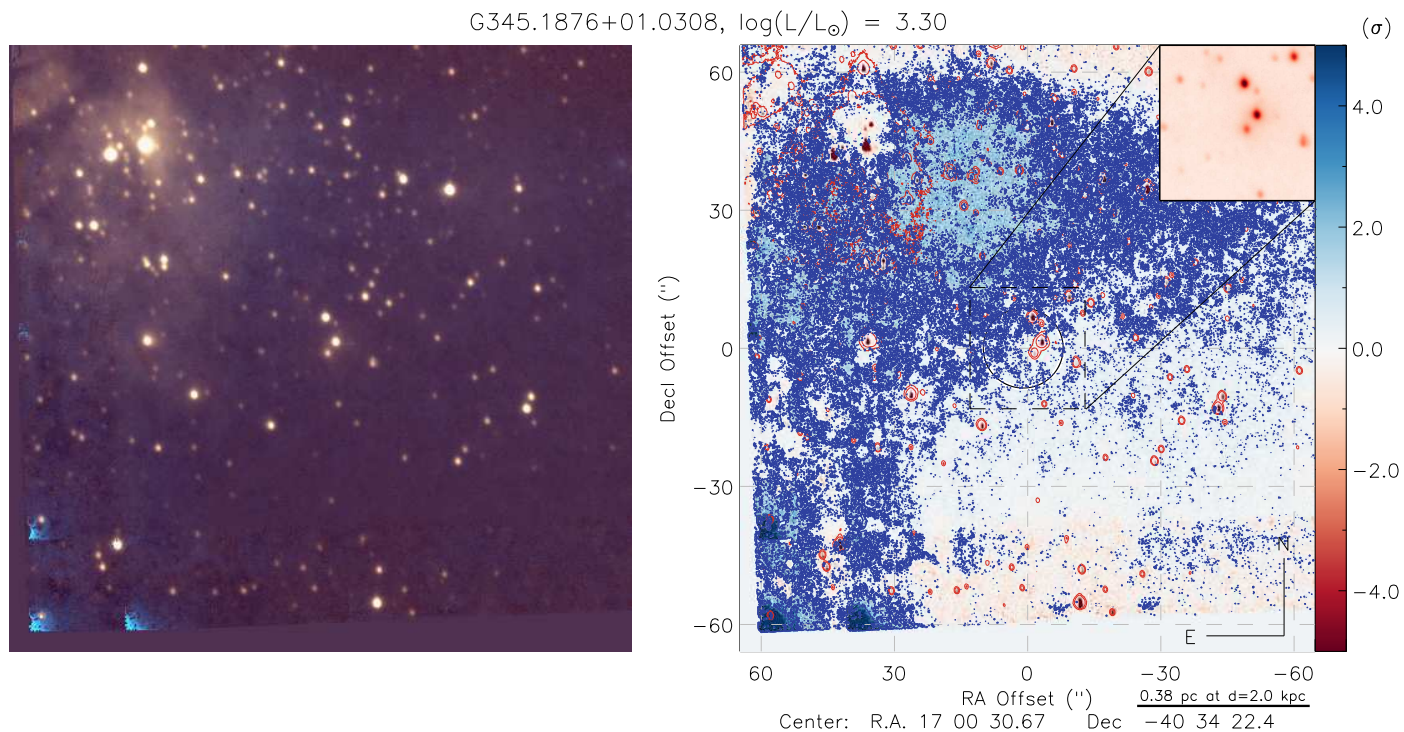

G345.6985-00.0894, $\log \left(L / L_{\odot}\right)=2.43$
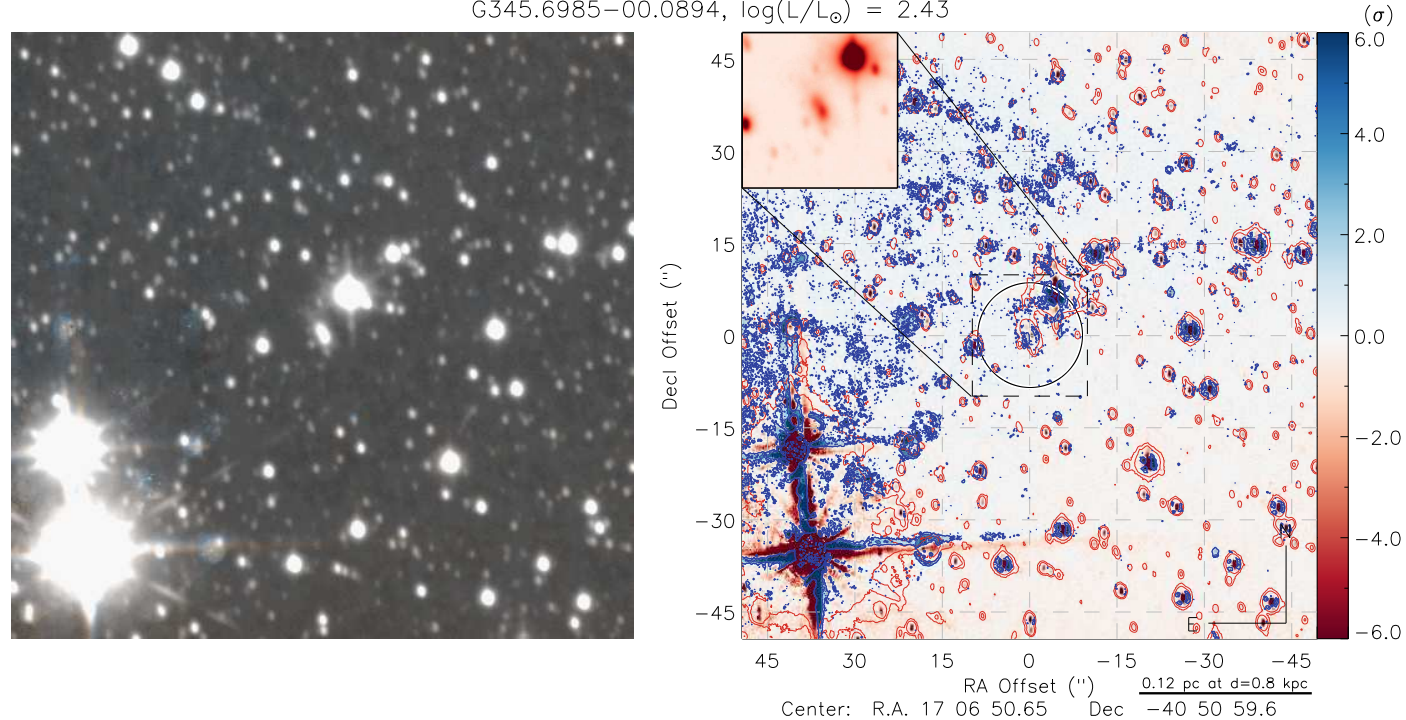
G347.0775-00.3927, $\log \left(L / L_{\text {, odot }}\right)=5.21$
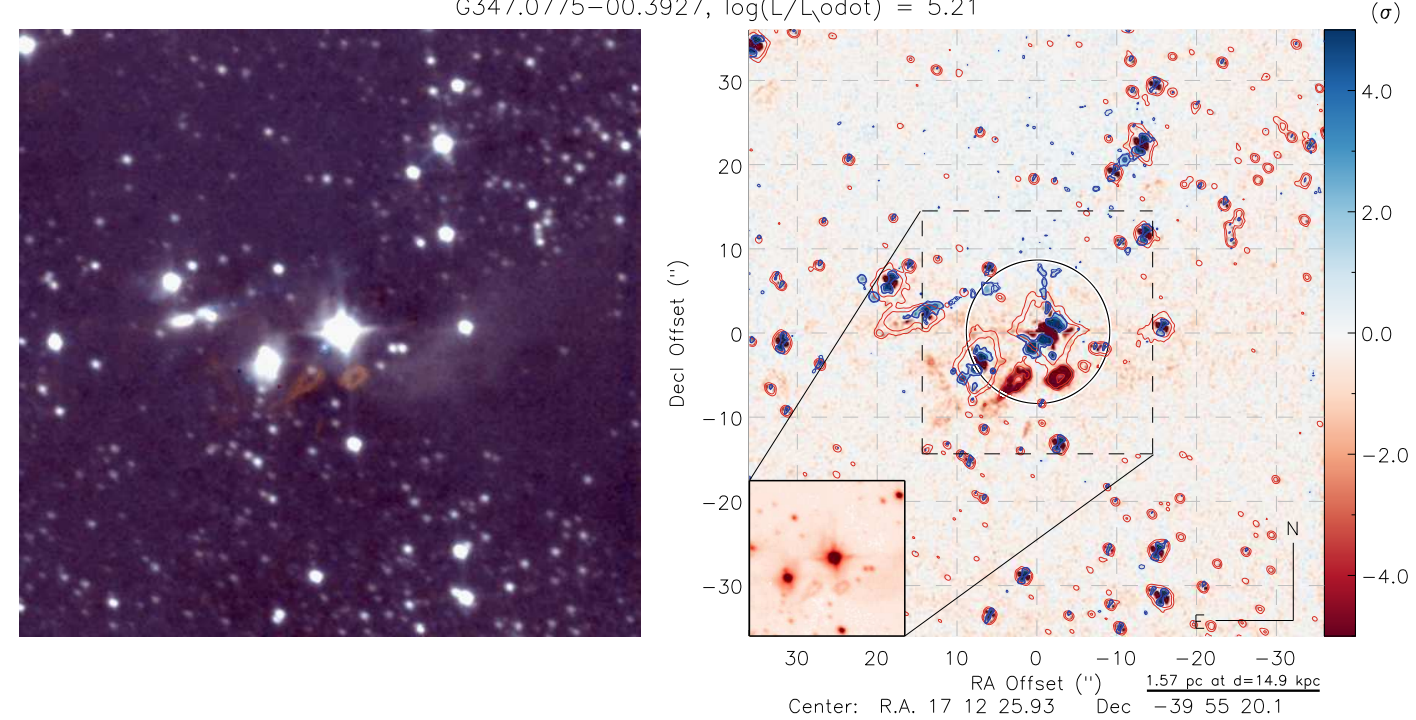

$G 348.0030+00.0728, \log \left(L / L_{\text {odot }}\right)=4.43$
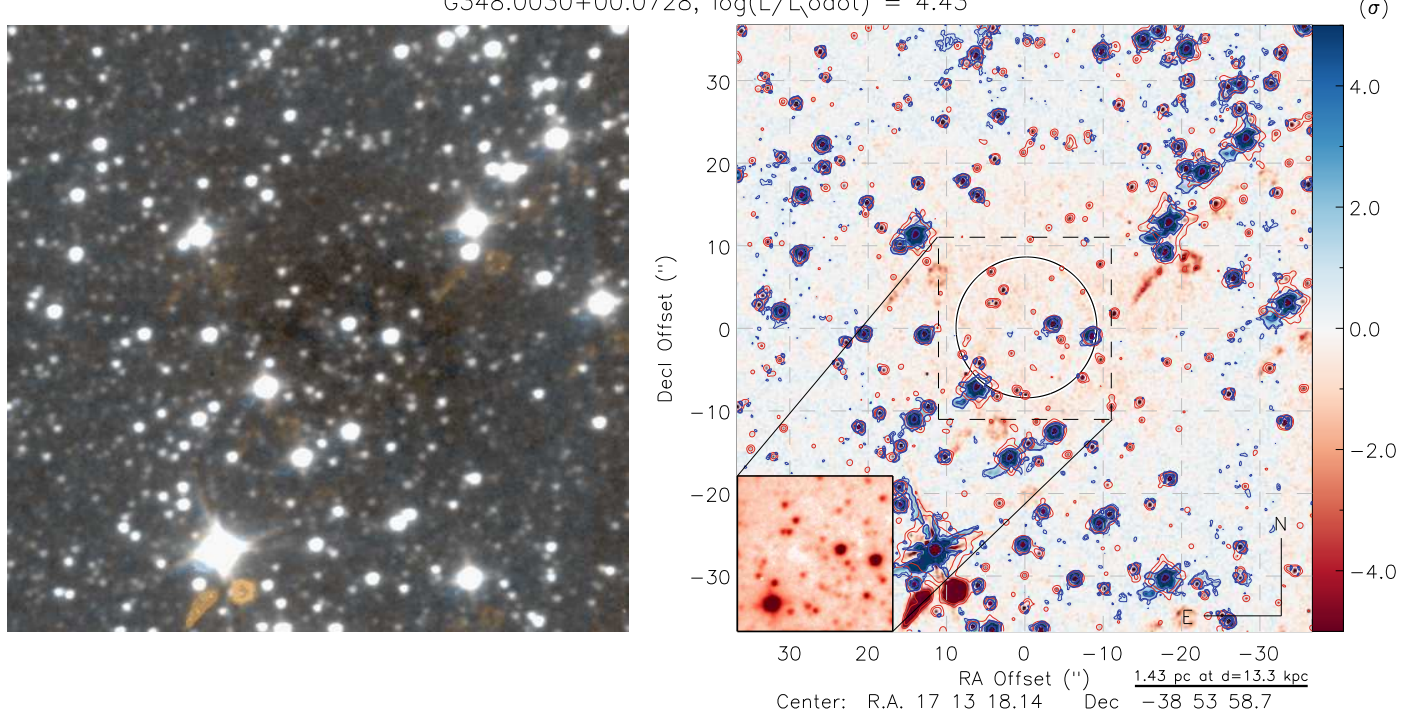

$G 348.5477+00.3721, \log \left(L / L_{\odot}\right)=2.05$
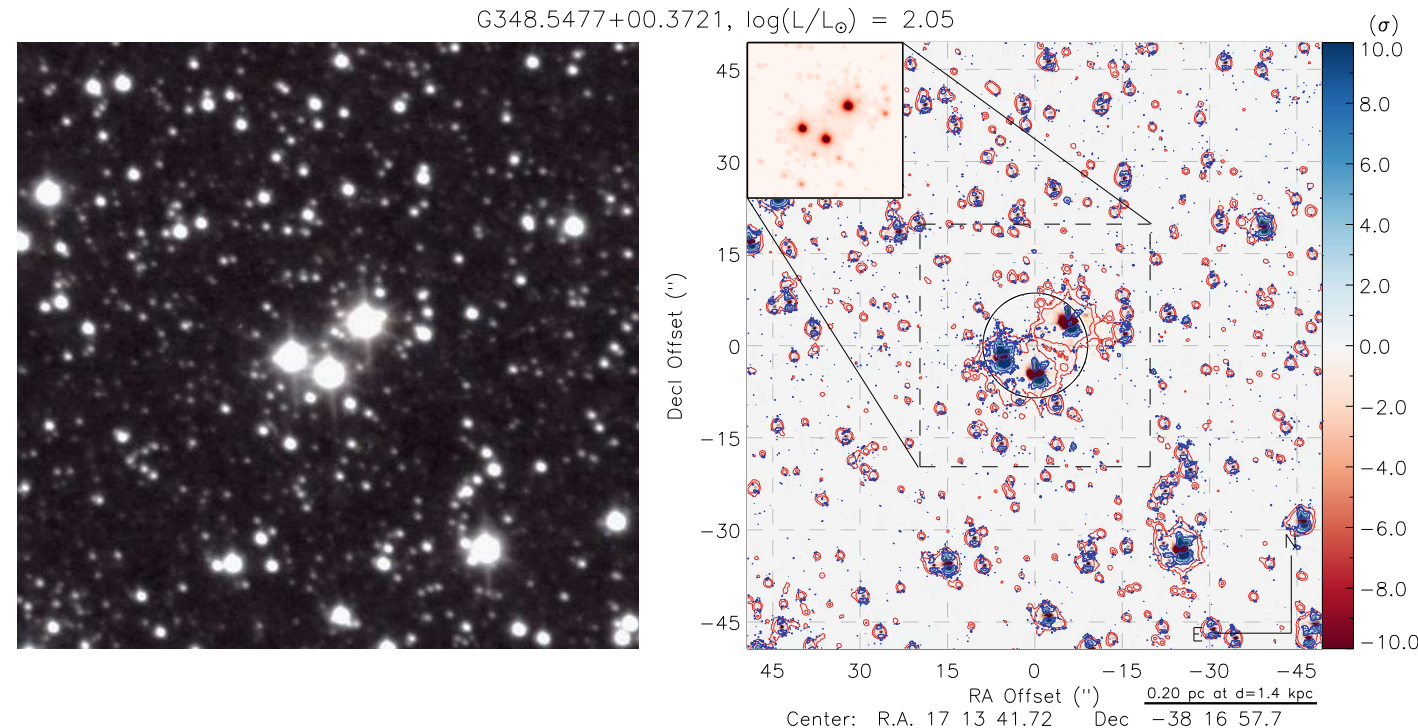


\section{Apêndice B}

\section{Rotinas em IDL Desenvolvidas Durante o Trabalho}

A seguir, são apresentadas as rotinas PREPARE_IMAGE.PRO e CREATE_IMAGES.PRO, escritas em linguagem IDL para a criação das imagens RGB e mapas de emissão em $\mathrm{H}_{2}$ dos candidatos a MYSOs do presente trabalho. Tais scripts estão em desenvolvimento em linguagem IRAF.

\section{B.1 prepare_images.pro}

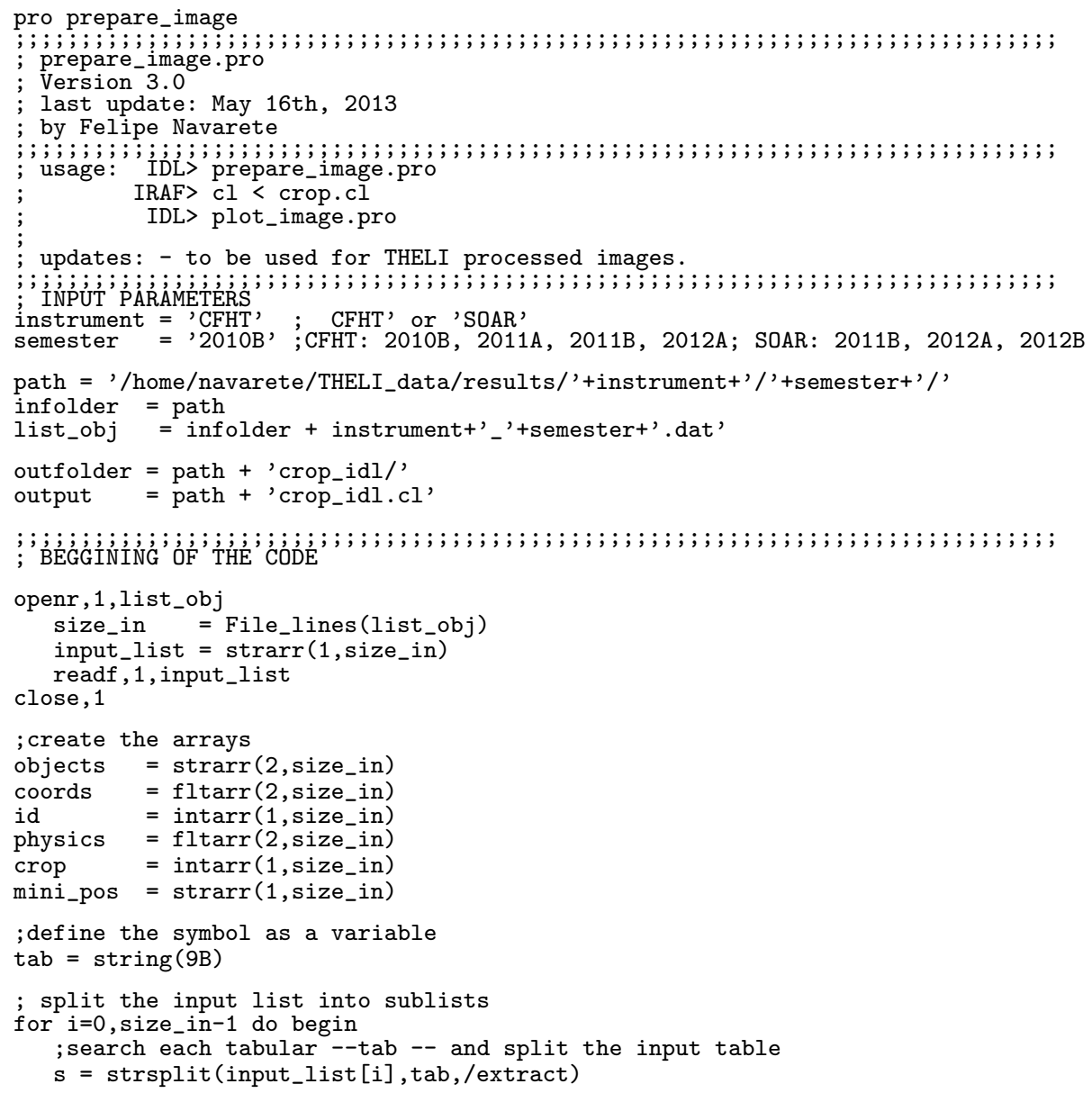




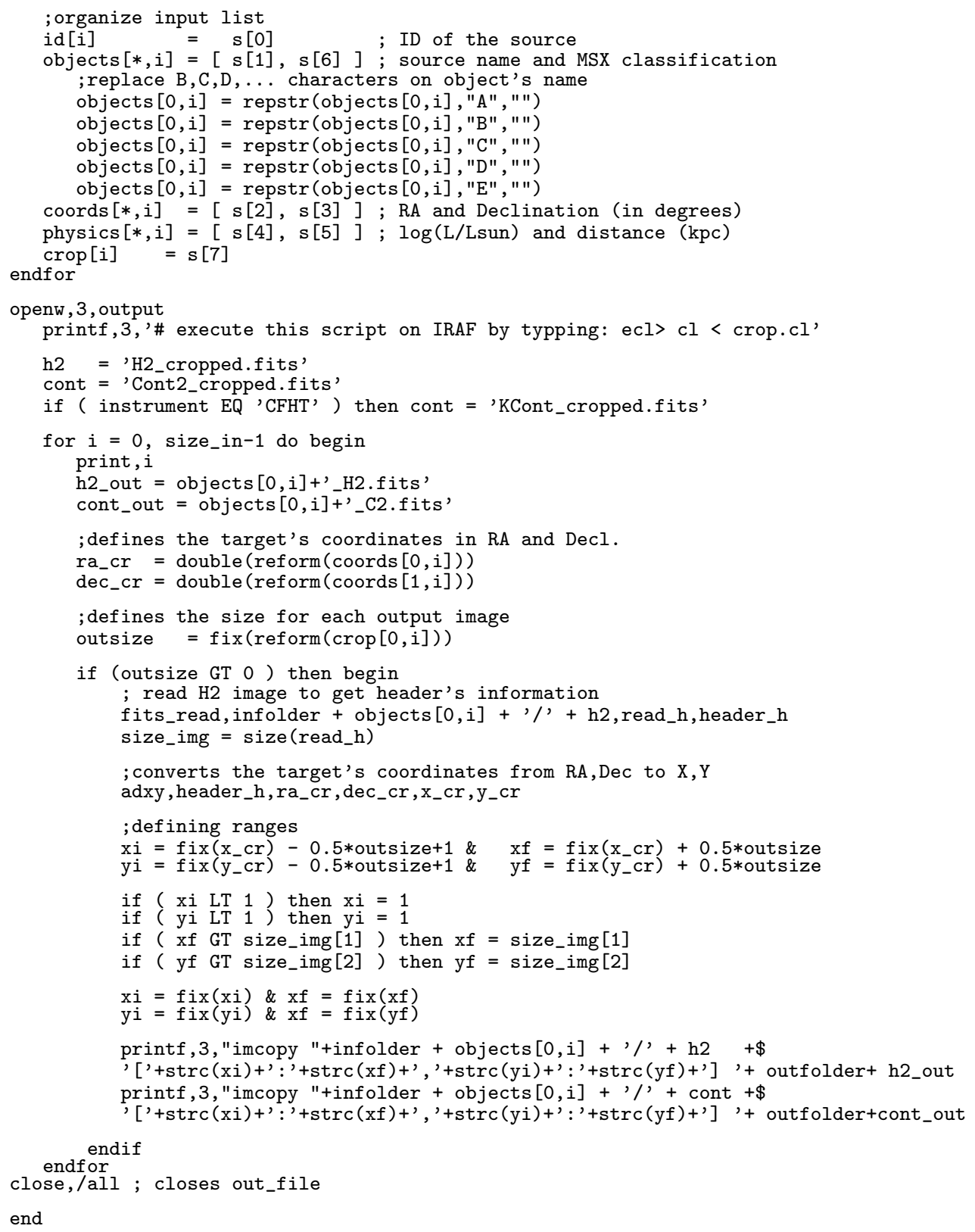




\section{B.2 create_images.pro}

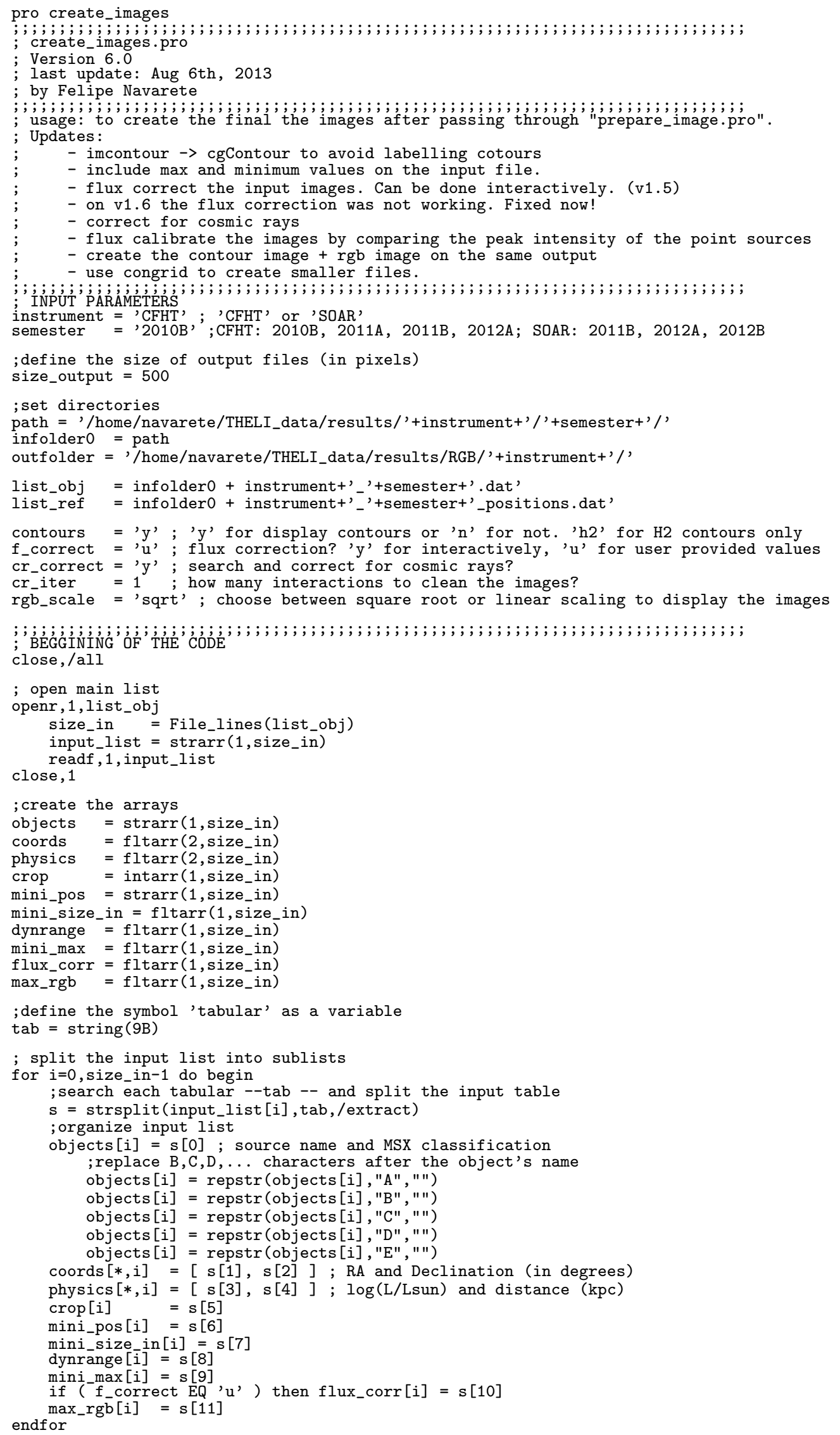


for $i=0$, size_in-1 do begin

print, "Working on "+objects[i]+" images..."

;redefine infolder

infolder = path + 'crop_idl/'

; define the name of the input images

h2 = objects $[0, i]+{ }^{\prime}$ H2.fits' \& cont $=\operatorname{objects}[0, i]+{ }^{\prime}$ _C2.fits'

; define names for output plots and fits

outps = outfolder + objects $[0, i]+' \cdot p s$ '

; read H2 image to get header's information

fits_read,infolder $+\mathrm{h} 2$, read_h, header_h

fits_read, infolder + cont, read_c, header_c

size_img = size (read_h)

; converts the target's coordinates from RA,Dec to $\mathrm{X}, \mathrm{Y}$

$r a_{-} c r=\operatorname{coords}[0, i] \quad \& d_{e} c_{-} c r=\operatorname{coords}[1, i]$

adxy, header_h, ra_cr, dec_cr, $x_{-} c r, y_{-} c r$

print,' Calculating statistics of input image'

; computes the sigma of the entire mask

mmm,read_c,mode_c, sigma_c

$\mathrm{mmm}$,read_h,mode_h, sigma_h

; subtract the mode of each image

img_c0 $=$ read_c - mode_c

img_h0 = read_h - mode_h

; get some info from the headers

pixscl $=\operatorname{abs}($ fxpar $($ header_c, 'CD1_1', datatype=0.D) $) * 3600$

f whm_h $=$ abs $($ fxpar $($ header_h, 'FWHM', datatype=0.D) $) /$ pixscl

$\mathrm{fwhm}_{-} \mathrm{c}=\operatorname{abs}($ fxpar $($ header_c, 'FWHM', datatype=0.D)) / pixscl

; get the lowest $f$ whm value

$f_{w h m}=f w h m$

if ( $f w h m_{-} c$ LT $\left.f w h m_{-} h\right)$ then $f w h m=f w h m_{-} h$

; cosmic rays correction

if ( cr_correct EQ 'y' ) then begin

print,"Correcting for cosmic rays..."

qzap, read_h, clean_h, maxiter=cr_iter

qzap, read_c, clean_c, maxiter $=c r$ iter

; save outputs

read_h $=$ clean_h

endif

clean_h

; start flux correction procedure

if ( $f_{\text {_correct }} \mathrm{EQ}$ ' $\mathrm{y}$ ') then begin

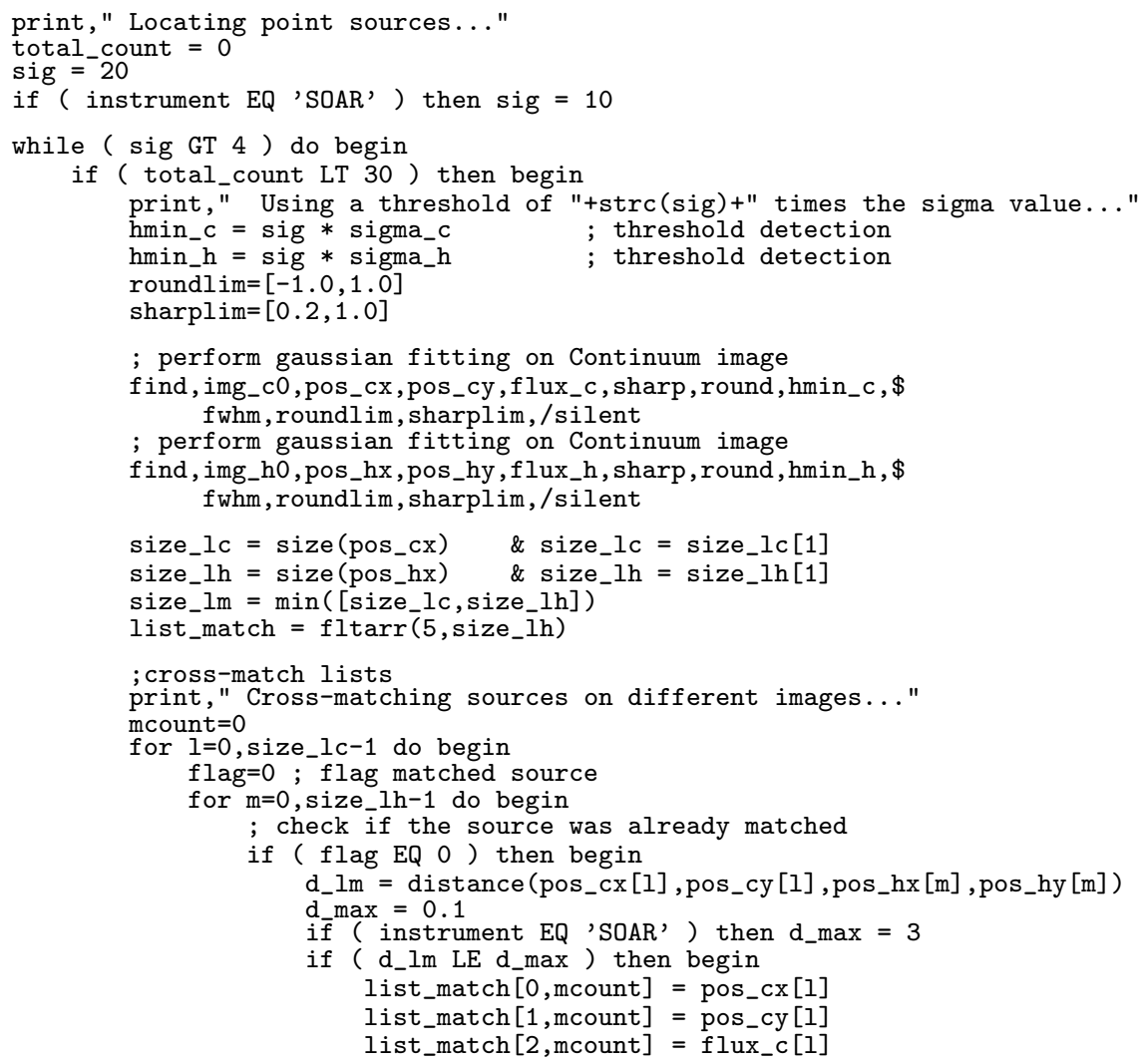




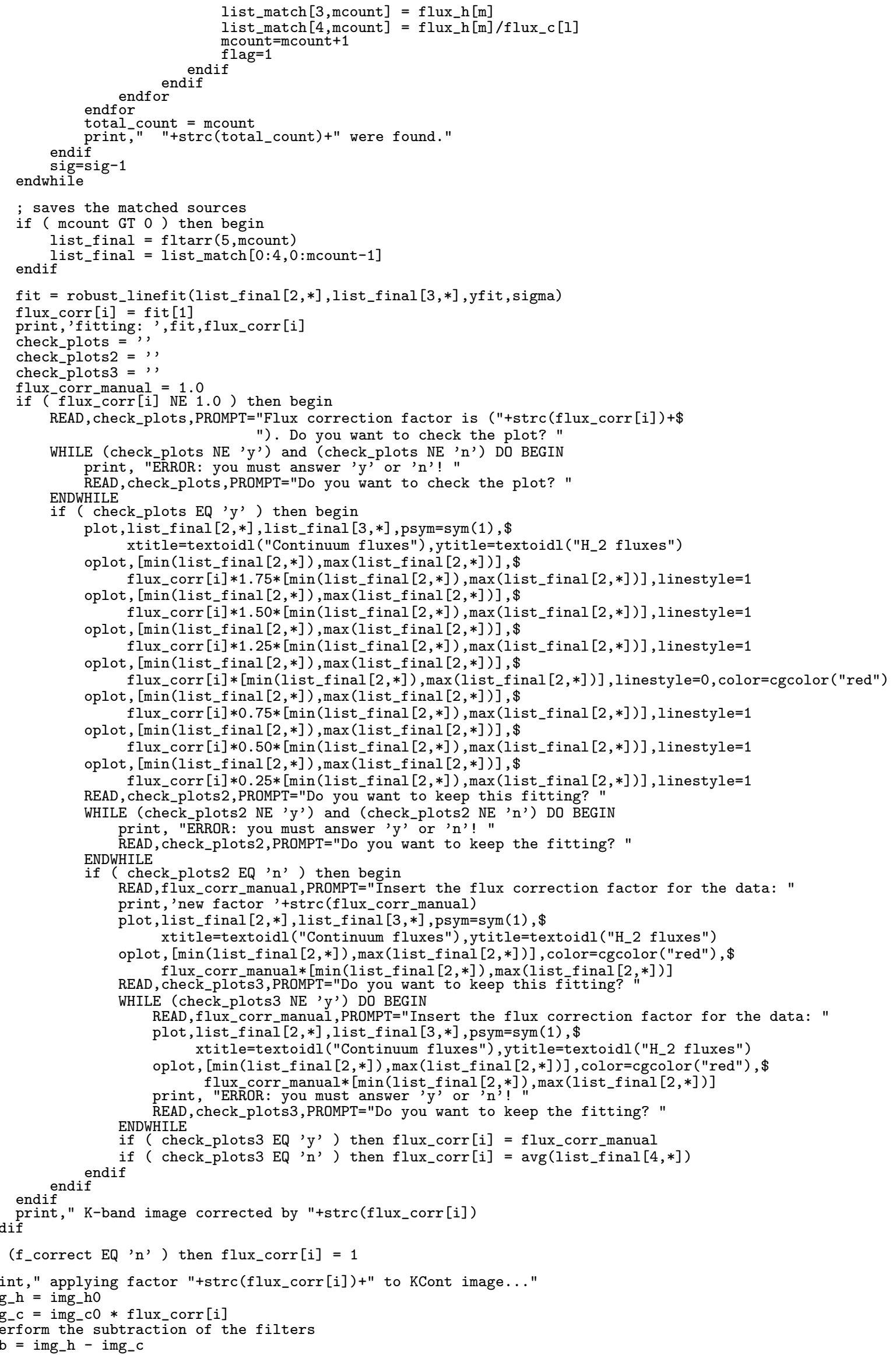


mmm, sub,mode_sub, sigma_sub

img_s $=\operatorname{smooth}($ sub / sigma_sub , 2, /edge_truncate)

img_c $=\operatorname{smooth}\left(\left(\operatorname{read}_{-} c-\operatorname{mode}_{-} c\right) / \operatorname{sigma}_{-} c, 2\right.$, /edge_truncate $)$

img_h $=\operatorname{smooth}($ (read_h - mode_h $) /$ sigma_h, 2, /edge_truncate $)$

; ; ; ; ; ; ; ; ; ; ; ; ; ; ; ; ; ; ; ; ; ; ; ;

;;;;;;;;;;;;;;;;;;;;;;;;;;;;;;;;; ;

; define the range of the RGB image

rgb_max $=$ max_rgb $[i]$

rgb_min $=-0.1 * \max \_r g b[i]$

if ( rgb_scale EQ 'linear') then begin

red = bytscl (img_c, $\min =r g b \_m i n, \max =r g b \_m a x$ )

green $=$ bytscl (img_g, $\left.\min =r g b \_m i n, \max =r g b \_m a x / 1.1\right)$

endif

blue = bytscl(img_h,min=rgb_min, $\left.\max =r g b \_m a x / 1.5\right)$

if ('rgb_scale EQ 'sqrt') then begin

red = bytscl (sqrt (bytscl (img_c, min=rgb_min, max=rgb_max)) )

green $=$ bytscl $\left(\right.$ sqrt $\left(\right.$ bytscl $\left(\right.$ img_g, $\left.\left.\left.\min =r g b \_m i n, \max =r g b \_m a x\right)\right)\right)$ endif

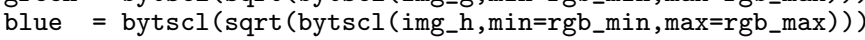

; interpolate the images to create smaller output files.

interp factor $=($ size_output $* 1.000) /($ size_img $[1] * 1.000)$

if ( interp_factor LT 1.0 ) then begin

print," Interpolating RGB image by a factor of "+strc(interp_factor)

red_interp = congrid(red,size_img[1]*interp_factor, $\$$

size_img [1]*interp_factor,/cubic,/center,/interp)

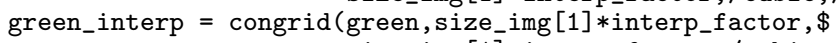

size_img[1]*interp_factor,/cubic,/center,/interp)

blue_interp = congrid(blue, size img[1]*interp_factor, $\$$

red = red_interp

green = green_interp

endif

size_img [1]*interp_factor,/cubic,/center,/interp)

print," Creating the plot..."

;;;;;;;;;;;;;;;;;;;;;;;;;;;;;;;;;;;;;;;;;;;;;;;;;;;;;;;;;;;;;;;;;;;;;;;

;;;;;;;;;;;;;;;;;;;;;;;;;;;;;;;;;;;;;;;;;;;;;;;;;;;;;;;;;;;;;;;;;;;;;;;;;;;;;;;;; device,file=outps, $x$ size=20,ysize=10,/color,/encapsulat

; defines position of the plot (img_contour) and colorbar (bar)

loc_img $=[0.52,0.15,0.89,0.93] \quad \&$ loc_bar $=[0.89,0.15,0.91,0.93]$

; defines position of the RGB image

position $=[0.05,0.15,0.45,0.93]$

xsize $=($ position $(2)-\operatorname{position}(0)) *$ !D.X_VSIZE

ysize $=$ (position(3) - position(1)) * ! D.Y_VSIZE

xstart $=$ position $(0) *$ ! D.X_VSIZE

ystart $=$ position $(1) *$ ! D.Y_VSIZE

; index the rgb vectors

colorimg = color_quan (red,green,blue, $r, g, b)$

tvlct, $r, g, b$

xtitle0="RA Offset" \& ytitle0="Decl Offset"

; add the scale parameter for the axis title

if ( instrument EQ 'CFHT') then begin

if ( size_img[1] LT 850 ) then begin

xtitle $=$ xtitle + , (")' \& ytitle $=$ ytitle $0+$, (")'

endif else begin

xtitle $=$ xtitle $0+"($ (') $"$ \& ytitle $=$ ytitle $0+"$ (')"

endif endelse

if (instrument EQ 'SOAR') then begin

if ( size_img[1] LT 2450) then begin

xtitle $=$ xtitle + , (")' \& ytitle = ytitle + , (")'

endif else begin

endif delse

; define the scale of the H2 emission maps

maxscale=dynrange [i] $\$$ minscale=-maxscale

ncolors $=256$; number of colors to be loaded on each table

charsize $=0.7$; size of the text

cont thick=0.1 ; contour thickness

; places the axes with WCS information

imcontour, img_c, header_c,pos=loc_img,/nodata, type $=0$,

extra $=\{$ xtitle:xtitle,ytitle:ytitle,charsize:charsize, \$

xthick:2,ythick:2\} 
cgimage, colorimg, pos=position, /overplot

; load the color-scale

CTLoad, 22, NColors=ncolors, /BREWER

img_s_displ = img_s

if ( interp_factor LT 1.0) then begin

print," Interpolating image by a factor of "+strc(interp_factor)

img_s_interp = congrid (img_s, size_img [1]*interp_factor, $\$$

endif

img_s_displ = img_s_interp size_img [1]*interp_factor,/cubic,/center,/interp)

; place the main image and the colorbar

cgimage,img_s_displ, minvalue=minscale, maxvalue=maxscale, pos=loc_img, /overplot

cgcolorbar, ncolors=ncolors, charsize=charsize,/vertical,/right,/brewer, $\$$ pos=loc_bar,tickint=2, format=' (F5.1)', range= [minscale, maxscale]

xyouts , 0.92,0.945, textoidl ('(\sigma)'), charsize=charsize, color=cgcolor ("black"),/normal

; recover the gray scale

cgLoadCT, 0, NColors=n_color

; creates grid with astrometric information ('type=0': 30"x30" grid)

radecgrid,img_c, header_c, type $=0$, /overplot,

_extra $=\{$ charsize: charsize, linestyle: 2 , thick: 0, color: cgcolor ("grey") $\}$

; gets pixel scale from header

crdel $=\operatorname{abs}($ fxpar $($ header_c , 'CD1_1', datatype $=0 . D))$

; converts the target's coordinates from RA,Dec to $\mathrm{X}, \mathrm{Y}$

$\mathrm{ra}$ cr $=\operatorname{coords}[0, i] \quad \& \mathrm{dec}_{-} \mathrm{cr}=\operatorname{coords}[1, \mathrm{i}]$

adxy, header_c, ra_cr, dec_cr, $x_{-}$cr, y_cr

; draw a circle over the target's coordinates

MSX_rad $=9$; $\operatorname{arcsec}$

rad_plot $=$ MSX_rad $/($ abs $($ crdel $) * 3600)$; in pixels

tvcircle,rad_plot, $x_{-} c r, y_{-} c r$, color=cgcolor ("white"),_extra $=\{$ thick:5, linestyle:0\}

tvcircle,rad_plot, $x_{-} c r, y_{-} c r$, color=cgcolor ("black"),_extra $=\{$ thick: 1 , linestyle:0\}

if ( contours EQ 'y') then begin

; define contour levels

if ( instrument EQ 'CFHT') then begin

$\mathrm{c}_{\text {_levels }}=[3,6]$
$\mathrm{h}$ levels $=[1,3]$

endif

if (instrument $\mathrm{EQ}$ ' $\mathrm{SOAR}$ ') then begin

h_levels $=[0.75,1,3]$

endif

c-levels $=[3,6]$

CTLoad, 24, NColors=ncolors, /brewer

cgcontour, smooth (img_c,2,/edge_truncate), levels=c_levels, label=0, /overplot, $\$$ extra $=\left\{c_{-}\right.$linestyle:0, c_thick: cont_thick,c_colors:25\}

; overlays the H2 contour (in black)

cgcontour, smooth (img_s, 2,/edge_truncate), levels=h_levels, label=0, /overplot,\$

endif _extra $=\left\{c_{-}\right.$linestyle:0, c_thick: cont_thick,c_colors:250\}

; define the compass

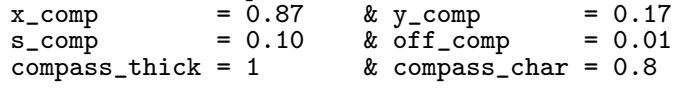

; creates compass

plots, [x_comp-s_comp*0.5, $x_{-}$comp] , [y_comp,y_comp], linestyle=0, color=cgcolor ("black"),/normal

plots, [x_comp, $x_{-}$comp] , [y_comp,y_comp+s_comp], linestyle=0, color=cgcolor ("black"),/normal

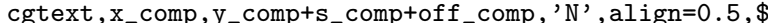
orientation $=0$, charthick=compass_char, size $=$ charsize, /normal

cgtext, $x_{-}$comp-s_comp*0.5-off_comp,y_comp-off_comp, 'E' , align $=0.5, \$$ orientation=0, charthick=compass_char, size=charsize,/normal

; places the target's name

text_source $=\operatorname{objects}[0, i]+\operatorname{textoidl}\left(', \log \left(L / L_{-} \operatorname{lodot}\right)={ }^{\prime}+\operatorname{strc}(\right.$ physics $\left.[0, i], f \circ r m a t='(F 5.2) ')\right)$ cgtext, $0.5,0.95$, text_source, align=0.5, orientation $=0$, size $=$ charsize $* 1.2, /$ normal

; define the length scale

$\mathrm{x}_{-}$scale $=0.99 *$ size_img $[1] \quad \& \quad \mathrm{y}_{-}$scale $=-0.09 *$ size_img [2]

scale_thick $=3 \quad \& \quad$ scale_font $=0 . \overline{5} 5 \quad \& \quad$ scale_text $=0.75$

; creates scale

size

ang_arcsec $=(\operatorname{abs}(\operatorname{crdel}) * 3600) *$ size_scale

ang_size $=$ ang_arcsec $*$ pi / 648000

ang_dist $=$ ang_size $*$ physics $[1, i] * 1000$

plots, [x_scale-size_scale, $x_{-}$scale], [y_scale, y_scale], linestyle $=0, \$$ thick=scale thick, color=cgcolor ("black")

scale_leg $=\operatorname{strc}\left(\right.$ ang_dist,format $\left.='(F 5.2)^{\prime}\right)+{ }^{\prime}$ pc at $d='+\$$ 
$\operatorname{strc}($ physics [1,i], format=' (F4.1)' ')+' kpc'

cgtext,x_scale-size_scale*0.5,y_scale*0.9, align=0.5, color=cgcolor ("black"), $\$$

scale_leg, charthick=scale_text, size=scale_font $* 0.95$

;; ; ; ; ; ; ; ; ; ; ; ; ; ; ; ; ; ; ; ; ; ; ; ; ; ; ; ; ; ; ; ; ; ; ; ; ; ; ; ; ; ; ; ; ; ; ; ; ; ; ; ; ; ;

; region for miniature [mxi:mxi+mdx,myi:myi+mdy]

mini_size = mini_size_in [i] ; relative size

if (mini_size EQ 1 ) then begin

$\mathrm{mxi}=0 \quad \& \quad \mathrm{mdx}=$ size_img $[1]-1^{-1}$

$\operatorname{myi}=0 \quad \& \quad \operatorname{mdy}=$ size_img $[2]-1$

endif else begin

$\mathrm{mdx}=\mathrm{fix}\left(\mathrm{size} \_\mathrm{img}[1] * \operatorname{mini}{ }_{-} \mathrm{size} * 2\right)$

$\operatorname{mdy}=f i x\left(s i z e_{-} i m g[2] * \operatorname{mini}\right.$ size $\left._{2} * 2\right)$

$\mathrm{mxi}=\mathrm{fix}(\mathrm{size}$ img $[1] *(0.5-\operatorname{mini}$ size $))$

myi $=$ fix (size_img $[2] *\left(0.5-\operatorname{mini}{ }_{-}\right.$size $\left.)\right)$

$\mathrm{mxf}=\mathrm{mxi}+\mathrm{mdx} \& \mathrm{myf}=\mathrm{myi}+\mathrm{mdy}$

; place a box over the zoomed region

plots, [mxi,mxf], [myi,myi], linestyle=2, thick=1, color=cgcolor ("black")

plots, [mxi,mxf], [myf, myf], linestyle=2,thick=1, color=cgcolor ("black")

plots, [mxi,mxi], [myi,myf], linestyle=2, thick=1, color=cgcolor ("black")

plots
endelse

plots, [mxf,mxf], [myi,myf], linestyle=2, thick=1, color=cgcolor ("black")

img_mini = img_c[mxi:mxi+mdx,myi:myi+mdy]

size_mini $=$ size(img_mini)

; miniature's position

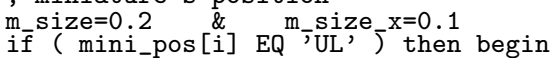

m_xi=loc_img [0]

endif

m_yi=loc_img[3]-m_size

if (mini_pos[i] EQ 'UR') then begin

$m_{-} x i=l o c \_i m g[2]-m_{-} s i z e \_x$

m_yi=loc_img [3]-m_size

if (mini_pos[i] EQ 'DL') then begin

$\mathrm{m}_{-} \mathrm{xi}=\mathrm{loc}$ _img $[0]$

endif

m_yi=loc_img [1]

; define the location of the miniature

loc_min $=\left[m_{-} \mathrm{xi}, \mathrm{m}_{-} \mathrm{yi}, \mathrm{m}_{-} \mathrm{xi}+\mathrm{m}_{-} \mathrm{size} \_\mathrm{x}, \mathrm{m}_{-} \mathrm{yi}+\mathrm{m}_{-} \mathrm{size}\right]$

cgLoadCT, 16, NColors $=256$, /brewer

displ_mini=bytscl (sqrt (bytscl (img_mini, $\min =-1, \max =\operatorname{mini} \max [i])$ ))

cgimage, displ_mini, pos=loc_min, /overplot

cgLoadCT , 0 , NColors $=256$

;places a rectangle around the miniature

plots, [m_xi,m_xi+m_size_x], [m_yi,m_yi], linestyle $=0$, thick $=2, \$$ color=cgcolor ("black"),/normal

plots, [m_xi,m_xi+m_size_x], [m_yi+m_size,m_yi+m_size], linestyle $=0, \$$ thick=2, color=cgcolor ("black"),/normal

plots, [m_xi,m_xi], [m_yi,m_yi+m_size], linestyle $=0$, thick $=2, \$$ color=cgcolor ("black"), /normal

plots, [m_xi+m_size_x,m_xi+m_size_x], [m_yi,m_yi+m_size], linestyle=0,\$ thick=2, color=cgcolor ("black"),/normal

$\mathrm{x}_{-} \mathrm{c}=\left(\right.$ loc_img $[2]+\mathrm{loc}_{-}$img $\left.[0]\right) * 0.5$

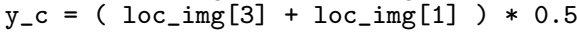

;include two guiding lines from the inner region to the miniature

if (mini_size NE 1 ) then begin

if ( mini_pos[i] EQ 'UL') then begin

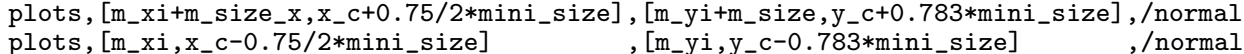
endif

if ('mini_pos[i] EQ 'UR') then begin

plots, [m_xi, x_c-0.75/2*mini_size]

[m_yi,y_c-0.783*mini_size]

/normal endif ,[m_yi+m_size, y_c $+0.783 *$ mini_size], $/$ normal

i pos [i] EQ 'DL') then begin

plots, [m_xi,x_c-0.75/2*mini_size] ,[m_yi+m_size,y_c+0.783*mini_size], /normal endif

plots, [m_xi+m_size_x, $x_{-} c+0.75 / 2 *$ mini_size], [m_yi,y_c-0.783*mini_size], /normal

device,/close

if ( os EQ 'l') then SET PLOT, ' $x$ ' ; Return plotting to linux.

if ( os EQ ' $\mathrm{W}$ ') then SET_PLOT, 'win' ; Return plotting to windows.

endfor

close, /all

end 